\author{
UNIVERSIDADE DE SÃO PAULO \\ ESCOLA POLITÉCNICA \\ DEPARTAMENTO DE ENGENHARIA DE PRODUÇÃO
}

ANGELO VARANDAS JUNIOR

UMA PROPOSTA PARA INTEGRAÇÃO DE ASPECTOS AMBIENTAIS DO ECODESIGN NO PROCESSO DE DESENVOLVIMENTO DE NOVOS PRODUTOS 
ANGELO VARANDAS JUNIOR

\title{
UMA PROPOSTA PARA INTEGRAÇÃO DE ASPECTOS AMBIENTAIS DO ECODESIGN NO PROCESSO DE DESENVOLVIMENTO DE NOVOS PRODUTOS
}

\author{
Tese apresentada à Escola \\ Politécnica da Universidade de São \\ Paulo para obtenção do título de \\ Doutor em Engenharia de Produção.
}

São Paulo 


\section{UMA PROPOSTA PARA INTEGRAÇÃO DE ASPECTOS AMBIENTAIS DO ECODESIGN NO PROCESSO DE DESENVOLVIMENTO DE NOVOS PRODUTOS}

Tese apresentada à Escola
Politécnica da Universidade de São
Paulo para obtenção do título de
Doutor em Engenharia de Produção.

Área de concentração: Qualidade e Engenharia do Produto.

Orientador: Paulo A. Cauchick Miguel Professor Livre Docente

São Paulo 
Este exemplar foi revisado e alterado em relação à versão original, sob responsabilidade única do autor e com a anuência de seu orientador.

São Paulo, 15 de dezembro de 2014.

Assinatura do autor

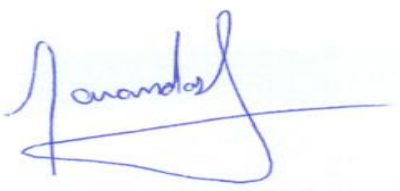

Assinatura do orientador

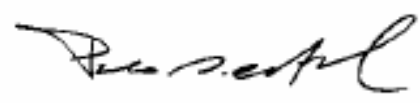

Catalogação-na-publicação

Varandas Junior, Angelo

Uma proposta para integração de aspectos ambientais do ecodesign no processo de desenvolvimento de novos produtos

/ A. Varandas Junior. -- versão corr. -- São Paulo, 2014. $287 \mathrm{p}$.

Tese (Doutorado) - Escola Politécnica da Universidade de São Paulo. Departamento de Engenharia de Produção.

1.Desenvolvimento de produtos 2.Ecodesign (Métodos; Ferramentas) I.Universidade de São Paulo. Escola Politécnica. Departamento de Engenharia de Produção Il.t. 


\section{AGRADECIMENTOS}

Agradeço inicialmente ao orientador deste trabalho, Prof. Dr. Paulo Augusto Cauchick Miguel, pela grande atenção dedicada durante esta trajetória.

Aos professores que participaram da banca examinadora, Profa. Dra. Marly Monteiro de Carvalho, Prof. Dr. Aldo Roberto Ometto, Prof. Dr. Carlos Henrique Pereira Mello e Prof. Dr. Eduardo de Senzi Zancul, pelos importantes comentários para melhoria da tese.

Aos amigos da Pós-Graduação, pela enorme ajuda, paciência e amizade.

A Escola Politécnica da Universidade de São Paulo, pela oportunidade de cursar o Doutorado nesta respeitada instituição.

A empresa USIMINAS, por permitir e incentivar a realização desta jornada acadêmica.

À minha família, em especial a minha mãe Benedita Lopes Varandas, por me apoiar nas decisões tomadas durante a minha vida pessoal e profissional.

À Danielle e Raul, meus grandes companheiros, pelo carinho e compreensão nos bons e nos maus momentos.

A todos que de alguma maneira contribuíram para a realização deste trabalho de pesquisa, e não foram citados. 


\section{RESUMO}

VARANDAS Jr., A. (2014). Uma proposta para integração de aspectos ambientais do ecodesign no processo de desenvolvimento de novos produtos. 2014. 287p. Tese (Doutorado) - Escola Politécnica, Universidade de São Paulo, São Paulo, 2014.

O aumento das exigências ambientais pela sociedade, mercado e legislação vem forçando os acadêmicos a buscarem formas de reduzir os impactos ambientais do produto durante todo o seu ciclo de vida. A integração de ferramentas de ecodesign no Processo de Desenvolvimento de Produtos (PDP) visa melhorar os requisitos ambientais do produto sem comprometer o seu desempenho, custo e características. Apesar dessa tendência, as estruturas de PDP não incorporam práticas ambientais de forma adequada. Assim, esse trabalho objetiva integrar práticas de ecodesign em uma estrutura de PDP. Para atingir esse propósito foi empregada uma análise sistemática da literatura mesclando técnicas de análise bibliométrica e de redes sociais, diagramas, mapeamento de 154 métodos de ecodesign, análise das características e questões ambientais de 80 estruturas de PDP e sistematização de 365 aspectos ambientais no PDP. Os resultados demonstram que as estruturas de PDP não enfatizam as fases de pré-desenvolvimento e pós-desenvolvimento que têm importância para redução do impacto ambiental. Portanto, foi elaborada uma proposta detalhada de integração analisando as características e contribuição de cada aspecto ambiental para minimizar o impacto ambiental do produto e sua relação com a função de cada tarefa do PDP. Na avaliação da proposta, verificou-se que nas fases de projeto conceitual e projeto detalhado houve menor aceitação quanto ao momento da integração dos aspectos ambientais, devido à interface dessas fases. Já no planejamento estratégico de projetos, planejamento de projeto e projeto informacional ocorreu desvio padrão alto nas notas, indicando divergência de opinião dos especialistas sobre o tema. Conclui-se que esse trabalho engloba um conjunto de práticas de ecodesign para suportar a tomada de decisão no PDP com objetivo de reduzir o impacto ambiental do produto durante todo o ciclo de vida.

Palavras-chaves: Processo de desenvolvimento de produtos (PDP). Ecodesign. Design for environment (DfE). Métodos e ferramentas. Análise bibliométrica. 


\begin{abstract}
VARANDAS Jr., A. (2014). A proposal to integration of environmental aspects of ecodesign into the process of developing new products. 2014. 287p. Doctoral Thesis. Post-graduate Program in Production Engineering, Polytechnic School, USP, São Paulo, 2014.
\end{abstract}

The society, market and legislation demands for sustainability have grown then academics have to revisit the issue and to search for ways to reduce the environmental impact of the product during its life cycle. The integration of ecodesign tools in the Product Development Process (PDP) aiming at the improvement the product environmental requirements without compromising its performance, cost or characteristics. However, in spite of this tendency, the structures of PDP still do not incorporate environmental practices in their activities in a proper manner. Therefore, the proposal of this work is integrating ecodesign practices in the tasks of PDP structure. To achieve this purpose was used the systematic literature review linking techniques such as bibliometric and social networking analysis, diagrams, mapping 154 ecodesign methods, analysis of the characteristics and environmental issues of 80 PDP structures and systematization of 365 environmental aspects in the PDP. The results demonstrate that the PDP structures do not emphasize the phases of pre-development and post-development that are important to reduce environmental impact. Therefore, a detailed proposal for integration was developed by analyzing the characteristics and contribution of each environmental aspect to minimize the environmental impact of the product and its relation to the function of each task of the PDP. In assessing the proposal, it was found that the phases of conceptual design and detailed design were less accepted about time of integration of environmental aspects, due to the interface of these phases. In the strategic planning of projects, project planning and informational project were a high standard deviation in the experts' evaluation, indicating divergence of opinion on the theme. In conclusion, this work includes a set of ecodesign practices to support decision making in the PDP in order to reduce the environmental impact of the product throughout its life cycle.

Key words: Product development process (PDP). Ecodesign. Design for environment (DfE). Methods and tools. Bibliometric analysis. 


\section{LISTA DE FIGURAS}

Figura 1.1 - Síntese das principais contribuições da pesquisa................................19

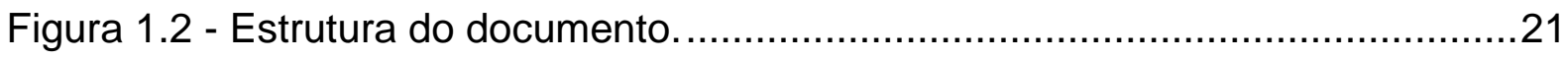

Figura 2.1 - Fases e etapas de condução do trabalho de pesquisa. ......................24

Figura 2.2 - Etapas metodológicas para realização do referencial teórico. ...............25

Figura 2.3 - Etapas da elaboração da proposta de estruturação do PDP com

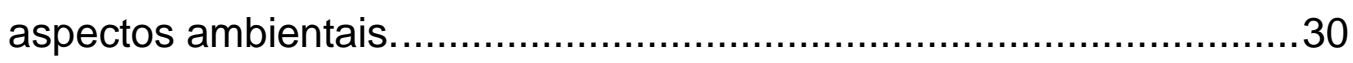

Figura 2.4 - Análise para integrar aspectos ambientais nas fases do PDP..............36

Figura 2.5 - Etapas da verificação em campo da proposta de estruturação do PDP

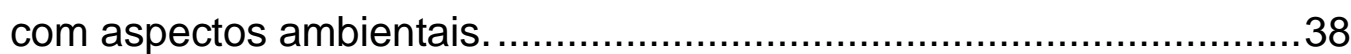

Figura 2.6 - Fluxo de escolha do teste de hipótese para variâncias.........................44

Figura 2.7 - Fluxo de tomada de decisão para teste de hipótese das médias. .........45

Figura 3.1 - Publicações disponíveis no ISI Web of Knowledge para os termos PLM,

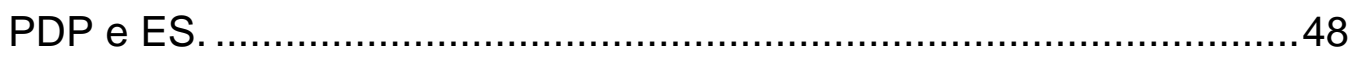

Figura 3.2 - Distribuição percentual e quantidade de publicações por 5 anos. ........49

Figura 3.3 - Classificação pelo tipo de abordagem de pesquisa nos estudos. .........50

Figura 3.4 - Classificação quanto à abordagem dos estudos................................51

Figura 3.5 - Classificação quanto à extensão dos estudos. ....................................52

Figura 3.6 - Classificação quanto à escolha do objeto de análise dos estudos........52

Figura 3.7 - Distribuição da utilização de documentação para coleta de dados

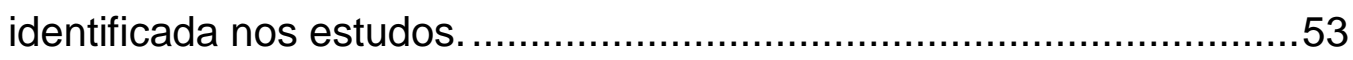

Figura 3.8 - Classificação do período analisado nos estudos.................................53

Figura 3.9 - Percentual de citações por ano dos 20 trabalhos mais citados sobre

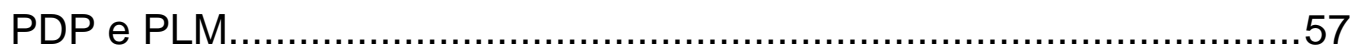

Figura 3.10 - Número de citações por ano dos trabalhos sobre PDP e PLM. .57

Figura 3.11 - Rede de palavras-chaves dos trabalhos mais citados sobre PDP e PLM. .58

Figura 3.12 - Rede de co-citação dos trabalhos mais citados sobre PDP e PLM.....59

Figura 3.13 - Rede de relações entre os trabalhos e referências mais citadas sobre PDP e PLM. .60

Figura 3.14 - Percentual de citações por ano dos 20 trabalhos mais citados sobre PDP e PLM (atualizado). 
Figura 3.15 - Número de citações por ano dos trabalhos citados mais sobre PDP e PLM (atualizado). . .62

Figura 3.16 - Percentual de citações por ano dos 20 trabalhos mais citados sobre PDP e ES.

Figura 3.17 - Número de citações dos 20 trabalhos mais citados sobre PDP e ES. 64 Figura 3.18 - Rede de palavras-chaves dos trabalhos mais citados sobre PDP e ES.

Figura 3.19 - Rede de citação cruzada dos trabalhos mais citados sobre PDP e ES.

Figura 3.20 - Percentual de citações por ano dos 20 trabalhos mais citados sobre PDP e ES (atualizado).

Figura 3.21 - Número de citações dos 20 trabalhos mais citados sobre PDP e ES (atualizado).

Figura 3.22 - Percentual de citações por ano dos 20 trabalhos mais citados sobre PLM e ES.

Figura 3.23 - Número de citações dos 20 trabalhos mais citados sobre PLM e ES. 71 Figura 3.24 - Rede de palavras-chaves dos trabalhos mais citados sobre PLM e ES.

Figura 3.25 - Rede de co-citação para os trabalhos mais citados sobre PLM e ES. 72 Figura 3.26 - Número de citações dos 20 trabalhos mais citados sobre PLM e ES (atualizado).

Figura 3.27 - Percentual de citações por ano dos 20 trabalhos mais citados sobre PLM e ES (atualizado).

Figura 3.28 - Número de citações dos trabalhos citados sobre PDP, PLM e ES. ....75

Figura 3.29 - Percentual de citações por ano dos trabalhos citados sobre PDP, PLM e ES. .76

Figura 3.30 - Número de citações dos trabalhos citados sobre PDP, PLM e ES (atualizado). .78

Figura 3.31 - Percentual de citações por ano dos trabalhos citados sobre PDP, PLM e ES (atualizado). .78

Figura 4.1 - Estrutura do PDP de Rozenfeld et al. (2006). .85

Figura 4.2 - Fases físicas do ciclo de vida do produto. 106

Figura 5.1 - Abrangência e fronteiras dos conceitos utilizados nessa pesquisa. ....109 Figura 5.2 - Evolução da preocupação ambiental na perspectiva das indústrias. ..110 
Figura 6.1 - Proposta de estrutura de PDP integrando aspectos ambientais. ........128

Figura 7.1 - Histograma das avaliações dos especialistas...................................158

Figura 7.2 - Pareto das avaliações dos especialistas........................................159

Figura 7.3 - Teste de normalidade das avaliações dos especialistas......................160

Figura 7.4 - Boxplot das avaliações por especialistas......................................160

Figura 7.5 - Boxplot das avaliações por especialistas.......................................161

Figura 7.6 - Teste de hipótese para igualdade de variância das avaliações. ..........162

Figura 7.7 - Teste de hipótese da mediana de Mood das avaliações por

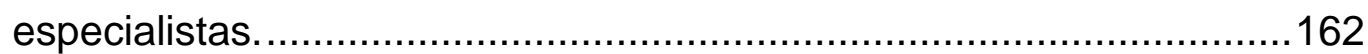

Figura 7.8 - Intervalo de confiança de acerto das avaliações dos especialistas. ....164

Figura 7.9 - Teste de Hipótese para avaliação das fases do PDP. ........................166

Figura 7.10 - Teste de Hipótese para avaliação dos especialistas........................167

Figura 7.11 - Teste de Hipótese para as notas médias dos especialistas...............167 


\section{LISTA DE TABELAS}

Tabela 2.1 - Publicações e citações dos conceitos encontrados na literatura. .27

Tabela 2.2 - Publicações e citações dos conceitos encontrados na literatura (atualizado). .28

Tabela 2.3 - Detalhes do mapeamento das estruturas de PDP na literatura. 31

Tabela 2.4 - Mapeamento dos métodos e ferramentas de ecodesign na literatura. .34

Tabela 2.5 - Exemplo de distribuição hierárquica dos aspectos ambientais. .35

Tabela 2.6 - Lista dos especialistas que participaram da consulta .39

Tabela 2.7 - Parâmetros do nível de confiabilidade interna (alfa de Cronbach). 43

Tabela 2.8 - Exemplo da estrutura utilizada para análise dos comentários dos especialistas

Tabela 3.1 - Estratificação do refinamento da busca combinada dos termos PLM, PDP e ES. 49

Tabela 3.2 - Definição dos termos utilizados na análise bibliométrica. .55

Tabela 3.3 - Os 20 trabalhos mais citados sobre PDP e PLM. .56

Tabela 3.4 - As referências citadas mais que 4 vezes sobre PDP e PLM. 59

Tabela 3.5 - Os 20 trabalhos mais citados sobre PDP e PLM (atualizado). 60

Tabela 3.6 - Os 20 trabalhos mais citados sobre PDP e ES. 63

Tabela 3.7 - As referências citadas mais que 4 vezes sobre PDP e ES. .66

Tabela 3.8 - Os 20 trabalhos mais citados sobre PDP e ES (atualizado).................67

Tabela 3.9 - Os 20 trabalhos mais citados sobre PLM e ES. 69

Tabela 3.10 - As referências citadas mais que 3 vezes sobre PLM e ES. 73

Tabela 3.11 - Os 20 trabalhos mais citados sobre PLM e ES (atualizado). .73

Tabela 3.12 - Os trabalhos citados pelo menos 1 vez sobre PDP, PLM e ES. .75

Tabela 3.13 - Os trabalhos citados pelo menos 1 vez sobre PDP, PLM e ES (atualizado). .77

Tabela 3.14 - Resultados dos indicadores das redes de palavras-chaves. .79

Tabela 4.1 - Estruturas de PDP encontradas na literatura (década de 60-70).

Tabela 4.2 - Estruturas de PDP encontradas na literatura (década de 80-90). 89

Tabela 4.3 - Estruturas de PDP encontradas na literatura (2000 até 2013). .94

Tabela 4.4 - Análise das fases mais utilizadas nas estruturas de PDP. 102

Tabela 5.1 - Definições do conceito de ecodesign selecionados da literatura. .112 
Tabela 5.2 - Exemplos de trabalhos sobre a integração do ecodesign no PDP ....114

Tabela 5.3 - Tipos de métodos e ferramentas de ecodesign 118

Tabela 5.4 - Classificação de métodos e ferramentas de ecodesign no PDP. .......120

Tabela 5.5 - Exemplo dos 154 métodos e ferramentas de ecodesign analisados.. 121

Tabela 5.6 - Exemplo de aspectos ambientais na forma bruta e os métodos e ferramentas de ecodesign relacionados. 124

Tabela 5.7 - Exemplo de aspectos ambientais de ecodesign. 125

Tabela 6.1 - Fase de Planejamento Estratégico de Produtos. 129

Tabela 6.2 - Fase de Planejamento do Projeto. 132

Tabela 6.3 - Fase de Projeto Informacional. 134

Tabela 6.4 - Fase de Projeto Conceitual. 137

Tabela 6.5 - Fase de Projeto Detalhado. 141

Tabela 6.6 - Fase de Preparação da Produção do Produto. 148

Tabela 6.7 - Fase de Lançamento do Produto. 151

Tabela 6.8 - Fase de Acompanhar Produto e Processo. 154

Tabela 6.9 - Fase de Descontinuar Produto no Mercado (DPM) 155

Tabela 7.1 - Resultados de confiabilidade interna do questionário aplicado. 157

Tabela 7.2 - Análise das avaliações dos especialistas para identificar clusters......163

Tabela 7.3 - Análise da avaliação por fase da proposta apresentada. 165

Tabela 7.4 - Avaliação do desvio padrão das notas das fases por especialista......165 Tabela 7.5 - Avaliação das notas médias das fases da proposta por especialista..165 Tabela 7.6 - Principais comentários dos especialistas sobre a proposta avaliada. .168 Tabela 7.7 - Análise qualitativa das sugestões de melhorias dos especialistas .170 


\section{LISTA DE ABREVIATURAS E DE SIGLAS}

ABNT

ACV

AFF

APP

BPM

CAPES

CHASSE

DfE

DfM

DfS

DPM

E2-PA

ECD

EDIT

EEA

E-FMEA

ELDA

ENPD

EOL

ERPA

ES

FMEA

GE

GP

IJLCA

ISO

ISO TS

Associação Brasileira de Normas Técnicas

Avaliação do Ciclo de Vida do produto

Alternative Function Fulfillment

Acompanhar Produto e Processo

Business Process Management

Coordenação de Aperfeiçoamento de Pessoal de Nível Superior

Checklist-based Assessment Support System for Ecodesign

Design for Environment

Design for Manufacturing

Design for Sustainability

Descontinuar Produto no Mercado

Environmental Efficiency Potential Assessment

Environmentally Conscious Design

Environmental Design Industrial Template

Environmental Effect Analysis

Environmental Failure Mode and Effects Analysis

End-of-Life Design Advisor

Environmental New Product Development

End of Life

Environmentally Responsible Product Assessment

Environment Sustainability

Failure Mode Effect Analysis

Green Engineering

Green Product

International Journal of Life Cycle Assessment

International Organization for Standardization

International Organization for Standardization Technical

Specification

JCP Journal of Cleaner Production

LCA Life Cycle Assessment 
LCC Life Cycle Costing

LCD Life Cycle Design

LCECA Life Cycle Environmental Cost Analysis

LP Lançamento do Produto

NPD New Product Development

PC Projeto Conceitual

PD Projeto Detalhado

PDP Processo de Desenvolvimento de Produto

PEP Planejamento Estratégico do Produto

PI Projeto Informacional

PLM Product Life Cycle Management

PP Planejamento do Projeto

PPP Preparação da Produção do Produto

QEP Qualidade e Engenharia do Produto

QFD Quality Function Deployment

QFDE Quality Function Deployment for Environment

ReSICLED Recovery Systems Modeling and Indicator Calculation Leading to

End-of-life-conscious Design

SD Sustainable Design

SLCM Strategic Life Cycle Management

SPD Sustainable Product Development

SPSD Sustainable Product and/or Service Development

SSC Sistemas, Subsistemas e Componentes

STRETCH Strategic Environmental Challenge

UFRGS Universidade do Rio Grande do Sul

UFSC Universidade Federal de Santa Catarina

UFSCar Universidade Federal de São Carlos

UNEP United Nations Environment Programme

UNISINOS Universidade do Vale do Rio dos Sinos

USP-EESC Escola de Engenharia de São Carlos da USP

USP-EP Escola Politécnica da Universidade de São Paulo

WCED World Comission on Environment and Development 


\section{SUMÁRIO}

AGRADECIMENTOS

i

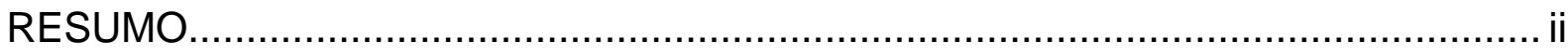

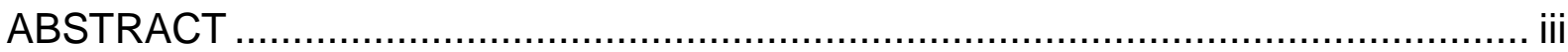

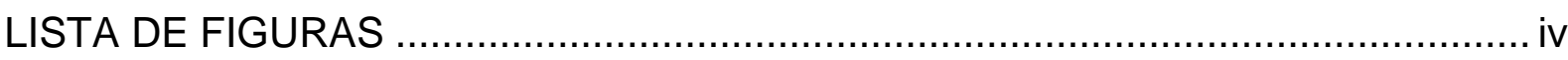

LISTA DE TABELAS .......................................................................... vii

LISTA DE ABREVIATURAS E DE SIGLAS............................................. ix

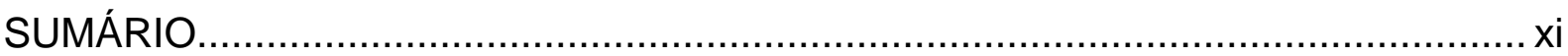

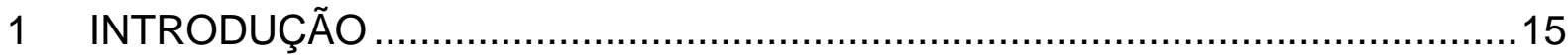

1.1 Relevância e contribuição original da pesquisa .......................................17

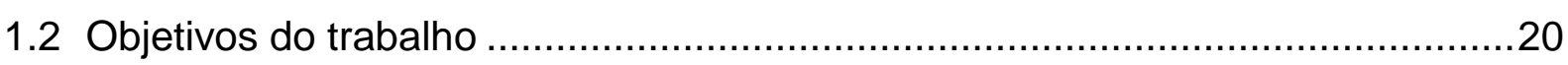

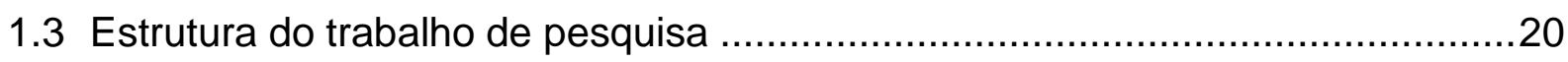

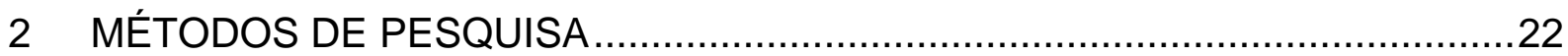

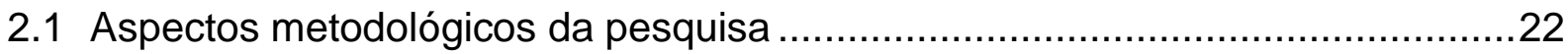

2.2 Fases e etapas do desenvolvimento da pesquisa.....................................23

2.2.1 Fase I: Referencial teórico ........................................................24

2.2.1.1 Etapa 1: Varredura horizontal (literature search) ..............................26

2.2.1.2 Etapa 2: Varredura vertical (literature review) .................................27

2.2.2 Fase II: Elaboração da proposta de estruturação do PDP com aspectos

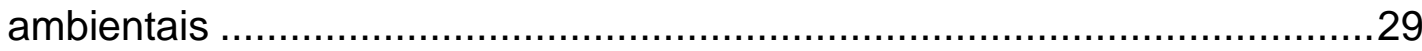

2.2.2.1 Etapa 3: Mapeamento e análise de conteúdo das estruturas de PDP...31

2.2.2.2 Etapa 4: Seleção de quais fases das estruturas de PDP utilizar para elaboração da proposta de integrar aspectos ambientais no PDP........32

2.2.2.3 Etapa 5: Mapeamento e seleção dos métodos e ferramentas de ecodesign

2.2.2.4 Etapa 6: Seleção de aspectos ambientais dos métodos e ferramentas de ecodesign

2.2.2.5 Etapa 7: Elaboração da proposta de estruturação do PDP com aspectos ambientais 
2.2.3 Fase III: Verificação em campo da proposta de estruturação do PDP com aspectos ambientais

2.2.3.1 Etapa 8: Planejamento da pesquisa de campo .....................................38

2.2.3.2 Etapa 9: Construção do instrumento de pesquisa ................................40

2.2.3.3 Etapa 10: Coleta de dados - Consulta com especialistas .......................41

2.2.3.4 Etapa 11: Análise de dados - Consulta com especialistas ...................42

2.2.3.4.1 Confiabilidade interna do instrumento de coleta de dados - Alfa de

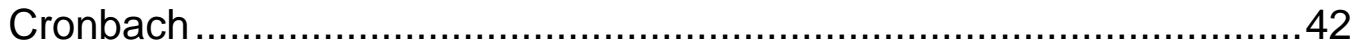

2.2.3.4.2 Análise quantitativa dos dados levantados em campo ........................43

2.2.3.4.3 Análise qualitativa das avaliações de discordância dos especialistas ...46

2.2.3.4.4 Etapa 12: Revisão e adequação da proposta de estruturação do PDP com aspectos ambientais

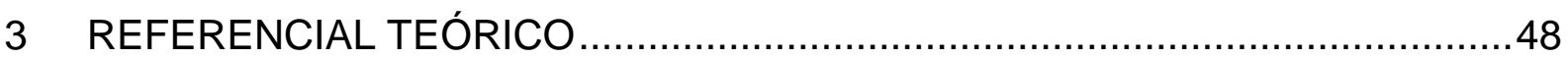

3.1 Revisão e classificação dos conceitos de PLM, PDP e ES ...............................48

3.2 Análise bibliométrica dos conceitos PLM, PDP e ES ……..............................54

3.2.1 Análise bibliométrica combinando os conceitos PDP e PLM ......................55

3.2.1.1 Atualização da análise bibliométrica combinando os conceitos PDP e

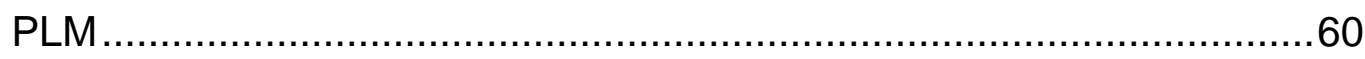

3.2.2 Análise bibliométrica combinando os conceitos PDP e ES.........................63

3.2.2.1 Atualização da análise bibliométrica combinando os conceitos PDP e ES

3.2.3 Análise bibliométrica combinando os conceitos PLM e ES.........................69

3.2.3.1 Atualização da análise bibliométrica combinando os conceitos PLM e ES

3.2.4 Análise bibliométrica dos conceitos PDP, PLM e ES ……........................75

3.2.4.1 Atualização da análise bibliométrica dos conceitos PDP, PLM e ES.....77

3.2.5 Análise dos indicadores de centralidade das redes sociais ........................79

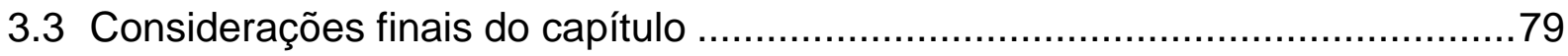

4 ANÁLISE E SELEÇÃO DAS FASES DAS ESTRUTURAS DE PDP ..................82

4.1 Caracterização do Processo de Desenvolvimento de Produtos..........................82

4.2 Mapeamento e análise de conteúdo das estruturas de PDP ...........................84 
4.3 Seleção de quais fases das estruturas de PDP utilizar para elaboração da proposta de integrar aspectos ambientais no PDP

4.4 Considerações finais do capítulo

5 IDENTIFICAÇÃO E SELEÇÃO DOS ASPECTOS AMBIENTAIS DOS MÉTODOS E FERRAMENTAS DE ECODESIGN ........................................109

5.1 Panorama do Desenvolvimento de Produtos Sustentáveis..............................110

5.2 Caracterização do Ecodesign ...........................................................112

5.3 Mapeamento de métodos e ferramentas de ecodesign .................................117

5.4 Seleção de aspectos ambientais dos métodos de ecodesign .........................124

5.5 Considerações finais do capítulo .............................................................126

6 PROPOSTA DE ESTRUTURAÇÃO DO PDP INTEGRANDO ASPECTOS

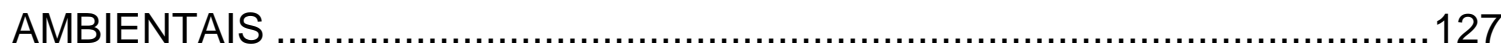

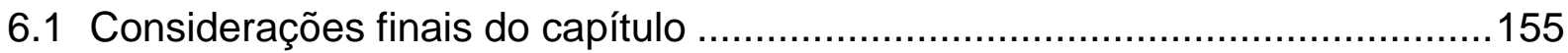

7 VERIFICAÇÃO EM CAMPO DA PROPOSTA DE ESTRUTURAÇÃO DO PDP

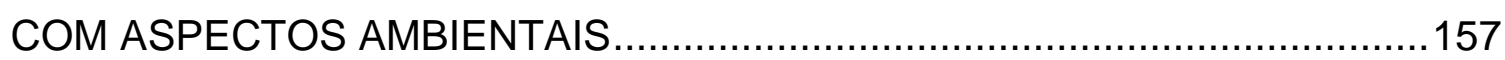

7.1 Confiabilidade interna do questionário - Alfa de Cronbach ............................157

7.2 Análise quantitativa dos dados levantados em campo ..................................158

7.3 Análise qualitativa das avaliações dos especialistas .....................................168

7.4 Considerações finais do capítulo ..........................................................176

8. CONCLUSÕES E SUGESTÕES PARA TRABALHOS FUTUROS ..................177

8.1 Sugestões para trabalhos futuros .............................................................181

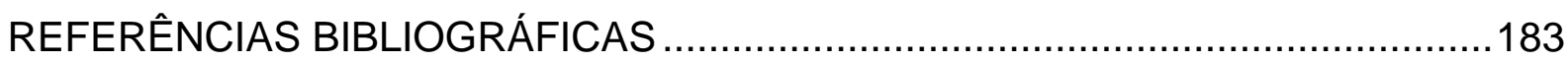

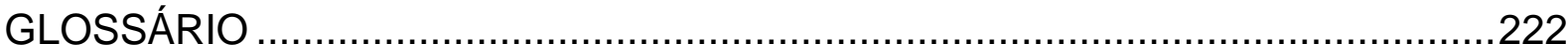

APÊNDICE I - Codificação da classificação dos trabalhos sobre Product Life Cycle Management (PLM), Product Development Process (PDP) e Environmental Sustainability (ES) .226 
APÊNDICE II - Apresentação dos trabalhos codificados em ordem alfabética 227

APÊNDICE III - Indicadores de centralidade, intermediação, proximidade e estatística descritiva das palavras-chaves sobre PDP, PLM e ES.229

APÊNDICE IV - Lista completa dos 154 métodos e ferramentas de ecodesign encontrados na literatura 231

APÊNDICE V - Os 365 aspectos ambientais identificados e extraídos dos métodos e ferramentas de ecodesign .255

APÊNDICE VI - Questionário utilizado na consulta aos especialistas. .263

APÊNDICE VII - Sugestões dos especialistas para melhoria da proposta. .275 


\section{INTRODUÇÃO}

A World Comission on Environment and Development (WCED) estabeleceu o conceito de desenvolvimento sustentável, que evoluiu para os pilares econômico, social e ambiental (ELKINGTON, 1994; BARBIERI et al., 2010; LEE et al., 2012). Nesta linha de atuação, o programa ambiental das Nações Unidas destaca o gerenciamento do ciclo de vida dos produtos para alcançar o desenvolvimento de produtos sustentáveis (UNEP, 2008). Desde então, a competição no mercado global vem aumentando a preocupação das empresas quanto ao meio ambiente, o que as leva a procurar meios de inserir aspectos ambientais no PDP (BAUMANN et al., 2002; PHAAL, 2006; KOVA'CS, 2006; NIDUMOLU, 2009; POULIKIDOU et al., 2014).

Neste contexto, a destinação dos produtos no fim de sua vida útil e o reaproveitamento destes, por meio de estratégias de fim de vida (tais como a remanufatura, reciclagem e reuso) vem sendo focados pelas empresas (MANZINI; VEZZOLI, 2005; KURK; EAGAN, 2008). De modo geral, existem nas empresas possibilidades de redução na utilização dos recursos energéticos necessários para a produção. Medidas como reaproveitamento dos materiais utilizados na fabricação dos produtos proporcionam limitações no uso de matérias-primas e da energia na conversão da matéria-prima reciclada (VAN BERKEL, 2007). A problemática da sustentabilidade ambiental (ES - Environment Sustainability) tem como característica o seu caráter sistêmico, que coloca fortes desafios conceituais e operacionais, sendo necessário um esforço conjunto de todas as áreas da empresa. São tratadas neste contexto muitas áreas de conhecimento que, a princípio, parecem distintas, mas cuja integração viabiliza a sustentabilidade ambiental (KRAUSE et al., 2006; COOPER, 2007; EBERT; DE MAN, 2008).

Entre as iniciativas existentes, tem-se a abordagem do gerenciamento do ciclo de vida dos produtos (PLM - Product Life Cycle Management), que envolve um grande número de processos de negócio que as empresas empregam para se manter competitivas, tais como (ROZENFELD et al., 2006): i) Pesquisa \& Desenvolvimento; ii) Desenvolvimento de produto; iii) Gestão de configuração das informações do produto e processo; iv) Acompanhamento do produto depois do lançamento e sua retirada do mercado; e v) Gestão dos processos de negócios (BPM - Business 
Process Management). Nesse sentido, o PLM considera a sustentabilidade ambiental na criação e desenvolvimento de um produto, com o objetivo de diminuir o impacto ambiental de sua produção, uso e descarte. Além do mais, os processos de negócio de PLM, que ocorrem após o desenvolvimento e durante a sua produção, garantem que as especificações de projeto sejam atendidas e que os processos de negócio que lidam com os produtos possam ser melhorados constantemente de forma cíclica e gradual (KILMANN, 1995; LUTTROPP; LAGERSTEDT, 2006).

Alinhado aos conceitos de PLM e sustentabilidade ambiental, destaca-se 0 Processo de Desenvolvimento de Produto (PDP), que é essencial na construção e sustentação de vantagem competitiva da empresa para fortalecer sua posição mercadológica. Este processo consiste em um conjunto de atividades para definir novos produtos, em que alternativas são identificadas e avaliadas com critérios previamente definidos (ROZENFELD et al., 2006). Sua função é integrar esses critérios e otimizá-los, considerando as restrições nos produtos, processos e organizacionais e, também, de custos com retrabalhos (CLARK; FUJIMOTO, 1991).

Pela importância dos conceitos de PLM, PDP e ES para redução do impacto ambiental e aumento da competitividade das empresas, surge à necessidade de se compreender melhor esses conceitos e suas interfaces. Assim sendo, nesse trabalho realiza-se uma revisão bibliográfica sobre esses conceitos, utilizando o método de busca bibliográfica proposto por Hart (2001) denominado "Trawling and Mining for Information", que visa realizar uma varredura horizontal sobre a inquietação de pesquisa e, depois, varredura vertical sobre o assunto de interesse. Fleury (2010) também cita que se deve fazer uma "literature research" para identificar de quais teorias pode-se partir ao abordar um fenômeno, e uma "literature review" como um aprofundamento na literatura sobre o conceito selecionado. Além disso, na elaboração do referencial teórico aplicou-se técnicas de classificação e codificação e análise bibliométrica da literatura, visando identificar possíveis tendências e lacunas nos trabalhos sobre esses três conceitos abordados.

Durante essas análises, constata-se a importância de intensificar mais estudos sobre os conceitos de ecodesign e PDP, pois esses conceitos foram identificados como clusters principais pela análise das redes sociais. Desta forma, foi realizada uma nova busca na literatura, aprofundando na integração dos conceitos de ecodesign e PDP e suas relações, com enfoque nas estruturas de PDP e nos métodos e ferramentas de ecodesign. Como na literatura existem muitas definições 
para o termo ecodesign, que variam conforme a área de aplicação adotou-se nesse trabalho a definição proposta pela norma ABNT ISO/TR 14062 (2002) e ISO 14006 (2011), que define o ecodesign como "Integração dos aspectos ambientais na concepção e desenvolvimento de produtos com o objetivo de reduzir os impactos ambientais durante todo o ciclo de vida do produto". Com base nos estudos de Baumann et al. (2002), Byggeth e Hochschorner (2006), Haastedt (2008), Poulikidou et al. (2014) e Goepp et al. (2014) sobre a integração do ecodesign e PDP, assumiuse para ser utilizada nesse trabalho a nomenclatura "aspecto ambiental" como sendo as estratégias, princípios e práticas gerenciais e operacionais de ecodesign que visam integrar preocupações ambientais no PDP e processos relacionados, considerando o impacto ambiental durante todo o ciclo de vida do produto. Segundo a ABNT NBR ISO 14062 (2002), esse conceito tem relação direta de causa-efeito com o impacto ambiental, que é definido como qualquer modificação do meio ambiente, adversa ou benéfica, que resulte no todo ou em parte dos aspectos ambientais da organização (MARIMON et al., 2011).

Desta forma, após a investigação teórica nos conceitos de PDP e ecodesign e análise dos trabalhos que sustentam as discussões sobre as interfaces entre eles, identificou-se como oportunidade de pesquisa para ser desenvolvida a "integração de aspectos ambientais nas estruturas de PDP", que tem sua justificativa embasada na relevância desse tema para o meio acadêmico e empresarial, conforme justificativas apresentadas na próxima seção.

\subsection{Relevância e contribuição original da pesquisa}

Os impactos ambientais e as mudanças climáticas têm exigido um maior empenho das empresas na busca por soluções sustentáveis para as atividades industriais, principalmente para a melhoria da gestão e estruturação do PDP (BAKSHI; FIKSEL, 2003). Além disso, existe a necessidade de equiparação de aspectos ambientais aos econômicos, para melhor suportar a tomada de decisões estratégicas e melhoria da gestão do PDP (LINDAHL et al., 2003).

Diante desse cenário, diversos autores citam a importância desse tema e muitas vantagens para as empresas utilizarem de práticas de ecodesign no PDP (ECHEVESTE et al., 2002; HOLDWAY; WALKER; HILTON, 2002; ABRE, 2006): 
maior eficiência de processos e utilização de recursos; diferenciação dos produtos e embalagens; inovação e incremento do conhecimento sobre o produto; retorno financeiro pela comercialização de produtos verdes; otimização da funcionalidade do produto; melhoria da marca e imagem da empresa; redução de riscos; fidelização de clientes; melhoria na comunicação; substituição de materiais poluidores e tóxicos; e redução de impactos ambientais durante todo o ciclo de vida do produto. Para Boks (2006), as principais vantagens da implementação do ecodesign estão relacionadas aos aspectos convencionais dos negócios, tais como a customização, organização e comunicação. A empresa também deve avaliar a sua capacidade de aplicar o ecodesign, tomando como base os seus fatores internos de motivação e externos como as regulamentações do meio ambiente e as alterações necessárias de reprojeto para adequar o produto as questões ambientais (VERCALSTEREN, 2001; BEY et al., 2013). Para Goffin (2012) as empresas ainda não estão preparadas para integrar práticas de ecodesign no PDP, elas precisam fazer modificações na estrutura de PDP para alcançar essa integração. Da mesma maneira, Murillo-Luna et al. (2011) afirmam que a principal dificuldade de se integrar práticas de ecodesign no PDP é advinda das barreiras internas das empresas.

Além dessas discussões sobre a integração de aspectos ambientais no PDP para se reduzir o impacto ambiental, outros estudos abordaram a relação entre ecodesign e sistemas de gestão, desempenho dos indicadores ambientais e avaliação do ciclo de vida do produto. Sintetizando os estudos que mais se aproximam do tema desse trabalho estão: o foco na integração do ecodesign com o PDP (JOHANSSON, 2002; PLATCHECK et al., 2008; LEWANDOWSKA; KURCZEWSKI, 2010; GOEPP et al., 2014; POULIKIDOU et al., 2014), o ecodesign como estratégia para melhoria ambiental do PDP (CHARTER, 1997; STEVELS, 1997; BHAMRA, 2004;) e análise dos métodos e ferramentas de ecodesign no PDP (BYGGETH; HOCHSCHORNER, 2006; GUELERE FILHO, 2009; PIGOSSO et al., 2010; BOVEA; PÉREZ-BELIS, 2012; LINDAHL; EKERMANN, 2013), integração da dimensão ambiental no gerenciamento de projetos de novos produtos (ROBICHAUD; ANANTATMULA, 2011; MARTENS et al., 2013; BRONES et al., 2014) e inserção da sustentabilidade no PDP (VIEGAS; SALLES, 2012).

$\mathrm{Na}$ literatura existem muitos métodos e ferramentas de ecodesign disponíveis com diferentes graus de complexidade, abordagens, custo, efetividade na redução do impacto ambiental, dificuldade de escolha e necessidade de especialistas para 
ajudar nessa integração (LE POCHAT et al., 2007; PIGOSSO; ROZENFELD, 2012). Devido a essa complexidade, falta de classificação para orientação na escolha adequada à aplicação dos instrumentos de ecodesign, as empresas não estão usando esses instrumentos de forma regular no PDP (BOKS; MCALOONE, 2009; SALGADO et al., 2010; O'HARE et al., 2010; DEUTZ et al., 2013). Por outro lado, apesar da necessidade de reduzir os impactos ambientais e vantagens da integração dos conceitos de ecodesign no PDP, identifica-se que poucas formas de estruturação do PDP incluem de maneira clara e detalhada como integrar os aspectos ambientais de ecodesign nas fases do PDP (SHERWIN; BHAMRA, 1999; LOFTHOUSE; BHAMRA, 2001; ROZENFELD et al., 2006).

Logo, fica evidente que existem muitas ferramentas de ecodesign disponíveis no mercado para ajudar a reduzir o impacto ambiental no PDP, mas que são pouco empregadas pelas empresas apesar de vários estudos indicarem vantagens dessa integração. Portanto, percebe-se que o tema integração de aspectos ambientais no PDP é relevante e que há uma lacuna no sentido de como fomentar essa integração no PDP das empresas para suprir a baixa utilização dos instrumentos de ecodesign, devido às dificuldades de aplicação. Assim, conseguiu-se delinear o problema de pesquisa e a contribuição do trabalho, que são ilustrados na Figura 1.1.
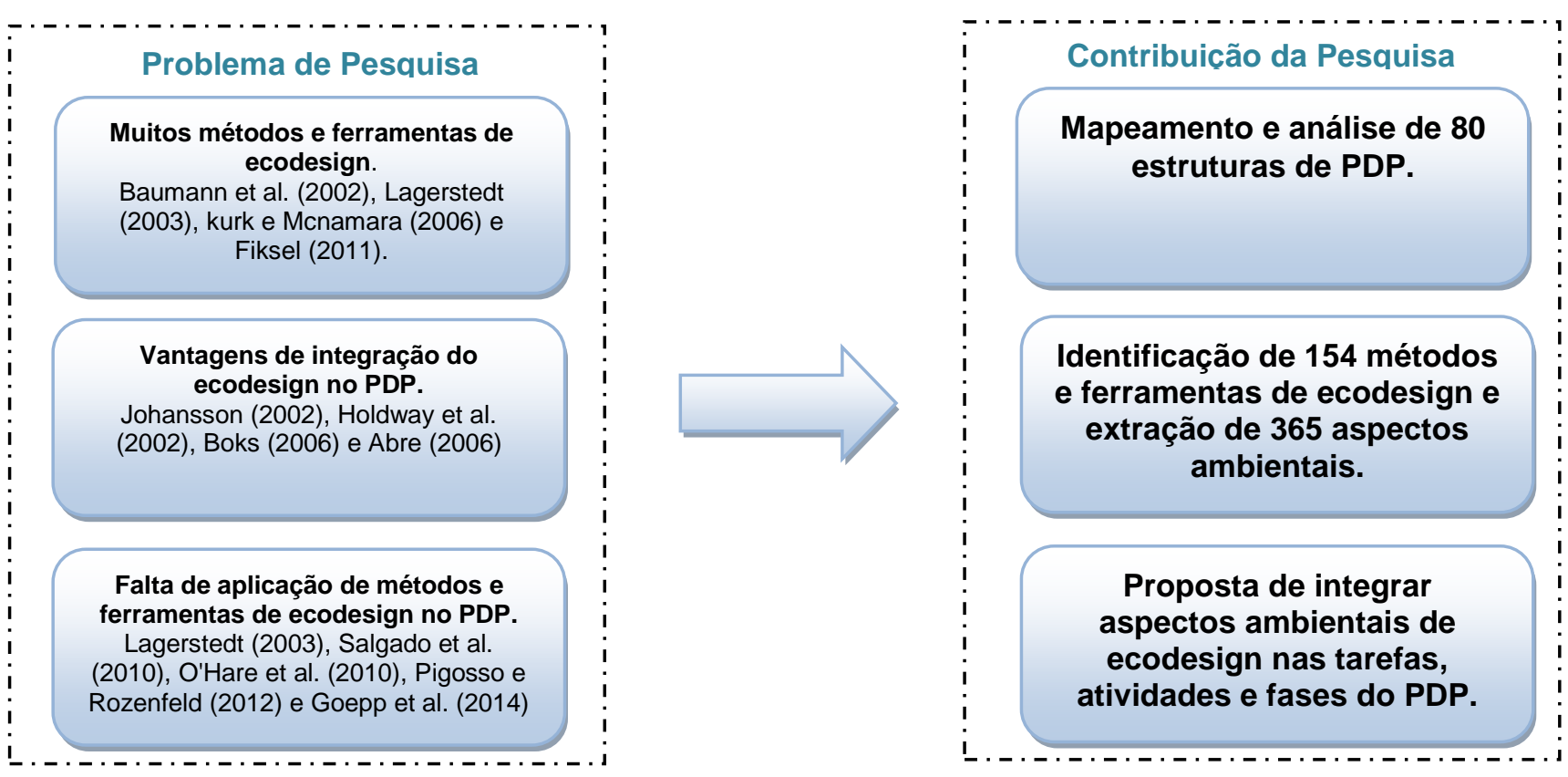

Figura 1.1 - Síntese das principais contribuições da pesquisa. 
Nesse sentido, esse trabalho propõe desenvolver uma proposta para integrar aspectos ambientais extraídos dos métodos e ferramentas de ecodesign no PDP, conforme os objetivos propostos a seguir.

\subsection{Objetivos do trabalho}

O objetivo geral da tese é estruturar o PDP considerando a integração de aspectos ambientais e possui os seguintes objetivos específicos:

- Analisar a importância ambiental nas estruturas de PDP.

- Mapear o estado da arte dos métodos e ferramentas de ecodesign específicos para aplicação no PDP.

- Sistematizar os principais aspectos ambientais apresentados nos métodos e ferramentas de ecodesign.

- Analisar a possibilidade de integração dos aspectos ambientais com a função de cada tarefa do PDP com objetivo de tomar ações durante o PDP visando à redução do impacto ambiental do produto durante o seu ciclo de vida.

Na próxima seção são descritos a função dos capítulos que compõem esse trabalho, bem como, os apêndices desenvolvidos.

\subsection{Estrutura do trabalho de pesquisa}

O presente trabalho está estruturado em três fases principais subdividida em oito capítulos, incluindo este introdutório, e sete apêndices que apresentam resultados adicionais das análises durante o desenvolvimento. O Capítulo 2, de "Métodos de Pesquisa", apresenta as escolhas e justificativas referentes aos aspectos metodológicos e operacionalização das etapas e instrumentos de coleta e análise de dados utilizados. O Capítulo 3, "Referencial Teórico", realiza uma busca sistemática na literatura para compreender a relação e interface sobre os conceitos de PLM, ES e PDP e identificar a oportunidade de pesquisa. O Capítulo 4, "Análise das fases das estruturas de PDP", investiga com maior profundidade as formas de estruturação do

PDP. O Capítulo 5, "Identificação dos aspectos ambientais dos métodos e ferramentas de ecodesign" complementa o referencial teórico sobre ecodesign e 
discorre sobre os trabalhos que abordam os instrumentos de ecodesign aplicados no PDP, as vantagens e desvantagens da utilização desse conceito e as dificuldades de integração com o PDP. No Capítulo 6, "Proposta de estruturação do PDP com aspectos ambientais", mostra a contribuição desse trabalho por meio da integração dos resultados dos Capitulo 4 com o Capítulo 5. O Capítulo 7, "Verificação da proposta de estruturação do PDP com aspectos ambientais", discute os resultados da análise de dados da consulta realizada com especialistas no tema abordado. No Capítulo 8, "Conclusões", são mostrados os resultados da tese com base nos objetivos preliminarmente definidos, as limitações e sugestões para trabalhos futuros. A Figura 1.2 ilustra os capítulos e os apêndices.

1-Introdução

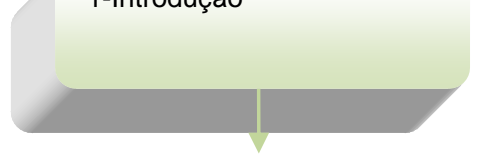

2-Métodos de Pesquisa

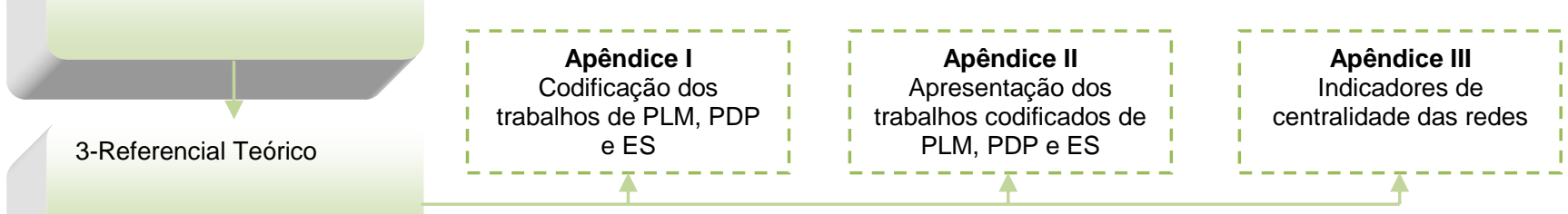

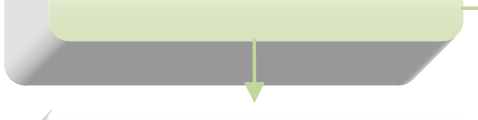

4- Análise e seleção das fases das estruturas de PDP

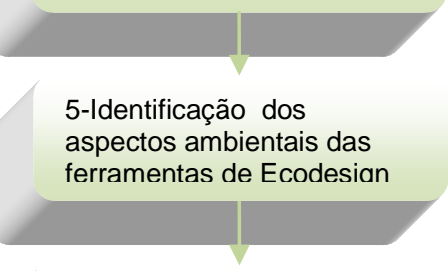

6-Proposta de estruturação do PDP com aspectos ambientais

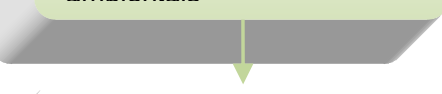

7-Verificação da proposta de estruturação do PDP

com aspectos ambientais

8-Conclusões

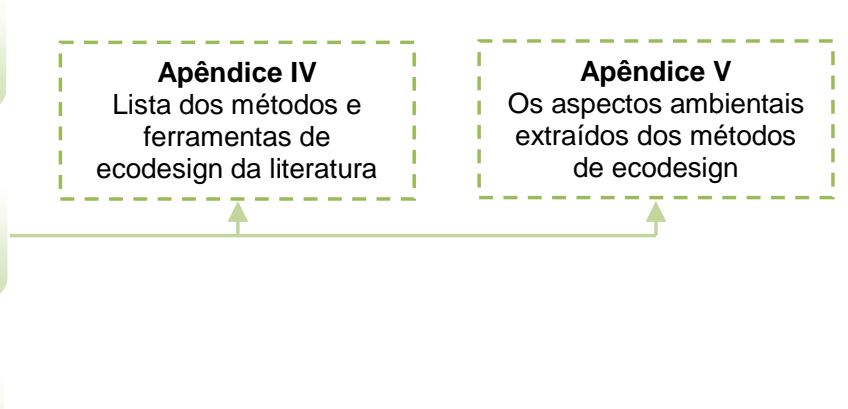

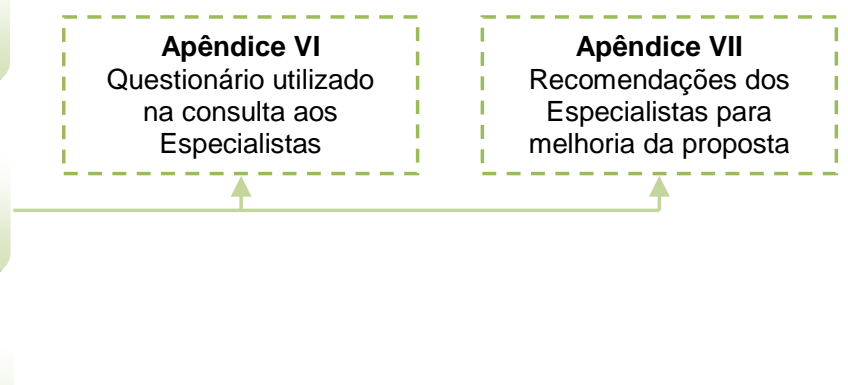

Figura 1.2 - Estrutura do documento.

Para atingir os objetivos propostos, a próxima seção sistematiza as etapas operacionais e os métodos e técnicas adotados durante a elaboração dessa tese. 


\section{MÉTODOS DE PESQUISA}

Segundo Gil (1999) a abordagem metodológica da pesquisa é necessária para que as etapas de realização do trabalho sejam conduzidas com maior rigor e objetividade, com foco e limitações bem definidos, chegando-se a resultados finais confiáveis e válidos, e permitindo que a pesquisa realizada tenha repetibilidade em outro ambiente. Nesse sentido, este capítulo descreve os aspectos metodológicos, as etapas de desenvolvimento e as justificativas das escolhas dos métodos e técnicas adotados para elaboração da proposta desse trabalho.

\subsection{Aspectos metodológicos da pesquisa}

$\mathrm{Na}$ literatura, verifica-se que não existe concordância sobre as tipologias dos métodos de pesquisa (GODOY, 1995; MAYS; POPE, 1996; MATTAR, 1996; FORZA, 2002; MIGUEL, 2007). Para Selltz et al. (1975) e Miguel et al. (2010) o mais importante sobre a escolha dos métodos de pesquisa é a sua associação com os objetivos propostos. Diante disso, o presente trabalho pode ser caracterizado como método hipotético-dedutivo, de natureza da abordagem combinada (qualitativa e quantitativa) e referente ao escopo da pesquisa como desenvolvimento teóricoconceitual, que é complementado com uma consulta aos especialistas sobre o tema abordado para verificar se a proposta apresentada está adequada.

O método dessa pesquisa é o hipotético-dedutivo, que segundo Köche (2002, p.69) esse método visa auxiliar na compreensão e interpretação da teoria sobre o tema abordado. Também, segue algumas etapas definidas por Popper $(1975 ; 1982)$ para o método hipotético-dedutivo, tais como: i) inicia com o conhecimento prévio da literatura sobre um tema e identifica uma lacuna de pesquisa (dificuldade de integração e aplicação de práticas de ecodesign no PDP), conforme demonstrado nos Capítulos 3, 4 e 5; ii) analisa a teoria, o contexto e as justificativas para construção de um modelo teórico (proposta de estruturação do PDP com aspectos ambientais), descrito no Capítulo 6; iii) realiza um teste estatístico para avaliar a proposta (consulta com especialistas); e iv) compara os resultados com a teoria para ajustar a proposta desenvolvida. 
Além disso, utiliza-se da combinação das abordagens quantitativa e qualitativa por proporcionar uma melhor coleta e subsídios para análise dos dados coletados na consulta feita aos especialistas. Essa escolha é fundamentada em Creswell e Plano Clark (2006) e Martins (2010), que cita a abordagem combinada mais eficiente que qualquer uma dessas duas abordagens de forma isolada. No levantamento e análise da avaliação dos especialistas sobre o grau de adequação da inserção de aspectos ambientais na estrutura de PDP é utilizada a abordagem quantitativa para análise estatística descritiva e testes de hipótese das avaliações dos especialistas, elaboração dos gráficos comparando as respostas e identificação de tendências e padrões da opinião. Como complemento, a abordagem qualitativa é usada para analisar se procedem os comentários e as justificativas dos especialistas e, consequentemente, obter mais evidências para discutir os resultados e ajustar a proposta com base no referencial teórico.

Em relação ao escopo da pesquisa, Berto e Nakano (2000) citam que o desenvolvimento teórico-conceitual envolve discussões conceituais a partir da literatura, revisões bibliográficas e modelagens conceituais. Logo, em termos de profundidade e amplitude do escopo da pesquisa este trabalho pode ser considerado como teórico-conceitual. Mais especificamente devido ao mapeamento, classificação e análise da literatura sobre os conceitos de ecodesign e PDP, visando identificar trabalhos relevantes sobre o tema e justificar as lacunas de pesquisa em termos de relevância mostrada no referencial teórico (CROOM, 2005). Ainda, corroborando para esse enquadramento como teórico-conceitual foi realizada uma revisão sistemática da literatura com o objetivo de atualizar o referencial teórico para suportar a análise e discussão de conceitos durante a elaboração da proposta.

A partir do mapeamento e recorte do tema da tese, descrito na fase de referencial teórico (Capítulo 3), foi escolhido e justificado os métodos e técnicas de pesquisa, conforme descrito nas próximas seções deste capítulo.

\subsection{Fases e etapas do desenvolvimento da pesquisa}

A condução dessa tese englobou vários métodos e técnicas de acordo com a necessidade de cada fase e etapa do trabalho. Esta seção descreve em detalhes as 
três principais fases do trabalho e as respectivas etapas que compõem cada fase. A Figura 2.1 representa como foi estruturada a operacionalização da pesquisa.

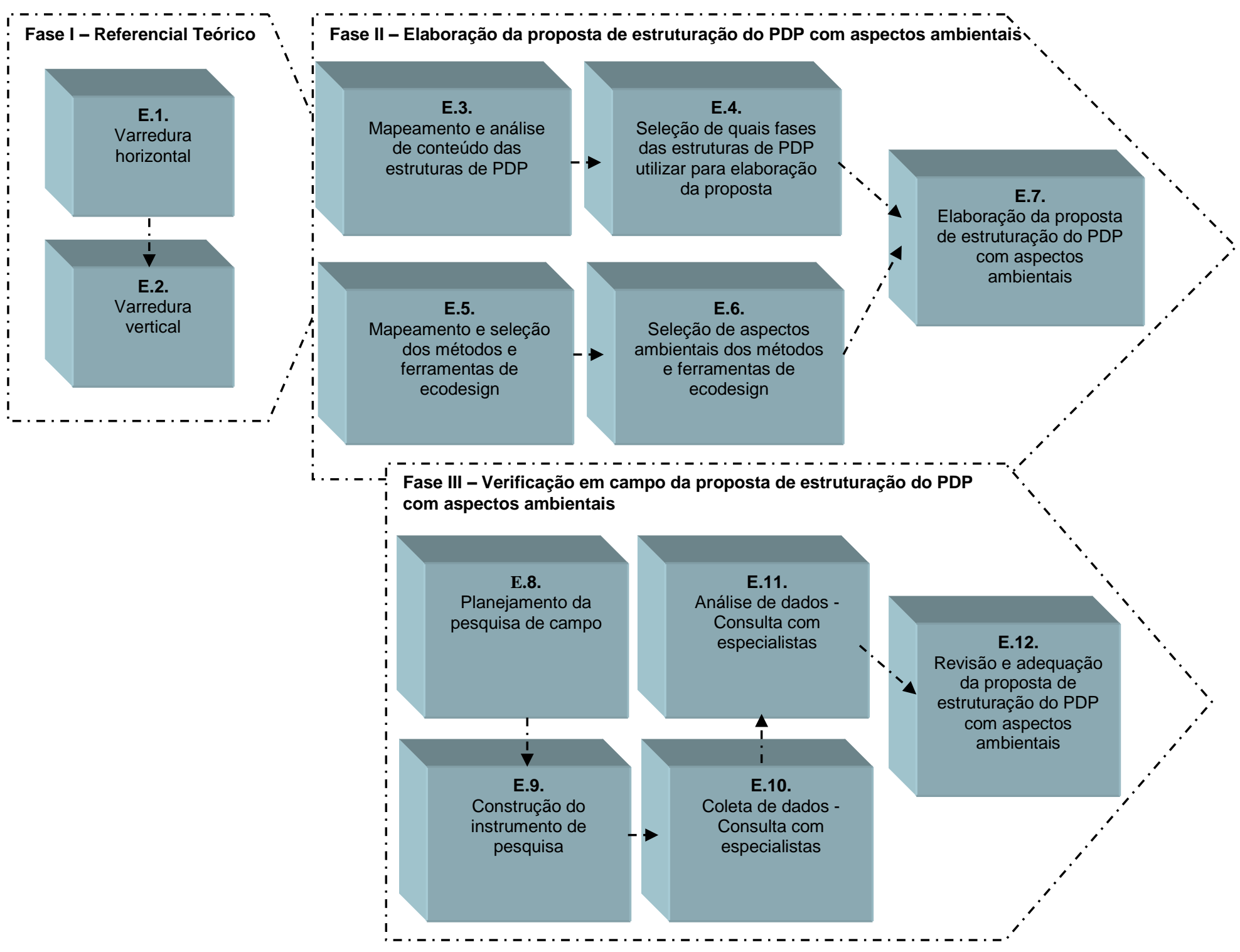

Figura 2.1 - Fases e etapas de condução do trabalho de pesquisa.

\subsubsection{Fase I: Referencial teórico}

O referencial teórico foi realizado conforme ilustra a Figura 2.2 e começou com a etapa de "varredura horizontal", conforme procedimentos propostos por Hart (2001) e Fleury (2010), que aborda os principais temas relacionados aos conceitos de PDP, PLM e sustentabilidade ambiental de maneira a adquirir mais conhecimento e dar subsídios à escolha do foco da pesquisa, durante essa etapa conseguiu-se 
classificar e codificar trabalhos relacionados aos conceitos abordados. Depois desta etapa, foi realizado um aprofundamento "vertical", ou seja, uma busca bibliográfica visando afunilar esses conceitos com objetivo de identificar uma lacuna na teoria. Nessa segunda etapa foram utilizados softwares (Sitkis e Ucinet) específicos para análise de redes sociais e identificou os temas ecodesign e PDP a serem melhor investigados. Após ter detectado os pontos relevantes na investigação sobre ecodesign e PDP, decidiu-se que o foco do trabalho seria nos métodos e ferramentas de ecodesign e nas estruturas de PDP, e conseqüentemente teve o direcionamento da busca bibliográfica para estes temas, que são detalhados na Fase II de elaboração da proposta (item 2.3.2).

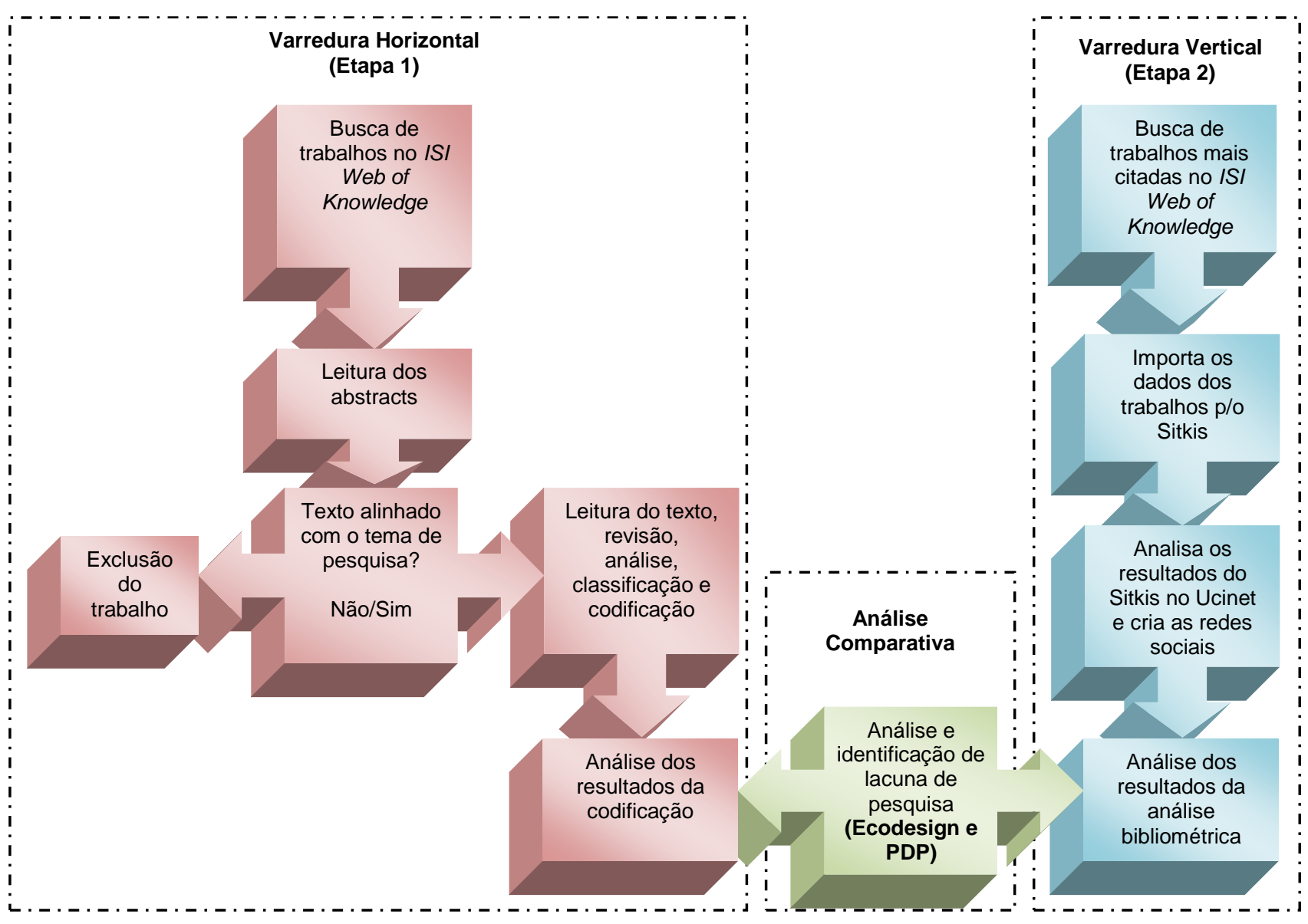

Figura 2.2 - Etapas metodológicas para realização do referencial teórico.

Diante dos procedimentos utilizados na revisão bibliográfica e com base na literatura (LITTELL et al., 2008; CONFORTO et al., 2011), a revisão bibliográfica desse trabalho pode ser caracterizada como uma revisão sistemática da literatura, pois foi conduzida de diversas formas e mesclando diferentes técnicas durante todo 
o processo, com o propósito de identificar de forma abrangente e sintetizar os resultados de trabalhos sobre um tema em particular, por meio de procedimentos organizados, de modo transparente e replicável em cada etapa da revisão.

\subsubsection{Etapa 1: Varredura horizontal (literature search)}

Essa primeira etapa do trabalho é caracterizada como teórico-conceitual mais especificamente voltada ao mapeamento e classificação da literatura sobre os conceitos de PLM, PDP e Sustentabilidade Ambiental (Environmental Sustainability ES). O seu propósito não foi de realização de uma análise crítica e nem comparativa entre as publicações selecionadas, mas visa identificar trabalhos relevantes, bem como lacunas de pesquisa existentes na literatura. É importante destacar que, para identificar, localizar e recuperar as publicações de interesse foi consultado a base de dados ISI Web of Knowledge (Web of Science) por meio do portal da Coordenação de Aperfeiçoamento de Pessoal de Nível Superior (CAPES). Essa base foi selecionada, pois é possível localizar todos os periódicos indexados cujo fator de impacto é calculado no Journal Citation Report (JCR), independentemente de sua base de origem (LOPES; CARVALHO, 2012).

$\mathrm{Na}$ consulta dos periódicos, buscaram-se como palavras-chaves os seguintes termos (sem aspas e sem refinamento por área de conhecimento): PLM, PDP e ES. Realizou-se a busca nos abstracts e nos textos completos, com recorte temporal dessa primeira etapa nos trabalhos publicados no período de 2006- 2010 e foram encontradas 1.070 publicações para o termo PLM, 14.611 publicações para o termo PDP e 5.582 publicações para o termo ES. Em seguida, foram realizadas novas buscas combinando esses termos no banco de dados para se ter um refinamento das publicações quanto ao tema abordado. Com esse refinamento, foram identificadas 479 publicações, que ao retirar as não disponíveis com acesso livre, aquelas referentes a patentes, as publicações duplicadas, e as publicações que pela leitura não estavam relacionadas ao tema analisado, resultaram 87 publicações para análise e classificação. Para a análise dos dados, foram considerados os artigos em periódicos, trabalhos de congressos e simpósios. Não foram considerados livros, dissertações e teses, pelo fato do portal da CAPES divulgar um número relativamente limitado deste tipo de publicação. 
$\mathrm{Na}$ fase de classificação dos trabalhos utilizou-se da técnica de fichamento adaptado dos formulários usados nos levantamentos de Martín et al. (1999) e Carnevalli e Miguel (2007), e com o uso do diagrama de afinidades e do diagrama em árvore foi possível organizar e agrupar os dados sobre o escopo das publicações por tipo (afinidades) e hierarquicamente (em árvore), visando analisar: (i) os conceitos de PLM, PDP e ES; (ii) os benefícios propostos pelas pesquisas; e (iii) as áreas de aplicação desses conceitos. Para permitir a visualização de todas as informações analisadas nesta etapa, os parâmetros de classificação e os resultados dos diagramas, foram elaborados codificações das publicações que são detalhados nos Apêndice I e Apêndice II. Desta maneira, foi possível identificar os trabalhos de cunho teórico e empírico, as abordagens metodológicas mais utilizadas, qual natureza da abordagem se aplica mais aos conceitos analisados e, ainda, quais as principais técnicas utilizadas para a coleta de dados e, por fim, qual o período analisado nesses trabalhos.

\subsubsection{Etapa 2: Varredura vertical (literature review)}

Na segunda etapa do referencial teórico foi realizada uma nova busca na mesma base de dados e com os parâmetros da Etapa 1 (item 2.2.1.1). Porém, nesta etapa o método utilizado foi o estudo bibliométrico por meio de análises de publicações e citações no período entre 1900 e 2011, conforme Tabela 2.1 .

Tabela 2.1 - Publicações e citações dos conceitos encontrados na literatura.

\begin{tabular}{|l|c|c|}
\hline \multicolumn{1}{|c|}{ Conceitos } & Publicações & Citações \\
\hline PLM e PDP & 129 & 1.237 \\
\hline PDP e ES & 103 & 526 \\
\hline PLM e ES & 41 & 339 \\
\hline PDP, PLM e ES & 6 & 33 \\
\hline
\end{tabular}

Esta busca foi atualizada em outubro de 2014 para complementar as análises da evolução do percentual e número de citações por ano dos trabalhos mais citados sobre os conceitos abordados. Verifica-se que houve um aumento considerável na quantidade de publicações e citações sobre os conceitos, conforme Tabela 2.2. 
Tabela 2.2 - Publicações e citações dos conceitos encontrados na literatura (atualizado).

\begin{tabular}{|l|c|c|}
\hline \multicolumn{1}{|c|}{ Conceitos } & Publicações & Citações \\
\hline PDP e PLM & 778 & 6.154 \\
\hline PDP e ES & 529 & 6.286 \\
\hline PLM e ES & 236 & 1.968 \\
\hline PDP, PLM e ES & 58 & 386 \\
\hline
\end{tabular}

Esta análise emprega o conceito de rede social, considerando atores (nós da rede) e seus relacionamentos (transações, interações e conexões). A partir dos atores e relacionamentos, define-se a rede social e interpreta-se o comportamento social do conjunto de atores que se relacionam entre si (WASSERMAN; FAUST, 1994; SCOTT, 2000; SORDI, 2009). Segundo vários autores, como Vanz e Caregnato (2003), Prasad e Tata (2005), Neely (2005), Pilkington e Meredith (2009) e Wang et al. (2012), por meio da análise bibliométrica de publicações e citações consegue-se identificar na literatura: padrões de relação, impacto de determinados autores dentro de uma comunidade científica, quais são as principais escolas do pensamento, os periódicos que mais publicaram, as áreas mais relacionadas à temática desse trabalho e a existência ou não de agrupamento bibliométrico que pode evidenciar um cluster de determinada corrente de pesquisa.

Como suporte para essa análise bibliométrica utilizou-se dois softwares: Sitkis (ver SCHILDT, 2002) e Ucinet (ver BORGATTI et al., 2002; LOPES; CARVALHO, 2012). O Sitkis foi aplicado para importação e depuração (correção de erros) dos dados salvos em arquivo de texto do ISI Web of Knowledge. O Ucinet auxiliou na elaboração das matrizes e mapas gráficos das redes de relacionamentos entre as palavras-chaves e temas correlatos.

As redes sociais foram analisadas englobando um conjunto de técnicas e focou em duas formas principais (SANTOS; BASTOS, 2007): i) do ponto de vista de suas características estruturais, que examina a rede como um todo e aborda o tamanho, a densidade, as distâncias geodésicas e a coesão das redes e ii) do ponto de vista morfológico ou posicional dos atores, que desce ao nível dos atores e suas ligações focando nas relações entre os indivíduos e procurando compreender os papéis que os atores desempenham na manutenção ou expansão das redes. Além disso, a estrutura de uma rede de inter-relações de citações pode ser analisada com base 
em diversos indicadores, dependendo do objetivo pretendido com a análise (WASSERMAN; FAUST, 1994). Assim, foram utilizados indicadores de centralidade que permitem analisar a rede tanto no seu conjunto como individualmente, facilitando a compreensão da importância relativa de cada ator e relações dentro da rede. Com base na importância dos indicadores da rede, além dos indicadores de centralidade (grau de centralidade e índice de centralização), a análise utiliza dos indicadores de densidade da rede, grau de intermediação e grau de proximidade para interpretar as redes de palavras-chaves. Para um arranjo claro foram utilizados critérios específicos de corte (quantidade de número de citações) e eliminados de antemão as publicações somente relacionadas a outro trabalho, denominados isolados, para facilitar a análise de cada rede social (SCHILDT; MATTSSON, 2006; BACKHAUS et al., 2011).

Com a análise bibliométrica identificaram-se clusters e tópicos de destaque na literatura referente aos conceitos abordados nessa tese (PDP e ecodesign), conforme mostra a Figura 3.18 no Capítulo 3. Segundo Backhaus et al. (2011), um cluster é definido como um grupo que contém pelo menos três publicações ligadas por três relacionamentos de citações. Nesse trabalho, o cluster foi identificado numa rede de citações cruzadas, que significa que os autores trabalham sobre temas correlatos.

Através da análise comparativa dos conceitos abordados nas publicações analisadas e nos resultados encontrados na etapa de varredura horizontal e varredura vertical desta fase de referencial teórico, identificou-se uma forte convergência para integração do conceito de ecodesign no PDP e, respectivamente, definiu e delimitou os conceitos teóricos a serem investigados nessa tese. Com base nessa lacuna foi necessário complementar o referencial teórico para elaboração da proposta desta tese (integrar aspectos ambientais no PDP), conforme os procedimentos metodológicos mostrados na Fase II (item 2.2.2).

\subsubsection{Fase II: Elaboração da proposta de estruturação do PDP com aspectos ambientais}

Esta fase contempla três pilares principais que estão divididos em cinco etapas, conforme mostra a Figura 2.3. 


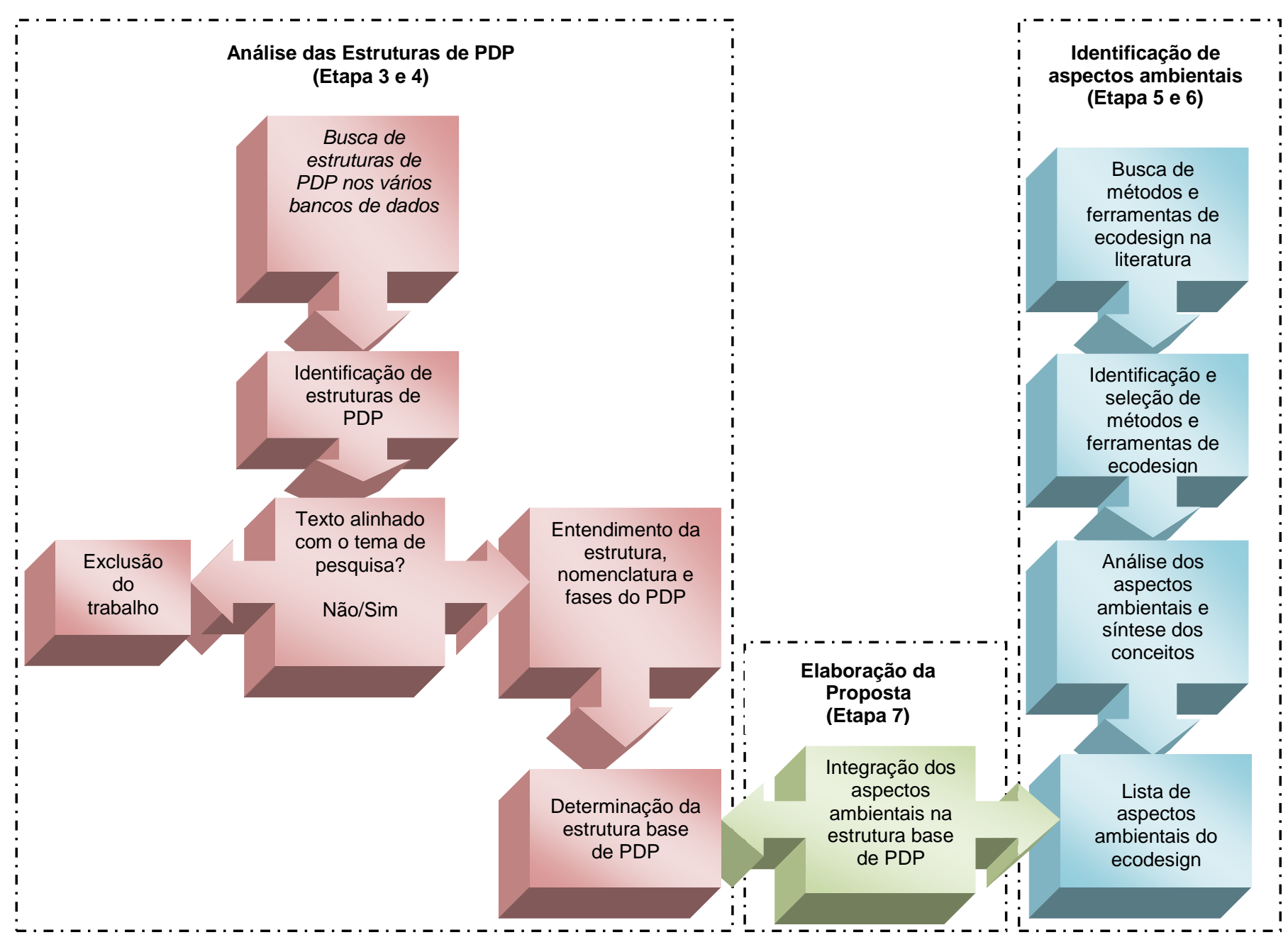

Figura 2.3 - Etapas da elaboração da proposta de estruturação do PDP com aspectos ambientais.

A análise das estruturas de PDP teve como objetivo identificar e selecionar as fases do PDP mais importantes para suportar a integração dos aspectos ambientais. Para identificação de aspectos ambientais foram levantados e analisados os métodos e ferramentas de ecodesign para sintetizar e selecionar os aspectos ambientais citados nessas ferramentas. Com base nesses dois conceitos, foi desenvolvida uma proposta integrando os aspectos ambientais do ecodesign nas fases do PDP com objetivo de reduzir o impacto ambiental do produto durante o seu ciclo de vida. Os detalhes da operacionalização metodológica dessas etapas são descritos nas próximas seções. 


\subsubsection{Etapa 3: Mapeamento e análise de conteúdo das estruturas de PDP}

A terceira etapa visou complementar a fase de referencial teórico no sentido de mapear e analisar as estruturas de desenvolvimento de produtos disponíveis na literatura. Para as buscas foram empregados os procedimentos da revisão sistemática proposta por Conforto et al. (2011, p.6) com objetivo de encontrar as formas mais importantes de estruturação do PDP e se na literatura existe alguma estrutura de PDP que considere a integração de aspectos ambientais. Nessa etapa foram utilizadas como ponto de partida as palavras-chaves e termos identificados na análise do referencial teórico sobre o conceito de PDP (Capítulo 3). Com base nisso e utilizando operadores lógicos disponíveis para buscas avançadas, se estabeleceu os strings a serem utilizados no levantamento nos bancos de dados. A Tabela 2.3 apresenta os parâmetros utilizados na busca nessa etapa.

Tabela 2.3 - Detalhes do mapeamento das estruturas de PDP na literatura.

\begin{tabular}{|c|c|c|}
\hline Base de Dados & String & Termos da busca cruzada \\
\hline $\begin{array}{l}\text { Compendex/EBSCO/ } \\
\text { Emerald/Google } \\
\text { Acadêmico/ } \\
\text { IEEE Xplore/ISI Web of } \\
\text { Science/ProQuest/SciELO/ } \\
\text { Science Direct/ } \\
\text { Scirus/Scopus/SIbiNet USP }\end{array}$ & $\begin{array}{l}\text { Design/Design of } \\
\text { product/Development of } \\
\text { product/Innovation/Innovation of } \\
\text { product/ } \\
\text { New product/New product } \\
\text { development/New product } \\
\text { development process/NPD/NPD } \\
\text { process/PD/PD process/Product } \\
\text { design/ } \\
\text { Product development/Product } \\
\text { development process/Product } \\
\text { innovation }\end{array}$ & $\begin{array}{l}\text { Proposed method/Proposed } \\
\text { methodology/Proposed } \\
\text { model/Reference } \\
\text { method/Reference } \\
\text { methodology/Reference model }\end{array}$ \\
\hline
\end{tabular}

Esse levantamento gerou 677 publicações sobre as formas de estruturação do PDP. Logo, utilizou alguns critérios durante a leitura das publicações para selecionar apenas os trabalhos que atendem aos objetivos da tese. Primeiramente, é importante definir os conceitos para padronizar o entendimento, conforme recomendado por Wacker (2004), então se escolheu uma definição para o conceito de estrutura de PDP para auxiliar na identificação das estruturas de PDP. A definição escolhida foi a proposta por Rozenfeld et al. (2006), que se refere a "todas as formas estruturadas e sistematizadas que facilitam a compreensão e controle do 
PDP de maneira integrada para auxiliar na tomada de decisão". Um termo atualmente usado na literatura são os modelos de referência do PDP, que permitem uma visão integrada do processo, destacando os seus elementos, suas estratégias, atividades, informações, recursos e organização, assim como, suas inter-relações. Além disso, para análise das estruturas de PDP foram selecionadas as que apresentavam figuras para representação das fases que compõe esse processo ou as que tinham descrições textuais para interpretação das estruturas de PDP.

Com base nesses parâmetros foi possível selecionar e analisar 80 estruturas de PDP e entender melhor o processo evolutivo dessas abordagens, os diferentes termos empregados para o mesmo significado, os objetivos das estruturas e áreas de aplicação, bem como, realizar um mapeamento das fases dessas estruturas de PDP. Devido às estruturas de PDP considerarem as fases em momentos diferentes do PDP foi utilizado à estrutura proposta por Rozenfeld et al. (2006) como referência para representação das fases das outras estruturas de PDP encontradas na literatura. Essa escolha se justifica por essa estrutura de PDP considerar todo o ciclo de vida do produto e integrar as macrofases de pré-desenvolvimento, desenvolvimento e pós-desenvolvimento. Por meio desse mapeamento, elaborou-se uma análise que foi separada em três períodos cronológicos diferentes de desenvolvimento, conforme mostrado na Tabela 4.1 (década de 60-70), Tabela 4.2 (década de 80-90) e Tabela 4.3 (anos 2000 até 2013) do Capítulo 4. Para discussão teórica dos principais conceitos dessas estruturas de PDP foi utilizado como base às referências clássicas de PDP (PAHL; BEITZ, 1977; CLARK; FUJIMOTO, 1991; WHEELWRIGHT; CLARK, 1992; COOPER, 1993; ROOZENBURG; EEKELS, 1995; ROZENFELD et al., 2006; ULRICH; EPPINGER, 2007; BACK et al., 2008).

\subsubsection{Etapa 4: Seleção de quais fases das estruturas de PDP utilizar para elaboração da proposta de integrar aspectos ambientais no PDP}

Esta quarta etapa tem a finalidade de selecionar uma estrutura de PDP como referência para o desenvolvimento da proposta de integrar aspectos ambientais no PDP. Para atingir esse objetivo foi realizada uma análise de quais são as fases mais citadas pelas estruturas de PDP selecionadas e identificar em quais momentos se 
tem possibilidade de inserir aspectos ambientais, conforme resultados apresentados na Tabela 4.4 (item 4.3). Para isso, foram listadas as fases do PDP e identificado a quantidade de vezes que cada fase do PDP foi citada e o percentual em relação as 80 estruturas de PDP analisadas. Também, foram sinalizados quais autores citam essas fases nas suas respectivas estruturas de PDP. Com base na análise das estruturas de PDP (item 4.3) percebe-se que não existe uma estrutura que integre de forma adequada os aspectos ambientais e que possa ser utilizada como referência. $\mathrm{Na}$ análise dos métodos e ferramentas de ecodesign (item 5.4) verifica-se e que é necessário considerar todas as fases do PDP, bem como, todas as fases do ciclo de vida do produto, pois os aspectos ambientais contemplados nos métodos e ferramentas de ecodesign podem ser aplicados em todas essas fases.

Por fim, essa etapa contribuiu desenvolvendo uma análise por fase das estruturas de PDP disponíveis na literatura e verificou que não existe uma estrutura de PDP que integre e detalhe em quais fases do PDP deve ocorrer à inserção de aspectos ambientais, corroborando com a importância dessa tese.

\subsubsection{Etapa 5: Mapeamento e seleção dos métodos e ferramentas de ecodesign}

Esta etapa também buscou aprofundar a fase de referencial teórico no sentido de identificar os principais métodos e ferramentas de ecodesign disponíveis na literatura. Essa busca partiu da lista de 107 métodos e ferramentas de ecodesign apresentados no trabalho de Pigosso (2012) e foi complementada com nova busca na literatura seguindo os procedimentos da revisão sistemática proposta por Conforto et al. (2011, p.6) com objetivo de encontrar mais subsídios para elaboração dessa proposta.

Para isso, foram utilizadas como ponto de partida as palavras-chaves e termos identificados na análise do referencial teórico sobre ecodesign (Capítulo 3), principalmente os conceitos citados nos trabalhos de Baumann et al. (2002), Bhamra (2004), Fiksel (2011) e Short et al. (2012). Ainda, foram utilizados operadores lógicos disponíveis para buscas avançadas nas procuras nos bancos de dados. A Tabela 2.4 apresenta os bancos de dados, os strings e os termos da busca cruzada utilizados nessa etapa. 
Tabela 2.4 - Mapeamento dos métodos e ferramentas de ecodesign na literatura.

\begin{tabular}{|l|l|l|}
\hline \multicolumn{1}{|c|}{ Base de Dados } & \multicolumn{1}{|c|}{ String } & \multicolumn{1}{c|}{ Termos da busca cruzada } \\
\hline Compendex/EBSCO/Emerald/ & Ecodesign/Eco-design/Design for & Method/Methodology/ \\
Google Acadêmico/IEEE & Environment (DfE)/Environmentally & Tools/ \\
Xplore/ISI Web of & Conscious Design (ECD)/Green & (strings do PDP) \\
Science/ProQuest/SciELO/ & Engineering (GE)/ & \\
Science Direct/Scirus/Scopus/ & Green Product (GP)/Sustainable & \\
SlbiNet USP & Design (SD)/Design for & \\
& Sustainability (DfS)/Sustainable & \\
& Product Development (SPD)/Life & \\
& Cycle Design (LCD)/Environmental & \\
& Product Development (EPD) & \\
\hline
\end{tabular}

Esse levantamento identificou 356 publicações sobre ecodesign, utilizando a busca cruzada combinando os termos com os strings para selecionar apenas os métodos e ferramentas de ecodesign relacionados ao PDP, foco dessa tese. Para analisar as publicações empregou-se a definição proposta por Baumann et al. (2002) do conceito de métodos e ferramentas de ecodesign como sendo "todos os meios estruturados para lidar com aspectos ambientais durante o PDP". Em seguida, analisou as classificações e os diferentes tipos de métodos e ferramentas de ecodesign disponíveis na literatura para ter uma melhor visão sobre essas ferramentas e auxiliar na identificação delas nas publicações.

Diante disso, os trabalhos foram analisados por meio da leitura e interpretação das publicações, utilizando como critério de seleção os que apresentam detalhes de aplicação e citam aspectos ambientais com objetivo de minimizar o impacto ambiental no PDP. Além disso, abordou publicações derivadas das publicações principais, que foram identificados pela análise das citações e referências utilizadas nos textos. Assim, nessa etapa foi possível compreender como essas ferramentas se aplicam no PDP e selecionar 154 métodos e ferramentas de ecodesign que estão sintetizados na Tabela 5.5 (item 5.3), para verificar o detalhamento ver Apêndice IV.

\subsubsection{Etapa 6: Seleção de aspectos ambientais dos métodos e ferramentas de ecodesign}

Nesta etapa procurou-se definir o conceito de aspecto ambiental para orientar na identificação e síntese de aspectos ambientais dos 154 métodos e ferramentas de ecodesign encontrados na etapa anterior (item 2.4.2.3). Com base nessas definições 
conceituais foram analisadas as ferramentas de ecodesign e delas extraídos os aspectos ambientais na sua forma bruta, ou seja, conforme estava descrito nas publicações e procedimentos disponíveis para sua aplicação.

Em seguida, devido à quantidade e diversidade de termos, conceitos e repetibilidade dos mesmos aspectos ambientais em vários métodos e ferramentas de ecodesign foi necessário fazer um processo de filtragem para descartar os repetidos e fazer uma interpretação dessa forma bruta para verificar se as diferentes nomenclaturas não tinham o mesmo significado. Para facilitar essa interpretação, utilizou-se do diagrama de afinidades e do diagrama em árvore para organizar e agrupar os aspectos ambientais em níveis hierárquicos, tendo como orientação as metodologias aplicadas nos trabalhos de Telenko et al. (2008) e Pigosso (2012). Essa análise facilitou a visualização dos aspectos ambientais por tipo de enfoque e permitiu separar, comparar e reescrevê-los utilizando termos conhecidos pela área de PDP. A Tabela 2.5 ilustra alguns exemplos dos níveis hierárquicos utilizados nas análises dos aspectos ambientais.

Tabela 2.5 - Exemplo de distribuição hierárquica dos aspectos ambientais.

\begin{tabular}{|c|c|c|c|c|}
\hline Autor & Nível 1 & Nível 2 & & Nível 3 \\
\hline $\begin{array}{l}\text { Telenko et } \\
\text { al. }(2008)\end{array}$ & $\begin{array}{l}\text { 1) Garantir entradas e saídas } \\
\text { saudáveis. } \\
\text { 2) Aumentar durabilidade de } \\
\text { produtos e componentes. } \\
\text { 3) Facilitar desmontagem, } \\
\text { separação e purificação. } \\
\text { 4) Minimizar o consumo de } \\
\text { recursos na fase de uso. } \\
\text { 5) Garantir a sustentabilidade } \\
\text { dos recursos. } \\
\text { 6) Minimizar o consumo de } \\
\text { recursos nas fases de } \\
\text { produção e transporte. }\end{array}$ & $\begin{array}{l}\text { 4.1) Incorporar características } \\
\text { para prevenir perda de } \\
\text { materiais. }\end{array}$ & & \\
\hline $\begin{array}{l}\text { Pigosso } \\
\text { (2012) }\end{array}$ & $\begin{array}{l}\text { 1) Minimizar consumo e } \\
\text { energia. } \\
\text { 2) Minimizar consumo de } \\
\text { materiais. } \\
\text { 3) Otimizar o tempo de vida do } \\
\text { produto. } \\
\text { 4) Estender a vida do material. } \\
\text { 5) Selecionar processos e } \\
\text { recursos com baixo impacto } \\
\text { ambiental. } \\
\text { 6) Facilitar a desmontagem. }\end{array}$ & $\begin{array}{l}\text { 1.1) Minimizar o consumo de } \\
\text { energia durante a } \\
\text { produção. }\end{array}$ & $\begin{array}{l}\text { 1.1.1) } \\
1.1 .2) \\
1.1 .3) \\
1.1 .4)\end{array}$ & $\begin{array}{l}\text { Equipamentos } \\
\text { eficientes. } \\
\text { Facilitar } \\
\text { manutenção. } \\
\text { Otimizar } \\
\text { transporte. } \\
\text { Monitorar o } \\
\text { consumo de } \\
\text { energia. }\end{array}$ \\
\hline
\end{tabular}


Uma síntese do resultado da estratificação e análise está listada na Tabela 5.7 (item 5.4) e todos os 365 aspectos ambientais identificados para integração com o PDP podem ser consultados em detalhes no Apêndice V. Os aspectos ambientais selecionados foram comparados com os identificados por Telenko et al. (2008) e Pigosso (2012). Os procedimentos para essa integração é o foco da próxima etapa.

\subsubsection{Etapa 7: Elaboração da proposta de estruturação do PDP com aspectos ambientais}

Para elaboração da proposta de estruturação do PDP com aspectos ambientais foram integrados os resultados da etapa 4 (item 2.2.2.2) de seleção das fases das estruturas de PDP (Capítulo 4) e da etapa 6 (item 2.2.2.4) de identificação e síntese dos aspectos ambientais dos métodos e ferramentas de ecodesign (Capítulo 5).

Para realizar a integração dos aspectos ambientais foi escolhido o nível de "tarefa" na estrutura de PDP, devido ao alinhamento com o objetivo inicial desse trabalho de elaborar uma proposta detalhada de estruturação do PDP considerando ações gerenciais e operacionais no PDP que reduzam o impacto ambiental do produto durante todo seu ciclo de vida. Essa análise abordou a relação entre a função de cada uma das tarefas do PDP para contribuir com a realização das atividades e com os objetivos das fases no PDP, bem como, se havia necessidade de criar novas tarefas e atividades, conforme exemplo ilustrado na Figura 2.4.
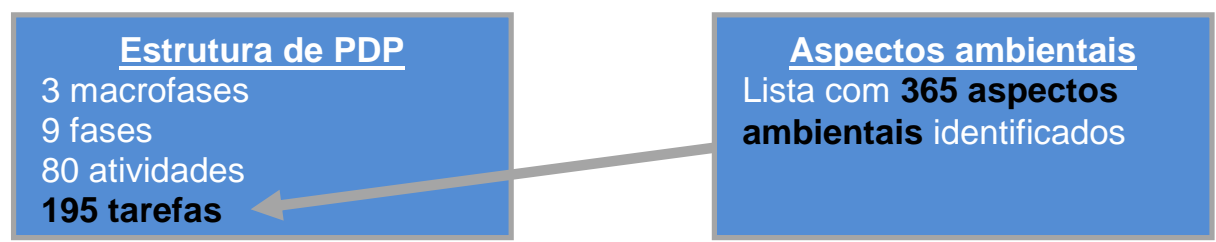

\begin{tabular}{|c|c|}
\hline \multicolumn{2}{|r|}{ Macrofase - Desenvolvimento } \\
\hline & Fase 3 - Projeto Informacional (PI) \\
\hline \multicolumn{2}{|c|}{ Atividade - 3.5 Definir requisitos do produto } \\
\hline Tarefa & Aspectos Ambientais \\
\hline Converter requisitos de & Definir os requisitos ambientais do produto e classificar com base \\
\hline $\begin{array}{l}\text { clientes em expressões } \\
\text { mensuráveis }\end{array}$ & $\begin{array}{l}\text { nos respectivos impactos ambientais e o cumprimento das funções } \\
\text { técnicas exigidas pelos clientes. }\end{array}$ \\
\hline $\begin{array}{l}\text { Qual é a função dessa } \\
\text { tarefa para contribuir com } \\
\text { a atividade e fase do PDP? }\end{array}$ & $\begin{array}{l}\text { Quais dos } 365 \text { aspectos ambientais identificados podem ser } \\
\text { inseridos nessa tarefa para contribuir com a redução do } \\
\text { impacto ambiental, considerando essa etapa do PDP? }\end{array}$ \\
\hline
\end{tabular}

Figura 2.4 - Análise para integrar aspectos ambientais nas fases do PDP. 
Em paralelo, foram analisadas quais são as características, preocupações e ações sugeridas de cada um dos 365 aspectos ambientais para contribuir com a redução do impacto ambiental do produto considerando as decisões que são tomadas em cada momento do PDP. Para auxiliar nessa alocação dos aspectos ambientais nas fases corretas do PDP foram numeradas as tarefas e codificado os aspectos ambientais para possibilitar a rastreabilidade da integração e análise. Também, utilizou como parâmetro do referencial teórico as propostas de integração do ecodesign no PDP dos trabalhos de Pigosso (2008), Guelere Filho (2009), Platcheck et al. (2008) e Viegas e Salles (2012).

Por fim, um aspecto ambiental pode ser inserido em mais de uma tarefa do PDP conforme sua amplitude e, portanto, foi adequada a descrição dos aspectos ambientais conforme a fase em que ele foi integrado no PDP, com intuito de facilitar o entendimento da equipe de desenvolvimento de novos produtos. Após elaborar a proposta com base na teoria foi necessário avaliar sua aceitação, conforme realizado na fase de verificação em campo da proposta com especialistas.

\subsubsection{Fase III: Verificação em campo da proposta de estruturação do PDP com aspectos ambientais}

Essa fase visa testar a proposta por meio de uma consulta de opinião aos especialistas em PDP e ecodesign para averiguar se os aspectos ambientais foram integrados nas tarefas corretas do PDP. Esta fase está dividida em três momentos complementares visando atingir o objetivo da tese, a primeira parte se concentra na escolha de quais métodos devem ser utilizados para realizar o levantamento de dados. Em seguida, com base nos dados gerados são analisadas e justificadas as ferramentas aplicadas para os testes estatísticos e discussão dos dados qualitativos com base na literatura. Como resultado dessa fase se tem a revisão da proposta desenvolvida, considerando a análise da opinião dos especialistas com os conceitos do referencial teórico. A Figura 2.5 mostra as etapas metodológicas utilizadas para verificação da adequação da proposta. 


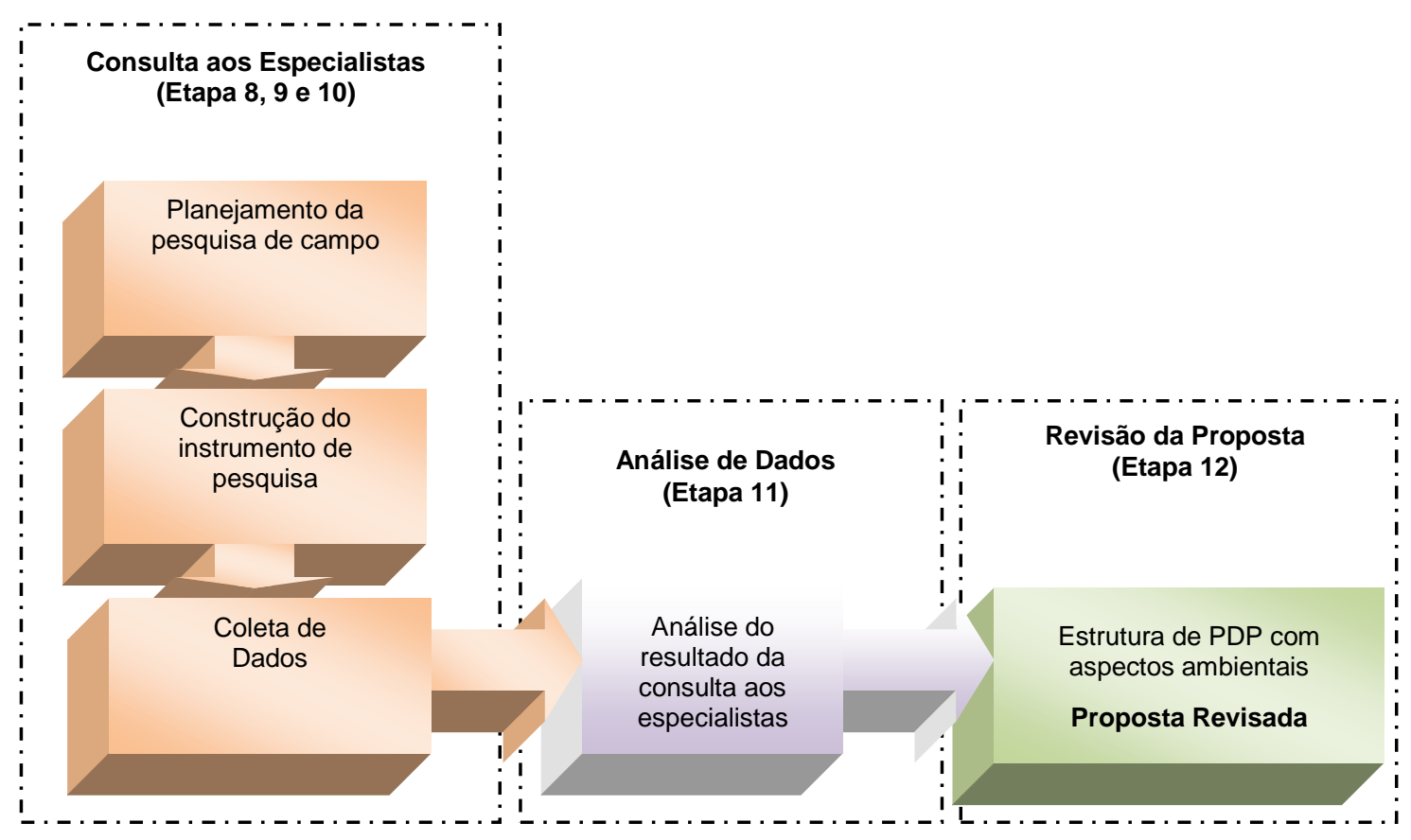

Figura 2.5 - Etapas da verificação em campo da proposta de estruturação do PDP com aspectos ambientais.

\subsubsection{Etapa 8: Planejamento da pesquisa de campo}

Essa etapa de planejamento da pesquisa de campo tem-se o objetivo de planejar o teste da validade da proposta desenvolvida nas etapas da Fase II (item 2.2.2). Para isso, foram identificados 133 potenciais pesquisadores que abordam esses temas, destes 11 não foram localizados por falta de endereço eletrônico, restando 122 potenciais pesquisadores que foram selecionados inicialmente com base na área de atuação descrita no Currículo Lattes da Plataforma do Conselho Nacional de Desenvolvimento Científico e Tecnológico (CNPq) relacionadas aos temas ecodesign e PDP.

Os questionários foram enviados para todos os potenciais pesquisadores sobre 0 tema e obteve-se o retorno de 10 pesquisadores por e-mail, que após ver o objetivo da consulta e a estrutura do questionário, responderam que o nível de detalhe exigido era alto e não podiam contribuir com o trabalho. Desta forma, para melhor selecionar os 19 pesquisadores que responderam o questionário foi revisado o critério de julgamento, em virtude da convicção inicial de que todos os potenciais pesquisadores identificados eram fontes de informações confiáveis e precisas para integrarem a amostra e contribuírem com a melhoria da proposta apresentada. 
Logo, o critério para seleção dos especialistas foi revisto e incluído como condições de elegibilidade para participação da consulta: i) ter publicações relacionadas ao tema da tese; ii) citar PDP ou ecodesign como palavras-chaves, áreas de atuação ou como experiência na descrição do Currículo Lattes; iii) ter experiência profissional ou acadêmica de mais de 10 anos sobre os temas abordados nesse trabalho; iv) possuir nível mínimo de pós-graduação de doutorando; v) estar associado a áreas correlatas ao tema desse trabalho nas universidades ou institutos de pesquisa do país; vi) ter formação acadêmica compatível com o tema abordado; e um critério eliminatório utilizado foi vii) ter respondido de forma adequada ao questionário de avaliação da estrutura proposta, conforme instruções de aplicação do instrumento de consulta. A Tabela 2.6 lista os especialistas que participaram da consulta.

Tabela 2.6 - Lista dos especialistas que participaram da consulta.

\begin{tabular}{|l|l|c|c|}
\hline \multicolumn{1}{|c|}{ Nome } & \multicolumn{1}{c|}{ Instituição } & Formação & Experiência \\
\hline Aldo R. Ometto & USP-EESC & Doutorado & 14 anos \\
\hline Andréa Cristina dos Santos & Universidade de Brasília & Doutorado & 11 anos \\
\hline Carlos Eduardo Sanches da Silva & Univ. Federal de Itajubá & Pós-Doutorado & 25 anos \\
\hline Cláudio Pereira de Sampaio & Univ. Estadual de Londrina & Doutorando & 23 anos \\
\hline Daniel Capaldo Amaral & USP-EESC & Doutorado & 16 anos \\
\hline Dóris Zwicker Bucci & Univ. Reg. Blumenau & Doutorado & 32 anos \\
\hline Eduardo de Senzi Zancul & USP-EP & Doutorado & 16 anos \\
\hline Istefani Carísio de Paula & UFRS & Pós-Doutorado & 13 anos \\
\hline Leonardo Nabaes Romano & Univ. Federal Santa Maria & Doutorado & 20 anos \\
\hline Marcelo Gitirana Gomes Ferreira & UFSC & Pós-Doutorado & 20 anos \\
\hline Miriam Borchardt & UNISINOS & Doutorado & 28 anos \\
\hline Osmar Possamai & UFSC & Doutorado & 30 anos \\
\hline Sergio Luis da Silva & UFSCar & Doutorado & 22 anos \\
\hline Tomoe Daniela Hamanaka Gusberti & UFRGS & Pós-Doutorado & 14 anos \\
\hline
\end{tabular}

Com base no critério de seleção definido, dos 19 pesquisadores que responderam ao questionário, 5 foram descartados por não atender aos critérios de seleção ou ter respondido de forma incompleta o questionário (não respondeu todas as fases do PDP). Assim, obteve-se a taxa de retorno de $17 \%$ e foram selecionados 14 especialistas para participar da consulta. A próxima etapa detalha como foi construído o instrumento de pesquisa (questionário). 


\subsubsection{Etapa 9: Construção do instrumento de pesquisa}

Após a definição do planejamento da pesquisa e decidido a amostra a ser analisada, foi elaborado o instrumento de pesquisa para a coleta de dados. Optou-se por um questionário, devido à possibilidade da racionalização do tempo de preenchimento, por permitir a aplicação simultânea aos especialistas e por atingir maior diversidade regional de acadêmicos no país. Foi então desenvolvido um questionário do tipo semi-estruturado não disfarçado, pelo qual o respondente tem prévio conhecimento dos objetivos da pesquisa (MARCONI; LAKATOS, 1996).

A construção do instrumento de pesquisa foi dividida em duas planilhas do Excel ${ }^{\circledR}$, sendo a primeira planilha com instruções para preenchimento do perfil do especialista, esclarecimentos dos objetivos da consulta, definição do significado de algumas siglas utilizadas na nomenclatura das fases da estrutura de PDP e detalhes da escala para avaliação da segunda planilha. A segunda planilha foi elaborada com base nas macrofases, fases, atividades e tarefas do PDP no qual foram inseridos aspectos ambientais para que os especialistas pudessem avaliar o nível de concordância com a proposta de integração apresentada. Cabe destacar ainda que essa planilha de avaliação foi elaborada seguindo a lógica das etapas do PDP de forma seqüencial para facilitar seu preenchimento pelos respondentes. Nessa planilha de avaliação foi pré-definido coletar dados quantitativos e qualitativos para se ter maior embasamento na discussão dos resultados, conforme justificado anteriormente nos aspectos metodológicos de pesquisa (item 2.1). Para maior compreensão da estrutura e dos pontos abordados no instrumento de pesquisa, consultar o Apêndice VI.

Para quantificar as respostas dos especialistas foi utilizada uma escala ordinal de avaliação Likert com amplitude de 1-5 ("1-concordo completamente", "2-concordo", "3-indiferente", "4-discordo" e "5-discordo completamente"). No caso da avaliação ser de "4-discordo" ou "5-discordo completamente" é solicitado ao respondente que justifique sua opinião e indique em qual fase do PDP é mais adequado integrar esse aspecto ambiental. Para esses casos, as justificativas são tratadas como um dado qualitativo para análise e melhoria da proposta. Em resumo, o questionário não gerou dúvidas pelos participantes da consulta, mas recebeu comentários dos especialistas que é muito extenso e que o tempo real para responder ao 
questionário é maior que o estimado nas instruções. Entretanto, os respondentes destacam que devido ao nível de detalhe exigido na elaboração da proposta o tamanho do questionário está adequado. A seguir são descritos as particularidades da etapa de coleta de dados.

\subsubsection{Etapa 10: Coleta de dados - Consulta com especialistas}

Considerando a descrição da etapa anterior (item 2.2.3.2), o tipo de amostra utilizada neste trabalho se caracteriza como uma amostragem não aleatória intencional, pois neste tipo de amostra (não probabilística) a seleção dos elementos da população que podem compor a amostra depende dos critérios de seleção do pesquisador (MATTAR, 1996).

Esta consulta aos especialistas não englobou teste piloto do questionário, apesar de ser sugerido pela literatura (FORZA, 2002). Porém, durante a elaboração do instrumento de pesquisa foram tomados alguns cuidados para assegurar que as instruções do questionário estavam claras para o seu correto preenchimento e de fácil entendimento dos objetivos da consulta. Também, foram feitos alguns ajustes para reduzir o tempo de resposta do questionário sem prejudicar o nível de detalhamento necessário para proposta como, por exemplo, padronizar o formato das avaliações com opções de escolha das notas da escala de Likert que também facilita a codificação e análise estatística dos dados coletados.

Como complemento para aumentar a taxa de retorno e oficializar a consulta, foi elaborado uma carta convite mostrada na integra no Apêndice VI e um texto padrão para ser enviado por e-mail aos especialistas identificados para participar da consulta. Todos esses cuidados visaram promover maior motivação aos respondentes e assim aumentar a taxa de retorno do levantamento.

Para envio dos questionários, os endereços dos e-mails dos especialistas foram retirados de artigos publicados, site das universidades e Currículo Lattes. O primeiro lote de e-mails foi enviado no final de outubro de 2013, sendo que após 15 dias foram enviados lembretes via e-mail da importância da participação do especialista para o sucesso do trabalho e um segundo lembrete foi enviado no começo de dezembro de 2013 informando que o encerramento do levantamento da consulta aconteceria após uma semana da data daquela mensagem. 
Após coletar os dados da consulta aos especialistas, a próxima etapa analisa os dados e discute os resultados dos testes estatísticos e da análise qualitativa dos comentários dos respondentes com base no referencial teórico.

\subsubsection{Etapa 11: Análise de dados - Consulta com especialistas}

A análise de dados dessa etapa utilizou o software Minitab® versão 16 para análise estatística e planilhas do Excel®. Esta etapa dividiu-se em três abordagens, sendo uma destinada a avaliar a confiabilidade interna dos dados levantados através do cálculo do coeficiente alfa de Cronbach para o questionário. A próxima abordagem quantitativa dos dados foi para interpretar estatisticamente a avaliação dos especialistas e verificar o nível de aceitação da estrutura proposta. A última abordagem realiza uma análise qualitativa das sugestões de melhorias e justificativas de discordância dos respondentes quanto ao momento de integração de aspectos ambientais nas fases do PDP.

\subsection{Confiabilidade interna do instrumento de coleta de dados - Alfa de Cronbach}

Para avaliar se os resultados obtidos eram confiáveis, dando maior robustez do questionário, decidiu-se realizar a aplicação do coeficiente alfa de Cronbach. Esse indicador é utilizado para medir a confiabilidade da consistência interna de uma escala, ou seja, para avaliar a magnitude em que os itens de um instrumento de coleta de dados (questionário) estão correlacionados (CORTINA, 1993). Para se calcular o coeficiente alfa de Cronbach utiliza-se da média das correlações entre as questões que fazem parte do instrumento de coleta de dados (STREINER, 2003), sendo que um grupo de questões que explora um mesmo conceito demonstra um elevado valor (ROGERS; SHMITI; MULLINS, 2002).

O cálculo desse coeficiente considera (X) como sendo uma matriz ( $\mathbf{n} \mathbf{x} \mathbf{k}$ ) que corresponde às respostas quantificadas de um questionário. Cada linha de (X) representa um avaliador e cada coluna representa uma questão. Dado que todos os itens de um questionário utilizam a mesma escala de medição, as variáveis utilizadas no cálculo são (LEONTITSIS; PAGGE, 2007): o número de questões do 
instrumento (k), a variância de cada questão $\left(\mathbf{S}^{2} \mathbf{i}\right)$, e a variância total $\left(\mathbf{S}^{2} \mathbf{s o m a}\right)$ de cada indivíduo (j) nos (k) itens, conforme mostra a equação 2.1 (CRONBACH, 2004; LEONTITSIS; PAGGE, 2007; HILL; HILL, 2008):

$$
\alpha=\frac{k}{k-1}\left(1-\frac{\sum_{i=1}^{k} s_{i}^{2}}{S_{\text {soma }}^{2}}\right)
$$

$\mathrm{Na}$ averiguação do coeficiente alfa de Cronbach aplicou-se a análise de resposta (Item Analysis) para cada etapa do questionário, ou seja, cada etapa do questionário contém uma determinada quantidade de questões (tarefas do PDP) que corresponde a uma das 9 fases do PDP. Também, foi realizado o cálculo desse indicador para o questionário como um todo considerando todas as 195 questões sem dividir em fases. A Tabela 2.7 mostra com base na literatura a relação entre o valor alfa com o nível de confiabilidade interna dos dados, lembrando que alguns autores como Cronbach (2004), Freitas e Rodrigues (2005), Hill; Hill (2008) e Hora et al. (2010) afirmam que um valor de alfa de Cronbach acima de 0,70 é considerado aceitável. Entretanto, é relevante ressaltar que na literatura ainda não existe um consenso entre os pesquisadores acerca da interpretação da confiabilidade de um questionário obtida a partir do valor deste coeficiente.

Tabela 2.7 - Parâmetros do nível de confiabilidade interna (alfa de Cronbach).

\begin{tabular}{|c|c|}
\hline Valor de alfa & Nível de Confiabilidade \\
\hline$>0,90$ & Muito Alta \\
\hline $0,75-0,90$ & Alta \\
\hline $0,60-0,75$ & Moderada \\
\hline $0,30-0,60$ & Baixa \\
\hline$<0,30$ & Muito Baixa \\
\hline
\end{tabular}

Fonte: Adaptado de Freitas e Rodrigues (2005) e Hill e Hill (2008).

\subsection{Análise quantitativa dos dados levantados em campo}

A análise quantitativa focou em alguns pontos chaves relacionados ao objetivo dessa tese sempre considerando nível de significância de $5 \%(\alpha=0,05)$ e dividiu-se em quatro tópicos descritos a seguir: 
i) Avaliar o nível de aceitação da proposta com base nas notas dos especialistas: Para realizar essa análise empregaram-se os gráficos de Histograma e Pareto de todas as notas, com o intuito de averiguar quais são as notas mais frequentes. Como complemento avaliou-se as principais características descritivas dos dados.

ii) Identificar clusters e agrupar os especialistas com base nas características das suas avaliações: Buscou-se verificar se os especialistas estão avaliando igualmente a proposta apresentada ou não. Para isso, foi realizado o teste de normalidade de Anderson-Darling (AD) para as notas por avaliador e observou que as mesmas não seguem uma distribuição normal. Logo, foram feitos gráficos Boxplot e Pareto para identificar grupos de especialistas com características similares de apoio ou não a proposta apresentada. Para escolher qual teste de hipótese para variância deveria ser realizado, utilizou-se o fluxo representado na Figura 2.6.

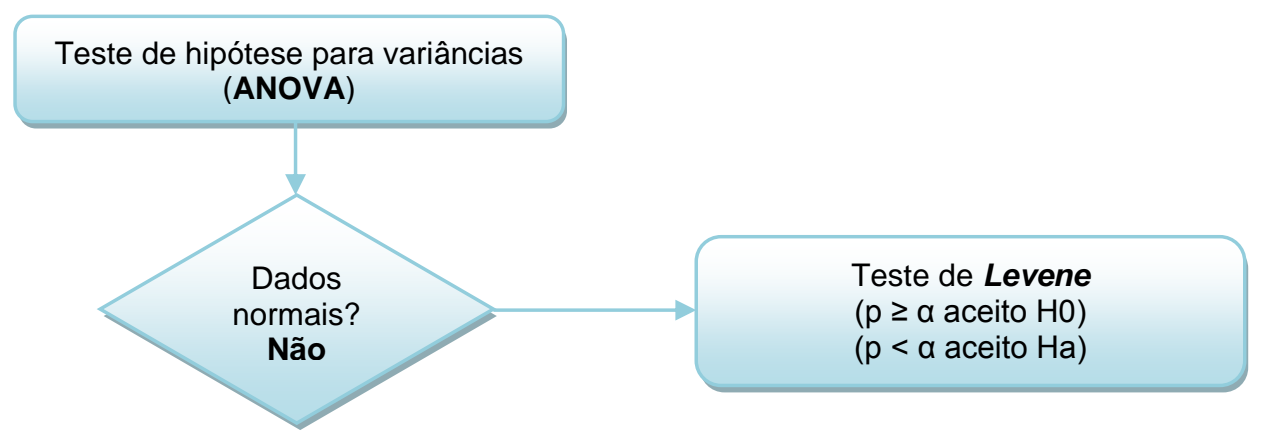

Figura 2.6 - Fluxo de escolha do teste de hipótese para variâncias.

Em seguida, optou-se por realizar o teste de Levene para análise de variância (MONTGOMERY, 2004). Esse teste é considerado robusto para comparação de variâncias quando as suposições básicas do teste de igualdade de variâncias não são satisfeitas e para comparação de variâncias de grupos de observações provenientes de distribuições contínuas e não necessariamente normais (LEVENE, 1960). Este teste também permitiu medir a homogeneidade e gerar gráfico comparando os resultados. Além disso, utilizou-se do teste de hipótese nãoparamétrico da mediana de Mood (Mood Median Test) para avaliar se a tendência central (mediana) das notas por avaliadores eram a mesma.

Após esses testes, foi efetuada uma análise de cluster exploratória utilizando a técnica hierárquica e tendo como critérios de similaridade para agrupamento a distância dos coeficientes de correlação dos dados analisados e o método da média 
do centróide como mecanismo de ligação. Essa análise gerou um dendrograma agrupando os avaliadores em três grupos, mas o resultado não ficou coerente com as análises visuais e estatísticas descritivas anteriores. Portanto, normalizou-se como concordância as notas (1 e 2) e discordância as notas (3, 4 e 5) e utilizando a ferramenta do Minitab® Attribute Agreement Analysis gerou os gráficos com base no acerto dos avaliadores quanto à resposta padrão, que no caso foram consideradas como padrão as notas de concordância $(\leq 2)$. Desta forma, conseguiu visualizar três grupos de avaliadores (apoiadores, opositores e indiferentes). Como complemento, sintetizou-se em uma planilha em Excelß e analisou a distribuição da porcentagem das notas de concordância plena e discordância plena.

iii) Comparar em quais fases do PDP há maior discordância para, posteriormente, direcionar a análise qualitativa para esses itens: Para avaliar a proposta de estruturação do PDP por fases utilizou-se de uma planilha em Excelß e analisou a distribuição das notas, médias e dispersão para cada avaliador nas fases do PDP.

iv) Realizar testes de hipótese para avaliar estatisticamente se a proposta deste trabalho foi aprovada ou rejeitada pelos especialistas que participaram da consulta: Para realizar o teste de hipótese considerando as médias das notas usou-se como referência o fluxo da Figura 2.7 para tomar a decisão de qual teste aplicar.

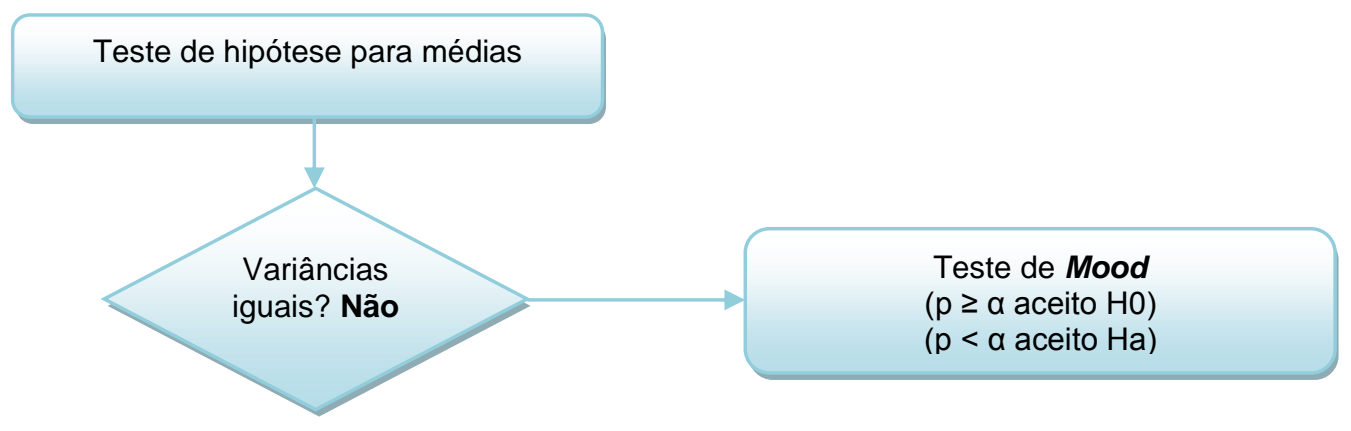

Figura 2.7 - Fluxo de tomada de decisão para teste de hipótese das médias.

Para finalizar as análises estatísticas foram feitas avaliações sobre o nível de aceitação da proposta desenvolvida nesse trabalho. Assim foi realizado um teste de hipótese para avaliar se a nota média era menor ou igual 2, ou seja, indicava concordância dos especialistas. Para todos esses testes estatísticos foram utilizados o teste 1-Sample $T$ Unilateral no Minitab® que calcula o intervalo de confiança e 
executa o teste de hipótese para a média de uma população com variância desconhecida, as hipóteses testadas seguem a equação 2.2:

HO: $\mu \leq 2$
На: $\mu>2$

Todas as hipóteses nulas contêm sempre uma igualdade sobre a qual deve obter evidências para rejeitá-la (DEVORE, 2006). O nível de significância utilizado representa a probabilidade de se incorrer no erro de rejeitar $\mathrm{H} 0$, quando a hipótese é de fato verdadeira. Foram realizados testes de hipótese para cada fase do PDP, cada especialista e cada nota, ambos os testes analisados de forma individual.

\subsection{Análise qualitativa das avaliações de discordância dos especialistas}

Para realizar a análise qualitativa, separou-se em tabelas uma para cada fase do PDP e foram inseridas apenas as atividades e tarefas que tiveram alguma avaliação de discordância ou comentário dos especialistas quanto à integração dos aspectos ambientais. Além disso, foram estratificados os comentários de cada especialista para cada tarefa e aspecto ambiental integrado ao PDP, conforme exemplo mostrado na Tabela 2.8.

Tabela 2.8 - Exemplo da estrutura utilizada para análise dos comentários dos especialistas.

\begin{tabular}{|c|c|}
\hline \multicolumn{2}{|c|}{$\begin{array}{l}\text { Macrofase - Pré-Desenvolvimento } \\
\text { Fase } 1 \text { - Planejamento Estratégico de Produtos (PEP) }\end{array}$} \\
\hline \multicolumn{2}{|c|}{ Atividade - 1.1 Definir escopo da revisão do plano estratégico de negócios } \\
\hline Tarefa - 1.1.2 & Sugestão de Melhoria \\
\hline $\begin{array}{l}\text { Avaliar competências no } \\
\text { time de planejamento } \\
\text { estratégico de produtos }\end{array}$ & $\begin{array}{l}\text { Especialista B: Avaliar competências é diferente de treinamentos. } \\
\text { Dependendo de quais as competências são necessárias, pode ser } \\
\text { viável a contratação. }\end{array}$ \\
\hline
\end{tabular}

Em seguida, foi analisada cada uma dessas sugestões de melhoria, com base no referencial teórico, para interpretar o ponto de vista dos especialistas e discutir os conceitos teóricos para decidir a necessidade de ajustar a proposta avaliada. Foram 
utilizadas como referência Rozenfeld et al. (2006) e as demais estruturas clássicas de PDP que possuem detalhes das atividades, dos conceitos empregados e limites das fases que compõe a estrutura de PDP (PAHL; BEITZ, 1977; CLARK; FUJIMOTO, 1991; WHEELWRIGHT; CLARK, 1992; COOPER, 1993; ROOZENBURG; EEKELS, 1995; ULRICH; EPPINGER, 2007; BACK et al., 2008) e, também, os principais trabalhos que abordaram a integração dos aspectos ambientais e métodos e ferramentas de ecodesign no PDP, como por exemplo: Cramer e Stevels (1997), Tischner et al. (2000), Baumann et al. (2002), Johansson (2002; 2006), Bhamra (2004), Luttropp e Lagerstedt (2006), Byggeth e Hochschorner (2006), Platcheck et al. (2008), Birch et al. (2012), Bovea e Perez-Belis (2012) e Pigosso et al. (2013). Essa análise gerou uma adequação da proposta, conforme procedimentos descritos na etapa 12.

\subsection{Etapa 12: Revisão e adequação da proposta de estruturação do PDP com aspectos ambientais}

Após análise dos comentários gerais e justificativas dos avaliadores realizados na etapa 11 (item 2.2.3.4.3) alguns pontos foram discutidos e revisados (Capítulo 7) na proposta inicial avaliada, buscando torná-la ainda mais alinhada a comunidade acadêmica. As revisões estão destacadas com fonte na cor azul na proposta apresentada no Capítulo 6.

Em suma, nesse capítulo de métodos de pesquisa buscou-se justificar as escolhas feitas e descrever de forma detalhada, clara e objetiva as principais fases, etapas e os procedimentos técnico-científicos adotados na condução do trabalho. A seguir é demonstrada a estrutura do referencial teórico que suporta a discussão teórico-conceitual para elaboração da proposta deste trabalho. 


\section{REFERENCIAL TEÓRICO}

A elaboração do referencial teórico engloba as etapas de varredura horizontal e varredura vertical, as quais tiveram suas operacionalizações descritas no Capítulo 2 de métodos de pesquisa (seção 2.3.1). As seções desse capítulo descrevem as análises realizadas no levantamento e apontam os principais resultados discutidos para embasamento teórico da proposta de trabalho.

\subsection{Revisão e classificação dos conceitos de PLM, PDP e ES}

Este mapeamento contempla 479 publicações que estão relacionadas da seguinte forma aos conceitos analisados: (242) publicações para PLM e PDP, (163) publicações para PDP e ES, (61) publicações para PLM e ES e (13) publicações para os conceitos PLM, PDP e ES. A distribuição da quantidade de publicações levantadas por ano está ilustrada na Figura 3.1.

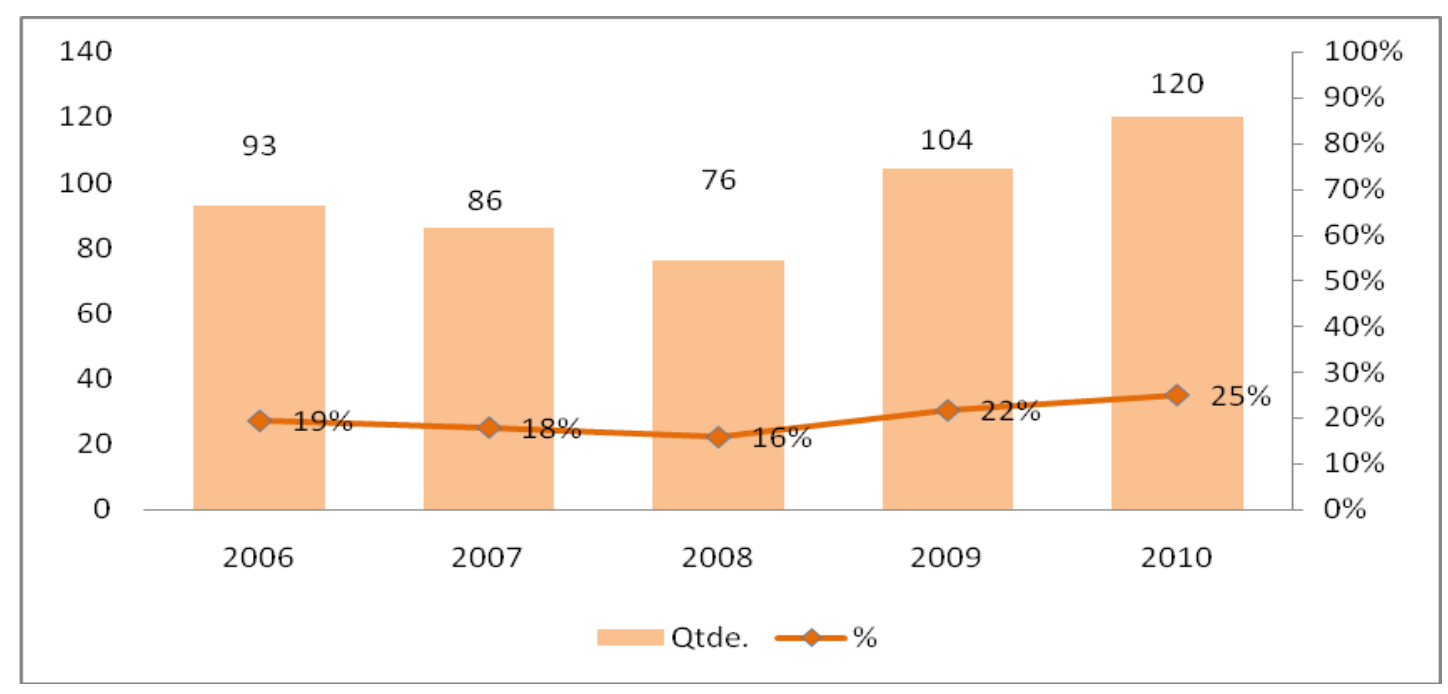

Figura 3.1 - Publicações disponíveis no ISI Web of Knowledge para os termos PLM, PDP e ES.

Do total de 479 publicações levantadas sobre os conceitos de PLM, PDP e ES, foram selecionadas 87 e organizadas segundo os critérios previamente citados (item 2.3.1.1), no qual os detalhes podem ser vistos no Apêndice I e Apêndice II. 
Analisando essas publicações verifica-se que são publicadas em 25 diferentes periódicos e em congressos. Além disso, em apenas 15\% dos casos, os periódicos apresentam mais de um artigo sobre o tema durante os cinco anos analisados, indicando que são dispersas as publicações sobre o assunto nos periódicos em geral, exceto no: Journal of Cleaner Production que teve 12 artigos publicados e o International Journal of Life Cycle Assessment com 8 artigos publicados. A Tabela 3.1 apresenta os periódicos e congressos que tiveram mais de um artigo publicado sobre o tema no período analisado e a Figura 3.2 mostra o percentual das publicações por ano analisadas neste trabalho.

Tabela 3.1 - Estratificação do refinamento da busca combinada dos termos PLM, PDP e ES.

\begin{tabular}{|l|c|c|c|c|c|c|}
\hline \multicolumn{1}{|c|}{ Periódicos } & $\mathbf{2 0 0 6}$ & $\mathbf{2 0 0 7}$ & $\mathbf{2 0 0 8}$ & $\mathbf{2 0 0 9}$ & $\mathbf{2 0 1 0}$ & Total \\
\hline Journal of Cleaner Production & 6 & 2 & 2 & 2 & & 12 \\
\hline International Journal of Life Cycle Assessment & 4 & & 2 & 2 & & 8 \\
\hline International Conference on PLM & & 3 & & & & 3 \\
\hline Conference on Life Cycle Engineering & & 2 & & & & 2 \\
\hline Concurrent Eng.-Research and Applications & & 1 & & 1 & & 2 \\
\hline European Journal of Operational Research & & 1 & & & 1 & 2 \\
\hline Inter. Journal of Computer Integ. Manuf. & & & 1 & 1 & & 2 \\
\hline Inter. Journal of Engineering Education & & 2 & & & & 2 \\
\hline International Journal of Production Economics & & & 2 & & & 2 \\
\hline Reliability Engineering \& System Safety & & 1 & & 1 & & 2 \\
\hline Total & $\mathbf{1 0}$ & $\mathbf{1 2}$ & $\mathbf{7}$ & $\mathbf{7}$ & $\mathbf{1}$ & $\mathbf{3 7}$ \\
\hline
\end{tabular}

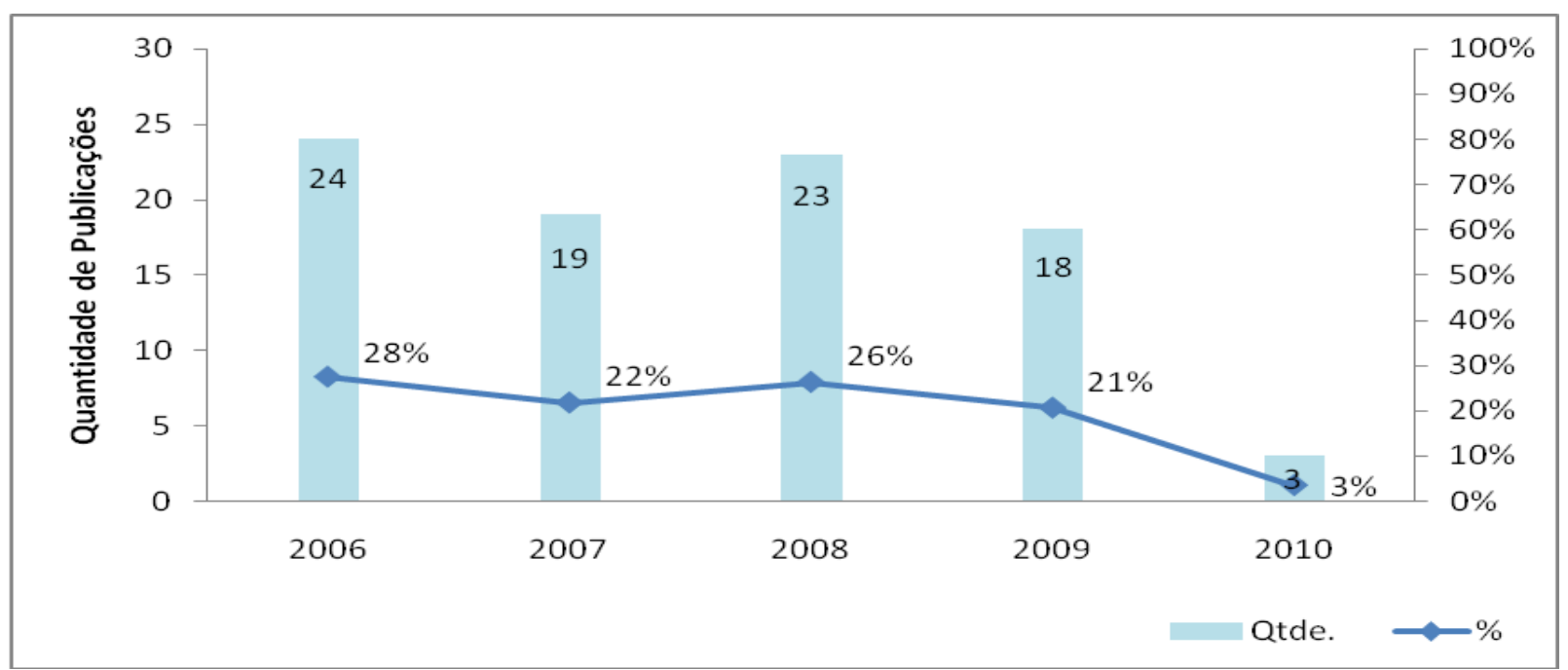

Figura 3.2 - Distribuição percentual e quantidade de publicações por 5 anos. 
Observa-se que existe uma oscilação pequena, mantendo-se em torno de 20 publicações por ano no período analisado. A queda na quantidade de publicações analisadas para o ano de 2010 é devido, principalmente, pela análise englobar as publicações até o mês de março de 2010. Comparando-se com dados da Figura 3.2, observa-se que, em geral, houve um aumento na quantidade de publicações sobre os três conceitos PDP, PLM e ES.

A Figura 3.3 classifica os trabalhos em grupos de abordagens metodológicas de pesquisa, sendo que os valores indicados nas colunas se referem à proporção de cada tipo de abordagem de pesquisa em relação ao total de trabalhos no período de cinco anos. Constata-se que o estudo de caso foi a abordagem metodológica mais adotada e, em segundo lugar, destacam-se os trabalhos teórico-conceituais. Nota-se ainda que não foram encontrados trabalhos classificados como pesquisa-ação ou experimento, sendo este último tipo um resultado esperado. Cabe destacar que algumas publicações foram classificadas em mais de um tipo de estudo por utilizarem abordagens de pesquisa multi-método ou, ainda, na adoção de dada abordagem, serem realizados testes com aplicações reais ou um maior aprofundamento, tais como nas situações de modelagem, seguida por estudo de caso e survey complementada por um estudo de caso.

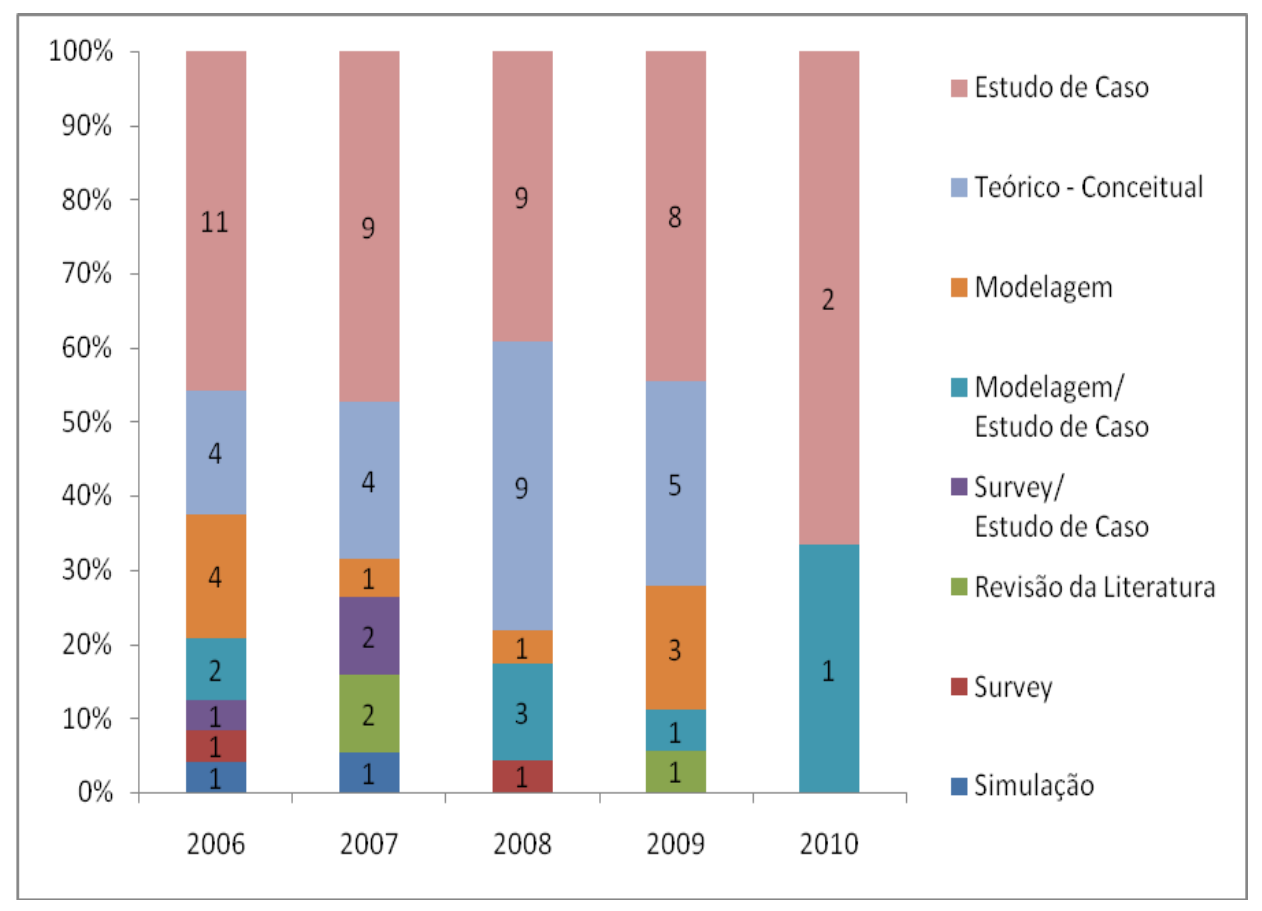

Figura 3.3 - Classificação pelo tipo de abordagem de pesquisa nos estudos. 
Sobre o apoio financeiro para as pesquisas, pouco mais de $26 \%$ dos estudos indicaram a existência de algum tipo de apoio. No entanto, não é possível afirmar que a maioria das pesquisas são realizadas com recursos próprios, pelo fato dessa informação ser omitida nas respectivas publicações. A Figura 3.4 apresenta a classificação dos trabalhos em relação à natureza das abordagens de pesquisa, sendo que os valores das colunas indicam o percentual de ocorrência destas abordagens em relação ao total de abordagens no período contemplado.

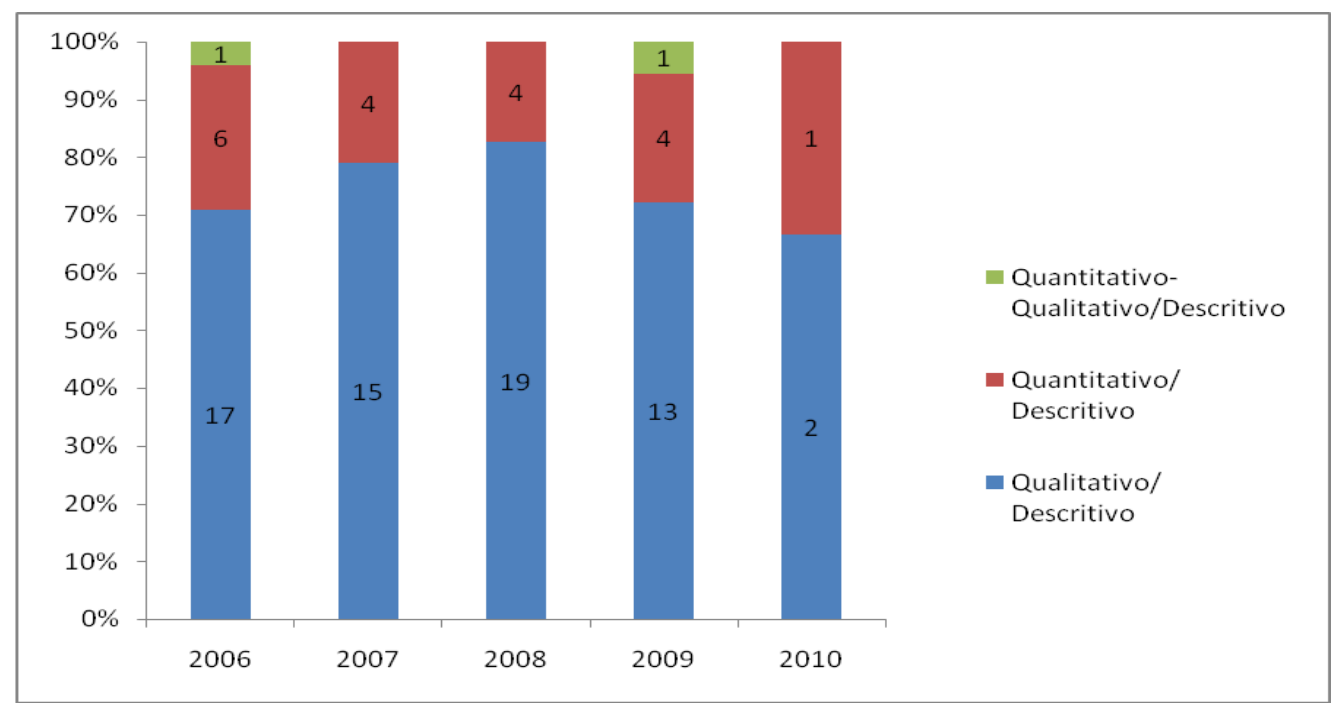

Figura 3.4 - Classificação quanto à abordagem dos estudos.

Verificou-se, portanto, que a abordagem de pesquisa qualitativa (76\%) tem sido mais adotada que a quantitativa (24\%), e, basicamente, só estudos descritivos (100\%) foram realizados. Isso se deve, em parte, pelo foco dos trabalhos serem, em geral, de caráter exploratório, pelo fato de ainda não estarem plenamente consolidados na literatura (com base em estudos empíricos), considerando os conceitos abordados. Em relação aos trabalhos que envolvem ambiente de análise regional, nacional ou internacional, a extensão é centralizada em ambiente nacional (90\%), conforme a Figura 3.5. Sobre o objeto de análise destas pesquisas, a maioria dos trabalhos considera empresas (81\%), como mostrado na Figura 3.6. 


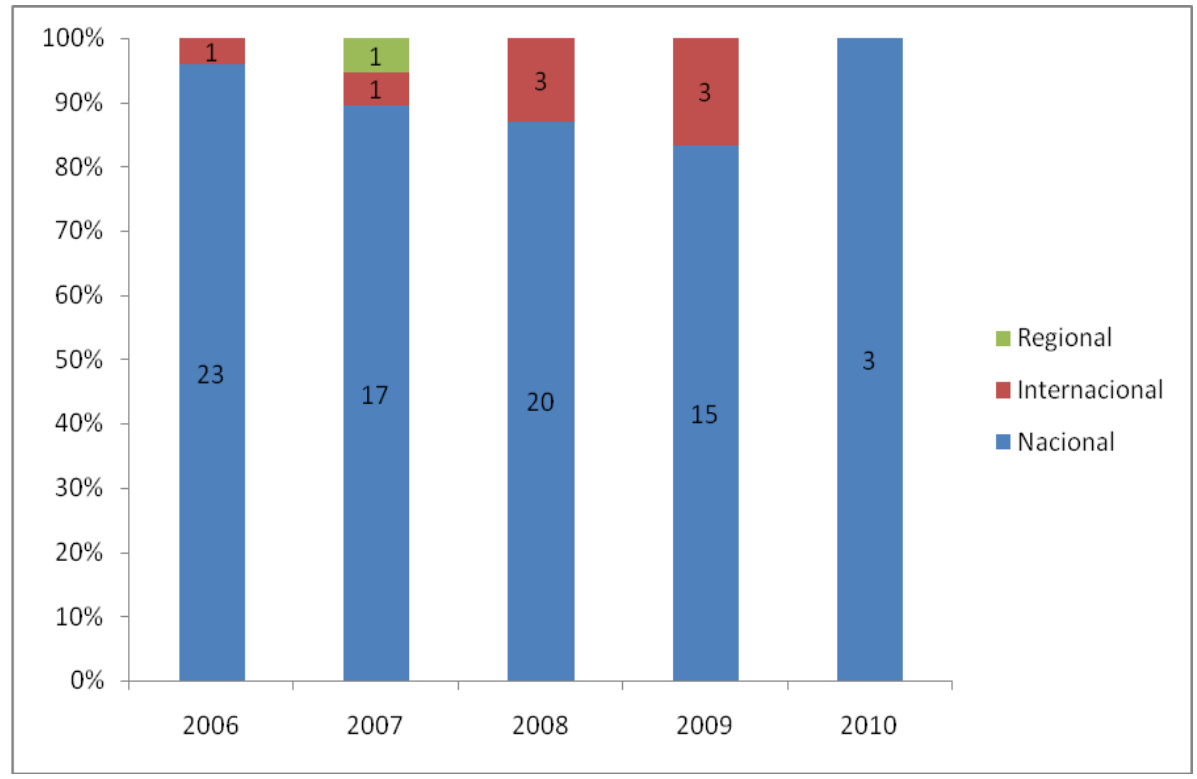

Figura 3.5 - Classificação quanto à extensão dos estudos.

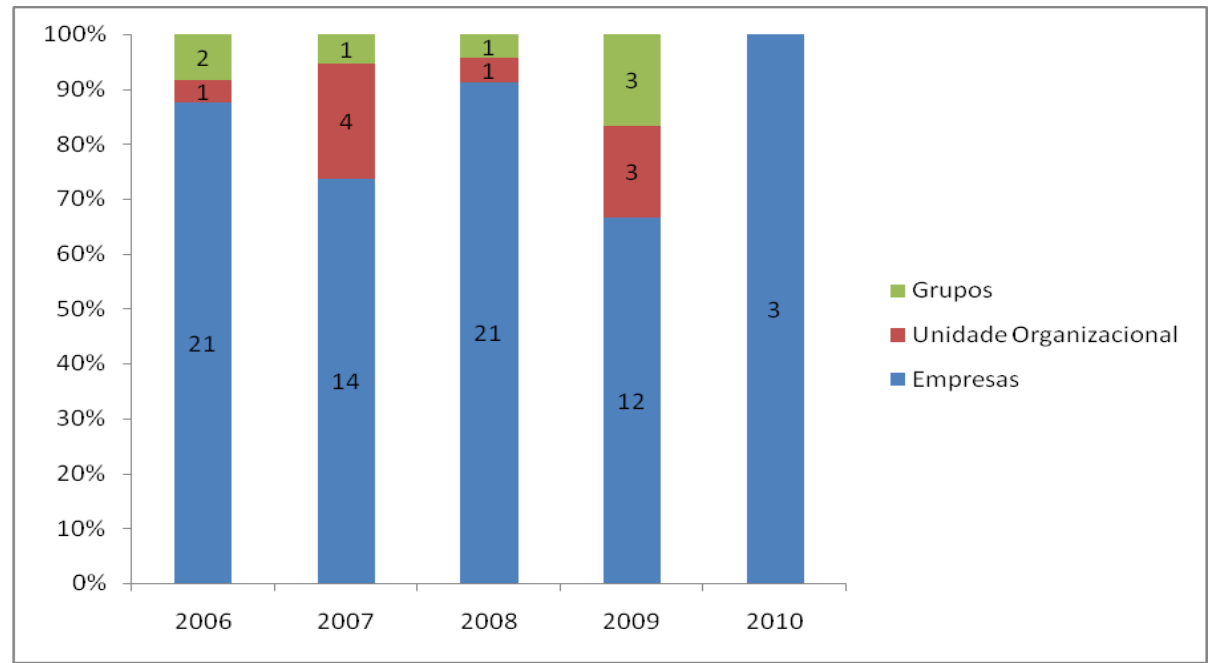

Figura 3.6 - Classificação quanto à escolha do objeto de análise dos estudos.

No caso da utilização de documentação direta e indireta para a coleta de dados foram consideradas aquelas que foram indicadas nos trabalhos. Verificou-se que 0 uso conjunto de revisão bibliográfica e de análise documental foi o com maior frequência (57\%). Por questões óbvias, a revisão bibliográfica também corresponde a quase um quinto do total, seguida pela análise documental (7\%). Entretanto, outros tipos de documentação também foram adotados como indica a Figura 3.7, ressaltando que em (66\%) foi utilizado mais de um tipo de documentação. 


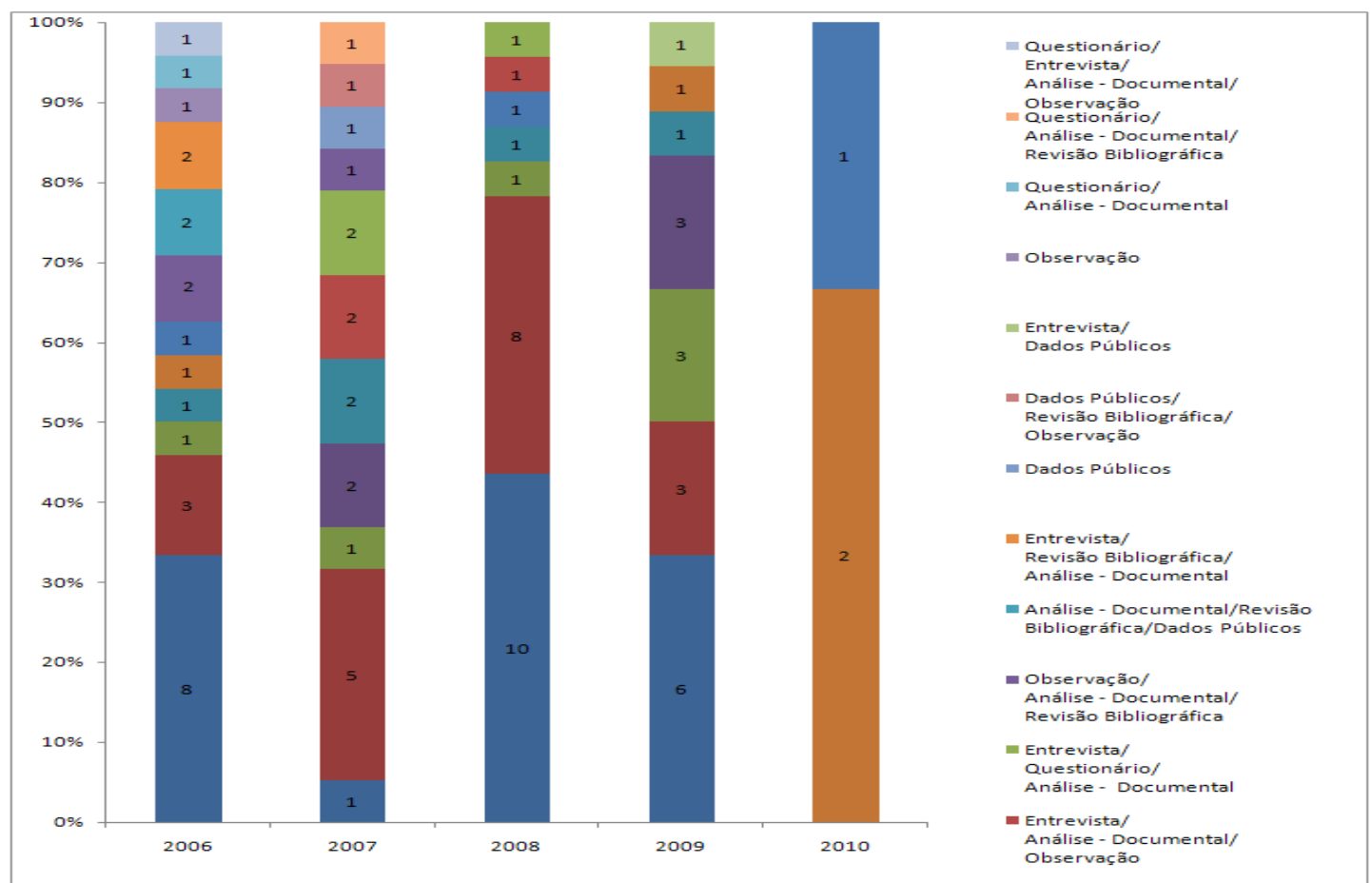

Figura 3.7 - Distribuição da utilização de documentação para coleta de dados identificada nos estudos.

Observou-se, que o estudo do tipo retrospectivo é o mais frequente com mais da metade dos trabalhos analisados, como demonstra a Figura 3.8, seguido do tipo atual (39\%) e, com menos frequência, o estudo longitudinal (8\%). Sobre os estudos de caso longitudinais (que analisam uma aplicação ao longo do tempo), verifica-se que existe uma carência desse tipo de estudos, que são relevantes para analisar a evolução dos conceitos referentes ao tema de pesquisa na extensão temporal.

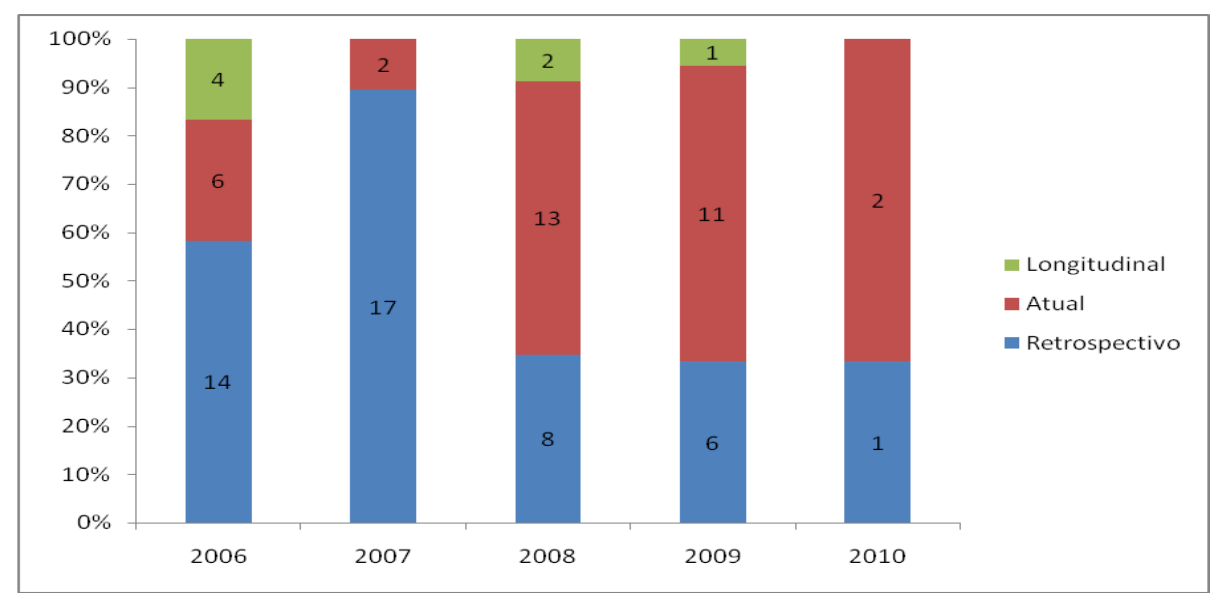

Figura 3.8 - Classificação do período analisado nos estudos. 
Sobre os conceitos utilizados nas publicações analisadas, verificou-se que $21 \%$ delas são sobre sustentabilidade ambiental (ES) que engloba Life Cycle Assessment (LCA); $21 \%$ sobre PDP junto com ES que aborda Design for Sustainability (DfS) e ecodesign; 20\% sobre PLM que considera End of Life (EOL), Life Cycle Costing (LCC) e Life Cycle Design (LCD); 16\% sobre PDP em conjunto com PLM que envolve Strategic Life Cycle Management (SLCM); 10\% sobre PDP; 10\% sobre PLM e ES e $2 \%$ com os três conceitos juntos.

Nas conclusões das publicações são relatados alguns benefícios alcançados e/ou propostos com a inserção dos conceitos de PLM e ES no PDP. Assim, identificou-se que 32\% referem-se a práticas de melhorias na gestão do PDP, 30\% investigaram variáveis que impactam no aumento de desempenho no PDP, 17\% buscam integrar informações de diferentes áreas e sistemas no PDP, 10\% envolvem suporte para a tomada de decisão pela alta administração no PDP, 8\% buscam inserir conceitos e ferramentas de sustentabilidade no PDP, e 1\% para duas outras (alinhamento da cadeia de demanda e gestão do PLM; e melhoria do controle e planejamento de alternativas para desenvolvimento de novos produtos para software considerando o ciclo de vida dos produtos).

No caso das áreas de aplicação dos conceitos analisados, foi verificado que $37 \%$ estão relacionados à ambientes complexos em termos de produto ou processo, $22 \%$ para a gestão das diversas fases do PDP, 17\% são focados, especificamente, para gestão de projetos e desenvolvimento de software, $11 \%$ para melhoria do PDP a partir das relações de colaboração na cadeia de suprimentos, $6 \%$ para desenvolvimento de tecnologia, 3\% para estimular a parceria no codesenvolvimento, $2 \%$ para estruturar programas de desenvolvimento educacional na área de engenharia, e 1\% para controle e planejamento da cadeia de demanda.

\subsection{Análise bibliométrica dos conceitos PLM, PDP e ES}

Após um primeiro contato com os conceitos PLM, PDP e ES obtidos durante a análise anterior (seção 3.1) foi realizada nova busca na literatura e utilizado da análise bibliométrica para um maior aprofundamento nesses conceitos, relações e interfaces. Para compreensão da análise bibliométrica, foram definidos os principais 
termos utilizados, conforme ilustra a Tabela 3.2. Na sequência, são apresentados os resultados da análise das redes sociais.

Tabela 3.2 - Definição dos termos utilizados na análise bibliométrica.

\begin{tabular}{|c|c|}
\hline Termo & Definição \\
\hline Rede social & $\begin{array}{l}\text { A rede é constituída por conjunto de atores (nós da rede) que se } \\
\text { relacionam (traços entre si) e visam à comunicação, troca e ajuda } \\
\text { mútua, e emerge a partir de interesses compartilhados e de situações } \\
\text { vivenciadas. }\end{array}$ \\
\hline Ator da rede & Nós da rede, podem ser: artigos, autores, palavras-chaves, etc. \\
\hline Relacionamento & $\begin{array}{l}\text { São as transações, interações e conexões entre esses diversos } \\
\text { atores. }\end{array}$ \\
\hline Rede de citação cruzada & $\begin{array}{l}\text { Permitem remeter, dentro do conjunto de artigos, quais autores } \\
\text { trabalham sobre temas correlatos. }\end{array}$ \\
\hline Rede de co-citação & $\begin{array}{l}\text { Mede a similaridade de citações entre os trabalhos, identificando o } \\
\text { volume de trabalhos que citaram conjuntamente os mesmos textos. }\end{array}$ \\
\hline Densidade da rede & $\begin{array}{l}\text { E o quociente de relações efetivamente existentes entre os atores das } \\
\text { redes pelo total de ligações possíveis de ocorrer. }\end{array}$ \\
\hline Grau de centralidade & $\begin{array}{l}\text { É a relação adjacente de um ator e pode ser dividida em grau de } \\
\text { entrada (quantidade de ligações que um ator recebe de outros atores) } \\
\text { e grau de saída (quantidade de ligações que um ator estabelece com } \\
\text { atores de um grupo). }\end{array}$ \\
\hline Grau de intermediação & $\begin{array}{l}\text { É a possibilidade que um ator tem para intermediar as comunicações } \\
\text { entre pares de atores, que não se relacionam diretamente. }\end{array}$ \\
\hline Grau de proximidade & Avalia a proximidade ou distância de um ator em relação aos outros. \\
\hline Caminhos geodésicos & $\begin{array}{l}\text { Caminho mais curto que um ator deve percorrer para se ligar a outros } \\
\text { atores. }\end{array}$ \\
\hline
\end{tabular}

Nas próximas seções são apresentados os resultados dos conceitos combinados, considerando os seguintes critérios de análise: trabalhos mais citados (número e percentual), redes de palavras-chaves, co-citação e as referências citadas.

\subsubsection{Análise bibliométrica combinando os conceitos PDP e PLM}

Conforme citado no capítulo de métodos de pesquisa, para as análises de evolução na quantidade e percentual de citações foram feitas atualizações adequando o período para de 1900 a outubro de 2014.

Para essa análise foram selecionados os 20 trabalhos mais citados como critério de corte, devido às redes de referências ficarem muito complexas (a ponto de não permitir visualização e análise). Esse critério de corte representa 838 citações (68\%) do total de citações sobre os dois conceitos mostrados na Tabela 3.3. 
Tabela 3.3 - Os 20 trabalhos mais citados sobre PDP e PLM.

\begin{tabular}{|l|l|c|}
\hline \multicolumn{1}{|c|}{ Autor } & \multicolumn{1}{|c|}{ Fonte da Publicação } & Citações \\
\hline Gunasekaran (1998) & International Journal of Production Research & 120 \\
\hline Griffin e Page (1993) & Journal of Product Innovation Management & 113 \\
\hline Kellner et al. (1999) & Journal of Systems and Software & 78 \\
\hline Rezayat (2000) & Computer-Aided Design & 73 \\
\hline Chulani et al. (1999) & IEEE Transactions on Software Engineering & 59 \\
\hline Djurdjanovic et al. (2003) & Advanced Engineering Informatics & 46 \\
\hline Fan et al. (2003) & Information Systems Research & 32 \\
\hline Ben-Arieh e Qian (2003) & International Journal of Production Economics & 30 \\
\hline Koberg et al. (1996) & Journal of Business Venturing & 28 \\
\hline Calantone and Benedetto (2000) & IEEE Transactions on Engineering Management & 27 \\
\hline Hameri e Nihtila (1998) & Computers in Industry & 27 \\
\hline Chen e Jan (2000) & Robotics and Computer-Integrated Manufacturing & 26 \\
\hline Wang et al. (1998) & Sloan Management Review & 26 \\
\hline Carmel e Becker (1995) & IEEE Transactions on Engineering Management & 25 \\
\hline Xie et al. (2002) & International Journal of Advanced Manufacturing Technology & 23 \\
\hline Aoyama (1998) & IEEE Software & 23 \\
\hline Stumpf et al. (1996) & Journal of Computing in Civil Engineering & 23 \\
\hline Schmid e John (2004) & Science of Computer Programming & 22 \\
\hline Santiago e Bifano (2005) & IEEE Transactions on Engineering Management & 19 \\
\hline Ammenberg e Sundin (2005) & Journal of Cleaner Production & 18 \\
\hline & & $\mathbf{8 3 8}$ \\
\hline
\end{tabular}

Analisando esses trabalhos, identifica-se que eles estão direcionados aos tópicos sobre implementação de redes para manufatura ágil; métricas para gerenciamento da performance do PDP; desenvolvimento de software para simulação de processos e análise de custos; PDP na cadeia de suprimentos; estratificação do PDP em fases; gerenciamento de dados do produto; utilização de ferramentas para tomada de decisão; PLM; sistema de gerenciamento ambiental dos produtos e integração. Neste grupo de trabalhos selecionados, observa-se que não há uma centralização de citações em um autor específico.

Esses trabalhos obtiveram uma evolução e dispersão das citações por autor a partir de 2008, sendo destaque o de Gunasekaran (1998) que fez um mapa conceitual para o desenvolvimento de um sistema de manufatura ágil, detalhando os seus principais fatores de produção, e o de Griffin e Page (1993) que analisou os principais indicadores de performance no PDP aplicados por pesquisadores e empresas. Em 2010 teve-se uma redução na quantidade de citações, devido à 
queda na utilização dos artigos de Griffin e Page (1993), Kellner et al. (1999), Djurdjanovic et al. (2003) e Fan et al. (2003) como embasamento teórico para os estudos realizados. A Figura 3.9 representa o percentual e a Figura 3.10 o número de citações por ano dos trabalhos mais citados sobre PDP e PLM.

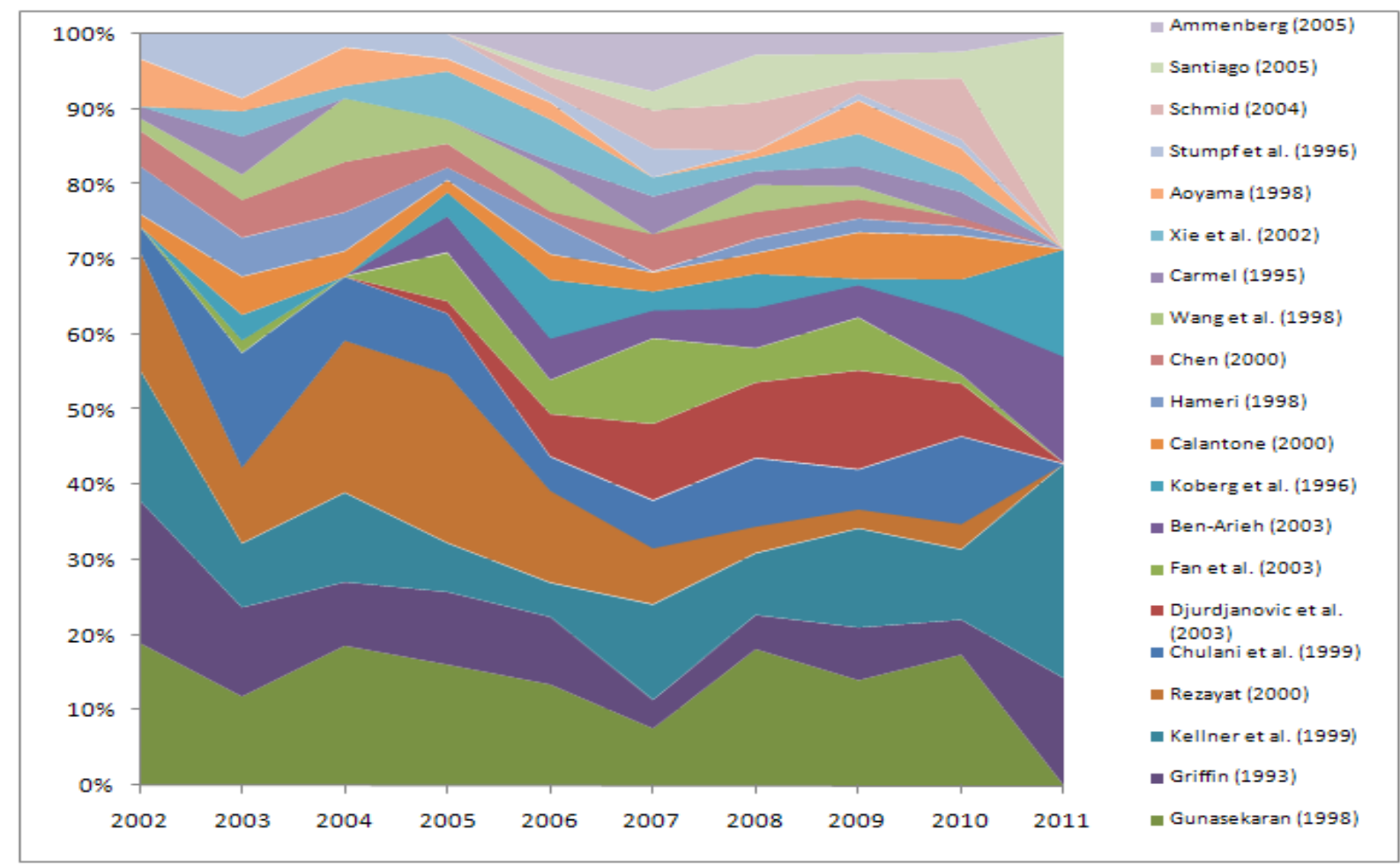

Figura 3.9 - Percentual de citações por ano dos 20 trabalhos mais citados sobre PDP e PLM.

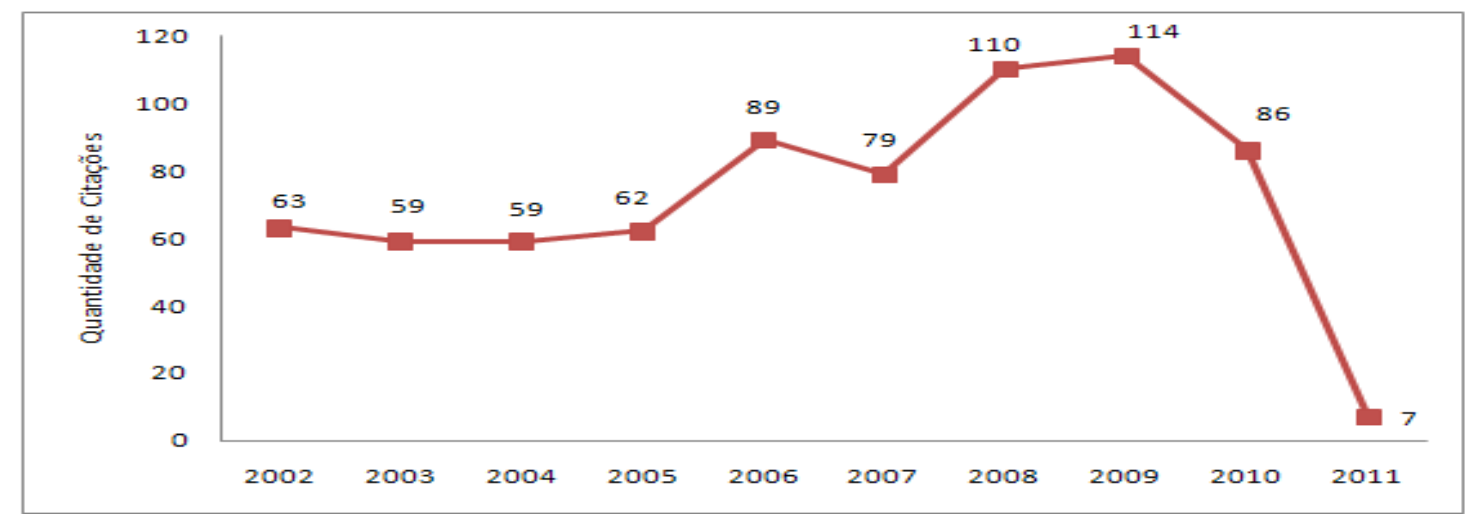

Figura 3.10 - Número de citações por ano dos trabalhos sobre PDP e PLM.

Avaliando as palavras-chaves da rede da Figura 3.11, as palavras com maior frequência nas relações são "product development" que está associado a 
"performance" e "management", a palavra "design" que está relacionada à "model', "concurrent engineering", "management" e "performance". Esta ocorrência e devido ao fato dos trabalhos buscarem melhorar o desempenho do PDP, com a utilização de estruturas de PDP como referências que integrem todas as fases do PDP.

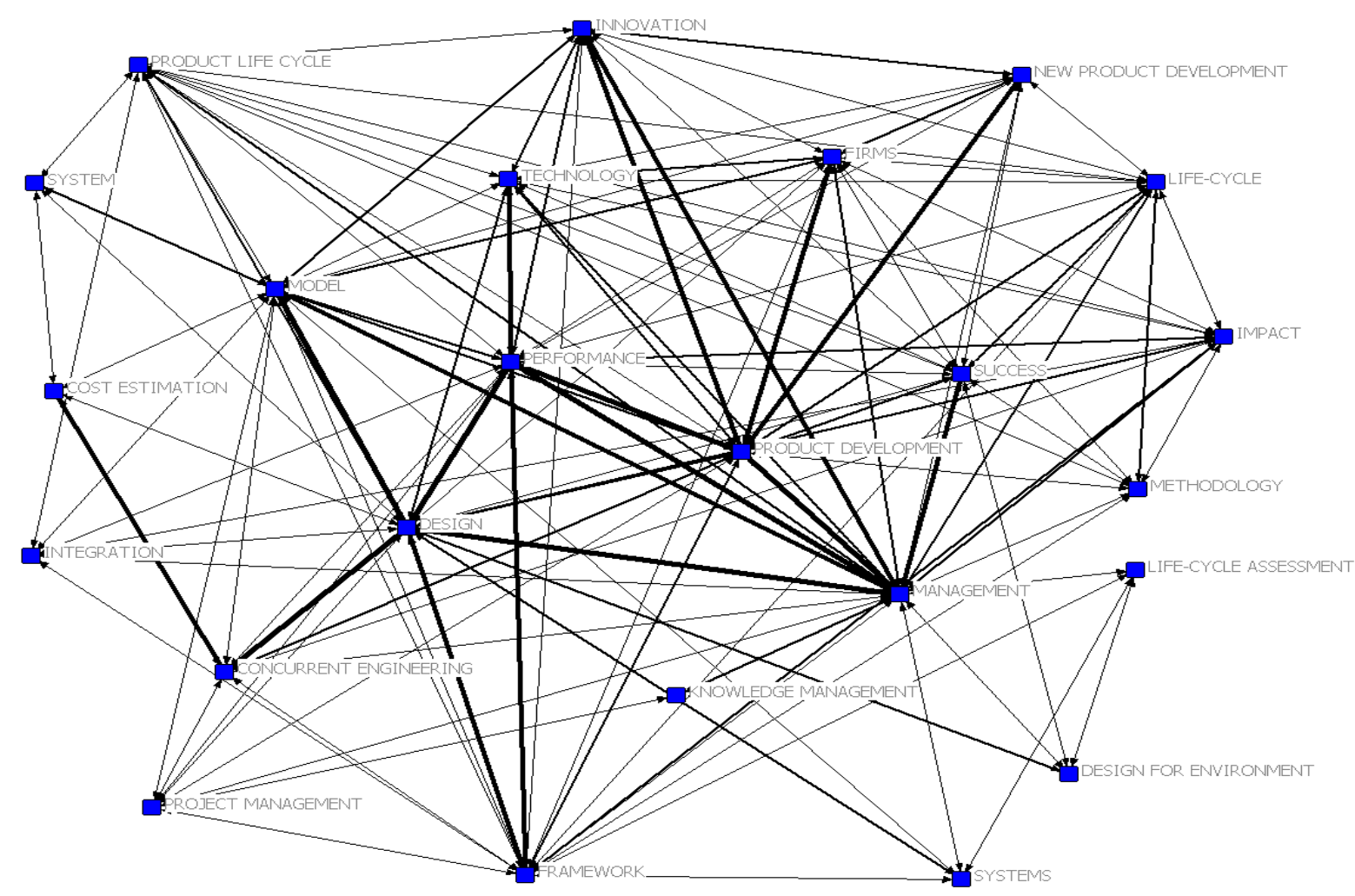

Figura 3.11 - Rede de palavras-chaves dos trabalhos mais citados sobre PDP e PLM.

Foi identificada uma rede de citações cruzadas entre os trabalhos de Kellner et al. (1999), Raffo e Kellner (2000) e Kouskouras e Georgiou (2007), o que demonstra que os autores investigam temas correlatos. Na Figura 3.12, tem-se o resultado da rede de co-citações que mediu a similaridade de citações entre os trabalhos, identificando o volume de trabalhos que citaram conjuntamente os mesmos textos. Nesta análise, observa-se a co-citação entre os trabalhos de Takeuchi e Nonaka (1986), Cooper (1990), Henderson e Clark (1990), Clark e Fujimoto (1991), Milson et al. (1992), Ulrich (1995), Sanderson e Uzumeri (1995), Sanchez e Mahoney (1996) e MacCormack et al. (2001). Isso se explica com base na proximidade dos temas 
desses trabalhos abordarem tópicos relacionados à gestão do PDP, tais como: arquitetura de produto, performance, stage gate e modularidade.

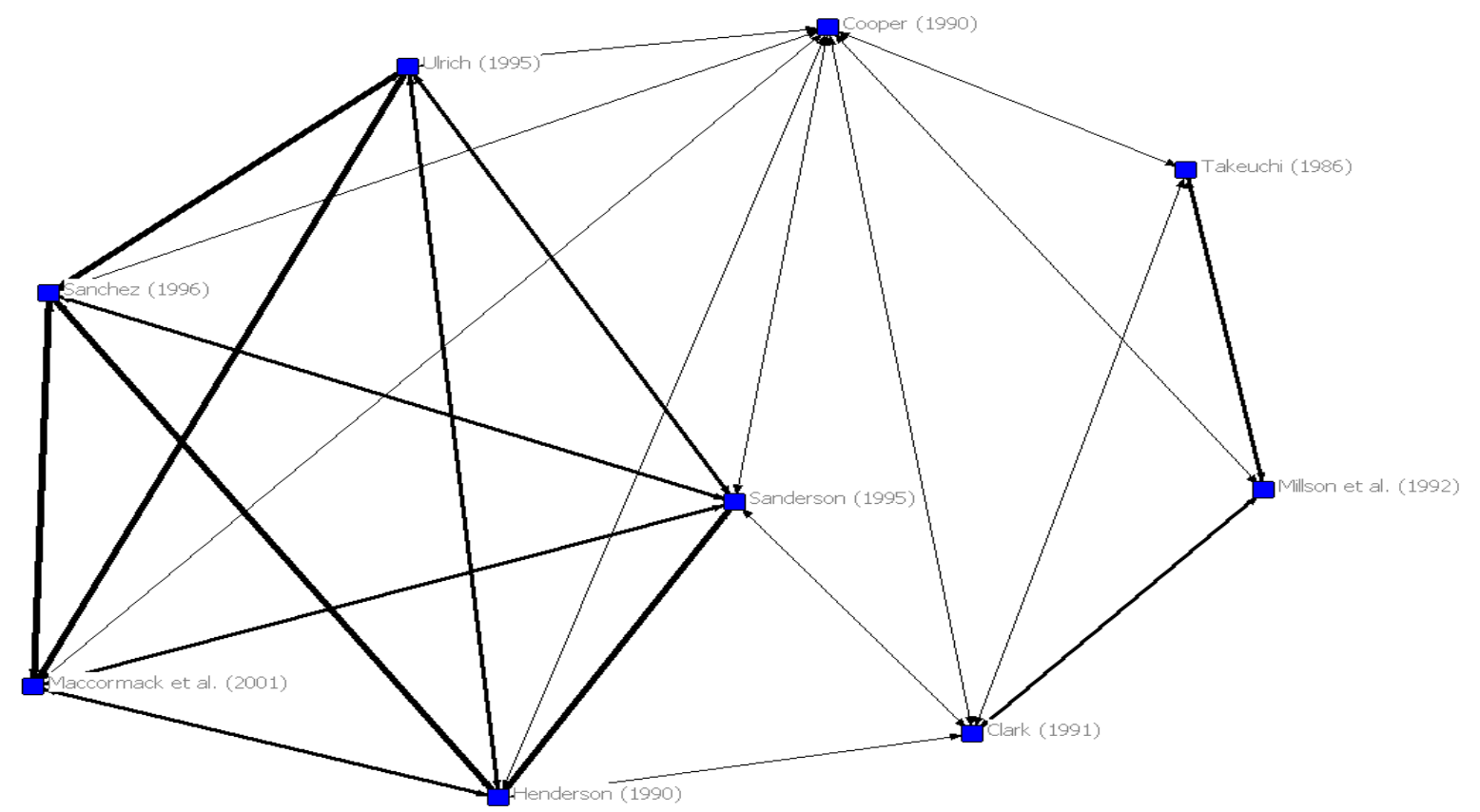

Figura 3.12 - Rede de co-citação dos trabalhos mais citados sobre PDP e PLM.

Para analisar as referências bibliográficas mais citadas, utilizou-se como critério de corte as referências citadas mais que 4 vezes, em função da grande quantidade. Com base nesse critério, obteve-se 8 referências, conforme Tabela 3.4.

Tabela 3.4 - As referências citadas mais que 4 vezes sobre PDP e PLM.

\begin{tabular}{|l|l|c|}
\hline \multicolumn{1}{|c|}{ Referência Utilizada } & \multicolumn{1}{c|}{ Fonte da Publicação } & Citações \\
\hline Prasad (1996) & Concurrent Engineering Fundamentals & 10 \\
\hline Clark e Fujimoto (1991) & Product Development Performance & 6 \\
\hline Eisenhardt (1989) & Academy of Management Review & 6 \\
\hline Abernathy e Utterback (1978) & Technology Review & 5 \\
\hline Henderson e Clark (1990) & Administrative Science Quarterly & 4 \\
\hline Krishnan et al. (1997) & Management Science & 4 \\
\hline Sanchez e Mahoney (1996) & Strategic Management Journal & 4 \\
\hline Ulrich (1995) & Research Policy & 4 \\
\hline & & \multicolumn{1}{c|}{ Total } \\
\hline
\end{tabular}

Para analisar a relação entre os trabalhos e as referências mais citadas sobre os dois conceitos foi elaborada a rede mostrada na Figura 3.13. Os círculos 
representam os trabalhos mais citados e os quadrados às referências mais citadas pelos trabalhos.

Legenda: Trabalho que cita Referência citada
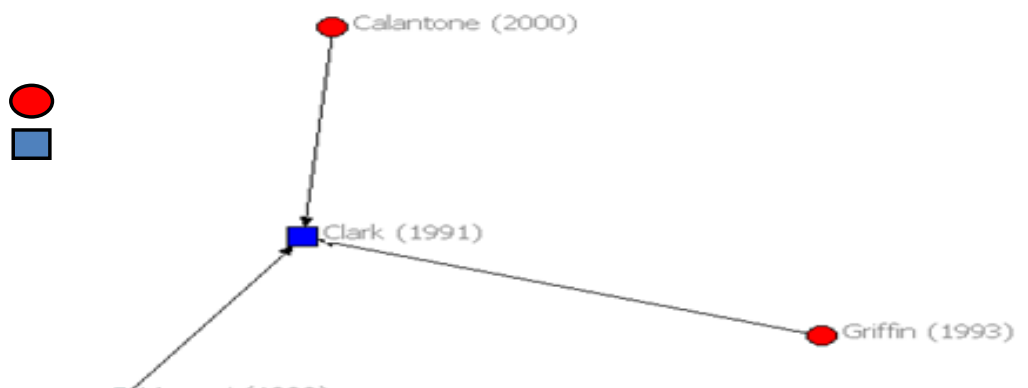

Figura 3.13 - Rede de relações entre os trabalhos e referências mais citadas sobre PDP e PLM.

Na rede da Figura 3.13, estão os seguintes trabalhos: o de Grifin e Page (1993), que mapeia os principais indicadores de perfomance utilizados no PDP, o trabalho de Hameri e Nihtila (1998) que analisa o estado da arte sobre o gerenciamento de dados de produtos no PDP e a publicação de Calantone e Benedetto (2000), que analisa o equilíbrio entre o desempenho do produto e o tempo de mercado. Esses trabalhos referenciam Clark e Fujimoto (1991) que aborda a estratégia e estruturação do PDP para atingir um melhor desempenho e, ainda, cria uma classificação quanto à complexidade do produto e complexidade organizacional.

\subsubsection{Atualização da análise bibliométrica combinando os conceitos PDP e PLM}

Nesta atualização em outubro de 2014 foram selecionados os 20 trabalhos mais citados que representa 2.395 citações $(38,9 \%)$ do total de citações sobre as publicações dos dois conceitos mostrados na Tabela 3.5.

Tabela 3.5 - Os 20 trabalhos mais citados sobre PDP e PLM (atualizado).

\begin{tabular}{|l|l|c|}
\hline \multicolumn{1}{|c|}{ Autor } & \multicolumn{1}{c|}{ Fonte da Publicação } & Citações \\
\hline Gungor e Gupta (1999) & Computers \& Industrial Engineering & 342 \\
\hline Kozlowski Pallardy (2002) & Botanical Review & 273 \\
\hline Hobday (1998) & Research Policy & 237 \\
\hline
\end{tabular}


Tabela 3.5 - Os 20 trabalhos mais citados sobre PDP e PLM (atualizado) continuação.

\begin{tabular}{|c|c|c|}
\hline Autor & Fonte da Publicação & Citações \\
\hline Gunasekaran (1998) & International Journal of Production Research & 175 \\
\hline Griffin e Page (1993) & Journal of Product Innovation Management & 108 \\
\hline Ortiz et al. (2009) & Construction and Building Materials & 119 \\
\hline Caddy (1999) & Reviews in Fish Biology and Fisheries & 113 \\
\hline Rezayat (2000) & Computer-Aided Design & 107 \\
\hline kellner et al. (1999) & Journal of Systems and Software & 107 \\
\hline Roy et al. (2009) & Journal of Food Engineering & 103 \\
\hline Attiwill (1994) & Forest Ecology and Management & 71 \\
\hline Thompson et al. (2009) & $\begin{array}{l}\text { Philosophical Transactions of the Royal Society B-Biological } \\
\text { Sciences }\end{array}$ & 92 \\
\hline Ramesh e Tiwana (1999) & Decision Support Systems & 85 \\
\hline Djurdjanovic et al. (2003) & Advanced Engineering Informatics & 83 \\
\hline Chulani et al. (1999) & IEEE Transactions on Software Engineering & 82 \\
\hline Ben-Arieh e Qian (2003) & International Journal of Production Economics & 71 \\
\hline Goktan e Miles (2011) & Management Decision & 63 \\
\hline Smith et al. (2005) & Meat Science & 56 \\
\hline Tervonen et al. (2009) & Journal of Nanoparticle Research & 54 \\
\hline \multirow[t]{2}{*}{ Fan et al. (2003) } & Information Systems Research & 54 \\
\hline & Total & 2.395 \\
\hline
\end{tabular}

Analisando os trabalhos da Tabela 3.3, percebe-se que alguns autores da análise anterior (item 3.2.1) permanecem entre os 20 mais citados, tais como: Gunasekaran (1998), Griffin e Page (1993), Rezayat (2000), kellner et al. (1999), Djurdjanovic et al. (2003), Chulani et al. (1999), Ben-Arieh e Qian (2003) e Fan et al. (2003) e surgiram outros autores que se destacaram em termos de citações. É importante destacar que pouca citação de trabalhos recentes pode ser devido a sua vida ainda curta de publicação.

Os três autores mais citados, Gungor e Gupta (1999), Kozlowski Pallardy (2002) e Hobday (1998), focam nas complexidades do processo de inovação considerando a importância da dimensão ambiental.

Nas Figuras 3.14 e 3.15 identifica-se uma tendência de aumento nas citações sobre os conceitos de PDP e PLM, que está sendo impulsionado por atores mais recentes como Ortiz et al. (2009), Roy et al. (2009) e Thompson et al. (2009). Estes trabalhos abordam principalmente o tema Life Cycle Assessment (LCA) no desenvolvimento de produtos. 


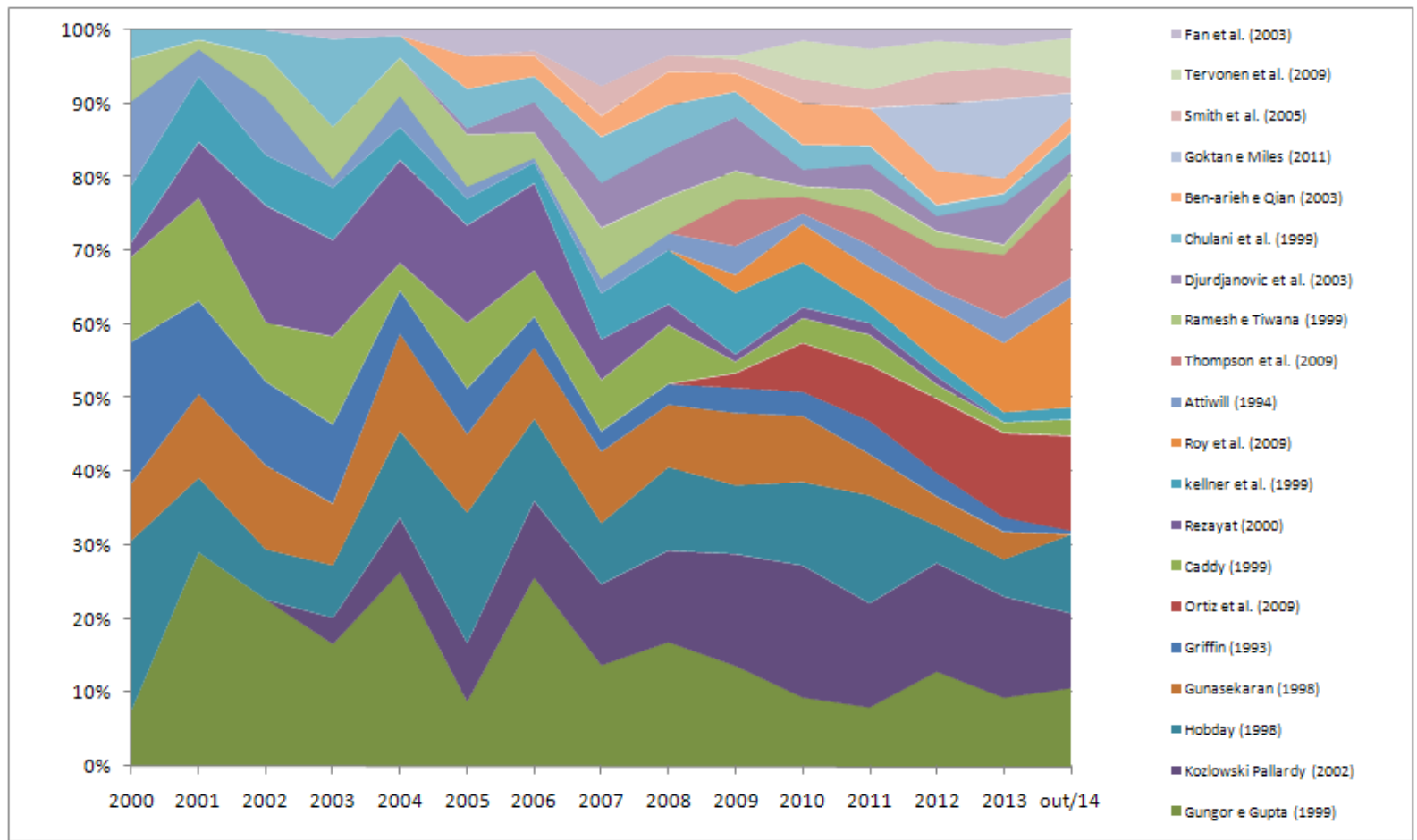

Figura 3.14 - Percentual de citações por ano dos 20 trabalhos mais citados sobre PDP e PLM (atualizado).

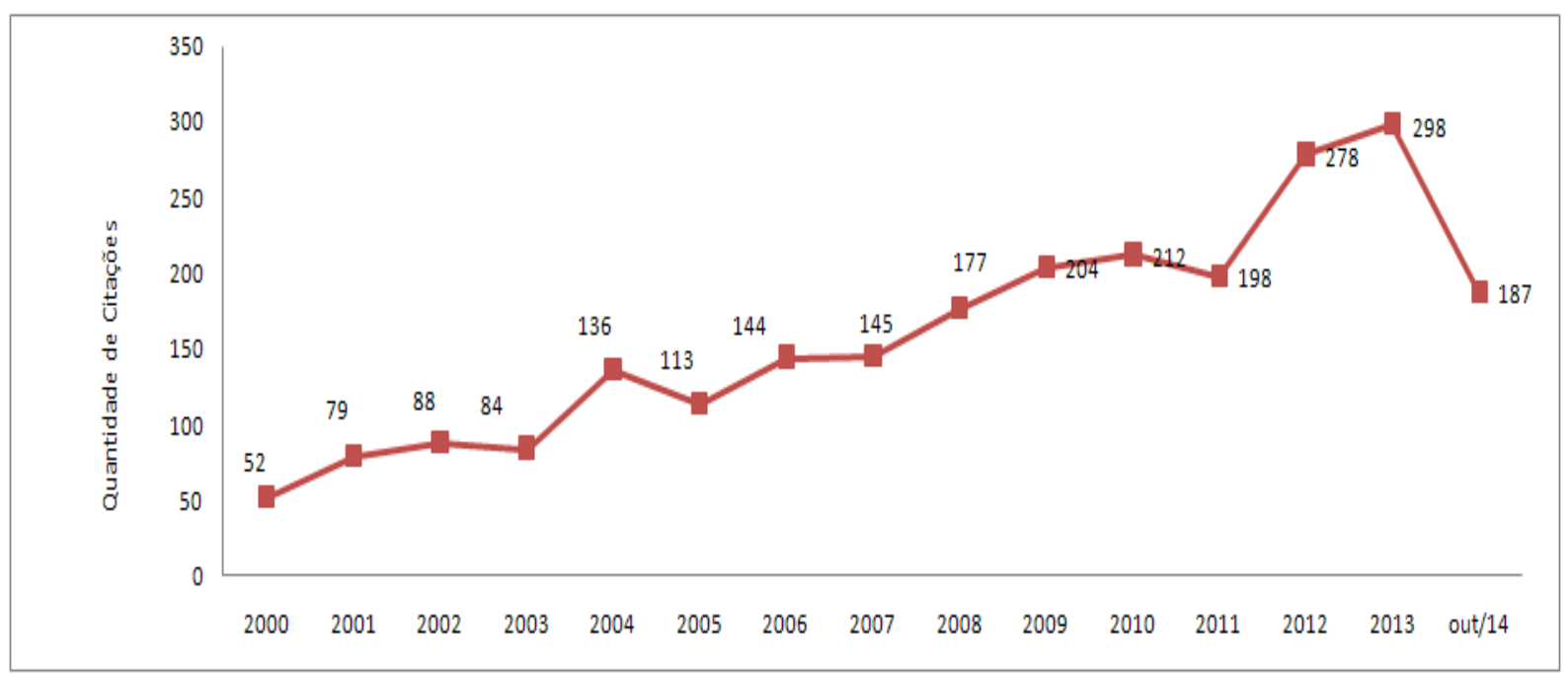

Figura 3.15 - Número de citações por ano dos trabalhos citados mais sobre PDP e PLM (atualizado). 


\subsubsection{Análise bibliométrica combinando os conceitos PDP e ES}

Prosseguindo a análise, combinando os conceitos de PDP e ES, utilizou-se os 20 trabalhos mais citados como critério de corte, que representa 362 citações $(69 \%)$ do total de citações sobre os conceitos, conforme a Tabela 3.6.

Tabela 3.6 - Os 20 trabalhos mais citados sobre PDP e ES.

\begin{tabular}{|l|l|c|}
\hline \multicolumn{1}{|c|}{ Autor } & \multicolumn{1}{c|}{ Fonte da Publicação } & Citações \\
\hline Krotscheck e Narodoslawsky (1996) & Ecological Engineering & 57 \\
\hline Stratful et al. (1999) & Environmental Technology & 32 \\
\hline Calantone e Benedetto (2000) & IEEE Transactions on Engineering Management & 27 \\
\hline Uhlin (1998) & Agricultural Systems & 27 \\
\hline Khan et al. (2004) & Journal of Cleaner Production & 24 \\
\hline Rennings et al. (2006) & Ecological Economics & 20 \\
\hline Pujari (2006) & Technovation & 19 \\
\hline Vachon e Klassen (2008) & International Journal of Production Economics & 18 \\
\hline Luttropp e Lagerstedt (2006) & Journal of Cleaner Production & 16 \\
\hline Kashefi e Mort (2004) & Health Expectations & 14 \\
\hline Ferreira et al. (2008) & Aquaculture & 13 \\
\hline Chen (2005) & Journal of Cleaner Production & 13 \\
\hline Waage (2007) & Journal of Cleaner Production & 12 \\
\hline Tilche e Galatola (2008) & Water Science and Technology & 11 \\
\hline Gallezot (2008) & Chemsuschem & 10 \\
\hline Tugnoli et al. (2008) & International Journal of Hydrogen Energy & 10 \\
\hline Kurk e Eagan (2008) & Journal of Cleaner Production & 10 \\
\hline Klopffer (2006) & International Journal of Life Cycle Assessment & 10 \\
\hline Kaatz et al. (2005) & Building Research and Information & 10 \\
\hline Rosenstrom e Kyllonen (2007) & Journal of Environmental Management & 9 \\
\hline & & $\mathbf{3 6 2}$ \\
\hline
\end{tabular}

$\mathrm{Na}$ Tabela 3.6, verifica-se que os trabalhos estão voltados para inserir aspectos ambientais no PDP, integrando toda a cadeia de suprimentos e se preocupando com a redução da emissão de gás no meio ambiente. Além disso, pesquisam tópicos correlatos como a biomassa, reciclagem, gerenciamento ambiental, ecodesign, ferramentas e indicadores para o PLM, integração da sustentabilidade e a necessidade de mudar a estratégia para o desenvolvimento sustentável de produtos.

O trabalho mais citado é o de Krotscheck e Narodoslawsky (1996) que utiliza o índice de processo sustentável com aspectos econômicos para avaliação ecológica 
do processo. O segundo é o de Stratful et al. (1999) que investiga as práticas e os benefícios da reciclagem de produtos químicos nos efluentes gerados pelas empresas. Essas citações mantiveram-se relativamente constantes, com pequeno crescimento até 2007. Entretanto, em 2008, houve uma elevação nas citações desses trabalhos. Inicialmente, elas estavam centralizadas em cinco autores Krotscheck e Narodoslawsky (1996), Uhlin (1998), Stratful et al. (1999), Calantone e Benedetto (2000) e Khan et al. (2004). A partir de 2009 outros trabalhos se destacaram como os de Kashefi e Mort (2004), Chen (2005), Pujari (2006), Rennings et al. (2006) e Vachon e Klassen (2008). A Figura 3.16 e 3.17 ilustram respectivamente o percentual e o número de citações dos trabalhos mais citados sobre os conceitos de PDP e ES.

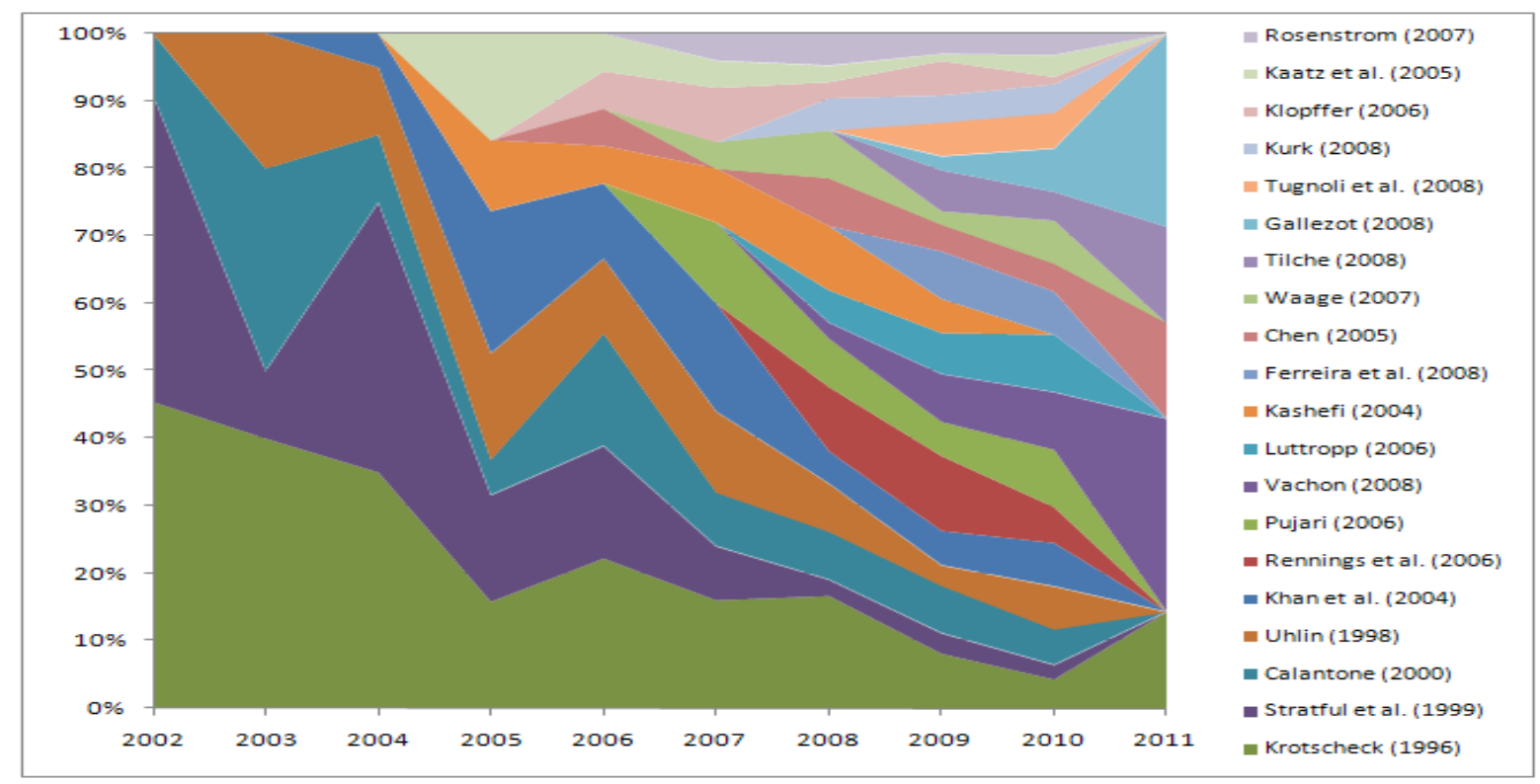

Figura 3.16 - Percentual de citações por ano dos 20 trabalhos mais citados sobre PDP e ES.

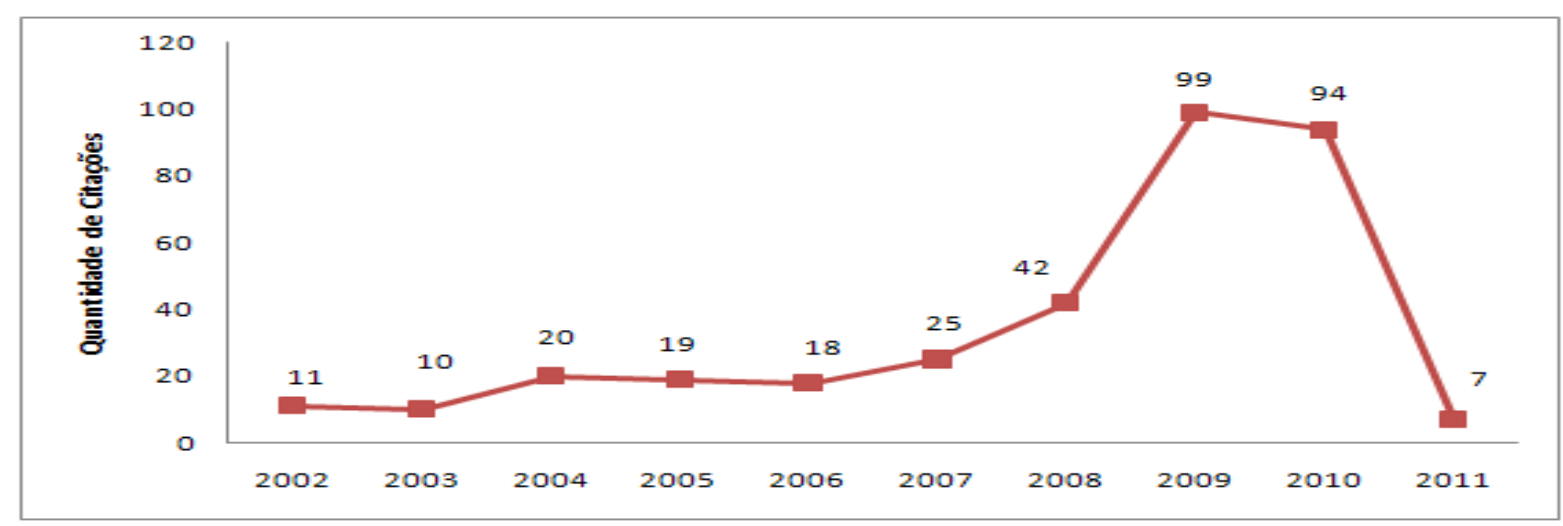

Figura 3.17 - Número de citações dos 20 trabalhos mais citados sobre PDP e ES. 
Examinando as relações entre as palavras-chaves da Figura 3.18, observa-se que a palavra "product development" está relacionada com uma maior freqüência a palavra "ecodesign", e que o tema "sustainability" tem alta interação com o tópico "performance". Essa rede mostra a importância da ponderação de aspectos ambientais, sociais e econômicos para melhoria da performance do PDP.

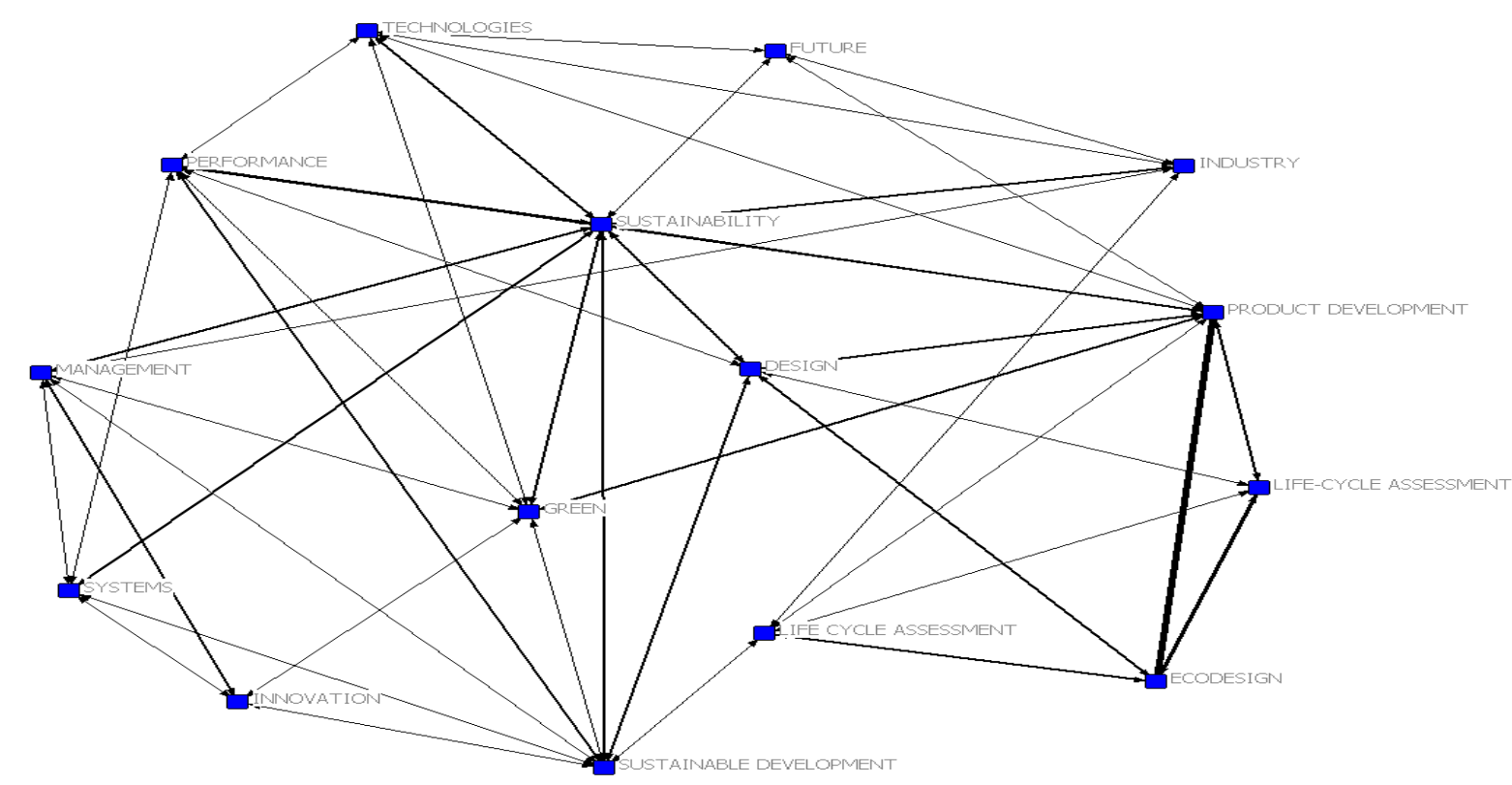

Figura 3.18 - Rede de palavras-chaves dos trabalhos mais citados sobre PDP e ES.

A rede de citações cruzadas permitiu identificar dois clusters principais um com foco em PDP e o outro com foco em ecodesign, conforme apresenta a Figura 3.19. Os trabalhos de Tingstrom et al. (2006), Petala et al. (2010) e Jabbour (2010) abordam temas correlatos, que estudam a inserção da sustentabilidade na gestão do PDP. Ainda, estão listados os trabalhos de Pujari (2006), Waage (2007), Cruz e Boehe (2008) e Collado-Ruiz e Ostad-Ahmad-Ghorabi (2010), que analisam questões ecológicas no design de novos produtos. Os demais trabalhos encontrados nessa mesma rede tratam em síntese da integração de questões socioambientais para melhoria do PDP. 


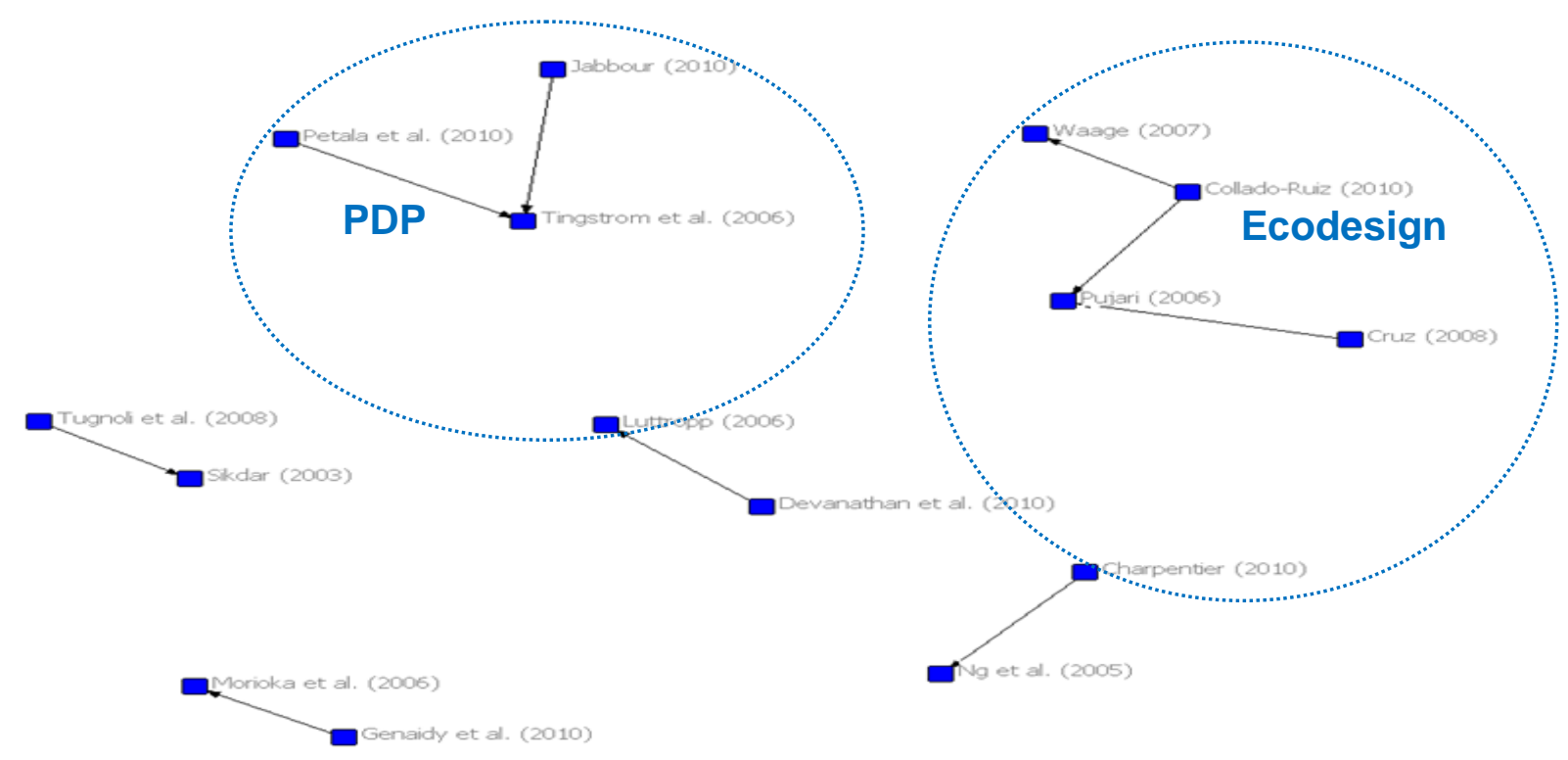

Figura 3.19 - Rede de citação cruzada dos trabalhos mais citados sobre PDP e ES.

$\mathrm{Na}$ rede de co-citações, observa-se a similaridade de citações entre os trabalhos de Porter e Vanderlinde (1995) e Hart (1997), devido aos temas destas publicações se concentrarem na estratégia e competitividade para 0 desenvolvimento sustentável. Para analisar as referências bibliográficas mais citadas, utilizou-se como critério de corte as citadas mais que 4 vezes, face à ampla quantidade de referências. Com base nesse critério, obteve-se 5 referências, mostradas na Tabela 3.7. Cabe destacar que o trabalho de Eisenhardt (1989) não é relacionado aos conceitos analisados, mas é um trabalho sobre métodos de pesquisa em gestão de operações.

Tabela 3.7 - As referências citadas mais que 4 vezes sobre PDP e ES.

\begin{tabular}{|l|lc|}
\hline \multicolumn{1}{|c|}{ Referência Utilizada } & \multicolumn{1}{c|}{ Fonte da Publicação } & Citações \\
\hline Brezet e Hemel (1997) & Ecodesign Promising & 4 \\
\hline Eisenhardt (1989) & Academy of Management Review & 4 \\
\hline Gladwin et al. (1995) & Academy of Management Review & 4 \\
\hline Hart (1997) & Harvard Business Review & 4 \\
\hline Porter e Vanderlinde (1995) & Harvard Business Review & 4 \\
\hline & \multicolumn{1}{|c|}{ Total } & $\mathbf{2 0}$ \\
\hline
\end{tabular}




\subsubsection{Atualização da análise bibliométrica combinando os conceitos PDP e ES}

Nesta atualização em outubro de 2014 foram selecionados os 20 trabalhos mais citados que representa 3.185 citações $(50,7 \%)$ do total de citações sobre os conceitos, conforme a Tabela 3.8.

Tabela 3.8 - Os 20 trabalhos mais citados sobre PDP e ES (atualizado).

\begin{tabular}{|l|l|c|}
\hline \multicolumn{1}{|c|}{ Autor } & \multicolumn{1}{c|}{ Fonte da Publicação } & Citações \\
\hline Mohanty et al. (2002) & Journal of Polymers and the Environment & 597 \\
\hline Song (2006) & Catalysis Today & 484 \\
\hline Lynd et al. (1999) & Biotechnology Progress & 397 \\
\hline Gavrilescu e Chisti (2005) & Biotechnology Advances & 176 \\
\hline Pitcher (2001) & Ecological Applications & 169 \\
\hline Vachon e Klassen et al. (2008) & International Journal of Production Economics & 167 \\
\hline Faruk et al. (2012) & Progress in Polymer Science & 134 \\
\hline Ortiz et al. (2009) & Construction and Building Materials & 119 \\
\hline Raymond et al. (2010) & Journal of Environmental Management & 98 \\
\hline Daily e Huang (2001) & International Journal of Operations \& Production & 98 \\
\hline Luttropp e Lagerstedt (2006) & Management & 95 \\
\hline Bebbington (1997) & Journal of Cleaner Production & 79 \\
\hline Corbett e klassen (2006) & Geographical Journal & 87 \\
\hline Hart e Milstein (1999) & M\&Som-Manufacturing \& Service Operations & 73 \\
\hline Gallezot (2008) & Management & 72 \\
\hline Pujari (2006) & Sloan Management Review & 72 \\
\hline Rennings et al. (2006) & Chemsuschem & 70 \\
\hline Manlay et al. (2007) & Technovation & 67 \\
\hline Jimenez-Gonzalez et al. (2004) & Ecological Economics & 66 \\
\hline Schillberg et al. (2005) & Agriculture Ecosystems \& Environment & 65 \\
\hline & International Journal of Life Cycle Assessment & 3.185 \\
\hline & Vaccine & Total \\
\hline
\end{tabular}

Analisando os trabalhos da Tabela 3.8, verifica-se que apenas cinco autores da análise anterior (item 3.2.2) continuam entre os mais citados, como por exemplo: Vachon e Klassen et al. (2008), Luttropp e Lagerstedt (2006), Gallezot (2008), Pujari (2006) e Rennings et al. (2006) e vários autores apareceram como relevantes em relação à quantidade de citações. 
Os trabalhos mais citados no período analisado, como Mohanty et al. (2002), Song (2006), Lynd et al. (1999) e Gavrilescu e Chisti (2005), abordam o tema de biotecnologia e quais os desafios para o desenvolvimento de produtos verdes com base em estratégias para controle de consumo de energia e emissão de $\mathrm{CO}_{2}$. Interpretando as Figuras 3.20 e 3.21, identifica-se uma elevação acentuada na quantidade de citações sobre os conceitos de PDP e ES juntos.

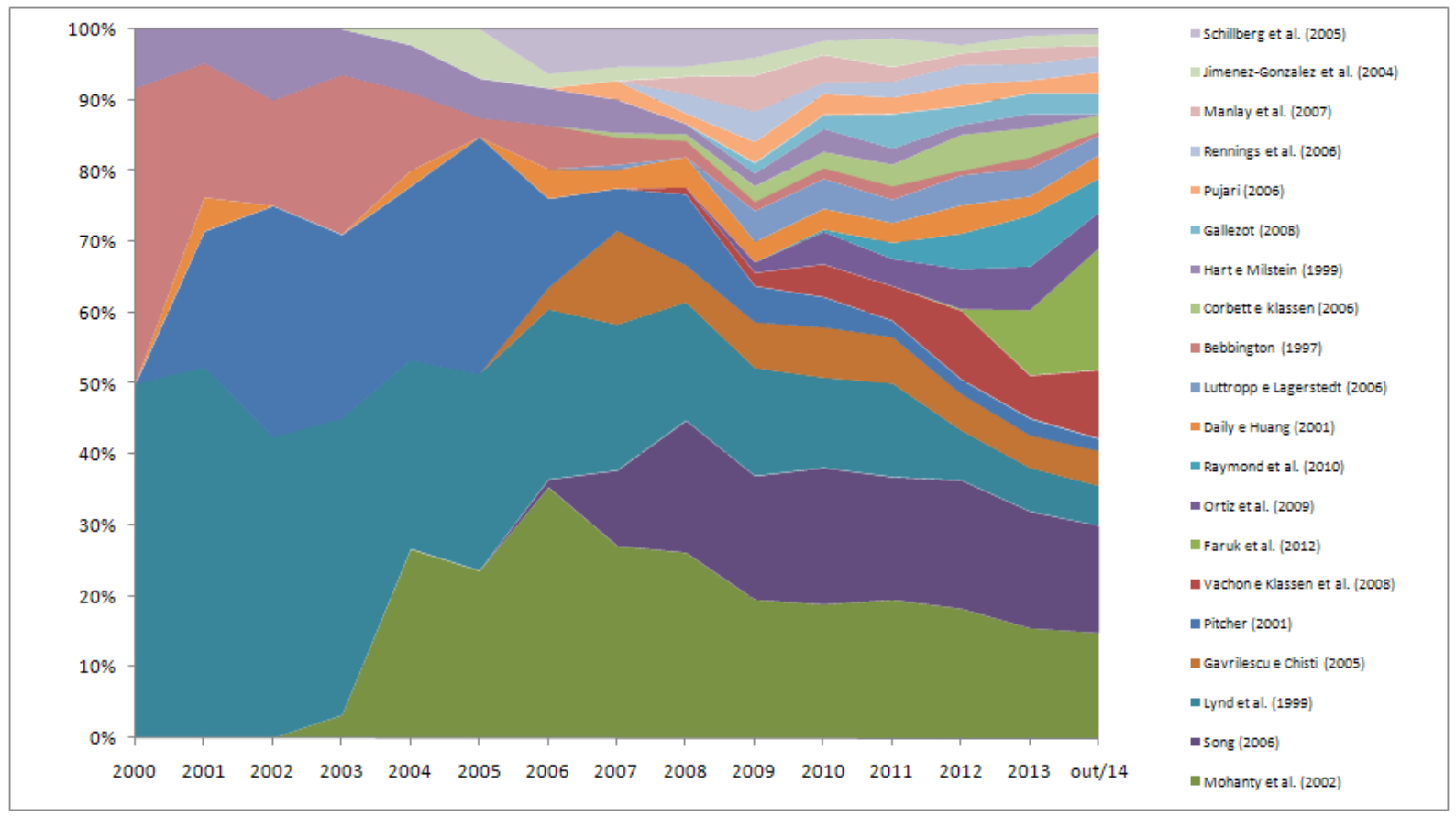

Figura 3.20 - Percentual de citações por ano dos 20 trabalhos mais citados sobre PDP e ES (atualizado).

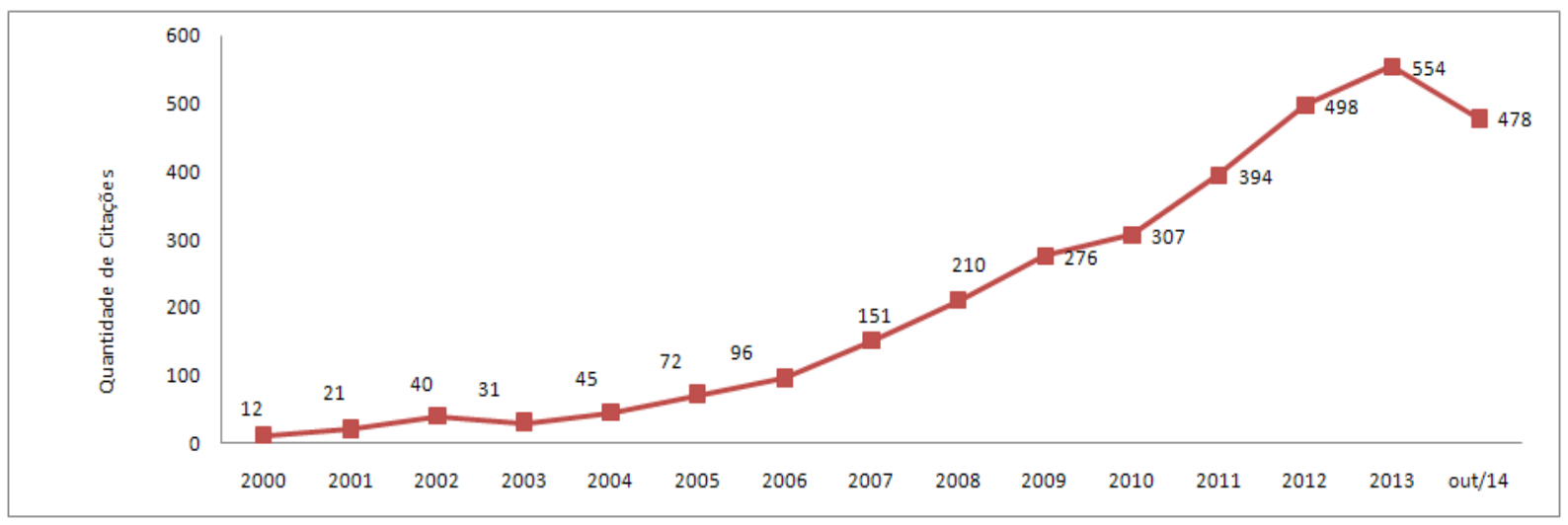

Figura 3.21 - Número de citações dos 20 trabalhos mais citados sobre PDP e ES (atualizado). 


\subsubsection{Análise bibliométrica combinando os conceitos PLM e ES}

Para esses conceitos foram identificados os 20 trabalhos mais citados como critério de corte, que representa 325 citações (96\%) do total de citações sobre os conceitos, como ilustra a Tabela 3.9.

Tabela 3.9 - Os 20 trabalhos mais citados sobre PLM e ES.

\begin{tabular}{|l|l|c|}
\hline \multicolumn{1}{|c|}{ Autor } & \multicolumn{1}{c|}{ Fonte da Publicação } & Citações \\
\hline Kohler e Hassler (2002) & Building Research and Information & 47 \\
\hline Wicke et al. (2008) & Biomass \& Bioenergy & 35 \\
\hline Maxwell e Van Der Vorst (2003) & Journal of Cleaner Production & 35 \\
\hline Linton et al. (2007) & Journal of Operations Management & 32 \\
\hline Calantone e Benedetto (2000) & IEEE Transactions on Engineering Management & 27 \\
\hline Klopffer (2003) & International Journal of Life Cycle Assessment & 22 \\
\hline Ashford (2002) & American Behavioral Scientist & 18 \\
\hline De Benedetto e KLEMES (2009) & Journal of Cleaner Production & 14 \\
\hline Van Der Werf et al. (2007) & Agriculture Ecosystems \& Environment & 14 \\
\hline Lippiatt (1999) & Journal of Construction Engineering and Management & 11 \\
\hline Coltro et al. (2006) & International Journal of Life Cycle Assessment & 10 \\
\hline Nakamura e Kondo (2006) & Ecological Economics & 9 \\
\hline Moffatt e Kohler (2008) & Building Research and Information & 8 \\
\hline Arena et al. (2004) & Industrial \& Engineering Chemistry Research & 8 \\
\hline Maxwell et al. (2006) & Journal of Cleaner Production & 7 \\
\hline Curran (2004) & Environmental Progress & 7 \\
\hline Rebitzer et al. (2003) & Environmental Progress & 7 \\
\hline Ny et al. (2006) & Journal of Industrial Ecology & 6 \\
\hline Pulido et al. (2007) & Journal of Tropical Ecology & 4 \\
\hline Schmidt e Butt (2006) & International Journal of Life Cycle Assessment & 4 \\
\hline & & 325 \\
\hline
\end{tabular}

Com base nos trabalhos da Tabela 3.9, percebe-se que as publicações estão direcionadas as questões de sustentabilidade na cadeia de suprimentos, análise dos impactos ambientais, estratégia para tomada de decisão, gerenciamento do ciclo de vida dos produtos por ferramentas, inserção da performance ambiental na estratégia, conceitos de reciclagem e final da vida útil dos produtos relacionados a sistemas ecológicos e sociais. O trabalho mais citado a respeito de PLM e ES é o de Kohler e Hassler (2002) que elabora um modelo para análise do ciclo de vida do produto e 
aplica indicadores de sustentabilidade na área de infra-estrutura e construção. Os outros dois trabalhos mais citados são do Maxwell e Van Der Vorst (2003) que descreve o método Sustainable Product and/or Service Development (SPSD) para orientar as empresas quanto aos obstáculos da inovação sustentável em termos de desenvolvimento de produtos e serviços e como superá-los e o de Wicke et al. (2008) que analisa diferentes sistemas de produção para fins energéticos e as implicações da emissão de gás para o efeito estufa.

Entre 2002 e 2006 as citações concentravam-se nos seguintes autores: Lippiatt (1999), Calantone e Benedetto (2000), Ashford (2002), Maxwell e Van Der Vorst (2003) e Klopffer (2003), em 2007 os trabalhos de Kohler e Hassler (2002), Linton et al. (2007), Van Der Werf et al. (2007) e Wicke et al. (2008) passaram a ter mais prestígio. A quantidade de trabalhos cresceu gradativamente até 2009 e em 2010 obteve-se um aumento significativo na nas citações, devido à maior utilização dos trabalhos de Wicke et al. (2008) com 24 citações e Linton et al. (2007) com 21 citações. A Figura 3.22 e 3.23 demonstram o número e o percentual de citações por ano dos trabalhos mais citados sobre os dois conceitos.

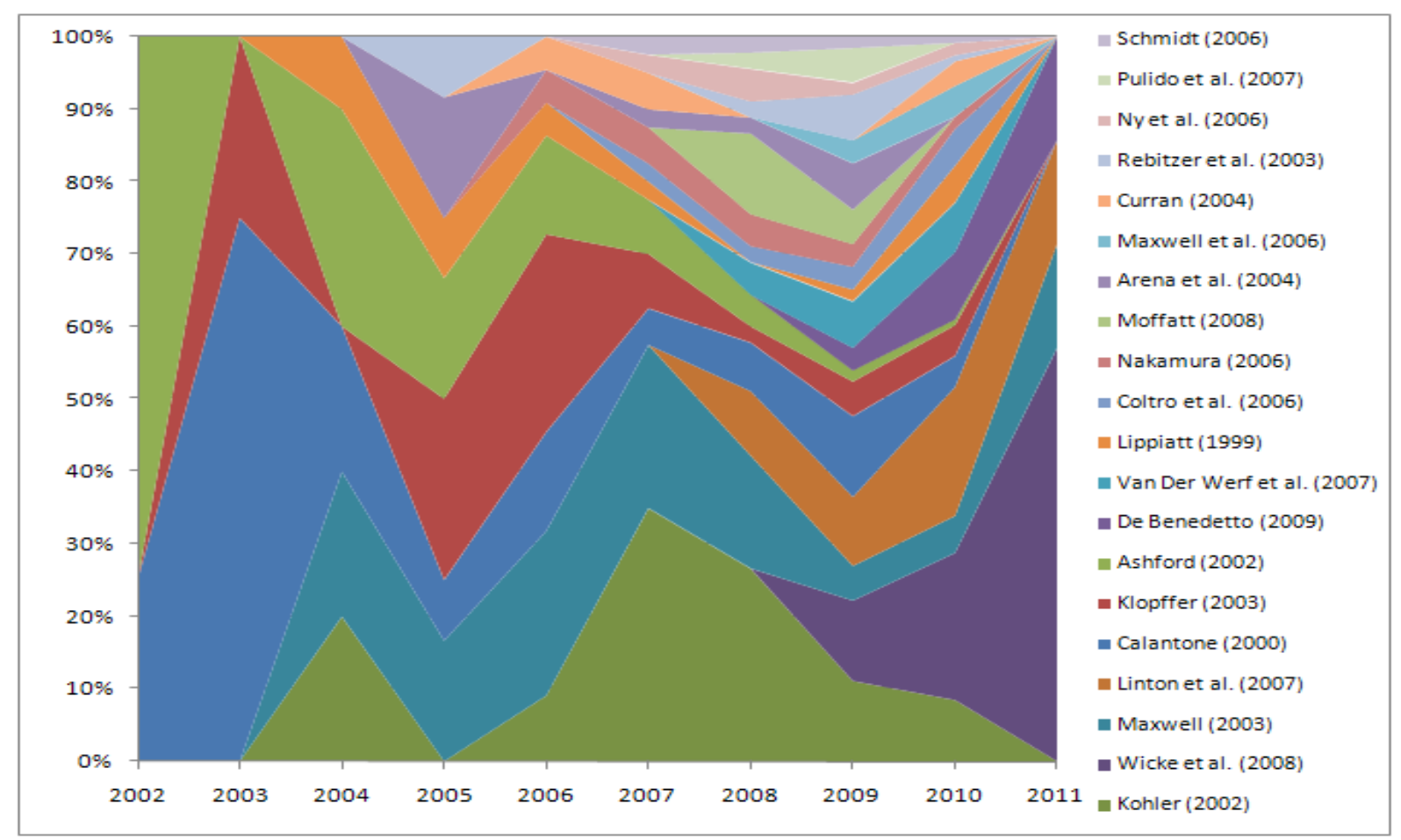

Figura 3.22 - Percentual de citações por ano dos 20 trabalhos mais citados sobre PLM e ES. 


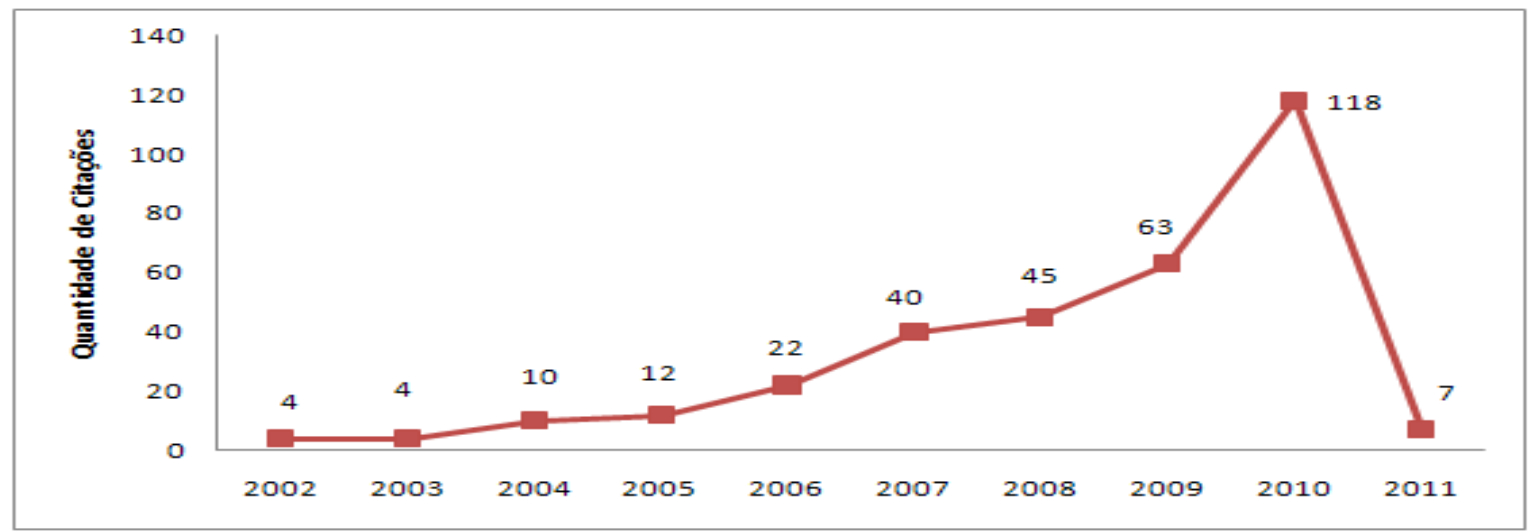

Figura 3.23 - Número de citações dos 20 trabalhos mais citados sobre PLM e ES.

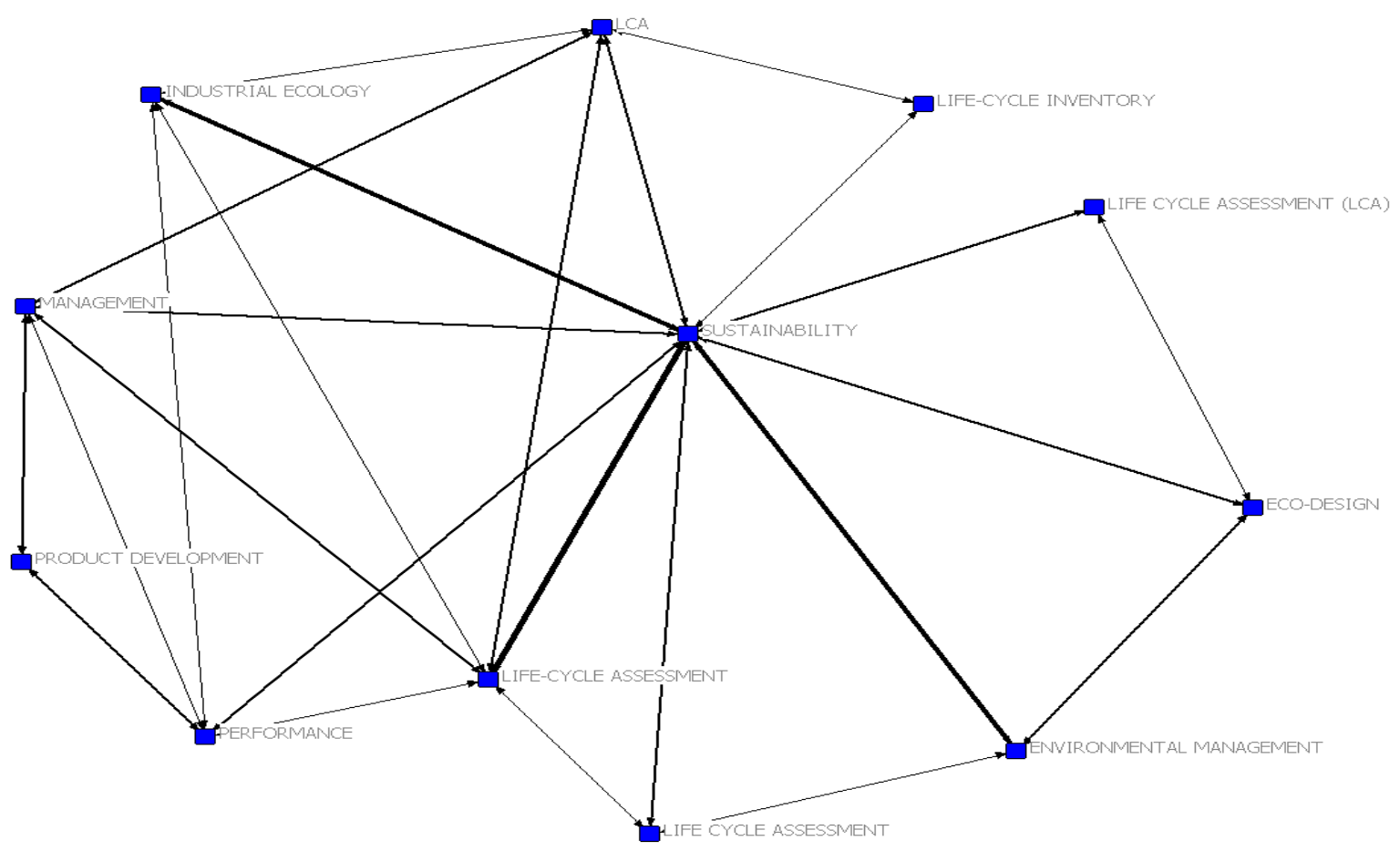

Figura 3.24 - Rede de palavras-chaves dos trabalhos mais citados sobre PLM e ES.

Analisando as afinidades entre as palavras-chaves da Figura 3.24, percebe-se que a palavra "sustainability" é central, pois está relacionada às demais palavras e com maior freqüência a palavra "life cycle assessment" e depois com "environmental management" e "industrial ecology". Considera-se que o termo sustentabilidade está relacionado com mais freqüência as demais palavras englobadas pelo conceito de PLM por ser um conceito abrangente e que exige que o gerenciamento do ciclo de vida atenda aos requisitos ambientais impostos. 
Foi identificado uma rede de citação cruzada, neste caso de auto-citação, entre os trabalhos de Maxwell e Van Der Vorst (2003) e Maxwell et al. (2006) sobre PLM e ES. Na rede da Figura 3.25, tem-se os resultados da rede de co-citações, que observa dois blocos de co-citações. No primeiro bloco estão os trabalhos de Dehaes et al. (1999), Norris (2001), Hunkeler e Rebitzer (2003), Rebitzer et al. (2003) e Dreyer et al. (2006), no qual a similaridade de citações se elucida pois os trabalhos abordam temas correlatos à sustentabilidade e ao ciclo de vida do produto. No segundo bloco, estão os trabalhos de Wackernagel e Rees (1996), Holmberg e Robert (2000), Kohler e Hassler (2002), Spence (2004) e Pennington et al. (2004) que são similares, pois estudam tópicos do ciclo de vida dos produtos, desenvolvimento sustentável, sistemas ecológicos e impactos ambientais.
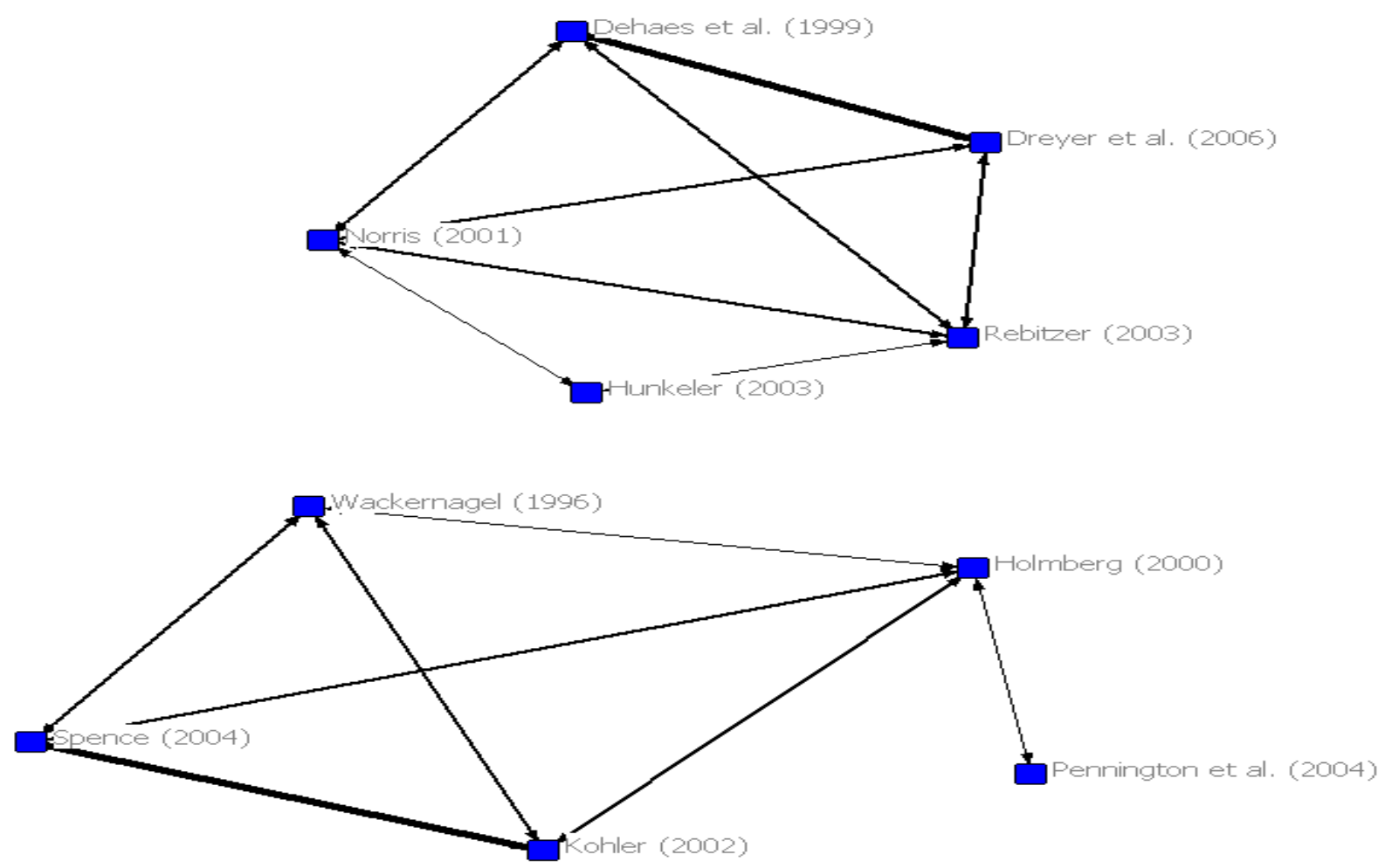

Figura 3.25 - Rede de co-citação para os trabalhos mais citados sobre PLM e ES.

Para analisar as referências bibliográficas mais citadas, utilizou-se como critério de corte as citadas mais que 3 vezes, em função da quantidade de referências. Com base nisso, obteve-se 8 referências indicadas na Tabela 3.10. 
Tabela 3.10 - As referências citadas mais que 3 vezes sobre PLM e ES.

\begin{tabular}{|l|l|c|}
\hline \multicolumn{1}{|c|}{ Autor } & \multicolumn{1}{c|}{ Fonte da Publicação } & Citações \\
\hline Dehaes et al. (1999) & International Journal of Life Cycle Assessment & 3 \\
\hline Dreyer et al. (2006) & The International Journal of Life Cycle Assessment & 3 \\
\hline Heijungs et al. (1992) & Environmental Life Cycle Assessment of Products & 3 \\
\hline Hunkeler e Rebitzer (2003) & The International Journal of Life Cycle Assessment & 3 \\
\hline Norris (2001) & The International Journal of Life Cycle Assessment & 3 \\
\hline Pennington et al. (2004) & Environment International & 3 \\
\hline Rebitzer (2002) & Cost Management in Supply Chains & 3 \\
\hline Wackernagel e Rees (1996) & Environment and Urbanization & 3 \\
\hline & \multicolumn{1}{|c|}{ Total } & $\mathbf{2 4}$ \\
\hline
\end{tabular}

\subsubsection{Atualização da análise bibliométrica combinando os conceitos PLM e ES}

Nesta atualização em outubro de 2014 foram identificados os 20 trabalhos mais citados que equivale a 1.059 citações $(53,8 \%)$ do total de citações sobre os conceitos, como ilustra a Tabela 3.11.

Tabela 3.11 - Os 20 trabalhos mais citados sobre PLM e ES (atualizado).

\begin{tabular}{|l|l|c|}
\hline \multicolumn{1}{|c|}{ Autor } & \multicolumn{1}{c|}{ Fonte da Publicação } & Citações \\
\hline Linton et al. (2007) & Journal of Operations Management & 198 \\
\hline Ortiz et al. (2009) & Construction and Building Materials & 119 \\
\hline Maxwell e Van der Vorst (2003) & Journal of Cleaner Production & 69 \\
\hline De Benedetto e Klemes (2009) & Journal of Cleaner Production & 54 \\
\hline Chaabane et al. (2012) & International Journal of Production Economics & 54 \\
\hline Van der Werf et al. (2007) & Agriculture Ecosystems \& Environment & 50 \\
\hline Klopffer (2003) & International Journal of Life Cycle Assessment & 47 \\
\hline Mermut e Eswaran (2001) & Geoderma & 39 \\
\hline Wu e Pagell (2011) & Journal of Operations Management & 38 \\
\hline Glendining et al. (2009) & Agricultural Systems & 37 \\
\hline Subramoniam et al. (2009) & Journal of Cleaner Production & 35 \\
\hline Song et al. (2009) & Philosophical Trans. Royal Soc. B-Biological Sciences & 34 \\
\hline Maxwell et al. (2006) & Journal of Cleaner Production & 30 \\
\hline Moffatt e Kohler (2008) & Building Research and Information & 28 \\
\hline Frey et al. (2006) & Journal of Industrial Ecology & 27 \\
\hline Lindner et al. (2010) & Ecological Modelling & 27 \\
\hline Gonzalez-Garcia et al. (2009) & International Journal of Life Cycle Assessment & 27 \\
\hline Ashford (2002) & American Behavioral Scientist & 25 \\
\hline Laurent et al. (2012) & Environmental Science \& Technology & 24 \\
\hline Ramani et al. (2010) & Journal of Mechanical Design & $\mathbf{1 . 0 5 9}$ \\
\hline & & \multicolumn{1}{|c|}{ Total } \\
\hline
\end{tabular}


Com base na Tabela 3.11, constata-se que os autores da análise anterior (item 3.2.3) prosseguem entre os mais citados, como por exemplo: Linton et al. (2007), Maxwell e Van der Vorst (2003), De Benedetto e Klemes (2009), Van der Werf et al. (2007), Klopffer (2003), Maxwell et al. (2006), Moffatt e Kohler (2008) e Ashford (2002) e entre os autores com mais citações surgiram Ortiz et al. (2009) e Chaabane et al. (2012), que abordam respectivamente o desenvolvimento sustentável com base no LCA e a participação da cadeia de suprimentos no desenvolvimento sustentável. As Figuras 3.26 e 3.27 demonstram que em 2008 houve uma mudança de patamar no número de citações por ano desses trabalhos sobre os dois conceitos.

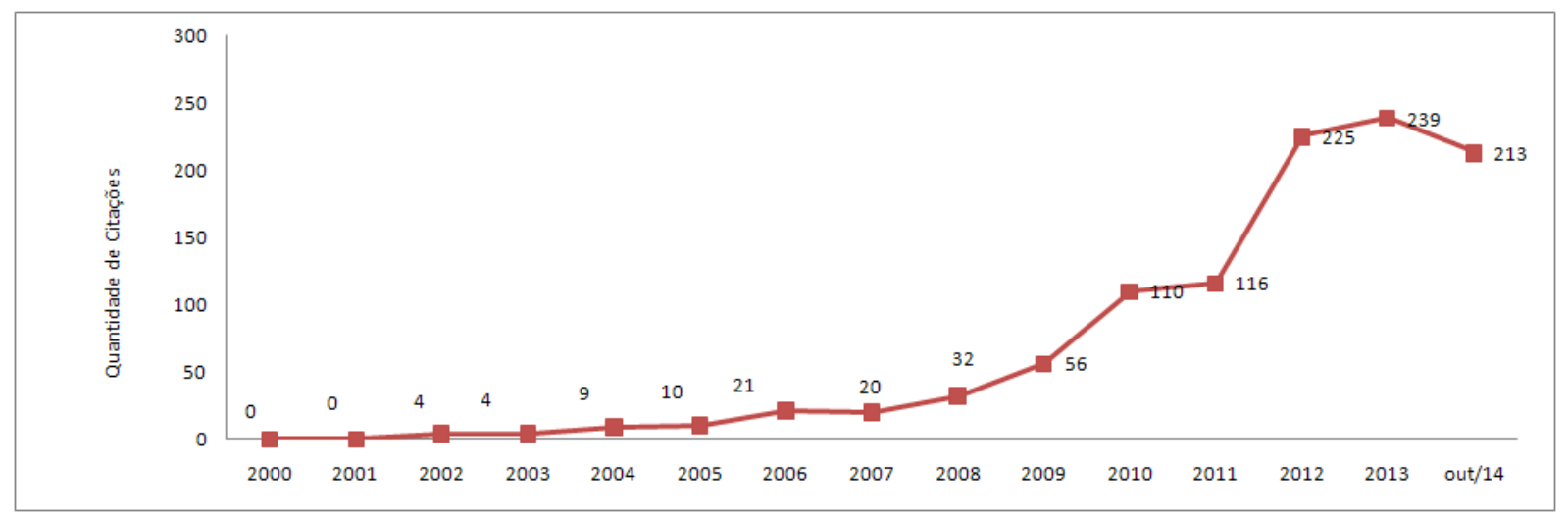

Figura 3.26 - Número de citações dos 20 trabalhos mais citados sobre PLM e ES (atualizado).

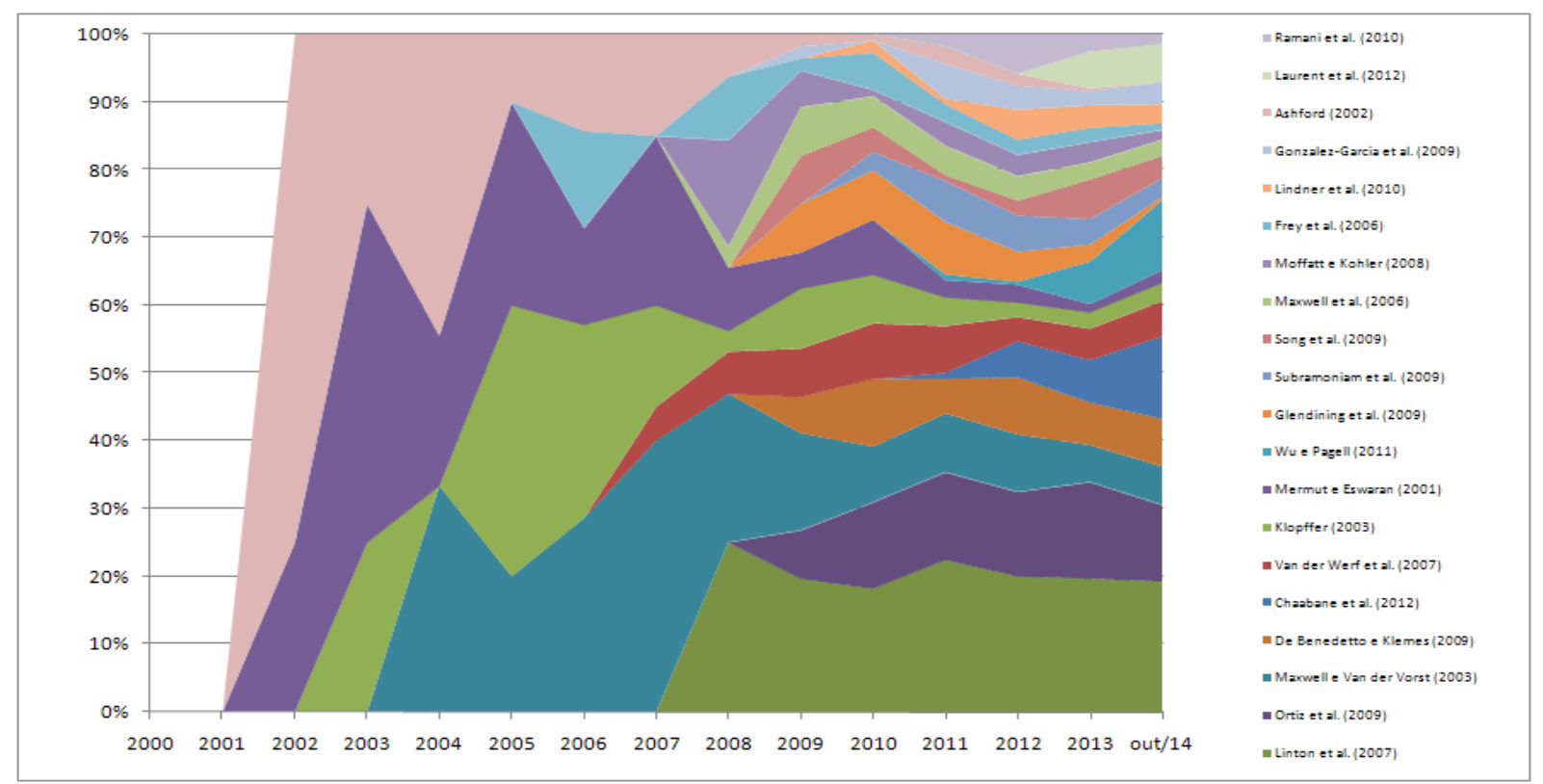

Figura 3.27 - Percentual de citações por ano dos 20 trabalhos mais citados sobre PLM e ES (atualizado). 


\subsubsection{Análise bibliométrica dos conceitos PDP, PLM e ES}

Para análise combinada desses três conceitos não foi utilizado critério de corte, devido à carência de trabalhos relacionados aos três conceitos juntos. Desta forma, os trabalhos selecionados foram citados pelo menos 1 vez e representam todas as citações sobre os três conceitos, mostrado na Tabela 3.12.

Tabela 3.12 - Os trabalhos citados pelo menos 1 vez sobre PDP, PLM e ES.

\begin{tabular}{|l|l|c|}
\hline \multicolumn{1}{|c|}{ Autor } & \multicolumn{1}{c|}{ Fonte da Publicação } & Citações \\
\hline Calantone e Benedetto (2000) & IEEE Transactions on Engineering Management & 27 \\
\hline Schmidt e Butt (2006) & International Journal of Life Cycle Assessment & 4 \\
\hline Cooper (2007) & International Journal of Engineering Education & 1 \\
\hline Beu e Mendicino (1997) & Environmental Progress & 1 \\
\hline & \multicolumn{1}{|c|}{ Total } & $\mathbf{3 3}$ \\
\hline
\end{tabular}

Com base nos trabalhos listados na Tabela 3.12, verifica-se que o trabalho mais citado foi o de Calantone e Benedetto (2000) que analisa o equilíbrio entre o desempenho do produto e o tempo de mercado. O outro trabalho mais citado foi de Schmidt e Butt (2006) que propõe ferramentas de gerenciamento da sustentabilidade no PDP, considerando aspectos econômicos, sociais e ambientais. Além disso, o trabalho de Cooper (2007) objetiva desenvolver conhecimentos interdisciplinares de sustentabilidade, Design for Environment (DfE) e Life Cycle Assessment (LCA) e o trabalho de Beu e Mendicino (1997) que descreve a experiência da Motorola em implementar uma estratégia de DfE no setor de semicondutores. Identifica-se que há poucos trabalhos sendo desenvolvidos que tratam dos três conceitos de forma integrada, conforme as Figuras 3.28 e 3.29.

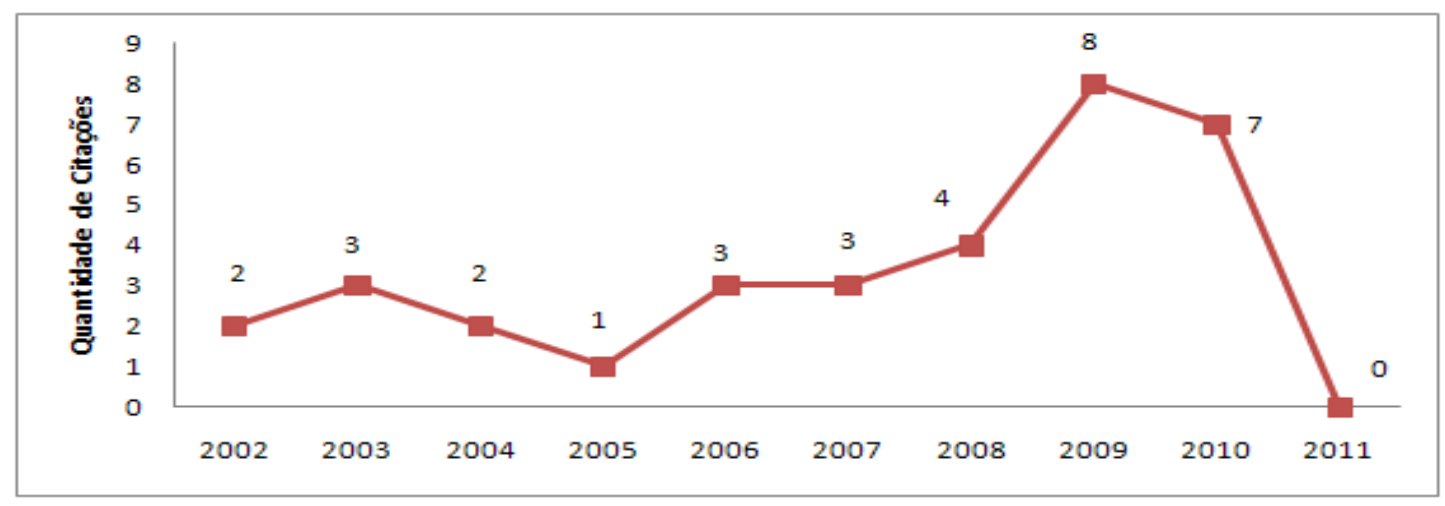

Figura 3.28 - Número de citações dos trabalhos citados sobre PDP, PLM e ES. 


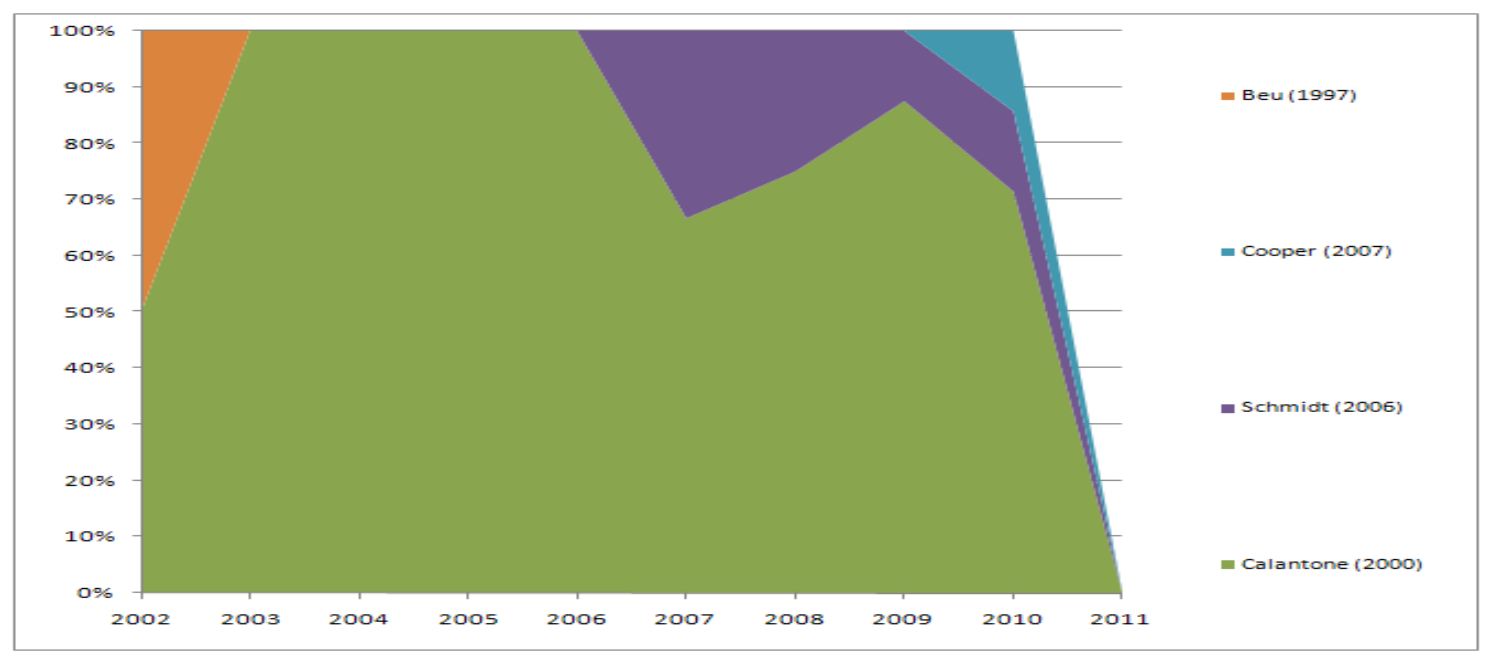

Figura 3.29 - Percentual de citações por ano dos trabalhos citados sobre PDP, PLM e ES.

Analisando as relações entre as palavras-chaves sobre PDP, PLM e ES, percebe-se que a palavra "sustainability" está relacionada à "DfE'. Não foi possível encontrar redes de citações cruzadas, co-citação e referências bibliográficas.

Os resultados dessa análise bibliométrica confirmam os resultados da seção anterior (item 3.1), que os trabalhos são publicados de forma dispersa em periódicos e congressos. Os periódicos que mais abordam os conceitos são: IEEE Transactions on Engineering Management; Journal of Cleaner Production; e International Journal of Life Cycle Assessment. Os autores relevantes em termos de quantidade de citações para os trabalhos selecionados sobre os temas de pesquisa são em ordem de importância: Gunasekaran (1998) e Griffin e Page (1993) para os conceitos de PDP e PLM; Krotscheck e Narodoslawsky (1996) e Stratful et al. (1999) para PDP e Sustentabilidade; Kohler e Hassler (2002), Wicke et al. (2008) e Maxwell e Van Der Vorst (2003) para os conceitos de PLM e Sustentabilidade; Calantone e Benedetto (2000), Schmidt e Butt (2006), Cooper (2007) e Beu e Mendicino (1997) para os três conceitos juntos. Os trabalhos que abordam o conceito de PLM consideram a visão de todo o ciclo de vida, desde a concepção até as etapas finais de reuso, remanufatura e reciclagem como estratégia para o fim da vida útil de produtos. Para os trabalhos que utilizam o conceito de ES, o foco está na avaliação dos impactos no meio ambiente, e o PDP busca desenvolver produtos com menor impacto ambiental, envolvendo princípios de ecodesign, mas que tragam também benefícios econômicos e sociais, termo mais conhecido como "Triple Bottom Line". 


\subsubsection{Atualização da análise bibliométrica dos conceitos PDP, PLM e ES}

Nesta atualização em outubro de 2014 foram selecionados todos os trabalhos com as respectivas citações (366) sobre os três conceitos, mostrado na Tabela 3.13.

Tabela 3.13 - Os trabalhos citados pelo menos 1 vez sobre PDP, PLM e ES (atualizado).

\begin{tabular}{|l|l|c|}
\hline \multicolumn{1}{|c|}{ Autor } & \multicolumn{1}{c|}{ Fonte da Publicação } & Citações \\
\hline Ortiz et al. (2009) & Construction and Building Materials & 119 \\
\hline Mermut e Eswaran (2001) & Geoderma & 47 \\
\hline Lindner et al. (2010) & Ecological Modelling & 27 \\
\hline Ramani et al. (2010) & Journal of Mechanical Design & 24 \\
\hline Garrigues et al. (2012) & Ecological Indicators & 18 \\
\hline Facanha e Horvath (2005) & Journal of Management in Engineering & 17 \\
\hline Evrendilek e Ertekin (2002) & Land Degradation \& Development & 14 \\
\hline Paivinen et al. (2012) & European Journal of Forest Research & 12 \\
\hline Herva e Roca (2013) & Journal of Cleaner Production & 10 \\
\hline Schmidt e Butt (2006) & International Journal of Life Cycle Assessment & 9 \\
\hline Choi e Fthenakis (2010) & Journal of Industrial Ecology & 8 \\
\hline Nikolopoulou e lerapetritou (2012) & Computers \& Chemical Engineering \\
\hline Jensen (2012) & International Journal of Physical Distribution \& & 7 \\
\hline Mosovsky et al. (2000) & Logistics Management & 7 \\
\hline Blengini et al. (2012) & Proceedings of the 2000 IEEE International \\
\hline Verghese et al. (2010) & Wymposium on Electronics and the Environment & 6 \\
\hline Cooper (2007) & Waste Management & 5 \\
\hline Teodosiu et al. (2012) & International Journal of Life Cycle Assessment & 5 \\
\hline Soosay et al. (2012) & International Journal of Engineering Education & 3 \\
\hline Arushanyan et al. (2014) & Environmental Engineering and Management Journal & 4 \\
\hline & Supply Chain Management an International Journal & 4 \\
\hline & Computers in Industry & 3 \\
\hline
\end{tabular}

Conforme a Tabela 3.13, os trabalhos de Schmidt e Butt (2006) e Cooper (2007) continuam aparecendo entre os mais citados em relação à análise (item 3.2.4), o estranho é o trabalho de Calantone e Benedetto (2000) não aparecer nessa busca. Porém, esses autores estão na busca combinada para os conceitos de PDP e PLM com 46 citações. 
De forma geral, os trabalhos que abordam os três conceitos juntos analisam o impacto ambiental, o desenvolvimento sustentável, ferramentas para avaliação do ciclo de vida dos produtos, reciclagem, embalagem sustentável e desenvolvimento de produto eco-eficiente. As Figuras 3.30 e 3.31 mostram que em 2012 houve um aumento no número de citações por ano desses trabalhos sobre os dois conceitos.

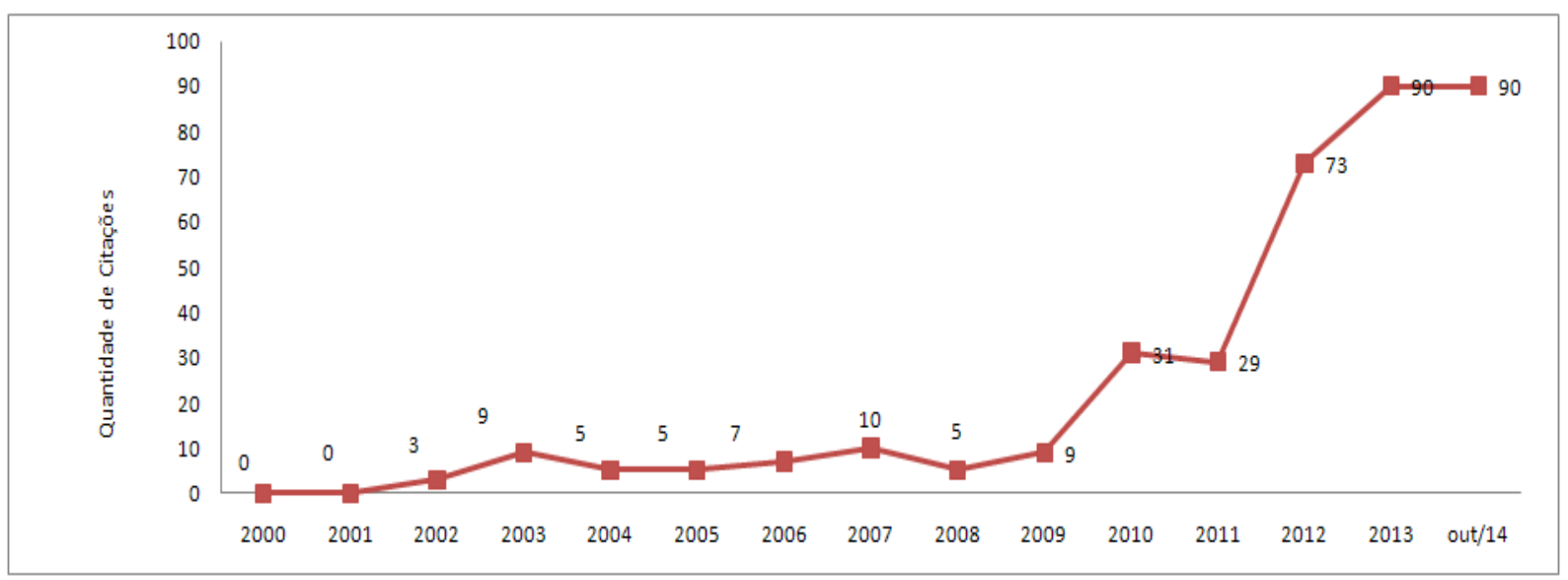

Figura 3.30 - Número de citações dos trabalhos citados sobre PDP, PLM e ES (atualizado).

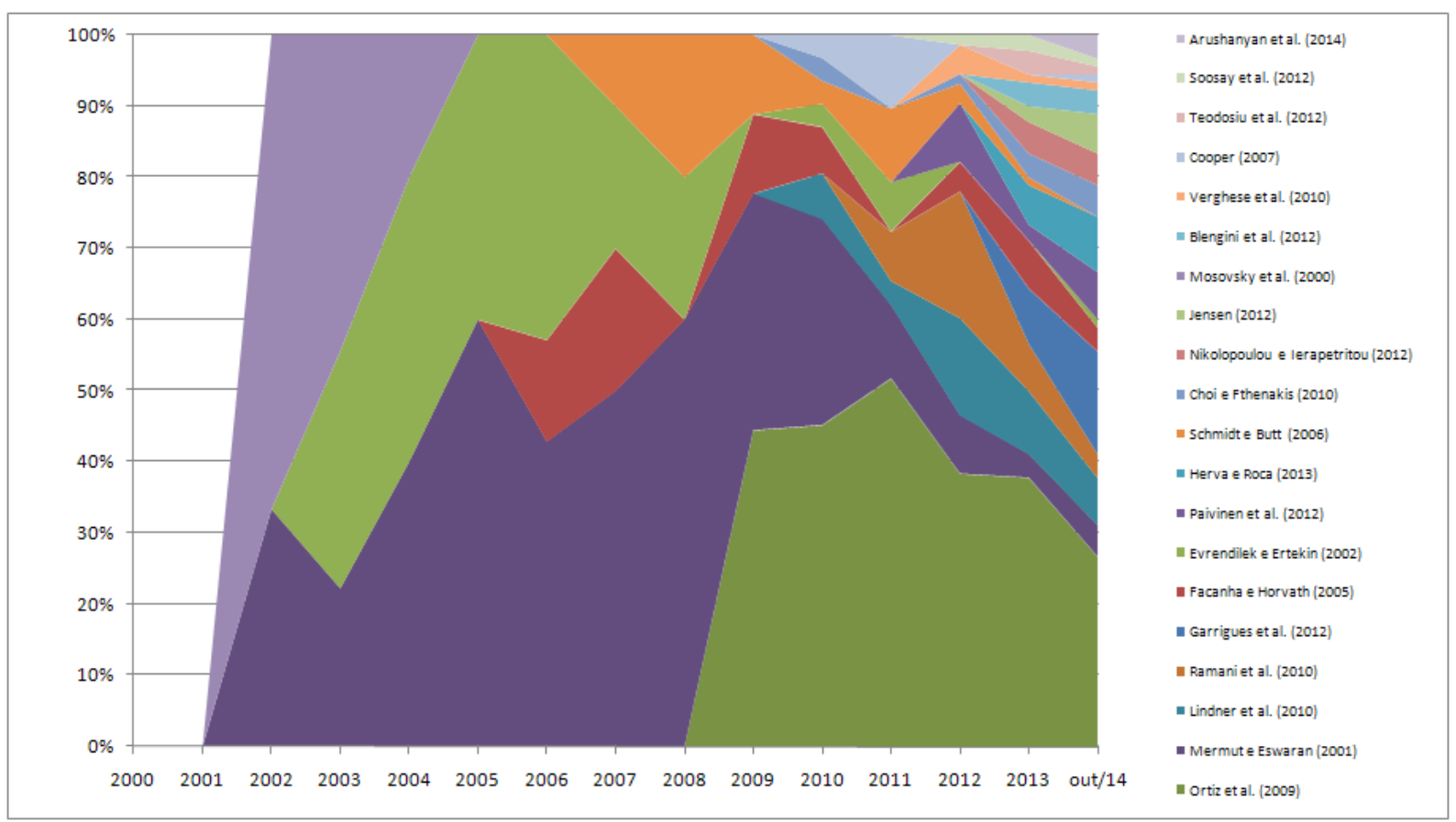

Figura 3.31 - Percentual de citações por ano dos trabalhos citados sobre PDP, PLM e ES (atualizado). 


\subsubsection{Análise dos indicadores de centralidade das redes sociais}

Nessa seção são discutidos os resultados dos indicadores de centralidade, densidade da rede, grau de intermediação e grau de proximidade para os conceitos analisados, conforme resumo na Tabela 3.14 e os detalhes estão no Apêndice III.

Tabela 3.14 - Resultados dos indicadores das redes de palavras-chaves.

\begin{tabular}{|l|c|c|c|c|}
\hline \multicolumn{1}{|c|}{ Conceitos } & Densidade & $\begin{array}{c}\text { Grau de } \\
\text { centralidade }\end{array}$ & $\begin{array}{c}\text { Grau de } \\
\text { intermediação }\end{array}$ & $\begin{array}{c}\text { Grau de } \\
\text { proximidade }\end{array}$ \\
\hline PDP e PLM & $1,79 \%$ & $6,18 \%$ & $42,47 \%$ & $\mathrm{NC}$ \\
\hline PDP e Sustainability & $2,08 \%$ & $5,15 \%$ & $42,47 \%$ & $\mathrm{NC}$ \\
\hline PLM e Sustainability & $20,20 \%$ & $23,44 \%$ & $5,55 \%$ & $23,33 \%$ \\
\hline PDP, PLM e Sustainability & $1,79 \%$ & $6,18 \%$ & $31,00 \%$ & $\mathrm{NC}$ \\
\hline
\end{tabular}

NC: A rede não está conectada. Tecnicamente, o grau de proximidade não pode ser computado, já que há distâncias infinitas.

$\mathrm{Na}$ análise dos resultados das redes de palavras-chaves combinando os conceitos de PDP, PLM e ES obteve-se uma baixa conectividade da rede de palavras-chaves. Na média, cada palavra-chave se relaciona com outras 12 , e as palavras-chaves "management", "design" e "sustainability" são centrais em termos de interações com um grau de centralidade de entrada igual ao de saída. As palavras "management" (16,50\%), "product development" (10,31\%), "life cycle assessment" $(10,05 \%)$ e "product life cycle" (8,59\%) obtiveram o maior grau de intermediação. O grau de proximidade da rede não foi identificado, pois existem infinitas distâncias. A palavra "management" teve o maior grau de proximidade e a menor distância geodésica, isso indica que essa palavra por ser utilizada de forma geral e por ser um termo abrangente possui uma melhor capacidade de se relacionar com os demais atores, o que seria esperado.

\subsection{Considerações finais do capítulo}

Este capítulo analisa a literatura e mostra à importância dos conceitos PDP, PLM e ES para as empresas obterem sucesso no mercado percebe-se que, relativamente, ainda existe certa escassez de trabalhos publicados que tratam os três temas em conjunto, apesar de terem sido desenvolvidos já há algum tempo. 
Pela análise de conteúdo das publicações abordadas (item 3.1 e 3.2), verifica-se que o tema PDP está ligado à necessidade de maior competitividade industrial, sendo este um resultado esperado das ações de melhoria do PDP. Grande ênfase é dada à gestão do PDP, envolvendo os aspectos como sequência de atividades, seleção e adoção de métodos de projeto, otimização do fluxo de informações e melhoria organizacional, notadamente com maior esforço para viabilizar o trabalho em equipes multidisciplinares. O foco é no processo empregado para o PDP que considerem os requisitos de desempenho, de custos e também de impacto no meio ambiente. Nesse sentido, são adotados métodos específicos de projeto, que consideram desde as fases iniciais do PDP, as questões críticas que terão impactos somente mais tarde, nas fases posteriores do ciclo de vida.

A Environmental Sustainability (ES) destaca a importância da inclusão do aspecto ambiental no PDP, buscando minimizar o uso dos recursos naturais e reduzir os impactos ambientais inerentes à produção. Destaca-se à estimativa e à avaliação dos impactos ambientais que podem ser atribuídos a um produto ao longo de seu ciclo de vida - consumo de energia, emissões, entre outros aspectos. Nesse sentido, é empregada a LCA para estimar o impacto ambiental ao longo das fases do ciclo de vida (produção, uso e descarte dos produtos). A fase de desenvolvimento é geralmente menos relevante, pois nela tipicamente os impactos no meio ambiente são menores. No entanto, deve-se observar que as decisões de projeto realizadas na fase de desenvolvimento determinam grande parte dos impactos ambientais que ocorrem nas fases seguintes do ciclo de vida. Isso evidencia a inter-relação entre PDP e ES. No PDP, abordagens e métodos como o DfS e o ecodesign são empregados desde a conceituação dos produtos para direcionar as escolhas sobre a estrutura, os materiais e os processos de produção. $O$ objetivo é antecipar 0 atendimento dos requisitos ambientais desde as etapas iniciais do desenvolvimento. Já a LCA é uma ferramenta que indica as consequências dessas escolhas de projeto no consumo de recursos e no meio ambiente.

O PLM destaca a necessidade de se promover uma visão completa do ciclo de vida do produto, compreendendo todas as fases pelas quais o produto passa. $O$ objetivo é possibilitar que requisitos das fases posteriores do ciclo de vida sejam considerados desde as fases iniciais de conceituação. Viabilizar essa visão na prática requer a integração de informações de várias áreas e sistemas. A ênfase está no apoio à gestão, integração e ao uso das informações atualizadas de 
produtos ao longo do ciclo de vida. Assim, se contribui para a otimização do PDP e para redução dos impactos ambientais, conforme a ênfase dada pela ES.

Em síntese, percebe-se uma forte convergência para integração do conceito de ecodesign nas práticas do PDP, que pode ser justificada com base na maior demanda de exigências ambientais pela sociedade e da necessidade das organizações em empregar a estratégia de fim de vida dos produtos (remanufatura, reciclagem e reuso) para cumprir aspectos ambientais exigidos pelo mercado. Sendo assim, os próximos Capítulos (4 e 5) retomam a revisão sistemática da literatura analisando as estruturas do PDP e quais são os aspectos ambientais dos métodos e ferramentas de ecodesign que estão sendo inseridos nesse processo, mas com foco na elaboração da proposta de estruturação do PDP com aspectos ambientais, conforme descrito no capítulo de métodos de pesquisa (Fase II, item 2.2.2). Com isso se obtém mais subsídios para a definição do problema, delineamento do contorno do tema e validação da proposta dessa tese. 


\section{ANÁLISE E SELEÇÃO DAS FASES DAS ESTRUTURAS DE PDP}

Este capítulo apresenta um levantamento e análise de 80 estruturas de PDP identificadas na literatura, com objetivo de selecionar as fases do PDP mais adequadas para desenvolvimento da proposta de estruturação do PDP integrando aspectos ambientais. Nesse sentido, são abordados os conceitos fundamentais, a organização e operacionalização das estruturas de PDP. No final desse capítulo, é realizada uma análise das fases mais citadas nas estruturas de PDP selecionadas, a qual suporta a escolha das fases utilizadas na elaboração da proposta desta tese.

\subsection{Caracterização do Processo de Desenvolvimento de Produtos}

Algumas mudanças no mercado mundial, como a globalização, a rápida evolução tecnológica e o aumento da competitividade, têm influenciado no aumento da demanda por novos produtos (AXARLOGLOU, 2004; DAVILA; EPSTEIN; SHELTON, 2007; KOTLER; KARTAJAYA; SETIAWAN, 2010). Esse ambiente competitivo tem exigido mais qualidade e velocidade no lançamento de novos produtos e, consequentemente, aumentado a complexidade do PDP e gerado uma maior preocupação com a eficiência e a eficácia desse processo (LIN et al., 2006; CROSS; SIVALOGANATHAN, 2007; DUYSTERS et al., 2008).

As empresas visando melhorar a gestão do PDP utilizam de estruturas de PDP, divididas em fases intercaladas por um ponto de decisão gerencial cujo objetivo é avaliar a possibilidade de continuidade do projeto e os riscos envolvidos nessa decisão (COOPER, 2008). Entretanto, essas estruturas de PDP podem variar na quantidade de fases e nível de detalhes, conforme alguns fatores (CLARK; FUJIMOTO, 1991; CLARK; WHEELWRIGHT, 1993; GARCIA; CALANTONE, 2002): tipo de produto, grau de inovação da tecnologia, amplitude de mudança de processo e projeto, complexidade do produto e complexidade organizacional.

Além da importância de utilizar uma estrutura de PDP como referência, Cooper (2008) sugere algumas ações para melhor gerir esse processo: o produto deve ser diferenciado proporcionando benefícios ao cliente, ter orientação para um mercado atrativo, ter velocidade para lançar o novo produto, dedicar mais tempo à macrofase de pré-desenvolvimento, integrar as áreas envolvidas no PDP e alinhar o PDP as 
estratégias da empresa. Como complemento, Barczak et al. (2009) concordam que há uma necessidade de melhorar a gestão do PDP focando na utilização de métodos e ferramentas de suporte ao PDP, na gestão das idéias, no treinamento em gestão de projetos, no apoio da comunicação da equipe e na participação da alta administração na liderança do PDP.

No entanto, não é tarefa simples estruturar e gerenciar o PDP para alcançar resultados positivos, devido o PDP ser interdisciplinar e multifuncional e, portanto, deve ser conduzido de forma integrada (BAXTER, 2000; BUSS; CUNHA, 2002; TIDD; BESSANT; PAVITT, 2008). Por isso, o PDP é constantemente objeto de investigação de várias disciplinas com diferentes perspectivas de análise e fragmentação do processo, com objetivos distintos que geram conflitos de interesses entre as áreas de conhecimento, como: marketing, engenharia, administração e design (MALTZ et al., 2001; HAQUE et al., 2003; KRISHNAN; LOCH, 2005).

No nível operacional do PDP, são empregados arranjos organizacionais alinhados com a estratégia e cultura da empresa para melhor estruturar esse processo, os arranjos podem aparecer na forma funcional, autônoma ou por projeto e matricial (SOUSA MENDES; TOLEDO, 2003). Em consonância, a importância da escolha da estrutura organizacional, Hultink e Robben (1995) mencionam que o monitoramento do PDP por meio de indicadores de desempenho impacta positivamente no resultado do PDP. Alguns autores como Griffin e Page (1993) e Driva et al. (2000) sugerem vários indicadores de desempenho para o PDP, de caráter financeiro ou operacional, que estão ligados ao desempenho do produto no mercado ou ao seu respectivo desenvolvimento.

Dentre os fatores de melhoria da gestão do PDP mencionados, destaca-se a necessidade de integração do PDP por meio de equipes multidisciplinares e utilização de ferramentas de suporte para execução das atividades do PDP, visando uma linguagem comum entre as equipes envolvidas no processo (ABDOMEROVIC; BLAKEMORE, 2002; BONNER; RUEKERT; WALKER, 2002; NOBELIUS, 2004; FREDERICKS, 2005; SONG; NOH, 2006).

Além de melhorar o desempenho do PDP e atender as exigências do mercado, outros temas relacionados a esse processo são abordados na literatura como, por exemplo: a relação do PDP com o ciclo de vida do produto desde a extração de matéria-prima até 0 seu descarte para sobrevivência das empresas (ROOZENBURG; EEKELS, 1995; CRAWFORD; BENEDETTO, 2000), a influência 
da gestão do conhecimento no PDP (AMARAL; ROZENFELD, 2003) as dificuldades de se trabalhar de forma colaborativa com times de projetos dispostos em locais distantes (SALMINEN et al., 2000). Também, podem ser vistos outros tópicos importantes da literatura relacionados ao tema de PDP identificados no trabalho de Varandas e Miguel (2012).

Diante do exposto, e com base no capítulo de referencial teórico, resume-se que o PDP é um tema amplo, complexo e recorrente principalmente no emprego de instrumentos de suporte na execução das atividades do PDP, com objetivo de um melhor desempenho em termos de qualidade, tempo e produtividade para atender 0 aumento das exigências do mercado. Após essa caracterização do PDP, a próxima seção faz um mapeamento das estruturas de PDP disponíveis na literatura e analisa os conteúdos e as suas diferenças essenciais.

\subsection{Mapeamento e análise de conteúdo das estruturas de PDP}

É importante destacar que há várias formas de estruturar o PDP, com diferentes quantidades de fases, atividades, aplicação de técnicas e utilização de ferramentas, conforme a particularidade de cada empresa. Entretanto, os objetivos dessas estruturas de PDP são praticamente os mesmos, ou seja, buscam aperfeiçoar a distribuição dos recursos, melhorar o fluxo de informações, reduzir o tempo e custos de desenvolvimento, minimizar os riscos e falhas e atingir o sucesso com o PDP (JOHANSSON, 2002; TZOKAS et al., 2004; CAMPOS; RIBEIRO, 2011).

Além disso, as estruturas de PDP devem representar claramente o esquema operacional do PDP para proporcionar uma visão macro das etapas do processo e facilitar o entendimento de todos os envolvidos e, ainda, dar suporte para tomada de decisões (KRISHNAN, ULRICH, 2001). Na opinião de Mendes (2008) e Schmidt et al. (2009) as estruturas de PDP podem ser específicas a uma empresa e, também, ser genérica e aplicável a qualquer tipo de PDP, indiferente da quantidade de fases, atividades e formas de controle. Por outro lado, Rudder et al. (2001) e Jung et al. (2008) destacam que é preciso considerar que as estruturas de PDP são interpretadas por diferentes pessoas que focam em características específicas da estrutura de PDP, quando as utilizam na rotina nas empresas. 
Logo, as empresas devem entender que essas estruturas de PDP são genéricas e precisam ser adequadas às suas necessidades, conforme as características dos projetos a serem desenvolvidos. Desta forma, pode-se definir o conceito de estrutura de PDP como uma forma de sistematizar, documentar e padronizar o PDP, para que ele possa ser integrado e utilizado pelos envolvidos no PDP (ROZENFELD et al., 2006; JUNG et al., 2008).

Como existem muitos trabalhos publicados na literatura propondo estruturas de PDP foi realizado um mapeamento na literatura e selecionado 80 estruturas de PDP, conforme procedimentos metodológicos descritos no capítulo de métodos de pesquisa (seção 2.2.2.1). Devido às estruturas de PDP considerarem as fases e atividades em momentos diferentes do PDP foi realizado um encaixe na estrutura de PDP proposta por Rozenfeld et al. (2006), que está ilustrada na Figura 4.1.

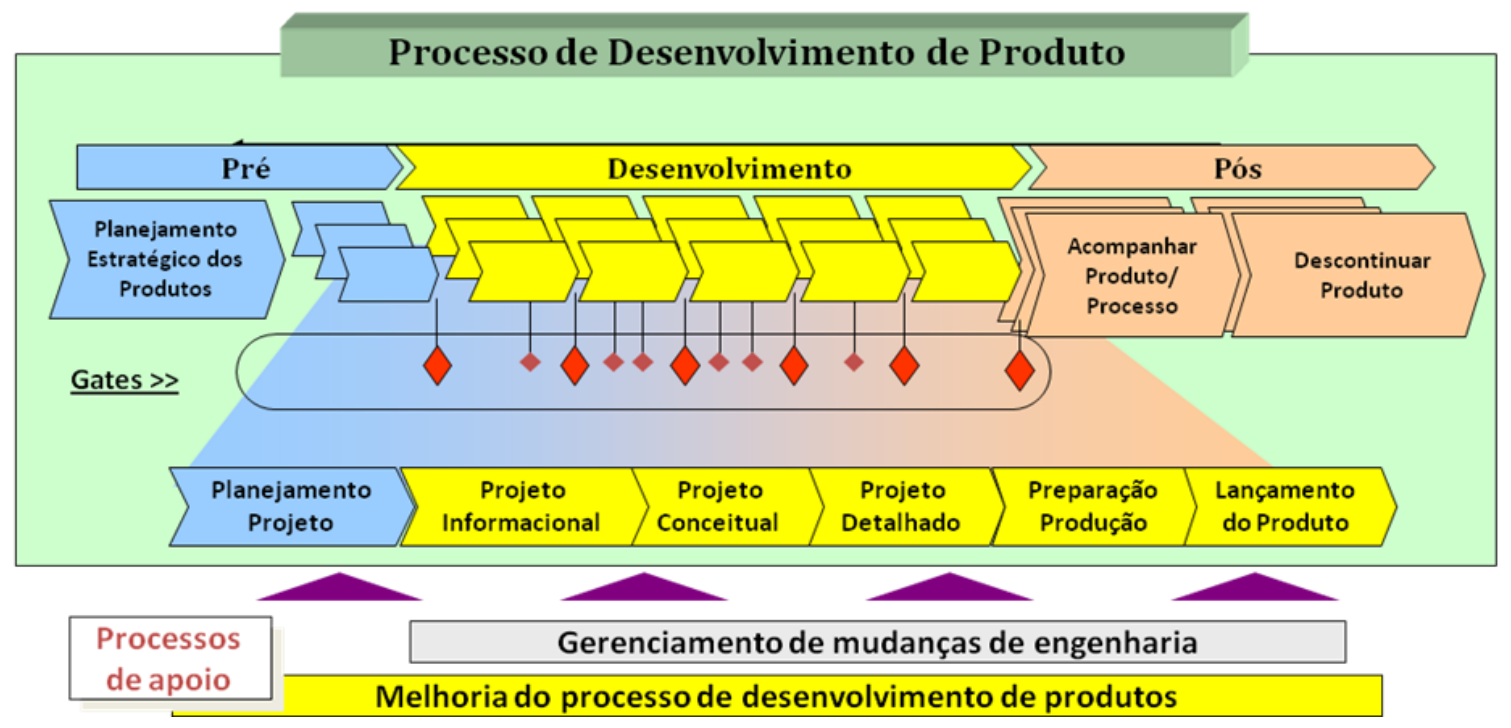

Figura 4.1 - Estrutura do PDP de Rozenfeld et al. (2006).

A estrutura de Rozenfeld et al. (2006) foi utilizada como referência por considerar todo o ciclo de vida do produto e possuir três macrofases (Pré-Desenvolvimento, Desenvolvimento e Pós-Desenvolvido) que englobam nove fases (Planejamento Estratégico dos Produtos, Planejamento do Projeto, Projeto Informacional, Projeto Conceitual, Projeto Detalhado, Preparação da Produção do Produto, Lançamento do Produto, Acompanhar produto e Processo e Descontinuar o Produto no Mercado), os detalhes da função de cada macrofase e fase dessa estrutura estão descritas na proposta de estruturação do PDP integrando aspectos ambientais (Capítulo 6). 
Esta análise estratificou as fases das 80 estruturas de PDP em um plano linear padrão, para poder visualizar as interfaces entre as fases, comparar e melhor compreendê-las. Também, buscou-se identificar as estruturas de PDP que integram aspectos ambientais nas suas fases para melhor discutir e embasar a elaboração da proposta deste trabalho. A seguir são apresentadas as estruturas de PDP divididas em três períodos distintos: década de 60 e 70, década de 80 e 90 e do ano 2000 até 2013. A Tabela 4.1 ilustra as fases das estruturas de PDP desenvolvidas no primeiro período e, em seguida, são discutidos os principais pontos da análise de conteúdo das estruturas de PDP. 
Tabela 4.1 - Estruturas de PDP encontradas na literatura (década de 60-70).

\begin{tabular}{|c|c|c|c|c|c|c|c|c|c|}
\hline \multirow[b]{3}{*}{ Autor } & \multicolumn{9}{|c|}{ Processo de Desenvolvimento de Produtos (PDP) } \\
\hline & \multicolumn{2}{|c|}{ Pré-Desenvolvimento } & \multicolumn{5}{|c|}{ Desenvolvimento } & \multicolumn{2}{|c|}{ Pós-Desenvolvimento } \\
\hline & $\begin{array}{l}\text { Planejamento } \\
\text { Estratégico dos } \\
\text { Produtos }\end{array}$ & $\begin{array}{l}\text { Planejamento do } \\
\text { Projeto }\end{array}$ & $\begin{array}{c}\text { Projeto } \\
\text { Informacional }\end{array}$ & Projeto Conceitual & Projeto Detalhado & $\begin{array}{l}\text { Preparação da } \\
\text { Produção do } \\
\text { Produto }\end{array}$ & $\begin{array}{l}\text { Lançamento do } \\
\text { Produto }\end{array}$ & $\begin{array}{c}\text { Acompanhar } \\
\text { Produto e Processo }\end{array}$ & $\begin{array}{c}\text { Descontinuar o } \\
\text { Produto no Mercado }\end{array}$ \\
\hline Asimow (1962) & $\begin{array}{l}\text { a) estudo de } \\
\text { viabilidade }\end{array}$ & & & b) projeto preliminar & c) projeto detalhado & $\begin{array}{l}\text { d) planejamento da } \\
\text { produção } \\
\text { e) produção }\end{array}$ & & & \\
\hline Archer (1971) & $\begin{array}{l}\text { a) formulação de } \\
\text { política }\end{array}$ & & b) análise preliminar & $\begin{array}{l}\text { c) estudo de } \\
\text { viabilidade } \\
\text { d) desenvolvimento de } \\
\text { projeto }\end{array}$ & $\begin{array}{l}\text { e) desenvolvimento de } \\
\text { protótipo } \\
\text { f) estudo de negócios }\end{array}$ & $\begin{array}{l}\text { g) planejamento da } \\
\text { produção } \\
\text { h) produção }\end{array}$ & $\begin{array}{l}\text { i) preparação de } \\
\text { mercado e } \\
\text { ferramentas } \\
\text { j) produção e vendas }\end{array}$ & & \\
\hline Kotler (1974) & $\begin{array}{l}\text { a) gerar idéias } \\
\text { b) efetuar triagem de } \\
\text { idéias }\end{array}$ & & & $\begin{array}{l}\text { c) desenvolvimento e } \\
\text { teste de conceito } \\
\text { d) desenvolvimento da } \\
\text { estratégia de } \\
\text { marketing } \\
\text { e) análise comercial }\end{array}$ & $\begin{array}{l}\text { f) desenvolver } 0 \\
\text { produto }\end{array}$ & & $\begin{array}{l}\text { g) teste no mercado } \\
\text { h) comercialização }\end{array}$ & & \\
\hline Pahl and Beitz (1977) & & & $\begin{array}{l}\text { a) especificar os } \\
\text { requisitos da tarefa a } \\
\text { partir do mercado, } \\
\text { empresa e economia }\end{array}$ & $\begin{array}{l}\text { b) determinar o } \\
\text { conceito do design } \\
\text { c) efetuar o design } \\
\text { preliminar ou layout } \\
\text { preliminar }\end{array}$ & $\begin{array}{l}\text { d) detalhar o design } \\
\text { ou ou layout definitivo } \\
\text { e) documentar }\end{array}$ & & & & \\
\hline Bonsiepe (1978) & $\begin{array}{l}\text { a) descobrir e } \\
\text { valorizar uma } \\
\text { necessidade } \\
\text { b) analisar }\end{array}$ & $\begin{array}{l}\text { c) formular o } \\
\text { problema } \\
\text { d) levantar os } \\
\text { requisitos } \\
\text { e) fracionar o } \\
\text { problema } \\
\text { f) hierarquizar os } \\
\text { problemas }\end{array}$ & $\begin{array}{l}\text { g) analisar as } \\
\text { soluções existentes }\end{array}$ & $\begin{array}{l}\text { h) desenvolver } \\
\text { alternativas } \\
\text { i) verificar e } \\
\text { selecionar alternativas }\end{array}$ & $\begin{array}{l}\text { j) elaborar os detalhes } \\
\text { particulares } \\
\text { k) prototipar } \\
\text { l) avaliar } \\
\text { m) modificar o } \\
\text { protótipo }\end{array}$ & n) fabricar pré-série & & & \\
\hline
\end{tabular}


Verifica-se nesse período (década de 60-70) que as primeiras estruturas de PDP elaboradas eram divididas em fases relacionadas ao projeto com definição das responsabilidades das áreas envolvidas no PDP, devido a uma maior preocupação com custos de retrabalho e viabilidade econômica do projeto. Também, consideravam o PDP como um sistema linear com fases e estágios discretos e dispostos de forma sequencial semelhante à metodologia de projeto, porém não havia integração das fases e áreas funcionais.

A característica central dessas estruturas de PDP está na coleta e análise de informações para entender o problema, desenvolver, testar e implementar conceitos alternativos. Além disso, as estruturas de PDP desse período foram desenvolvidas com a visão de apenas uma das áreas específicas de conhecimento e, consequentemente, as fases e estágios utilizados na estruturação do PDP eram direcionados aos interesses de uma dessas áreas de conhecimento.

Fica claro pela análise da Tabela 4.1 que nessas estruturas de PDP, ainda, não havia preocupação com as fases de pós-desenvolvimento que têm a função de acompanhamento do desempenho do produto e cuidados com impacto ambiental relacionados com o descarte do produto e embalagem. 
Tabela 4.2 - Estruturas de PDP encontradas na literatura (década de 80-90).

\begin{tabular}{|c|c|c|c|c|c|c|c|c|c|}
\hline \multirow[b]{3}{*}{ Autor } & \multicolumn{9}{|c|}{ Processo de Desenvolvimento de Produtos (PDP) } \\
\hline & \multicolumn{2}{|c|}{ Pré-Desenvolvimento } & \multicolumn{5}{|c|}{ Desenvolvimento } & \multicolumn{2}{|c|}{ Pós-Desenvolvimento } \\
\hline & $\begin{array}{l}\text { Planejamento } \\
\text { Estratégico dos } \\
\text { Produtos }\end{array}$ & $\begin{array}{l}\text { Planejamento do } \\
\text { Projeto }\end{array}$ & $\begin{array}{c}\text { Projeto } \\
\text { Informacional }\end{array}$ & Projeto Conceitual & Projeto Detalhado & $\begin{array}{l}\text { Preparação da } \\
\text { Produção do } \\
\text { Produto }\end{array}$ & $\begin{array}{l}\text { Lançamento do } \\
\text { Produto }\end{array}$ & $\begin{array}{c}\text { Acompanhar } \\
\text { Produto e Processo }\end{array}$ & $\begin{array}{c}\text { Descontinuar o } \\
\text { Produto no Mercado }\end{array}$ \\
\hline $\begin{array}{l}\text { Booz, Allen \& } \\
\text { Hamilton (1982) }\end{array}$ & $\begin{array}{l}\text { a) desenvolvimento de } \\
\text { estratégia de novo } \\
\text { produto } \\
\text { b) gerar idéias } \\
\text { c) seleção e avaliação } \\
\text { d) análise do negócio }\end{array}$ & & \multicolumn{3}{|c|}{ e) desenvolvimento de produto } & f) teste & g) comercialização & & \\
\hline Saren (1984) & $\begin{array}{l}\text { a) geração de idéia } \\
\text { b) seleção }\end{array}$ & & c) análise comercial & \multicolumn{2}{|c|}{ d) desenvolvimento técnico } & e) teste & f) comercialização & & \\
\hline VDI - 2221 (1985) & & & $\begin{array}{l}\text { a) entendendo a } \\
\text { tarefa }\end{array}$ & $\begin{array}{l}\text { b) determinar funções } \\
\text { e suas estruturas } \\
\text { c) procurar principios } \\
\text { de soluçōes e } \\
\text { combinaçōes }\end{array}$ & $\begin{array}{l}\text { d) dividir em módulos } \\
\text { factiveis de realização } \\
\text { e) desenvolver layout } \\
\text { de módulos chaves } \\
\text { f) completar layout } \\
\text { global }\end{array}$ & $\begin{array}{l}\text { g) preparação da } \\
\text { produção e instruções } \\
\text { de operação }\end{array}$ & & & \\
\hline $\begin{array}{l}\text { Andreasen and Hein } \\
\text { (1987) }\end{array}$ & $\begin{array}{l}\text { a) identificando uma } \\
\text { oportunidade }\end{array}$ & & \multicolumn{3}{|l|}{$\begin{array}{l}\text { b) plano do produto } \\
\text { c) produto preliminar }\end{array}$} & $\begin{array}{l}\text { d) preparação para } \\
\text { produção }\end{array}$ & $\begin{array}{l}\text { e) lançamento do } \\
\text { produto }\end{array}$ & & \\
\hline $\begin{array}{l}\text { Park and Zaltman } \\
\text { (1987) }\end{array}$ & $\begin{array}{l}\text { a) gerar idéias } \\
\text { b) selecionar as idéias }\end{array}$ & & & $\begin{array}{l}\text { c) gerar o conceito do } \\
\text { produto } \\
\text { d) analisar a } \\
\text { performance do } \\
\text { mercado } \\
\text { e) desenhar o mix de } \\
\text { marketing }\end{array}$ & & & $\begin{array}{l}\text { f) teste de mercado } \\
\text { g) comercialização }\end{array}$ & & \\
\hline Suh (1988) & $\begin{array}{l}\text { a) identificar uma } \\
\text { necessidade social }\end{array}$ & & $\begin{array}{l}\text { b) determinar os } \\
\text { requisitos funcionais }\end{array}$ & $\begin{array}{l}\text { c) determinar os } \\
\text { atributos do produto }\end{array}$ & d) prototipar & e) produzir o produto & & & \\
\hline $\begin{array}{l}\text { Clark and Fujimoto } \\
\text { (1991) }\end{array}$ & & & & $\begin{array}{l}\text { a) concepçãa do } \\
\text { produto }\end{array}$ & $\begin{array}{l}\text { b) planejamento do } \\
\text { produto } \\
\text { c) projeto do produto }\end{array}$ & $\begin{array}{l}\text { d) projeto do processo } \\
\text { e) produção piloto }\end{array}$ & & & \\
\hline $\begin{array}{l}\text { Graf and Saguy } \\
\text { (1991) }\end{array}$ & \multicolumn{4}{|l|}{\begin{tabular}{|l|} 
a) seleção \\
b) viabilidade
\end{tabular}} & \multicolumn{2}{|l|}{ c) desenvolvimento } & d) comercialização & e) manutenção & \\
\hline Rosenthal (1992) & a) validação da idéia & & & b) projeto conceitual & $\begin{array}{l}\text { c) especificação e } \\
\text { projeto } \\
\text { d) protótipo, produção } \\
\text { e teste }\end{array}$ & $\begin{array}{l}\text { e) inicio da } \\
\text { manufatura }\end{array}$ & & & \\
\hline $\begin{array}{l}\text { Wheelwright and } \\
\text { Clark (1992) }\end{array}$ & $\begin{array}{l}\text { a) conceito } \\
\text { b) planejamento do } \\
\text { produto }\end{array}$ & & \multicolumn{5}{|c|}{$\begin{array}{l}\text { c) engenharia do produto/processo } \\
\text { d) produção piloto/aumento da produção }\end{array}$} & & \\
\hline Cooper (1993) & a) idealização & & \multicolumn{2}{|c|}{ b) investigação preliminar } & $\begin{array}{l}\text { c) investigação } \\
\text { detalhada } \\
\text { d) desenvolvimento } \\
\text { e) teste e validação }\end{array}$ & \multicolumn{2}{|c|}{$\begin{array}{l}\text { f) teste e validação } \\
\text { g) produção e lançamento }\end{array}$} & & \\
\hline
\end{tabular}


Tabela 4.2 - Estruturas de PDP encontradas na literatura (década de 80-90) - continuação.

\begin{tabular}{|c|c|c|c|c|c|c|c|c|c|}
\hline \multirow[b]{3}{*}{ Autor } & \multicolumn{9}{|c|}{ Processo de Desenvolvimento de Produtos (PDP) } \\
\hline & \multicolumn{2}{|c|}{ Pré-Desenvolvimento } & \multicolumn{5}{|c|}{ Desenvolvimento } & \multicolumn{2}{|c|}{ Pós-Desenvolvimento } \\
\hline & $\begin{array}{l}\text { Planejamento } \\
\text { Estratégico dos } \\
\text { Produtos }\end{array}$ & $\begin{array}{l}\text { Planejamento do } \\
\text { Projeto }\end{array}$ & $\begin{array}{l}\text { Projeto } \\
\text { Informacional }\end{array}$ & Projeto Conceitual & Projeto Detalhado & $\begin{array}{l}\text { Preparação da } \\
\text { Produção do } \\
\text { Produto }\end{array}$ & $\begin{array}{l}\text { Lançamento do } \\
\text { Produto }\end{array}$ & \begin{tabular}{|c|} 
Acompanhar \\
Produto e Processo
\end{tabular} & $\begin{array}{l}\text { Descontinuar o } \\
\text { Produto no Mercado }\end{array}$ \\
\hline Slack et al. (1993) & $\begin{array}{l}\text { a) geração do } \\
\text { conceito } \\
\text { b) triagem }\end{array}$ & & & c) projeto preliminar & $\begin{array}{l}\text { d) avaliação e } \\
\text { melhoria } \\
\text { e) prototipagem e } \\
\text { projeto final }\end{array}$ & & & & \\
\hline Urban and Hauser (1993) & $\begin{array}{l}\text { a) identificar } \\
\text { oportunidades }\end{array}$ & & & $\begin{array}{l}\text { b) projeto } \\
\text { c) testar }\end{array}$ & & & d) introdução & $\begin{array}{l}\text { e) gerenciamento do } \\
\text { ciclo de vida }\end{array}$ & \\
\hline APQP (1994) & a) planejamento & & & \multicolumn{2}{|c|}{$\begin{array}{l}\text { b) desenvolvimento e projeto do produto } \\
\text { c) desenvolvimento e projeto do processo }\end{array}$} & $\begin{array}{l}\text { d) validação do } \\
\text { produto e do processo }\end{array}$ & $\begin{array}{l}\text { e) feedback, avaliação } \\
\text { e ação corretiva }\end{array}$ & & \\
\hline Fuller (1994) & $\begin{array}{l}\text { a) identificar idéias } \\
\text { b) selecionar as idéias }\end{array}$ & & & \multicolumn{2}{|c|}{$\begin{array}{l}\text { c) desenvolvimento do projeto do produto } \\
\text { d) desenvolvimento do projeto do processo }\end{array}$} & e) produção & $\begin{array}{l}\text { f) teste com } \\
\text { consumidores } \\
\text { g) teste de mercado }\end{array}$ & & \\
\hline Ingle (1994) & a) identificar produto & & b) desmontar & c) medir e testar & $\begin{array}{l}\text { d) recuperar o projeto } \\
\text { e) desenvolver } \\
\text { protótipos e testar } \\
\text { f) desenvolver } \\
\text { produtos e processos }\end{array}$ & & & & \\
\hline MacFie (1994) & & & & $\begin{array}{l}\text { a) geração do } \\
\text { conceito } \\
\text { b) selecionar o } \\
\text { conceito }\end{array}$ & $\begin{array}{l}\text { c) desenvolvimento do } \\
\text { produto } \\
\text { d) testar o produto } \\
\text { e) desenvolvimento de } \\
\text { embalagem }\end{array}$ & f) produção & g) lançamento & & \\
\hline Nijssen and Lieshoult (1995) & $\begin{array}{l}\text { a) geração de idéias } \\
\text { b) seleção de idéias }\end{array}$ & & & $\begin{array}{l}\text { c) desenvolvimento de } \\
\text { conceito e teste } \\
\text { d) estratégia de } \\
\text { mercado }\end{array}$ & $\begin{array}{l}\text { e) análise economica } \\
\text { de negócio } \\
\text { f) desenvolvimento do } \\
\text { produto }\end{array}$ & & $\begin{array}{l}\text { g) teste de mercado } \\
\text { h) comercialização }\end{array}$ & & \\
\hline Rudolph (1995) & \multicolumn{3}{|l|}{ a) definição do produto } & \multicolumn{3}{|c|}{ b) implementação do produto } & \multicolumn{2}{|l|}{ c) introdução do produto } & \\
\hline $\begin{array}{l}\text { Roozenburg and Eekels } \\
\text { (1995) }\end{array}$ & \begin{tabular}{|l|} 
a) formulação de \\
objetivos e estratégias \\
b) politica de produto \\
c) geração e seleçãoo \\
de idéias \\
d) idéia de novo \\
negócio
\end{tabular} & & & $\begin{array}{l}\text { e) desenvolvimento do } \\
\text { f) desenvolvimento do } \\
\text { g) estudo de mercado }\end{array}$ & $\begin{array}{l}\text { projeto } \\
\text { prototipo }\end{array}$ & $\begin{array}{l}\text { h) desenvolvimento } \\
\text { da produção } \\
\text { i) planejamento da } \\
\text { produção } \\
\text { j) preparação do } \\
\text { ferramental e do } \\
\text { mercado }\end{array}$ & k) produção e vendas & & \\
\hline
\end{tabular}


Tabela 4.2 - Estruturas de PDP encontradas na literatura (década de 80-90) - continuação.

\begin{tabular}{|c|c|c|c|c|c|c|c|c|c|}
\hline \multirow[b]{3}{*}{ Autor } & \multicolumn{9}{|c|}{ Processo de Desenvolvimento de Produtos (PDP) } \\
\hline & \multicolumn{2}{|c|}{ Pré-Desenvolvimento } & \multicolumn{5}{|c|}{ Desenvolvimento } & \multicolumn{2}{|c|}{ Pós-Desenvolvimento } \\
\hline & $\begin{array}{l}\text { Planejamento } \\
\text { Estratégico dos } \\
\text { Produtos }\end{array}$ & $\begin{array}{l}\text { Planejamento do } \\
\text { Projeto }\end{array}$ & $\begin{array}{c}\text { Projeto } \\
\text { Informacional }\end{array}$ & Projeto Conceitual & Projeto Detalhado & $\begin{array}{l}\text { Preparação da } \\
\text { Produção do } \\
\text { Produto }\end{array}$ & $\begin{array}{l}\text { Lançamento do } \\
\text { Produto }\end{array}$ & $\begin{array}{c}\text { Acompanhar } \\
\text { Produto e Processo }\end{array}$ & $\begin{array}{c}\text { Descontinuar o } \\
\text { Produto no Mercado }\end{array}$ \\
\hline McGrath (1996) & $\begin{array}{l}\text { a) avaliação do } \\
\text { conceito }\end{array}$ & \multicolumn{2}{|c|}{ b) especificação e planejamento } & c) desenvolvimento & \multicolumn{2}{|l|}{ d) avaliação e teste } & $\begin{array}{l}\text { e) lançamento do } \\
\text { produto }\end{array}$ & & \\
\hline $\begin{array}{l}\text { Ertas and Jones } \\
\text { (1996) }\end{array}$ & $\begin{array}{l}\text { a) identificação de } \\
\text { necessidade }\end{array}$ & & & $\begin{array}{l}\text { b) conceitualização } \\
\text { c) análise de } \\
\text { viabilidade } \\
\text { d) projeto preliminar }\end{array}$ & e) projeto detalhado & $\begin{array}{l}\text { f) planejamento da } \\
\text { produção/projeto de } \\
\text { ferramentas } \\
\text { g) produção }\end{array}$ & & & \\
\hline Dickson (1997) & a) gerar idéias & & & $\begin{array}{l}\text { b) desenvolvimento de } \\
\text { conceito } \\
\text { c) plano de } \\
\text { desenvolvimento }\end{array}$ & $\begin{array}{l}\text { d) desenvolver e } \\
\text { testar }\end{array}$ & & e) lançar no mercado & & \\
\hline Earle (1997) & $\begin{array}{l}\text { a) planejamento e } \\
\text { estratégia do produto }\end{array}$ & & \multicolumn{3}{|c|}{ b) criação, projeto e desenvolvimento do produto } & $\begin{array}{l}\text { c) processo de } \\
\text { produção, estratégia } \\
\text { de marketing, produto } \\
\text { comercial e garantia } \\
\text { da qualidade }\end{array}$ & \multicolumn{2}{|c|}{ d) lançamento e pós-lançamento } & \\
\hline Prasad (1997) & $\begin{array}{l}\text { a) definição da } \\
\text { missão da empresa }\end{array}$ & & & $\begin{array}{l}\text { b) definição do } \\
\text { conceito }\end{array}$ & $\begin{array}{l}\text { c) engenharia e } \\
\text { análise } \\
\text { d) projeto do produto } \\
\text { e) prototipagem } \\
\text { f) planejamento e } \\
\text { operacionalização de } \\
\text { engenharia }\end{array}$ & $\begin{array}{l}\text { g) operacionalização e } \\
\text { controle da produção } \\
\text { h) fabricação }\end{array}$ & & $\begin{array}{l}\text { i) melhoria, suporte e } \\
\text { entrega continuas }\end{array}$ & \\
\hline BS 7000 (1997) & a) inicio & b) planejamento & & c) viabilidade & $\begin{array}{l}\text { d) desenvolvimento de } \\
\text { projeto (separado em } \\
\text { modelo) }\end{array}$ & e) manufatura & f) operação & & g) disposição \\
\hline $\begin{array}{l}\text { Fleischer and Liker } \\
\text { (1997) }\end{array}$ & $\begin{array}{l}\text { a) identificação de } \\
\text { necessidade do } \\
\text { cliente }\end{array}$ & & & $\begin{array}{l}\text { b) desenvolvimento de } \\
\text { conceito } \\
\text { c) análise de mercado }\end{array}$ & $\begin{array}{l}\text { d) projeto de protótipo } \\
\text { e) construção/teste de } \\
\text { protótipo } \\
\text { f) projeto final }\end{array}$ & $\begin{array}{l}\text { g) projeto de } \\
\text { ferramentas/fazer } \\
\text { ferramentas/instalar } \\
\text { ferramentas/comprar } \\
\text { partes }\end{array}$ & $\begin{array}{l}\text { h) lançamento do } \\
\text { produto }\end{array}$ & & \\
\hline Peters et al. (1999) & a) idéia & & & b) conceito & c) projeto & $\begin{array}{l}\text { d) pré-produção e } \\
\text { validação }\end{array}$ & $\begin{array}{l}\text { e) produção e } \\
\text { distribuição }\end{array}$ & f) pós-empresa & \\
\hline
\end{tabular}


Durante o período intermediário (década de 80-90), houve um aumento significativo na qualidade e quantidade de detalhes nas estruturas de PDP, devido à necessidade de reduzir as incertezas do PDP, aumentar a velocidade e flexibilidade do PDP, organizar as informações, integrar as atividades e áreas participantes do processo, facilitar a tomada de decisão, melhorar a performance e qualidade, reduzirem os riscos, atender as necessidades dos clientes, gerenciar as fases do PDP e principalmente minimizar as diferenças de ponto de vista das diversas áreas do conhecimento.

Como contribuição desse período, alguns pesquisadores como Clark e Fujimoto (1991), Cooper (1993) e Prasad (1997) romperam com os seus domínios de conhecimento de suas áreas de origem para poderem analisar o PDP sem a visão direcionada de uma área específica e contribuir com a teoria sobre o PDP. Assim, esses autores citados acima focaram em consolidar os temas de controle gerencial e da integração do PDP, que resultou em novos conceitos e abordagens como o Desenvolvimento Integrado de Produto (DIP) e Engenharia Simultânea (ES), que buscam respectivamente gerenciar diferentes áreas de conhecimento e realizar atividades simultaneamente.

As estruturas de PDP como as de Andreasen e Hein (1987), Rosenthal (1992), Wheelwright e Clark (1992) e Prasad (1997) passaram a segmentar o processo em fases sobrepostas para aumentar a velocidade da execução de atividades e tarefas paralelas do processo, bem como, a utilizar de feedbacks gerenciais e loops no fluxo de informações das diferentes fases para auxiliar na tomada de decisão. Em geral, essas estruturas de PDP desenvolvidas nesse período passaram a ter as estruturas de PDP desenvolvidas anteriormente como base, portanto possuem uma visão mais abrangente do PDP e da complexidade desse processo.

Além disso, as estruturas de PDP incorporaram novos métodos e ferramentas de suporte ao PDP, integraram toda a cadeia de suprimentos e mudaram a visão do PDP para um processo do negócio da empresa voltado para atender as necessidades dos clientes. Assim, surgiram algumas normas de qualidade e guias de projeto de produto (VDI-2221, 1985; APQP, 1994; BS-7000, 1997) que passaram a caminhar junto com as estruturas de PDP no nível de detalhes e integração das fases e suas interfaces, documentação do processo, tomada de decisão, informações de entrada e saída e, também, criaram indicadores para medir o desempenho do PDP. 
As estruturas de PDP (WHEELWRIGHT; CLARK, 1992; COOPER, 1993) passaram a ter um maior cuidado com a gestão do processo, assemelhando-se aos modelos de projeto, devido principalmente a esquematizar as fases e o funcionamento dos Gates de passagem de fases do PDP para destacar a necessidade de avaliações e controle durante o andamento do projeto. É importante frisar que embora tenham uma representação esquemática, a maioria dessas estruturas do PDP é cíclica com loops de análise para aprofundamento de alguns conceitos e retroalimentação no fluxo de informações.

Para Roozenburg e Eekels (1995) até a década de 90, as estruturas do PDP tiveram três enfoques essenciais:

i) Foco na fase de projeto, que tinha o objetivo de solucionar os problemas e estruturar um raciocínio lógico denominado de ciclo básico de projeto (análise, síntese, simulação, avaliação e decisão) para auxiliar na efetivação do projeto;

II) Foco em segmentar o projeto de engenharia, dividindo-o em quatro fases (especificação do projeto, projeto conceitual, projeto definitivo e projeto detalhado);

III) Foco nas estruturas de fases do PDP, que são formadas pelas fases do projeto do produto, parte da preparação e desenvolvimento da produção e do plano de marketing transformando a visão do PDP como parte do negócio.

Observa-se pela distribuição das fases das estruturas de PDP, na Tabela 4.2, que nesse período ainda continua-se tendo uma baixa atenção à função de acompanhamento do desempenho do produto e medidas para redução do impacto ambiental, tais como: utilizar de estratégias de reciclagem, remanufatura e descarte dos produtos e embalagens. Além disso, a fase de planejamento do projeto apesar de ser destacado pela sua função relacionada à gestão do projeto, tópico considerado importante para os autores das estruturas nesse período, ela é pouco demonstrada como uma fase de referência nas estruturas de PDP analisadas.

A seguir, são mostradas as estruturas de PDP referentes ao período mais recente (2000 até 2013), que são listadas em ordem cronológica na Tabela 4.3. 
Tabela 4.3 - Estruturas de PDP encontradas na literatura (2000 até 2013).

\begin{tabular}{|c|c|c|c|c|c|c|c|c|c|}
\hline \multirow[b]{3}{*}{ Autor } & \multicolumn{9}{|c|}{ Processo de Desenvolvimento de Produtos (PDP) } \\
\hline & \multicolumn{2}{|c|}{ Pré-Desenvolvimento } & \multicolumn{5}{|c|}{ Desenvolvimento } & \multicolumn{2}{|c|}{ Pós-Desenvolvimento } \\
\hline & $\begin{array}{l}\text { Planejamento } \\
\text { Estratégico dos } \\
\text { Produtos }\end{array}$ & $\begin{array}{l}\text { Planejamento do } \\
\text { Projeto }\end{array}$ & $\begin{array}{c}\text { Projeto } \\
\text { Informacional }\end{array}$ & Projeto Conceitual & Projeto Detalhado & $\begin{array}{l}\text { Preparação da } \\
\text { Produção do } \\
\text { Produto }\end{array}$ & $\begin{array}{l}\text { Lançamento do } \\
\text { Produto }\end{array}$ & $\begin{array}{c}\text { Acompanhar } \\
\text { Produto e Processo }\end{array}$ & $\begin{array}{c}\text { Descontinuar o } \\
\text { Produto no Mercado }\end{array}$ \\
\hline Baxter (2000) & $\begin{array}{l}\text { a) oportunidade de } \\
\text { negócio }\end{array}$ & $\begin{array}{l}\text { b) especificações do } \\
\text { projeto }\end{array}$ & & c) projeto conceitual & $\begin{array}{l}\text { d) projeto de } \\
\text { configuração } \\
\text { e) projeto detalhado }\end{array}$ & $\begin{array}{l}\text { f) projeto de } \\
\text { fabricação }\end{array}$ & & & \\
\hline $\begin{array}{l}\text { Crawford and } \\
\text { Benedetto (2000) }\end{array}$ & $\begin{array}{l}\text { a) identificação e } \\
\text { seleção de } \\
\text { oportunidades }\end{array}$ & & & $\begin{array}{l}\text { b) gerar o conceito } \\
\text { c) avaliar o conceito }\end{array}$ & \multicolumn{2}{|c|}{ d) desenvolvimento técnico } & $\begin{array}{l}\text { e) lançamento no } \\
\text { mercado }\end{array}$ & & \\
\hline Kaminski (2000) & $\begin{array}{l}\text { a) especificar } \\
\text { tecnicamente as } \\
\text { necessidades } \\
\text { b) estudar a } \\
\text { viabilidade }\end{array}$ & & & $\begin{array}{l}\text { c) efetuar o projeto } \\
\text { básico }\end{array}$ & $\begin{array}{l}\text { d) efetuar o projeto } \\
\text { executivo }\end{array}$ & e) planejar a produção & f) executar & & \\
\hline $\begin{array}{l}\text { Nwabueze and Law } \\
(2001)\end{array}$ & $\begin{array}{l}\text { a) planejamento } \\
\text { estratégico } \\
\text { b) geração de idéia }\end{array}$ & & & $\begin{array}{l}\text { c) desenvolvimento de } \\
\text { conceito } \\
\text { d) estratégia de } \\
\text { mercado }\end{array}$ & $\begin{array}{l}\text { e) análise economica } \\
\text { de negócio } \\
\text { f) desenvolvimento do } \\
\text { produto }\end{array}$ & & $\begin{array}{l}\text { g) teste de mercado } \\
\text { h) lançamento }\end{array}$ & $\begin{array}{l}\text { i) monitoramento pós- } \\
\text { lançamento }\end{array}$ & $\begin{array}{l}\text { j) gerenciamento do } \\
\text { ciclo de vida }\end{array}$ \\
\hline $\begin{array}{l}\text { Kalpic and Bernus } \\
\text { (2001) }\end{array}$ & $\begin{array}{l}\text { a) criar idéia } \\
\text { b) investigação de } \\
\text { mercado } \\
\text { c) coletar e selecionar } \\
\text { idéias }\end{array}$ & & & $\begin{array}{l}\text { d) proposta de projeto } \\
\text { e) avaliação da } \\
\text { proposta de projeto }\end{array}$ & $\begin{array}{l}\text { f) desenvolver o } \\
\text { produto }\end{array}$ & $\begin{array}{l}\text { g) preparar a } \\
\text { produção } \\
\text { h) teste de produção e } \\
\text { pós-cálculo } \\
\text { i) validar produto e } \\
\text { projeto }\end{array}$ & $\begin{array}{l}\text { j) certificar produto e } \\
\text { fazer marketing } \\
\text { h) determinar novo } \\
\text { fornecedor }\end{array}$ & & \\
\hline $\begin{array}{l}\text { Tischner and Charter } \\
\text { (2001) }\end{array}$ & a) conceitualização & & b) avaliação & c) conceitos de refino & d) protótipo, teste de $\mathrm{m}$ & nercado e manufatura & $\begin{array}{l}\text { e) lançamento no } \\
\text { mercado }\end{array}$ & & \\
\hline $\begin{array}{l}\text { Buss and Cunha } \\
\text { (2002) }\end{array}$ & $\begin{array}{l}\text { a) avaliação de } \\
\text { oportunidade }\end{array}$ & & & $\begin{array}{l}\text { b) concepção do } \\
\text { produto } \\
\text { c) estratégia } \\
\text { preliminar }\end{array}$ & $\begin{array}{l}\text { d) desenvolvimento do } \\
\text { sistema técnico }\end{array}$ & $\begin{array}{l}\text { e) desenvolvimento da } \\
\text { produção }\end{array}$ & f) lançamento & & \\
\hline ISO/TR 14062 (2002) & a) planejamento & & & b) projeto conceitual & c) projeto detalhado & d) teste e protótipo & $\begin{array}{l}\text { e) lançamento de } \\
\text { mercado }\end{array}$ & f) revisão do produto & \\
\hline Toledo et al. (2002) & $\begin{array}{l}\text { a) pré- } \\
\text { desenvolvimento }\end{array}$ & & $\begin{array}{l}\text { b) desenvolvimento } \\
\text { b1) conceito do prod }\end{array}$ & & & & & c) pós-desenvolvimentc & \\
\hline Unger (2003) & & & & $\begin{array}{l}\text { a) planejamento do } \\
\text { produto }\end{array}$ & $\begin{array}{l}\text { b) seleção e projeto } \\
\text { do processo } \\
\text { c) criação de } \\
\text { especificação } \\
\text { d) projeto no nivel de } \\
\text { sistema } \\
\text { e) projeto detalhado } \\
\text { f) protótipo e teste }\end{array}$ & g) lançamento & & & \\
\hline Buijs (2003) & $\begin{array}{l}\text { a) situação } \\
\text { estratégica da } \\
\text { empresa } \\
\text { b) área de pesquisa }\end{array}$ & & & c) projeto conceitual & & $\begin{array}{l}\text { d) projeto do produto } \\
\text { e) lançamento do prod }\end{array}$ & & & \\
\hline
\end{tabular}


Tabela 4.3 - Estruturas de PDP encontradas na literatura (2000 até 2013) - continuação.

\begin{tabular}{|c|c|c|c|c|c|c|c|c|c|}
\hline \multirow[b]{3}{*}{ Autor } & \multicolumn{9}{|c|}{ Processo de Desenvolvimento de Produtos (PDP) } \\
\hline & \multicolumn{2}{|c|}{ Pré-Desenvolvimento } & \multicolumn{5}{|c|}{ Desenvolvimento } & \multicolumn{2}{|c|}{ Pós-Desenvolvimento } \\
\hline & $\begin{array}{l}\text { Planejamento } \\
\text { Estratégico dos } \\
\text { Produtos }\end{array}$ & $\begin{array}{l}\text { Planejamento do } \\
\text { Projeto }\end{array}$ & $\begin{array}{c}\text { Projeto } \\
\text { Informacional }\end{array}$ & Projeto Conceitual & Projeto Detalhado & $\begin{array}{l}\text { Preparação da } \\
\text { Produção do } \\
\text { Produto }\end{array}$ & $\begin{array}{l}\text { Lançamento do } \\
\text { Produto }\end{array}$ & $\begin{array}{c}\text { Acompanhar } \\
\text { Produto e Processo }\end{array}$ & $\begin{array}{c}\text { Descontinuar o } \\
\text { Produto no Mercado }\end{array}$ \\
\hline Echeveste (2003) & $\begin{array}{l}\text { a) avaliação } \\
\text { preliminar do mercado }\end{array}$ & & & $\begin{array}{l}\text { b) desenvolvimento do } \\
\text { conceito }\end{array}$ & $\begin{array}{l}\text { c) desenvolvimento do } \\
\text { projeto do produto } \\
\text { d) desenvolvimento do } \\
\text { protótipo } \\
\text { e) desenvolvimento do } \\
\text { ferramental }\end{array}$ & $\begin{array}{l}\text { f) planejamento da } \\
\text { produção } \\
\text { g) desenvolvimento da } \\
\text { produção }\end{array}$ & $\begin{array}{l}\text { h) liberação para } \\
\text { vendas }\end{array}$ & & \\
\hline Penso (2003) & $\begin{array}{l}\text { a) planejamento } \\
\text { estratégico } \\
\text { b) planejamento do } \\
\text { portfólio de produtos }\end{array}$ & $\begin{array}{l}\text { c) planejamento de } \\
\text { produto }\end{array}$ & $\begin{array}{l}\text { d) projeto } \\
\text { informacional }\end{array}$ & e) projeto conceitual & f) projeto detalhado & $\begin{array}{l}\text { g) preparação da } \\
\text { produção }\end{array}$ & $\begin{array}{l}\text { h) lançamento do } \\
\text { produto }\end{array}$ & $\begin{array}{l}\text { i) acompanhamento } \\
\text { do produto }\end{array}$ & $\begin{array}{l}\text { j) retirada do produto } \\
\text { do mercado }\end{array}$ \\
\hline Romano (2003) & & $\begin{array}{l}\text { a) planejamento do } \\
\text { projeto }\end{array}$ & $\begin{array}{l}\text { b) projeto } \\
\text { informacional }\end{array}$ & $\begin{array}{l}\text { c) projeto conceitual } \\
\text { d) projeto preliminar }\end{array}$ & e) projeto detalhado & $\begin{array}{l}\text { f) preparação da } \\
\text { produção }\end{array}$ & $\begin{array}{l}\text { g) lançamento do } \\
\text { produto }\end{array}$ & h) validação & \\
\hline Gobe et. al. (2004) & $\begin{array}{l}\text { a) geração de idéias } \\
\text { b) triagem de idéias }\end{array}$ & & & $\begin{array}{l}\text { c) desenvolvimento de } \\
\text { conceito }\end{array}$ & $\begin{array}{l}\text { d) teste de conceito } \\
\text { e) análise de negócios } \\
\text { f) desenvolvimento de } \\
\text { produto e marca } \\
\text { g) avaliação do mix do } \\
\text { produto }\end{array}$ & & $\begin{array}{l}\text { h) teste de mercado } \\
\text { i) lançamento do } \\
\text { produto }\end{array}$ & $\begin{array}{l}\text { j) acompanhamento } \\
\text { do desenvolvimento } \\
\text { do produto }\end{array}$ & \\
\hline Paula (2004) & $\begin{array}{l}\text { a) identificação e } \\
\text { seleção da } \\
\text { oportunidade de } \\
\text { negócio }\end{array}$ & & & $\begin{array}{l}\text { b) geração e seleção } \\
\text { de conceito }\end{array}$ & $\begin{array}{l}\text { c) detalhamento e } \\
\text { seleção do conceito } \\
\text { detalhado } \\
\text { d) desenvolvimento e } \\
\text { análise do produto e } \\
\text { processo }\end{array}$ & $\begin{array}{l}\text { e) execução da } \\
\text { produção e do plano } \\
\text { de marketing }\end{array}$ & $\begin{array}{l}\text { f) conclusão do PDP } \\
\text { g) registro do produto n } \\
\text { avaliação pós-vendas }\end{array}$ & na ANVISA e lançamen & nto do produto e \\
\hline Santos (2004) & & & $\begin{array}{l}\text { a) projeto } \\
\text { informacional }\end{array}$ & $\begin{array}{l}\text { b) projeto conceitual } \\
\text { c) projeto preliminar }\end{array}$ & d) projeto detalhado & $\begin{array}{l}\text { e) preparação para } \\
\text { produção }\end{array}$ & & & \\
\hline Dym and Little (2004) & $\begin{array}{l}\text { a) necessidade do } \\
\text { cliente/definição do } \\
\text { problema }\end{array}$ & & & $\begin{array}{l}\text { b) projeto conceitual } \\
\text { c) projeto preliminar }\end{array}$ & $\begin{array}{l}\text { d) projeto detalhado } \\
\text { e) projeto de } \\
\text { comunicação }\end{array}$ & $\begin{array}{l}\text { f) projeto final } \\
\text { (especificação de } \\
\text { fabricação e } \\
\text { documentaçãa) }\end{array}$ & & & \\
\hline $\begin{array}{l}\text { Alves and Sacchelli } \\
\text { (2005) }\end{array}$ & $\begin{array}{l}\text { a) desenvolvimento de } \\
\text { mercado }\end{array}$ & & $\begin{array}{l}\text { b) desenvolvimento do } \\
\text { atendimento }\end{array}$ & o c) desenvolvimento do & projeto & $\begin{array}{l}\text { d) desenvolvimento da } \\
\text { produção }\end{array}$ & $\begin{array}{l}\text { e) desenvolvimento de } \\
\text { entrega }\end{array}$ & & \\
\hline $\begin{array}{l}\text { Martins and Laugeni } \\
(2005)\end{array}$ & a) geração de idéia & & $\begin{array}{l}\text { b) especificações } \\
\text { funcionais } \\
\text { c) seleção do produto }\end{array}$ & d) projeto preliminar & $\begin{array}{l}\text { e) construção do } \\
\text { protótipo } \\
\text { f) testes }\end{array}$ & g) projeto final & h) introdução & i) avaliação & \\
\hline Pahl et al. (2005) & a) planejamento e escle & larecimento da tarefa o & le projeto & $\begin{array}{l}\text { b) projeto conceitual } \\
\text { c) projeto preliminar } \\
\text { ou anteprojeto }\end{array}$ & d) projeto detalhado & & & & \\
\hline
\end{tabular}


Tabela 4.3 - Estruturas de PDP encontradas na literatura (2000 até 2013) - continuação.

\begin{tabular}{|c|c|c|c|c|c|c|c|c|c|}
\hline \multirow[b]{3}{*}{ Autor } & \multicolumn{9}{|c|}{ Processo de Desenvolvimento de Produtos (PDP) } \\
\hline & \multicolumn{2}{|c|}{ Pré-Desenvolvimento } & \multicolumn{5}{|c|}{ Desenvolvimento } & \multicolumn{2}{|c|}{ Pós-Desenvolvimento } \\
\hline & $\begin{array}{l}\text { Planejamento } \\
\text { Estratégico dos } \\
\text { Produtos }\end{array}$ & $\begin{array}{l}\text { Planejamento do } \\
\text { Projeto }\end{array}$ & $\begin{array}{l}\text { Projeto } \\
\text { Informacional }\end{array}$ & Projeto Conceitual & Projeto Detalhado & $\begin{array}{l}\text { Preparação da } \\
\text { Produção do } \\
\text { Produto }\end{array}$ & $\begin{array}{l}\text { Lançamento do } \\
\text { Produto }\end{array}$ & $\begin{array}{l}\text { Acompanhar } \\
\text { Produto e Processo }\end{array}$ & $\begin{array}{c}\text { Descontinuar o } \\
\text { Produto no Mercado }\end{array}$ \\
\hline Paula and Cheng (2005) & $\begin{array}{l}\text { a) desenvolvimento da } \\
\text { pesquisa } \\
\text { b) avaliação dos } \\
\text { resultados da } \\
\text { pesquisa } \\
\text { c) identificação de } \\
\text { oportunidades } \\
\text { d) estudo de } \\
\text { viabilidade técnica e } \\
\text { econômica }\end{array}$ & & & & $\begin{array}{l}\text { e) desenvolvimento e } \\
\text { testes do protótipo }\end{array}$ & $\begin{array}{l}\text { f) planejamento para } \\
\text { a comercialização do } \\
\text { produto }\end{array}$ & & & \\
\hline Ford and Coulston (2005) & $\begin{array}{l}\text { a) identificação de } \\
\text { problema/pesquisa/es } \\
\text { pecificaçãa de } \\
\text { requisitos }\end{array}$ & & & $\begin{array}{l}\text { b) geração de } \\
\text { conceito } \\
\text { c) projeto }\end{array}$ & $\begin{array}{l}\text { d) protótipo e } \\
\text { construção } \\
\text { e) integração de } \\
\text { sistema } \\
\text { f) teste de sistema }\end{array}$ & $\begin{array}{l}\text { g) entrega e } \\
\text { aprovação }\end{array}$ & & $\begin{array}{l}\text { h) manutenção e } \\
\text { atualização }\end{array}$ & \\
\hline Sun and Wing (2005) & $\begin{array}{l}\text { a) geração de idéias e } \\
\text { projeto conceitual }\end{array}$ & & \multicolumn{2}{|c|}{ b) definição e especificação } & \multicolumn{2}{|c|}{ c) desenvolvimento e protótipo } & \multicolumn{2}{|l|}{ d) comercialização } & \\
\hline Thier (2005) & $\begin{array}{l}\text { a) avaliação das } \\
\text { necessidades de } \\
\text { mercado }\end{array}$ & $\begin{array}{l}\text { b) planejamento do } \\
\text { produto }\end{array}$ & & \multicolumn{2}{|c|}{$\begin{array}{l}\text { c) desenvolvimento do produto } \\
\text { d) desenvolvimento do processo } \\
\text { e) desenvolvimento do marketing }\end{array}$} & $\begin{array}{l}\text { f) preparação para } \\
\text { produção }\end{array}$ & $\begin{array}{l}\text { g) lançamento do } \\
\text { produto }\end{array}$ & $\begin{array}{l}\text { h) melhoria continua } \\
\text { do produto }\end{array}$ & $\begin{array}{l}\text { i) retirada do produto } \\
\text { do mercado }\end{array}$ \\
\hline Prasnikar and Skerlj (2006) & a) geração de idéias & & & $\begin{array}{l}\text { b) avaliação } \\
\text { preliminar }\end{array}$ & $\begin{array}{l}\text { c) desenvolvimento } \\
\text { laboratorial } \\
\text { d) desenvolvimento de } \\
\text { tecnologia }\end{array}$ & & $\begin{array}{l}\text { e) registro } \\
\text { f) lançamento }\end{array}$ & & \\
\hline Alvarenga (2006) & & & $\begin{array}{l}\text { a) estudo da } \\
\text { viabilidade do projeto } \\
\text { inclusivo }\end{array}$ & $\begin{array}{l}\text { b) projeto preliminar } \\
\text { do produto inclusivo }\end{array}$ & $\begin{array}{l}\text { c) projeto detalhado } \\
\text { do produto inclusivo }\end{array}$ & & & & \\
\hline Barbalho (2006) & $\begin{array}{l}\text { a) estratégia } \\
\text { b) portfólio }\end{array}$ & $\begin{array}{l}\text { d) planejamento do } \\
\text { projeto }\end{array}$ & c) especificaçōes & e) concepção & $\begin{array}{l}\text { f) planejamento } \\
\text { técnico } \\
\text { g) otimização } \\
\text { h) homologação }\end{array}$ & i) validação & j) lançamento & k) monitoramento & \\
\hline Brasil (2006) & $\begin{array}{l}\text { a) planejamento } \\
\text { estratégico de } \\
\text { produtos }\end{array}$ & $\begin{array}{l}\text { b) gerenciamento de } \\
\text { projetos } \\
\text { c) planejamento de } \\
\text { projetos }\end{array}$ & $\begin{array}{l}\text { d) projeto } \\
\text { informacional }\end{array}$ & \multicolumn{3}{|c|}{$\begin{array}{l}\text { e) processo de concepção } \\
\text { f) configuração do sistema produto e processo } \\
\text { g) detalhamento e execução do produto e processo } \\
\text { h) validaçãa do sistema produto e processo }\end{array}$} & $\begin{array}{l}\text { i) lançamento do } \\
\text { produto } \\
\text { j) produção e } \\
\text { fornecimento }\end{array}$ & $\begin{array}{l}\text { k) monitoramento do } \\
\text { produto no mercado }\end{array}$ & \\
\hline Crul e Diehl (2006) & $\begin{array}{l}\text { b) desenvolvimento de } \\
\text { uma análise SWOT e } \\
\text { definição dos } \\
\text { objetivos } \\
\text { c) seleção do produto } \\
\text { f) desenvolvimento da } \\
\text { estratégia e do } \\
\text { briefing com foco no } \\
\text { design sustentável } \\
\text { g) geração e seleção } \\
\text { de ideias }\end{array}$ & $\begin{array}{l}\text { a) criação da equipe e } \\
\text { planejamento do } \\
\text { projeto }\end{array}$ & $\begin{array}{l}\text { d) definição de } \\
\text { requisitos } \\
\text { sustentáveis para o } \\
\text { produto } \\
\text { e) análise de } \\
\text { impactos }\end{array}$ & $\begin{array}{l}\text { h) desenvolvimento } \\
\text { dos conceitos }\end{array}$ & $\begin{array}{l}\text { i) avaliação sob a } \\
\text { visão do design } \\
\text { sustentável }\end{array}$ & & & $\begin{array}{l}\text { j) implementação e } \\
\text { acompanhamento }\end{array}$ & \\
\hline
\end{tabular}


Tabela 4.3 - Estruturas de PDP encontradas na literatura (2000 até 2013) - continuação.

\begin{tabular}{|c|c|c|c|c|c|c|c|c|c|}
\hline \multirow[b]{3}{*}{ Autor } & \multicolumn{9}{|c|}{ Processo de Desenvolvimento de Produtos (PDP) } \\
\hline & \multicolumn{2}{|c|}{ Pré-Desenvolvimento } & \multicolumn{5}{|c|}{ Desenvolvimento } & \multicolumn{2}{|c|}{ Pós-Desenvolvimento } \\
\hline & $\begin{array}{l}\text { Planejamento } \\
\text { Estratégico dos } \\
\text { Produtos }\end{array}$ & $\begin{array}{l}\text { Planejamento do } \\
\text { Projeto }\end{array}$ & $\begin{array}{c}\text { Projeto } \\
\text { Informacional }\end{array}$ & Projeto Conceitual & Projeto Detalhado & $\begin{array}{l}\text { Preparação da } \\
\text { Produção do } \\
\text { Produto }\end{array}$ & $\begin{array}{l}\text { Lançamento do } \\
\text { Produto }\end{array}$ & $\begin{array}{l}\text { Acompanhar } \\
\text { Produto e Processo }\end{array}$ & $\begin{array}{c}\text { Descontinuar o } \\
\text { Produto no Mercado }\end{array}$ \\
\hline $\begin{array}{l}\text { MacGregor et al } \\
(2006)\end{array}$ & $\begin{array}{l}\text { a) estratégia de } \\
\text { produto } \\
\text { b) estratégia de } \\
\text { tecnologia }\end{array}$ & & $\begin{array}{l}\text { c) desenvolvimento } \\
\text { d) desenvolvimento }\end{array}$ & $\begin{array}{l}\text { e produto } \\
\text { le tecnologia }\end{array}$ & & & & & \\
\hline $\begin{array}{l}\text { Rozenfeld et al. } \\
\text { (2006) }\end{array}$ & $\begin{array}{l}\text { a) planejamento } \\
\text { estratégico dos } \\
\text { produtos }\end{array}$ & $\begin{array}{l}\text { b) planejamento do } \\
\text { projeto }\end{array}$ & $\begin{array}{l}\text { c) projeto } \\
\text { informacional }\end{array}$ & d) projeto conceitual & e) projeto detalhado & $\begin{array}{l}\text { f) preparação da } \\
\text { produção do produto }\end{array}$ & $\begin{array}{l}\text { g) lançamento do } \\
\text { produto }\end{array}$ & $\begin{array}{l}\text { h) acompanhar } \\
\text { produto e processo }\end{array}$ & $\begin{array}{l}\text { i) descontinuar o } \\
\text { produto }\end{array}$ \\
\hline Souza (2007) & $\begin{array}{l}\text { a) identificar a } \\
\text { oportunidade } \\
\text { b) coletar e preparar } \\
\text { as informaçōes } \\
\text { iniciais }\end{array}$ & $\begin{array}{l}\text { c) formação da equipe } \\
\text { multifuncional }\end{array}$ & & $\begin{array}{l}\text { d) desmontar (coletar } \\
\text { informações do } \\
\text { produto) }\end{array}$ & $\begin{array}{l}\text { e) medir e testar } \\
\text { (coletar informações } \\
\text { dos componentes) } \\
\text { f) especificar e } \\
\text { documentar } \\
\text { g) prototipar } \\
\text { h) revisar os } \\
\text { resultados }\end{array}$ & & & & \\
\hline $\begin{array}{l}\text { Thomke and Nimgade } \\
\text { (2007) }\end{array}$ & $\begin{array}{l}\text { a) entender e } \\
\text { observar o mercado }\end{array}$ & & & b) visualizar/realizar & c) avaliar e refinar & $\begin{array}{l}\text { d) implementar } \\
\text { (detalhamento de } \\
\text { engenharia) }\end{array}$ & $\begin{array}{l}\text { e) implementar } \\
\text { (ligação com a } \\
\text { produçâa) }\end{array}$ & & \\
\hline $\begin{array}{l}\text { Ulrich and Eppinger } \\
(2007)\end{array}$ & $\begin{array}{l}\text { a) processos de deser } \\
\text { organizaçōes } \\
\text { b) planejamento do pr } \\
\text { c) identificaçãa das ne } \\
\text { consumidor } \\
\text { d) gerenciamento de } \\
\text { desenvolvimento de p }\end{array}$ & $\begin{array}{l}\text { nvolvimento e } \\
\text { roduto } \\
\text { ecessidades do } \\
\text { projeto de } \\
\text { roduto }\end{array}$ & $\begin{array}{l}\text { e) especificações do } \\
\text { f) geraçãa de concei } \\
\text { g) seleção de conce } \\
\text { h) teste do conceito }\end{array}$ & $\begin{array}{l}\text { produto } \\
\text { os } \\
\text { os }\end{array}$ & $\begin{array}{l}\text { i) arquitetura do } \\
\text { produto } \\
\text { j) desenho industrial } \\
\text { k) projeto para } \\
\text { manufatura } \\
\text { I) prototipagem } \\
\text { m) projeto robusto }\end{array}$ & $\begin{array}{l}\text { n) economia para o } \\
\text { desenvolvimento de } \\
\text { produtos } \\
\text { o) projeto de patente }\end{array}$ & & & \\
\hline Back et al. (2008) & & $\begin{array}{l}\text { a) planejamento do } \\
\text { projeto }\end{array}$ & $\begin{array}{l}\text { b) projeto } \\
\text { informacional }\end{array}$ & $\begin{array}{l}\text { c) projeto conceitual } \\
\text { d) projeto preliminar }\end{array}$ & e) projeto detalhado & $\begin{array}{l}\text { f) preparação da } \\
\text { produção }\end{array}$ & $\begin{array}{l}\text { g) lançamento do } \\
\text { produto }\end{array}$ & $\begin{array}{l}\text { h) validação do } \\
\text { produto }\end{array}$ & \\
\hline Colenci Neto (2008) & $\begin{array}{l}\text { a) planejamento } \\
\text { estratégico }\end{array}$ & b) planejamento & & c) elaboração & $\begin{array}{l}\text { d) construção } \\
\text { e) teste } \\
\text { f) homologação }\end{array}$ & g) implantação & & $\begin{array}{l}\text { h) manutenção e } \\
\text { suporte } \\
\text { j) controle do projeto }\end{array}$ & $\begin{array}{l}\text { i) descontinuidade do } \\
\text { produto }\end{array}$ \\
\hline Nascimento (2008) & & & & $\begin{array}{l}\text { a) processos de } \\
\text { inicialização }\end{array}$ & $\begin{array}{l}\text { b) processos de } \\
\text { desenvolvimento } \\
\text { interativo }\end{array}$ & $\begin{array}{l}\text { c) processos de } \\
\text { operação } \\
\text { d) processos de apoio }\end{array}$ & & & \\
\hline
\end{tabular}


Tabela 4.3 - Estruturas de PDP encontradas na literatura (2000 até 2013) - continuação.

\begin{tabular}{|c|c|c|c|c|c|c|c|c|c|}
\hline \multirow[b]{3}{*}{ Autor } & \multicolumn{9}{|c|}{ Processo de Desenvolvimento de Produtos (PDP) } \\
\hline & \multicolumn{2}{|c|}{ Pré-Desenvolvimento } & \multicolumn{5}{|c|}{ Desenvolvimento } & \multicolumn{2}{|c|}{ Pós-Desenvolvimento } \\
\hline & $\begin{array}{l}\text { Planejamento } \\
\text { Estratégico dos } \\
\text { Produtos }\end{array}$ & $\begin{array}{l}\text { Planejamento do } \\
\text { Projeto }\end{array}$ & $\begin{array}{c}\text { Projeto } \\
\text { Informacional }\end{array}$ & Projeto Conceitual & Projeto Detalhado & $\begin{array}{l}\text { Preparação da } \\
\text { Produção do } \\
\text { Produto }\end{array}$ & $\begin{array}{l}\text { Lançamento do } \\
\text { Produto }\end{array}$ & $\begin{array}{l}\text { Acompanhar } \\
\text { Produto e Processo }\end{array}$ & $\begin{array}{c}\text { Descontinuar o } \\
\text { Produto no Mercado }\end{array}$ \\
\hline Santos (2008) & $\begin{array}{l}\text { a) planejamento } \\
\text { estratégico do produto }\end{array}$ & $\begin{array}{l}\text { b) planejamento do } \\
\text { projeto do produto }\end{array}$ & $\begin{array}{l}\text { c) projeto } \\
\text { informacional }\end{array}$ & d) projeto conceitual & e) projeto detalhado & $\begin{array}{l}\text { f) preparação para } \\
\text { produção }\end{array}$ & $\begin{array}{l}\text { g) lançamento do } \\
\text { produto }\end{array}$ & $\begin{array}{l}\text { h) acompanhar } \\
\text { produto e processo } \\
\text { j) processos de apoio } \\
\text { ao PDP }\end{array}$ & $\begin{array}{l}\text { i) descontinuidade do } \\
\text { produto }\end{array}$ \\
\hline Freitas (2010) & $\begin{array}{l}\text { a) planejamento } \\
\text { estratégico do produto }\end{array}$ & $\begin{array}{l}\text { b) planejamento do } \\
\text { projeto do produto }\end{array}$ & $\begin{array}{l}\text { c) projeto } \\
\text { informacional }\end{array}$ & d) projeto conceitual & e) projeto detalhado & $\begin{array}{l}\text { f) preparação para } \\
\text { produção }\end{array}$ & $\begin{array}{l}\text { g) lançamento do } \\
\text { produto }\end{array}$ & $\begin{array}{l}\text { h) acompanhar } \\
\text { produto e processo }\end{array}$ & $\begin{array}{l}\text { i) descontinuidade do } \\
\text { produto }\end{array}$ \\
\hline Bucci (2010) & $\begin{array}{l}\text { a) planejamento } \\
\text { estratégico }\end{array}$ & $\begin{array}{l}\text { b) planejamento do } \\
\text { projeto }\end{array}$ & $\begin{array}{l}\text { c) projeto } \\
\text { informacional }\end{array}$ & d) projeto conceitual & e) projeto detalhado & f) lote piloto & g) lançamento & h) acompanhamento & i) retirada \\
\hline Yeh et al. (2010) & $\begin{array}{l}\text { a) proposta de } \\
\text { desenvolvimento }\end{array}$ & $\begin{array}{l}\text { b) planejamento do } \\
\text { projeto }\end{array}$ & & c) projeto conceitual & $\begin{array}{l}\text { d) projeto do produto } \\
\text { e) protótipo e teste } \\
\text { f) desenvolvimento do } \\
\text { processo e teste piloto }\end{array}$ & g) manufatura & & & \\
\hline $\begin{array}{l}\text { Campos e Ribeiro } \\
\text { (2011) }\end{array}$ & $\begin{array}{l}\text { a) planejamento do } \\
\text { portfólio de produtos }\end{array}$ & $\begin{array}{l}\text { b) planejamento do } \\
\text { projeto }\end{array}$ & $\begin{array}{l}\text { c) projeto } \\
\text { informacional }\end{array}$ & d) projeto conceitual & e) projeto detalhado & \multicolumn{2}{|c|}{$\begin{array}{l}\text { f) preparação da produção e lançamento do } \\
\text { produto }\end{array}$} & $\begin{array}{l}\text { g) acompanhamento } \\
\text { do produto e processo }\end{array}$ & $\begin{array}{l}\text { h) retirada do produto } \\
\text { do mercado }\end{array}$ \\
\hline Salgado (2011) & $\begin{array}{l}\text { a) gestão estratégica } \\
\text { b) gestão de portfólio }\end{array}$ & & & $\begin{array}{l}\text { c) conceituação do } \\
\text { produto } \\
\text { d) preparação do } \\
\text { projeto }\end{array}$ & $\begin{array}{l}\text { e) projeto executivo } \\
\text { f) teste e } \\
\text { homologação }\end{array}$ & \multicolumn{2}{|c|}{ g) produção e lançamento } & h) acompanhamento & i) descontinuação \\
\hline $\begin{array}{l}\text { Souza Mendes and } \\
\text { Toledo (2011) }\end{array}$ & \begin{tabular}{|l} 
a) estratégia \\
b) portfólio \\
c) conceito preliminar
\end{tabular} & $\begin{array}{l}\text { d) planejamento do } \\
\text { projeto }\end{array}$ & & & & & & & \\
\hline $\begin{array}{l}\text { Viegas and Salles } \\
\text { (2012) }\end{array}$ & & a) planejar & & $\begin{array}{l}\text { b) desenvolvimento do } \\
\text { conceito }\end{array}$ & $\begin{array}{l}\text { c) projeto do sistema } \\
\text { d) projeto detalhado } \\
\text { e) teste e refinamento }\end{array}$ & $\begin{array}{l}\text { f) análise financeira e } \\
\text { aspectos legais }\end{array}$ & & & \\
\hline Bigliardi et al. (2013) & $\begin{array}{l}\text { a) identificação e } \\
\text { geração de idéia } \\
\text { b) seleção da idéia }\end{array}$ & & & $\begin{array}{l}\text { b) desenvolvimento do } \\
\text { conceito do produto }\end{array}$ & $\begin{array}{l}\text { c) teste do conceito } \\
\text { do produto } \\
\text { d) desenvolvimento de } \\
\text { estratégia de mercado }\end{array}$ & $\begin{array}{l}\text { e) manufatura do } \\
\text { produto } \\
\text { f) teste do produto no } \\
\text { mercado }\end{array}$ & $\begin{array}{l}\text { g) lançamento do } \\
\text { produto }\end{array}$ & & \\
\hline
\end{tabular}


As estruturas de PDP mais recentes (do ano 2000 até 2013) continuam buscando melhorar a gestão e integração do PDP e percebe-se pela visualização da Tabela 4.3 que todas as fases do PDP são utilizadas, complementando as estruturas de PDP desenvolvidas nos períodos anteriores. Segundo Campos e Ribeiro (2011) essas estruturas de PDP abordam outros recortes relacionados ao tema PDP, tais como: aperfeiçoar as práticas de gestão, considerar todo o ciclo de vida do produto, integrar ferramentas de apoio, alinhar a estratégia da organização com o PDP, integrar toda a cadeia de fornecedor e clientes, analisar as implicações da gestão do conhecimento, melhorar o fluxo de informações, utilizar conceito de modularidade, definir responsabilidades e dar suporte para tomada de decisão.

Além disso, nota-se que alguns pesquisadores de mestrado e doutorado (PENSO, 2003; ECHEVESTE, 2003; ROMANO, 2003; PAULA, 2004; BARBALHO, 2006) buscam adaptar estruturas de PDP genéricas em propostas específicas de estruturação do PDP para determinados setores industriais ou para um tipo específico de projeto ou produto.

Nesse mesmo período, aspectos ambientais passaram a serem considerados conceitos importantes para as empresas continuarem competitivas no mercado. Indicativos ambientais mostram que as abordagens anteriores do PDP não atendem aos requisitos estabelecidos de sustentabilidade ambiental para o presente e futuro (BAKSHI; FIKSEL, 2003; LINDAHL et al., 2003). Diante desse cenário, começaram a surgir novas estruturas de PDP (PAHL et al., 2005; ROZENFELD et al., 2006; BACK et al., 2008; BUCCI, 2010; VIEGAS; SALLES, 2012), preocupadas com impacto ambiental dos produtos nas fases finais do processo (end of pipe), tais como: a destinação dos produtos e embalagens no fim de sua vida útil, menos consumo de materiais, o reaproveitamento de materiais por meio de estratégias de remanufatura, reciclagem e reuso.

Com objetivo de inserir aspectos ambientais nas estruturas de PDP a proposta de Tischner e Charter (2001) destaca-se por desenvolver uma estrutura de PDP que utiliza de ferramentas específicas do ecodesign em conjunto com os demais conceitos de desenvolvimento de produtos, de forma associada e equilibrada e interagindo com outras ações das equipes desse processo. Em paralelo, também surgiu à norma ISO/TR 14062 (2002) com objetivo de orientar as empresas na integração de aspectos ambientais no PDP. 
Finalizando a análise das estruturas de PDP mais recentes, fica evidente que a integração de aspectos ambientais ainda não está sendo realizada de forma clara, estruturada e detalhada, conforme as necessidades das empresas e exigências do mercado e sociedade.

De modo geral, na análise de conteúdo das 80 estruturas de PDP encontradas na literatura, podem ser observadas divergências de enfoque devido à área de conhecimento que as propõe, ou seja, nas estruturas de PDP desenvolvidas com a visão de marketing, como por exemplo: kotler (1974), Park e Zaltman (1987), Cooper (1993), Dickson (1997), Crawford e Benedetto (2000) destacam as macrofases de pré-desenvolvimento e pós-desenvolvimento e se aprofundam mais nos aspectos mercadológicos da organização e de suporte ao cliente após o lançamento do produto no mercado. Em contra partida, as estruturas de PDP desenvolvidas pelos pesquisadores oriundos da área de engenharia, tais como: Pahl e Beitz (1977), Clark e Fujimoto (1991), Roozenburg e Eekles (1995) e Kaminski (2000) focam na macrofase de desenvolvimento do PDP e se aprofundam e detalham mais as atividades de projeto e engenharia de produto. Na outra vertente, as estruturas de PDP propostas pela área de design, como dos autores Archer (1971) e Bonsiepe (1978) demonstram uma preocupação em estruturar o PDP para melhor definir o problema de design, no sentido de projeto, e facilitar aos participantes dessa fase a proposição de soluções alternativas de desenvolvimento.

Por fim, resumindo a análise de conteúdo das estruturas de PDP verifica-se que a visão inicial do PDP com foco em atividades sequenciais e maior atenção à macrofase de desenvolvimento adotou a visão do PDP como um processo do negócio, alinhando o PDP ao planejamento estratégico da empresa, integrando todas as áreas internas e externas da empresa e incluindo outras áreas de conhecimento como meio ambiente. Porém, a integração de aspectos ambientais nas estruturas de PDP para orientar na redução do impacto ambiental do produto ainda está em fase de desenvolvimento com poucas estruturas de PDP citando de forma geral a importância dessa integração, mas não deixando claro como proceder para que isso aconteça, ou seja, não citam em que fases do PDP deve se integrar o ecodesign e nem explicam como operacionalizar essa integração. 


\subsection{Seleção de quais fases das estruturas de PDP utilizar para elaboração da proposta de integrar aspectos ambientais no PDP}

Essa seção tem o objetivo de selecionar uma estrutura de PDP para ser utilizada como base para o desenvolvimento da proposta dessa tese. Porém, conforme mostrado na seção anterior (item 4.2) existe muitas estruturas de PDP com abordagens diferentes que resultam na distribuição das fases em momentos distintos no PDP com nível de profundidade e detalhamento de acordo com o tipo de processo e produto desenvolvido. Além disso, as estruturas de PDP identificadas não contemplam aspectos ambientais.

Devido à dificuldade em escolher uma estrutura de PDP como referência, optouse por avaliar quais são as fases mais utilizadas nas 80 estruturas de PDP encontradas na literatura e verificar em quais fases há possibilidade de inserir aspectos ambientais com objetivo de reduzir o impacto ambiental do produto. Esta análise busca justificar a escolha de quais fases serão utilizadas na elaboração da presente proposta, considerando se há possibilidade de inserir aspectos ambientais nessas fases. A Tabela 4.4 mostra as fases do PDP mais utilizadas pelas estruturas de PDP identificadas na literatura e analisadas anteriormente (seção 4.2) e os respectivos autores que as citam. 
Tabela 4.4 - Análise das fases mais utilizadas nas estruturas de PDP.

\begin{tabular}{|c|c|c|c|}
\hline $\begin{array}{l}\text { Fases do Processo de } \\
\text { Desenvolvimento de Produtos (PDP) }\end{array}$ & $\begin{array}{l}\text { Número de } \\
\text { vezes citada }\end{array}$ & $\begin{array}{c}\text { Referências que mencionam } \\
\text { a fase do PDP }\end{array}$ & $\begin{array}{l}\text { Há possibilidade de inserir aspectos } \\
\text { ambientais? }\end{array}$ \\
\hline $\begin{array}{l}\text { Planejamento Estratégico dos } \\
\text { Produtos }\end{array}$ & $\begin{array}{c}69 \\
(86,25 \%)\end{array}$ & $\begin{array}{l}\text { Asimow (1962), Archer (1971), Kotler (1974), Bonsiepe (1978), Booz, Allen \& Hamilton (1982), Saren (1984), Andreasen and Hein } \\
\text { (1987), Park and Zaltman (1987), Suh (1988), Graf and Saguy (1991), Rosenthal (1992), Wheelwright and Clark (1992), Cooper } \\
\text { (1993), Slack et al. (1993), Urban and Hauser (1993), APQP (1994), Fuller (1994), Ingle (1994), Nijssen and Nieshoult (1995), } \\
\text { Rudolph (1995), McGrath (1996), Ertas and Jones (1996), Dickson (1997), Earle (1997), Prasad (1997), BS 7000 (1997), Fleischer } \\
\text { and Liker (1997), Roozenburg and Eekels (1999), Peters et al. (1999), Baxter (2000), Crawford and Benedetto (2000), Kaminski } \\
\text { (2000), Nwabueze and Law (2001), Kalpic and Bernus (2001), Tischner and Charter (2001), Buss and Cunha (2002), ISO/TR 14062 } \\
\text { (2002), Toledo et al. (2002), Buijs (2003), Echeveste (2003), Penso (2003), Gobe et. al. (2004), Paula (2004), Dym and Little (2004), } \\
\text { Alves and Sacchelli (2005), Martins and Laugeni (2005), Pahl et al. (2005), Paula and Cheng (2005), Prasnikar and Skerlj (2005), } \\
\text { Ford and Coulston (2005), Sun and Wing (2005), Thier (2005), Barbalho (2006), Brasil (2006), Crul e Diehl (2006), MacGregor et al } \\
\text { (2006), Rozenfeld et al. (2006), Souza (2007), Thomke and Nimgade (2007), Ulrich and Eppinger (2007), Colenci Neto (2008), } \\
\text { Santos (2008), Freitas (2010), Bucci (2010), Yeh et al. (2010), Campos e Ribeiro (2011), Salgado (2011), Souza Mendes and Toledo } \\
\text { (2011), Bigliardi et al. (2013). }\end{array}$ & $\begin{array}{l}\text { Sim. Análise política, econômica, social, } \\
\text { tecnológica, ambiental e legal. } \\
\end{array}$ \\
\hline Planejamento do Projeto & $\begin{array}{c}25 \\
(31,25 \%)\end{array}$ & $\begin{array}{l}\text { Bonsiepe (1978), Graf and Saguy (1991), Rudolph (1995), McGrath (1996), BS } 7000 \text { (1997), Baxter (2000), Penso (2003), Romano } \\
\text { (2003), Pahl et al. (2005), Thier (2005), Barbalho (2006), Brasil (2006), Crul e Diehl (2006), Rozenfeld et al. (2006), Souza (2007), } \\
\text { Ulrich and Eppinger (2007), Back et al. (2008), Colenci Neto (2008), Santos (2008), Freitas (2010), Bucci (2010), Yeh et al. (2010), } \\
\text { Campos e Ribeiro (2011), Souza Mendes and Toledo (2011), Viegas and Salles (2012). }\end{array}$ & $\begin{array}{l}\text { Sim. Definir as pessoas envolvidas em } \\
\text { cada fase do ciclo de vida do produto. } \\
\text { Elaborar o escopo do produto, no qual } \\
\text { descreve as caracteristicas, } \\
\text { funcionalidades e desempenho ambiental } \\
\text { desejado do produto. }\end{array}$ \\
\hline Projeto Informacional & $\begin{array}{c}36 \\
(45 \%)\end{array}$ & $\begin{array}{l}\text { Archer (1971), Pahl and Beitz (1977), Bonsiepe (1978), Booz, Allen \& Hamilton (1982), Saren (1984), VDI - } 2221 \text { (1985), Andreasen } \\
\text { and Hein (1987), Suh (1988), Graf and Saguy (1991), Wheelwright and Clark (1992), Cooper (1993), Ingle (1994), Rudolph (1995), } \\
\text { McGrath (1996), Earle (1997), Tischner and Charter (2001), Toledo et al. (2002), Penso (2003), Romano (2003), Santos (2004), } \\
\text { Alves and Sacchelli (2005), Martins and Laugeni (2005), Pahl et al. (2005), Sun and Wing (2005), Alvarenga (2006), Barbalho } \\
\text { (2006), Brasil (2006), Crul e Diehl (2006), MacGregor et al (2006), Rozenfeld et al. (2006), Ulrich and Eppinger (2007), Back et al. } \\
\text { (2008), Santos (2008), Freitas (2010), Bucci (2010), Campos e Ribeiro (2011). }\end{array}$ & $\begin{array}{l}\text { Sim. Identificar os requisitos ambientais } \\
\text { dos clientes do produto. } \\
\text { Detalhar ciclo de vida do produto e definir } \\
\text { seus clientes. }\end{array}$ \\
\hline Projeto Conceitual & $\begin{array}{c}78 \\
(97,50 \%)\end{array}$ & $\begin{array}{l}\text { Asimow (1962), Archer (1971), Kotler (1974), Pahl and Beitz (1977), Bonsiepe (1978), Booz, Allen \& Hamilton (1982), Saren (1984), } \\
\text { VDI - } 2221 \text { (1985), Andreasen and Hein (1987), Park and Zaltman (1987), Suh (1988), Clark and Fujimoto (1991), Graf and Saguy } \\
\text { (1991), Rosenthal (1992), Wheelwright and Clark (1992), Cooper (1993), Slack et al. (1993), Urban and Hauser (1993), APQP } \\
\text { (1994), Fuller (1994), Ingle (1994), MacFie (1994), Nijsen and Nieshoult (1995), Rudolph (1995), McGrath (1996), Ertas and Jones } \\
\text { (1996), Dickson (1997), Earle (1997), Prasad (1997), BS 7000 (1997), Fleischer and Liker (1997), Roozenburg and Eekels (1999), } \\
\text { Peters et al. (1999), Baxter (2000), Crawford and Benedetto (2000), Kaminski (2000), Nwabueze and Law (2001), Kalpic and Bernus } \\
\text { (2001), Tischner and Charter (2001), Buss and Cunha (2002), ISO/TR 14062 (2002), Toledo et al. (2002), Unger (2003), Buijs } \\
\text { (2003), Echeveste (2003), Penso (2003), Romano (2003), Gobe et. al. (2004), Paula (2004), Santos (2004), Dym and Little (2004),, } \\
\text { Alves and Sacchelli (2005), Martins and Laugeni (2005), Pahl et al. (2005), Prasnikar and Skerlj (2005), Ford and Coulston (2005), } \\
\text { Sun and Wing (2005), Thier (2005), Alvarenga (2006), Barbalho (2006), Brasil (2006), Crul e Diehl (2006), MacGregor et al (2006), } \\
\text { Rozenfeld et al. (2006), Souza (2007), Thomke and Nimgade (2007), Ulrich and Eppinger (2007), Back et al. (2008), Colenci Neto } \\
\text { (2008), Nascimento (2008), Santos (2008), Freitas (2010), Bucci (2010), Yeh et al. (2010), Campos e Ribeiro (2011), Salgado } \\
\text { (2011), Viegas and Salles (2012), Bigliardi et al. (2013). }\end{array}$ & $\begin{array}{l}\text { Sim. Desenvolver soluções ambientais } \\
\text { alternativas para concepção do produto } \\
\text { em termos de sistemas, sub-sistemas e } \\
\text { componentes. } \\
\end{array}$ \\
\hline
\end{tabular}


Tabela 4.4 - Análise das fases mais utilizadas nas estruturas de PDP - continuação.

\begin{tabular}{|c|c|c|c|}
\hline $\begin{array}{l}\text { Fases do Processo de } \\
\text { Desenvolvimento de Produtos (PDP) }\end{array}$ & $\begin{array}{l}\text { Número de } \\
\text { vezes citada }\end{array}$ & $\begin{array}{c}\text { Referências que mencionam } \\
\text { a fase do PDP }\end{array}$ & $\begin{array}{l}\text { Há possibilidade de inserir aspectos } \\
\text { ambientais? }\end{array}$ \\
\hline Projeto Detalhado & $\begin{array}{c}79 \\
(98,75 \%)\end{array}$ & 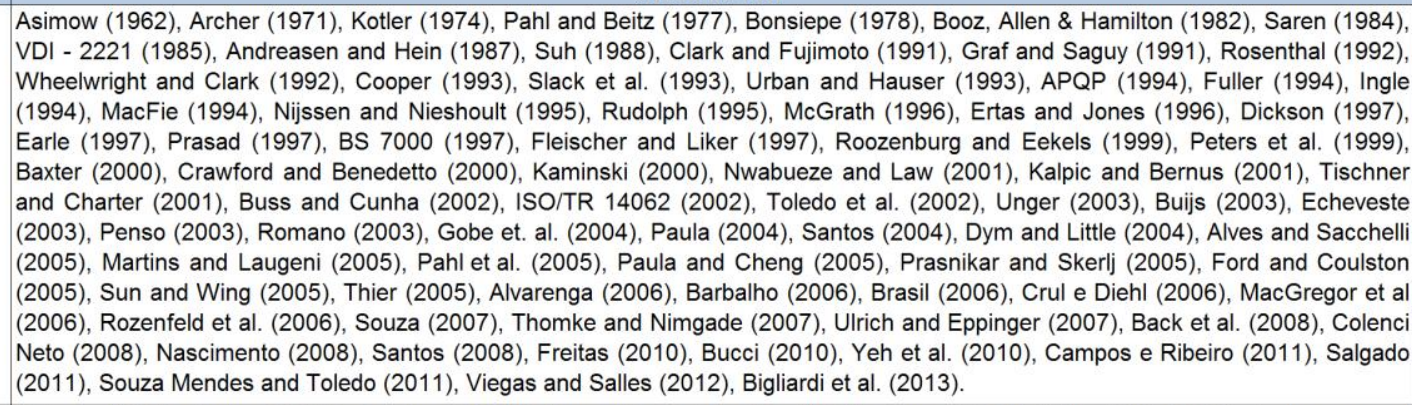 & $\begin{array}{l}\text { Sim. Definir especificações finais do } \\
\text { produto, integrando e avaliando os } \\
\text { componentes e processo de fabricação. } \\
\text { Além disso, deve-se considerar o plano } \\
\text { de fim de vida do produto como } \\
\text { montagem, desmontagem, embalagem, } \\
\text { reciclagem, reuso e disposição. }\end{array}$ \\
\hline $\begin{array}{l}\text { Preparação da Produção do } \\
\text { Produto }\end{array}$ & $\begin{array}{c}65 \\
(81,25 \%)\end{array}$ & $\begin{array}{l}\text { Asimow (1962), Archer (1971), Bonsiepe (1978), Booz, Allen \& Hamilton (1982), Saren (1984), VDI - 2221 (1985), Andreasen and } \\
\text { Hein (1987), Suh (1988), Clark and Fujimoto (1991), Graf and Saguy (1991), Rosenthal (1992), Wheelwright and Clark (1992), } \\
\text { Cooper (1993), APQP (1994), Fuller (1994), MacFie (1994), Rudolph (1995), McGrath (1996), Ertas and Jones (1996), Earle (1997), } \\
\text { Prasad (1997), BS 7000 (1997), Fleischer and Liker (1997), Roozenburg and Eekels (1999), Peters et al. (1999), Baxter (2000), } \\
\text { Crawford and Benedetto (2000), Kaminski (2000), Kalpic and Bernus (2001), Tischner and Charter (2001), Buss and Cunha (2002), } \\
\text { ISO/TR 14062 (2002), Toledo et al. (2002), Unger (2003), Buijs (2003), Echeveste (2003), Penso (2003), Romano (2003), Paula } \\
\text { (2004), Santos (2004), Dym and Little (2004), Alves and Sacchelli (2005), Martins and Laugeni (2005), Pahl et al. (2005), Paula and } \\
\text { Cheng (2005), Ford and Coulston (2005), Sun and Wing (2005), Thier (2005), Barbalho (2006), Brasil (2006), MacGregor et al } \\
\text { (2006), Rozenfeld et al. (2006), Thomke and Nimgade (2007), Ulrich and Eppinger (2007), Back et al. (2008), Colenci Neto (2008), } \\
\text { Nascimento (2008), Santos (2008), Freitas (2010), Bucci (2010), Yeh et al. (2010), Campos e Ribeiro (2011), Salgado (2011), } \\
\text { Viegas and Salles (2012), Bigliardi et al. (2013). }\end{array}$ & $\begin{array}{l}\text { Sim. Testar e definir os parametros } \\
\text { ambientais de controle de produto e } \\
\text { processo e homologar o processo. } \\
\text { Avaliar o processo de produção, logistica } \\
\text { com fornecedores e processo de } \\
\text { manutenção. }\end{array}$ \\
\hline Lançamento do Produto & $\begin{array}{c}53 \\
(66,25 \%)\end{array}$ & $\begin{array}{l}\text { Archer (1971), Kotler (1974), Booz, Allen \& Hamilton (1982), Saren (1984), Andreasen and Hein (1987), Park and Zaltman (1987), } \\
\text { Graf and Saguy (1991), Wheelwright and Clark (1992), Cooper (1993), Urban and Hauser (1993), APQP (1994), Fuller (1994), } \\
\text { MacFie (1994), Nijssen and Nieshoult (1995), Rudolph (1995), McGrath (1996), Dickson (1997), Earle (1997), BS 7000 (1997), } \\
\text { Fleischer and Liker (1997), Roozenburg and Eekels (1999), Peters et al. (1999), Crawford and Benedetto (2000), Kaminski (2000), } \\
\text { Nwabueze and Law (2001), Kalpic and Bernus (2001), Tischner and Charter (2001), Buss and Cunha (2002), ISO/TR } 14062 \text { (2002), } \\
\text { Unger (2003), Buijs (2003), Echeveste (2003), Penso (2003), Romano (2003), Gobe et. al. (2004), Paula (2004), Alves and Sacchelli } \\
\text { (2005), Martins and Laugeni (2005), Prasnikar and Skerlj (2005), Sun and Wing (2005), Thier (2005), Barbalho (2006), Brasil } \\
\text { (2006), MacGregor et al (2006), Rozenfeld et al. (2006), Thomke and Nimgade (2007), Back et al. (2008), Santos (2008), Freitas } \\
\text { (2010), Bucci (2010), Campos e Ribeiro (2011), Salgado (2011), Bigliardi et al. (2013). }\end{array}$ & $\begin{array}{l}\text { Sim.Iniciar a produção para } \\
\text { comercialização, documentar o } \\
\text { lançamento e atualizar o plano de fim de } \\
\text { vida do produto. Também, definir as } \\
\text { vendas, distribuição, suporte ao cliente e } \\
\text { as campanhas de marketing. }\end{array}$ \\
\hline Acompanhar Produto e Processo & $\begin{array}{c}28 \\
(35 \%)\end{array}$ & $\begin{array}{l}\text { Graf and Saguy (1991), Urban and Hauser (1993), Rudolph (1995), Earle (1997), Prasad (1997), Peters et al. (1999), Nwabueze and } \\
\text { Law (2001), ISO/TR } 14062 \text { (2002), Toledo et al. (2002), Penso (2003), Romano (2003), Gobe et. al. (2004), Paula (2004), Martins } \\
\text { and Laugeni (2005), Ford and Coulston (2005), Sun and Wing (2005), Thier (2005), Barbalho (2006), Brasil (2006), Crul e Diehl } \\
\text { (2006), Rozenfeld et al. (2006), Back et al. (2008), Colenci Neto (2008), Santos (2008), Freitas (2010), Bucci (2010), Campos e } \\
\text { Ribeiro (2011), Salgado (2011). }\end{array}$ & $\begin{array}{l}\text { Sim. } \\
\text { Oportunidades de melhorias para } \\
\text { adequação ambiental do produto e } \\
\text { serviços e registrar lições aprendidas. }\end{array}$ \\
\hline Descontinuar o Produto no Mercado & $\begin{array}{c}13 \\
(16,25 \%)\end{array}$ & $\begin{array}{l}\text { BS } 7000 \text { (1997), Nwabueze and Law (2001), Toledo et al. (2002), Penso (2003), Paula (2004), Thier (2005), Rozenfeld et al. (2006), } \\
\text { Colenci Neto (2008), Santos (2008), Freitas (2010), Bucci (2010), Campos e Ribeiro (2011), Salgado (2011). }\end{array}$ & $\begin{array}{l}\text { Sim. Receber o produto de volta, utilizar } \\
\text { os coneitos de reciclagem, ramanufatura } \\
\text { reutilizar e descartar. }\end{array}$ \\
\hline
\end{tabular}


Analisando a Tabela 4.4 com um total de 80 estruturas de PDP obtidas na literatura e distribuídas por fases utilizadas, verifica-se que na macrofase de PréDesenvolvimento do PDP a fase de Planejamento do Projeto é menos utilizada $(31,25 \%)$ e que a maioria dos autores dessas estruturas de PDP dá maior importância ao alinhamento da fase de Planejamento Estratégico do Produto, que relaciona 0 portfólio de produtos existentes com a identificação de novas oportunidades de produto para montar a carteira de projetos a serem desenvolvidos.

$\mathrm{Na}$ macrofase de Desenvolvimento do PDP a fase de Projeto Informacional também é a menos explorada (45\%) em relação às demais fases dessa macrofase do PDP, que abordam as atividades de concepção do produto, definição das especificações do produto, elaboração do protótipo, homologação do processo e produto, produção piloto até o lançamento do produto no mercado. Visualiza-se pela análise que a macrofase de Pós-Desenvolvimento do PDP é a menos citada nas estruturas de PDP, ou seja, as fases de Acompanhar Produto e Processo (35\%) e Descontinuar o Produto no Mercado (16,25\%) têm as menores quantidades de citações em relação às demais fases do PDP. Isso pode ser explicado devido às estruturas clássicas não abordarem os conceitos de estratégias de remanufatura, reciclagem, coleta e descarte de produto, ou seja, elas ainda não têm uma visão de todas as fases do ciclo de vida do produto que é relevante para minimizar o impacto ambiental do produto.

Apesar de alguns autores (PAHL et al., 2005; ROZENFELD et al., 2006) citarem que em todas as fases do PDP há possibilidade de se minimizar os impactos ambientais, a maioria destaca que é importante integrar os aspectos ambientais nas fases iniciais do PDP (SHERWIN; BHAMRA, 1999; LOFTHOUSE; BHAMRA, 2001; JOHANSSON, 2002; BAUMANN et al., 2002; BOKS, 2006; ROZENFELD et al., 2006; TELENKO, 2009; DEVANATHAN et al., 2010; KENGPOL; BOONKANIT, 2011). Neste sentido, Rebitzer et al. (2004) enfatizam que quanto mais tarde forem tomadas as decisões de projeto durante o PDP há menos oportunidades para redução do impacto ambiental do produto durante todo o seu ciclo de vida.

Alguns trabalhos acadêmicos têm sido desenvolvidos sobre esse tema, de integrar aspectos ambientais no PDP, como Pigosso (2008) e Guelere Filho (2009) que inseriram métodos e ferramentas de ecodesign nas fases iniciais da estrutura de PDP de Rozenfeld et al. (2006). Nesses trabalhos os autores citados consideraram desde a fase de planejamento estratégico de produto até a fase de projeto detalhado 
do PDP e enfatizam que a maioria dos métodos e ferramentas de ecodesign considera todas as fases do ciclo de vida do produto.

Para contribuir com a utilização de práticas de ecodesign no PDP, Pigosso, Rozenfeld e McAloone (2013) propuseram um modelo de avaliação da maturidade ambiental do PDP que visa auxiliar as empresas na gestão dessa integração e inserir práticas gerenciais de ecodesign no PDP. Naquele trabalho esses autores utilizam como referência as fases do PDP desde o planejamento estratégico do produto até a fase de acompanhamento e monitoramento do produto. Nesta mesma linha de pesquisa, Platcheck et al. (2008) buscam melhorar a sustentabilidade dos produtos desenvolvidos para o setor industrial de eletro-eletrônicos inserindo variáveis de ecodesign nas fases iniciais de concepção do produto e de desenvolvimento no PDP. Para analisar o projeto de produtos sustentáveis Viegas e Salles (2012) utilizaram a estrutura de PDP desenvolvida por Ulrich e Eppinger (2007) como base de referência para proposição da estrutura de PDP e introduzem atribuições sustentáveis desde as fases iniciais do PDP até a fase de preparação da produção na macrofase de desenvolvimento.

Pela análise da literatura constata-se que, apesar da preocupação com aspectos ambientais ter surgido na década de 70, ainda não é explicito nem detalhado nas estruturas de PDP em quais fases e quais são as práticas para amenizar os impactos ambientais, ou seja, esse tema permanece em fase embrionária de desenvolvimento. Além disso, percebe-se que a maioria das estruturas de PDP não considera a inserção de aspectos ambientais no PDP, isso reflete na baixa utilização das macrofases de Pré-Desenvolvimento e Pós-Desenvolvimento do PDP nas 80 estruturas analisadas. É interessante salientar, que nas fases iniciais do PDP são tomadas decisões importantes para melhoria ambiental do produto em termos de definição de especificação e escolha de alternativas de conceito de produto e projeto. Na macrofase de Pós-Desenvolvimento é que se obtêm informações do produto para melhoria do projeto e fazer as adequações para reduzir o impacto ambiental do produto durante todas as fases do ciclo de vida do produto.

Para alinhar ao objetivo geral da proposta deste trabalho é importante abordar todas as macrofases e fases do PDP e ainda considere os impactos ambientais de todas as fases físicas do ciclo de vida do produto, conforme mostra a Figura 4.2. 


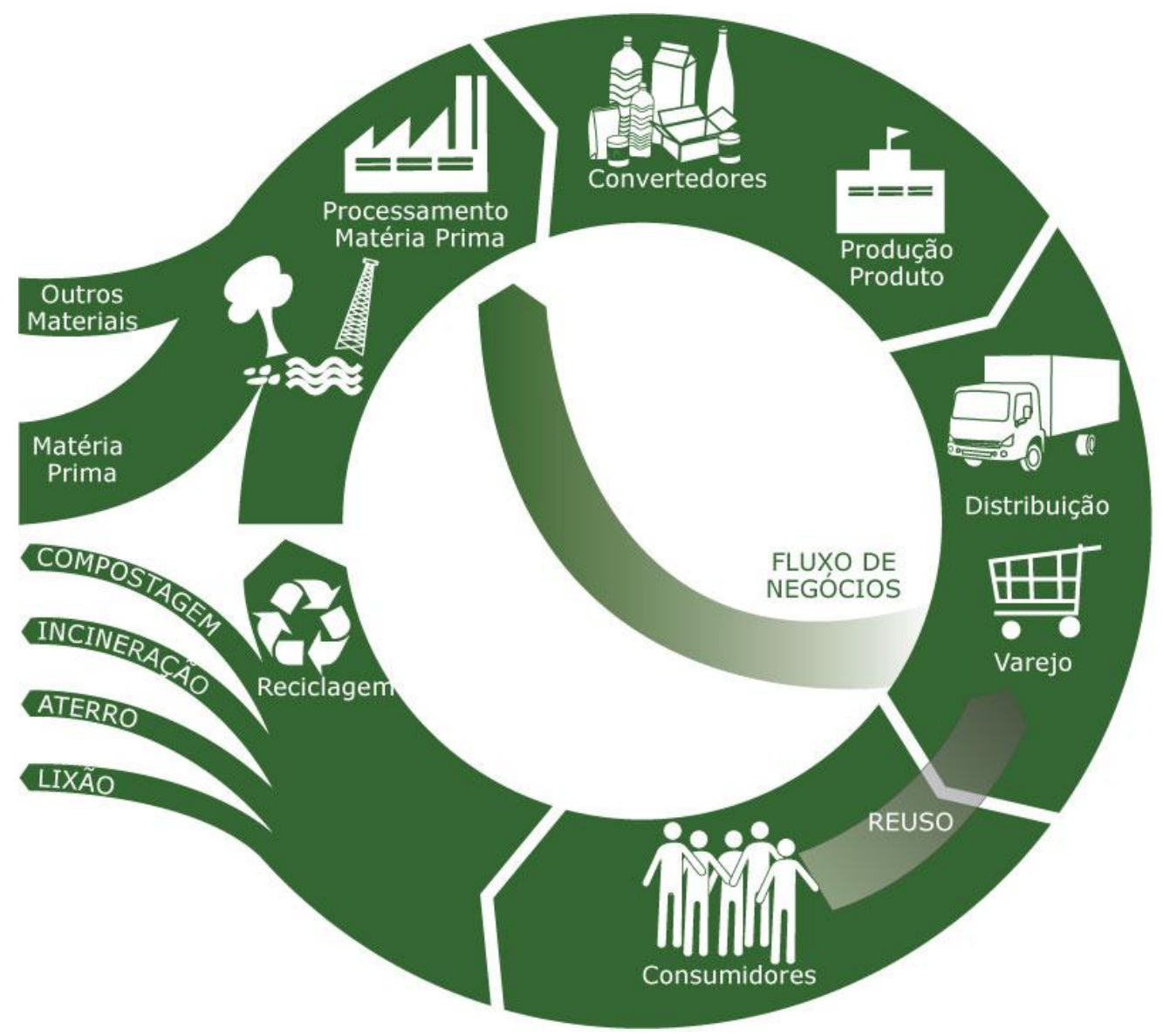

Figura 4.2 - Fases físicas do ciclo de vida do produto.

O PDP exerce influência e é influenciado em todas as fases do ciclo de vida do produto, desde a extração de matéria-prima, concepção ao descarte e retirada do produto do mercado. Logo, o PDP deve definir e delimitar o ciclo de vida do produto e selecionar os métodos e ferramentas para auxiliar na sua gestão. Durante esse processo, diversas áreas geram informações que são envolvidas em diferentes momentos do PDP, como a área de marketing que foca na macrofase de uso e serviços na macrofase de pós-desenvolvimento do PDP. A área de engenharia que foca na fase de desenvolvimento e visa analisar requisitos críticos de projeto que possam impactar ao longo do ciclo de vida do produto. A área de gestão ambiental se preocupa em medir o impacto ambiental dos produtos após seu desenvolvimento, ou seja, durante as fases de produção até o descarte utilizando de ferramentas para avaliar esse impacto como o LCA. Nessa linha de avaliação dos impactos ambientais, a área de custos trata em analisar o custo total do projeto durante as macrofases de produção, uso e serviços e descarte do produto para auxiliar os 
projetistas nas decisões de engenharia. A área de gestão de dados procura estruturar as informações do produto geradas durante todo esse processo utilizando a abordam de PLM.

Portanto, devido à relação entre as fases do PDP com as fases físicas do ciclo de vida do produto para reduzir o impacto ambiental é importante na elaboração dessa proposta considerar todas as fases do PDP, pois os aspectos ambientais extraídos dos métodos e ferramentas de ecodesign mapeados no Capítulo 5 (item 5.3) têm ações para auxiliar na tomada de decisão em todas as fases do PDP com objetivo de reduzir o impacto ambiental durante todo o ciclo de vida do produto.

\subsection{Considerações finais do capítulo}

Este capítulo tem um papel importante no desenvolvimento da proposta desta tese, pois nessa etapa define-se qual estrutura de PDP é mais adequada para ser utilizada como referência para inserir os aspectos ambientais extraídos dos métodos e ferramentas de ecodesign. Porém, devido à grande variedade e dificuldade em escolher uma única estrutura de PDP, optou-se por avaliar quais são as fases mais utilizadas nas 80 estruturas de PDP mapeadas na literatura e verificar em quais fases há possibilidade de inserir aspectos ambientais com objetivo de reduzir o impacto ambiental do produto.

Diante disso, como uma das contribuições dessa tese, desenvolveu-se uma análise por fase das estruturas de PDP que serviu para melhor compreender e comparar as estruturas de PDP disponíveis na literatura. Também, foi possível verificar que poucas estruturas de PDP integram aspectos ambientais ou citam superficialmente estratégias de ecodesign para reduzir o impacto ambiental dos produtos durante o ciclo de vida, como reduzir o consumo de materiais e embalagens, utilizar práticas de reutilização, remanufatura e reciclagem.

$\mathrm{Na}$ análise das fases mais utilizadas pelas 80 estruturas de PDP percebe-se que as fases menos citadas são: Planejamento do Projeto, Projeto Informacional, Acompanhar Produto e Processo e Descontinuar o Produto no Mercado. Confirmando a pouca utilização de estratégias de fim de vida do produto e embalagem, que é relevante para reduzir o impacto ambiental do produto. Além disso, na análise de quais fases é possível integrar aspectos ambientais foi 
constatada a importância de considerar todas as fases do PDP, devido aos aspectos ambientais das ferramentas de ecodesign serem distribuídos por todo o PDP.

Portanto, apesar da preocupação com aspectos ambientais ter surgido há bastante tempo, ainda é um tema em desenvolvimento inicial pelos pesquisadores da área de desenvolvimento de novos produtos. Isso pode ser checado nas estruturas de PDP analisadas da literatura, que não utilizam de forma sistematizada e detalhada a integração de práticas para amenizar os impactos ambientais. Logo, essa é uma das principais justificativas para elaboração desse trabalho, que tem o objetivo de propor uma estrutura de PDP integrando aspectos ambientais em todas as fases do PDP, visando contribuir com o avanço do conhecimento sobre esse tema. 


\section{IDENTIFICAÇÃO E SELEÇÃO DOS ASPECTOS AMBIENTAIS DOS MÉTODOS E FERRAMENTAS DE ECODESIGN}

Este capítulo apresenta um complemento da revisão da literatura e mostra o recorte da pesquisa, dando uma visão dos conceitos mais abrangentes como o desenvolvimento de produtos sustentáveis e afunilando na análise do conceito de ecodesign, o qual é abordado em detalhes por ser foco dessa tese junto com o PDP, conforme ilustrado na Figura 5.1. Na análise do ecodesign são apresentadas as principais definições, diferentes pontos de vista, os principais métodos e ferramentas de ecodesign, a dificuldade de integrá-los ao PDP e uma proposta alternativa para inserir aspectos ambientais no PDP.

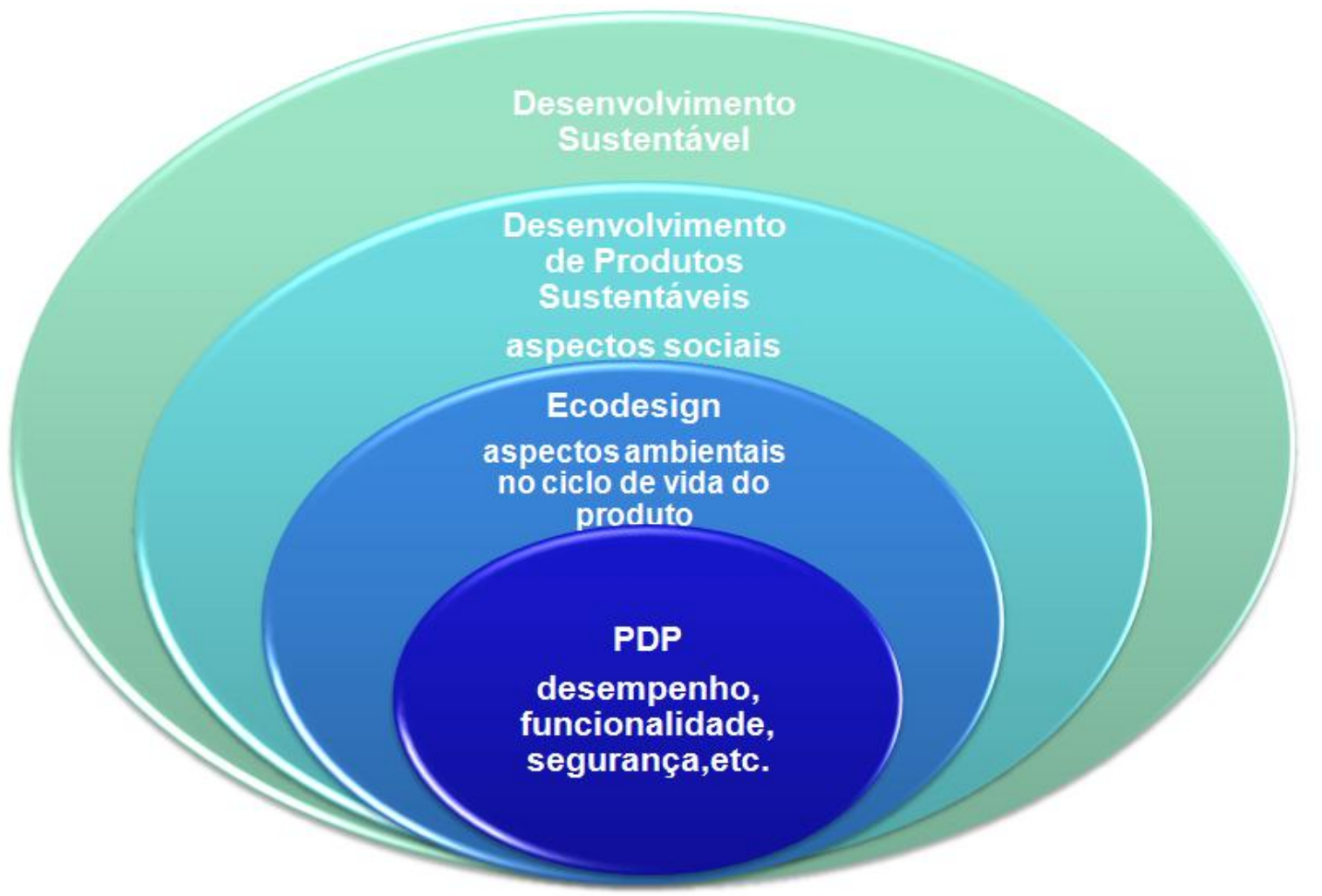

Figura 5.1 - Abrangência e fronteiras dos conceitos utilizados nessa pesquisa.

$\mathrm{Na}$ Figura 5.1, verifica-se a abrangência e fronteiras dos conceitos e que 0 ecodesign acrescenta ao PDP aspectos ambientais relacionados ao ciclo de vida do produto. O desenvolvimento de produtos sustentável é mais amplo que o conceito de ecodesign, pois acrescenta ao PDP os aspectos sociais, além dos econômicos e ambientais (TISCHNER; CHARTER, 2001). O desenvolvimento sustentável é o 
desenvolvimento de produtos sustentáveis quando se considera o sistema de produção e consumo, esses dois termos são tratados nesse trabalho como sinônimos. As próximas seções discutem cada conceito e suas particularidades para o embasamento teórico da tese.

\subsection{Panorama do Desenvolvimento de Produtos Sustentáveis}

As primeiras preocupações ambientais começaram por volta dos anos 60 com base na redução dos recursos naturais, da capacidade de recuperação dos ecossistemas e do aumento da geração de resíduos. Na década de 70, o foco se voltou para a necessidade de tratamento de resíduos nas indústrias devido ao surgimento de contaminações acidentais ao meio ambiente. Nesse período, segundo Johansson (2002) a abordagem utilizada era de fim-de-tubo que cumpria a legislação ambiental através de tratamento e disposição dos dejetos industriais. Em seguida, passou a utilizar outros conceitos como de tecnologias limpas, reprojeto, design para reciclabilidade, manufaturabilidade, durabilidade e desmaterialização de produtos (DIEHL; BREZET, 2004; MANZINI; VEZZOLI, 2005; KURK; EAGAN, 2008).

Nos anos 80 , surgiu o conceito de desenvolvimento sustentável, que evoluiu para o conceito de Triple Bottom Line. Para Fiksel (2001) os princípios desse tripé significam: prosperidade econômica e continuidade dos negócios e dos stakeholders; bem estar social e igualdade para empregados e comunidade; e proteção ambiental e conservação de recursos a nível local e global. A Figura 5.2 mostra a evolução da preocupação ambiental pelas indústrias.

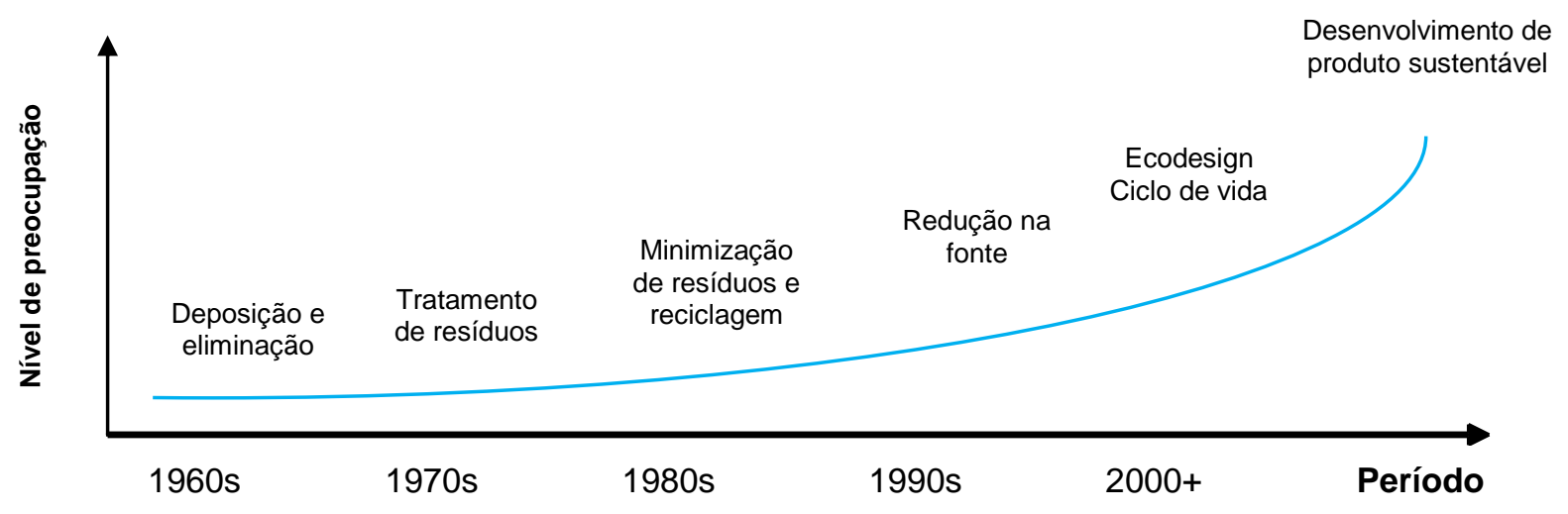

Figura 5.2 - Evolução da preocupação ambiental na perspectiva das indústrias. 
Desde então, vem crescendo as exigências de sustentabilidade ambiental pela sociedade, mercado e legislação, forçando os acadêmicos a revisitarem esse assunto e as organizações a buscarem formas de reduzir os impactos ambientais no PDP (MAXWELL; VORST, 2003). Segundo Bakshi e Fiksel (2003) para responder a essas exigências é preciso repensar os produtos e processos, considerando as interferências que os materiais geram ao meio ambiente durante todo o ciclo de vida do produto. Além disso, deve-se atender às demandas do presente elevando a produtividade no uso de recursos para não comprometer as necessidades das futuras gerações (WCED, 1988; SELIGER et al., 2006).

Tischner e Charter (2001) citam que algumas empresas já estão avaliando questões de sustentabilidade ambiental no negócio, como: quais os regulamentos a serem seguidos; quais materiais utilizam menos recursos e não prejudicam o meio ambiente; se aplicam técnicas de produção limpa; e se há compromisso ambiental na cadeia de suprimentos. Guimarães (2006) e Santos (2009) acrescentam outras questões importantes relativas ao impacto ambiental no PDP, como por exemplo: fluxo e nível de volume de produção e consumo; projeto de sistemas produto e serviço, ciclo de vida do produto; embalagens e logística.

Os produtos sustentáveis podem ser definidos como soluções que atendem às necessidades e demandas sociais, minimizando impactos negativos e maximizando impactos positivos nas dimensões ambiental, econômica e social ao longo do seu ciclo de vida (WEENEN, 1995; LUTTROPP; KARLSON, 2001; DIEHL; BREZET, 2004). A abordagem do ciclo de vida constitui-se como uma premissa para que um produto seja considerado sustentável, uma vez que a dimensão ambiental só pode ser alcançada com a redução significativa dos impactos causados pela extração, transformação, utilização e reutilização dos materiais. A abordagem proposta por McDonough e Braungart (2002) conhecida como cradle to cradle (do berço ao túmulo) define que os produtos são concebidos para assumir outra forma ou função após o descarte, ou seja, os processos e produtos não biodegradáveis são caracterizados por ciclos artificiais que não causam prejuízos ao meio ambiente. Os autores Manzini e Vezzoli (2005) apresentam estratégias de projeto para o PDP sustentável propondo a utilização de ferramentas como LCA, DfE, e utilização de softwares para seleção de materiais de baixo impacto.

Finalizando, esta seção buscou dar uma visão macro da evolução das preocupações ambientais referentes ao conceito de desenvolvimento de produtos 
sustentáveis. A seguir, é realizada uma discussão sobre o conceito ecodesign pontuando as definições, as exigências e dificuldades de se integrar ao PDP.

\subsection{Caracterização do Ecodesign}

O ecodesign surgiu na década de 90, quando empresas do setor de eletrônica nos Estados Unidos começaram a se preocupar com o impacto ambiental no PDP e resolveram organizar-se otimizando os recursos disponíveis com foco em reduzir o impacto ambiental e compartilhar os benefícios entre os envolvidos no processo, inclusive o cliente final (WIMMER, 2002). Desde então, vem aumentando as exigências para que as empresas utilizem o conceito de ecodesign no PDP, como: a pressão externa e requisitos legais; os interesses econômicos; a percepção e valorização do consumidor; e a disponibilidade de novas tecnologias (BOKS, 2006).

$\mathrm{Na}$ literatura, podem ser encontradas diversas nomenclaturas para o conceito de ecodesign, que geram confusão de entendimento (BAUMANN et al., 2002; BHAMRA, 2004; FIKSEL, 2011; SHORT et al., 2012; GOEPP et al., 2014): Ecodesign, Design for Environment (DfE), Environmentally Conscious Design (ECD), Green Engineering (GE), Green Product (GP), Sustainable Design (SD), Design for Sustainability (DfS), Sustainable Product Development (SPD), Life Cycle Design (LCD), Environmental Product Development (EPD), entre outros termos. Além disso, apesar do mesmo significado da terminologia ecodesign e DfE, existe uma diferença no uso, ou seja, o termo ecodesign é mais utilizado na Europa e o termo DfE é mais aplicado nos Estados Unidos da América (KURK; EAGAN, 2008; BRONES et al., 2013). Embora o conceito de ecodesign seja amplamente aceito pelo mundo acadêmico, ha várias definições, conforme listado na Tabela 5.1.

Tabela 5.1 - Definições do conceito de ecodesign selecionados da literatura.

\begin{tabular}{|c|c|}
\hline Autor & Definição de ecodesign \\
\hline $\begin{array}{l}\text { Graedel e } \\
\text { Allenby (1995) }\end{array}$ & $\begin{array}{l}\text { É uma prática que integra aspectos ambientais no PDP e aos procedimentos de } \\
\text { projeto de engenharia e processo, sem alterar outras características como preço, } \\
\text { performance e padrões de qualidade. }\end{array}$ \\
\hline $\begin{array}{l}\text { Brezet e Van } \\
\text { Hemel (1997) }\end{array}$ & $\begin{array}{l}\text { O ecodesign integra aspectos ambientais em todos os estágios do PDP, com } \\
\text { objetivo de controlar o impacto ambiental do produto durante todo o seu ciclo de } \\
\text { vida, considerando as etapas de produção, uso e fim de vida. }\end{array}$ \\
\hline $\begin{array}{ll}\text { Van } & \text { Hemel } \\
(1998) & \end{array}$ & $\begin{array}{l}\text { E a luta sistemática e consistente para melhorar o perfil ambiental dos produtos em } \\
\text { todos os estágios do ciclo de vida, incluindo a reciclagem e o desmantelamento. }\end{array}$ \\
\hline
\end{tabular}


Tabela 5.1 - Definições do conceito de ecodesign selecionados da literatura -

continuação.

\begin{tabular}{|c|c|}
\hline Autor & Definição de ecodesign \\
\hline $\begin{array}{l}\text { Tischner et al. } \\
\text { (2000) }\end{array}$ & $\begin{array}{l}\text { O ecodesign significa ter consciência no PDP, incluindo aspectos ambientais no } \\
\text { planejamento do produto, processo de projeto e desenvolvimento, como um dos } \\
\text { critérios: funcionalidade, lucratividade, segurança, confiança, ergonomia e estética. }\end{array}$ \\
\hline $\begin{array}{l}\text { Sherwin } \\
\text { Ewans (2000) }\end{array}$ & $\begin{array}{l}\text { O ecodesign é o projeto de produto, serviço ou sistema com o objetivo de } \\
\text { minimizar todo tipo de impacto ambiental. }\end{array}$ \\
\hline $\begin{array}{l}\text { Lewis et al. } \\
(2001)\end{array}$ & $\begin{array}{l}\text { É uma solução técnica e criativa que determina como um produto interage com o } \\
\text { ambiente e os seus utilizadores. Ele implica na necessidade de encontrar o } \\
\text { equilíbrio entre as exigências ecológicas e econômicas, relativas ao PDP. }\end{array}$ \\
\hline $\begin{array}{l}\text { Johansson } \\
(2002)\end{array}$ & $\begin{array}{l}\text { O ecodesign se refere às ações no PDP para minimizar o impacto ambiental do } \\
\text { produto durante todo o ciclo de vida, sem comprometer outros critérios essenciais } \\
\text { como performance e custo. }\end{array}$ \\
\hline Bhamra (2004) & $\begin{array}{l}\text { O ecodesign é uma sistemática integração de aspectos ambientais no projeto de } \\
\text { processo com foco no ciclo de vida do produto, desde o berço ao túmulo. }\end{array}$ \\
\hline $\begin{array}{l}\text { Wimmer et al. } \\
\text { (2004) }\end{array}$ & É integrar aspectos ambientais no projeto e desenvolvimento de produtos. \\
\hline $\begin{array}{l}\text { Sakao et al. } \\
(2005)\end{array}$ & $\begin{array}{l}\text { O ecodesign incorpora aspectos ambientais no PDP como o aquecimento global, } \\
\text { consumo de recursos e uso de substâncias perigosas, pensando no ciclo de vida. }\end{array}$ \\
\hline $\begin{array}{l}\text { Schischke } \\
(2005)\end{array}$ & $\begin{array}{l}\text { O ecodesign é a redução dos impactos ambientais de todo o ciclo de vida por meio } \\
\text { da melhoria da concepção dos produtos. }\end{array}$ \\
\hline $\begin{array}{l}\text { Alonso Garcia } \\
(2006)\end{array}$ & $\begin{array}{l}\text { O ecodesign integra critérios ambientais no projeto de produtos e serviços com } \\
\text { intuito de reduzir o impacto ambiental na produção e no ciclo de vida do produto. }\end{array}$ \\
\hline $\begin{array}{l}\text { Karlsson e } \\
\text { Luttropp (2006) }\end{array}$ & $\begin{array}{l}\text { O ecodesign é um método de PDP que objetiva a redução do impacto ambiental e } \\
\text { usa a criatividade para gerar produtos e processos mais eficientes sob o ponto de } \\
\text { vista da sustentabilidade. }\end{array}$ \\
\hline $\begin{array}{l}\text { Borchardt et al. } \\
\text { (2008) }\end{array}$ & $\begin{array}{l}\text { O ecodesign é uma alternativa de projeto que propõe que as análises dos } \\
\text { aspectos econômicos e ecológicos caminhem juntas no projeto de produtos. }\end{array}$ \\
\hline $\begin{array}{l}\text { Park e Tahara } \\
\text { (2008) }\end{array}$ & $\begin{array}{l}\text { O ecodesign é uma atividade que identifica os aspectos ambientais de um produto } \\
\text { e integre-os no processo de projeto numa fase inicial do seu desenvolvimento. }\end{array}$ \\
\hline $\begin{array}{l}\text { Telenko et al. } \\
(2008)\end{array}$ & $\begin{array}{l}\text { O ecodesign é um campo da metodologia de projeto do produto que inclui } \\
\text { métodos, ferramentas e princípios que ajudam o projetista a reduzir o impacto } \\
\text { ambiental. }\end{array}$ \\
\hline $\begin{array}{l}\text { Platcheck et al. } \\
\text { (2008) }\end{array}$ & $\begin{array}{l}\text { O ecodesign é uma visão holística que começa no momento que se conhecem os } \\
\text { problemas ambientais e suas causas, e influência no conceito e seleção de } \\
\text { materiais, produção, uso, reuso, reciclagem e disposição final de produtos. }\end{array}$ \\
\hline $\begin{array}{l}\text { Fuad-Luke } \\
(2009)\end{array}$ & $\begin{array}{l}\text { E um processo de design que considera os impactos ambientais associados a um } \\
\text { produto ao longo de toda a sua vida, desde a aquisição de matérias-primas até a } \\
\text { produção, fabricação e uso de fim da vida. Ao mesmo tempo em que reduz os } \\
\text { impactos ambientais, o ecodesign visa melhorar os aspectos estéticos e funcionais } \\
\text { do produto com a devida consideração às necessidades sociais e éticas. }\end{array}$ \\
\hline $\begin{array}{l}\text { Pigosso et al. } \\
\text { (2010) }\end{array}$ & $\begin{array}{l}\text { O ecodesign visa desenvolver produtos ecoeficientes e implica na introdução } \\
\text { sistemática de requisitos ambientais às fases iniciais do PDP sem comprometer, } \\
\text { no entanto, critérios clássicos tido como fatores de sucesso comercial dos } \\
\text { produtos: preço, tempo de desenvolvimento, qualidade, custo, segurança e } \\
\text { estética. }\end{array}$ \\
\hline $\begin{array}{l}\text { Plouffe et al. } \\
\text { (2011) }\end{array}$ & $\begin{array}{l}\text { Levar em consideração o impacto ambiental desde a fase de seleção de matérias- } \\
\text { primas, processo de produção, estoque, transporte, uso e disposição final. }\end{array}$ \\
\hline Ihobe (2011) & $\begin{array}{l}\text { O ambiente é levado em conta nas decisões durante o PDP como um fator } \\
\text { adicional e importante. }\end{array}$ \\
\hline
\end{tabular}

Existem várias definições similares de ecodesign na literatura para os trabalhos que abordam a integração deste conceito ao PDP. Também, percebe-se que o termo 
ecodesign está em constante evolução e constantemente é redefinido pelos pesquisadores, conforme o avanço do conhecimento sobre esse tema e área de aplicação. Nessa tese, é adotada a definição de ecodesign das normas ABNT ISO/TR 14062 (2002) e ISO 14006 (2011) que engloba as definições citadas na Tabela 5.1 e descreve o ecodesign como "Integração dos aspectos ambientais na concepção e desenvolvimento de produtos com o objetivo de reduzir os impactos ambientais durante todo o ciclo de vida do produto". Para ABNT ISO/TR 14062 (2002) e ISO 14006 (2011) essa integração conduz a uma melhoria contínua da performance ambiental do produto por meio da inovação tecnológica e melhorias para organização como aumento da competitividade, relação com clientes e stakeholders. Na literatura existem trabalhos que abordam a integração do ecodesign no PDP, a Tabela 5.2 ilustra alguns deles.

Tabela 5.2 - Exemplos de trabalhos sobre a integração do ecodesign no PDP.

\begin{tabular}{|c|c|}
\hline Autor & Detalhamento \\
\hline Cramer e Stevels (1997) & $\begin{array}{l}\text { Desenvolveram um guia ambiental para projetistas da Philips, } \\
\text { denominando Strategic Environmental Challenge (STRETCH), no } \\
\text { qual por meio da técnica de brainstorming formularam uma } \\
\text { estratégia ambiental e identificaram novas oportunidades de negócio. }\end{array}$ \\
\hline Tischner et al. (2000) & $\begin{array}{l}\text { Elaboraram uma lista estratégica para ser utilizada para melhorar o } \\
\text { desempenho ambiental de um conceito ou para comparar diferentes } \\
\text { conceitos de produto. Essa lista apresenta sugestões de melhoria } \\
\text { ambiental, com base no ciclo de vida. Esses autores desenvolveram } \\
\text { ferramentas analíticas e comparativas do ecodesign, tais como: } \\
\text { análise ABC, checklist de ecodesign, e ecoconcept spiderweb. }\end{array}$ \\
\hline Bitencourt (2001) & $\begin{array}{l}\text { Propôs uma metodologia de reprojeto de produtos para o meio } \\
\text { ambiente, cuja aplicação foi exemplificada através de um estudo de } \\
\text { caso do reprojeto de uma cafeteira elétrica. }\end{array}$ \\
\hline Lofthouse e Bhamra (2001) & $\begin{array}{l}\text { Desenvolveu uma ferramenta (site na internet) para auxiliar os } \\
\text { projetistas no desenvolvimento sustentável de produtos. }\end{array}$ \\
\hline Johansson (2002) & $\begin{array}{l}\text { Realizou uma revisão dos principais fatores de sucesso para } \\
\text { integração do ecodesign ao PDP e estruturou esses fatores em seis } \\
\text { áreas de interesse: gerenciamento, relação com o cliente, relação } \\
\text { com fornecedores, processo de desenvolvimento, competência e } \\
\text { motivação. }\end{array}$ \\
\hline Lagerstedt (2003) & $\begin{array}{l}\text { Descreveu um modelo para identificar prioridades funcionais e de } \\
\text { meio ambiente nas fases iniciais do PDP. Forneceu também um } \\
\text { conjunto de regras para o DfE que sintetiza as principais ferramentas } \\
\text { e métodos existentes. }\end{array}$ \\
\hline Kindlein et al. (2003) & $\begin{array}{l}\text { Descreveram um modelo para o PDP, inserindo as variáveis } \\
\text { ambientais durante as fases de desenvolvimento e detalhamento do } \\
\text { produto, sugerindo algumas estratégias e ferramentas de ecodesign } \\
\text { ao longo do PDP. }\end{array}$ \\
\hline Malaguti (2005) & $\begin{array}{l}\text { Apresentou um manual de requisitos ambientais para o } \\
\text { desenvolvimento de produtos com base na ABNT/ISO TR } 14062 \\
\text { (2002) e descreveu exemplos práticos de aplicação de critérios } \\
\text { ambientais no PDP. }\end{array}$ \\
\hline
\end{tabular}


Tabela 5.2 - Exemplos de trabalhos sobre a integração do ecodesign no PDP continuação.

\begin{tabular}{|c|c|}
\hline Autor & Detalhamento \\
\hline $\begin{array}{l}\text { Byggeth e Hochschorner } \\
\text { (2006) }\end{array}$ & $\begin{array}{l}\text { Foram analisadas diferentes ferramentas de ecodesign e verificado } \\
\text { como elas contribuem em situações de trade-off envolvendo } \\
\text { perspectivas de sustentabilidade para aquisição e PDP. }\end{array}$ \\
\hline $\begin{array}{l}\text { Luttropp e Lagerstedt } \\
\text { (2006) }\end{array}$ & $\begin{array}{l}\text { Prepararam algumas regras (The Ten Golden Rules) sintetizando } \\
\text { diversos guias e manuais utilizados por diversas empresas com } \\
\text { intuito de inserir aspectos ambientais desde as fases iniciais do PDP. } \\
\text { Propuseram três listas (black, gray and white) classificando quais } \\
\text { substâncias químicas poderiam ou não ser utilizadas no } \\
\text { desenvolvimento de carros da Volvo, conforme o grau de impacto à } \\
\text { saúde e o meio ambiente. }\end{array}$ \\
\hline Stevels (2007) & $\begin{array}{l}\text { Descreve sua experiência, como conselheiro sênior ambiental e } \\
\text { professor, durante o período de 1993-2007 com análise de } \\
\text { ecodesign em produtos eletrônicos. }\end{array}$ \\
\hline Seuring e Muller (2008) & $\begin{array}{l}\text { Fizeram uma revisão da literatura sobre os trabalhos que abordam o } \\
\text { gerenciamento sustentável na cadeia de suprimentos, com base em } \\
\text { duas estratégias: riscos e performance, e produtos sustentáveis. }\end{array}$ \\
\hline Platcheck et al. (2008) & $\begin{array}{l}\text { Elaboraram uma proposta de metodologia para concepção de } \\
\text { equipamentos eletro-eletrônicos com a visão do ecodesign, para isso } \\
\text { inserem variáveis ambientais nas fases do PDP. }\end{array}$ \\
\hline $\begin{array}{l}\text { Pigosso (2008) } \\
\text { Guelere Filho (2009) }\end{array}$ & $\begin{array}{l}\text { Com base no modelo de referência do PDP de Rozenfeld et al. } \\
\text { (2006) recomendam a incorporação de algumas ferramentas de } \\
\text { ecodesign nas fases de planejamento estratégico de produto, projeto } \\
\text { informacional, projeto conceitual e projeto detalhado. }\end{array}$ \\
\hline Pigosso et al. (2010) & $\begin{array}{l}\text { Analisam alguns métodos e ferramentas de ecodesign que integram } \\
\text { diferentes estratégias de fim de vida, com foco na remanufatura para } \\
\text { reduzir o impacto do ciclo de vida dos produtos. }\end{array}$ \\
\hline $\begin{array}{l}\text { Bovea and Pérez-Belis } \\
(2012)\end{array}$ & $\begin{array}{l}\text { Revisam e classificam alguns métodos e ferramentas de ecodesign } \\
\text { que foram desenvolvidas para avaliar requisitos ambientais do } \\
\text { produto e facilitar sua integração no PDP. Esse trabalho serve de } \\
\text { guia para os projetistas escolherem a ferramenta que melhor se } \\
\text { adapte as suas necessidades. }\end{array}$ \\
\hline $\begin{array}{l}\text { Brones et al. (2013) } \\
\text { Brones e Marly (2014) }\end{array}$ & $\begin{array}{l}\text { Mapearam } 52 \text { trabalhos sobre a integração do ecodesign no PDP. } \\
\text { Analisaram e identificaram um padrão sistêmico dos modelos, a } \\
\text { partir de conceitos associados aos fatores de sucesso da gestão da } \\
\text { inovação juntos a princípios de sustentabilidade ambiental no âmbito } \\
\text { empresarial. Além disso, fizeram uma segmentação em três níveis } \\
\text { (micro, meso e macro) para comparar os modelos. }\end{array}$ \\
\hline Goepp et al. (2014) & $\begin{array}{l}\text { Esses autores fizeram um trabalho visando melhorar a integração } \\
\text { das ferramentas de ecodesign no PDP, por meio da compreensão do } \\
\text { processo das empresas e da avaliação da contribuição dos métodos } \\
\text { de ecodesign para o desempenho do PDP. }\end{array}$ \\
\hline
\end{tabular}

Um dos trabalhos mais recentes sobre a integração do ecodesign no PDP é apresentado por Brones e Marly (2014), que mapeiam vários trabalhos e identificam características importantes que dificultam essa integração. Um ponto identificado, é que a maioria dos trabalhos não especifica uma estrutura de PDP como referência para integração dos conceitos de ecodesign e PDP e, também, foca mais na gestão ambiental sem abordar as práticas de gestão do PDP. 
Apoiado na importância da integração do conceito de ecodesign no PDP, os trabalhos de Lofthouse e Bhamra (2001) e Johansson (2002) ratificam que essa integração deve ser feita desde as fases iniciais do PDP para não restringir as opções de melhorias ambientais, por causa da maioria das decisões técnicas já terem sido tomadas. Nas outras fases do PDP, as opções de melhoria ambiental se limitam aos processos de produção, logística e reciclagem (MASUl et al., 2003; BYGGETH; HOCHSCHORNER, 2006). Além disso, identifica-se uma similaridade na preocupação com algumas estratégias para reduzir o impacto ambiental, tais como: redução do consumo de materiais; escolha de materiais com menor impacto ambiental; utilização de materiais recicláveis ou passíveis de reuso; ampliação da vida útil do produto e redução do consumo de recursos naturais em todo ciclo de vida do produto. Também, são citados vários métodos e ferramentas de ecodesign como alternativas para se minimizar o impacto ambiental no PDP, sem comprometer o desempenho, custo e características do produto.

Porém, alguns autores como Bahmaed et al. (2005), Luttropp e Lagerstedt (2006), Lofthouse (2006) e Le Pochat et al. (2007) destacam as dificuldades para implementação do conceito de ecodesign nas empresas, tais como: falta de conhecimento dos envolvidos; falta de métodos de avaliação do impacto ambiental; envolvimento dos stakeholders; muitos métodos e ferramentas de ecodesign disponíveis; falta de normas internacionais regulamentadoras do ecodesign; necessidade de especialistas para aplicarem as ferramentas, aumento da quantidade de informações relativa aos aspectos ambientais e o tradicional trade-off entre aspectos ambientais e econômicos. Na visão de Boks (2006) essas interferências estão relacionadas a problemas sociais e psicológicos, como: as lacunas existentes entre a visão dos proponentes e dos executores, a complexidade organizacional e a falta de cooperação. Já Theyel (2000) cita que muitas vezes no planejamento estratégico das empresas não estão inclusos aspectos ambientais.

Apesar da dificuldade de integração do ecodesign ao PDP, outros autores citam muitas vantagens para as empresas (ECHEVESTE et al., 2002; HOLDWAY; WALKER; HILTON, 2002; ABRE, 2006): maior eficiência de processos e utilização de recursos; diferenciação dos produtos e embalagens; inovação e incremento do conhecimento sobre o produto; retorno financeiro pela comercialização de produtos verdes; otimização da funcionalidade do produto; melhoria da marca e imagem da empresa; redução de riscos; fidelização de clientes; melhoria na comunicação; 
substituição de materiais poluidores e tóxicos; e redução de impactos ambientais durante o uso e disposição. Para Boks (2006), as vantagens da implementação do ecodesign estão relacionadas aos aspectos convencionais dos negócios, como a customização, organização e comunicação. A empresa deve avaliar a sua capacidade de aplicar o conceito de ecodesign, tomando como base os seus fatores internos de motivação e externos como as regulamentações ambientais e as alterações de reprojeto para adequar o produto (VERCALSTEREN, 2001).

Pela análise dos trabalhos sobre a integração do ecodesign no PDP, verifica-se que os métodos e ferramentas de ecodesign têm sido considerados como uma das principais alternativas para se minimizar o impacto ambiental nos processos industriais (BOKS, 2006). Diante disso, na próxima seção são analisados os instrumentos de ecodesign, com objetivo de melhor entender a relação dessas ferramentas com o PDP.

\subsection{Mapeamento de métodos e ferramentas de ecodesign}

A necessidade de incorporar aspectos ambientais no PDP levou ao constante desenvolvimento de métodos e ferramentas de ecodesign (BAUMANN et al., 2002; HALLSTEDT, 2008). Nesse trabalho, métodos e ferramentas de ecodesign são todos os meios estruturados (instrumentos, melhores práticas, softwares, documentos de apoio, informações, diretrizes, estratégias, etc.) para lidar com aspectos ambientais durante o PDP (BAUMANN et al., 2002). Existe uma enorme variedade desses instrumentos com diversas finalidades de uso, que podem ser aplicados para avaliar o impacto ambiental, identificar aspectos ambientais críticos no produto e processo, realizar análise comparativa de estratégias de melhoria de projeto ambiental, comparação de soluções alternativas e beneficiar simultaneamente usuários, empresas e meio ambiente (BAUMANN et al., 2002; KURK; MCNAMARA, 2006; FIKSEL, 2011).

Entretanto, existe limitações na aplicação dos métodos e ferramentas de ecodesign no PDP, devido a diversas barreiras tanto por parte desses instrumentos como dos usuários (PIGOSSO et al., 2013): competência e experiência nas empresas, motivação para o uso das ferramentas, informações disponíveis sobre as ferramentas e tempo e recursos para selecionar e aplicar esses métodos. Para 
compreender esses instrumentos a Tabela 5.3 apresenta as características dos

principais tipos de ferramentas de ecodesign e relaciona alguns exemplos.

Tabela 5.3 - Tipos de métodos e ferramentas de ecodesign.

\begin{tabular}{|c|c|c|}
\hline $\begin{array}{l}\text { Métodos e } \\
\text { Ferramentas }\end{array}$ & Características & Exemplos \\
\hline Checklist & $\begin{array}{l}\text { Os checklists são na maioria qualitativos e utilizados para verificar } \\
\text { se os parâmetros ambientais foram ou não considerados no PDP, } \\
\text { como o consumo de energia e utilização de materiais tóxicos. }\end{array}$ & $\begin{array}{l}\text { Ecodesign } \\
\text { Checklist Method } \\
\text { (ECM) }\end{array}$ \\
\hline $\begin{array}{l}\text { Ferramentas } \\
\text { analíticas }\end{array}$ & $\begin{array}{l}\text { São ferramentas quantitativas para a avaliação e medição } \\
\text { detalhada do desempenho ambiental dos produtos, com base nas } \\
\text { suas características, em fases especificas do PDP e ciclo de vida. } \\
\text { Elas podem ser aplicadas de forma combinada para analisar os } \\
\text { trade-offs entre aspectos ambientais e econômicos. }\end{array}$ & $\begin{array}{l}\text { LCA, } \\
\text { Environmental } \\
\text { Design Cost, } \\
\text { AT\&T's Green } \\
\text { Design Tool. }\end{array}$ \\
\hline $\begin{array}{l}\text { Ferramentas de } \\
\text { avaliação e } \\
\text { classificação }\end{array}$ & $\begin{array}{l}\text { São ferramentas quantitativas simples consistindo em um sistema } \\
\text { de classificação em métricas e escala de avaliação pré- } \\
\text { estabelecida, são utilizadas em substituição ao LCA para avaliar } \\
\text { os aspectos do PDP. }\end{array}$ & $\begin{array}{l}\text { MIPS (Material } \\
\text { Input Per Service } \\
\text { Unit), CED } \\
\text { (Cumulative Energy } \\
\text { Demand }\end{array}$ \\
\hline $\begin{array}{l}\text { Ferramenta } \\
\text { organizacional }\end{array}$ & $\begin{array}{l}\text { São utilizadas para organizar tarefas e integrar funções } \\
\text { empresariais com os stakeholders no ecodesign. Elas incluem } \\
\text { organizar workshops de sensibilização para a discussão de } \\
\text { aspectos prioritários e definir qual estratégia e ferramenta utilizar. }\end{array}$ & DfE matrix \\
\hline Frameworks & $\begin{array}{l}\text { Os frameworks contêm uma idéia do que deveria guiar os } \\
\text { aspectos ambientais no PDP e são acompanhados de diretrizes } \\
\text { para deixar os produtos verdes. }\end{array}$ & $\begin{array}{l}\text { DfE, Life Cycle } \\
\text { Design, DfR, } \\
\text { Ecodesign, DfS }\end{array}$ \\
\hline Guidelines & $\begin{array}{l}\text { São guias de referência que dão diretrizes gerais para melhoria } \\
\text { do desempenho ambiental durante o PDP, variando no nível de } \\
\text { detalhes. }\end{array}$ & $\begin{array}{l}10 \text { Guidelines for } \\
\text { Ecodesign e } \\
\text { Remanufacturing } \\
\text { Guidelines }\end{array}$ \\
\hline $\begin{array}{l}\text { Indicadores } \\
\text { ambientais }\end{array}$ & $\begin{array}{l}\text { Utiliza de dados médios para as fases do ciclo de vida do } \\
\text { produto, com base nesses dados uma avaliação de impacto } \\
\text { ambiental é realizada utilizando um dos métodos e ferramentas } \\
\text { disponível, levando assim a pontuação do indicador. }\end{array}$ & $\begin{array}{l}\text { Eco-indicator 99, } \\
\text { Eco-indicator tool } \\
\text { (Eco-it) }\end{array}$ \\
\hline $\begin{array}{l}\text { Lista de } \\
\text { materiais } \\
\text { restritos }\end{array}$ & $\begin{array}{l}\text { Muitas empresas controlam os materiais utilizados em seus } \\
\text { produtos, por meio de listas de materiais restritos, com base nas } \\
\text { normas, legislação e investigação interna da empresa. Essas } \\
\text { listas fornecem requisitos ambientais bem definidos, integrando } \\
\text { os aspectos ambientais na fase inicial do projeto. }\end{array}$ & $\begin{array}{l}\text { Volvo's black, gray } \\
\text { and white lists }\end{array}$ \\
\hline $\begin{array}{l}\text { Manuais e } \\
\text { normas }\end{array}$ & $\begin{array}{l}\text { São para apoiar as empresas sobre os procedimentos que devem } \\
\text { ser seguidos para facilitar a integração dos aspectos ambientais } \\
\text { no PDP. }\end{array}$ & ISO/TR 14062 \\
\hline Matriz & $\begin{array}{l}\text { São ferramentas que contém uma escala pré-definida para a } \\
\text { avaliação do desempenho ambiental de produtos, através da } \\
\text { relação entre dois aspectos relevantes. As matrizes qualitativas } \\
\text { podem promover o conceito de ciclo de vida e fornecer um meio } \\
\text { ilustrativo para avaliar os trade-offs e as interações entre os } \\
\text { critérios de projeto. }\end{array}$ & $\begin{array}{l}\text { MECO Matrix, MET } \\
\text { Matrix, DfE Matrix, } \\
\text { e Eco-Function } \\
\text { Matrix. }\end{array}$ \\
\hline $\begin{array}{l}\text { Software e } \\
\text { sistemas } \\
\text { especialistas }\end{array}$ & $\begin{array}{l}\text { O intuito dessas ferramentas computacionais é suportar a } \\
\text { manipulação de enormes quantidades de informações ambientais } \\
\text { de forma rápida. Além disso, eliminam o caráter subjetivo e } \\
\text { possibilidade de erros em avaliações feitas por profissionais, cujo } \\
\text { conhecimento de aspectos ambientais seja limitado. }\end{array}$ & $\begin{array}{l}\text { Green Design } \\
\text { Advisor, EIME } \\
\text { software }\end{array}$ \\
\hline
\end{tabular}

Fonte: Adaptado de Wrisberg et al. (2002), Baumann et al. (2002), Dewulf (2003), Knight e Jenkins (2009), Pigosso e Rozenfeld (2012), Poulikidou (2012). 
Pela análise dos tipos de métodos e ferramentas de ecodesign verifica-se que não existe consenso sobre a definição das características desses tipos de instrumentos. No entanto, os métodos de ecodesign buscam contribuir para que os aspectos ambientais relacionados ao produto sejam considerados durante o PDP e todo o ciclo de vida, com objetivo de minimizar o impacto ambiental. Esses instrumentos podem ser aplicados em fases distintas do PDP, de acordo com as diferentes finalidades. Algumas ferramentas mais complexas (software, ferramentas analíticas e LCA) são pouco utilizadas devido a fatores como custo, falta de detalhes disponíveis para a escolha e aplicação e dificuldade para transferência de conhecimentos entre especialistas ambientais e os membros do time de PDP. Por outro lado, os métodos prescritivos (manuais, normas, checklists, guidelines e matrizes) por serem simples e de fácil aplicação, são os mais utilizados pelas empresas (BAUMANN et al., 2002).

Porém, o que se identifica na literatura é que eles variam em termos de níveis de detalhes e complexidade, necessidade de dados qualitativos ou quantitativos e conhecimento para sua utilização no PDP. Por isso, muitos trabalhos estão sendo desenvolvidos para auxiliar as empresas na identificação e seleção das ferramentas mais adequadas para cada tipo de produto e processo (BAUMANN et al., 2002; KNIGHT; JENKINS, 2009; BIRCH et al., 2012). É importante ao selecionar um instrumento de ecodesign considerar o objetivo e aplicação no contexto do PDP e outros critérios como (LUTTROPP; LAGERSTEDT, 2006; BYGGETH; HOCHSCHORNER, 2006; FARGNOLI; SAKAO, 2008; BOVEA; PEREZ-BELIS, 2012): nível de informação disponível, perspectiva de ciclo de vida, a natureza dos dados de entrada, a qualidade dos dados esperados, o objetivo da realização do estudo, a dependência do tempo de ferramenta, identificar situações do tipo de negócio ou produto, o usuário pretendido, suporte na tomada de decisão, ser capaz de identificar e lidar com situações de trade-off, em qual fase do PDP será utilizado e para que situação essas ferramentas são eficazes.

Nessa mesma linha, Knight e Jenkins (2009) apontaram que vários métodos e ferramentas de ecodesign não são totalmente genéricos e, portanto, não podem ser diretamente aplicados aos diferentes tipos de estrutura e características de PDP. Logo, além de selecionar o instrumento mais adequado é necessário fazer alguns ajustes nos mesmos para integrá-los com sucesso ao PDP. Com intuito de ajudar na seleção correta de métodos e ferramentas de ecodesign para utilização no PDP, 
vários pesquisadores estudaram e propuseram critérios de classificação dessas ferramentas, conforme mostra a Tabela 5.4.

Tabela 5.4 - Classificação de métodos e ferramentas de ecodesign no PDP.

\begin{tabular}{|c|c|}
\hline Autor & Critérios de classificação dos métodos e ferramentas de ecodesign \\
\hline $\begin{array}{l}\text { Mathieux et al. } \\
(2001)\end{array}$ & $\begin{array}{l}\text { Propuseram uma classificação em dois grupos, os que realizam avaliações } \\
\text { como o LCA e os que oferecem recomendações ou informações ambientais. }\end{array}$ \\
\hline $\begin{array}{l}\text { Lewis et al. } \\
\text { (2001) }\end{array}$ & $\begin{array}{l}\text { Para esses autores as ferramentas se classificam em: custo, tempo necessário, } \\
\text { simplicidade de uso e eficácia na disponibilização de informação útil. Eles } \\
\text { dividiram as ferramentas em analíticas e criativas, sendo que as ferramentas de } \\
\text { cada um destes grupos têm de ser usada na procura de novas soluções. }\end{array}$ \\
\hline $\begin{array}{l}\text { Baumann et al. } \\
\text { (2002) }\end{array}$ & $\begin{array}{l}\text { Classificaram nas seguintes categorias: frameworks, checklists e guidelines, } \\
\text { avaliação e priorização, analítica, software e sistemas, e organizacional. }\end{array}$ \\
\hline $\begin{array}{l}\text { Tischner and } \\
\text { Nickel (2003) }\end{array}$ & $\begin{array}{l}\text { As ferramentas de ecodesign podem organizar-se por objetivos, no qual os } \\
\text { objetivos estão relacionados à: análises ambientais, seleção de prioridades e } \\
\text { potenciais melhorias, suporte à geração de idéias e design, coordenação com } \\
\text { critérios de custo/benefício, avaliação e produtividade. }\end{array}$ \\
\hline $\begin{array}{l}\text { Byggeth e } \\
\text { Hochschorner } \\
\text { (2006) }\end{array}$ & $\begin{array}{l}\text { Essas autoras classificaram os instrumentos quanto aos seus objetivos em três } \\
\text { categorias: ferramentas de análise para avaliar o impacto ambiental dos } \\
\text { produtos, ferramentas de comparação do desempenho ambiental de diferentes } \\
\text { produtos e ferramentas prescritivas para guiar no PDP com menos impacto } \\
\text { ambiental. }\end{array}$ \\
\hline Chaves (2007) & $\begin{array}{l}\text { Separou os métodos em três grupos: de priorização que avaliam o produto e } \\
\text { identificam prioridades e gargalos, de orientação que guia na tomada de } \\
\text { decisão para soluções sustentáveis, e de avaliação que quantifica a melhoria } \\
\text { ambiental obtida no final do projeto. }\end{array}$ \\
\hline $\begin{array}{l}\text { Telenko et al. } \\
\text { (2008) }\end{array}$ & $\begin{array}{l}\text { Essa autora afirma que a maioria dos métodos e ferramentas podem ser } \\
\text { classificados em duas categorias: avaliação do ciclo de vida (LCA) e princípios e } \\
\text { diretrizes para o ecodesign. }\end{array}$ \\
\hline $\begin{array}{l}\text { Pigosso e } \\
\text { Rozenfeld } \\
\text { (2012) }\end{array}$ & $\begin{array}{l}\text { Esses autores classificaram utilizando os seguintes critérios: natureza do } \\
\text { objetivo principal do método/ferramenta (prescritiva, comparativa ou analítica); } \\
\text { tipo de ferramenta utilizada pelo método/ferramenta (checklist, guideline, matriz, } \\
\text { software); natureza dos dados de entrada e saída (qualitativos ou quantitativos); } \\
\text { área de pesquisa em que foi originado (ecodesign/gestão ambiental ou PDP); } \\
\text { nível atual de desenvolvimento (teórico, experimental ou consolidado); nível de } \\
\text { detalhamento do método/ferramenta (superficial, sucinto ou completo); e mais } \\
\text { três critérios abertos: aspectos ambientais considerados; fases do ciclo de vida } \\
\text { consideradas; e método de avaliação de impacto ambiental. }\end{array}$ \\
\hline $\begin{array}{l}\text { Bovea e Pérez- } \\
\text { Belis (2012) }\end{array}$ & $\begin{array}{l}\text { Realizaram uma análise classificando os métodos e ferramentas conforme o } \\
\text { nível de dificuldade e tempo requerido para implantar, pelo objetivo da } \\
\text { ferramenta (análise das forças e fraquezas ambientais, seleção de melhoria } \\
\text { potencial, e geração de alternativas de projeto) também separaram em } \\
\text { qualitativa, semi-quantitativa e quantitativa, se tem perspectiva de ciclo de vida, } \\
\text { as relações com as ferramentas tradicionais do PDP e em quais fases do PDP } \\
\text { se aplicam. }\end{array}$ \\
\hline $\begin{array}{l}\text { Poulikidou } \\
\text { (2013) }\end{array}$ & $\begin{array}{l}\text { Realizou a compilação de métodos e ferramentas de ecodesign que são } \\
\text { utilizados para integração de aspectos ambientais no PDP. A classificação } \\
\text { proposta está dividida em três categorias: prescritiva, analítica e ferramentas } \\
\text { que identificam estratégia de design. }\end{array}$ \\
\hline
\end{tabular}

Nas classificações apresentadas na Tabela 5.4 o trabalho de Baumann et al. (2002) é um dos mais relevantes e mostra os seguintes resultados: não é 
comprovada a eficiência das ferramentas para redução do impacto ambiental no PDP; a fase de projeto conceitual é a que mais influência no desempenho ambiental do produto; e não há alinhamento estratégico entre as atividades corporativas e o PDP. Outro trabalho interessante foi realizado por Pigosso e Rozelfeld (2012) que fizeram um levantamento para descobrir o estado da arte sobre os métodos e ferramentas de ecodesign. Eles buscaram contribuir para que as empresas possam escolher de forma apropriada os instrumentos de ecodesign disponíveis para serem aplicados no PDP. Além disso, identificaram que as ferramentas surgem principalmente na área de ecodesign, sendo que os referentes ao PDP são desenvolvidos por meio de adaptações de ferramentas tradicionais do PDP. Também, concluíram que a maioria dos métodos de ecodesign não apresenta um sistema de avaliação do impacto ambiental e, apesar do intenso desenvolvimento teórico e da validação experimental desses instrumentos, ainda não há uma aplicação satisfatória pelas empresas.

Após analisar os estudos realizados sobre métodos e ferramentas de ecodesign, buscou-se na literatura, conforme procedimentos metodológicos descritos no capítulo de métodos de pesquisa (seção 2.2.2.3), mapear os principais métodos e ferramentas de ecodesign e entender melhor como essas ferramentas se aplicam no PDP. Assim, foi possível identificar e selecionar 154 métodos e ferramentas de ecodesign. A Tabela 5.5 sintetiza os métodos e ferramentas de ecodesign mapeados e a lista completa com detalhes está disponível no Apêndice IV.

Tabela 5.5 - Exemplo dos 154 métodos e ferramentas de ecodesign analisados.

\begin{tabular}{|l|l|}
\hline \multicolumn{1}{|c|}{ Métodos e ferramentas de ecodesign } & \multicolumn{1}{c|}{ Referências } \\
\hline ABC Analysis & Byggeth e Hochschorner (2006) \\
\hline Alternative Function Fulfillment (AFF) & Van Der Zwan e Bhamra (2003) \\
\hline AT\&T's Green Design Tool & Poyner e Simon (1995), kassahun et al. (1995) \\
\hline D4N & Murtagh et al. (1999) \\
\hline Design Abacus & Bhamra e Lofthouse (2007) \\
\hline DfE Matrix & Yarwood e Eagan (1998) \\
\hline Dominance Matrix or Paired Comparison & Byggeth e Hochschorner (2006) \\
\hline Eco-Compass technique & Sun et. al. (2003) \\
\hline Ecodesign Checklist Method (ECM) & Wimmer (1999) \\
\hline Ecodesign Pilot & Wimmer et al. (2005) \\
\hline Ecodesign Web & Bhamra e Lofthouse (2007) \\
\hline Eco-FMEA & Lindahl (2001) \\
\hline Eco-Indicator tool (Eco-it) & Pré Consultants (2000), Qian et al. (2001) \\
\hline Eco-Products Tool & Namikawa (2005) \\
\hline Eco-Redesign & Bovea e Wang (2007) \\
\hline
\end{tabular}


Tabela 5.5 - Exemplo dos 154 métodos e ferramentas de ecodesign analisados continuação.

\begin{tabular}{|c|c|}
\hline Métodos e ferramentas de ecodesign & Referências \\
\hline Eco-roadmap & Donnelly et al. (2006) \\
\hline Eco-Value Analysis (Eco-VA) & Oberender e Birkhofer (2004) \\
\hline End-of-Life Design Advisor (ELDA) & Sun et al. (2003) \\
\hline Environment Design Support Tool (EDST) & Yu et al. (1999) \\
\hline Environment Effect Analysis (EEA) & Lindahl (2001) \\
\hline Environmental Design Industrial Template (EDIT) & Spicer e Wang (1997) \\
\hline Environmental Design Strategy Matrix (EDSM) & Lagerstedt (2003) \\
\hline $\begin{array}{l}\text { Environmental Efficiency Potential Assessment } \\
\text { method (E2-PA) }\end{array}$ & Nagata et al. (2001) \\
\hline Environmental FMEA (E-FMEA) & Lindhal (1999) \\
\hline Environmental Objective Deployment (EOD) & Karlsson (1997) \\
\hline Environmental Product Life Cycle Matrix (EPLC) & Gertsakis et al. (1997) \\
\hline Environmentally Conscious QFD (ECQFD) & Vinodh e Rathod (2009) \\
\hline $\begin{array}{l}\text { Environmentally Responsible Product } \\
\text { Assessment Matrix (ERPA) }\end{array}$ & $\begin{array}{l}\text { Hochschorner e Finnveden (2003), Lee et al. } \\
\text { (2003), Byggeth e Hochschorner (2006) }\end{array}$ \\
\hline GrEEEn Method & Lichtenvort et al. (2003) \\
\hline Green Design Advisor (GDA) & Ferrendier et al. (2002), Sun et al. (2003) \\
\hline House of Ecology (HoE) & Halog et al. (2001) \\
\hline LiDS-wheel (Life Cycle Design Strategies) & Byggeth e Hochschorner (2006) \\
\hline Life Cycle Assessment (LCA) & $\begin{array}{l}\text { Sakao et al. (2005), Lee et al. (2003), ISO } \\
14040 \text { (2006), Tingstrom e Karlsson (2006) }\end{array}$ \\
\hline Life Cycle Environmental Cost Analysis (LCECA) & Senthil kumaran et al. (2001) \\
\hline Life Cycle Quality Function Deployment (LC-QFD) & Ernzer e Birkhofer (2005) \\
\hline Matriz MECO & $\begin{array}{l}\text { Hochschorner e Finnveden (2003), Byggeth e } \\
\text { Hochschorner (2006) }\end{array}$ \\
\hline Matriz MET & $\begin{array}{l}\text { Ueno et al. (2001), Byggeth e Hochschorner } \\
\text { (2006) }\end{array}$ \\
\hline Method to Assess the Adaptability of Products & Willems et al. (2003) \\
\hline $\begin{array}{l}\text { Methodology based on MCDM techniques to } \\
\text { Identifying the greatest environmental impact } \\
\text { value }\end{array}$ & Bastante-Ceca et al. (2006) \\
\hline Philips Fast Five Awareness & Byggeth e Hochschorner (2006) \\
\hline Phillips strategic environmental challenge & Stevels (1999) \\
\hline Product Life Cycle Planning (LCP) & Kobayashi (2005) \\
\hline QFD for Environment (QFDE) & Sakao et al. (2001), Masui et al. (2001) \\
\hline $\begin{array}{l}\text { Readiness Assessment for Implementing DfE } \\
\text { Strategies (RAILS) }\end{array}$ & Van Hemel (1995) \\
\hline (ReSICLED) & Mathieux et al. (2006) \\
\hline Remanufacturing Guidelines & ljomah et al. (2007) \\
\hline Streamlined Life Cycle Assessment (SLCA) & Bennett e Graedel (2000) \\
\hline Ten Golden Rules & Luttropp e Lagerstedt (2006) \\
\hline The Eco-Function Matrix & Lagerstedt (2003) \\
\hline Volvo's Black, Gray and White lists & Luttropp e Lagerstedt (2006) \\
\hline
\end{tabular}

Analisando os 154 métodos e ferramentas de ecodesign encontrados na literatura, percebe-se que dependendo das características da sua origem e finalidade, eles são direcionados para fases específicas do PDP. Os instrumentos que tem abordagens de ecodesign são empregados nas fases iniciais do PDP (das 
fases conceituais do PDP até o projeto detalhado) visando auxiliar nas escolhas com menor impacto ambiental sobre a estrutura, os materiais e os processos de produção. No entanto, os métodos e ferramentas desenvolvidos a partir do conceito de LCA são utilizados nas fases finais do PDP (da fase de projeto detalhado até a retirada do produto do mercado) devido ao LCA ser uma ferramenta retrospectiva que necessita de informações detalhadas do produto e processo e avalia as consequências das escolhas de projeto no consumo de recursos e no impacto ao meio ambiente durante todo o ciclo de vida do produto.

Uma parte dos métodos e ferramentas analisados são adaptações ambientais de ferramentas clássicas de suporte ao PDP (FMEA, QFD, Análise de Valor e Matriz Design), como: E-FMEA que identifica, avalia e previne deficiências relacionadas à segurança do produto incluindo aspectos ambientais; QFD for Environment (QFDE) que avalia se o produto atende as exigências ambientais do cliente; Life Cycle Environmental Cost Analysis (LCECA) que visa facilitar o projeto e reprojeto com baixo custo considerando todos os requisitos que o cliente está disposto a pagar para obter o benefício ambiental; e DfE Matrix que faz uma avaliação qualitativa dos requisitos ambientais pelo time de projeto. Além disso, outros métodos são sínteses de estratégias e melhores práticas desenvolvidas por empresas (Philips, Volvo, HP, AT\&T, etc.), que definem diretrizes, regras e listas de verificação com objetivo de reduzir o impacto ambiental e cumprir regulamentações ambientais.

Em resumo, os métodos e ferramentas analisados foram desenvolvidos para avaliar o impacto ambiental no PDP e facilitar a integração de aspectos ambientais nesse processo. Esses instrumentos variam desde guias e indicadores ambientais simples até análises mais complexas com utilização de softwares para problemas ambientais específicos que consideram multi-critérios e várias categorias ambientais e estágios do ciclo de vida do produto. O que pode diferenciá-los é a forma de estruturação, capacidade de análise de dados qualitativos ou quantitativos, qualidade das informações, dificuldade de aplicação, conhecimentos ambientais prévios e necessidade de customização.

Por fim, essa análise corrobora com a opinião de outros autores (LINDAHL, 2005; LOFTHOUSE, 2006; PIGOSSO et al., 2013) sobre a variedade de ferramentas e a dificuldade das empresas em escolher e aplicá-las no PDP. Portanto, com objetivo de facilitar a integração de práticas de ecodesign no PDP optou-se nessa tese por 
extrair os aspectos ambientais dos métodos e ferramentas de ecodesign, conforme mostra a próxima seção.

\subsection{Seleção de aspectos ambientais dos métodos de ecodesign}

Devido à dificuldade de escolher os métodos e ferramentas de ecodesign mais adequados para cada fase do PDP, a alternativa encontrada para integrar 0 ecodesign ao PDP foi de analisar cada um dos 154 métodos e ferramentas de ecodesign mapeados na literatura e, por meio dos procedimentos metodológicos descritos no Capítulo 2 (item 2.2.2.3), identificar aspectos ambientais que contribuem com a redução do impacto ambiental no PDP. A Tabela 5.6 mostra exemplos desses instrumentos e os respectivos aspectos ambientais identificados, para verificar os detalhes da lista completa com os 154 métodos e ferramentas de ecodesign e os respectivos aspectos ambientais na forma bruta, vêr o Apêndice IV.

Tabela 5.6 - Exemplo de aspectos ambientais na forma bruta e os métodos e ferramentas de ecodesign relacionados.

\begin{tabular}{|l|l|}
\hline \multicolumn{1}{|c|}{ Métodos de Ecodesign } & \multicolumn{1}{c|}{ Aspectos Ambientais (Forma Bruta) } \\
\hline 10 Guidelines for ecodesign & - Focar na redução do consumo de energia em todas as \\
& - fases do ciclo de vida do produto \\
- Aumento do tempo de vida do produto & - Usar o mínimo de material possível \\
- Usar materiais reciclados & - Fazer seu produto reciclável \\
\hline ABC analysis & - Toxidade de materiais \\
& - Extração de matéria prima \\
& - Poluição do ar e da água \\
& - Avaliação dos impactos ambientais do produto \\
& - Perspectiva de ciclo de vida \\
\hline AT\&T matrix & - Consumo de materiais \\
& - Uso de energia \\
\hline Alternative function fulfillment (AFF) & - Resíduos líquidos, sólidos e gasosos \\
& - Quantificar o impacto ambiental do produto \\
& - Entrada de materiais \\
& - Uso e consumo de energia \\
& - Emissões tóxicas \\
\hline - Atentar aos regulamentos externos \\
\hline - Solução alternativa com menos impacto ambiental \\
- Fazer um perfil ambiental do produto \\
system for ecodesign (CHASSE)
\end{tabular}


Em seguida, devido aos aspectos ambientais estarem na forma bruta foi necessário prepará-los para serem integrados ao PDP, conforme metodologia apresentada na etapa 6 do capítulo de métodos de pesquisa (item 2.2.2.4). Uma síntese do resultado da lapidação desses aspectos ambientais está listada na Tabela 5.7 e o restante dos 365 aspectos ambientais identificados e preparados para integração com o PDP pode ser consultado no Apêndice V.

Tabela 5.7 - Exemplo de aspectos ambientais de ecodesign.

\section{Síntese dos 365 Aspectos Ambientais}

1. Acumular conhecimentos com os feedbacks das implicações das escolhas feitas

2. Preferir produtos com adaptabilidade

3. Agrupar os componentes com o mesmo ciclo de vida em módulo para minimizar o seu impacto ambiental

4. Ajustar automaticamente para consumo mínimo de energia

5. Alterar para baterias recarregáveis

6. Analisar a legislação atual e futura e as necessidades atuais e emergentes do cliente em termos de sustentabilidade e meio ambiente relevantes ao produto

7. Analisar a sustentabilidade de dois produtos comparando as suas características ambientais

8. Analisar e monitorar a viabilidade ambiental dos projetos

9. Analisar os impactos ambientais que a tecnologia pode causar

10. Analisar todas as informações ambientais e econômicas de um produto

11. Analisar comparativamente a alternativa ambiental com o produto atual utilizando de métricas

12. Analisar as pegadas ecológicas (carbono, água, energia, emissão, ambiente de trabalho e impactos tóxicos)

13. Analisar a destinação dos resíduos

14. Analisar o efeito a exposição das substâncias químicas

15. Analisar e medir as fontes de energia e sua eficiência

16. Aplicar estruturas entrelaçadas para aumentar a rigidez

17. Aplicar técnicas estruturais de materiais para minimizar o volume total do material

18. Reduzir o aquecimento global

19. Garantir alta taxa de retorno de produtos no fim de vida

20. Garantir a segurança ambiental no estágio de uso

21. Garantir alta confiança do produto

22. Garantir que as juntas e parafusos são facilmente acessíveis

23. Garantir que os controles de recursos sejam fáceis de operar e entender

24. Garantir que os resíduos são à base de água ou biodegradáveis

25. Atentar aos regulamentos externos

Os aspectos ambientais antes de serem integrados ao PDP podem ter sido agrupados em uma frase e/ou reescritos no momento da integração, visando se adequar a função da tarefa do PDP. A versão final da descrição dos aspectos ambientais é apresentada na estrutura proposta deste trabalho no próximo capítulo. 


\subsection{Considerações finais do capítulo}

Neste capítulo foi possível delinear o contorno sobre a parte ambiental da proposta de estruturação do PDP integrando aspectos ambientais, para isso foi discutido desde os conceitos mais abrangentes até os aspectos ambientais que representa um dos pilares dessa tese junto com as estruturas de PDP. Nessa análise do ecodesign são apontados os diferentes pontos de vista dos principais pesquisadores sobre o tema, os trabalhos mais relevantes em relação às formas de classificação das ferramentas e a dificuldade de integrá-los ao PDP. Essa dificuldade de integração e a pouca aplicação por parte das empresas, se destaca na literatura e muitos trabalhos discorrem sobre esse problema e concluem que são vários fatores que influenciam como a complexidade na escolha da ferramenta mais adequada e a necessidade de especialistas para sua aplicação. Neste sentido, embora diversos métodos de ecodesign para o PDP já tenham sido desenvolvidos, nota-se a existência de lacunas no que tange às aplicações práticas nas empresas. Como alternativa a essa dificuldade de integração dos conceitos, essa tese extraiu os principais aspectos ambientais dos métodos e ferramentas de ecodesign, visando eliminar a necessidade de escolha de um instrumento específico e facilitar a utilização pelas empresas. Assim, uma das contribuições desse trabalho, foi identificar 154 métodos e ferramentas de ecodesign e deles extrair e analisar 365 aspectos ambientais para serem utilizados na elaboração da proposta.

Outro tópico bastante discutido na literatura é quanto ao momento correto para integração do ecodesign nas fases do PDP, que devem ser realizados desde as fases iniciais do PDP para não restringir as opções ambientais. Porém, pela análise das ferramentas de ecodesign, percebe-se que dependendo das características da sua origem e finalidade, esses instrumentos são direcionados para fases específicas do PDP e não só para as fases iniciais como apontado.

Por fim, para que as empresas possam de forma adequada atender a esses questionamentos de inserção de aspectos ambientais no PDP, existe a necessidade delas utilizarem estruturas de PDP adequadas e que incorporem os aspectos ambientais de ecodesign durante todas as fases do PDP, considerando todo o ciclo de vida do produto. Logo, visando contribuir com essa lacuna no próximo capítulo é apresentada a proposta dessa tese para integrar aspectos ambientais no PDP. 


\section{PROPOSTA DE ESTRUTURAÇÃO DO PDP INTEGRANDO ASPECTOS AMBIENTAIS}

Essa proposta de estruturação do PDP considerando aspectos ambientais foi desenvolvida com base na lacuna de pesquisa identificada na revisão bibliográfica (Capítulo 3). Para essa elaboração foi realizado um aprofundamento na teoria sobre o conceito de PDP para entender as formas de estruturação do PDP (Capítulo 4) e, também, no conceito de ecodesign focando nos métodos e ferramentas e nas abordagens para integração do ecodesign ao PDP (Capítulo 5). Com base nessas análises da teoria, verificou-se que as estruturas de PDP apresentadas não contemplam aspectos ambientais para reduzir o impacto ambiental no PDP e que os métodos e ferramentas de ecodesign são pouco utilizados pelas empresas no PDP. Logo, como contribuição da tese foi proposto uma estruturação do PDP integrando aspectos ambientais para auxiliar as empresas a desenvolver produtos com menor impacto ambiental. É importante destacar, que esta proposta foi revisada com base nos resultados da consulta feita com especialistas (Capítulo 7), e as alterações em relação à proposta original estão destacadas com a fonte na cor azul.

A estrutura de PDP proposta utiliza como referência Rozenfeld et al. (2006) e está dividida em quatro níveis hierárquicos: macrofase, fase, atividade e tarefa. A integração de aspectos ambientais na estrutura de PDP foi feita no nível das tarefas, conforme os procedimentos metodológicos descritos no Capítulo 2 (item 2.2.2.5). É importante destacar que os aspectos ambientais podem ser aplicados em mais de uma tarefa do PDP e estão distribuídos ao longo de todo o PDP. Além disso, trata-se de uma proposta de PDP com visão integrada, considerando todo o ciclo de vida do produto, realizando revisão de cada fase por meio de Gates. Essa proposta é genérica e pode ser adaptada as diferentes necessidades e complexidades do desenvolvimento de novos produtos, bem como, utilizada como guia para orientar na inserção de aspectos ambientais nas atuais estruturas utilizadas pelas empresas. A Figura 6.1 mostra como foi esquematizada a proposta de estruturação do PDP integrando aspectos ambientais e, em seguida, são descritos as funções de cada macrofase e fase da estrutura de PDP proposta. Também, destaca-se a importância da integração de cada aspecto ambiental que foram inseridos nas tarefas do PDP para contribuir com a minimização do impacto ambiental do produto. 


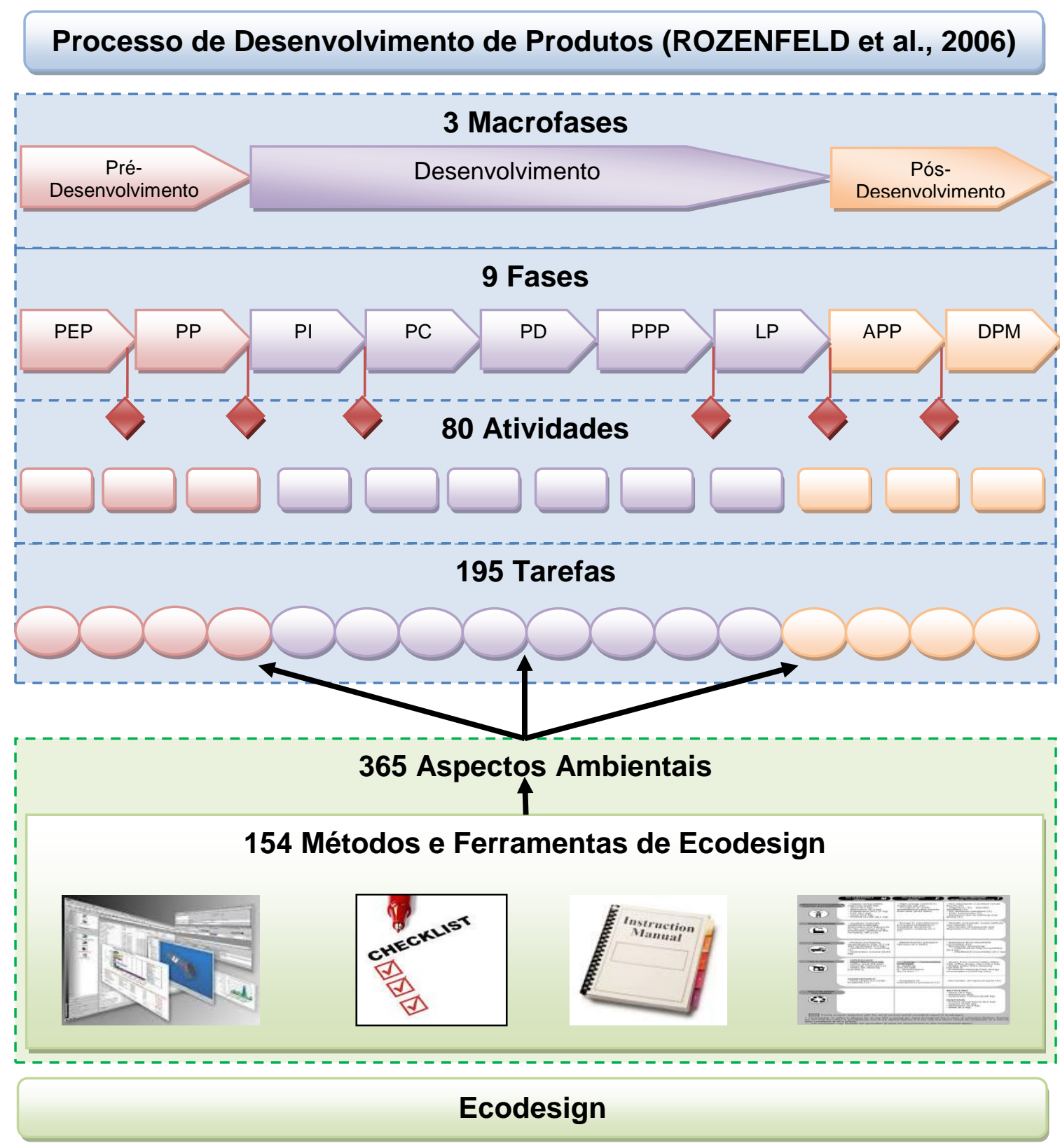

Figura 6.1 - Proposta de estrutura de PDP integrando aspectos ambientais.

A macrofase de Pré-Desenvolvimento engloba as primeiras etapas do PDP, nas quais as decisões são mais estratégicas e tomadas com alto grau de incerteza. No início do processo busca-se identificar as oportunidades de mercado, alinhar a estratégia do novo produto com as estratégias competitivas da empresa, mapear as informações de mercado, avaliar as tendências tecnológicas a serem adotadas no conceito do produto e alocar os recursos para o PDP. Esta macrofase está subdividida em duas fases, a fase de Planejamento Estratégico do Produto (PEP) e a fase de Planejamento do Projeto (PP). 
A fase de Planejamento Estratégico de Produtos (PEP) tem a função de obter um plano contendo o portfólio de produtos da empresa que serão desenvolvidos, com o objetivo de orientá-la a atingir as metas estratégicas de negócio. Nesta fase, foram inseridos aspectos ambientais com intuito de equalizar a importância ambiental com outros fatores estratégicos da empresa, bem como, sinalizar que existem novas tecnologias disponíveis no mercado que geram menos impacto ambiental e que precisa haver um plano de desenvolvimento da equipe de projeto em relação aos conceitos de ecodesign e, ainda, deve-se criar um histórico desse conhecimento ambiental gerado durante o PDP para posteriormente ser consultado, disseminado e utilizado por toda a organização. A Tabela 6.1 mostra os aspectos ambientais com códigos para rastreabilidade que foram inseridos nas tarefas com os respectivos números que indicam as atividades e fases do PDP.

Tabela 6.1 - Fase de Planejamento Estratégico de Produtos.

\begin{tabular}{|c|c|}
\hline Fase & $\begin{array}{l}\text { Macrofase - Pré-Desenvolvimento } \\
\text { - Planejamento Estratégico de Produtos (PEP) }\end{array}$ \\
\hline Atividade - 1.1 Definir e & copo da revisão do plano estratégico de negócios \\
\hline Tarefa - 1.1.1 & Aspectos Ambientais - Código $(33,120,177,250,272)$ \\
\hline $\begin{array}{l}\text { Analisar } 0 \text { plano } \\
\text { estratégico de negócios }\end{array}$ & $\begin{array}{l}\text { Formular e implementar uma estratégia ou política ambiental para suportar a } \\
\text { tomada de decisão nas questões relacionadas com a redução do impacto } \\
\text { ambiental. Dentro desta estratégia ambiental deve-se avaliar a possibilidade } \\
\text { de aplicação de métodos e ferramentas de ecodesign, que facilite a análise e } \\
\text { avaliação do impacto ambiental dos produtos e processos. Além disso, deve- } \\
\text { se na elaboração do plano estratégico de negócios avaliar as seguintes } \\
\text { diretrizes: Analisar as vantagens de se obter certificação ambiental } \\
\text { implantar normas ambientais internas na organização; Analisar a } \\
\text { possibilidade de envolver toda a cadeia de suprimentos para melhorar a } \\
\text { performance ambiental e definir as responsabilidades; Definir uma estratégia } \\
\text { de eficiência energética para reduzir as perdas de energia; e Definir uma } \\
\text { forma de captar, avaliar e priorizar estratégias ambientais promissoras. }\end{array}$ \\
\hline Tarefa-1.1.2 & Aspectos Ambientais - Código $(38,265,292,336)$ \\
\hline $\begin{array}{l}\text { Avaliar competências no } \\
\text { time de planejamento } \\
\text { estratégico de produtos }\end{array}$ & $\begin{array}{l}\text { Definir um programa de desenvolvimento e treinamento para melhorar a } \\
\text { conhecimento dos profissionais sobre o conceito e práticas de ecodesign, } \\
\text { bem como, de normas do sistema de gestão ambiental. Também, caso não } \\
\text { se tenha competência pode-se contratar uma empresa especializada para } \\
\text { dar consultoria sobre esse assunto. }\end{array}$ \\
\hline Atividade - 1.2 Planejar & tividades para a revisão do plano estratégico de negócios \\
\hline Tarefa - 1.2.1 & Aspectos Ambientais - Código $(9,58,70)$ \\
\hline $\begin{array}{l}\text { Planejar os recursos } \\
\text { físicos necessários em } \\
\text { cada reunião }\end{array}$ & $\begin{array}{l}\text { Envolver funcionários da área de meio ambiente no time de planejamento } \\
\text { estratégico de produtos. }\end{array}$ \\
\hline Tarefa - 1.2.2 & Aspectos Ambientais - Código (139) \\
\hline $\begin{array}{lrr}\text { Preparar plano } & \text { de } \\
\text { comunicação e } & \text { de } \\
\text { riscos } & & \end{array}$ & $\begin{array}{l}\text { Definir uma plataforma de comunicação entre as prioridades funcionais e os } \\
\text { impactos ambientais do produto e processo. }\end{array}$ \\
\hline
\end{tabular}


Tabela 6.1 - Fase de Planejamento Estratégico de Produtos - continuação.

\begin{tabular}{|c|c|}
\hline \multicolumn{2}{|c|}{$\begin{array}{l}\text { Macrofase - Pré-Desenvolvimento } \\
\text { Fase 1 - Planejamento Estratégico de Produtos (PEP) }\end{array}$} \\
\hline \multicolumn{2}{|c|}{ Atividade - 1.3 Consolidar informações sobre tecnologia e mercado } \\
\hline Tarefa - 1.3.1 & Aspectos Ambientais - Código $(23,55,88,90,154,178,330,361)$ \\
\hline $\begin{array}{l}\text { Identificar necessidade } \\
\text { de dados e planejar } \\
\text { coleta }\end{array}$ & $\begin{array}{l}\text { Definir uma área responsável por identificar, coletar, analisar e centralizar } \\
\text { todas as informações ambientais sobre tecnologia e mercado. Nesta análise } \\
\text { devem-se avaliar os impactos ambientais do produto durante todo o ciclo de } \\
\text { vida. O objetivo é avaliar o alinhamento do produto com a legislação } \\
\text { ambiental atual e futura e se também atende as perspectivas ambientais do } \\
\text { cliente. }\end{array}$ \\
\hline Tarefa - 1.3.2 & Aspectos Ambientais - Código $(103,195)$ \\
\hline Consolidar informações & $\begin{array}{l}\text { Desenvolver e implantar uma base de dados (Biblioteca Ambiental) com as } \\
\text { principais características ambientais dos materiais, componentes e } \\
\text { processos considerando todo o ciclo de vida do produto. Com base nessa } \\
\text { base de dados, pode-se identificar oportunidades de melhorias ambientais e } \\
\text { tomar ações para reduzir o impacto ambiental. }\end{array}$ \\
\hline \multicolumn{2}{|c|}{ Atividade - 1.4 Revisar o plano estratégico de negócios } \\
\hline Tarefa - 1.4.1 & Aspectos Ambientais - Código (76) \\
\hline $\begin{array}{l}\text { Revisar segmentação } \\
\text { do mercado }\end{array}$ & Acompanhar e analisar as tendências ambientais dos produtos no mercado. \\
\hline Tarefa - 1.4.2 & Aspectos Ambientais - Código $(23,90,154,330,361)$ \\
\hline $\begin{array}{l}\text { Revisar tendências } \\
\text { tecnológicas }\end{array}$ & $\begin{array}{l}\text { Acompanhar e analisar os impactos ambientais que a tecnologia pode } \\
\text { causar. }\end{array}$ \\
\hline Tarefa - 1.4.3 & Aspectos Ambientais - Código $(38,292)$ \\
\hline Revisar competências & $\begin{array}{l}\text { Adequar o programa de desenvolvimento e treinamento dos funcionários } \\
\text { conforme as necessidades ambientais da empresa e exigências do mercado. }\end{array}$ \\
\hline Tarefa - 1.4.4 & Aspectos Ambientais - Código $(97,230,324)$ \\
\hline Revisar metas & $\begin{array}{l}\text { Avaliar o desempenho ambiental dos produtos e processos e estimar novas } \\
\text { metas ambientais a serem alcançadas. }\end{array}$ \\
\hline Tarefa - 1.4.5 & Aspectos Ambientais - Código $(115,322)$ \\
\hline Preparar documento & $\begin{array}{l}\text { Elaborar e controlar toda a documentação ambiental do processo de } \\
\text { desenvolvimento de produtos. }\end{array}$ \\
\hline \multicolumn{2}{|c|}{ Atividade - 1.5 Analisar o portfólio de produtos da empresa } \\
\hline Tarefa $-\mathbf{1 . 5 . 1}$ & Aspectos Ambientais - Código $(18,65,67,86,13$ \\
\hline $\begin{array}{l}\text { Revisar/definir } \\
\text { metodologia de } \\
\text { avaliação de portfólio }\end{array}$ & $\begin{array}{l}\text { Inserir na metodologia de avaliação de portfólio de produtos critérios para } \\
\text { analisar ponderadamente os impactos ambientais do produto, a voz do cliente } \\
\text { e a viabilidade técnica e econômica dos projetos. }\end{array}$ \\
\hline Tarefa $-\mathbf{1 . 5 . 2}$ & Aspectos Ambientais - Código $(51,97,230,324,328)$ \\
\hline $\begin{array}{l}\text { Avaliar o desempenho } \\
\text { dos produtos }\end{array}$ & $\begin{array}{l}\text { Definir critérios de desempenho ambiental para avaliar o produto e comparar } \\
\text { os projetos do portfólio. Esses critérios devem verificar se o produto atende } \\
\text { aos requisitos e regulamentações ambientais, qual o consumo de energia e se } \\
\text { causa prejuízo a saúde humana, biodiversidade, ecossistema e vegetação. }\end{array}$ \\
\hline Tarefa - 1.5.3 & $\begin{array}{l}\text { Aspectos Ambientais - Código }(10,19,23,90,103,154,256,287,330 \text {, } \\
361 \text { ) }\end{array}$ \\
\hline $\begin{array}{l}\text { Avaliar tecnologias e } \\
\text { plataformas utilizadas }\end{array}$ & $\begin{array}{l}\text { Avaliar o impacto ambiental das tecnologias propostas no portfólio de } \\
\text { produtos, consultando a base de dados (Biblioteca Ambiental) e a } \\
\text { especificação técnica dos equipamentos. Desta forma, pode-se escolher a } \\
\text { tecnologia que não gera resíduos para disposição, não utiliza materiais tóxicos } \\
\text { e nem oriundos de fontes escassas. }\end{array}$ \\
\hline Tarefa - 1.5.4 & Aspectos Ambientais - Código (70) \\
\hline $\begin{array}{l}\text { Consolidar lista de } \\
\text { idéias de novos } \\
\text { produtos e analisar os } \\
\text { projetos }\end{array}$ & $\begin{array}{l}\text { Elaborar a lista de idéias e classificá-la conforme o impacto ambiental dos } \\
\text { produtos e identificar oportunidades ambientais comparando os conceitos } \\
\text { iniciais propostos. }\end{array}$ \\
\hline
\end{tabular}


Tabela 6.1 - Fase de Planejamento Estratégico de Produtos - continuação.

\begin{tabular}{|c|c|}
\hline \multicolumn{2}{|c|}{$\begin{array}{l}\text { Macrofase - Pré-Desenvolvimento } \\
\text { Fase } 1 \text { - Planejamento Estratégico de Produtos (PEP) }\end{array}$} \\
\hline \multicolumn{2}{|c|}{ Atividade - 1.6 Propor mudanças no portfólio de produtos } \\
\hline Tarefa - 1.6.1 & Aspectos Ambientais - Código $(18,86)$ \\
\hline $\begin{array}{lr}\text { Identificar } & \text { produtos } \\
\text { projetos a } & \text { serem } \\
\text { descontinuados, } & \\
\text { abandonados } & \text { e } \\
\text { congelados } & \text { ou } \\
\text { iniciados } & \end{array}$ & $\begin{array}{l}\text { Definir critérios de viabilidade ambiental para analisar, priorizar e selecionar os } \\
\text { projetos que continuarão no portfólio. }\end{array}$ \\
\hline \multicolumn{2}{|c|}{ Atividade - 1.7 Verificar viabilidade do portfólio de produtos } \\
\hline Tarefa - 1.7.1 & Aspectos Ambientais - Código $(18,25,72,89,204,271,301,343)$ \\
\hline $\begin{array}{l}\text { Avaliar viabilidade } \\
\text { econômica e ambiental } \\
\text { do portfólio de projetos }\end{array}$ & $\begin{array}{l}\text { Na análise de viabilidade econômica do portfólio de projetos inserir critérios } \\
\text { ambientais que impactam no custo final do produto, tais como: Transformar } \\
\text { os impactos ambientais em valores monetários; } \\
\text { Incluir os custos diretos e indiretos relativos aos impactos ambientais } \\
\text { potenciais do produto; Analisar os custos de reciclagem, montagem, } \\
\text { desmontagem, disposição, etc.; Considerar as taxas e penalidades } \\
\text { ecológicas; e Calcular o custo do produto considerando todo o ciclo de vida } \\
\text { do produto. }\end{array}$ \\
\hline Tarefa - 1.7.2 & Aspectos Ambientais - Código $(38,262,292)$ \\
\hline Avaliar competências & $\begin{array}{l}\text { Adequar o programa de desenvolvimento e treinamento dos funcionários, } \\
\text { conforme as necessidades de conhecimento ambiental para cada projeto ou } \\
\text { tecnologia. }\end{array}$ \\
\hline \multicolumn{2}{|c|}{ Atividade - 1.8 Decidir início do planejamento de um produto do portfólio } \\
\hline Tarefa - 1.8.1 & Aspectos Ambientais \\
\hline $\begin{array}{l}\text { Monitorar o portfólio de } \\
\text { produtos e identificar a } \\
\text { data dos novos projetos }\end{array}$ & Retirado o aspecto ambiental. \\
\hline
\end{tabular}

$\mathrm{Na}$ fase de Planejamento do Projeto (PP) busca-se fazer um plano do projeto contendo todas as atividades necessárias para execução correta do projeto, tais como: elaboração de escopo do projeto, cronograma, orçamento, pessoal que deve ser envolvido e as responsabilidades, recursos e informações necessárias, analise de riscos e indicadores de desempenho. Esse plano do projeto é utilizado para gestão do projeto e deve ser atualizado constantemente para acompanhar a sua evolução no PDP.

Nesta fase a proposta de integrar aspectos ambientais enfatiza a necessidade de criar indicadores ambientais para melhor gestão do projeto, inserir os custos ambientais no orçamento do projeto, pontuar os riscos potenciais de impacto ambiental do produto, quantificar os custos ambientais para serem utilizados nas análises de viabilidade do projeto, atender os requisitos ambientais do cliente e compartilhar as responsabilidades ambientais do produto com os fornecedores. A Tabela 6.2 apresenta as funções da integração ambiental nessa fase do PDP. 
Tabela 6.2 - Fase de Planejamento do Projeto.

\begin{tabular}{|c|c|}
\hline & $\begin{array}{l}\text { Macrofase - Pré-Desenvolvimento } \\
\text { Fase } 2 \text { - Planejamento do Projeto (PP) }\end{array}$ \\
\hline Atividade - 2.1 Definir in & teressados do projeto \\
\hline Tarefa - 2.1.1 & Aspectos Ambientais - Código $(120,141,195)$ \\
\hline $\begin{array}{l}\text { Montagem da equipe } \\
\text { com os interessados do } \\
\text { projeto }\end{array}$ & $\begin{array}{l}\text { Envolver a área de meio ambiente na equipe de PDP e utilizar o } \\
\text { conhecimento dos interessados e envolvidos no projeto (cadeia de } \\
\text { suprimentos, stakeholders e clientes) para contribuir com a melhoria da } \\
\text { performance ambiental do produto. }\end{array}$ \\
\hline Tarefa - 2.1.2 & Aspectos Ambientais - Código $(38,292)$ \\
\hline $\begin{array}{l}\text { Desenvolvimento da } \\
\text { equipe para a execução } \\
\text { do projeto }\end{array}$ & $\begin{array}{l}\text { Adequar o programa de desenvolvimento e treinamento dos profissionais } \\
\text { envolvidos no desenvolvimento do projeto, conforme as necessidades de } \\
\text { conhecimento ambiental para cada produto, processo e tecnologia. }\end{array}$ \\
\hline Atividade - 2.2 Definir es & copo do produto \\
\hline Tarefa - 2.2.1 & Aspectos Ambientais - Código $(9,55,95,336)$ \\
\hline $\begin{array}{l}\text { Definir diretrizes básicas } \\
\text { que o produto deverá } \\
\text { atender }\end{array}$ & $\begin{array}{l}\text { Definir as premissas ambientais que o produto deve atender com base nos } \\
\text { requisitos do cliente, nas normas do sistema de gestão ambiental e } \\
\text { legislação ambiental. }\end{array}$ \\
\hline Atividade - 2.3 Avaliar ris & $\operatorname{scos}$ \\
\hline Tarefa - 2.3.1 & Aspectos Ambientais - Código $(69,93,194,220)$ \\
\hline $\begin{array}{l}\text { Planejar avaliação de } \\
\text { risco do projeto de DP }\end{array}$ & $\begin{array}{l}\text { Planejar avaliar os riscos de impacto ambiental do produto para cada } \\
\text { passagem de fase do PDP, dando um maior enfoque nas fases iniciais de } \\
\text { desenvolvimento do conceito do produto. }\end{array}$ \\
\hline Tarefa $-\mathbf{2} .3 .2$ & $\begin{array}{l}\text { Aspectos Ambientais - Código }(7,23,41,52,56,69,75,135,148,154 \text {, } \\
237,261,289,290,297,361,364)\end{array}$ \\
\hline $\begin{array}{l}\text { Identificar e caracterizar } \\
\text { os riscos potenciais }\end{array}$ & $\begin{array}{l}\text { Identificar os riscos potenciais de impacto ambiental do produto e a } \\
\text { responsabilidade da empresa durante todo o ciclo de vida do produto. Para } \\
\text { isso, deve-se caracterizar o perfil ambiental do produto comparando com a } \\
\text { base de dados (Biblioteca Ambiental) e avaliando outros riscos potenciais: } \\
\text { Impactos ambientais da tecnologia; Impactos da destinação dos resíduos, } \\
\text { capacidade de armazenamento, destruição e utilização de aterros sanitários; } \\
\text { Impactos ambientais da extração de recursos, emissões relevantes e uso do } \\
\text { solo; Riscos potenciais à saúde e ao meio ambiente, devido à exposição a } \\
\text { substâncias tóxicas e químicas; e Perspectiva legal do produto. }\end{array}$ \\
\hline Tarefa - 2.3.3 & Aspectos Ambientais - Código $(9,58,69,364)$ \\
\hline $\begin{array}{l}\text { Analisar } \\
\text { qualitativamente e } \\
\text { quantitativamente os } \\
\text { riscos potenciais }\end{array}$ & $\begin{array}{l}\text { Analisar os riscos potenciais do perfil ambiental do produto com relação à } \\
\text { legislação ambiental e as necessidades atuais e emergentes do cliente. }\end{array}$ \\
\hline Tarefa -2.3 .4 & Aspectos Ambientais - Código $(69,105,213)$ \\
\hline $\begin{array}{l}\text { Planejar, controlar e } \\
\text { monitorar ações em } \\
\text { resposta aos riscos } \\
\text { potenciais }\end{array}$ & $\begin{array}{l}\text { Avaliar os riscos potenciais e propor soluções para minimizar o impacto } \\
\text { ambiental, tais como: Instalar proteção contra a emissão de poluentes e } \\
\text { substâncias perigosas; e Desenvolver plano de contingência para } \\
\text { reabilitação em caso de acidente ambiental. }\end{array}$ \\
\hline Atividade - 2.4 Preparar & orçamento do projeto \\
\hline Tarefa - 2.4.1 & Aspectos Ambientais - Código $(38,292,336)$ \\
\hline $\begin{array}{l}\text { Previsões dos custos } \\
\text { relacionados às } \\
\text { atividades e recursos }\end{array}$ & $\begin{array}{l}\text { Planejar custos com implantação, desenvolvimento e treinamento dos } \\
\text { profissionais em métodos e ferramentas de ecodesign. Além disso, } \\
\text { considerar os custos com manutenção do sistema de gestão ambiental e } \\
\text { divulgação das melhores práticas de ecodesign. }\end{array}$ \\
\hline
\end{tabular}


Tabela 6.2 - Fase de Planejamento do Projeto - continuação.

\begin{tabular}{|c|c|}
\hline & $\begin{array}{l}\text { Macrofase - Pré-Desenvolvimento } \\
\text { Fase } 2 \text { - Planejamento do Projeto (PP) }\end{array}$ \\
\hline Atividade - 2.5 Analisar & a viabilidade econômica do projeto \\
\hline Tarefa - 2.5.1 & Aspectos Ambientais - Código (72) \\
\hline Definir custo-alvo & $\begin{array}{l}\text { Definir metas de custo do projeto considerando as estimativas de custos } \\
\text { ambientais para todo o ciclo de vida do produto. }\end{array}$ \\
\hline Tarefa $\mathbf{- 2 . 5 . 2}$ & Aspectos Ambientais - Código $(18,20,25,64,67,72)$ \\
\hline $\begin{array}{l}\text { Realizar avaliação } \\
\text { econômica }\end{array}$ & $\begin{array}{l}\text { Aprofundar nos critérios de viabilidade ambiental citados na atividade de } \\
\text { análise de portfólio e quantificar esses custos para realizar uma análise } \\
\text { econômica mais precisa dos projetos. }\end{array}$ \\
\hline Atividade - 2.6 Definir ir & dicadores de desempenho \\
\hline Tarefa - 2.6.1 & Aspectos Ambientais - Código $(92,93,94,196,215)$ \\
\hline $\begin{array}{l}\text { Selecionar indicadores } \\
\text { de desempenho mais } \\
\text { adequados conforme o } \\
\text { impacto ambiental e a } \\
\text { fase do ciclo de vida do } \\
\text { produto }\end{array}$ & $\begin{array}{l}\text { Selecionar, integrar e ponderar os indicadores de desempenho ambiental } \\
\text { com base nos pontos ambientais críticos do produto e processo. Esses } \\
\text { indicadores devem estar relacionados com o impacto ambiental do produto } \\
\text { em cada case do ciclo de vida, conforme os seguintes exemplos: Indicador } \\
\text { do potencial de reciclagem que quantifica a aplicabilidade de um } \\
\text { produto/material para diferentes rotas de reciclagem; Indicadores de emissão } \\
\text { de gases de efeito estufa e depleção da camada de ozônio; Indicadores de } \\
\text { consumo de energia, água e materiais; Indicadores de intensidade de } \\
\text { duração que avalia as economias de recursos para a produção e } \\
\text { manutenção de um produto que tem uma vida útil maior; e Indicadores de } \\
\text { intensidade de recuperação que mede a economia de recursos por } \\
\text { recuperação de materiais ou a porcentagem de material reciclado. }\end{array}$ \\
\hline Atividade -2.7 & preparar aquisições \\
\hline Tarefa - 2.7.1 & Aspectos Ambientais - Código $(42,118,119)$ \\
\hline $\begin{array}{l}\text { Preparar requerimentos } \\
\text { de aquisição e } \\
\text { identificar fornecedores } \\
\text { potenciais e parceiros }\end{array}$ & $\begin{array}{l}\text { Na elaboração da documentação para selecionar os fornecedores, inserir } \\
\text { questões para avaliar a capacidade de produção, preocupação ambiental e } \\
\text { se os mesmos atendem a legislação ambiental. Para isso pode-se utilizar o } \\
\text { conceito de logística reversa. }\end{array}$ \\
\hline Tarefa -2.7 .2 & Aspectos Ambientais - Código $(141,325)$ \\
\hline $\begin{array}{l}\text { Planejar a gestão dos } \\
\text { relacionamentos com os } \\
\text { fornecedores }\end{array}$ & $\begin{array}{l}\text { Planejar de no momento de elaborar o contrato com os fornecedores } \\
\text { selecionados, atentar às cláusulas de responsabilidade ambiental de cada } \\
\text { parte. }\end{array}$ \\
\hline Atividade - 2.8 Preparar & plano de projeto \\
\hline Tarefa -2.8 .1 & Aspectos Ambientais - Código $(115,322)$ \\
\hline $\begin{array}{l}\text { Discussão e redação do } \\
\text { plano de projeto }\end{array}$ & $\begin{array}{l}\text { Discutir os aspectos ambientais do produto e seus impactos e inserir toda a } \\
\text { documentação pertinente no plano de projeto. }\end{array}$ \\
\hline
\end{tabular}

$\mathrm{Na}$ macrofase de Desenvolvimento se estabelece os conceitos do produto com as especificações meta de projeto e processo e os aspectos tecnológicos que serão utilizados durante o desenvolvimento, produção e distribuição do produto ao cliente final. Esta macrofase está subdividida nas fases de Projeto Informacional (PI), Projeto Conceitual (PC), Projeto Detalhado (PD), Preparação da Produção do Produto (PPP) e Lançamento do Produto (LP). A primeira fase de Projeto Informacional $(\mathrm{PI})$ tem a função de analisar as informações levantadas nas fases anteriores do PDP e elaborar as especificações meta do produto para que a equipe de projeto desenvolva alternativas para concepção do produto. Nessa análise, 
busca-se ponderar as necessidades e requisitos dos clientes com as restrições para desenvolver o projeto. Nesse momento do PDP, a proposta de inserir aspectos ambientais está em orientar a equipe de projeto a pensar em novas soluções para resolver os problemas de projeto ponderando os requisitos funcionais com os ambientais, manter o alinhamento com a estratégia de mercado da empresa e atender as necessidades ambientais dos clientes e legislação. Além disso, é preciso planejar os impactos ambientais do produto durante todas as etapas do ciclo de vida (desenvolvimento, produção, uso e serviços e descarte) e quais as soluções alternativas para mitigá-los. A Tabela 6.3 ilustra como foi estruturada a fase de Projeto Informacional (PI) do PDP considerando os aspectos ambientais.

Tabela 6.3 - Fase de Projeto Informacional.

\begin{tabular}{|c|c|}
\hline \multicolumn{2}{|c|}{ Macrofase - Desenvolvimento } \\
\hline \multicolumn{2}{|c|}{ Atividade - 3.1 Atualizar o plano do projeto informacional } \\
\hline Tarefa - 3.1.1 & Aspectos Ambientais - Código $(33,120,177,250,272)$ \\
\hline $\begin{array}{l}\text { Atualizar o escopo do } \\
\text { produto }\end{array}$ & $\begin{array}{l}\text { Revisar e atualizar o escopo do produto com base na redução de impactos } \\
\text { ambientais definidos nas fases anteriores de Planejamento Estratégico de } \\
\text { Produto e Planejamento do Projeto. }\end{array}$ \\
\hline Tarefa-3.1.2 & Aspectos Ambientais - Código $(193,301,328)$ \\
\hline $\begin{array}{l}\text { Atualizar estimativa de } \\
\text { orçamento do projeto }\end{array}$ & $\begin{array}{l}\text { Atualizar as estimativas de orçamento do projeto conforme as alternativas } \\
\text { ambientais forem sendo definidas, como a escolha da estratégia de fim de } \\
\text { vida do produto a ser utilizada (reciclagem, recuperação, disposição, etc.). }\end{array}$ \\
\hline Tarefa - 3.1.3 & Aspectos Ambientais - Código $(9,58,69,364)$ \\
\hline Avaliar novos riscos & $\begin{array}{l}\text { Analisar os riscos potenciais do perfil ambiental do produto com relação à } \\
\text { legislação ambiental e as necessidades atuais e emergentes do cliente. }\end{array}$ \\
\hline Tarefa - 3.1.4 & Aspectos Ambientais - Có \\
\hline $\begin{array}{l}\text { Definir/atualizar os } \\
\text { critérios de passagem } \\
\text { dos Gates }\end{array}$ & $\begin{array}{l}\text { Atualizar os critérios de avaliação ambiental do produto para verificar se o } \\
\text { projeto deve ser congelado, abandonado ou passar para próxima fase do } \\
\text { PDP. }\end{array}$ \\
\hline \multicolumn{2}{|c|}{ Atividade - 3.2 Revisar e atualizar o escopo do produto } \\
\hline Tarefa - 3.2.1 & Aspectos Ambientais - Código \\
\hline $\begin{array}{l}\text { Análise do problema de } \\
\text { projeto }\end{array}$ & $\begin{array}{l}\text { Pensar em novas soluções ambientais para resolver os problemas de projeto } \\
\text { e pesquisar maneiras alternativas para fornecer o mesmo serviço, visando } \\
\text { atender as necessidades ambientais por meio de técnicas de uso } \\
\text { compartilhado, produtos com multi-função, materiais mais leves, etc. }\end{array}$ \\
\hline Tarefa-3.2.2 & Aspectos Ambientai \\
\hline $\begin{array}{lr}\text { Analisar } & \text { tecnologias } \\
\text { disponíveis } & e \\
\text { necessárias } & \end{array}$ & $\begin{array}{l}\text { Revisar e analisar o impacto ambiental das tecnologias disponíveis visando } \\
\text { minimizar o impacto ambiental. }\end{array}$ \\
\hline Tarefa - 3.2.3 & Aspectos Ambientais - Código $(9,55,95,261,336)$ \\
\hline $\begin{array}{l}\text { Pesquisar padrões } / \\
\text { normas, patentes e } \\
\text { legislação }\end{array}$ & $\begin{array}{l}\text { Pesquisar as informações ambientais disponíveis sobre o produto, por meio } \\
\text { de consulta as leis sobre uso de substâncias tóxicas, proibições e restrições } \\
\text { de uso, tendência da legislação, patentes e normas de gestão ambiental. }\end{array}$ \\
\hline
\end{tabular}


Tabela 6.3 - Fase de Projeto Informacional - continuação.

\begin{tabular}{|c|c|}
\hline & $\begin{array}{l}\text { Macrofase - Desenvolvimento } \\
\text { Fase } 3 \text { - Projeto Informacional (PI) }\end{array}$ \\
\hline Atividade - 3.2 Revisar e & atualizar o escopo do produto \\
\hline Tarefa - 3.2.4 & Aspectos Ambientais - Código $(70,76,90,130,138)$ \\
\hline $\begin{array}{l}\text { Pesquisar produtos } \\
\text { concorrentes e similares }\end{array}$ & $\begin{array}{l}\text { Pesquisar no mercado soluções ambientais utilizadas nos produtos } \\
\text { concorrentes e analisar a aplicabilidade no projeto em desenvolvimento. } \\
\text { Com isso consegue-se identificar oportunidades de melhoria ambiental para } \\
\text { o produto. }\end{array}$ \\
\hline Atividade - 3.3 Detalhar & ciclo de vida do produto e definir seus clientes \\
\hline Tarefa - 3.3.1 & Aspectos Ambientais - Código $(2,140)$ \\
\hline $\begin{array}{l}\text { Refinar o ciclo de vida } \\
\text { do produto }\end{array}$ & $\begin{array}{l}\text { Identificar e detalhar as fases do ciclo de vida do produto que apresentam o } \\
\text { maior impacto ambiental, considerando o consumo de energia. Além disso, } \\
\text { precisa-se pensar em outros aspectos ambientais relacionados, como por } \\
\text { exemplo: Estender a expectativa de vida dos materiais e serviços; e Agrupar } \\
\text { os componentes com o mesmo ciclo de vida em módulo para minimizar o } \\
\text { seu impacto ambiental no fim de vida. }\end{array}$ \\
\hline Tarefa - 3.3.2 & Aspectos Ambientais - Código $(141,263)$ \\
\hline $\begin{array}{l}\text { Definir os clientes do } \\
\text { projeto ao longo do ciclo } \\
\text { de vida físico }\end{array}$ & $\begin{array}{l}\text { Planejar o ciclo de vida do produto considerando todas as etapas (do berço } \\
\text { ao túmulo) os respectivos impactos ambientais e como serão mitigados para } \\
\text { atender as expectativas dos clientes. Também definir qual é o papel e } \\
\text { responsabilidade dos clientes para minimizar o impacto ambiental. }\end{array}$ \\
\hline Atividade - 3.4 Identifica & r os requisitos dos clientes do produto \\
\hline Tarefa - 3.4.1 & Aspectos Ambientais - Código $(141,325)$ \\
\hline $\begin{array}{l}\text { Coletar e classificar as } \\
\text { necessidades dos } \\
\text { clientes de cada fase do } \\
\text { ciclo de vida }\end{array}$ & $\begin{array}{l}\text { Estabelecer os objetivos gerais e ambientais do ciclo de vida alvo, por meio } \\
\text { da coleta e avaliação das necessidades ambientais dos clientes. }\end{array}$ \\
\hline Tarefa $-\mathbf{3 . 4 . 2}$ & Aspectos Ambientais - Código $(68,134,212,321)$ \\
\hline $\begin{array}{l}\text { Definir os requisitos dos } \\
\text { clientes }\end{array}$ & $\begin{array}{l}\text { Definir os requisitos ambientais do cliente com base na análise ponderada } \\
\text { das necessidades dos clientes em termos de função, uso e perspectiva } \\
\text { ambiental. }\end{array}$ \\
\hline Tarefa - 3.4.3 & Aspectos Ambientais - Código $(64,68,212)$ \\
\hline $\begin{array}{l}\text { Valorar os requisitos } \\
\text { dos clientes }\end{array}$ & $\begin{array}{l}\text { Avaliar os requisitos do cliente com base na valorização e ponderação dos } \\
\text { requisitos ambientais e a necessidade de atender as regulamentações } \\
\text { ambientais. }\end{array}$ \\
\hline Atividade - 3.5 Definir re & quisitos do produto \\
\hline Tarefa -3.5 .1 & Aspectos Ambientais - Código $(64,68,212)$ \\
\hline $\begin{array}{l}\text { Converter requisitos de } \\
\text { clientes em expressões } \\
\text { mensuráveis }\end{array}$ & $\begin{array}{l}\text { Definir os requisitos ambientais do produto e classificar com base nos } \\
\text { respectivos impactos ambientais e o cumprimento das funções técnicas } \\
\text { exigidas pelos clientes. }\end{array}$ \\
\hline Tarefa - 3.5.2 & Aspectos Ambientais - Código $(64,65,67,68,71,139)$ \\
\hline $\begin{array}{l}\text { Analisar, classificar e } \\
\text { hierarquizar } \\
\text { requisitos do produto }\end{array}$ & $\begin{array}{l}\text { Estabelecer uma plataforma de comunicação entre as prioridades funcionais } \\
\text { e os impactos ambientais para analisar, classificar e hierarquizar os } \\
\text { requisitos de projeto do produto. }\end{array}$ \\
\hline Atividade - 3.6 Definir es & pecificações meta do produto \\
\hline Tarefa - 3.6.1 & Aspectos Ambientais - Código $(64,65,67,68)$ \\
\hline $\begin{array}{l}\text { Valorar requisitos do } \\
\text { produto }\end{array}$ & Valoração dos requisitos ambientais do produto. \\
\hline Tarefa $-\mathbf{3 . 6 . 2}$ & Aspectos Ambientais - Código $(74,77,175,231)$ \\
\hline $\begin{array}{l}\text { Analisar perfil técnico e } \\
\text { de mercado }\end{array}$ & $\begin{array}{l}\text { Descrever o perfil ambiental do produto com base na análise dos produtos } \\
\text { concorrentes e similares encontrados na pesquisa de mercado. }\end{array}$ \\
\hline
\end{tabular}


Tabela 6.3 - Fase de Projeto Informacional - continuação.

\begin{tabular}{|c|c|}
\hline & $\begin{array}{l}\text { Macrofase - Desenvolvimento } \\
\text { Fase } 3 \text { - Projeto Informacional (PI) }\end{array}$ \\
\hline Atividade - 3.6 Definir es & pecificações meta do produto \\
\hline Tarefa - 3.6.3 & Aspectos Ambientais - Código $(55,69,326)$ \\
\hline $\begin{array}{l}\text { Analisar restrições de } \\
\text { projeto do produto } \\
\text { (contrato, ambientais, } \\
\text { legislação, normas.) }\end{array}$ & $\begin{array}{l}\text { Revisar os riscos potenciais e avaliar novas restrições ambientais de projeto } \\
\text { do produto, com base nos requisitos do cliente e no sistema de gestão } \\
\text { ambiental e legislação. }\end{array}$ \\
\hline Tarefa -3.6 .4 & $\begin{array}{l}\text { Aspectos Ambientais - Código }(3,4,5,6,31,33,34,36,40,41,87,88 \\
100,108,109,124,126,128,129,130,136,146,147,148,149,150,151 \\
152,153,154,162,174,180,184,187,189,234,235,236,256,296,305 \\
329,360,361)\end{array}$ \\
\hline $\begin{array}{l}\text { Elaborar o conjunto de } \\
\text { especificações-meta do } \\
\text { produto }\end{array}$ & $\begin{array}{l}\text { Elaborar um conjunto de especificações-meta do produto alinhando os } \\
\text { requisitos do cliente, estratégia de mercado da empresa com os seguintes } \\
\text { aspectos ambientais, para se minimizar o impacto ambiental: Escolher } \\
\text { tecnologias com opções de ajuste automático para consumo mínimo de } \\
\text { energia; Especificar materiais e componentes confiáveis para ter segurança } \\
\text { ambiental no estágio de uso; Escolher juntas e parafusos facilmente } \\
\text { acessíveis; Especificar controles de recursos simples de operar e entender; } \\
\text { Optar por tecnologias que geram resíduos à base de água ou } \\
\text { biodegradáveis; Pensar em alternativas para facilitar a atualização e } \\
\text { adaptação do produto; Especificar materiais com maior durabilidade, } \\
\text { resistência e tempo de vida; Especificar materiais e componentes visando } \\
\text { um produto com maior funcionalidade; Especificar produto com } \\
\text { características ergonômicas adequadas; Minimizar o número de } \\
\text { componentes, conexões e diferentes materiais; Preferir estrutura modular; } \\
\text { Pensar em alternativas para evitar a geração de resíduos para disposição; } \\
\text { Escolher componentes de alta eficiência energética e de fontes renováveis e } \\
\text { limpas; Selecionar materiais não misturados, não compostos e não ligados; } \\
\text { Especificar materiais que não necessitam de tratamento adicional de } \\
\text { superfície ou tintas; Optar por materiais recicláveis ou reciclados } \\
\text { especialmente aqueles dentro da empresa ou para os quais existe um } \\
\text { mercado ou precisa ser estimulado; Pensar em articulações de modo que } \\
\text { elas sejam separáveis manualmente ou empregam apenas ferramentas } \\
\text { simples; Evitar dobras estreitas e buracos, para facilitar a limpeza; } \\
\text { Especificar materiais com espessura menor e mais leve; e Escolher } \\
\text { tecnologia, materiais e energia renovável. }\end{array}$ \\
\hline Atividade - 3.7 Monitorar & a viabilidade econômico-financeira do produto \\
\hline Tarefa-3.7.1 & Aspectos Ambientais \\
\hline $\begin{array}{l}\text { Avaliar mudanças nas } \\
\text { condições de mercado, } \\
\text { características técnicas } \\
\text { e indicadores }\end{array}$ & Retirado o aspecto ambiental. \\
\hline Tarefa - 3.7.2 & Aspectos Ambientais - Código $(18,20,25,64,67,72)$ \\
\hline $\begin{array}{l}\text { Avaliar possíveis } \\
\text { desvios e impactos no } \\
\text { projeto }\end{array}$ & $\begin{array}{l}\text { Analisar e monitorar a viabilidade econômica do projeto com base nos } \\
\text { impactos ambientais das escolhas feitas para o produto. }\end{array}$ \\
\hline Atividade - 3.8 Documen & tar as decisões tomadas e registrar lições aprendidas \\
\hline Tarefa -3.8 .1 & Aspectos Ambientais - Código $(1,103,195)$ \\
\hline $\begin{array}{l}\text { Documentar } \\
\text { decisões tomadas e e } \\
\text { registrar } r \quad \text { lições } \\
\text { aprendidas }\end{array}$ & $\begin{array}{l}\text { Acumular conhecimentos com os feedbacks das implicações das escolhas } \\
\text { feitas e documentar através da atualização da base de dados (Biblioteca } \\
\text { Ambiental) durante o ciclo de vida do produto. Além disso, deve-se divulgar } \\
\text { esse conhecimento de melhores práticas de ecodesign as pessoas } \\
\text { envolvidas no PDP. }\end{array}$ \\
\hline
\end{tabular}


$\mathrm{Na}$ fase de Projeto Conceitual (PC) ocorre a concepção do produto, no qual a equipe de projeto, com base nas especificações metas propostas na fase anterior, define a tecnologia, o processo de fabricação, a arquitetura e as características esperadas para atender a função do produto. Nessa fase conceitual, os aspectos ambientais integrados nas tarefas do PDP visam orientar a equipe de projeto em relação à importância de se considerar o impacto ambiental já nas escolhas conceituais do produto. Também é interessante visualizar uma estratégia de fim de vida do produto e destaca-se que é possível atender aos requisitos dos clientes combinando alternativas ambientais e funcionais de projeto. Na concepção do produto é importante apontar quais são os sistemas, subsistemas e componentes que precisam ser melhores avaliados em termos de integração e impacto ambiental na fase de Projeto Detalhado (PD). A Tabela 6.4 mostra a fase de Projeto Conceitual (PC) e os respectivos aspectos ambientais inseridos em cada tarefa do PDP.

Tabela 6.4 - Fase de Projeto Conceitual.

\begin{tabular}{|c|c|}
\hline & $\begin{array}{l}\text { Macrofase - Desenvolvimento } \\
\text { Fase } 4 \text { - Projeto Conceitual (PC) }\end{array}$ \\
\hline Atividade - 4.1 Atualizar & o plano do projeto conceitual \\
\hline Tarefa -4.1 .1 & Aspectos Ambientais - Código $(33,120,177,250,272)$ \\
\hline $\begin{array}{l}\text { Atualizar o escopo do } \\
\text { produto }\end{array}$ & $\begin{array}{l}\text { Revisar e atualizar o escopo do produto com base na redução de impactos } \\
\text { ambientais definidos na fase anterior de Projeto Informacional. }\end{array}$ \\
\hline Tarefa - 4.1.2 & Aspectos Ambientais - Código $(193,301,328)$ \\
\hline $\begin{array}{l}\text { Atualizar estimativa de } \\
\text { orçamento do projeto }\end{array}$ & $\begin{array}{l}\text { Atualizar as estimativas de orçamento do projeto conforme as alternativas } \\
\text { ambientais forem sendo definidas, como a escolha da estratégia de fim de } \\
\text { vida do produto a ser utilizada (reciclagem, recuperação, disposição, etc.) }\end{array}$ \\
\hline Tarefa - 4.1.3 & Aspectos Ambientais - Código $(93,94,196,215)$ \\
\hline $\begin{array}{lr}\text { Atualizar, } & \text { monitorar, } \\
\text { valorar e definir } & \text { novos } \\
\text { indicadores } & \text { de } \\
\text { desempenho } & \end{array}$ & $\begin{array}{l}\text { Atualizar e monitorar os indicadores de desempenho ambiental com base } \\
\text { nos pontos ambientais críticos do produto e processos. }\end{array}$ \\
\hline Tarefa - 4.1.4 & Aspectos Ambientais - Código $(9,52,53,54,58,69,175,192,364)$ \\
\hline Avaliar novos riscos & $\begin{array}{l}\text { Analisar os riscos potenciais do perfil ambiental do produto com relação à } \\
\text { legislação ambiental e as necessidades atuais e emergentes do cliente. }\end{array}$ \\
\hline Tarefa -4.1 .5 & Aspectos Ambientais - Código (51) \\
\hline $\begin{array}{l}\text { Definir/atualizar os } \\
\text { critérios de passagem } \\
\text { dos Gates }\end{array}$ & $\begin{array}{l}\text { Atualizar os critérios de avaliação ambiental do produto para verificar se o } \\
\text { projeto deve ser congelado, abandonado ou passar para próxima fase do } \\
\text { PDP. }\end{array}$ \\
\hline
\end{tabular}


Tabela 6.4 - Fase de Projeto Conceitual - continuação.

\begin{tabular}{|c|c|}
\hline \multirow{2}{*}{\multicolumn{2}{|c|}{$\begin{array}{l}\text { Macrofase - Desenvolvimento } \\
\text { Fase } 4 \text { - Projeto Conceitual (PC) }\end{array}$}} \\
\hline & \\
\hline Tarefa - 4.2.1 & $\begin{array}{l}\text { Aspectos Ambientais - Código }(3,6,31,33,34,35,36,40,87,88,100 \\
\text { 108, 109, } 124,126,128,129,130,136,147,162,176,179,180,181,182 \\
183,184,185,186,187,188,189,193,217,224,234,256,296,302,303 \\
304,305,310,311,313,329,341,342,361)\end{array}$ \\
\hline $\begin{array}{ll}\text { Analisar } & \text { as } \\
\text { especificações-meta } & \text { do } \\
\text { produto } & \end{array}$ & $\begin{array}{l}\text { Analisar os requisitos do produto especificados na fase anterior de Projeto } \\
\text { Informacional e definir o perfil ambiental do produto, considerando as } \\
\text { alternativas disponíveis e as características funcionais esperada pelo } \\
\text { mercado. }\end{array}$ \\
\hline Tarefa -4.2 .2 & $\begin{array}{l}\text { Aspectos Ambientais - Código }(73,122,123,124,125,126,127,128, \\
129,130,131,132,133,134,135,137)\end{array}$ \\
\hline $\begin{array}{l}\text { Identificar as funções do } \\
\text { produto e estabelecer a } \\
\text { função global }\end{array}$ & $\begin{array}{l}\text { Identificar as funções técnicas do produto e acrescentar as expectativas } \\
\text { ambientais do cliente para estabelecer a função global. }\end{array}$ \\
\hline Tarefa - 4.2.3 & $\begin{array}{l}\text { Aspectos Ambientais - Código }(122,123,124,125,126,127,128,129, \\
130,131,132,133,134,135,137,221,257,258)\end{array}$ \\
\hline $\begin{array}{l}\text { Estabelecer estruturas } \\
\text { funcionais alternativas e } \\
\text { selecionar }\end{array}$ & $\begin{array}{l}\text { Avaliar a performance ambiental das alternativas de modelo do produto com } \\
\text { base em critérios ambientais definidos em conjunto com a funcionalidade e } \\
\text { utilidade do produto e selecionar a estrutura funcional mais adequada. }\end{array}$ \\
\hline \multicolumn{2}{|c|}{ Atividade - 4.3 Desenvolver as alternativas de solução para o produto } \\
\hline Tarefa - 4.3.1 & Aspectos Ambientais - Código $(59,75,231,353)$ \\
\hline $\begin{array}{l}\text { Desenvolver } r \text { as } \\
\text { alternativas de solução } \\
\text { para o produto }\end{array}$ & $\begin{array}{l}\text { Desenvolver alternativas tecnológicas verdes para fornecer o mesmo serviço } \\
\text { e buscar a redução dos consumos de materiais e energia, uso de } \\
\text { substâncias tóxicas, pensar em novas maneiras de uso compartilhado e } \\
\text { produtos com multi-função. }\end{array}$ \\
\hline \multicolumn{2}{|c|}{ Atividade - 4.4 Definir arquitetura para o produto } \\
\hline Tarefa - 4.4.1 & $\begin{array}{l}\text { Aspectos Ambientais - Código }(30,31,140,142,162,163,164,165,166 \text {, } \\
167,168,169,170,171,172,173,232,233,238,268,306,307,308,309 \\
312,314,316,317,318,319,320,321,330,331,332,351,355)\end{array}$ \\
\hline $\begin{array}{l}\text { Identificar } \quad \text { Sistemas, } \\
\text { Subsistemas } \\
\text { Componentes (SSC) }\end{array}$ & $\begin{array}{l}\text { Identificar e combinar as alternativas ambientais e funcionais de projeto que } \\
\text { atendem aos requisitos do cliente e apontar os SSCs que precisam ser } \\
\text { melhor analisados em termos de integração e impacto ambiental. Para essa } \\
\text { melhor estruturação do produto, deve-se direcionar as escolhas com base } \\
\text { nos seguintes aspectos ambientais: Facilitar as atualizações, reparos e } \\
\text { reciclagem dos componentes e produto; Atentar nas preparações e } \\
\text { substâncias tóxicas; Estender a expectativa de vida dos materiais e serviços; } \\
\text { Minimizar cabos e fios entre as submontagens para arquitetura do produto; } \\
\text { Reduzir o número de ligações que não podem ser desfeitas; Reduzir o uso } \\
\text { de plásticos; Reduzir o padrão de consumo de energia dos subsistemas que } \\
\text { não estão em uso; Reduzir o tempo de montagem e desmontagem; Reduzir } \\
\text { o volume de material e quantidade de peças que integram as funções; Usar } \\
\text { o conceito de reengenharia e modularidade; Repensar a forma das } \\
\text { estruturas, dos componentes, juntas e partes; Selecionar materiais } \\
\text { recicláveis; Selecionar processos que reduzem a geração de resíduos e } \\
\text { descartes de materiais durante a produção; Optar por sistemas com } \\
\text { eficiência de energia nos estágios de operação e uso; e Escolher estrutura } \\
\text { superficial ou aberta para facilitar o acesso aos subconjuntos. }\end{array}$ \\
\hline Tarefa - 4.4.2 & Aspectos Ambientais - Código $(252,268,344)$ \\
\hline $\begin{array}{l}\text { Definir integração entre } \\
\text { SSCs das alternativas } \\
\text { de projeto }\end{array}$ & $\begin{array}{l}\text { Organizar os SSCs em módulos hierárquicos por estética, reparação e } \\
\text { protocolo de fim de vida, focando nas alternativas de projeto que usem a } \\
\text { menor quantidade possível de elementos de junção. }\end{array}$ \\
\hline
\end{tabular}


Tabela 6.4 - Fase de Projeto Conceitual - continuação.

\begin{tabular}{|c|c|}
\hline & $\begin{array}{l}\text { Macrofase - Desenvolvimento } \\
\text { Fase } 4 \text { - Projeto Conceitual (PC) }\end{array}$ \\
\hline Atividade - 4.5 Analisar & Sistemas, Subsistemas e Componentes (SSC) \\
\hline Tarefa - 4.5.1 & Aspectos Ambientais - Código $(60,61,252,344)$ \\
\hline $\begin{array}{l}\text { Identificar e analisar } \\
\text { aspectos críticos do } \\
\text { produto }\end{array}$ & $\begin{array}{l}\text { Analisar os SSCs que foram identificados como críticos anteriormente, em } \\
\text { termos de integração e impacto ambiental, e descrever as escolhas } \\
\text { conceituais feitas para os SSCs como tecnologia, forma e materiais } \\
\text { dimensionados. }\end{array}$ \\
\hline Tarefa -4.5 .2 & $\begin{array}{l}\text { Aspectos Ambientais - Código }(6,16,26,28,34,59,75,100,101,110, \\
117,122,123,124,125,126,127,128,129,130,131,135,136,142,143, \\
145,155,156,157,158,160,167,168,169,171,191,198,200,207,208, \\
209,210,211,230,231,239,241,242,243,244,245,246,247,273,274, \\
276,277,278,279,280,281,282,283,284,285,286,287,288,339,347, \\
349,350,351,357)\end{array}$ \\
\hline $\begin{array}{l}\text { Definir parâmetros } \\
\text { principais (forma, } \\
\text { materiais, dimensões e } \\
\text { capacidades) }\end{array}$ & $\begin{array}{l}\text { Selecionar os principais parâmetros ambientais críticos do projeto, } \\
\text { considerando o seu ciclo de vida e a estratégia de fim de vida planejada. } \\
\text { Para definir o perfil ambiental do produto deve-se atentar aos seguintes } \\
\text { aspectos ambientais para minimizar o impacto ambiental: Aplicar estruturas } \\
\text { entrelaçadas para aumentar a rigidez e eliminar encaixes fracos entre os } \\
\text { componentes; Aplicar técnicas estruturais de materiais para minimizar o } \\
\text { volume total do material; Analisar a composição do material (número de } \\
\text { componentes, diferentes materiais, mais leves e com menos área); } \\
\text { Decompor, desmaterializar e integrar materiais e componentes de maneira } \\
\text { rápida e econômica; Definir parâmetros de tolerância ambiental; Projetar } \\
\text { para reciclagem e reuso e utilizar materiais reciclados; Especificar material } \\
\text { dobrável, flexível, de encaixe ou desmontável para distribuir os produtos em } \\
\text { um estado compacto; Especificar adesivos compatíveis com as etiquetas, } \\
\text { revestimentos e pigmentos que não interferem com a limpeza; Especificar } \\
\text { componentes de alta eficiência energética e energia de fonte mais limpa e } \\
\text { renovável; Especificar materiais não misturados, não compostos e não } \\
\text { ligados para a reciclagem mutuamente compatíveis; Especificar materiais } \\
\text { que não necessitam de tratamento adicional de superfície ou tintas; } \\
\text { Especificar os melhores materiais para proteger os produtos da sujeira, } \\
\text { corrosão e uso; Especificar substâncias não perigosas e de forma } \\
\text { ambientalmente limpa à saúde do usuário; Especificar articulações de modo } \\
\text { que elas sejam separáveis manualmente ou empreguem apenas ferramentas } \\
\text { simples; Estruturar o produto para evitar gerar resíduos e minimizar o } \\
\text { desperdício de material na produção; Facilitar a manutenção, remanufatura e } \\
\text { teste de componentes; Implantar mecanismos automáticos para reiniciar o } \\
\text { produto na sua configuração mais eficiente; Implantar plataformas } \\
\text { reutilizáveis e substituíveis de módulos e componentes; Incorporar controles } \\
\text { intuitivos para economia de recursos e operação parcial (stand by); } \\
\text { Incorporar projetos com conservação de energia; e Usar refil para produtos } \\
\text { de consumo. }\end{array}$ \\
\hline Atividade - 4.6 Definir e & gonomia e estética \\
\hline Tarefa - 4.6.1 & Aspectos Ambientais - Código $(229 ; 252)$ \\
\hline $\begin{array}{l}\text { Definir ergonomia e } \\
\text { estética }\end{array}$ & $\begin{array}{l}\text { Balancear o desempenho ambiental com a estética e funcionalidade do } \\
\text { produto para assegurar essas características durante todo o período de vida } \\
\text { útil do produto. }\end{array}$ \\
\hline Atividade - 4.7 Definir fo & rnecedores e parcerias de co-desenvolvimento \\
\hline Tarefa - 4.7.1 & Aspectos Ambientais - Código $(42,55,102)$ \\
\hline $\begin{array}{l}\text { Definir fornecedores e } \\
\text { parcerias de co- } \\
\text { desenvolvimento }\end{array}$ & $\begin{array}{l}\text { Descentralizar atividades para reduzir volumes transportados e selecionar } \\
\text { fornecedores com capacidade de produção e adequação a legislação } \\
\text { ambiental. É importante desenvolver parceiros de co-desenvolvimento para } \\
\text { contribuir com a melhoria da performance ambiental do produto. }\end{array}$ \\
\hline
\end{tabular}


Tabela 6.4 - Fase de Projeto Conceitual - continuação.

\begin{tabular}{|c|c|}
\hline & $\begin{array}{l}\text { Macrofase - Desenvolvimento } \\
\text { Fase } 4 \text { - Projeto Conceitual (PC) }\end{array}$ \\
\hline Atividade - 4.8 Seleciona & ar a concepção do produto \\
\hline Tarefa - 4.8.1 & Aspectos Ambientais - Código $(16,17,59,65,77,78,79,191,194,263)$ \\
\hline $\begin{array}{l}\text { Analisar as concepções } \\
\text { alternativas }\end{array}$ & $\begin{array}{l}\text { Analisar as concepções alternativas comparando as suas características } \\
\text { ambientais com as de um produto atual como referência. Além disso, deve- } \\
\text { se avaliar o alinhamento das concepções alternativas com a voz do cliente e } \\
\text { as implicações ambientais durante todo o ciclo de vida do produto. }\end{array}$ \\
\hline Tarefa - 4.8.2 & Aspectos Ambientais - Código $(64,65,67,68)$ \\
\hline $\begin{array}{l}\text { Valorar as concepções } \\
\text { alternativas }\end{array}$ & Valorar as concepções ambientais alternativas do produto. \\
\hline Tarefa - 4.8.3 & Aspectos Ambientais - Código $(11,64,65,67,68)$ \\
\hline $\begin{array}{l}\text { Selecionar concepções } \\
\text { mais adequadas }\end{array}$ & $\begin{array}{l}\text { Analisar os impactos ambientais conforme o conceito do produto for sendo } \\
\text { definido, considerando os SSCs e sua integração. }\end{array}$ \\
\hline Atividade - 4.9 Planejar c & processo de manufatura macro/Definir plano macro de processo \\
\hline Tarefa -4.9 .1 & $\begin{array}{l}\text { Aspectos Ambientais - Código (14, 23, 32, 90, 154, 161, 209, 221, } 222 \text {, } \\
223,330,340,361,362)\end{array}$ \\
\hline $\begin{array}{l}\text { Planejar e definir o } \\
\text { plano de processo de } \\
\text { manufatura e o ciclo de } \\
\text { vida do produto }\end{array}$ & $\begin{array}{l}\text { Desenvolver o plano macro de processo com base nas alternativas } \\
\text { tecnológicas com menos impacto ambiental, visando utilizar equipamentos } \\
\text { para montagem de produtos no mesmo local de fabricação, conservação de } \\
\text { energia e otimização da distribuição e logística. }\end{array}$ \\
\hline Atividade - 4.10 Monitora & ar a viabilidade econômico-financeira do produto \\
\hline Tarefa $-\mathbf{4 . 1 0 . 1}$ & Aspectos Ambientais - Código $(18,76,90,93,94,130,138,196,215)$ \\
\hline $\begin{array}{l}\text { Avaliar mudanças nas } \\
\text { condições de mercado, } \\
\text { características técnicas } \\
\text { e indicadores }\end{array}$ & $\begin{array}{l}\text { Monitorar as condições do mercado e avaliar potenciais oportunidades } \\
\text { ambientais. }\end{array}$ \\
\hline Tarefa -4.10 .2 & Aspectos Ambientais - Código $(18,20,25,64)$ \\
\hline $\begin{array}{lr}\text { Avaliar } & \text { possíveis } \\
\text { desvios e impactos no } \\
\text { projeto }\end{array}$ & $\begin{array}{l}\text { Analisar e monitorar a viabilidade ambiental do projeto com base nos } \\
\text { impactos ambientais das escolhas feitas para o produto. }\end{array}$ \\
\hline Tarefa -4.10 .3 & Aspectos Ambientais - Código $(93,94,196,197,215)$ \\
\hline $\begin{array}{l}\text { Analisar } \quad \text { novas } \\
\text { premissas e indicadores }\end{array}$ & $\begin{array}{l}\text { Identificar os aspectos ambientais críticos das escolhas feitas para o produto } \\
\text { e desenvolver ou atualizar os indicadores ambientais. }\end{array}$ \\
\hline Atividade - 4.11 Docume & ntar as decisões tomadas e registrar lições aprendidas \\
\hline Tarefa - 4.11.1 & Aspectos Ambientais - Código $(1,75,103,195)$ \\
\hline $\begin{array}{l}\text { Documentar } \\
\text { decisões tomadas } \\
\text { registrar e } \\
\text { aprendidas }\end{array}$ & $\begin{array}{l}\text { Acumular conhecimentos com os feedbacks das implicações das escolhas } \\
\text { feitas e documentar através da atualização da base de dados (Biblioteca } \\
\text { Ambiental) durante o ciclo de vida do produto. Além disso, deve-se divulgar } \\
\text { esse conhecimento de melhores práticas de ecodesign as pessoas } \\
\text { envolvidas no PDP. }\end{array}$ \\
\hline
\end{tabular}

Essa fase de Projeto Detalhado (PD) avalia e detalhada as informações técnicas da concepção do produto e consequentemente define os SSC com as tolerâncias e elabora a documentação final da especificação do produto, que será enviada ao processo de fabricação. Nessa etapa, são realizados os testes necessários, elaboração do material de suporte, projeto de embalagem do produto, desenvolvimento dos fornecedores, planejamento do processo de fabricação e montagem dos SSC e a homologação do produto. Nessa fase, os aspectos 
ambientais integrados se concentram mais no processo de fabricação, através de orientações para conservação de energia e otimização da distribuição e logística. Também, enfatiza-se a necessidade de aplicar conceitos de remanufatura, recondicionamento, reparabilidade e reuso de materiais e componentes para reduzir o impacto ambiental do produto e processo. Outro ponto importante é a embalagem que precisa ser tratada como parte integrante do produto e, portanto, deve-se avaliar o seu impacto ambiental. Por fim, deve-se pensar num plano de descarte e retirada do produto considerando os respectivos impactos ambientais. A Tabela 6.5 mostra a integração dos aspectos ambientais na fase de Projeto Detalhado (PD).

Tabela 6.5 - Fase de Projeto Detalhado.

\begin{tabular}{|c|c|}
\hline & $\begin{array}{l}\text { Macrofase - Desenvolvimento } \\
\text { Fase } 5 \text { - Projeto Detalhado (PD) }\end{array}$ \\
\hline Atividade - 5.1 Atualizar & o plano do projeto detalhado \\
\hline Tarefa -5.1 .1 & Aspectos Ambientais - Código $(33,120,177,250,272)$ \\
\hline $\begin{array}{l}\text { Atualizar o escopo do } \\
\text { produto }\end{array}$ & $\begin{array}{l}\text { Revisar e atualizar o escopo do produto com base na redução de impactos } \\
\text { ambientais definidos na fase anterior de Projeto Conceitual. }\end{array}$ \\
\hline Tarefa - 5.1.2 & Aspectos Ambientais - Código $(193,301,328)$ \\
\hline $\begin{array}{l}\text { Atualizar estimativa de } \\
\text { orçamento do projeto }\end{array}$ & $\begin{array}{l}\text { Atualizar as estimativas de custo ambiental do projeto, conforme as escolhas } \\
\text { ambientais forem sendo definidas. }\end{array}$ \\
\hline Tarefa - 5.1.3 & Aspectos Ambientais - Código $(93,94,196,215)$ \\
\hline $\begin{array}{lr}\text { Atualizar, } & \text { monitorar, } \\
\text { valorar e definir } & \text { novos } \\
\text { indicadores } & \text { de } \\
\text { desempenho } & \end{array}$ & $\begin{array}{l}\text { Atualizar e monitorar os indicadores de desempenho ambiental com base } \\
\text { nos pontos ambientais críticos do produto e processos. }\end{array}$ \\
\hline Tarefa -5.1 .4 & Aspectos Ambientais - Código $(9,29,58,69,325,333,364)$ \\
\hline Avaliar novos riscos & $\begin{array}{l}\text { Identificar novos riscos potenciais de impacto ambiental do produto, } \\
\text { conforme for evoluindo as definições de conceito do projeto. }\end{array}$ \\
\hline Tarefa - 5.1.5 & Aspectos Ambientais - Código (51) \\
\hline $\begin{array}{l}\text { Definir/atualizar os } \\
\text { critérios de passagem } \\
\text { dos Gates }\end{array}$ & $\begin{array}{l}\text { Atualizar os critérios de avaliação ambiental do produto para verificar se o } \\
\text { projeto deve ser congelado, abandonado ou passar para próxima fase do } \\
\text { PDP. }\end{array}$ \\
\hline Atividade - 5.2 Criar e de & talhar SSC, documentação e configuração \\
\hline Tarefa - 5.2.1 & $\begin{array}{l}\text { Aspectos Ambientais - Código }(30,140,162,163,164,165,166,167 \text {, } \\
168,169,170,171,172,173,238,306,308,309,312,314,317,319,330 \text {, } \\
331,332,351,355)\end{array}$ \\
\hline $\begin{array}{l}\text { Criar, reutilizar, procurar } \\
\text { e codificar SSCs }\end{array}$ & $\begin{array}{l}\text { Criar, detalhar e codificar os SSCs selecionados na fase de Projeto } \\
\text { Conceitual e procurar soluções ambientais para aumentar a vida útil do } \\
\text { produto e reduzir o impacto ambiental dos SSCs. Para isso utilizar os } \\
\text { aspectos ambientais listados na fase anterior de Projeto Conceitual. }\end{array}$ \\
\hline Tarefa - 5.2.2 & Aspectos Ambientais - Código $(28,101)$ \\
\hline Especificar tolerâncias & $\begin{array}{l}\text { Definir parâmetros de tolerância e aplicar técnicas estruturais de materiais } \\
\text { para minimizar o volume total do produto. }\end{array}$ \\
\hline
\end{tabular}


Tabela 6.5 - Fase de Projeto Detalhado - continuação.

\section{Macrofase - Desenvolvimento}

Fase 5 - Projeto Detalhado (PD)

Atividade - 5.2 Criar e detalhar SSC, documentação e configuração

Tarefa $\mathbf{- 5 . 2 . 3}$

Integrar os SSCs
Aspectos Ambientais - Código (2, 26, 98, 104, 136, 226, 277, 344)

Integrar os SSCs com o mesmo ciclo de vida em módulo para minimizar o seu impacto ambiental e aplicar estruturas entrelaçadas para aumentar a rigidez do produto. Além disso, projetar a menor quantidade possível de elementos de junção e optar por partes e produtos que possam ser reparados e desmontados de maneira rápida e econômica e que utilizem ferramentas padronizadas.

Tarefa $\mathbf{- 5 . 2 . 4}$

Aspectos Ambientais - Código (1, 103, 139, 194, 195, 197)

Completar BOM Completar o Bill of Material (BOM) com os impactos e documentos ambientais dos itens selecionados para arquitetura do produto.

\section{Atividade - 5.3 Decidir por fazer ou comprar SSC}

Tarefa - 5.3.1

Levantar informações

de custos, tempo,

capacidades $\mathrm{e}$

competências para 0

desenvolvimento/forneci

mento dos SSCs

\section{Tarefa - 5.3.2}

Decidir entre

desenvolver e produzir

ou comprar SSC

\section{Atividade - 5.4 Desenvolver fornecedores}

Tarefa - 5.4.1

Selecionar fornecedores

Aspectos Ambientais - Código (40, 42, 55, 118, 119)

Selecionar fornecedores estratégicos com capacidade de produção e adequação a legislação ambiental. Além disso, desenvolver parcerias com fornecedores dispostos em contribuir com a redução da quantidade e coleta de embalagens.

\section{Atividade - 5.5 Planejar o processo de fabricação e montagem}

Tarefa $\mathbf{- 5 . 5 . 1}$

Aspectos Ambientais - Código (14, 19, 32, 79, 81, 161, 209, 223, 275, 340, 362)

Planejar processo de fabricação macro

Tarefa $\mathbf{- 5 . 5 . 2}$

Planejar processo de montagem macro

Tarefa $\mathbf{- 5 . 5 . 3}$

Planejar macro processo de fabricação para o fluxo de operação em uma única direção e avaliar o balanço dos materiais tóxicos utilizados e as possibilidades de remoção e tratamento. Optar por alternativas tecnológicas com menos impacto ambiental, projetando equipamentos para montagem de produtos no mesmo local de fabricação, pensar em conservação de energia e otimização da distribuição e logística.

Aspectos Ambientais - Código $(200,338,351,362,364)$

Planejar macroprocesso de montagem utilizando de plataformas reutilizáveis e substituíveis de módulos e componentes. Deve-se planejar pensando nas seguintes práticas de desmontagem e reciclagem: Utilizar equipamentos para montagem de produtos no mesmo local de fabricação; Soldar com materiais compatíveis; Utilizar ciclos fechados para substâncias tóxicas; e Usar estrutura superficial ou aberta para facilitar o acesso aos subconjuntos. Aspectos Ambientais - Código (6, 26, 27, 28, 100, 101, 110, 122, 123, $124,128,129,131,134,135,136,137,143,167,168,169,171,198,200$, $207,208,209,252,278,279,356,357$ )

Desdobrar parâmetros Desdobrar os parâmetros críticos dos SSCs com base nos aspectos críticos dos componentes fabricados
Desdobrar os parâmetros críticos dos SSCs
ambientais listados na fase de Projeto Conceitual. 
Tabela 6.5 - Fase de Projeto Detalhado - continuação.

\begin{tabular}{|c|c|}
\hline \multicolumn{2}{|c|}{$\begin{array}{l}\text { Macrofase - Desenvolvimento } \\
\text { Fase } 5 \text { - Projeto Detalhado (PD) }\end{array}$} \\
\hline \multicolumn{2}{|c|}{ Atividade - 5.5 Planejar o processo de fabricação e montagem } \\
\hline Tarefa - 5.5.4 & Aspectos Ambientais - Código $(63,275,334)$ \\
\hline $\begin{array}{l}\text { Definir e Sequenciar } \\
\text { operações }\end{array}$ & Simplificar a operação e definir o fluxo de produção em uma única direção. \\
\hline Tarefa $-\mathbf{5 . 5 . 5}$ & Aspectos Ambientais - Código $(106,151,352,359)$ \\
\hline $\begin{array}{l}\text { Selecionar / Especificar } \\
\text { máquinas } \\
\text { equipamentos }\end{array}$ & $\begin{array}{l}\text { Selecionar e especificar máquinas e equipamentos com melhor performance } \\
\text { ambiental, que possuam controles para minimizar o consumo de } \\
\text { consumíveis e energia. }\end{array}$ \\
\hline Tarefa $-\mathbf{5 . 5 . 6}$ & Aspectos Ambientais - Código $(184,277,305,307,319,334,335)$ \\
\hline Especificar fixação & $\begin{array}{l}\text { Especificar fixação objetivando reduzir o número de conexões, facilitar } 0 \\
\text { acesso as juntas e parafusos e simplificar a desmontagem dos componentes } \\
\text { para manutenção. }\end{array}$ \\
\hline Tarefa - 5.5.7 & Aspectos Ambientais - Código $(159,291,331)$ \\
\hline Especificar inspeção & $\begin{array}{l}\text { Inspecionar áreas e equipamentos relacionados com impacto ambiental, } \\
\text { como: tratamento de efluentes, filtros de gás, áreas de descarte, etc. }\end{array}$ \\
\hline Tarefa $\mathbf{- 5 . 5 . 8}$ & Aspectos Ambientais - Código (159) \\
\hline $\begin{array}{l}\text { Selecionar / Especificar } \\
\text { métodos e ferramental }\end{array}$ & $\begin{array}{l}\text { Selecionar e especificar métodos e ferramentas com perfil ambiental } \\
\text { adequado às necessidades de operação e a legislação ambiental. }\end{array}$ \\
\hline Tarefa - 5.5.9 & Aspectos Ambientais - Código $(5,49,59,152,190,298,348)$ \\
\hline $\begin{array}{l}\text { Calcular parâmetros de } \\
\text { trabalho }\end{array}$ & $\begin{array}{l}\text { Calcular parâmetros de trabalho considerando a geração de resíduos, } \\
\text { consumo e perda de energia e biodegradabilidade e toxidade dos materiais. }\end{array}$ \\
\hline Tarefa $-\mathbf{5 . 5 . 1 0}$ & Aspectos Ambientais - Código $(105,111,205)$ \\
\hline $\begin{array}{l}\text { Descrever instruções de } \\
\text { trabalho }\end{array}$ & $\begin{array}{l}\text { Desenvolver procedimentos operacionais considerando os impactos } \\
\text { ambientais dos materiais e processos e plano de contingência para } \\
\text { reabilitação em caso de acidente ambiental. }\end{array}$ \\
\hline Tarefa - 5.5.11 & Aspectos Ambientais - Código $(15,37,94,299,331,354)$ \\
\hline $\begin{array}{l}\text { Criar informações / } \\
\text { documentos de apoio ao } \\
\text { operador }\end{array}$ & $\begin{array}{l}\text { Elaborar procedimentos operacionais que incluam práticas de ecodesign } \\
\text { para realização das atividades, como descarte de materiais de maneira } \\
\text { correta, coleta seletiva de lixo, uso adequado de água, impressão de papel } \\
\text { em frente e verso. }\end{array}$ \\
\hline Tarefa $-\mathbf{5 . 5 . 1 2}$ & Aspectos Ambientais - Código (358) \\
\hline $\begin{array}{l}\text { Simular processo de } \\
\text { fabricação }\end{array}$ & Usar sistemas de simulação para otimizar processo de transformação. \\
\hline Tarefa -5.5 .13 & Aspectos Ambientais - Código $(1,103,139,195,197)$ \\
\hline Atualizar BOM & $\begin{array}{l}\text { Finalizar o Bill of Material (BOM) com os impactos e documentos ambientais } \\
\text { dos itens selecionados para arquitetura do produto. }\end{array}$ \\
\hline \multicolumn{2}{|c|}{ Atividade - 5.6 Projetar recursos de fabricação } \\
\hline Tarefa $-\mathbf{5 . 6 . 1}$ & Aspectos Ambientais - Código $(6,13,79,365)$ \\
\hline $\begin{array}{l}\text { Projetar Ferramentas e } \\
\text { Dispositivos }\end{array}$ & $\begin{array}{l}\text { Projetar ferramentas e dispositivos padronizados para serem utilizados para } \\
\text { diferentes aplicações e que sejam adequados as normas ambientais. }\end{array}$ \\
\hline Tarefa -5.6 .2 & $\begin{array}{l}\text { Aspectos Ambientais - Código }(3,7,15,17,47,51,63,94,106,120,151 \text {, } \\
187,190,207,209,218,228,246,248,249,269,274,291,293,295,308, \\
310,329,332,348,354,359,361)\end{array}$ \\
\hline $\begin{array}{l}\text { Projetar Máquinas e } \\
\text { Equipamentos }\end{array}$ & $\begin{array}{l}\text { Projetar máquinas e equipamentos com melhor performance ambiental, que } \\
\text { possuam controle para consumir menos consumíveis e energia. }\end{array}$ \\
\hline
\end{tabular}


Tabela 6.5 - Fase de Projeto Detalhado - continuação.

\begin{tabular}{|c|c|}
\hline & $\begin{array}{l}\text { Macrofase - Desenvolvimento } \\
\text { Fase } 5 \text { - Projeto Detalhado (PD) }\end{array}$ \\
\hline Atividade - 5.6 Projetar $r$ & ecursos de fabricação \\
\hline Tarefa $-\mathbf{5 . 6 . 3}$ & $\begin{array}{l}\text { Aspectos Ambientais - Código }(21,23,33,44,56,106,107,123,132 \text {, } \\
154,200,201,203,219,220,228,256,264,291,294,295,300,348)\end{array}$ \\
\hline $\begin{array}{l}\text { Projetar } \quad \text { Instalações } \\
\text { (Fábrica) }\end{array}$ & $\begin{array}{l}\text { Projetar instalações que atendam aos requisitos ambientais das normas do } \\
\text { sistema de gestão ambiental e legislação ambiental. Utilizar os aspectos } \\
\text { ambientais listados para auxiliar na escolha da melhor opção em termos de } \\
\text { redução do impacto ambiental: Analisar os impactos ambientais que a } \\
\text { tecnologia pode causar; Analisar o efeito a exposição das substâncias } \\
\text { químicas; Optar por processos que utilizam menos consumíveis e energia; } \\
\text { Escolher instalações para reciclar grande quantidade de resíduos do } \\
\text { processo; Pensar em disposição de resíduos (incineração, reciclagem, } \\
\text { aterro, doação e venda) e tratamento de efluentes; Projetar instalação com } \\
\text { melhor eficiência energética; Avaliar a entrada de materiais no processo; } \\
\text { Projetar processos limpos com alta eficiência de produção; Evitar tecnologias } \\
\text { que utilizem materiais tóxicos; Possuir opções de operação (stand by) para } \\
\text { minimizar o consumo de energia; Planejar rotas de transporte para minimizar } \\
\text { emissões de gases oriundos dos veículos; Projetar para recuperar e } \\
\text { conservar energia; Reduzir as etapas de produção quando possível; e } \\
\text { Pensar em co-geração de energia. }\end{array}$ \\
\hline Tarefa -5.6 .4 & $\begin{array}{l}\text { Aspectos Ambientais - Código }(21,23,24,33,44,106,107,123,132 \text {, } \\
154,219,256,264,291,295,300,348)\end{array}$ \\
\hline Avaliar projeto & $\begin{array}{l}\text { Avaliar o projeto com base nos impactos ambientais das escolhas de } \\
\text { recursos de fabricação. }\end{array}$ \\
\hline Atividade - 5.7 Avaliar S & SC, configuração e documentação do produto e processo \\
\hline Tarefa - 5.7.1 & Aspectos Ambientais - Código $(101,28)$ \\
\hline $\begin{array}{l}\text { Avaliar tolerância } \\
\text { analiticamente }\end{array}$ & $\begin{array}{l}\text { Definir parâmetros de tolerância ambiental com base nas normas do sistema } \\
\text { de gestão ambiental, legislação, necessidade dos clientes e percepção dos } \\
\text { stakeholders. }\end{array}$ \\
\hline Tarefa $\mathbf{- 5 . 7 . 2}$ & Aspectos Ambientais - Código $(82,172)$ \\
\hline $\begin{array}{l}\text { Planejar os testes } \\
\text { (produto e processo) }\end{array}$ & $\begin{array}{l}\text { Planejar os testes considerando o sistema em que o produto será inserido e } \\
\text { a vida útil planejada. }\end{array}$ \\
\hline Tarefa - 5.7.3 & Aspectos Ambientais - Código $(82,83,172)$ \\
\hline Executar os testes & $\begin{array}{l}\text { Conduzir teste piloto para avaliar o desempenho ambiental dos materiais e } \\
\text { usar mecanismos de feedback para indicar a quantidade de energia, água e } \\
\text { recursos que estão sendo consumidos. }\end{array}$ \\
\hline Tarefa $-\mathbf{5 . 7 . 4}$ & Aspectos Ambientais - Código $(50,51,82,152,172,190,213,227)$ \\
\hline $\begin{array}{l}\text { Avaliar os resultados e } \\
\text { planejar ações }\end{array}$ & $\begin{array}{l}\text { Avaliar a performance ambiental e técnica do produto e processo e identificar } \\
\text { quais são os atributos ambientais que precisam ser melhorados junto com os } \\
\text { métodos de produção utilizados. Analisar a possibilidade de instalar proteção } \\
\text { contra a emissão de poluentes e substâncias perigosas e perdas durante o } \\
\text { processo. }\end{array}$ \\
\hline Tarefa $-\mathbf{5 . 7 . 5}$ & Aspectos Ambientais - Código $(1,103,112,113,114,115,195,322)$ \\
\hline $\begin{array}{l}\text { Avaliar consonância da } \\
\text { documentação com as } \\
\text { normas }\end{array}$ & $\begin{array}{l}\text { Verificar se a documentação atende aos requisitos do sistema de gestão } \\
\text { ambiental, incluindo os requisitos e informações de embalagens e } \\
\text { disposição. }\end{array}$ \\
\hline
\end{tabular}


Tabela 6.5 - Fase de Projeto Detalhado - continuação.

\begin{tabular}{|c|c|}
\hline \multicolumn{2}{|c|}{$\begin{array}{c}\text { Macrofase - Desenvolvimento } \\
\text { Fase } 5 \text { - Projeto Detalhado (PD) }\end{array}$} \\
\hline \multicolumn{2}{|c|}{ Atividade - 5.8 Otimizar produto e processo } \\
\hline Tarefa - 5.8.1 & $\begin{array}{l}\text { Aspectos Ambientais - Código }(35,45,46,73,83,85,142,169,173,216 \text {, } \\
223,227,236,253,260,363)\end{array}$ \\
\hline Finalizar aplicação DfX & $\begin{array}{l}\text { Otimizar a eficiência do produto e processo para toda uma gama de } \\
\text { condições de operação e uso. Focar na redução do consumo de recursos e } \\
\text { energia, minimização da necessidade de transporte para reduzir emissões } \\
\text { dos veículos e impacto ambiental. Complementar, utilizando de conceitos de } \\
\text { remanufatura, recondicionamento, reparabilidade e reuso dos SSCs. }\end{array}$ \\
\hline Tarefa $-\mathbf{5 . 8 . 2}$ & Aspectos Ambientais - Código $(31,36,180)$ \\
\hline $\begin{array}{l}\text { Ajustar tolerância dos } \\
\text { SSCs }\end{array}$ & $\begin{array}{l}\text { Ajustar parâmetros de tolerância dos SSCs visando garantir a segurança } \\
\text { ambiental no estágio de uso, aumentar a durabilidade e resistência do } \\
\text { produto. }\end{array}$ \\
\hline Tarefa $-\mathbf{5 . 8 . 3}$ & Aspectos Ambientais - Código $(31,36,180,199)$ \\
\hline $\begin{array}{l}\text { Executar ações de } \\
\text { correção de falhas }\end{array}$ & $\begin{array}{l}\text { Aplicar ferramentas para identificação de falhas ambientais, revisão dos } \\
\text { impactos ambientais e do plano de ação, conforme forem feitas alterações } \\
\text { no projeto do produto e processo. }\end{array}$ \\
\hline \multicolumn{2}{|c|}{ Atividade - 5.9 Criar material de suporte do produto } \\
\hline Tarefa $-\mathbf{5 . 9 . 1}$ & Aspectos Ambientais - Código $(77,111,175,176,205,231)$ \\
\hline $\begin{array}{l}\text { Criar manual de } \\
\text { operação do produto }\end{array}$ & $\begin{array}{l}\text { Elaborar manual de operação do produto, inserindo instruçães e perfil } \\
\text { ambiental do produto, tais como: composição química, se utiliza substâncias } \\
\text { tóxicas, regras de coleta e tratamento de resíduos, formas de disposição no } \\
\text { fim de vida e plano de contingência para reabilitação em caso de acidente } \\
\text { ambiental. }\end{array}$ \\
\hline Tarefa - 5.9.2 & Aspectos Ambientais - Código $(1,38,292,336)$ \\
\hline $\begin{array}{l}\text { Criar material de } \\
\text { treinamento }\end{array}$ & $\begin{array}{l}\text { Planejar curso de melhorias de eficiência de processo e treinamento dos } \\
\text { funcionários sobre práticas de ecodesign e como usar materiais verdes de } \\
\text { forma inteligente. Por exemplo, utilizar material multimídia com interações } \\
\text { on-line e com uma visão de toda a vida útil do produto }\end{array}$ \\
\hline Tarefa - 5.9.3 & Aspectos Ambientais - Código $(163,165,182,225,301,328)$ \\
\hline $\begin{array}{ll}\text { Criar manual de } \\
\text { descontinuidade } & \text { do } \\
\text { produto } & \end{array}$ & $\begin{array}{l}\text { Criar manual de descontinuidade de produto explicando a estratégia de fim } \\
\text { de vida e os impactos ambientais. }\end{array}$ \\
\hline \multicolumn{2}{|c|}{ Atividade - 5.10 Projetar embalagem } \\
\hline Tarefa - 5.10.1 & $\begin{array}{l}\text { Aspectos Ambientais - Código }(14,32,116,118,121,144,161,223,227 \text {, } \\
304,340,350)\end{array}$ \\
\hline $\begin{array}{l}\text { Avaliar a distribuição do } \\
\text { produto: transporte e } \\
\text { entrega }\end{array}$ & $\begin{array}{l}\text { Avaliar a eficiência da distribuição e logística do produto, abordando a } \\
\text { possibilidade de produzir onde há consumo para minimizar a distância de } \\
\text { transporte, distribuição direta ao consumidor, uso de embalagens } \\
\text { reutilizáveis durante a distribuição e maximizar oportunidades de reuso e } \\
\text { redução de perdas de embalagens durante o transporte. }\end{array}$ \\
\hline Tarefa $-\mathbf{5 . 1 0 . 2}$ & Aspectos Ambientais - Código $(113,121,144,178,304,323,350)$ \\
\hline $\begin{array}{l}\text { Definir as formas e as } \\
\text { sinalizações das } \\
\text { embalagens do produto }\end{array}$ & $\begin{array}{l}\text { Definir alternativas ambientais para embalagem e disponibilizar informações } \\
\text { ambientais do produto nas embalagens para suporte aos usuários nas fases } \\
\text { de uso e descarte. }\end{array}$ \\
\hline
\end{tabular}


Tabela 6.5 - Fase de Projeto Detalhado - continuação.

\begin{tabular}{|c|c|}
\hline \multicolumn{2}{|c|}{$\begin{array}{l}\text { Macrofase - Desenvolvimento } \\
\text { Fase } 5 \text { - Projeto Detalhado (PD) }\end{array}$} \\
\hline \multicolumn{2}{|c|}{ Atividade - 5.10 Projetar embalagem } \\
\hline Tarefa $-\mathbf{5 . 1 0 . 3}$ & $\begin{array}{l}\text { Aspectos Ambientais - Código }(8,21,40,57,75,99,100,143,206,216 \text {, } \\
253,266,267,304)\end{array}$ \\
\hline $\begin{array}{l}\text { Identificar os elementos } \\
\text { críticos }\end{array}$ & $\begin{array}{l}\text { Identificar os elementos críticos do projeto da embalagem que podem causar } \\
\text { impacto ambiental, tais como: Classificar e selecionar as substâncias } \\
\text { químicas utilizadas na impressão, que podem ser críticas ao meio ambiente } \\
\text { e saúde humana; Reduzir o desperdício de embalagens; Analisar a } \\
\text { deterioração e a vida útil da embalagem; Evitar procedimentos na } \\
\text { embalagem que consomem energia; Integrar o desenvolvimento da } \\
\text { embalagem para transporte e embalagem para o produto; e Organizar o } \\
\text { retorno da embalagem para disposição, reuso ou reciclagem. }\end{array}$ \\
\hline Tarefa $-\mathbf{5 . 1 0 . 4}$ & Aspectos Ambientais - Código $(14,170,240,267)$ \\
\hline $\begin{array}{l}\text { Adequar embalagem } \\
\text { aos elementos críticos }\end{array}$ & $\begin{array}{l}\text { Preferir embalagens e rótulos ambientais retornáveis, conforme as opções } \\
\text { de impressão, empacotamento do produto e distribuição, e com fácil } \\
\text { separação dos diferentes tipos de materiais da embalagem do produto. }\end{array}$ \\
\hline Tarefa $-\mathbf{5 . 1 0 . 5}$ & $\begin{array}{l}\text { Aspectos Ambientais - Código }(98,111,116,121,144,150,202,205, \\
\text { 240) }\end{array}$ \\
\hline Projetar embalagem & $\begin{array}{l}\text { Projetar a embalagem pontuando os seguintes aspectos ambientais: Analisar } \\
\text { os impactos ambientais da embalagem; Cumprir as funções ambientais e } \\
\text { técnicas; Eliminar embalagens secundárias e terciárias quando possível; } \\
\text { Projetar embalagens reciclável, retornável, reutilizável e ecológica; Evitar a } \\
\text { utilização de embalagens sem função específica; Evitar materiais tóxicos na } \\
\text { embalagem do produto; Imprimir instruções claras para reciclagem da } \\
\text { embalagem; Minimizar o peso e número de diferentes materiais utilizados } \\
\text { para produzir a embalagem; e Projetar embalagem como parte do produto. }\end{array}$ \\
\hline Tarefa - 5.10.6 & Aspectos Ambientais - Código $(118,119,120)$ \\
\hline $\begin{array}{l}\text { Planejar processo de } \\
\text { embalagem }\end{array}$ & $\begin{array}{l}\text { Encorajar os fornecedores a reduzir a quantidade e tipo de embalagem, bem } \\
\text { como, ajudar na coleta das embalagens. }\end{array}$ \\
\hline \multicolumn{2}{|c|}{ Atividade - 5.11 Planejar fim de vida do produto } \\
\hline Tarefa -5.11 .1 & Aspectos Ambientais - Código $(32,140,2$ \\
\hline $\begin{array}{l}\text { Definir plano de retirada } \\
\text { do mercado }\end{array}$ & $\begin{array}{l}\text { Definir o plano de retirada do produto do mercado com base na avaliação do } \\
\text { desempenho do produto durante todo o ciclo de vida do produto } \\
\text { (desenvolvimento, produção, uso e serviços e descarte) e os respectivos } \\
\text { impactos ambientais em cada fase. Para essa decisão, deve-se analisar as } \\
\text { vantagens e desvantagens de se estender a expectativa de vida dos } \\
\text { materiais e serviços e tomar algumas providências em relação a minimizar o } \\
\text { consumo de energia durante a logística reversa do produto. }\end{array}$ \\
\hline Tarefa -5.11 .2 & $\begin{array}{l}\text { Aspectos Ambientais - Código }(39,63,163,186,242,255,259,260,275 \text {, } \\
309,335)\end{array}$ \\
\hline $\begin{array}{l}\text { Definir plano } \\
\text { descontinuidade } \\
\text { produção }\end{array}$ & $\begin{array}{l}\text { Definir o plano de descontinuidade da produção e identificar os possíveis } \\
\text { impactos ambientais com parada de operação, desmontagem de máquinas e } \\
\text { equipamentos, tratamento de resíduos e como serão reduzidos esses } \\
\text { impactos ambientais. }\end{array}$ \\
\hline Tarefa - 5.11.3 & Aspectos Ambientais - Código $(41,91,111,164,182,237,256,345,346)$ \\
\hline $\begin{array}{l}\text { Definir plano } \\
\text { descarte }\end{array}$ & $\begin{array}{l}\text { Definir plano de descarte do produto observando a estratégia de fim de vida } \\
\text { e os seguintes aspectos ambientais: Garantir alta taxa de retorno de } \\
\text { produtos no fim de vida; Disponibilizar ao usuário final instruções para } \\
\text { disposição e tratamento; Incineração de substâncias não perigosas e com } \\
\text { recuperação de energia; Avaliar a capacidade de armazenamento e } \\
\text { destruição de resíduos; Considerar possibilidade de trituração e triagem; } \\
\text { Usar aterro controlado; e Usar camadas de material reciclado onde o } \\
\text { material virgem é necessário. }\end{array}$ \\
\hline
\end{tabular}


Tabela 6.5 - Fase de Projeto Detalhado - continuação.

\begin{tabular}{|c|c|}
\hline & $\begin{array}{l}\text { Macrofase - Desenvolvimento } \\
\text { Fase } 5 \text { - Projeto Detalhado (PD) }\end{array}$ \\
\hline Atividade - 5.11 Planejar & fim de vida do produto \\
\hline Tarefa -5.11 .4 & Aspectos Ambientais - Código $(37,163,164,165,166,171)$ \\
\hline $\begin{array}{l}\text { Definir plano de } \\
\text { reciclagem }\end{array}$ & $\begin{array}{l}\text { Definir plano de reciclagem e reuso do produto e materiais, considerando a } \\
\text { estratégia de fim de vida e os aspectos ambientais: Aumentar a taxa de } \\
\text { coleta de materiais em geral; Facilitar a compactação do produto no fim de } \\
\text { vida; Facilitar a desmontagem, reparos e tratamento; Facilitar a separação e } \\
\text { classificação; Facilitar a coleta e transporte no fim de vida do produto; e } \\
\text { Facilitar a combustão na incineração, utilizar materiais com alta energia. }\end{array}$ \\
\hline Atividade - 5.12 Testar e & homologar produto \\
\hline Tarefa $-\mathbf{5 . 1 2 . 1}$ & Aspectos Ambientais - Código $(1,103,115,195,322)$ \\
\hline $\begin{array}{l}\text { Verificar } \\
\text { documentação }\end{array}$ & $\begin{array}{l}\text { Elaborar e controlar a documentação com perfil ambiental do produto e } \\
\text { componentes de acordo com as exigências do sistema de gestão ambiental. }\end{array}$ \\
\hline Tarefa -5.12 .2 & Aspectos Ambientais - Código $(50,51)$ \\
\hline $\begin{array}{l}\text { Verificar } \\
\text { funcionalidade } \\
\text { produto }\end{array}$ & $\begin{array}{l}\text { Avaliar a performance ambiental do produto com base em critérios } \\
\text { ambientais definidos em conjunto com a funcionalidade e utilidade do } \\
\text { produto. }\end{array}$ \\
\hline Tarefa $-\mathbf{5 . 1 2 . 3}$ & Aspectos Ambientais - Código $(68,212,321,322)$ \\
\hline $\begin{array}{l}\text { Verificar o atendimento } \\
\text { aos requisitos e normas }\end{array}$ & $\begin{array}{l}\text { Verificar se o produto atende aos requisitos ambientais do cliente, das } \\
\text { normas do sistema de gestão ambiental e legislação ambiental. }\end{array}$ \\
\hline Tarefa - 5.12.4 & Aspectos Ambientais - Código (250) \\
\hline $\begin{array}{l}\text { Obter certificado de } \\
\text { homologação }\end{array}$ & Obter certificação ambiental do produto. \\
\hline Atividade - 5.13 Enviar d & ocumentação do produto a parceiros \\
\hline Tarefa $-\mathbf{5 . 1 3 . 1}$ & Aspectos Ambientais - Código $(115,206,322)$ \\
\hline $\begin{array}{l}\text { Enviar documentação } \\
\text { do produto a parceiros }\end{array}$ & $\begin{array}{l}\text { Disponibilizar documentação com perfil ambiental do produto e embalagem, } \\
\text { incluindo informações regulatórias, instruções para manuseio seguro, } \\
\text { disposição e tratamento e redução de desperdício de materiais durante o uso } \\
\text { pelo usuário. }\end{array}$ \\
\hline Atividade - 5.14 Monitor & ar a viabilidade econômico-financeira do produto \\
\hline Tarefa -5.14 .1 & Aspectos Ambientais - Código $(18,76,90,93,94,130,138,196,215)$ \\
\hline $\begin{array}{l}\text { Avaliar mudanças nas } \\
\text { condições de mercado, } \\
\text { características técnicas } \\
\text { e indicadores }\end{array}$ & $\begin{array}{l}\text { Monitorar as condições do mercado e avaliar potenciais oportunidades } \\
\text { ambientais. }\end{array}$ \\
\hline Tarefa -5.14 .2 & Aspectos Ambientais - Código $(18,20,25,64)$ \\
\hline 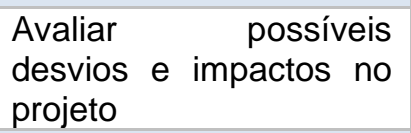 & $\begin{array}{l}\text { Analisar e monitorar a viabilidade ambiental do projeto com base nos } \\
\text { impactos ambientais das escolhas feitas para o produto. }\end{array}$ \\
\hline Tarefa - 5.14.3 & Aspectos Ambientais - Código $(92,93,94,196,215)$ \\
\hline $\begin{array}{l}\text { Analisar } \quad \text { novas } \\
\text { premissas e indicadores }\end{array}$ & $\begin{array}{l}\text { Identificar os pontos ambientais críticos das escolhas feitas para o produto e } \\
\text { desenvolver ou atualizar os indicadores ambientais. }\end{array}$ \\
\hline Atividade - 5.15 Docume & ntar as decisões tomadas e registrar lições aprendidas \\
\hline Tarefa - 5.15.1 & Aspectos Ambientais - Código $(1,103,195)$ \\
\hline $\begin{array}{l}\text { Documentar } r \\
\text { decisões tomadas e e } \\
\text { registrar } \quad \text { lições } \\
\text { aprendidas }\end{array}$ & $\begin{array}{l}\text { Acumular conhecimentos com os feedbacks das implicações das escolhas } \\
\text { feitas e documentar através da atualização da base de dados (Biblioteca } \\
\text { Ambiental) durante o ciclo de vida do produto. Além disso, deve-se divulgar } \\
\text { esse conhecimento de melhores práticas de ecodesign as pessoas } \\
\text { envolvidas no PDP. }\end{array}$ \\
\hline
\end{tabular}

A fase de Preparação da Produção do Produto (PPP) tem a função de testar e planejar a produção através do lote piloto, liberar o produto para a produção com as 
especificações de produção e manutenção, capacitação pessoal e da logística com os fornecedores. Essa fase tem o objetivo de realizar a homologação do processo, para assegurar que a empresa consiga produzir o produto com qualidade, requisitos do cliente e volume da declaração de escopo do projeto. Assim, o produto resultante do lote piloto pode ser certificado e liberado para produção. Para integrar os aspectos ambientais nessa fase do PDP foram analisados os riscos operacionais que prejudicam a saúde humana e o meio ambiente, e sugerido ações à equipe de projeto para identificar melhorias ambientais no produto e no processo. Os principais pontos tratados foram quanto à necessidade de gerenciar melhor o consumo e desperdício de energia, água e recursos durante o processo de fabricação, bem como, da importância do tratamento de resíduos para reduzir o impacto ambiental. A Tabela 6.6 exibe a estruturação da fase de Preparação da Produção do Produto (PPP) com a integração de aspectos ambientais.

Tabela 6.6 - Fase de Preparação da Produção do Produto.

\begin{tabular}{|c|c|}
\hline \multirow{2}{*}{\multicolumn{2}{|c|}{$\begin{array}{c}\text { Macrofase - Desenvolvimento } \\
\text { Fase } 6 \text { - Preparação da Produção do Produto (PPP) } \\
\text { Atividade - } 6.1 \text { Obter recursos de fabricacão }\end{array}$}} \\
\hline & \\
\hline Tarefa - 6.1.1 & Aspectos Ambientais - Código $(96,143,254,260,337,351)$ \\
\hline $\begin{array}{l}\text { Desenvolver recursos } \\
\text { de fabricação não } \\
\text { comprados }\end{array}$ & $\begin{array}{l}\text { Desenvolver recursos para tornar a produção mais limpa, com alta eficiência } \\
\text { energética e de produção. São características desejáveis que esses recursos } \\
\text { evitem a geração de resíduos e desperdício de material, tenham } \\
\text { padronização de uso de componentes e partes, sejam de fácil reparação e } \\
\text { modernização, que utilizem estrutura superficial ou aberta para facilitar o } \\
\text { acesso aos subconjuntos e usem de tecnologia e energia renovável e } \\
\text { materiais recicláveis. }\end{array}$ \\
\hline Tarefa-6.1.2 & Aspectos Ambientais - Código $(42,83,133,207)$ \\
\hline $\begin{array}{l}\text { Comprar recursos de } \\
\text { fabricação }\end{array}$ & $\begin{array}{l}\text { Comprar recursos de fabricação de fornecedores certificados por normas } \\
\text { ambientais e avaliar se a especificação desses recursos atende as mesmas } \\
\text { exigências e características de desenvolvimento interno de recursos de } \\
\text { fabricação. }\end{array}$ \\
\hline \multicolumn{2}{|c|}{ Atividade - 6.2 Planejar produção piloto } \\
\hline Tarefa - 6.2.1 & Aspectos Ambientais - Código $(42,64,83,133,207,270)$ \\
\hline $\begin{array}{l}\text { Verificar disponibilidade } \\
\text { dos equipamentos em } \\
\text { uso } \quad \text { e } \\
\text { operacionalidade } \\
\text { recursos novos }\end{array}$ & Avaliar o impacto ambiental dos novos recursos de produção. \\
\hline \multicolumn{2}{|c|}{ Atividade - 6.3 Receber e instalar recursos } \\
\hline Tarefa - 6.3.1 & Aspectos Ambientais - Código $(218,290)$ \\
\hline Montar e instalar & $\begin{array}{l}\text { Montar e instalar os novos recursos de processo visando, por meio de ajuste } \\
\text { do layout, otimizar o fluxo de materiais e consumo de energia. }\end{array}$ \\
\hline Tarefa -6.3 .2 & Aspectos Ambientais - Código $(95,96,336)$ \\
\hline Testar e aprovar recurso & $\begin{array}{l}\text { Testar e verificar se os recursos estão adequados as normas do sistema de } \\
\text { gestão ambiental e legislação. }\end{array}$ \\
\hline
\end{tabular}


Tabela 6.6 - Fase de Preparação da Produção do Produto - continuação.

\begin{tabular}{|c|c|}
\hline Fase & $\begin{array}{l}\text { Macrofase - Desenvolvimento } \\
6 \text { - Preparação da Produção do Produto (PPP) }\end{array}$ \\
\hline Atividade - 6.4 Produzir & Lote Piloto \\
\hline Tarefa - 6.4.1 & Aspectos Ambientais - Código $(19,21,49,82,364)$ \\
\hline Produzir Lote Piloto & $\begin{array}{l}\text { Conduzir teste piloto para avaliar o uso de materiais tóxicos, perda total de } \\
\text { processo e os impactos ambientais da geração de resíduos. Se utilizar } \\
\text { substâncias tóxicas optar por ciclos fechados para minimizar o impacto } \\
\text { ambiental. }\end{array}$ \\
\hline Atividade - 6.5 Homolog & ar processo \\
\hline Tarefa -6.5 .1 & Aspectos Ambientais - Código $(48,49,61,66,69,75,82,364)$ \\
\hline Avaliar lote piloto & $\begin{array}{l}\text { Analisar com base em diferentes condições de operação se o lote piloto } \\
\text { atende aos requisitos ambientais e funcionais do produto, especificado nas } \\
\text { fases anteriores de Projeto. Avaliar os riscos operacionais que prejudicam a } \\
\text { saúde humana e o meio ambiente e identificar oportunidades de melhorias } \\
\text { ambientais do produto e processo. }\end{array}$ \\
\hline Tarefa -6.5 .2 & Aspectos Ambientais - Código $(93,94,196,215,248,303,359)$ \\
\hline $\begin{array}{l}\text { Avaliar meios de } \\
\text { medição }\end{array}$ & $\begin{array}{l}\text { Usar mecanismos de medição para gerenciar o consumo e desperdício de } \\
\text { energia, água e recursos durante o processo. Pode criar indicadores para } \\
\text { avaliação e monitoramento desses consumos, tratamento de resíduos e do } \\
\text { impacto ambiental nos equipamentos e processo. }\end{array}$ \\
\hline Tarefa -6.5 .3 & Aspectos Ambientais - Código $(41,44)$ \\
\hline $\begin{array}{l}\text { Avaliar capabilidade de } \\
\text { processo }\end{array}$ & $\begin{array}{l}\text { Avaliar a capacidade de armazenamento, tratamento de efluentes e } \\
\text { disposição de resíduos (incineração, reciclagem, aterro, doação e venda). }\end{array}$ \\
\hline Atividade - 6.6 Otimizar & produção \\
\hline Tarefa - 6.6.1 & $\begin{array}{l}\text { Aspectos Ambientais - Código }(13,132,208,219,226,300,315,331 \text {, } \\
334,337,358)\end{array}$ \\
\hline Otimizar produção & $\begin{array}{l}\text { Otimizar a eficiência do processo para toda uma gama de condições de } \\
\text { operação e uso. Focar na simplificação do processo e no aumento da } \\
\text { produtividade dos recursos e na redução do consumo de energia, } \\
\text { embalagem, movimentação e impacto ambiental. Utilizar conceitos de } \\
\text { remanufatura, recondicionamento, reparabilidade e reuso. }\end{array}$ \\
\hline Atividade - 6.7 Certifice & produto \\
\hline Tarefa - 6.7.1 & Aspectos Ambientais - Código $(212,336)$ \\
\hline $\begin{array}{l}\text { Avaliar exigências de } \\
\text { regulamentação }\end{array}$ & $\begin{array}{l}\text { Verificar se o produto atende aos requisitos ambientais das normas de } \\
\text { sistema de gestão ambiental e legislação ambiental. }\end{array}$ \\
\hline Tarefa - 6.7.2 & Aspectos Ambientais - Código $(9,65,84,88,191)$ \\
\hline $\begin{array}{l}\text { Submeter ao cliente }{ }^{\circ} \\
\text { processo de aprovação }\end{array}$ & $\begin{array}{l}\text { Apresentar aos interessados (clientes, sociedade, stakeholders, etc.) as } \\
\text { características ambientais do produto e possíveis certificações ambientais } \\
\text { como "selo verde" para verificar o nível de aceitação do produto. }\end{array}$ \\
\hline Tarefa -6.7 .3 & Aspectos Ambientais - Código $(116,121,144,161,227,340)$ \\
\hline $\begin{array}{l}\text { Avaliar os serviços } \\
\text { associados ao produto }\end{array}$ & $\begin{array}{l}\text { Avaliar a eficiência ambiental das embalagens e serviços de distribuição e } \\
\text { logística. }\end{array}$ \\
\hline Tarefa - 6.7.4 & Aspectos Ambientais - Código $(115,322)$ \\
\hline $\begin{array}{l}\text { Obter documentação } \\
\text { para certificação }\end{array}$ & $\begin{array}{l}\text { Elaborar e controlar a documentação com perfil ambiental do produto e } \\
\text { processo para suportar a certificação e manutenção ambiental. }\end{array}$ \\
\hline Atividade - 6.8 Desenvol & ver processo de produção \\
\hline Tarefa - 6.8.1 & Aspectos Ambientais - Código $(25,178,212)$ \\
\hline $\begin{array}{l}\text { Desenvolver processo, } \\
\text { planejamento e controle } \\
\text { da produção }\end{array}$ & $\begin{array}{l}\text { Desenvolver processo de produção que contemple sistemáticas de controle } \\
\text { das informações ambientais, e definir as responsabilidades para auxiliar na } \\
\text { gestão e tomada de decisão. }\end{array}$ \\
\hline
\end{tabular}


Tabela 6.6 - Fase de Preparação da Produção do Produto - continuação.

\begin{tabular}{|c|c|}
\hline Fase & $\begin{array}{l}\text { Macrofase - Desenvolvimento } \\
6 \text { - Preparação da Produção do Produto (PPP) }\end{array}$ \\
\hline Atividade - 6.8 Desenvol & ver processo de produção \\
\hline Tarefa - 6.8.2 & Aspectos Ambientais - Código $(102,173,236,264,327,340,358)$ \\
\hline $\begin{array}{l}\text { Desenhar os processos } \\
\text { de logística e relação de } \\
\text { entrega de produtos aos } \\
\text { clientes }\end{array}$ & $\begin{array}{l}\text { Definir os limites de responsabilidades ambientais dos envolvidos nesse } \\
\text { processo e abordar os seguintes aspectos ambientais na definição desse } \\
\text { desenho: Descentralizar atividades para reduzir volumes transportados; } \\
\text { Produzir onde há consumo, para que a distribuição seja direta ao } \\
\text { consumidor; Facilitar o transporte e coleta de produto no fim de vida; } \\
\text { Minimizar a necessidade de transporte de materiais e componentes, } \\
\text { incluindo a disposição; Planejar rotas de transporte de recebimento e } \\
\text { distribuição para minimizar emissões dos veículos; e Utilizar de ferramentas } \\
\text { de simulação para avaliar a eficiência desse processo. }\end{array}$ \\
\hline Tarefa - 6.8.3 & Aspectos Ambientais - Código $(1,103,195,198)$ \\
\hline $\begin{array}{l}\text { Selecionar/desenvolver } \\
\text { ferramentas de apoio }\end{array}$ & $\begin{array}{l}\text { Desenvolver no sistema de gestão ambiental ferramentas e materiais de } \\
\text { apoio para ensinar os profissionais a usar métodos e ferramentas de } \\
\text { ecodesign e consultar o banco de dados (Biblioteca Ambiental). }\end{array}$ \\
\hline Atividade - 6.9 Desenvol & ver processo de manutenção \\
\hline Tarefa -6.9 .1 & Aspectos Ambientais - Código $(45,167,168,177,251,252,281,335)$ \\
\hline $\begin{array}{l}\text { Definir política de } \\
\text { manutenção }\end{array}$ & $\begin{array}{l}\text { Definir uma política de manutenção com a visão estratégica para reciclagem, } \\
\text { reuso, desmontagem, reparos e recondicionamento. }\end{array}$ \\
\hline Tarefa -6.9 .2 & Aspectos Ambientais - Código $(45,167,168,177,281,335)$ \\
\hline $\begin{array}{l}\text { Definir procedimentos } \\
\text { da manutenção }\end{array}$ & $\begin{array}{l}\text { Definir procedimentos de manutenção alinhados com o Planejamento } \\
\text { Estratégico e política ambiental da empresa. }\end{array}$ \\
\hline Atividade - 6.10 Ensinar & pessoal \\
\hline Tarefa -6.10 .1 & Aspectos Ambientais - Código $(38,292)$ \\
\hline $\begin{array}{l}\text { Mapear competências } \\
\text { necessárias e definir } \\
\text { cursos de treinamento } \\
\text { de pessoal }\end{array}$ & $\begin{array}{l}\text { Planejar curso de melhorias de eficiência de processo e treinamento dos } \\
\text { funcionários sobre práticas de ecodesign e como usar materiais verdes de } \\
\text { forma inteligente. }\end{array}$ \\
\hline Atividade - 6.11 Monitor & ar a viabilidade ec \\
\hline Tarefa - 6.11.1 & Aspectos Ambientais - Código $(18,76,86,90,93,94,130,138,196,215)$ \\
\hline $\begin{array}{l}\text { Avaliar mudanças nas } \\
\text { condições de mercado, } \\
\text { características técnicas } \\
\text { e indicadores }\end{array}$ & $\begin{array}{l}\text { Monitorar as condições do mercado e avaliar potenciais oportunidades } \\
\text { ambientais. }\end{array}$ \\
\hline Tarefa-6.11.2 & Aspectos Ambientais - Códic \\
\hline 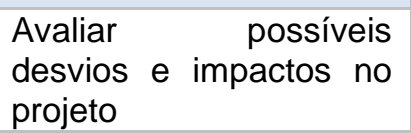 & $\begin{array}{l}\text { Analisar e monitorar a viabilidade ambiental do projeto com base nos } \\
\text { impactos ambientais das escolhas feitas para o produto. }\end{array}$ \\
\hline Tarefa - 6.11.3 & Aspectos Ambientais - Código $(93,94,196,215)$ \\
\hline $\begin{array}{l}\text { Analisar } \quad \text { novas } \\
\text { premissas e indicadores }\end{array}$ & $\begin{array}{l}\text { Identificar os pontos ambientais críticos das escolhas feitas para o produto e } \\
\text { desenvolver ou atualizar os indicadores ambientais. }\end{array}$ \\
\hline Atividade - 6.12 Docume & ntar as decisões tomadas e registrar lições aprendidas \\
\hline Tarefa - 6.12.1 & Aspectos Ambientais - Código $(1,103,195,199)$ \\
\hline $\begin{array}{l}\text { Documentar } \\
\text { decisões tomadas e e } \\
\text { registrar } \\
\text { aprendidas }\end{array}$ & $\begin{array}{l}\text { Acumular conhecimentos com os feedbacks das implicações das escolhas } \\
\text { feitas e documentar através da atualização da base de dados (Biblioteca } \\
\text { Ambiental) durante o ciclo de vida do produto. Além disso, deve-se divulgar } \\
\text { esse conhecimento de melhores práticas de ecodesign as pessoas } \\
\text { envolvidas no PDP. }\end{array}$ \\
\hline
\end{tabular}


A fase de Lançamento do Produto (LP) encerra a macrofase de Desenvolvimento do PDP e trata da comercialização e da logística de distribuição para a colocação do produto no mercado. Nesta fase, também são inseridas as atividades de atendimento ao cliente e assistência técnica. Nesse momento do PDP pouco se pode fazer quanto aos impactos ambientais do produto, porém é necessário acompanhar a vida útil do produto e atualizar o plano de fim de vida em termos de retirada do mercado, descontinuidade da produção, descarte e reciclagem. Além disso, sugere a área de marketing utilizar como vantagem competitiva as características ambientais do produto nas campanhas publicitárias (selo verde, material reciclável, certificação ambiental, etc.). E o mais importante nesse momento é acumular conhecimento com os feedbacks das implicações das escolhas feitas durante o ciclo de vida do produto e atualizar a base de dados ambiental da empresa para divulgar esse conhecimento na organização. A Tabela 6.7 ilustra a inserção de aspectos ambientais na fase de Lançamento do Produto (LP).

Tabela 6.7 - Fase de Lançamento do Produto.

\begin{tabular}{|c|c|}
\hline & $\begin{array}{l}\text { Macrofase - Desenvolvimento } \\
\text { Fase } 7 \text { - Lançamento do Produto (LP) }\end{array}$ \\
\hline Atividade - 7.1 Planeja & ançamento \\
\hline Tarefa - 7.1.1 & Aspectos Ambientais - Código (9) \\
\hline $\begin{array}{l}\text { Analisar e sintetizar as } \\
\text { novas condições para a } \\
\text { realização do projeto }\end{array}$ & $\begin{array}{l}\text { Analisar a legislação atual e futura e as necessidades atuais e emergentes } \\
\text { do cliente em termos de necessidades ambientais relevantes ao produto. }\end{array}$ \\
\hline Tarefa - 7.1.2 & Aspectos Ambientais - Código $(33,120,177,250,272)$ \\
\hline $\begin{array}{l}\text { Atualizar o escopo do } \\
\text { produto }\end{array}$ & $\begin{array}{l}\text { Revisar e atualizar o escopo do produto com base na redução de impactos } \\
\text { ambientais definidos na fase anterior de Projeto Detalhado. }\end{array}$ \\
\hline Tarefa - 7.1.3 & Aspectos Ambientais - Código $(193,301,328)$ \\
\hline $\begin{array}{l}\text { Atualizar estimativa de } \\
\text { orçamento do projeto }\end{array}$ & $\begin{array}{l}\text { Atualizar as estimativas de custo ambiental do projeto, conforme as escolhas } \\
\text { ambientais forem sendo definidas. }\end{array}$ \\
\hline Tarefa-7.1.4 & Aspectos Ambientais - Código $(93,94,196,215)$ \\
\hline $\begin{array}{l}\text { Atualizar, monitorar, } \\
\text { valorar e definir novos } \\
\text { indicadores de } \\
\text { desempenho }\end{array}$ & $\begin{array}{l}\text { Atualizar e monitorar os indicadores de desempenho ambiental com base } \\
\text { nos pontos ambientais críticos do produto e processos. }\end{array}$ \\
\hline Tarefa - 7.1.5 & Aspectos Ambientais - Código $(9,12,58,69,364)$ \\
\hline Avaliar novos riscos & $\begin{array}{l}\text { Identificar novos riscos potenciais de impacto ambiental do produto, } \\
\text { conforme for evoluindo as avaliações do produto e processo. }\end{array}$ \\
\hline Tarefa - 7.1.6 & Aspectos Ambientais - Código (51) \\
\hline $\begin{array}{l}\text { Definir/atualizar os } \\
\text { critérios de passagem } \\
\text { dos Gates }\end{array}$ & $\begin{array}{l}\text { Atualizar os critérios de avaliação ambiental do produto para verificar se o } \\
\text { projeto deve ser congelado, abandonado ou passar para próxima fase do } \\
\text { PDP. }\end{array}$ \\
\hline
\end{tabular}


Tabela 6.7 - Fase de Lançamento do Produto - continuação.

\begin{tabular}{|c|c|}
\hline & $\begin{array}{l}\text { Macrofase - Desenvolvimento } \\
\text { Fase } 7 \text { - Lançamento do Produto (LP) }\end{array}$ \\
\hline Atividade - 7.2 Desenvo & ver processo de vendas \\
\hline Tarefa - 7.2.1 & Aspectos Ambientais - Código $(38,265,292,336)$ \\
\hline $\begin{array}{l}\text { Treinar equipe de } \\
\text { vendas e profissionais } \\
\text { de apoio a venda }\end{array}$ & $\begin{array}{l}\text { Treinar a equipe de vendas para utilizar as características ambientais do } \\
\text { produto (selo verde, material reciclável e certificação ambiental) para } \\
\text { promover as vendas. }\end{array}$ \\
\hline Atividade - 7.3 Desenvo & ver processo de distribuição \\
\hline Tarefa - 7.3.1 & Aspectos Ambientais - Código $(102,173,236,264,340,358)$ \\
\hline $\begin{array}{l}\text { Desenhar processo de } \\
\text { distribuição e definir } \\
\text { logística }\end{array}$ & $\begin{array}{l}\text { Definir processos de distribuição e logística utilizando de ferramentas de } \\
\text { simulação para avaliar a eficiência energética desse processo. Além disso, } \\
\text { analisar os impactos ambientais das alternativas disponíveis e definir os } \\
\text { responsáveis pelo impacto ambiental de cada etapa do processo. }\end{array}$ \\
\hline Tarefa - 7.3.2 & Aspectos Ambientais - Código $(32,119,161,340)$ \\
\hline $\begin{array}{l}\text { Fechar acordos com } \\
\text { distribuidores }\end{array}$ & $\begin{array}{l}\text { Fechar acordos com distribuidores buscando colaboração para melhoria da } \\
\text { performance ambiental, como por exemplo, em reduzir as perdas de } \\
\text { embalagem no transporte e apoiar na coleta das embalagens. }\end{array}$ \\
\hline Atividade - 7.4 Desenvo & ver processo de atendimento ao cliente \\
\hline Tarefa - 7.4.1 & Aspectos Ambientais - Código $(1,38,265)$ \\
\hline $\begin{array}{l}\text { Desenvolver sistema de } \\
\text { apoio a atendimento ao } \\
\text { cliente }\end{array}$ & $\begin{array}{l}\text { O atendimento ao cliente deve ter suporte dos profissionais de meio } \\
\text { ambiente e da assistência técnica para esclarecer dúvidas específicas do } \\
\text { produto. }\end{array}$ \\
\hline Tarefa - 7.4.2 & Aspectos Ambientais - Código $(38,265,292,336)$ \\
\hline $\begin{array}{l}\text { Treinar pessoal de } \\
\text { atendimento ao cliente }\end{array}$ & Sistema de gestão ambiental e programas de ecodesign. \\
\hline Atividade - 7.5 Desenvo & ver processo de assistência técnica \\
\hline Tarefa - 7.5.1 & Aspectos Ambientais - Código $(321,322,336)$ \\
\hline $\begin{array}{l}\text { Desenhar processo de } \\
\text { assistência técnica }\end{array}$ & $\begin{array}{l}\text { Considerar os requisitos do sistema de gestão ambiental na definição das } \\
\text { responsabilidades do processo de assistência técnica. }\end{array}$ \\
\hline Tarefa -7.5 .2 & Aspectos Ambientais - Código $(1,103,175,195)$ \\
\hline $\begin{array}{l}\text { Desenvolver } \\
\text { documentação de } \\
\text { assistência técnica }\end{array}$ & $\begin{array}{l}\text { Desenvolver documentação detalhada sobre o perfil ambiental do produto e } \\
\text { processo para dar assistência técnica aos clientes, inclusive informações e } \\
\text { instruções ambientais sobre manutenção, disposição, tratamento, } \\
\text { embalagem, operação, rótulos e manuseio seguro de materiais tóxicos. }\end{array}$ \\
\hline Tarefa - 7.5.3 & Aspectos Ambientais - Código $(1,103,175,195)$ \\
\hline $\begin{array}{l}\text { Desenvolver sistema de } \\
\text { apoio a assistência } \\
\text { técnica }\end{array}$ & $\begin{array}{l}\text { Utilizar a base de dados (Biblioteca Ambiental) com o perfil ambiental do } \\
\text { produto e processo, procedimentos operacionais com as implicações } \\
\text { ambientais e normas do sistema de gestão ambiental. }\end{array}$ \\
\hline Tarefa - 7.5.4 & Aspectos Ambientais - Código $(38,265,292,336)$ \\
\hline $\begin{array}{l}\text { Treinar pessoal de } \\
\text { assistência técnica }\end{array}$ & Sistema de gestão ambiental e programas de ecodesign. \\
\hline Atividade - 7.6 Promov & r marketing de lançamento \\
\hline Tarefa - 7.6.1 & Aspectos Ambientais - Código (59, 77, 231, 250, 353) \\
\hline $\begin{array}{l}\text { Desenvolver } \\
\text { propaganda }\end{array}$ & $\begin{array}{l}\text { Inserir e destacar na campanha publicitária do produto a inovação das } \\
\text { características ambientais do produto junto com as funcionais, tais como selo } \\
\text { verde, material reciclável e certificação ambiental. }\end{array}$ \\
\hline Atividade - 7.7 Gerenc & r lançamento \\
\hline Tarefa - 7.7.1 & Aspectos Ambientais - Código $(50,51,120)$ \\
\hline $\begin{array}{l}\text { Gerenciar resultados e } \\
\text { aceitação inicial }\end{array}$ & $\begin{array}{l}\text { Acompanhar e analisar se os resultados do produto no mercado estão } \\
\text { atendendo aos requisitos ambientais e funcionais do produto, especificado } \\
\text { anteriormente nas fases de desenvolvimento. }\end{array}$ \\
\hline Tarefa - 7.7.2 & Aspectos Ambientais - Código $(50,51,70,120)$ \\
\hline $\begin{array}{l}\text { Gerenciar satisfação do } \\
\text { cliente }\end{array}$ & $\begin{array}{l}\text { Avaliar a importância das funções ambientais do produto para o cliente e } \\
\text { identificar potenciais necessidades ambientais. }\end{array}$ \\
\hline
\end{tabular}


Tabela 6.7 - Fase de Lançamento do Produto - continuação.

\begin{tabular}{|c|c|}
\hline & $\begin{array}{l}\text { Macrofase - Desenvolvimento } \\
\text { Fase } 7 \text { - Lançamento do Produto (LP) }\end{array}$ \\
\hline Atividade - 7.8 Atualizar & plano de fim de vida \\
\hline Tarefa - 7.8.1 & Aspectos Ambientais - Código $(12,15,46,47,182,252,301,328)$ \\
\hline $\begin{array}{l}\text { Atualizar plano de fim } \\
\text { de vida }\end{array}$ & $\begin{array}{l}\text { Acompanhar a vida útil dos componentes e produto e atualizar o plano de fim } \\
\text { de vida em termos de retirada do mercado, descontinuidade da produção, } \\
\text { descarte e reciclagem. }\end{array}$ \\
\hline Atividade - 7.9 Monitora & a viabilidade econômico-financeira do produto \\
\hline Tarefa - 7.9.1 & Aspectos Ambientais - Código $(18,43,76,90,93,94,130,138,196,215)$ \\
\hline $\begin{array}{l}\text { Avaliar mudanças nas } \\
\text { condições de mercado, } \\
\text { características técnicas } \\
\text { e indicadores }\end{array}$ & $\begin{array}{l}\text { Monitorar as condições do mercado e avaliar potenciais oportunidades } \\
\text { ambientais. }\end{array}$ \\
\hline Tarefa - 7.9.2 & Aspectos Ambientais - Código $(18,20,64)$ \\
\hline $\begin{array}{l}\text { Avaliar possíveis } \\
\text { desvios e impactos no } \\
\text { projeto }\end{array}$ & $\begin{array}{l}\text { Analisar e monitorar a viabilidade ambiental do projeto com base nos } \\
\text { impactos ambientais das escolhas feitas para o produto. }\end{array}$ \\
\hline Tarefa - 7.9.3 & Aspectos Ambientais - Código $(93,94,196,215)$ \\
\hline $\begin{array}{l}\text { Analisar novas } \\
\text { premissas e indicadores }\end{array}$ & $\begin{array}{l}\text { Identificar os pontos ambientais críticos das escolhas feitas para o produto e } \\
\text { desenvolver ou atualizar os indicadores ambientais. }\end{array}$ \\
\hline Atividade - 7.10 Docum & ntar as decisões tomadas e registrar lições aprendidas \\
\hline Tarefa - 7.10.1 & Aspectos Ambientais - Código $(1,103,195)$ \\
\hline $\begin{array}{l}\text { Documentar as } \\
\text { decisões tomadas e } \\
\text { registrar lições } \\
\text { aprendidas }\end{array}$ & $\begin{array}{l}\text { Acumular conhecimentos com os feedbacks das implicações das escolhas } \\
\text { feitas e documentar através da atualização da base de dados (Biblioteca } \\
\text { Ambiental) durante o ciclo de vida do produto. Além disso, deve-se divulgar } \\
\text { esse conhecimento de melhores práticas de ecodesign as pessoas } \\
\text { envolvidas no PDP. }\end{array}$ \\
\hline
\end{tabular}

A macrofase de Pós-Desenvolvimento do PDP realiza avaliação da satisfação do cliente, auditorias pós-projeto, acompanhamento do desempenho técnico do produto durante todo o ciclo de vida, identifica melhorias para o produto e processo, e armazena as lições aprendidas com os feedbacks. Esta macrofase está dividida em duas fases, a de Acompanhar Produto e Processo (APP) e a fase de Descontinuar Produto do Mercado (DPM). A primeira fase, de Acompanhar Produto e Processo (APP), visa garantir o acompanhamento da performance do produto na produção e no mercado, identificando oportunidades de melhorias e garantindo que a retirada do produto cause menos impacto possível aos consumidores e meio ambiente. Nesta fase do PDP, os aspectos ambientais inseridos nas tarefas têm o objetivo principal de orientar a equipe de desenvolvimento a coletar informações do desempenho ambiental do produto durante todo o ciclo de vida para poder adquirir conhecimento, armazená-los e utilizar na melhoria do PDP. A Tabela 6.8 ilustra os aspectos ambientais introduzidos nas tarefas da fase de Acompanhar Produto e Processo. 
Tabela 6.8 - Fase de Acompanhar Produto e Processo.

\begin{tabular}{|c|c|}
\hline \multicolumn{2}{|c|}{$\begin{array}{c}\text { Macrofase - Pós-Desenvolvimento } \\
\text { Fase } 8 \text { - Acompanhar Produto e Processo (APP) }\end{array}$} \\
\hline \multicolumn{2}{|c|}{ Atividade - 8.1 Avaliar satisfação do cliente } \\
\hline Tarefa - 8.1.1 & Aspectos Ambientais - Código $(38,70,93,191,196,215)$ \\
\hline $\begin{array}{l}\text { Planejar e realizar a } \\
\text { avaliação }\end{array}$ & $\begin{array}{l}\text { Utilizar indicadores para avaliar a importância das funções ambientais do } \\
\text { produto no cliente e identificar oportunidades de melhorias. }\end{array}$ \\
\hline \multicolumn{2}{|c|}{$\begin{array}{l}\text { Atividade - } 8.2 \text { Monitorar desempenho do produto (técnico, econômico, de produção e de } \\
\text { serviços) }\end{array}$} \\
\hline Tarefa - 8.2.1 & Aspectos Ambientais - Código $(22,97,179,230,324)$ \\
\hline $\begin{array}{l}\text { Monitorar } \\
\text { desempenho técnico do } \\
\text { processo e do produto } \\
\text { no mercado e nos } \\
\text { serviços associados }\end{array}$ & $\begin{array}{l}\text { Avaliar o desempenho ambiental do produto e processo com base no } \\
\text { atendimento das conformidades e confiabilidade ambiental. }\end{array}$ \\
\hline Tarefa - 8.2.2 & Aspectos Ambientais - Código $(25,64)$ \\
\hline $\begin{array}{l}\text { Monitorar custos e } \\
\text { avaliação econômica do } \\
\text { produto }\end{array}$ & $\begin{array}{l}\text { Monitorar todas as informações ambientais e econômicas do produto com } \\
\text { objetivo de reduzir custos de fim de vida. }\end{array}$ \\
\hline Tarefa - 8.2.3 & Aspectos Ambientais - Código $(50,51,52,64)$ \\
\hline $\begin{array}{l}\text { Monitorar aspectos } \\
\text { relacionados ao meio- } \\
\text { ambiente }\end{array}$ & $\begin{array}{l}\text { Avaliar a performance ambiental do produto com base em critérios } \\
\text { ambientais definidos em conjunto com a funcionalidade e utilidade do } \\
\text { produto. Verificar se o produto atende aos requisitos ambientais do cliente, } \\
\text { das normas do sistema de gestão ambiental e legislação. }\end{array}$ \\
\hline Tarefa - 8.2.4 & Aspectos Ambientais - Código $(1,103,195)$ \\
\hline $\begin{array}{l}\text { Consolidar informações } \\
\text { sobre desempenho } \\
\text { (técnico, econômico, } \\
\text { ambiental, de produção } \\
\text { e de serviços) }\end{array}$ & $\begin{array}{l}\text { Acumular conhecimentos com os feedbacks do cliente, durante o ciclo de } \\
\text { vida do produto. Além disso, deve-se divulgar esse conhecimento de } \\
\text { melhores práticas de ecodesign as pessoas envolvidas no PDP. }\end{array}$ \\
\hline \multicolumn{2}{|c|}{ Atividade - 8.3 Realizar auditoria pós-projeto } \\
\hline Tarefa - 8.3.1 & Aspectos Ambientais - Código $(38,70,195)$ \\
\hline $\begin{array}{l}\text { Planejar os focos da } \\
\text { auditoria }\end{array}$ & $\begin{array}{l}\text { Planejar coleta dos resultados ambientais do produto para direcionar } \\
\text { melhorias na gestão do PDP. }\end{array}$ \\
\hline \multicolumn{2}{|c|}{ Atividade - 8.4 Registrar lições aprendidas } \\
\hline Tarefa - 8.4.1 & Aspectos Ambientais - Código $(1,103,195)$ \\
\hline $\begin{array}{l}\text { Registrar } \\
\text { aprendidas }\end{array}$ & $\begin{array}{l}\text { Acumular conhecimentos com os feedbacks das implicações das escolhas } \\
\text { feitas e documentar atualizando a base de dados (Biblioteca Ambiental) } \\
\text { durante o ciclo de vida do produto. Divulgar esse conhecimento de melhores } \\
\text { práticas de ecodesign aos envolvidos no PDP. }\end{array}$ \\
\hline
\end{tabular}

A última fase do PDP, Descontinuar Produto no Mercado (DPM), tem início com a devolução do produto pelo cliente e a empresa deve estar preparada para receber o produto devolvido e acionar o plano de fim de vida para atender essa demanda. Em síntese, esta fase engloba o recebimento do produto retornado, a descontinuidade da produção e o término da assistência técnica do produto e, consequentemente, do atendimento ao cliente e reposição de peças sobressalentes. Nessa fase do PDP, as orientações ambientais integradas nas tarefas referem-se a preparar o recebimento do produto com base na estratégia de fim de vida selecionada (reciclagem, 
desmontagem, descarte, incineração, trituração e disposição em aterro) e planejar a descontinuidade do produto avaliando os respectivos impactos ambientais e como serão solucionados. Além disso, esta fase serve para retroalimentar informações de melhoria ao processo de desenvolvimento de produtos, com base nos resultados do produto e nos impactos ambientais das escolhas feitas para todo o ciclo de vida.

Tabela 6.9 - Fase de Descontinuar Produto no Mercado (DPM).

\begin{tabular}{|c|c|}
\hline Fas & $\begin{array}{l}\text { Macrofase - Pós-Desenvolvimento } \\
9 \text { - Descontinuar Produto no Mercado (DPM) }\end{array}$ \\
\hline Atividade - 9.1 Analisar & e aprovar descontinuidade do produto \\
\hline Tarefa - 9.1.1 & Aspectos Ambientais - Código $(10,45)$ \\
\hline $\begin{array}{l}\text { Analisar, planejar e } \\
\text { aprovar descontinuidade } \\
\text { do produto }\end{array}$ & $\begin{array}{l}\text { Analisar todas as fases da vida útil do produto e planejar a sua } \\
\text { descontinuidade avaliando os respectivos impactos ambientais e como serão } \\
\text { solucionados. }\end{array}$ \\
\hline Atividade - 9.2 Preparar & e acompanhar o recebimento do produto \\
\hline Tarefa - 9.2.1 & Aspectos Ambientais - Código $(91,142,177,203,225,253,272,328)$ \\
\hline $\begin{array}{l}\text { Preparar e acompanhar } \\
\text { o recebimento do } \\
\text { produto }\end{array}$ & $\begin{array}{l}\text { Preparar o recebimento do produto com base na estratégia de fim de vida } \\
\text { selecionada (reciclagem, desmontagem, descarte, incineração, trituração e } \\
\text { disposição em aterro). }\end{array}$ \\
\hline Atividade - 9.3 Finalizar & suporte ao produto \\
\hline Tarefa -9.3 .1 & Aspectos Ambientais - Código $(182,186)$ \\
\hline $\begin{array}{l}\text { Finalizar suporte ao } \\
\text { produto }\end{array}$ & $\begin{array}{l}\text { Finalizar suporte ao produto de forma a preservar a imagem da empresa em } \\
\text { termos de responsabilidade ambiental. }\end{array}$ \\
\hline Atividade - 9.4 Avaliaçã & geral e encerramento do projeto \\
\hline Tarefa - 9.4.1 & Aspectos Ambientais - Código $(2,64,67,68)$ \\
\hline $\begin{array}{l}\text { Avaliação geral } \mathrm{e} \\
\text { encerramento do projeto }\end{array}$ & $\begin{array}{l}\text { Avaliar os resultados do produto e os impactos ambientais das escolhas } \\
\text { feitas para o desenvolvimento de produto, considerando todo o ciclo de vida. }\end{array}$ \\
\hline
\end{tabular}

\subsection{Considerações finais do capítulo}

Essa proposta de estruturação do PDP com a integração de aspectos ambientais tem o objetivo de levantar pontos de atenção quanto ao impacto ambiental no PDP e apresentar sugestões de ações estratégicas e operacionais durante a realização das tarefas do PDP, que colaborem para se desenvolver produtos alinhados com as exigências ambientais da sociedade e da necessidade das organizações em cumprir aspectos ambientais exigidos pelo mercado.

Na parte da estrutura de PDP, como a proposta não apresenta inovação nesse aspecto, descreveu-se de forma sucinta as funções e objetivos das fases e macrofases desse processo, pois se entende que esse tema esteja bem desenvolvido na literatura sobre gestão do processo de desenvolvimento de novos 
produtos. O enfoque maior da proposta está na discussão da importância dos aspectos ambientais e na definição de quais momentos (tarefas) do PDP eles podem ser integrados e de que forma, visando orientar a equipe de projeto e de desenvolvimento do produto a pensar de forma organizada e antecipada em soluções alternativas para reduzir o impacto ambiental do produto e processo.

Desta forma, espera-se que as empresas utilizem essa proposta como guia para auxiliar na adequação ambiental de suas estruturas de PDP e que o resultado de sua aplicação seja o desenvolvimento de produtos ecoeficientes. Como nesse trabalho de tese sua aplicação não foi possível, busca-se no próximo capítulo avaliar a proposta de estruturação do PDP com aspectos ambientais junto aos especialistas sobre o tema abordado, para saber se atende à sua proposição. 


\section{VERIFICAÇÃO EM CAMPO DA PROPOSTA DE ESTRUTURAÇÃO DO PDP COM ASPECTOS AMBIENTAIS}

Esse capítulo tem o objetivo de apresentar uma discussão da avaliação da proposta de estruturação do PDP com a integração de aspectos ambientais. Para isso foi realizado uma consulta aos especialistas da área de PDP e ecodesign. A análise de dados dividiu-se em três seções, sendo uma destinada a avaliar a confiabilidade interna do questionário através do cálculo do coeficiente alfa de Cronbach, a segunda seção realiza uma análise quantitativa dos dados e tem o objetivo de interpretar estatisticamente a avaliação dos especialistas e verificar o nível de aceitação da estruturação proposta. A terceira seção realiza uma análise qualitativa das sugestões de melhoria e justificativas de discordância dos respondentes quanto ao momento de integração de aspectos ambientais nas tarefas do PDP, essa análise utiliza o referencial teórico como base para discussão. Os métodos e ferramentas utilizados na coleta e análise de dados foram descritos em detalhes nas seções do Capítulo 2 de métodos de pesquisa.

\subsection{Confiabilidade interna do questionário - Alfa de Cronbach}

Para calcular o coeficiente alfa de Cronbach utilizou-se do software Minitab® versão 16 e com a análise de resposta (Item Analysis) de cada etapa do questionário obteve-se os valores que estão estratificados por cada fase do PDP na Tabela 7.1.

Tabela 7.1 - Resultados de confiabilidade interna do questionário aplicado.

\begin{tabular}{|ll|c|c|}
\hline \multicolumn{1}{|c|}{ Fases do PDP } & Questões & Valor de alfa \\
\hline 1. & Planejamento Estratégico de Produtos (PEP) & $1-19$ & 0,7948 \\
\hline 2. & Planejamento do Projeto (PP) & $20-33$ & 0,8316 \\
\hline 3. & Projeto Informacional (PI) & $34-55$ & 0,8880 \\
\hline 4. & Projeto Conceitual (PC) & $56-78$ & 0,8929 \\
\hline 5. & Projeto Detalhado (PD) & $79-137$ & 0,9814 \\
\hline 6. & Preparação da Produção do Produto (PPP) & $138-161$ & 0,9664 \\
\hline 7. & Lançamento do Produto (LP) & $162-184$ & 0,9581 \\
\hline 8. & Acompanhar Produto e Processo (APP) & $185-191$ & 0,9181 \\
\hline 9. & Descontinuar Produto no Mercado (DPM) & $192-195$ & 0,8119 \\
\hline
\end{tabular}


Os valores obtidos por fase do questionário utilizado estão acima de 0,7900 , que demonstra alta confiabilidade interna do instrumento utilizado. Também, foi realizado o cálculo desse indicador para o questionário como um todo considerando todas as 195 questões sem dividir em fases e obteve-se um coeficiente alfa de Cronbach de 0,9870 , que confirma a alta confiabilidade interna do questionário desta consulta.

\subsection{Análise quantitativa dos dados levantados em campo}

Esta análise quantitativa focou em alguns pontos chaves relacionados ao objetivo dessa, de propor uma estrutura de PDP considerando aspectos ambientais: i) avaliar o nível de aceitação da proposta com base nas notas dos especialistas; ii) identificar clusters e agrupar os especialistas com base nas características das suas avaliações; iii) checar em quais fases do PDP há maior discordância para, posteriormente, direcionar a análise qualitativa para esses itens; e iv) realizar testes de hipótese para avaliar estatisticamente se a proposta deste trabalho foi aprovada ou rejeitada pelos especialistas que participaram da consulta.

Inicialmente, avaliou-se o gráfico de Histograma de todas as notas, com o intuito de averiguar quais são as notas mais frequentes, que conforme observado na Figura 7.1 é a nota (2-concordância), seguido de perto pela nota (1-concordância plena). As demais notas são bem menos frequentes (3-indiferente, 4-discordância e 5discordância plena). Nessa mesma figura também se consegue visualizar as principais características descritivas dos dados da amostra analisada, tais como: média, desvio padrão e variância.

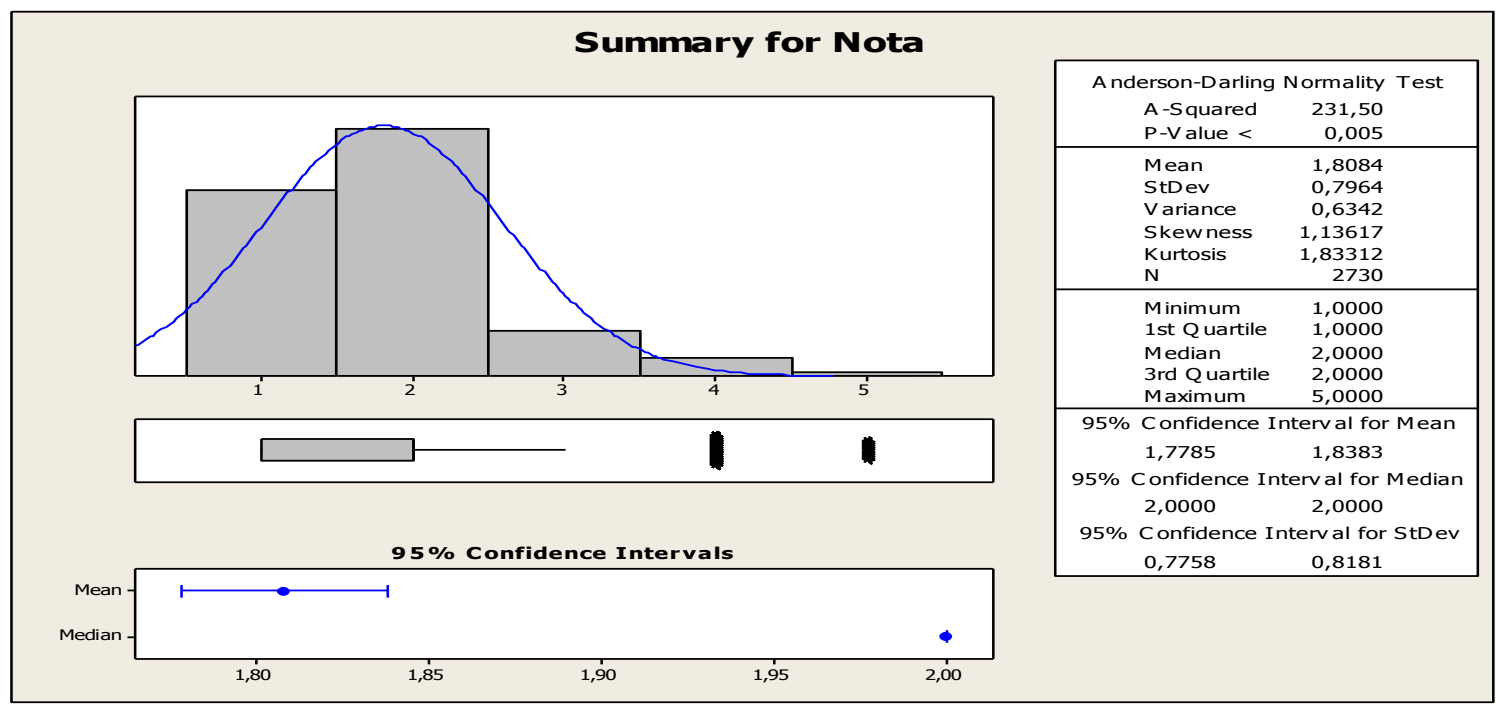

Figura 7.1 - Histograma das avaliações dos especialistas. 
Em seguida, utilizou-se do gráfico de Pareto ilustrado na Figura 7.2 que faz essencialmente a mesma análise anterior do Histograma, no entanto pode-se observar claramente que os especialistas de uma forma geral concordam com a proposta apresentada, sendo que $86,8 \%$ das respostas são de concordância $(37,3 \%$ de concordância plena e 49,5\% de concordância), 8,9\% são indiferentes e apenas $4,3 \%$ de discordância (3,5\% de discordância e 0,8\% de discordância plena).

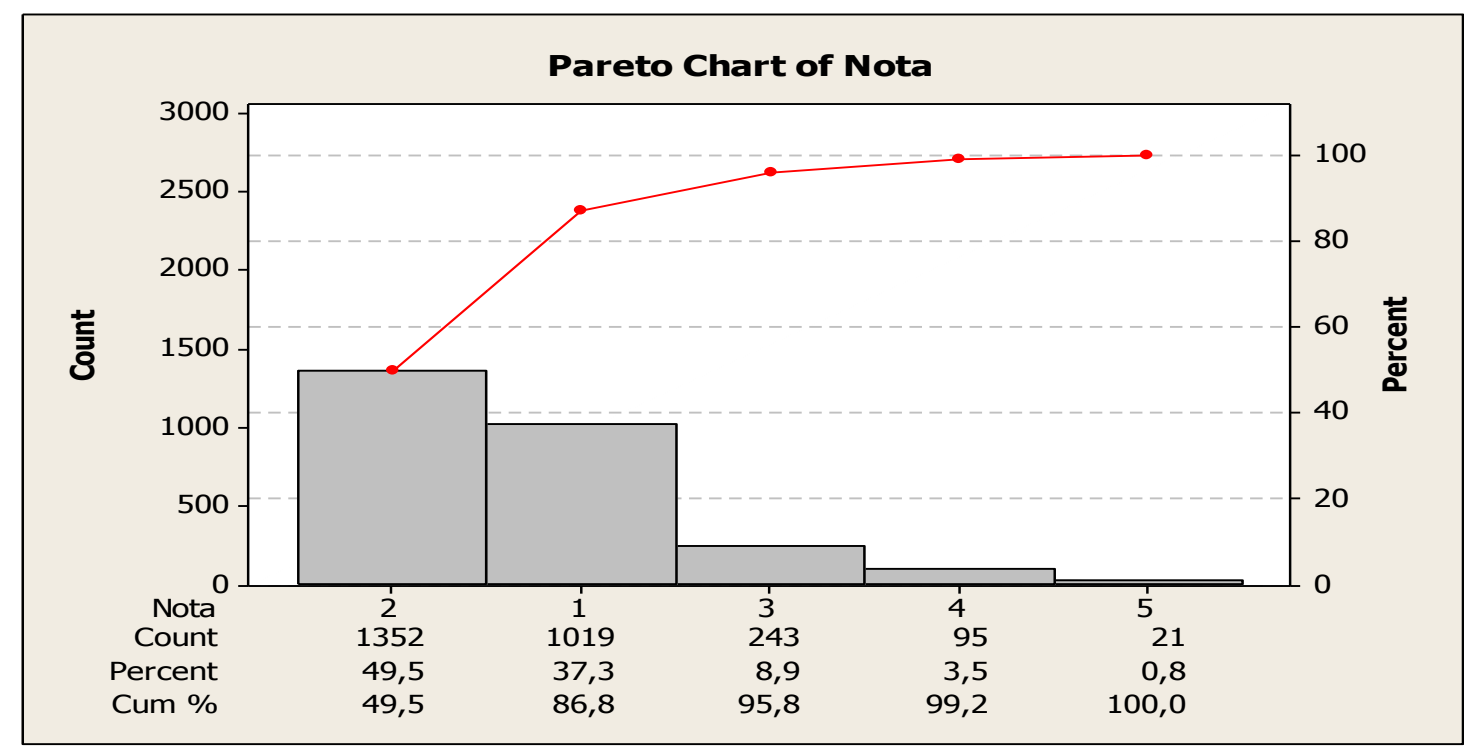

Figura 7.2 - Pareto das avaliações dos especialistas.

A próxima etapa visa verificar se os especialistas estão avaliando igualmente a proposta apresentada ou não. Para isso, foi realizado o teste de normalidade de Anderson-Darling (AD) para as notas por avaliador, onde a Figura 7.3 mostra que os valores de probabilidade do teste ( $p$-value) são menores que o nível de significância de $5 \%(\alpha=0,05)$. Desta forma, infere-se que nenhum dos dados segue a distribuição normal, isto é importante para se direcionar quais as ferramentas e testes serão utilizados nas próximas etapas dessa análise estatística.

Logo, para checar se há ou não a existência de especialistas que apóiam ou não a proposta, foi feito um gráfico Boxplot para as notas por avaliador, onde se observa na Figura 7.4 que há alguns avaliadores que possuem mais notas de concordância (1 e 2), como os especialistas "A", "B", "D" e "M", entre outros. 


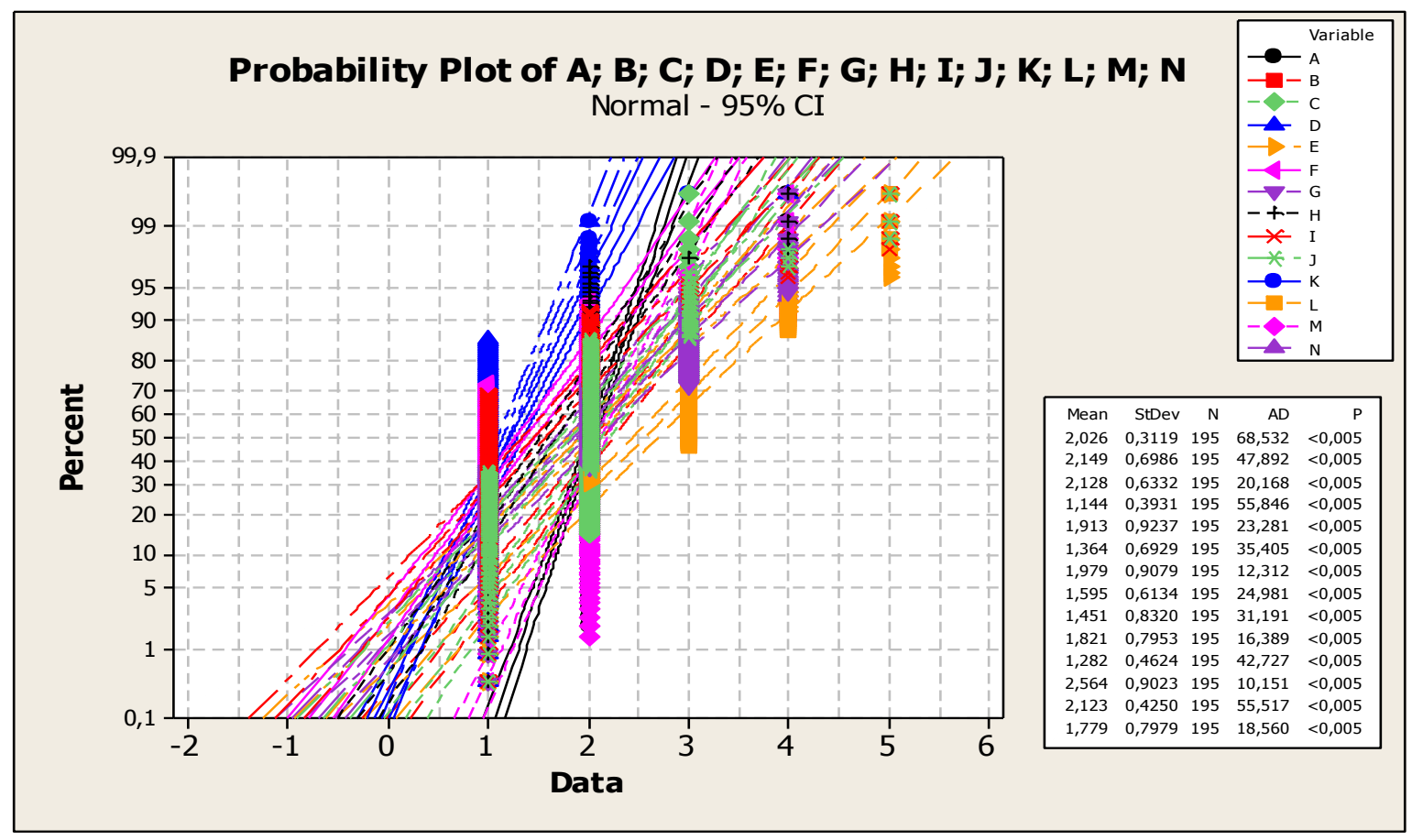

Figura 7.3 - Teste de normalidade das avaliações dos especialistas.

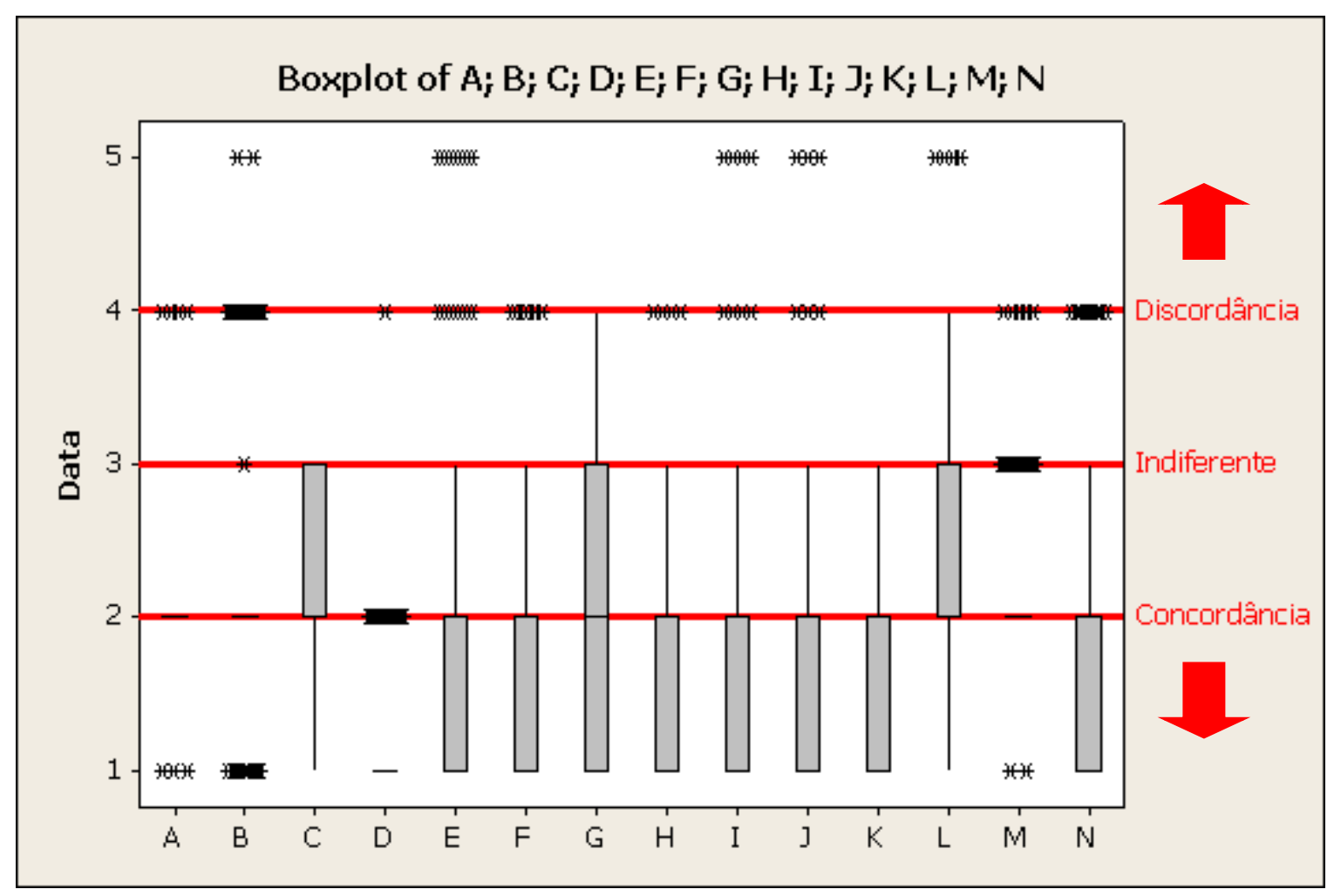

Figura 7.4 - Boxplot das avaliações por especialistas. 
Além disso, o gráfico de Pareto da Figura 7.5 corrobora com a análise do Boxplot anterior, avaliando a frequência de cada nota para cada avaliador. Assim, pode-se perceber que os avaliadores "D", "F" e "K" são os maiores apoiadores da proposta de estruturação do PDP com aspectos ambientais e que o especialista "L" parece ser o que mais discorda da proposta apresentada.

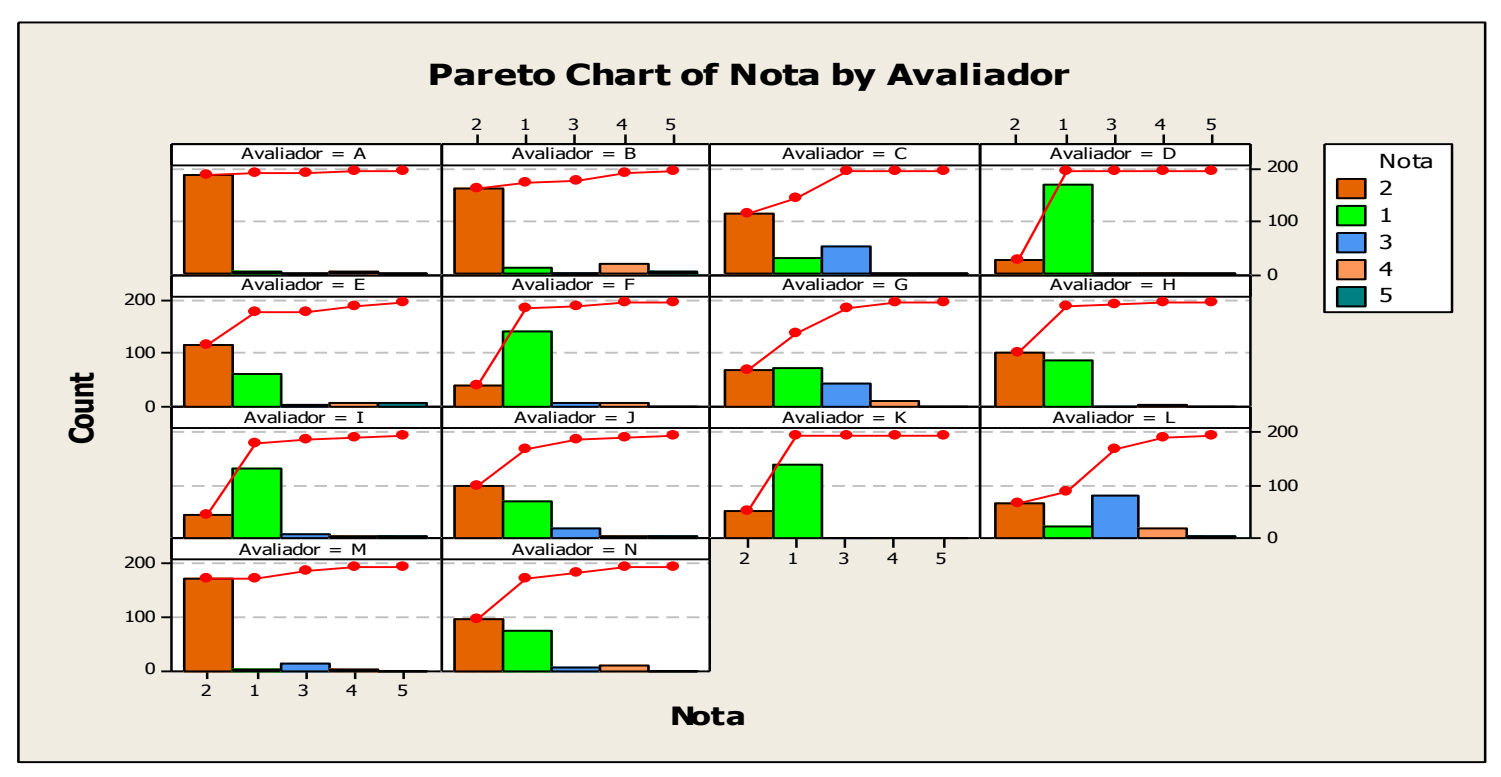

Figura 7.5 - Boxplot das avaliações por especialistas.

Pelas análises antecedentes (Boxplot e Pareto) observa-se que há comportamentos bem distintos entre os avaliadores, embora não existe forte resistência por nenhum especialista parece haver dois ou mais grupos (um de forte concordância) e um de menor concordância (leve indiferença) a estrutura proposta. Como o teste de normalidade foi rejeitado, optou-se por realizar o teste de hipótese para a variância proposto por Levene e verificou na Figura 7.6 que as notas dos avaliadores não variam igualmente, ou seja, há no mínimo um avaliador com variância diferente e, portanto foi constatado que a hipótese $\mathrm{H} 0$ é reprovada. $\mathrm{O}$ teste de Bartlett também comprovou a diferença de variância entre as notas dos avaliadores (MONTGOMERY, 2004). 


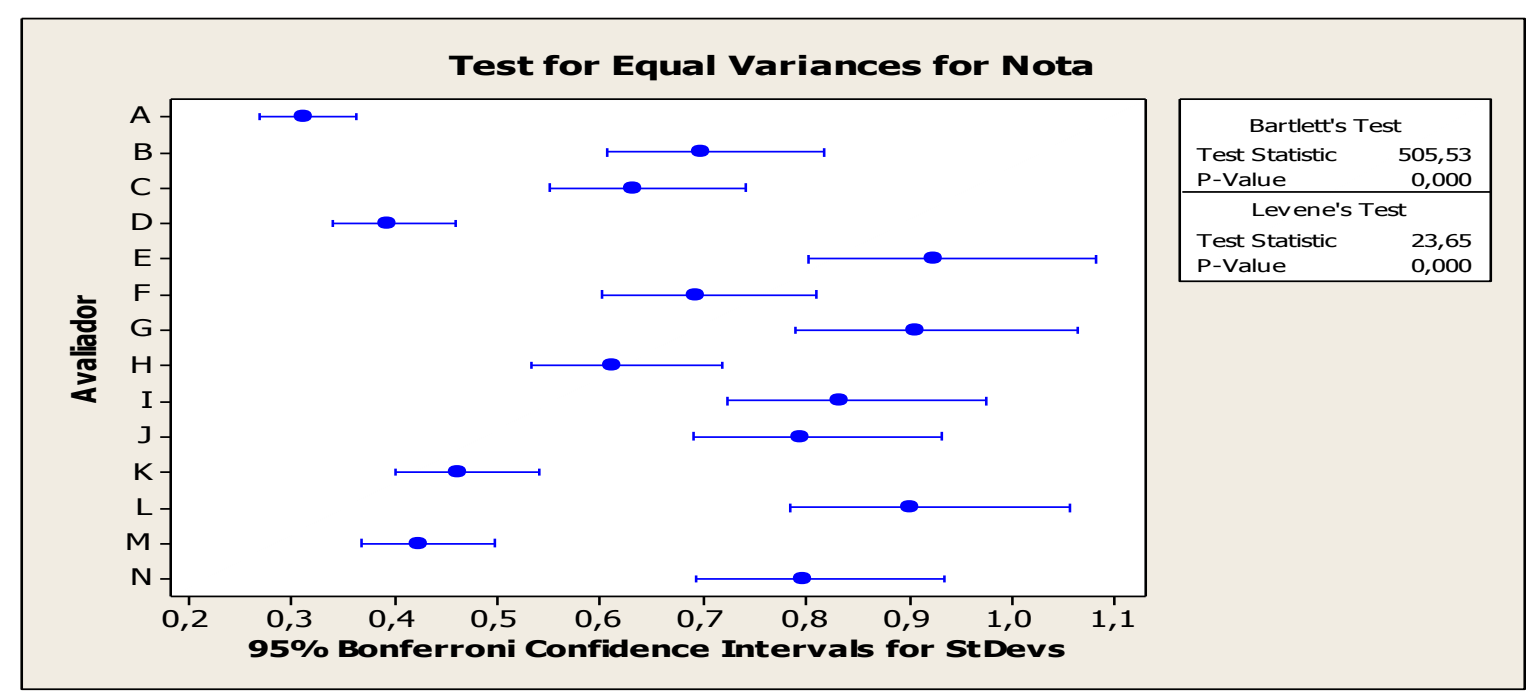

Figura 7.6 - Teste de hipótese para igualdade de variância das avaliações.

Além disso, devido aos dados não apresentarem normalidade, estabeleceu-se a utilização do teste de hipótese não-paramétrico da mediana de Mood (Mood Median Test) para avaliar se a tendência central das notas por avaliadores eram a mesma, sendo neste caso a tendência central representada pela mediana, e checa-se na Figura 7.7 que as medianas dos resultados dos avaliadores não são iguais.

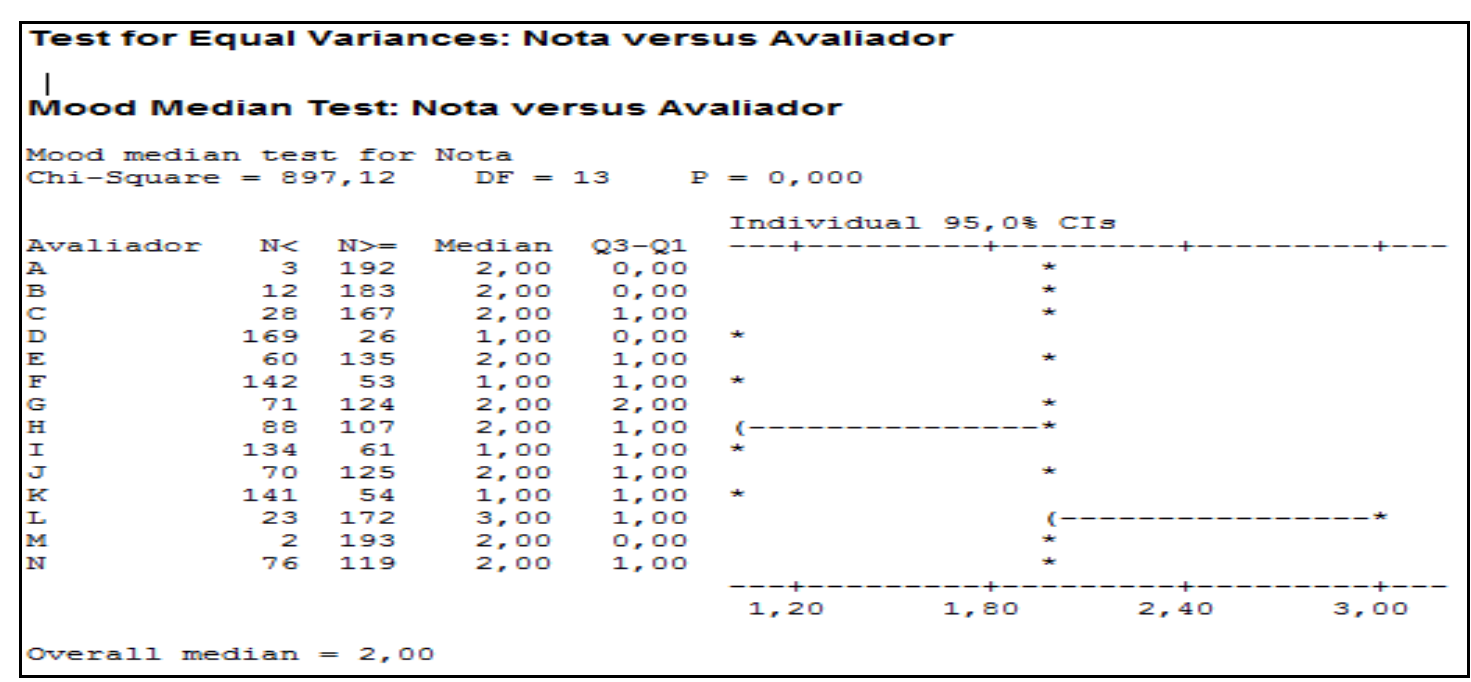

Figura 7.7 - Teste de hipótese da mediana de Mood das avaliações por especialistas.

O próximo passo foi realizar uma análise de cluster exploratória utilizando a técnica hierárquica e tendo como critérios de similaridade para agrupamento a distância dos coeficientes de correlação dos dados analisados e o método da média 
do centróide como mecanismo de ligação. Essa análise gerou um dendrograma agrupando os avaliadores em três grupos, mas o resultado não ficou coerente com as análises visuais e estatísticas dos dados, pois o agrupamento isolou o avaliador de menor nota, o de maior nota e os demais especialistas em um único grupo. Portanto, para avaliar os especialistas quanto à concordância com a proposta, foi utilizado a nota média para ordenar os especialistas, uma vez que ela representa o centro de gravidade dos dados de cada avaliador. Avaliando a Tabela 7.2 são vislumbrados três diferentes grupos, forte apoiadores com os especialistas "D" e "K" (nota média baixa e baixo desvio padrão), forte resistores com os especialistas "L" e "B" (nota média alta e alto desvio padrão) e um grupo intermediário com os especialistas "J" e "E". Também, percebe-se que os desvios padrões de forma macro aumentam com a redução da nota média.

Tabela 7.2 - Análise das avaliações dos especialistas para identificar clusters.

\begin{tabular}{|c|c|c|c|c|c|c|}
\hline Avaliador & $\begin{array}{c}\text { Média } \\
(\mu)\end{array}$ & $\begin{array}{l}\text { Desvio Padrão } \\
(\sigma)\end{array}$ & $\begin{array}{c}\text { Nota } 1 \\
(\%)\end{array}$ & $\begin{array}{c}\text { Concordância } \\
(\%)\end{array}$ & $\begin{array}{c}\text { Nota } 5 \\
(\%)\end{array}$ & $\begin{array}{c}\text { Discordância } \\
(\%)\end{array}$ \\
\hline D & 1,143589744 & 0,393107414 & $87 \%$ & $99 \%$ & $0 \%$ & $1 \%$ \\
\hline K & 1,282051282 & 0,462440743 & $72 \%$ & $99 \%$ & $0 \%$ & $0 \%$ \\
\hline $\mathbf{F}$ & 1,364102564 & 0,692927147 & $73 \%$ & $94 \%$ & $0 \%$ & $3 \%$ \\
\hline I & 1,451282051 & 0,831986752 & $69 \%$ & $92 \%$ & $2 \%$ & $4 \%$ \\
\hline H & 1,594871795 & 0,613402173 & $45 \%$ & $97 \%$ & $0 \%$ & $2 \%$ \\
\hline $\mathbf{N}$ & 1,779487179 & 0,797928855 & $39 \%$ & $89 \%$ & $0 \%$ & $6 \%$ \\
\hline $\mathbf{J}$ & 1,820512821 & 0,795340648 & $36 \%$ & $87 \%$ & $2 \%$ & $3 \%$ \\
\hline$E$ & 1,912820513 & 0,923680303 & $31 \%$ & $90 \%$ & $4 \%$ & $8 \%$ \\
\hline G & 1,979487179 & 0,907920329 & $36 \%$ & $71 \%$ & $0 \%$ & $6 \%$ \\
\hline A & 2,025641026 & 0,31189308 & $2 \%$ & $98 \%$ & $0 \%$ & $2 \%$ \\
\hline $\mathbf{M}$ & 2,123076923 & 0,425029737 & $1 \%$ & $89 \%$ & $0 \%$ & $3 \%$ \\
\hline C & 2,128205128 & 0,633249156 & $14 \%$ & $73 \%$ & $0 \%$ & $0 \%$ \\
\hline B & 2,148717949 & 0,698625969 & $6 \%$ & $90 \%$ & $1 \%$ & $10 \%$ \\
\hline $\mathbf{L}$ & 2,564102564 & 0,902312944 & $12 \%$ & $46 \%$ & $2 \%$ & $12 \%$ \\
\hline
\end{tabular}

Normalizando em concordância as notas (1 e 2) e discordância as notas (3, 4 e 5) e utilizando a ferramenta do Minitab® "Attribute Agreement Analysis", que gera os gráficos com base no acerto dos avaliadores quanto à resposta padrão, que no caso foram consideradas como padrão as notas de concordância (1 e 2). O resultado desta avaliação foi muito condizente com 0 demonstrado na Tabela 7.2, demonstrando três grupos de avaliadores (forte apoiadores, opositores e indiferentes). Mas, o nível de aceitação da proposta foi bem alto, sendo o mais baixo de todos com $46 \%$, e a grande maioria estando acima de $87 \%$ de concordância com 
a proposta de estruturação do PDP com aspectos ambientais. Nessa análise consegue-se visualizar o intervalo de confiança de acerto para cada especialista e verifica-se que o especialista "L" é o que possui menor concordância com a proposta apresentada, conforme pode ser visto na próxima Figura 7.8.

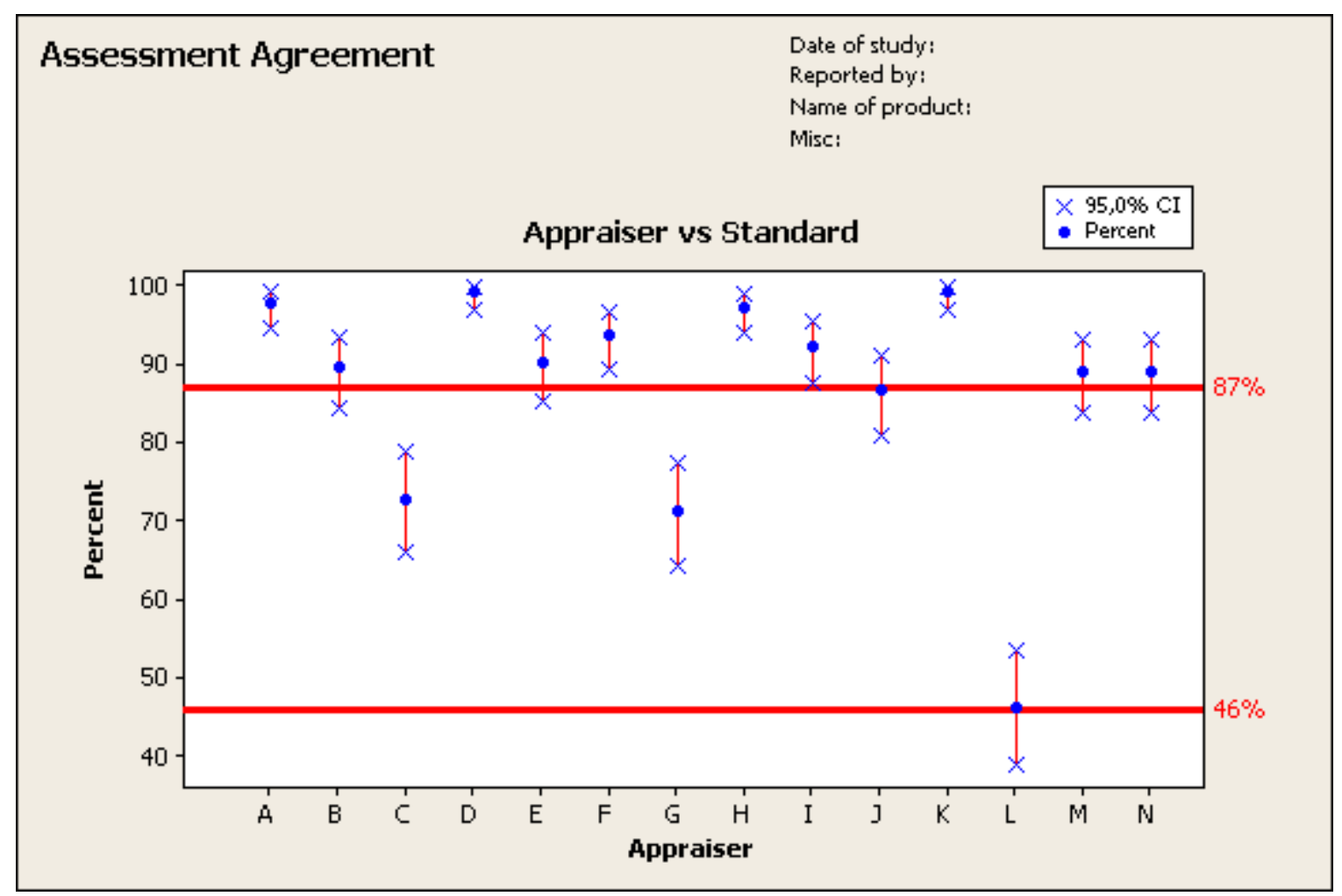

Figura 7.8 - Intervalo de confiança de acerto das avaliações dos especialistas.

Para avaliar a proposta por fases procurou-se analisar a distribuição das notas, as notas médias e a dispersão para cada avaliador e fase do PDP. Na Tabela 7.3 foram avaliadas as fases, juntando-se todos os avaliadores, onde foi percebido que as fases de menor aceitação foram de Projeto Conceitual (PC) e Projeto Detalhado (PD), que possuem baixa média e alto desvio padrão. Cabe ressaltar que as fases de Planejamento Estratégico de Projetos (PEP), Planejamento de Projeto (PP) e Projeto Informacional (PI) possuíram um desvio padrão alto, ou seja, forte discordância entre os avaliadores sobre os mesmos pontos, mas no geral o resultado das avaliações foi bom, demonstrando haver mais resultados favoráveis. 
Tabela 7.3 - Análise da avaliação por fase da proposta apresentada.

\begin{tabular}{|l|c|c|c|c|c|c|c|c|}
\hline \multicolumn{1}{|c|}{ Fases do PDP } & $\begin{array}{c}\text { Nota } \\
\mathbf{1}\end{array}$ & $\mathbf{2}$ & $\mathbf{2}$ & $\mathbf{4}$ & $\mathbf{5}$ & $\begin{array}{c}\text { Média } \\
(\boldsymbol{\mu})\end{array}$ & $\begin{array}{c}\text { Desvio } \\
\text { Padrão }(\boldsymbol{\sigma})\end{array}$ & Total \\
\hline Planej. Estratégico de Produtos & $42 \%$ & $44 \%$ & $7 \%$ & $6 \%$ & $1 \%$ & 1,7969 & 0,8709 & 266 \\
\hline Planejamento do Projeto & $45 \%$ & $40 \%$ & $4 \%$ & $9 \%$ & $2 \%$ & 1,8163 & 0,9958 & 196 \\
\hline Projeto Informacional & $44 \%$ & $45 \%$ & $3 \%$ & $6 \%$ & $3 \%$ & 1,7922 & 0,9459 & 308 \\
\hline Projeto Conceitual & $32 \%$ & $55 \%$ & $10 \%$ & $4 \%$ & $0 \%$ & 1,8509 & 0,7380 & 322 \\
\hline Projeto Detalhado & $34 \%$ & $50 \%$ & $13 \%$ & $2 \%$ & $1 \%$ & 1,8595 & 0,7875 & 826 \\
\hline Prep. da Produção do Produto & $36 \%$ & $49 \%$ & $14 \%$ & $1 \%$ & $0 \%$ & 1,8035 & 0,7228 & 336 \\
\hline Lançamento do Produto & $37 \%$ & $55 \%$ & $7 \%$ & $2 \%$ & $0 \%$ & 1,7360 & 0,6617 & 322 \\
\hline Acompanhar Produto e Processo & $35 \%$ & $60 \%$ & $5 \%$ & $0 \%$ & $0 \%$ & 1,7040 & 0,5599 & 98 \\
\hline Descontinuar Produto no Mercado & $48 \%$ & $50 \%$ & $0 \%$ & $2 \%$ & $0 \%$ & 1,5535 & 0,6005 & 56 \\
\hline
\end{tabular}

As Tabelas 7.4 e 7.5 desdobram os indicadores por avaliador em desvio padrão e média, sendo que assim, foi novamente constatado que as fases de PI e PC possuem notas mais baixas e maior dispersão entre as notas dos avaliadores. Além disso, observa-se que o avaliador "L" é o de maior nota (discordância) e de maior variação, e as fases de Projeto Conceitual e Projeto Detalhado possuem resultados piores nos avaliadores de menor concordância (A, B, L e M).

Tabela 7.4 - Avaliação do desvio padrão das notas das fases por especialista.

\begin{tabular}{|c|c|c|c|c|c|c|c|c|c|c|c|c|c|c|}
\hline \multicolumn{15}{|c|}{ Desvio Padrão $(\sigma)$ por Avaliador } \\
\hline Fase & A & B & C & D & E & $\mathbf{F}$ & G & $\mathbf{H}$ & I & $\mathbf{J}$ & K & $\mathbf{L}$ & M & $\mathbf{N}$ \\
\hline PEP & 0,3153 & 1,4266 & 0,5015 & 0,4524 & 1,0145 & 0,6967 & 1,0116 & 0,8377 & 0,7493 & 0,684 & 0,5073 & 0,6882 & 0,3153 & 1,0706 \\
\hline PP & 0 & 0,9972 & 0,6157 & 0,8516 & 1,4525 & 0,4688 & 0,6794 & 0 & 1,2666 & 0,5136 & 0,4258 & 1,5619 & 0 & 1,0716 \\
\hline PI & 0 & 0,9535 & 0,5096 & 0,3513 & 0,8528 & 0,4767 & 0,7673 & 0,9902 & 1,5825 & 1,1396 & 0,4767 & 1,1668 & 0,8541 & 0,4676 \\
\hline PC & 0 & 0,5146 & 0,5623 & 0,487 & 0,8958 & 1,0388 & 0,9002 & 0,487 & 0,499 & 0,7928 & 0,4705 & 0,7777 & 0,2085 & 0,3876 \\
\hline PD & 0,5071 & 0 & 0,5685 & 0,1825 & 1,0105 & 0,6634 & 0,9278 & 0,406 & 0,6518 & 0,8198 & 0,4291 & 0,6554 & 0,2604 & 0,3784 \\
\hline PPP & 0 & 0,4082 & 0,4945 & 0,3807 & 0 & 0,4149 & 1,018 & 0,4815 & 0,5758 & 0,5316 & 0,4484 & 0,4815 & 0,55 & 0,4149 \\
\hline LP & 0 & 0,5762 & 0,2085 & 0 & 0 & 0,9451 & 0,9493 & 0,3876 & 0,3444 & 0,5588 & 0,3444 & 0,5069 & 0,3444 & 0,3666 \\
\hline APP & 0,378 & 0 & 0,378 & 0 & 0 & 0,5345 & 0,7559 & 0 & 0 & 0,488 & 0,378 & 0,5345 & 0 & 0 \\
\hline DPM & 0 & 0 & 0,5 & 0 & 0 & 0,5 & 0,5 & 0 & 0 & 0 & 0 & 1,4142 & 0 & 0,5774 \\
\hline
\end{tabular}

Tabela 7.5 - Avaliação das notas médias das fases da proposta por especialista.

\begin{tabular}{|c|c|c|c|c|c|c|c|c|c|c|c|c|c|c|}
\hline \multicolumn{15}{|c|}{ Média $(\mu)$ por Avaliador } \\
\hline Fase & A & B & C & D & E & $\mathbf{F}$ & G & H & I & $\mathbf{J}$ & K & $\mathbf{L}$ & M & $\mathbf{N}$ \\
\hline PEP & 1,8947 & 2,4211 & 1,8421 & 1,2632 & 1,8421 & 1,4737 & 2,3684 & 1,5789 & 1,3158 & 1,3684 & 1,4211 & 1,8421 & 2,1053 & 2,4211 \\
\hline PP & 2 & 1,9286 & 1,9286 & 1,4286 & 1,5714 & 1,2857 & 2 & 1 & 1,7143 & 1,5714 & 1,2143 & 2,8571 & 2 & 2,9286 \\
\hline PI & 2 & 2,6364 & 1,4545 & 1,1364 & 1,1818 & 1,3182 & 1,7273 & 1,8636 & 1,8636 & 2,1818 & 1,3182 & 1,8636 & 2,4091 & 2,1364 \\
\hline PC & 2 & 2,087 & 1,9565 & 1,3478 & 1,5652 & 1,4783 & 1,913 & 1,3478 & 1,3913 & 2,087 & 1,6957 & 2,8261 & 2,0435 & 2,1739 \\
\hline PD & 2,1356 & 2 & 2,5085 & 1,0339 & 2,339 & 1,3559 & 2,0339 & 1,7966 & 1,5424 & 1,9831 & 1,2373 & 2,8644 & 2,0339 & 1,1695 \\
\hline PPP & 2 & 2,0833 & 2,625 & 1,1667 & 2 & 1,2083 & 1,9167 & 1,6667 & 1,375 & 1,75 & 1,125 & 2,8333 & 2,2917 & 1,2083 \\
\hline LP & 2 & 2,1739 & 1,9565 & 1 & 2 & 1,4348 & 2,087 & 1,1739 & 1,1304 & 1,6957 & 1,1304 & 2,4348 & 2,1304 & 1,9565 \\
\hline APP & 1,8571 & 2 & 1,8571 & 1 & 2 & 1,4286 & 1,7143 & 2 & 1 & 1,2857 & 1,1429 & 2,5714 & 2 & 2 \\
\hline DPM & 2 & 2 & 1,75 & 1 & 2 & 1,25 & 1,25 & 2 & 1 & 1 & 1 & 2 & 2 & 1,5 \\
\hline
\end{tabular}


Para finalizar as análises estatísticas foram feitas avaliações sobre o nível de aceitação da proposta desenvolvida nesse trabalho, assim foi realizado um teste de hipótese para avaliar se a nota média era menor ou igual 2, ou seja, indicava concordância dos especialistas. Para todos os testes estatísticos foram utilizados o teste 1-Sample T Unilateral no Minitab® onde as hipóteses seguem a equação 2.2 descrita no capitulo de métodos (item 2.2.3.4.2). O primeiro teste de hipótese apresentado na Figura 7.9 foi feito para cada fase do PDP de forma individual, onde cada fase possuiu um valor ( $p$-value $>0,05)$, assim nos permite afirmar com mais de $95 \%$ de confiança que a média das notas para cada fase é menor ou igual a 2 , que por consequência aprova todas as fases da proposta avaliada pelos especialistas.

\begin{tabular}{|c|c|c|c|c|c|c|c|c|}
\hline \multicolumn{9}{|c|}{ One-Sample T: Avaliação por Fase } \\
\hline Test of $\mathrm{I}$ & $a=2$ & $v s>2$ & & & & & & \\
\hline \multirow[b]{2}{*}{ Variable } & & & & & 958 & Lower & & \\
\hline & $\mathrm{N}$ & Mean & StDev & SE Mean & & Bound & I & $\mathrm{P}$ \\
\hline Fase 1 & 266 & 1,7970 & 0,8710 & 0,0534 & & 1,7088 & $-3,80$ & 1,000 \\
\hline Fase 2 & 196 & 1,8163 & 0,9959 & 0,0711 & & 1,6988 & $-2,58$ & 0,995 \\
\hline Fase 3 & 308 & 1,7922 & 0,9459 & 0,0539 & & 1,7033 & $-3,86$ & 1,000 \\
\hline Fase 4 & 322 & 1,8509 & 0,7380 & 0,0411 & & 1,7831 & $-3,62$ & 1,000 \\
\hline Fase 5 & 826 & 1,8596 & 0,7876 & 0,0274 & & 1,8144 & $-5,12$ & 1,000 \\
\hline Fase 6 & 336 & 1,8036 & 0,7228 & 0,0394 & & 1,7385 & $-4,98$ & 1,000 \\
\hline Fase 7 & 322 & 1,7360 & 0,6617 & 0,0369 & & 1,6752 & $-7,16$ & 1,000 \\
\hline Fase 8 & 98 & 1,7041 & 0,5600 & 0,0566 & & 1,6101 & $-5,23$ & 1,000 \\
\hline Fase 9 & 56 & 1,5536 & 0,6006 & 0,0803 & & 1,4193 & $-5,56$ & 1,000 \\
\hline
\end{tabular}

Figura 7.9 - Teste de Hipótese para avaliação das fases do PDP.

Fazendo uma análise similar por avaliador percebe-se na Figura 7.10 que a maior parte dos avaliadores aprova a proposta (com nota média menor que 2). Porém, foi constatado que 4 avaliadores não aprovam (com notas médias maiores que 2) a proposta de estruturação do PDP com aspectos ambientais. É importante destacar que as notas médias maiores que 2 foram do avaliador "B" $(2,14)$, avaliador "C" $(2,12)$, avaliador "L" $(2,56)$, avaliador "M" $(2,12)$ que estão muito mais próximas da concordância e da avaliação indiferente do que da discordância da proposta. 


\begin{tabular}{|c|c|c|c|c|c|c|c|}
\hline \multicolumn{8}{|c|}{ One-Sample T: Por Avaliador (A - N) } \\
\hline \multicolumn{8}{|c|}{ Test of mu $=2$ vs $>2$} \\
\hline & & & & & 95의 Lower & & \\
\hline Variable & N & Mean & StDev & SE Mean & Bound & I & P \\
\hline A & 195 & 2,0256 & 0,3119 & 0,0223 & 1,9887 & 1,15 & 0,126 \\
\hline B & 195 & 2,1487 & 0,6986 & 0,0500 & 2,0660 & 2,97 & 0,002 \\
\hline C & 195 & 2,1282 & 0,6332 & 0,0453 & 2,0533 & 2,83 & 0,003 \\
\hline D & 195 & 1,1436 & 0,3931 & 0,0282 & 1,0971 & $-30,42$ & 1,000 \\
\hline $\mathrm{E}$ & 195 & 1,9128 & 0,9237 & 0,0661 & 1,8035 & $-1,32$ & 0,905 \\
\hline $\mathbf{F}$ & 195 & 1,3641 & 0,6929 & 0,0496 & 1,2821 & $-12,81$ & 1,000 \\
\hline G & 195 & 1,9795 & 0,9079 & 0,0650 & 1,8720 & $-0,32$ & 0,624 \\
\hline $\mathrm{H}$ & 195 & 1,5949 & 0,6134 & 0,0439 & 1,5223 & $-9,22$ & 1,000 \\
\hline I & 195 & 1,4513 & 0,8320 & 0,0596 & 1,3528 & $-9,21$ & 1,000 \\
\hline J & 195 & 1,8205 & 0,7953 & 0,0570 & 1,7264 & $-3,15$ & 0,999 \\
\hline $\mathrm{K}$ & 195 & 1,2821 & 0,4624 & 0,0331 & 1,2273 & $-21,68$ & 1,000 \\
\hline L & 195 & 2,5641 & 0,9023 & 0,0646 & 2,4573 & 8,73 & 0,000 \\
\hline M & 195 & 2,1231 & 0,4250 & 0,0304 & 2,0728 & 4,04 & 0,000 \\
\hline N & 195 & 1,7795 & 0,7979 & 0,0571 & 1,6850 & $-3,86$ & 1,000 \\
\hline
\end{tabular}

Figura 7.10 - Teste de Hipótese para avaliação dos especialistas.

Como participaram dessa consulta 14 especialistas, ainda há um total de 10 avaliadores que aprovam a proposta desenvolvida nesse trabalho. Desta forma, verifica-se que há uma aprovação por $71,4 \%$ dos avaliadores, o que pode ser considerado substancial para essa proposta inicial. Fazendo uma análise similar pelas notas médias dos avaliadores verifica-se na Figura 7.11 que a maior parte dos avaliadores aprova a proposta (com nota média menor que 2).

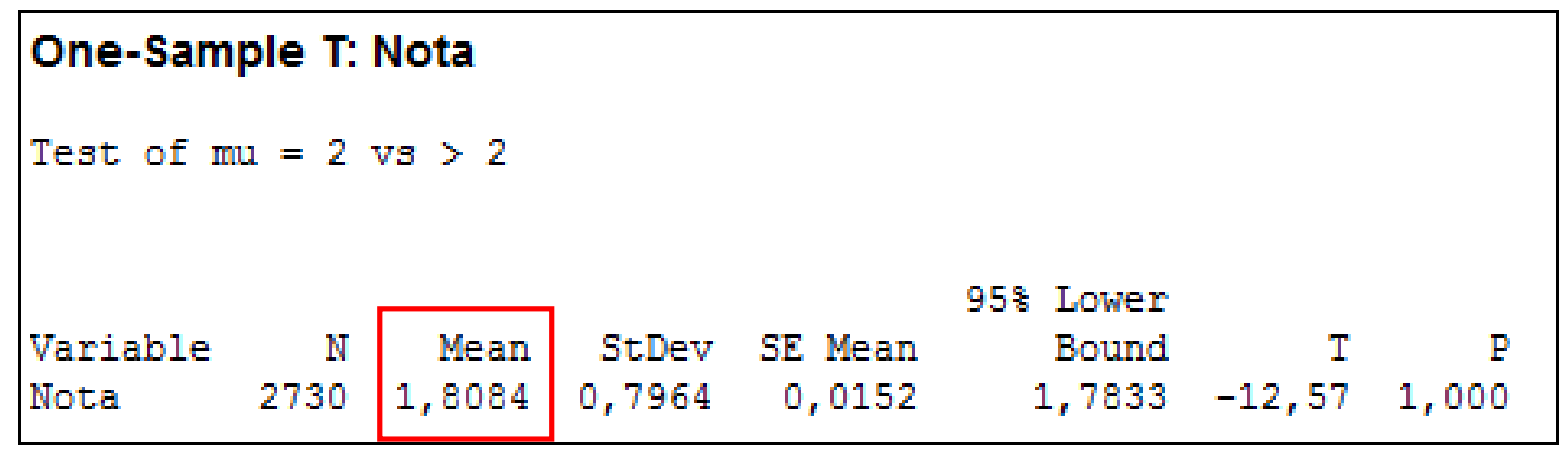

Figura 7.11 - Teste de Hipótese para as notas médias dos especialistas.

Pelos testes de hipóteses (por fase, avaliador e nota) realizados pode-se concluir que a proposta foi bem aceita pelos especialistas que participaram da consulta, pois a média das notas é inferior a 2 (que indica concordância). A seguir na análise qualitativa, são discutidos os comentários gerais dos especialistas, assim pretendese melhorar a proposta desse trabalho e elevar o nível de aceitação. 


\title{
7.3 Análise qualitativa das avaliações dos especialistas
}

\author{
Esta análise qualitativa dos dados é embasada pelos conceitos apresentados no \\ referencial teórico sobre PDP e ecodesign e enfoca na interpretação dos \\ comentários e na justificativa das discordâncias da avaliação dos especialistas sobre \\ a proposta de inserção de aspectos ambientais no PDP. A Tabela 7.6 sintetiza os \\ principais comentários dos 14 especialistas que participaram da consulta.
}

Tabela 7.6 - Principais comentários dos especialistas sobre a proposta avaliada.

\begin{tabular}{|c|c|}
\hline Especialista & Comentários Gerais \\
\hline A & $\begin{array}{l}\text { De modo geral, concordo na maioria dos itens, no que se refere ao que ele está } \\
\text { perguntando: "a atividade está adequada à fase do PDP?" No entanto, questiono } \\
\text { um pouco a viabilidade de se aplicar a proposta, visto que é uma proposta } \\
\text { genérica. Uma questão crítica é que em diversos itens foi apenas acrescentado o } \\
\text { termo "ambiental" nas atividades. Isso é muito geral. Poderia especificar pelo } \\
\text { menos em reduzir/eliminar/não gerar impactos ambientais negativos no ciclo de } \\
\text { vida do produto. O único ponto em que discordo foi em relação ao desenvolvimento } \\
\text { da embalagem. Pois, em alguns casos, a embalagem é extremamente crítica, } \\
\text { podendo até representar maior impacto ambiental que o próprio produto. Por isso, } \\
\text { o desenvolvimento da embalagem deve acontecer junto com o do produto, e não } \\
\text { apenas no Projeto Detalhado. Nessa fase, pode ser muito tarde para se conseguir } \\
\text { algum ganho ambiental efetivo. Mas de maneira geral, acho que você fez um bom } \\
\text { e minucioso trabalho. }\end{array}$ \\
\hline B & Sem comentários gerais. \\
\hline C & Sem comentários gerais. \\
\hline D & $\begin{array}{l}\text { Sobre a sua proposta, entendo que seja uma abordagem de ótica mais racionalista } \\
\text { do processo (solução racional de problemas), bem próxima da engenharia, correto? } \\
\text { Como o desenvolvimento de produtos com melhor desempenho ambiental } \\
\text { (ecodesign) também passa por entender melhor o consumidor, suas expectativas e } \\
\text { necessidades, penso que poderia ser enriquecido com elementos que permitissem } \\
\text { à empresa incluir no processo essas questões, o que não é fácil. Talvez uma } \\
\text { consulta a ferramentas etnográficas pudesse trazer subsídios ao processo. Digo } \\
\text { isso porque a questão do usuário, quando se fala em sustentabilidade, é algo que } \\
\text { não dá para subestimar, pode ser a diferença entre o produto ter sucesso ou } \\
\text { fracassar, independente de ser "eco" ou não. Penso ainda que essa dimensão do } \\
\text { consumidor deva ser uma questão central já na fase estratégica, e não } \\
\text { posteriormente. Entendo que a estratégia começa com as pessoas e deve ser } \\
\text { construída de fora para dentro do negócio, trazendo no seu bojo também as } \\
\text { questões da sustentabilidade. Bem, é isso, fiz esses comentários porque seu tema } \\
\text { é algo que me interessa muito e pelo que vejo trará uma bela contribuição para a } \\
\text { área, e que pretendo ler assim que estiver concluída. }\end{array}$ \\
\hline E & Sem comentários gerais. \\
\hline $\mathbf{F}$ & $\begin{array}{l}\text { Gostei da forma que você realizou a proposta, incluindo as tarefas em cada } \\
\text { atividade do modelo. Nesse caso evitou um descritivo prévio do modelo para que } \\
\text { os especialistas pudessem avaliar melhor. Eu fiz dessa forma, mas achei mais } \\
\text { prático a sua maneira. }\end{array}$ \\
\hline G & Sem comentários gerais. \\
\hline
\end{tabular}


Tabela 7.6 - Principais comentários dos especialistas sobre a proposta avaliada continuação.

\begin{tabular}{|c|l|}
\hline Especialista & \multicolumn{1}{|c|}{ Comentários Gerais } \\
\hline $\mathbf{H}$ & $\begin{array}{l}\text { Muito interessante seu trabalho, mas confesso que para fins de facilitar o } \\
\text { questionamento, poderia ter feito as perguntas em blocos de menor detalhamento. }\end{array}$ \\
\hline $\mathbf{I}$ & Sem comentários gerais. \\
\hline $\mathbf{J}$ & $\begin{array}{l}\text { Sem comentários gerais. } \\
\text { Kiz pequenos comentários no que se referem à relação empresa compradora x } \\
\text { fornecedores (deve ser considerado que nem sempre o comprador tem poder de } \\
\text { influenciar o fornecedor, caso o fornecedor seja dominante no mercado, o } \\
\text { comprador não consegue impor ou sugerir qualquer ação do fornecedor, exemplo: } \\
\text { fornecimento de aço no Brasil. Idem para cliente, em se tratando de produto } \\
\text { destinado ao consumidor final, o mesmo nem sempre tem condições de exigir ou } \\
\text { entender que requisitos ambientais sejam atendidos. }\end{array}$ \\
\hline $\mathbf{L}$ & $\begin{array}{l}\text { Sem comentários gerais. } \\
\text { Não é difícil respondê-lo, embora um pouco longo, o que entendo inevitável dado o } \\
\text { foco da pesquisa. }\end{array}$ \\
\hline $\mathbf{N}$ & O roteiro era um tanto extenso e acabei demorando a poder preencher. \\
\hline
\end{tabular}

De modo geral, a proposta foi bem aceita pelos especialistas que participaram da consulta, havendo uma percepção da sua contribuição para o tema pesquisado, do seu caráter orientativo e do alto nível de detalhamento da integração dos aspectos ambientais nas fases do PDP. Nesses comentários gerais dos avaliadores percebese a preocupação com o desenvolvimento da embalagem dos produtos em paralelo com o desenvolvimento do próprio produto, devido a sua relevância na participação do impacto ambiental do produto. Também, a importância do entendimento das expectativas dos consumidores junto com as questões de sustentabilidade já na parte estratégica no inicio do PDP. Por outro lado, alguns especialistas acharam o instrumento de coleta de dados extenso devido principalmente ao nível de detalhamento e, ainda, as atividades e tarefas relacionadas a revisões ou atualizações do andamento do processo que se repetem em praticamente todas as fases PDP. Essa parte dos comentários será adequada na revisão da proposta junto com os pontos relevantes da análise das discordâncias, realizada a seguir.

A análise das sugestões de melhoria dos especialistas foi realizada com base no referencial teórico e estão separadas em tópicos por macrofase e fases do PDP. Devido ao tamanho e nível de detalhamento da proposta aqui são citadas apenas as atividades do PDP e a discussão teórica sobre o motivo dessa discordância quanto ao momento de integração no PDP. As atividades e tarefas do PDP seguem a numeração de referência apresentada na estrutura de PDP proposta (Capítulo 6) 
junto com os detalhes dos aspectos ambientais. As sugestões de melhorias por especialista podem ser consultadas no Apêndice VII e na Tabela 7.7 são discutidos os pontos relevantes apontados pelos especialistas que participaram da consulta, visando revisar e melhorar a proposta. É importante frisar que os comentários sobre as atividades genéricas e de passagem de fase (documentar as decisões tomadas e registrar lições aprendidas, atualizar o plano do projeto, monitorar a viabilidade econômica e financeira do produto) que são repetidas durante o PDP foram supridos desta discussão, pois são recomendações relativas à aplicação do questionário.

Tabela 7.7 - Análise qualitativa das sugestões de melhorias dos especialistas.

\section{MACROFASE DE PRÉ-DESENVOLVIMENTO}

Fase 1 - Planejamento Estratégico de Produtos (PEP)

Atividade 1.1 (Tarefa 1.1.2): Entende-se o comentário do especialista que avaliar competência é diferente de treinamento, mas o objetivo dessa inserção foi de considerar a necessidade de conhecimento sobre práticas de ecodesign no PDP. No caso de não ter essa competência seria interessante desenvolver essa habilidade por meio de treinamentos ou como sugeriu o próprio especialista pode-se contratar uma empresa especializada para dar consultoria sobre esse assunto. Atividade 1.2 (Tarefa 1.2.1): Entende-se a opinião do especialista de postergar esta tarefa para fase de Planejamento do Projeto devido suas características serem de gerenciamento de projeto. Mas, nessa atividade o foco está na alta administração que vai definir a estratégia de negócios da organização e precisa-se planejar como será realizada a condução dessas reuniões para discussão da revisão do plano estratégico de negócios, prazos, recursos, plano de comunicação e plano de riscos.

Atividade 1.3 (Tarefa 1.3.1/1.3.2): Avaliando a opinião dos especialistas sobre as tarefas serem realizadas na fase de Projeto Informacional, discorda-se pois não é possível traçar uma estratégia e definir linhas de produtos sem conhecer profundamente o mercado, os competidores e as tendências tecnológicas e de mercado. Em relação à biblioteca, o objetivo é manter um histórico dos produtos desenvolvidos pela empresa e servir de referência para tomada de decisão no PDP.

Atividade 1.4 (Tarefa 1.4.2/1.4.4/1.4.5): No caso da tarefa de preparar documento acredita-se que a documentação irá iniciar nesta etapa e deve ser desenvolvida e atualizada ao longo de todo o ciclo de vida do produto. Quanto à tarefa de "revisar metas" nesse momento está se falando de metas estipuladas pela alta direção da empresa para a unidade de negócio e não se referindo a projetos. $\mathrm{Na}$ tarefa de "revisar tendências tecnológicas" o foco está na análise de cenários que já foram consolidados, atentando as tecnologias que devem predominar no horizonte de planejamento e nas metas de desempenho dos produtos.

Atividade 1.5 (Tarefa 1.5.1/1.5.2/1.5.3/1.5.4): Na tarefa de avaliar o desempenho dos produtos entende-se que seja na fase de Projeto Informacional, porém é importante na fase de análise do portfólio de projetos já ter algum critério ambiental para comparar as idéias que farão parte da lista de projetos da carteira de desenvolvimento. Atualmente, os clientes estão mais exigentes quanto ao impacto ambiental dos produtos, logo se afirma que desenvolver produtos mais verdes seja um diferencial competitivo, assim como custo e qualidade. Portanto, é interessante inserir questões ambientais nessa fase inicial de seleção de novas idéias para o PDP, sendo essa análise aplicada também à Atividade 1.6 (Tarefa 1.6.1). 
Tabela 7.7 - Análise qualitativa das sugestões de melhorias dos especialistas continuação.

\section{MACROFASE DE PRÉ-DESENVOLVIMENTO \\ Fase 1 - Planejamento Estratégico de Produtos (PEP)}

Atividade 1.7 (Tarefa 1.7.1/1.7.2): Na tarefa de avaliar competências percebe-se a preocupação do especialista, mas analisa-se que na avaliação do portfólio é possível prever a necessidade de incorporação de novas tecnologias e conhecimentos para os próximos períodos, que precisarão do desenvolvimento ou aquisição de novas competências, seja pela empresa ou de parceiros estratégicos. Quando se fala em viabilidade econômica do portfólio de projetos, seria realizar um fluxo de caixa de todos os projetos e produtos da empresa, e considerar os impactos ambientais para fazer os cálculos.

Atividade 1.8 (Tarefa 1.8.1): O especialista tem razão quando cita que nessa atividade ainda não se têm projetos para acompanhar, pois nesse momento existe apenas uma minuta de cada projeto do portfólio com uma primeira definição do produto. Portanto, o aspecto ambiental deve ser retirado e inserido em uma fase de desenvolvimento de produto.

\section{MACROFASE DE PRÉ-DESENVOLVIMENTO}

Fase 2 - Fase de Planejamento do Projeto (PP)

Atividade 2.1 (Tarefa 2.1.1/2.1.2): Na tarefa de desenvolvimento da equipe para a execução do projeto considera-se relevante o ponto de vista dos especialistas, mas nesta atividade podem-se planejar algumas ações para fomentar o desenvolvimento do trabalho em equipe, como por exemplo: separar um local para equipe trabalhar próxima, programar reuniões presenciais regulares, realizar treinamento e capacitação do time de projeto. Na tarefa de montagem da equipe com os interessados no projeto, concorda-se com a opinião de que interessados são mais que apenas a equipe de projeto, tem o gerente de projeto, clientes, fornecedores, co-desenvolvedores, organização executora e financiadora do projeto.

Atividade 2.2 (Tarefa 2.2.1): Compreende-se o comentário do especialista que essa atividade deve vir antes no Planejamento Estratégico de Produtos, mas nessa atividade de definição do escopo do produto é importante o gerente de projeto estudar a minuta do projeto e o portfólio de produtos e consultar documentos de escopo de outros produtos da empresa para obter mais informações e conhecimento para definir as diretrizes básicas que o produto deve atender.

Atividade 2.3 (Tarefa 2.3.2/2.3.3/2.3.4): As sugestões de melhoria dos especialistas são coerentes e úteis. A atividade de avaliar riscos é feita com base nas informações disponíveis nas tarefas anteriores como: declaração do escopo do projeto, cronograma do projeto, minuta do projeto e as políticas de gerenciamento de riscos da organização, etc.

Atividade 2.4 (Tarefa 2.4.1): Realmente, a opinião do especialista é exata, pois certificação é uma opção estratégica da empresa e não está diretamente relacionada apenas ao projeto em desenvolvimento.

Atividade 2.5 (Tarefa 2.5.1/2.5.2): Referente aos comentários dos especialistas, a análise de viabilidade econômica e financeira já foi feita na fase de Planejamento Estratégico de Produtos para definição do portfólio de produtos. Está certa a afirmação do especialista, porém nesse momento da fase de Planejamento de Projeto a função desta atividade é de definir os principais indicadores financeiros do projeto relacionados ao produto final, que servirão de referência para as próximas fases do PDP e é um critério para manter a decisão de executar ou não o projeto.

Atividade 2.6 (Tarefa 2.6.1): As opiniões dos especialistas são válidas. A sugestão de indicadores ambientais macros foi para dar uma idéia para as empresas das possibilidades, mas cada um deve criar indicadores conforme a sua necessidade e o tipo de produto e processo a ser desenvolvido. Em relação a essa atividade ser realizada na fase de Planejamento Estratégico de Produtos, discorda-se porque esses indicadores são para gestão no nível operacional.

Atividade 2.7 (Tarefa 2.7.1/2.7.2): A preocupação dos especialistas é que nesse momento ainda não se tem informação suficiente, e está correto. Porém, essas tarefas têm uma visão mais ampla e são de planejamento do que será adquirido, quando e qual a relação com os fornecedores. Além disso, prepara a documentação utilizada para fazer cotações e avaliação dos fornecedores. 
Tabela 7.7 - Análise qualitativa das sugestões de melhorias dos especialistas continuação.

\section{MACROFASE DE DESENVOLVIMENTO \\ Fase 3 - Fase de Projeto Informacional (PI)}

Atividade 3.1 (Tarefa 3.1.1/3.1.2/3.1.3/3.1.4): Essa atividade tem o objetivo de compatibilizar o planejamento desta fase com o efetuado na fase de Planejamento do Projeto, mas a avaliação dos especialistas é pertinente. Pois, o plano do projeto já foi aprovado e não há sentido em uma atividade de atualização do plano de projeto informacional, a não ser que exista um período de tempo muito grande entre a aprovação do plano do projeto e o início da execução do projeto. No entanto, como esta proposta é genérica essa possibilidade existe.

Atividade 3.3 (Tarefa 3.3.1/3.3.2): Os pontos de atenção levantados estão coerentes, como o papel do fornecedor no compartilhamento da responsabilidade ambiental. Quanto ao ciclo de vida ser definido na fase de Projeto Detalhado, nesse momento é realizado uma análise inicial com base no conhecimento existente sobre produtos similares ou em produtos já desenvolvidos.

Atividade 3.4 (Tarefa 3.4.1/3.4.2/3.4.3): O ponto de vista do especialista está correto quanto à inserção do aspecto ambiental, pois nessa atividade ainda não se trata de requisitos do produto, mas apenas dos requisitos dos clientes.

Atividade 3.6 (Tarefa 3.6.1/3.6.4): As avaliações de que alguns itens dos aspectos ambientais estão mais relacionados às fases de Projeto Conceitual e Projeto Detalhado está certa. Porque especificações-meta do produto são parâmetros quantitativos e mensuráveis que o produto projetado deverá ter. Entretanto, o objetivo de integrar esses aspectos ambientais é de mostrar as inúmeras possibilidades existentes para se reduzir o impacto ambiental, que podem ser avaliadas na elaboração das especificações meta do produto.

\section{MACROFASE DE DESENVOLVIMENTO}

Fase 4 - Fase de Projeto Conceitual (PC)

Atividade 4.2 (Tarefa 4.2.2): A visão dos especialistas que esse aspecto ambiental deve ser realizado na fase de Projeto Informacional está inadequada. Essa tarefa tem a função de ajudar a equipe de projeto a descrever o produto em um nível abstrato e representar suas funções para desenvolver o conceito do produto.

Atividade 4.4 (Tarefa 4.4.2): Era esperada essa discussão se o aspecto ambiental deve ser colocado na fase de Projeto Conceitual ou Projeto Detalhado, devido à interface e proximidade dessas fases. Com base na literatura, verifica-se que na fase de Projeto Conceitual são obtidos vários resultados que são completados durante a fase de Projeto Detalhado, como por exemplo, a definição dos processos de fabricação que são realizadas na fase conceitual e depois as atividades de especificação e documentação são realizadas na fase de detalhamento. Portanto, o aspecto ambiental foi aplicado nessa atividade para que os envolvidos no PDP já comecem a pensar em alternativas no nível de fabricação dos SSC para redução do impacto ambiental. Em relação ao comentário de um dos especialistas sobre os elementos de junção não serem críticos para o impacto ambiental, identifica-se na literatura o oposto, pois muitos dos métodos e ferramentas de ecodesign citam que é importante analisar esses componentes pensando no seu fim de vida visando reduzir o número de componentes, facilitar a desmontagem e reutilização, estas práticas estão nos conceitos Design for Assembly (DfA) e Design for Manufacturing (DfM).

Atividade 4.5 (Tarefa 4.5.1/4.5.2): É um refinamento da Atividade (4.4) de definir arquitetura para o produto e gerou a mesma dúvida dos especialistas na atividade anterior, de que ela deveria acontecer na fase de Projeto Detalhado. Portanto, a discussão da atividade anterior se aplica nessa atividade também, devido se estar modelando conceitualmente o funcionamento do produto com base no seu impacto ambiental durante o seu ciclo de vida e que se não for avaliado nessa fase conceitual poderá ocasionar atividades de reprojeto.

Atividade 4.6 (Tarefa 4.6.1): A integração de aspecto ambiental está alinhada com a avaliação do especialista de que é importante focar na durabilidade do produto para que ele atinja sua expectativa de vida útil. 
Tabela 7.7 - Análise qualitativa das sugestões de melhorias dos especialistas continuação.

\section{MACROFASE DE DESENVOLVIMENTO \\ Fase 4 - Fase de Projeto Conceitual (PC)}

Atividade 4.7 (Tarefa 4.7.1): Um especialista acha que o momento correto de inserção do aspecto ambiental é antes, outro especialista acredita que seja na fase de Preparação da Produção do Produto. Devido às divergências de opiniões e com base na teoria, acredita-se que o momento correto de se definir fornecedores e pensar em fazer parcerias com co-desenvolvimento seja nessa atividade, pois nesse momento que se define os SSC.

Atividade 4.8 (Tarefa 4.8.1/4.8.2/4.8.3): Os aspectos ambientais estão de acordo com a opinião do especialista de que essas tarefas possuem uma interação muito grande. Por isso, a forma mais adequada de aplicá-las seria de utilizar uma ferramenta como, por exemplo, a matriz de decisão (PUGH, 1991), considerando os aspectos ambientais como critérios.

Atividade 4.9 (Tarefa 4.9.1): Na opinião do especialista deve acontecer na fase de Projeto Detalhado e Preparação da Produção do Produto. Porém, na fase de Projeto Conceitual já pode identificar possíveis processos de fabricação, principalmente para os componentes no qual existe mais de um método de fabricação.

\section{MACROFASE DE DESENVOLVIMENTO}

Fase 5 - Fase de Projeto Detalhado (PD)

Atividade 5.2 (Tarefa 5.2.1/5.2.2/5.2.3): A observação do especialista sobre que o ponto das tolerâncias não é minimizar o volume, mas especificar as tolerâncias necessárias para reduzir a fabricação dos componentes, e em relação a executar está atividade na fase de Projeto Conceitual são pertinentes. Esta atividade da fase de Projeto Detalhado dá prosseguimento à fase anterior e tem como objetivo desenvolver e finalizar as especificações do produto para serem encaminhadas a Preparação da Produção do Produto e outras fases de desenvolvimento do produto. Como foi explicado antes à integração e superposição entre essas fases dificulta entender os limites e interfaces das atividades em cada fase.

Atividade 5.3 (Tarefa 5.3.1/5.3.2): Houve uma dúvida no entendimento do termo "componentes ecológicos". O sentido utilizado nesse trabalho foi de se produzir componentes que não prejudiquem o meio ambiente, seja na extração da matéria-prima ou no seu processo de fabricação, por isso foi utilizada essa denominação relacionada à ecologia. Quanto à decisão de fazer ou comprar ela deve ser realizada na fase de Projeto Detalhado, pois após se obter as características dos SSC e a sequência macro de fabricação na fase de Projeto Conceitual é nessa fase que se detalha as informações para obter os custos e decidir fazer ou comprar (make-or-buy). Essa discussão também se aplica para a Atividade 5.4 (Tarefa 5.4.1), porque desde a fase de Planejamento Estratégico do Produto se está em contato com os fornecedores, na fase de Projeto Conceitual são fechadas algumas parcerias de co-desenvolvimento, mas só nesse momento se têm informações detalhadas para fechar contratos de fornecimento.

Atividade 5.5 (Tarefa 5.5.1/5.5.2/5.5.3/5.5.4/5.5.5/5.5.6/5.5.7/5.5.8/5.5.9/5.5.10/5.5.11/5.5.12/5.5.13): Os especialistas divergem entre si sobre em qual fase deve ser realizada essa atividade de PDP, seja na fase de Projeto Conceitual, Projeto Detalhado ou na Preparação da Produção do Produto. Na tarefa de "Criar informações/documentos de apoio ao operador" o especialista está certo quando afirma que essa tarefa se refere aos documentos de apoio ao operador, e não às normas ambientais da empresa. Na tarefa de "Especificar inspeção" os especialistas acharam vaga à proposta de inserir o aspecto ambiental "Exigir alguns serviços e ferramentas para inspeção ambiental", o objetivo seria de ter meios de checar se os processos de fabricação estão causando algum dano ao meio ambiente. A opinião do especialista está coerente sobre a tarefa de "Selecionar/Especificar métodos e ferramental" que não ficou claro a relação ambiental com a ergonômica do aspecto ambiental.

Atividade 5.6 (Tarefa 5.6.2/5.6.3): Um dos especialistas discordou, mas não justificou sua avaliação, portanto foram analisados novamente os aspectos ambientais inseridos nessa atividade com base na literatura, mas não se identificou discrepância em relação ao referencial teórico que justifique essa avaliação. 
Tabela 7.7 - Análise qualitativa das sugestões de melhorias dos especialistas continuação.

\section{MACROFASE DE DESENVOLVIMENTO \\ Fase 5 - Fase de Projeto Detalhado (PD)}

Atividade 5.7 (Tarefa 5.7.1/5.7.2/5.7.3/5.7.4/5.7.5): Houve discordâncias de entendimento, sendo que nessa fase no teste piloto não se está mais avaliando alternativas de materiais, já seria material final e quanto ao termo "tolerância ambiental". Concorda-se que nessa fase de Projeto Detalhado não se está mais analisando alternativas. Com respeito ao termo tolerância ambiental, se refere aos limites aceitáveis na legislação e especificação dos clientes a cerca da concentração ou intensidade de agentes nocivos abaixo da qual a maioria dos expostos não deverá apresentar danos à saúde ou meio ambiente.

Atividade 5.8 (Tarefa 5.8.2/5.8.3): Um dos especialistas percebeu um erro na descrição do aspecto ambiental. Ele está correto, pois não se elabora metodologia no PDP e sim se aplica uma existente, como por exemplo, o método Taguchi de projeto robusto, Failure Modes and Effects Analysis (FMEA) e do Design for $X(\mathrm{DfX})$. Em relação à dúvida na tarefa de "Ajustar tolerância dos SSC" é a mesma explicação com respeito ao termo tolerância ambiental da Atividade 5.7, com objetivo de garantir a segurança ambiental no estágio de uso, aumentar a durabilidade e resistência do produto. Atividade 5.9 (Tarefa 5.9.1/5.9.2/5.9.3): A sugestão do especialista de utilizar material multimídia com interações on-line e com uma visão de toda a vida útil do produto é relevante para melhoria da percepção dos participantes do PDP quanto ao impacto ambiental do produto.

Atividade 5.10 (Tarefa 5.10.1/5.10.2/5.10.3/5.10.4/5.10.5/5.10.6): Ocorreu uma convergência na opinião de vários especialista da importância de se desenvolver a embalagem em paralelo com o produto desde as fases iniciais de Projeto Informacional e Projeto Conceitual e se encontrar nessa atividade do Projeto Detalhado. Outro ponto é no recolhimento e coleta das embalagens, que deve considerar que os fornecedores irão querer ganhar algo em troca para colaborar.

Atividade 5.11 (Tarefa 5.11.1/5.11.2/5.11.3/5.11.4): O sentimento de alguns especialistas de que essa atividade poderia ser realizada nas fases anteriores da macrofase de pré-desenvolvimento e, também, nas fases da macrofase de pós-desenvolvimento está de acordo com a proposta apresentada. O objetivo principal dessa atividade é consolidar essas informações num plano de fim de vida, que contém as diretrizes de descarte, reciclagem e reuso a serem consideradas na aprovação dos Gates e monitoradas durante todo o ciclo de vida do produto.

Atividade 5.12 (Tarefa 5.12.1/5.12.2/5.12.3/5.12.4): Para esclarecer são convergidas as informações do produto e após o ciclo de otimização. Sua função é verificar se o protótipo atende as normas da garantia da qualidade antes de sua produção, em termos de documentação, funcionalidade e requisitos.

Atividade 5.13 (Tarefa 5.13.1): Um especialista entende que essa atividade pode ocorrer posteriormente na fase de Preparação da Produção do Produto, Lançamento do Produto e Acompanhar Produto e Processo. Acredita-se que o envio de documentos aos parceiros depende do tipo de relacionamento, como por exemplo, se o fornecedor participa do time de desenvolvimento ele tem acesso às informações durante todo o PDP, se é um cliente que participa da atividade de homologação ele que define quando quer receber, e assim por diante. O mais importante é disponibilizar as informações para evitar problemas de interface no produto final.

\section{MACROFASE DE DESENVOLVIMENTO}

Fase 6 - Fase de Preparação da Produção do Produto (PPP)

Atividade 6.1 (Tarefa 6.1.1/6.1.2): Um especialista acredita que essa atividade poderia ser realizada nas fases de Projeto Conceitual ou Projeto Detalhado e esse raciocínio está correto. Alguns recursos são obtidos nessas fases quando se tem certeza da solução adotada para não atrasar o lançamento do projeto, mas o restante não.

Atividade 6.2 (Tarefa 6.2.1): Um especialista percebe que essa atividade poderia também ser realizada na fase anterior de Projeto Detalhado. Logo, afirma-se que essa atividade deve ser realizada nesse momento, devido à necessidade de combinação da programação da produção de um projeto com a operação de produção. Além disso, deve-se planejar a homologação do processo, certificação do produto e desenvolvimento de processos de produção e manutenção. 
Tabela 7.7 - Análise qualitativa das sugestões de melhorias dos especialistas -

\author{
continuação.
}

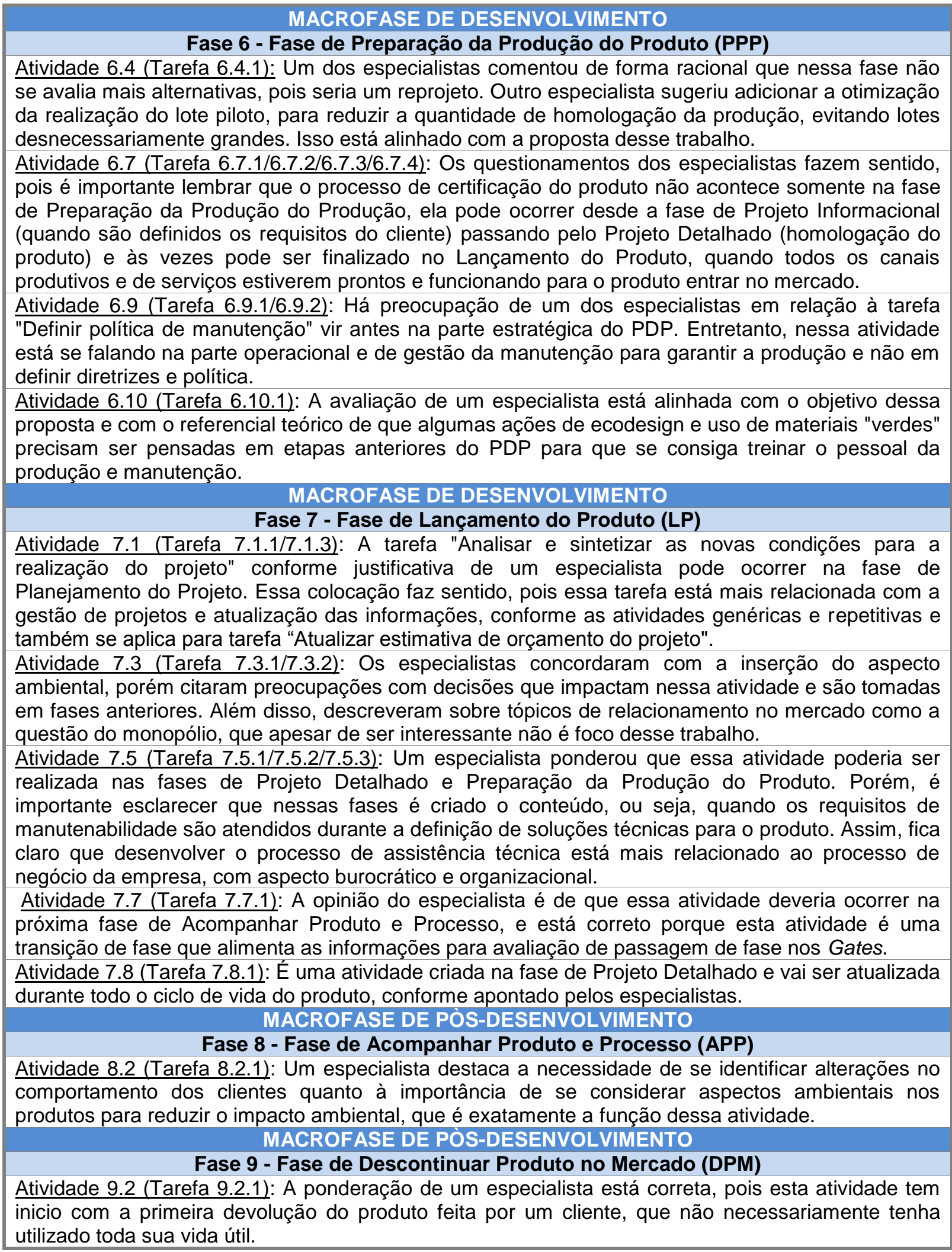




\subsection{Considerações finais do capítulo}

É importante destacar, o uso do software Minitab® versão 16 auxiliou de maneira significativa nas análises estatísticas e na avaliação da confiabilidade interna do questionário, que teve um coeficiente alfa de Cronbach por fase acima de 0,79 , que caracteriza alta confiabilidade interna do instrumento utilizado na coleta de dados. Esse resultado prova que os especialistas cumpriram o seu papel na avaliação do questionário, além de contribuírem com observações e sugestões de melhoria da proposta apresentada. Segundo os comentários dos especialistas, a proposta é detalhada, possui um caráter orientativo e traz uma contribuição significativa sobre o tema abordado.

A análise quantitativa com base no acerto dos avaliadores quanto à resposta padrão das notas de concordância ( 1 e 2) confirma a concordância da proposta na visão dos especialistas, resultando em um consenso de aceitação superior a $87 \%$. Além disso, realizando testes de hipótese (por fase, por avaliador e por nota) podese concluir que a proposta é aceita pelos especialistas, pois a média das notas é inferior a 2 (que indica concordância).

Um ponto de destaque identificado quando se realiza uma análise combinada da abordagem quantitativa com a qualitativa é que as fases de menor aceitação quanto ao momento da integração de aspectos ambientais foram de Projeto Conceitual (PC) e Projeto Detalhado (PD), devido principalmente a interface e proximidade entre as funções dessas fases. Cabe também ressaltar que as fases de Planejamento Estratégico de Projetos (PEP), Planejamento de Projeto (PP) e Projeto Informacional (PI) possuíram um desvio padrão alto, ou seja, forte discordância entre os especialistas sobre os mesmos pontos avaliados.

Por fim, analisando os comentários dos avaliadores destacam-se alguns pontos que são revisados na proposta (Capítulo 6), buscando torná-la ainda mais adequada a opinião dos especialistas.

Em seguida, no próximo capítulo, apresentam-se as conclusões desta tese, as principais contribuições originais para o tema abordado, as limitações desta pesquisa e oportunidades para trabalhos futuros sobre o tema de integração de aspectos ambientais de ecodesign e PDP. 


\section{CONCLUSÕES E SUGESTÕES PARA TRABALHOS FUTUROS}

Para finalizar esse trabalho são apresentadas nesse capítulo as principais conclusões referentes aos resultados da tese em relação aos objetivos inicialmente propostos, seguido pelas limitações identificadas no trabalho e oportunidades para pesquisas futuras.

Inicialmente, cabe destacar a relação identificada entre os conceitos que deram origem a esse trabalho (PLM, PDP e ES), pois há uma necessidade de se ter uma visão completa do ciclo de vida do produto, compreendendo todas as suas fases. Para que isso ocorra, deve haver uma integração de informações de várias áreas e sistemas para apoiar à gestão, integração e uso de dados e informações atualizadas sobre os aspectos ambientais associados aos produtos ao longo do seu ciclo de vida. Assim, possibilita-se contribuir para a gestão de operações do PDP e para redução dos impactos ambientais decorrentes das decisões tomadas no desenvolvimento dos produtos.

Diante disso, o principal objetivo dessa tese foi de propor uma forma de integração dos conceitos de ecodesign e PDP, devido à importância desse tema em relação ao aumento das exigências ambientais pela legislação, mercado, e sociedade. Para isso, foi selecionado na literatura um conjunto de práticas de ecodesign para dar suporte à tomada de decisão durante o PDP com objetivo de reduzir o impacto ambiental dos produtos por todo o ciclo de vida e, ainda, foram analisadas as características e preocupações ambientais das estruturas de PDP encontradas na literatura.

Pela análise das estruturas de PDP, observa-se que elas estão ligadas à necessidade de maior competitividade industrial e buscam aperfeiçoar as práticas de gestão do desenvolvimento de produtos. Nota-se também, que há divergências de enfoque nas estruturas de PDP conforme a área de conhecimento que as propõe (marketing, engenharia, design) e, consequentemente, diferenças na distribuição das fases em momentos distintos no PDP, com nível de profundidade e detalhamento de acordo com as características do processo de desenvolvimento e do produto desenvolvido. Constatou-se ainda que poucas estruturas de PDP disponíveis na literatura integram aspectos ambientais e, quando isso ocorre, é realizada de maneira superficial. Nesse sentido, analisando as fases que compõe as 
estruturas de PDP verifica-se que as macrofases de pré-desenvolvimento e pósdesenvolvimento são menos abordadas, porém nessas fases são tomadas decisões importantes para melhoria ambiental do produto como, por exemplo: a definição de especificação e escolha de alternativas de conceito de produto e projeto e, nas fases finais do PDP, a obtenção de informações importantes do desempenho do produto para melhoria do projeto e, consequentemente, fazer as adequações para reduzir o impacto ambiental do produto durante todas as fases do ciclo de vida.

Sobre as estruturas de PDP pode se concluir que elas estão em constante desenvolvimento acompanhando as necessidades teóricas e organizacionais, porém sobre a integração de aspectos ambientais nas estruturas de PDP verifica-se que as publicações mais recentes estão começando a disponibilizar meios de inserir a questão ambiental nesse processo.

Por outro lado, durante a análise do conceito de ecodesign percebe-se a importância da inclusão do aspecto ambiental no PDP, buscando avaliar e minimizar o uso dos recursos naturais, consumo de energia, emissões e redução dos impactos ambientais atribuídos a um produto ao longo de seu ciclo de vida. Nesta análise foram mapeados 154 métodos e ferramentas de ecodesign e extraídos 365 aspectos ambientais, sendo investigado como ocorre à integração no PDP. Em relação ao momento de integração, constata-se que os aspectos ambientais são úteis para qualquer fase do PDP. Entretanto, deve-se enfatizar que as decisões de projeto conceitual realizadas na fase de desenvolvimento determinam grande parte dos impactos ambientais que ocorrem nas fases seguintes do ciclo de vida. De modo análogo, na fase de planejamento estratégico é importante estabelecer uma política ambiental e definir diretrizes para se planejar ações que minimize o impacto ambiental do produto.

Desse modo, conclui-se em relação aos métodos e ferramentas de ecodesign, que na literatura não há consenso em que fases do PDP devem ser feitas a inserção de aspectos ambientais. O que se interpreta pela análise realizada é que os métodos com abordagens de ecodesign são empregados nas fases iniciais do PDP visando auxiliar nas escolhas com menor impacto ambiental sobre a estrutura do produto, os materiais e os processos de produção. Por outro lado, as ferramentas desenvolvidas a partir do conceito de LCA são retrospectivas e utilizadas nas fases finais do PDP para avaliação das consequências das escolhas de projeto no consumo de recursos e no impacto ao meio ambiente durante todo o ciclo de vida do 
produto. Ademais, há diversas barreiras para essa integração. Uma dessas barreiras é interna às empresas que parecem ainda não estarem preparadas para integrar práticas de ecodesign no PDP e não desejam fazer modificações na suas estruturas de desenvolvimento de produto. Uma outra barreira é pela perspectiva dos usuários das ferramentas, que, em geral, não têm experiência e motivação para o uso, bem como carecem de informações disponíveis sobre as ferramentas e recursos para selecionar e aplicá-las.

Diante disso, o desenvolvimento da proposta dessa tese oferece uma alternativa para reduzir os problemas de integração e uso de práticas de ecodesign no PDP. Assim possibilita-se minimizar a necessidade de escolha de um instrumento específico de ecodesign pelas empresas. A principal característica da presente proposta de estruturação do PDP com aspectos ambientais está no seu embasamento teórico-conceitual, nível de detalhamento e na sua capacidade de orientar e se adaptar aos diversos tipos de desenvolvimento de produto. Conclui-se que a proposta é ampla e oferece uma inovação simplificando a forma de integrar os conceitos de ecodesign no PDP.

A proposta desenvolvida foi submetida à avaliação de especialistas sobre o tema abordado, por meio de uma consulta, e verificou-se um nível razoável de aceitação da estrutura desenvolvida. Os pontos de discordância em relação ao momento de integração de alguns aspectos ambientais nas tarefas do PDP foram discutidos com base na literatura e, quando necessário, alterações menores foram realizadas. Da mesma forma foi feito com as sugestões de melhoria dos especialistas a respeito da descrição dos aspectos ambientais e de alguns conceitos relacionados ao desenvolvimento de produtos. Na análise dos resultados dos especialistas, verificouse que as fases do PDP de menor aceitação quanto ao momento da integração de aspectos ambientais foram as de projeto conceitual e projeto detalhado, isso pode ser justificado com base na diferença de entendimento dos especialistas sobre as interfaces, limites e proximidade entre as funções dessas fases. As fases de planejamento estratégico de projetos, planejamento de projeto e projeto informacional possuíram um desvio padrão alto nas notas de avaliação, indicando divergência de opinião dos especialistas sobre o tema.

Como conclusão sobre a avaliação realizada, pode-se afirmar que a divergência de opinião dos especialistas sobre as fases iniciais de PDP durante as respostas do questionário demonstra que não há um entendimento comum das funções das 
tarefas e atividades dessas fases do PDP. Como consequência, essa divergência conceitual sobre o objetivo dessas fases iniciais do PDP se agrava ainda mais quando se insere aspectos ambientais para serem analisados. Isso implica que há uma necessidade de se aprofundar os estudos nesse sentido, principalmente sobre as fases iniciais do PDP em relação às questões ambientais. Corroborando com essa afirmativa, o resultado da análise das fases mais citadas nas estruturas de PDP encontradas na literatura demonstra que essas fases do pré-desenvolvimento do produto são pouco abordadas. Além disso, pelos comentários gerais dos avaliadores percebe-se uma preocupação com o desenvolvimento da embalagem do produto (em situações em que isso procede) em paralelo com o desenvolvimento do próprio produto, devido a sua relevância na participação do impacto ambiental. Os especialistas também destacam a necessidade do entendimento das expectativas dos consumidores quanto aos requisitos do produto junto com as preocupações ambientais no início do PDP, para que se possa definir uma estratégia competitiva visando melhorar os requisitos ambientais do produto sem comprometer o seu desempenho, custo e características.

Com relação à proposta elaborada, pode-se concluir que ela se diferencia dos demais estudos realizados até o momento sobre a integração de ecodesign no PDP por empregar uma nomenclatura clara e de fácil entendimento por pessoas que não sejam das áreas técnicas de ecodesign e PDP, identificar cada tarefa e cada aspecto ambiental para permitir uma melhor rastreabilidade da metodologia de integração, integrar os aspectos ambientais no menor nível hierárquico possível (tarefa) considerando todas as fases do PDP e por ter uma visão da possibilidade de ocorrer impactos ambientais durante todo o ciclo de vida do produto. Além disso, a proposta foi desenvolvida com base numa extensa e detalhada revisão bibliográfica sobre PDP e ecodesign no qual mapeia o estado da arte sobre métodos e ferramentas de ecodesign e sintetiza conhecimentos relevantes sobre o tema analisado.

Sendo assim, conclui-se que essa proposta inicial possibilita acrescentar à discussão sobre a integração dos aspectos ambientais, principalmente, nas fases do PDP que são menos abordadas pelas estruturas de PDP utilizadas como referência pela academia. Além disso, é essencial enfatizar que os objetivos inicialmente estabelecidos foram atingidos, inclusive gerando contribuições para o tema 
selecionado, principalmente no sentido de introduzir um guia orientativo que indica ações para se integrar as melhores práticas de ecodesign ao PDP.

\subsection{Sugestões para trabalhos futuros}

A integração de práticas de ecodesign no desenvolvimento de novos produtos é um processo complexo e qualquer trabalho neste tema possui limitações, como no caso desta tese. A primeira foi devido a não aplicar a estrutura proposta em um estudo empírico para avaliar sua adaptabilidade em um PDP existente ou implementá-lo em uma empresa que ainda não tem o PDP formalizado. Outra limitação foi a impossibilidade de se analisar com mais ênfase a integração de aspectos ambientais específicos em determinadas fases do PDP e, consequentemente, sugerir quais são os métodos e ferramentas de ecodesign aplicáveis e mais adequados para cada momento do PDP. É importante destacar que devido à análise estatística englobar uma amostra pequena de 14 especialistas, os resultados desta análise apresenta menor relevância do que a análise qualitativa. Logo, poderia se repetir a consulta acrescentando mais participantes que possam contribuir com o avanço do conhecimento sobre o tema tratado.

A análise dos resultados deste trabalho e as limitações citadas acima evidenciam algumas oportunidades para novos trabalhos sobre a integração dos conceitos de ecodesign e PDP. Assim sendo, recomenda-se a realização de trabalhos de pesquisa para aprofundar a aplicabilidade desta proposta de estruturação do PDP integrando aspectos ambientais quanto às implicações das contingências inerentes aos diferentes tipos de empresa e PDP, assim pode-se ampliar e/ou refinar a proposta desenvolvida. Com base no resultado da avaliação da proposta realizada pelos especialistas verifica-se, também, que novos trabalhos podem focar nas fases iniciais do PDP, onde se obteve maior divergência de opinião pelos especialistas ou nas fases de projeto conceitual e projeto detalhado que teve a menor aceitação quanto ao momento da integração de aspectos ambientais devido a diferença de entendimento sobre as interfaces dessas fases.

Nesse sentido, outra sugestão para trabalhos futuros seria uma análise sobre a integração dos conceitos PDP, PLM e ES, delineando o contorno entre as interfaces, basicamente em função da escassez de estudos desse tipo. Além disso, deve-se 
aprofundar os estudos de análise bibliométrica com aplicação de ferramentas específicas para disseminar essa técnica na área de engenharia de produção.

Finalizando, durante a realização desse trabalho surgiram algumas questões que podem nortear a busca na literatura por lacunas para se desenvolver novos trabalhos sobre o tema integração de ecodesign no PDP, tais como:

i) Analisar quais são as principais barreiras para integração de aspectos ambientais no PDP. $\mathrm{Na}$ análise da literatura vários autores citam pontos que influenciam nesse tópico, tais como: a falta de conhecimento dos envolvidos; falta de métodos de avaliação do impacto ambiental; envolvimento dos stakeholders; muitos métodos e ferramentas de ecodesign disponíveis; falta de normas internacionais regulamentadoras do ecodesign; necessidade de especialistas para aplicarem as ferramentas, aumento da quantidade de informações relativa aos aspectos ambientais e o tradicional trade-off entre aspectos ambientais e econômicos.

ii) Avaliar se o intenso desenvolvimento de métodos e ferramentas de ecodesign tem capacidade de absorção e aplicação pelas empresas. Pela análise da literatura verifica-se que há muitos métodos e ferramentas similares que variam em termos de níveis de detalhes e complexidade, necessidade de dados qualitativos ou quantitativos e conhecimento para sua utilização no PDP. Também, alguns trabalhos citam que as empresas não estão aplicando esses instrumentos no PDP.

iii) Verificar se utilização de práticas de ecodesign realmente reduz o impacto ambiental dos produtos desenvolvidos e traz vantagens competitivas para as empresas. Na literatura muitos trabalhos apontam vantagens competitivas e financeiras de se integrar o conceito de ecodesign no PDP, como a fidelização de clientes, maior eficiência de processos e utilização de recursos. 


\section{REFERÊNCIAS BIBLIOGRÁFICAS}

ABDOMEROVIC, M.; BLAKEMORE, G. Project process interactions. International Journal of Project Management, v.20, n.4, p.315-323, 2002.

ABERNATHY, W.J.; UTTERBACK, J.M. Patterns of industrial innovation. Technology Review, v.80, p.40-47, 1978.

ALONSO GARCIA, M. La Norma de ecodiseño UNE1503001. CONAMA, Congreso Nacional del Medio Ambiente, en Los retos del desarrollo sostenible en España, Madrid, 2006.

ALVARENGA, F.B. Uma abordagem metodológica para o projeto de produtos Inclusivos. Tese (Doutorado). Faculdade de Engenharia Mecânica, Universidade Estadual de Campinas, Campinas, p.218, 2006.

ALVES, F.H.; SACCHELLI, C.M. Proposta de uma metodologia de gestão do desenvolvimento de produtos em empresas de móveis sob medida. In: $V$ Congresso Brasileiro de Gestão de Desenvolvimento de Produtos. Anais, Curitiba, PR, 2005.

AMARAL, D.C.; ROZENFELD, H. Gerenciamento de conhecimentos explícitos sobre o processo de desenvolvimento de produtos. In: IV Congresso Brasileiro de Gestão de Desenvolvimento de Produtos. Anais, Gramado, Rio Grande do Sul, 2003.

AMMENBERG, J.; SUNDIN, E. Products in environmental management systems: drivers, barriers and experiences. Journal of Cleaner Production, v.13, n.4, p.405415, 2005.

ANDREASEN, M.M.; HEIN, L. Integrated product development. New York: Springer-Verlag, 1987.

AOYAMA, M. Web-based agile software development. IEEE Software, v.15, n.6, p.56, 1998.

APQP. Advanced Planning of Quality Products. AIAG. Chrysler Corporation, Ford Motor Company, General Motors Corporation. Issued Jun, 1994.

ARCHER, B.L. La estructura del proceso del diseño. In: BROADBENT, G.et al. (Eds.) Metodologia del diseño arquitectonico. Barcelona: Editorial Gustavo Gili, p.153-221, 1971.

ARENA, U.; MASTELLONE, M.L.; PERUGINI, F. Environmental assessment of paper waste management options by means of LCA methodology. Industrial \& Engineering Chemistry Research, v.43, n.18, p.5702-5714, 2004.

ARUSHANYAN, Y.; EKENER-PETERSEN, E.; FINNVEDEN, G. Lessons learned Review of LCAs for ICT products and services. Computers in Industry, v.65, n.2, p.211-234, 2014. 
ASHFORD, N.A. Government and environmental innovation in Europe and North America. American Behavioral Scientist, v.45, n.9, p.1417-1434, 2002.

ASIMOV, M. Introduction to design: fundamentals of engineering design. [S.I.]: Prentice Hall, 1962. (Traduzido para o português: Introdução ao projeto de engenharia. São Paulo: Mestre Jou, 1968).

ASSOCIAÇÃO BRASILEIRA DE EMBALAGEM - ABRE. Dados de mercado, 2006. Disponível <http:// www.abre.org.br> [acesso em 24.10.06]

ASSOCIAÇÃO BRASILEIRA DE NORMAS TÉCNICAS. ISO/TR 14062: Gestão ambiental: integração de aspectos ambientais no projeto e desenvolvimento do produto. Rio de Janeiro: ABNT, 2002.

ATTIWILL, P.M. Ecological disturbance and the conservative management of eucalypt forests in Australia. Forest ecology and Management, v.63, n.2-3, p.301346, 1994.

AURICH, J.C.; SCHWEITZER, E.; FUCHS, C. Life cycle management of industrial product-service systems. 14th CIRP Conference on Life Cycle Engineering, Tokyo, Japan, Jun, p.171-176, 2007.

AXARLOGLOU, K. New Products and Market Competition. International Advances in Economic Research, v.10, n.3, p.226-234, 2004.

BACCILE, N.; BABONNEAU, F.; THOMAS, B.; CORADIN, T. Introducing ecodesign in silica sol-gel materials. Journal of Materials Chemistry, v.19, n.45, p.8537-8559, 2009.

BACK, N. et al. Projeto integrado de produtos: planejamento, concepção e modelagem. Barueri: Manole, 2008.

BACKHAUS, K.; LÜGGER, K.; KOCH, M. The structure and evolution of business-tobusiness marketing: A citation and co-citation analysis. Industrial Marketing Management, v.40, n.6, p.940-951, 2011.

BAHMAED, L.; BOUKHALFA, A.; DJEBABRA, M. Eco-conception in the industrial firms: methodological proposition. Management of Environmental Quality: An International Journal, v.16, n.5, p.530-547, 2005.

BAKSHI, B.R.; FIKSEL, J. The Quest for Sustainability: challenges for process systems engineering. AlChe Journal, v.49, n.6, p.1350-1358, 2003.

BARBALHO, S.C.M. Modelo de referência para o desenvolvimento de produtos mecatrônicos: proposta e aplicações. São Carlos, 2006. 256p. Tese (Doutorado) - Escola de Engenharia de São Carlos, Universidade de São Paulo, São Carlos, 2006.

MASCARENHAS, M. P.; ALEX, W. Triple Bottom Line da Sustentabilidade: Uma Análise em Empresas Nacionais Produtoras de Óleos e Gorduras. Revista de Administração, Contabilidade e Sustentabilidade, v.3, n.1, p.62-79, 2013. 
BARCZAK, G.; GRIFFIN, A.; KAHN, K.B. Perspective: trends and drivers of success in NPD practices: Results of the 2003 PDMA best practices study. Journal of Product Innovation Management, v.26, p.3-23, 2009.

BARRY, E.J.; KEMERER, C.E.; SLAUGHTER, A.S. Environmental volatility, development decisions, and software volatility: a longitudinal analysis. Management Science, v.52, n.3, p.448-464, 2006.

BASTANTE-CECA, M. Propuesta metodologica para la cuanti_cacion de la ecoe_ciencia de los products industriales a partir de la evaluacion del valor funcional y de los impactos economico y ambiental. Ph.D, thesis, Universidad Politiecnica de Valencia (UPV), Valencia, Spain, 2006.

BAUMANN, H.; BOONS, F.; BRAGD, A. Mapping the green product development field: engineering, policy and business perspectives. Journal of Cleaner Production, v.10, p.409-425, 2002.

BAXTER, M. Projeto de produto: guia prático para o design de novos produtos. 2. ed. rev. São Paulo: Edgard Blucher, 2000.

BEBBINGTON, A. Social capital and rural intensification: local organizations and islands of sustainability in the rural Andes. Geographical Journal, v.163, p.189-197, 1997.

BELKADI, F.; TROUSSIER, N.; HUET, F.; GIDEL, T.; BONJOUR, E.; EYNARD, B. Innovative PLM-based approach for collaborative design between OEM and suppliers: Case study of aeronautic industry. 2nd IFIP Topical Session on Computer-Aided Innovation Held at the 20th World Computer Congress, Milan, Italy, Sep, v.277, p.157-168, 2008.

BEN MAHMOUD-JOUINI, S.; LENFLE, S. Platform re-use lessons from the automotive industry. International Journal of Operations \& Production Management, v.30, n.1, p.98-124, 2010.

BEN-ARIEH, D.; QIAN, L. Activity-based cost management for design and development stage. International Journal of Production Economics, v.83, n.2, p.169-183, 2003.

BENNETT, E.B.; GRAEDEL, T.E. Conditioned air: evaluating an environmentally preferable service. Environmental Science \& Technology, v.34, n.4, p.541-545, 2000.

BERGEA, O.; KARLSSON, R.; HEDLUND-ASTROM, A.; JACOBSSON, P.; LUTTROPP, C. Education for sustainability as a transformative learning process: a pedagogical experiment in ecodesign doctoral education. Journal of Cleaner Production, v.14, n.15/16, p.1431-1442, 2006.

BERTO, R.M.v.S., NAKANO, D.N. A Produção Científica nos Anais do Encontro Nacional de Engenharia de Produção: Um Levantamento de Métodos e Tipos de Pesquisa. Produção, v.9, n.2, p.65-76, 2000. 
BERTOLINI, M.; COLACINO, P.; DELNEVO, N.; PETRONI, A. Stakeholders' influence and internal championing of product stewardship in the Italian food packaging industry. 4th International Conference on Product Lifecycle Management, Stezzano, Italy, Jul, p.117-126, 2007.

BEU, L.; MENDICINO, L. Application of design for environment concepts to the semiconductor industry. Environmental Progress, v.16, n.4, p.245-250, 1997.

BEY, N.; HAUSCHILD, M.Z.; MCALOONE, T.C. Drivers and barriers for implementation of environmental strategies in manufacturing companies. CIRP Ann. Manuf. Technol. v.62, p.43-46, 2013.

BHAMRA, T. Ecodesign: the search for new strategies in product development. Journal of Engineering Manufacture, v.218, n.5, p.557-569, 2004.

BHAMRA, T; LOFTHOUSE, V. Design for sustainability: a practical approach. Gower Publishing, England, 2007.

BIDOKHTI, N. The impact of reliability requirements on development life cycle. 54th Annual Reliability and Maintainability Symposium, Las Vegas, NV, Jan, p.308312, 2008.

BIGLIARD, B.; BOTTANI, E.; RINALDI, M. The new product development process in the mechanical industry: evidences from some Italian case studies. International Journal of Engineering, Science and Technology, v.5, n.2, p.1-23, 2013.

BIRCH, A.; HON, K.K.B.; SHORT, T. Structure and output mechanisms in Design for Environment (DfE) tools. Journal of Cleaner Production, n.35, p.50-58, 2012.

BITENCOURT, C.A. Desenvolvimento de uma metodologia de reprojeto de produto para o meio ambiente. 2001. 185 f. Dissertação (Mestrado em Engenharia Mecânica). Universidade Federal de Santa Catarina, Florianópolis, 2001.

BLENGINI, G.A.; BUSTO, M.; FANTONI, M.; FINO, D. Eco-efficient waste glass recycling: Integrated waste management and green product development through LCA. Waste Management, v.32, n.5, p.1000-1008, 2012.

BOKS, C. The soft side of ecodesign. Journal of Cleaner Production, n.14, p.13461356, 2006.

BOKS, C.; MCALOONE, T.C. Transitions in sustainable product design research. International Journal of Product Development, v.9, p.429-449, 2009.

BONNER, J.M. et al. Upper management control of new product development projects and project performance. The Journal of Product Innovation Management, v.19, n.3, p.233-245, 2002.

BONSIEPE, G. Teoría y práctica del diseño industrial. Elementos para una manualística crítica. Barcelona: Gustavo Gili, 1978. (Comunicación Visual).

BOOZ, ALLEN, HAMILTON. New product Development for the 1980s. Booz Allen Hamilton Consultants, New York, 1982. 
BORCHARDT, M.; POLTOSI, L.A.C.; SELLITTO, M.A.; PEREIRA, G.M. Considerações sobre ecodesign: um estudo de caso na indústria eletrônica automotiva, Ambiente \& Sociedade, v.XI, n.2, p.341-353, 2008.

BORDOLOI, S.; GUERRERO, H.H. Design for control: A new perspective on process and product innovation. International Journal of Production Economics, v.113, n.1, p.346-358, 2008.

BORGATTI, S.; EVERETT, M.; FREEMAN L. Ucinet for Windows: software for social network analysis. Analytic Technologies, 2002.

BOVEA, M.D.; PEREZ-BELIS, V. A taxonomy of ecodesign tools for integrating environmental requirements into the product design process. Journal of Cleaner Production, v.20, p.61-71, 2012.

BOVEA, M.D.; WANG, B. Redesign Methodology for Developing Environmentally Conscious Products. International Journal of Production Research, v.45, p.40574072, 2007.

BRASIL, A.D. Modelo para estruturação de um processo formal de desenvolvimento de Produtos fundamentado em conceitos de gestão do conhecimento. SC: PPGEM/UFSC, 2006. 293p.: il. Tese de Doutorado, Programa de Pós-Graduação em Engenharia Mecânica, Universidade Federal de Santa Catarina, 2006.

BREZET, H.; HEMEL, C.V. Ecodesign: promising approach to sustainable production and consumption. United Nations Environmental Programme - UNEP, Paris, ISBN 92-807-1631-X, 1997.

BRITISH STANDARDS INSTITUTION. Design management systems - BS 7000. Guide to managing the design of manufactured products. London: BSI, 1997.

BRONES, F.; CARVALHO, M.M. From 50 to 1: integrating literature toward a systemic ecodesign model. Journal of Cleaner Production, p.1-14, 2014. http://dx.doi.org/10.1016/j.jclepro.2014.07.036.

BRONES, F.; CARVALHO, M.M.; ZANCUL, E.S. Ecodesign in project management: a missing link for the integration of sustainability in product development? Journal of Cleaner Production, n.80, p.106-118, 2014.

BRONES, F.A.; CARVALHO, M.M.; AMATO NETO, J. Modelos de integração do ecodesign: revisão sistemática da literatura com foco sistêmico. 4tn International Workshop Advances in Cleaner Production, Integrated cleaner production into sustainability strategies. São Paulo, Brazil, Mai, 2013.

BROY, $M$. From system requirements documents to integrated system modeling artifacts. 9th ACM Symposium on Document Engineering, Munich, Germany, September, p.98-98, 2009.

BUCCI, D.Z. Processo de desenvolvimento de produto-embalagem: uma proposta orientada à sustentabilidade. Tese (Doutorado) - Universidade Federal de Santa Catarina, Florianópolis, SC, p.497, 2010. 
BUGANZA, T.; VERGANTI, R. Life-cycle flexibility: How to measure and improve the innovative capability in turbulent environments. Journal of Product Innovation Management, v.23, n.5, p.393-407, 2006.

BUIJS, J. Modelling product innovation processes, from linear logic to circular chaos. Creativity and Innovation Management. v.12, n.2, p.76-93, 2003.

BUSS, C.O.; CUNHA, G.D. Modelo referencial para o processo de desenvolvimento de novos produtos. In: XXII SIMPÓSIO DE GESTÃO DA INOVAÇÃO TECNOLÓGICA, Salvador, BA, 2002.

BYGGETH, S.; HOCHSCHORNER, E. Handling trade-offs in Ecodesign tools for sustainable product development and procurement. Journal of Cleaner Production, n.14, p.1420-1430, 2006.

CADDY, J.F. Fisheries management in the twenty-first century: will new paradigms apply? Reviews in Fish Biology and Fisheries, v.9, n.1, p.1-43, 1999.

CALANTONE, R.J.; DI BENEDETTO, C.A. Performance and time to market: Accelerating cycle time with overlapping stages. IEEE Transactions on Engineering Management, v.47, n.2, p.232-244, 2000.

CAMPOS, S.U.; RIBEIRO, J.L.D. Um modelo de referência para o processo de desenvolvimento de produtos de empresas do setor moageiro de trigo. Produção, v.21, n.3, p.379-391, 2011.

CARMEL, E.; BECKER, S. A process model for packaged software-development. IEEE Transactions on Engineering Management, v.42, n.1, p.50-61, 1995.

CARNEVALLI, J.A. CAUCHICK MIGUEL, P.A. Revisão, análise e classificação da literatura sobre o QFD: tipos de pesquisa, dificuldades de uso e benefícios do método. Gestão \& Produção, v.14, n.3, p.557-579, 2007.

CEBON, P.; HAUPTMAN, O.; SHEKHAR, C. Product modularity and the product life cycle: new dynamics in the interactions of product and process technologies. International Journal of Technology Management, v.42, n.4, p.365-386, 2008.

CHAABANE, A.; RAMUDHIN, A.; PAQUET, M. Design of sustainable supply chains under the emission trading scheme. International Journal of Production Economics, v.135, n.1, p.37-49, 2012.

CHANG, Y.C.; CHENG, F.T.; WANG, T.L. Novel semiconductor business model Engineering chain for the semiconductor industry. IEEE International Conference on Robotics and Automation, Rome, Italy, Apr, v.1-10, p.1597-1602, 2007.

CHARTER, M. Managing the eco-design process. Journal of sustainable Product Design, v.2, p.48-51, 1997.

CHAVES, L. Design for Enviromental Sustainability: design strategies, methods and tools in the furniture sector. 231f. Tese de Doutorado, Politecnico di Milano University, 2007. 
CHEN, C.C. Incorporating green purchasing into the frame of ISO 14000. Journal of Cleaner Production, v.13, n.9, p.927-933, 2005.

CHEN, Y.M.; JAN, Y.D. Enabling allied concurrent engineering through distributed engineering information management. Robotics and Computer-Integrated Manufacturing, v.16, n.1, p.9-27, 2000.

CHOI, J.; FTHENAKIS, V. Economic feasibility of recycling photovoltaic modules. Journal of Industrial Ecology, v.14, n.6, p.947-964, 2010.

CHULANI, S.; BOEHM, B.; STEECE, B. Bayesian analysis of empirical software engineering cost models. IEEE Transactions on Software Engineering, v.25, n.4, p.573-583, 1999.

CIOLKOWSKI, M.; SOTO, M. Towards a comprehensive approach for assessing open source projects. Joint Meeting of the International Workshop on Software Measurement (IWSM), Munich, Germany, Nov, v.5338, p.316-330, 2008.

CLARK, K.B.; FUJIMOTO, T. Product development performance: strategy, organization and management in the world auto industry. Boston: Harvard Business School Press, 1991.

CLARK, K.B.; WHEELWRIGHT, S.C. Managing new product and process development. New York: The Free Press, 1993.

CLARK, K.B.; WHEELWRIGHT, S.C. Revolutionizing product development: quantum leaps in speed, efficiency and quality. New York: The Free Press, 1992.

COLENCI NETO, A. Proposta de um modelo de referência para o desenvolvimento de software com foco na certificação do MPS.Br. Tese (doutorado) - Escola de Engenharia de São Carlos, Universidade de São Paulo, São Carlos, p.182, 2008.

COLLADO-RUIZ D.; OSTAD-AHMAD-GHORABI, H. Influence of environmental information on creativity. Design Studies, v.31, n.5, p.479-498, 2010.

COLTRO, L; MOURAD, A.L.; OLIVEIRA, P.A.P.L.V. Environmental profile of Brazilian green coffee. International Journal of Life Cycle Assessment, v.11, n.1, p.16-21, 2006.

CONFORTO, E.C.; AMARAL, D.C.; SILVA, S.L. Roteiro para revisão bibliográfica sistemática: aplicação no desenvolvimento de produtos e gerenciamento de projetos. Anais. VIII Congresso Brasileiro de Gestão de Desenvolvimento de Produtos, Setembro, Porto Alegre, RS, 2011.

COOPER, J.; GODWIN, C.; HALL, E. S. Modeling process and material alternatives in life cycle assessments. International Journal of Life Cycle Assessment, v.13, n.2, p.115-123, 2008.

COOPER, J.S. Evolution of an interdisciplinary course in sustainability and design for environment. International Journal of Engineering Education, v.23, n.2, p.294300, 2007. 
COOPER, R.G. Stage-gate systems - a new tool for managing new products. Business Horizons, v.33, n.3, p.44-54, 1990.

COOPER, R.G. Winning at new products: accelerating the process from idea to launch. Reading: Perseus Books, 1993.

CORBETT, C.J.; KLASSEN, R.D. Extending the horizons: Environmental excellence as key to improving operations. M\&Som-Manufacturing \& Service Operations Management, v.8, n.1, p.5-22, 2006.

CORDELLA, M.; TUGNOLI, A.; SPADONI, G.; SANTARELLI, F.; ZANGRANDO, T. LCA of an Italian lager beer. International Journal of Life Cycle Assessment, v.13, n.2, p.133-139, 2008.

CORTINA, J.M. What is coefficient alpha? An examination of theory and applications. Journal of Applied Psychology. v.78, p.98-104, 1993.

CRAMER, J.M.; STEVELS, A.L.N. Strategic environmental product planning within Philips sound \& vision. Environmental Quality Management, v.7, p.91-102, 1997.

CRAWFORD, C.M.; BENEDETTO, C.A. New products management. 6ed. Chicago: McGraw Hill, 2000.

CRESWELL, J.W.; PLANO CLARK. V.L. Book Review: Designing and Conducting Mixed Methods Research, Thousand Oaks, CA, 2006.

CRONBACH, J.L. My current $\mathrm{t}$ procedures. Educational and Psychological Measurement, v.64, n.3, 2004.

CROOM, S. Topic Issues and Methodological Concerns for Operations Management Research. EDEN Doctoral Seminar on Research Methodology in Operations Management, Brussels, Belgium, 31st Jan.-4th Feb, 2005.

CROSS, M.S.; SIVALOGANATHAN, S. Specialist Knowledge Identification, Classification, and Usage in Company-specific new Product Development Processes. Institution of Mechanical Engineers, v.221, n.8, p.285-1298, 2007.

CRUL, M.R.M., DIEHL, J.C. Design for Sustainability: A Practical Approach for Developing Economies. United Nations Environment Programme, Delft University of Technology, November, p.130, 2006. Disponível em: <http://www.unep.fr/scp/publications/details.asp?id=DTI/0826/PA>. Acesso em: out. 2006.

CRUZ, L.B.; BOEHE, D.M. CSR in the global marketplace Towards sustainable global value chains. Management Decision, v.46, n.8, p.1187-1209, 2008.

CURRAN, M.A. The status of life-cycle assessment as an environmental management tool. Environmental Progress, v.23, n.4, p.277-283, 2004.

DA SILVA, C.M.; LOUBACH, D.S.; CUNHA, A.M. Applying the use case points effort estimation technique to avionics systems. IEEE/AIAA 27th Digital Avionics Systems Conference, St Paul, MN, Oct, v.1/2, p.1070-1079, 2008. 
DAILY, B.F.; HUANG, S.C. Achieving sustainability through attention to human resource factors in environmental management. International Journal of Operations \& Production Management, v.21, n.12, p.1539-1552, 2001.

DAVILA, T.; EPSTEIN, M.; SHELTON, R. As regras da inovação. Porto Alegre: Bookman, 2007.

DE BENEDETTO, L.; KLEMES, J. The environmental performance strategy map: an integrated LCA approach, to support the strategic decision-making process. Journal of Cleaner Production, v.17, n.10, p.900-906, 2009.

DEHAES, H.A.; JOLLIET, O.; FINNVEDEN, G.; HAUSCHILD, M.; KREWITT, W.; MÜLLER-WENK, R. Best available practice regarding impact categories and category indicators in life cycle impact assessment. Background document for the second working group on Life Cycle Impact Assessment of SETAC-Europe (WIA-2). International Journal of Life Cycle Assessment, v.4, n.2, p.66-74, 1999.

DEHGHANIAN, F.; MANSOUR, S. A framework for moving toward for sustainable supply chain management. 38th International Conference on Computers and Industrial Engineering, Beijing, China, Oct, v.1/3, p.1059-1066, 2008.

DEUTZ, P.; MCGUIRE, M.; NEIGHBOUR, G. Eco-design practice in the context of a structured design process: an interdisciplinary empirical study of UK manufacturers. Journal of Cleaner Production, v.39, p.117-128, 2013.

DEVANATHAN, S.; RAMANUJAN, D.; BERNSTEIN, W.Z. Integration of Sustainability Into Early Design Through the Function Impact Matrix. Journal of Mechanical Design, v.132, n.8, article number: 081004, 2010.

DEWULF, W. A pro-active approach to ecodesign: framework and tools. PhD Dissertation, KU Leuven, Mechanical Engineering Department, Leuven, 2003.

DICKSON, P. Marketing Management. Forth Worth: The Dryden Prees, 1997.

DIEHL, J.C.; BREZET, H. Design for Sustainability: an approach for international development, transference and local implementation. In: International Conference Environmental Management for Sustainable Universities, 2004, Monterrey. Proceedings... Monterrey: Tecnológico de Monterrey. p.1-10, 2004.

DJURDJANOVIC, D.; LEE, J.; NI, J. Watchdog Agent - an infotronics-based prognostics approach for product performance degradation assessment and prediction. Advanced Engineering Informatics, v.17, n.3-4, p.109-125, 2003.

DONNELLY, K.; BECKETT-FURNELL, Z.; TRAEGER, S.; OKRASINSKI, T.; HOLMAN, S. Eco-design implemented through a product-based environmental management system. Journal of Cleaner Production, v.14, n.15/16, p.1357-1367, 2006.

DREYER, L.C.; HAUSCHILD, M.Z.; SCHIERBECK, J. A framework for social life cycle impact assessment. The International Journal of Life Cycle Assessment, v.11, n.2, p.8-97, 2006. 
DRIVA, $\mathrm{H}$. et al. Measuring product development performance in manufacturing organizations. International Journal of Production Economics, v.63, n.2, p.147159, 2000.

DUYSTERS, G.; VAN WEELE, A.J.; WYNSTRA, F.; VAN ECHTELT, F.E. Managing supplier involvement in new product development. The Journal of Product Innovation Management, v.25, p.180-201, 2008.

DYM, C.L.; LITTLE, P. Introdução à engenharia: uma abordagem baseada em projeto. 3. ed. Porto Alegre: Bookman, 2004.

EARLE, M.D. Changes in the food product development process. Trends in food Science \& Technology, v.8, p.19-24, 1997.

EBERT, C.; DE MAN, J. Effectively utilizing project, product and process knowledge. Information and Software Technology, v.50, n.6, p.579-594, 2008.

ECHEVESTE, M.E.S. Uma abordagem para a estruturação e controle do processo de desenvolvimento de produtos. Porto Alegre: UFRGS. Tese de Doutorado, PPGEP/UFRGS, 2003.

ECHEVESTE, M.E.S; SAURIN, T.; DANILEVICZ, A. Avaliação do uso de prática de ecodesign nas indústrias do Rio Grande do Sul: um estudo Introdutório. Produto e Produção, v.6, n.1, p.9-23, 2002.

EISENHARDT, K.M. Building Theories from Case Study Research. Academy of Management Review, v.14, n.4, p.535-550, 1989.

ELGHALI, L.; CLIFT, R.; BEGG, K.G.; MCLAREN, S. Decision support methodology for complex contexts. Proceedings of the Institution of Civil Engineers-Engineering Sustainability, v.161, n.1, p.7-22, 2008.

ELKINGTON, J. Towards the sustainable corporation: win-win-win business strategies, For Sustainable Development, California Management Review, 1994.

ERNZER, M.; BIRKHOFER, H. Requirements for environmentally friendly and marketable products environmentally friendly product development. Methods and tools (pp. 194-206). London: Springer-Verlag, 2005.

ERTAS, A.; JONES, J.C. The engineering design process, John Wiley \& Sons, New York, 1996.

EUN, J.H.; SON, J.H.; MOON, J.M.; CHUNG, J.S. Integration of life cycle assessment in the environmental information system. International Journal of Life Cycle Assessment, v.14, n.4, p.364-373, 2009.

EVRENDILEK, F.; ERTEKIN, C. Agricultural sustainability in Turkey: Integrating food, environmental and energy securities. Land Degradation \& Development, v.13, n.1, p.61-67, 2002.

FACANHA, C.; HORVATH, A. Environmental Assessment of Logistics Outsourcing. Journal of Management in Engineering, v.21, n.1, p.27-37, 2005. 
FAN, M.; STALLAERT, J.; WHINSTON, A.B. Decentralized mechanism design for supply chain organizations using an auction market. Information Systems Research, v.14, n.1, p.1-22, 2003.

FARGNOLI, M.; KIMURA, F. Screening life cycle modeling for sustainable product design. 12th CIRP International Conference on Life Cycle Engineering, Grenoble, France, Apr, p.281-292, 2006.

FARGNOLI, M.; SAKAO, T. Coordinating ecodesign methods in early stages of industrial product design. International Journal of Environmentally Conscious Design \& Manufacturing. v.14, n.2, p.35-65, 2008.

FARUK, O.; BLEDZKI, A.K.; FINK, H.; SAIN, M. Biocomposites reinforced with natural fibers: 2000-2010. Progress in Polymer Science, v.37, n.11, p.1552-1596, 2012.

FERREIRA, J.G.; HAWKINS, A.J.S.; MONTEIRO, P. Integrated assessment of ecosystem-scale carrying capacity in shellfish growing areas. Aquaculture, v.275, n.1-4, p.138-151, 2008.

FERRENDIER, S.; MATHIEUX, F.; REBITZER, G.; SIMON, M.; FROELICH, D. Ecodesign Guide (ECOLIFE Thematic Network) - Environmental Improved Product Design Case Studies of the European Electrical and Electronics Industry, 2002.

FIKSEL, J. Design for the Environment: A Guide to Sustainable Product Development (2nd ed.). USA: McGraw-Hill, 2011.

FIKSEL, J. Measuring sustainability in ecodesign. In: Sustainable Solutions: developing products and services for the future, ed. Martin Charter and Ursula Tischner. Wiltshire: Greenleaf, p.165-187, 2001.

FIXSON, S.K. Modularity and commonality research: past developments and future opportunities. Concurrent Engineering-Research and Applications, v.15, n.2, p.85-111, 2007.

FLEISCHER, M.; LIKER, J.K. Concurrent Engineering Effectiveness: Integrating Product Development Across Organizations. Hanser Gardner Publications, Cincinnati, OH, 1997.

FLEURY, A. Planejamento do projeto de pesquisa e definição do modelo teórico. In: CAUCHICK MIGUEL, P.A. (Org.). Metodologia de pesquisa em engenharia de produção e gestão de operações. Rio de Janeiro: Elsevier, p.33-44, 2010.

FORZA, C. Survey Research in Operations Management: a Process-based Perspective. International Journal of Operations \& Production Management, v.22, n.2, p.152-194, 2002.

FREDERICKS, E. Cross-functional involvement in new product development. Qualitative Market Research: an International Journal, v.8, n.3, p.327-341, 2005. 
FREITAS, A.L.P.; RODRIGUES, S.G. A avaliação da confiabilidade de questionário: uma análise utilizando o coeficiente alfa de Cronbach. XII SIMPEP - Bauru-SP, 2005.

FREITAS, F.L. Modelo de referência para o processo de desenvolvimento de produtos das empresas nascentes de base tecnológica da incubadora MIDI Tecnológico. Dissertação (mestrado) - Universidade Federal de Santa Catarina, Centro Tecnológico. Programa de Pós-Graduação em Engenharia de Produção.Florianópolis, SC, p.225, 2010.

FREY, S.D.; HARRISON, D.J.; BILLETT, E.H. Ecological footprint analysis applied to mobile phones. Journal of Industrial Ecology, v.10, n.1-2, p.199-216, 2006.

FUAD-LUKE, A. The Eco-Design Handbook: A Complete Sourcebook for the Home and Office, 3rd ed. London: Thames \& Hudson, 2009.

FULLER, W.G. New food product development: from concept to marketplace. Florida: CRC Press LLC, 1984.

GALLEZOT, P. Catalytic Conversion of Biomass: Challenges and Issues. Chemsuschem, v.1, n.8-9, p.734-737, 2008.

GARCIA, R.; CALANTONE, R. A critical look at technological innovation typology and innovativeness terminology: a literature review. The Journal of Product Innovation Management, v.19, p.110-132, 2002.

GARRIGUES, E.; CORSON, M.S.; ANGERS, D.A.; VAN DER WERF, H.M.G.; WALTER, C. Soil quality in Life Cycle Assessment: Towards development of an indicator. Ecological Indicators, v.18, p.434-442, 2012.

GAVRILESCU, M.; CHISTI, Y. Biotechnology - a sustainable alternative for chemical industry. Biotechnology Advances, v.23, n.7-8, p.471-499, 2005.

GENAIDY, A.; KARWOWSKI, W. A roadmap for a methodology to assess, improve and sustain intra- and inter-enterprise system performance with respect to technology-product life cycle in small and medium manufacturers. Human Factors and Ergonomics in Manufacturing, v.18, n.1, p.70-84, 2008.

GERSTAKIS, J.; LEWIS, H.; RYAN, C. A Guide to Ecoredesign - Improving the Environmental Performance of Manufactured Products. Centre for Design at Royal Melbourne Institute of Technology, RMIT, Melbourne, Australia, 1997.

GIL, A.C. Como elaborar projetos de pesquisa. São Paulo: Atlas, 1999.

GIUDICE, F.; BALLISTERI, F.; RISITANO, G.A concurrent design method based on DFMA-FEA integrated approach. Concurrent Engineering-Research and Applications, v.17, n.3, p.183-202, 2009.

GLADWIN, T.N.; KENNELLY J.J.; KRAUSE, T.S. Shifting paradigms for sustainable development - implications for management theory and research. Academy of Management Review, v.20, n.4, p.874-907, 1995. 
GLENDINING, M.J.; DAILEY, A.G.; WILLIAMS, A.G.; VAN EVERT, F.K.; GOULDING, K.W.T.; WHITMORE, A.P. Is it possible to increase the sustainability of arable and ruminant agriculture by reducing inputs? Agricultural Systems, v.99, n.2/3, p.117-125, 2009.

GOBE, A.C.; MOREIRA, J.C.T.; PEREZ, M.C.; CARRAMENHA, P.R.C.; PASQUALE, P.P. Gerência de produtos. São Paulo: Saraiva, 2004.

GODOY, A.S. Introdução à pesquisa qualitativa e suas possibilidades. Revista de Administração de Empresas, v.35, n.2, p.57-63, 1995.

GOEPP, V.; Rose, B.; Caillaud, E. Coupling reference modelling and performance evaluation for the effective integration of eco-design tools into the design process. International Journal of Computer Integrated Manufacturing, v.27, n.3, p.242265, 2014.

GOFFIN, K. Sustainability and new product development. Chapter 6. In: Cranfield on Corporate Sustainability, p.105-118, 2012.

GOKTAN, A.B.; MILES, G. Innovation speed and radicalness: are they inversely related? Management Decision, v.49, n.3-4, p.533-547, 2011.

GONZALEZ-GARCIA, S.; BERG, S.; FEIJOO, G.; TERESA MOREIRA, M. Environmental impacts of forest production and supply of pulpwood: Spanish and Swedish case studies. International Journal of Life Cycle Assessment, v.14, n.4, p.340-353, 2009.

GRAEDEL, T.; ALLENBY, B. Design for Environment. Prentice Hall, 1995.

GRAF, E.; SAGUY, S. Food product development: From concept to the marketplace. Van Nostrand Reinhold, New York, 1991.

GRIFFIN, A. Metrics for measuring product development cycle time. Journal of Product Innovation Management, v.10, n.2, p.112-125, 1993.

GRIFFIN, A.; PAGE, A.L. An interim report on measuring product development success and failure. Journal of Product Innovation Management, v.10, n.2, p.291308, sep. 1993.

GUELERE FILHO, A. Integração do ecodesign ao modelo unificado para a gestão do processo de desenvolvimento de produtos: estudo de caso em uma grande empresa de linha branca. 2009. Tese (Doutorado) - Escola de Engenharia de São Carlos, Universidade de São Paulo, São Carlos, p.285, 2009.

GUIMARÃES, L.B.M. A ecologia no projeto de produto: design sustentável, design verde, ecodesign. In: GUIMARÃES, L. B. M. Ergonomia de produto. 5. ed. Porto Alegre: FEENG, 2006.

GUNASEKARAN, A. Agile manufacturing: enablers and an implementation framework. International Journal of Production Research, v.36, n.5, p.1223-1247, 1998. 
GUNGOR, A; GUPTA, S.M. Issues in environmentally conscious manufacturing and product recovery: a survey. Computers \& Industrial Engineering, v.36, n.4, p.811853, 1999.

HALLSTEDT, S. A foundation for sustainable product development. Dissertation. Blekinge Institute of Technology Sweden, 2008.

HALOG, A.; SCHULTMANN, F.; RENTZ, O. Using quality function deployment for technique selection for optimum environmental performance improvement. Journal of Cleaner Production, v.9, n.5, p.387-394, 2001.

HAMERI, A.P.; NIHTILA, J. Product data management - exploratory study on stateof-the-art in one-of-a-kind industry. Computers in Industry, v.35, n.3, p.195-206, 1998.

HAN, K.H.; DO, N. An object-oriented conceptual model of a collaborative product development management (CPDM) system. International Journal of Advanced Manufacturing Technology, v.28, n.7/8, p.827-838, 2006.

HAQUE, B. et al. The application of business process modelling to organisational analysis of concurrent engineering environments. Technovation, v.23, n.2, p.147162, 2003.

HART, C. Doing a literature search: a comprehensive guide for the social sciences. London. Sage Publications, 2001.

HART, S.L. Beyond greening: Strategies for a sustainable world. Harvard Business Review, v.75, n.1, p.66-76, 1997.

HART, S.L.; MILSTEIN, M.B. Global sustainability and the creative destruction of industries. Sloan Management Review, v.41, n.1, p.23, 1999.

HAUSCHILD, M.Z.; DREYER, L.C.; JORGENSEN, A. Assessing social impacts in a life cycle perspective - Lessons learned. CIRP Annals-Manufacturing Technology, v.57, n.1, p.21-24, 2008.

HAWKINS, T.R., SINGH, B., MAJEAU-BETTEZ, G., STROMMAN, A.H. Comparative environmental life cycle assessment of conventional and electric vehicles. Journal Ind. Ecol., v.17, n.1, p.158-160, 2013.

HEIJUNGS, R. et al. Environmental Life Cycle Assessment of Products Backgrounds. Leiden University. The Netherlands. Oct, 1992.

HENDERSON, R.M.; CLARK, K.B. Architectural innovation - the reconfiguration of existing product technologies and the failure of established firms. Administrative Science Quarterly, v.35, n.1, p.9-30, 1990.

HERVA, M.; ROCA, E. Review of combined approaches and multi-criteria analysis for corporate environmental evaluation. Journal of Cleaner Production, v.39, p.355371, 2013. 
HILL, M.M.; HILL, A. Investigação por questionário. 2.ed. rev. e corr. Lisboa: Sílabo, p.377, 2008.

HOBBY, C.; RYDELL, N.; SJOGREN, E.; WILLIAMS, W. IT products. Going beyond green - can high performance and sustainability co-exist? IEEE International Symposium on Sustainable Systems and Technology, Tempe, AZ, May, p.117-120, 2009.

HOBDAY, M. Product complexity, innovation and industrial organization. Research Policy, v.26, n.6, p.689-710, 1998.

HOCHSCHORNER, E.; FINNVEDEN, G. Life cycle approach in the procurement process: The case of defence materiel. International Journal of Life Cycle Assessment, v.11, n.3, p.200-208, 2006.

HOLDWAY, R.D.; WALKER, HILTON, M. Ecodesign and successful packaging. Design Management Journal, v.13, n.4, p.45-53, 2002.

HOLMBERG, J.; ROBERT, K.H. Backcasting - a framework for strategic planning. International Journal of Sustainable Development and World Ecology, v.7, n.4, p.291-308, 2000.

HORA, H.R.M.; MONTEIRO, G.T.R.; ARICA, J. Confiabilidade em Questionários para Qualidade: Um Estudo com o Coeficiente Alfa de Cronbach. Produto \& Produção, v.11, n.2, p.85-103, 2010.

HUANG, A.H. A model for environmentally sustainable information systems development. Journal of Computer Information Systems, v.49, n.4, p.114-121, 2009.

HULTINK, E.J.; ROBBEN, H.S. J. Measuring new product success: the difference that time perspective makes. Journal of Product Innovation Management, v.12, n.5, p.392-405, nov. 1995.

HUNKELER, D.; REBITZER, G. Life cycle costing - Paving the road to sustainable development? International Journal of Life Cycle Assessment, v.8, n.2, p.109110, 2003.

IHOBE. Manual práctico de ecodiseño. Operativa de implantación en 7 pasos. Sociedad Pública de Gestión Ambiental. Gobierno Vasco. España, 2011.

IJOMAH, W.; MCMAHON, C.; HAMMOND G.; NEWMAN, S. Development of robust design-for-remanufacturing guidelines tofurther the aims of sustainable development. International Journal of Production Research, v.45, n.18-19, p.4513-4536, 2007.

INGLE, K.A. Reverse engineering. New York: McGraw- Hill, p.240,1994.

INTERNATIONAL STANDARD, ISO 14006. Environmental management systems - Guidelines for incorporating ecodesign. Geneva, 2011. 
INTERNATIONAL STANDARD, ISO 14040. Environmental management. Life cycle assessment. Principles and framework: International Organization for Standardization, 2006.

JABBOUR, C.J.C. In the eye of the storm: exploring the introduction of environmental issues in the production function in Brazilian companies. International Journal of Production Research, v.48, n.21, p.6315-6339, 2010.

JAWAHIR, I.S.; ROUCH, K.E.; DILLON, O.W.; HOLLOWAY, L.; HALL, A. Design for sustainability (DFS): New challenges in developing and implementing a curriculum for next generation design and manufacturing engineers. International Journal of Engineering Education, v.23, n.6, p.1053-1064, 2007.

JENSEN, J. Product carbon footprint developments and gaps. International Journal of Physical Distribution \& Logistics Management, v.42, n.4, p.338-354, 2012.

JIANG, Z.G.; ZHANG, H.; FU, C.; JIANG, D.R. The operation mode of green manufacturing based information technology. International Conference on Informational Technology and Environmental System Science, Jiaozuo, China, May, p.465-470, 2008.

JIMENEZ-GONZALEZ, C.; CURZONS, A.D.; CONSTABLE, D.J.C.; CUNNINGHAM, V.L. Cradle-to-gate life cycle inventory and assessment of pharmaceutical compounds. International Journal of Life Cycle Assessment, v.9, n.2, p.114-121, 2004.

JOHANSSON, G. Incorporating environmental concern in product development. Management of Environmental Quality: An International Journal, v.17, n.4, p.421436, 2006.

JOHANSSON, G. Success factor for integration of Ecodesign in product development: A review of state of the art. Environmental Management and Health, v.13, n.1, p.98-107, 2002.

JOORE, P. The V-Cycle for system innovation translating a broad societal need into concrete product service solutions: the multifunctional centre Apeldoorn case. Journal of Cleaner Production, v.16, n.11, p.1153-1162, 2008.

JUNG C.F.; RIBEIRO, J.L.D.; ECHEVESTE, M.E.S.; TEN CATEN, C.S. Uma Discussão de Modelos de Desenvolvimento de Produto e suas Características Lineares e Sistêmicas. VIII SEPROSUL - Semana de Engenharia de Produção SulAmericana, Bento Gonçalves, Brasil, Nov, 2008.

JUTTNER, U; GODSELL, J.; CHRISTOPHER, M.G. Demand chain alignment competence - delivering value through product life cycle management. 22nd IMP Conference, Milan, Italy, v.35, n.8, p.989-1001, 2006.

KAATZ, E.; ROOT, D.; BOWEN, P. Broadening project participation through a modified building sustainability assessment. Building Research and Information, v.33, n.5, p.441-454, 2005. 
KALPIC, B.; BERNUS, P. Business process in modelling in industry - the powerful tool in enterprise management. Computer in Industry, v.47, p.299-318, 2002.

KAMINSKI, P.C. Desenvolvendo produtos com planejamento, criatividade e qualidade. Rio de Janeiro: LTC, 2000.

KARLSSON M. Green concurrent engineering. Assuring environmental performance in product development. Licentiate thesis. IIEEE, Lund University, Sweden; 1997.

KARLSSON, R.; LUTTROPP, C. EcoDesign: what's happening? An overview of the subject area of EcoDesign and of the papers in this special issue. Journal of Cleaner Production, v.14, n.15/16, p.1291-1298, 2006.

KASHEFI, E.; MORT, M. Grounded citizens' juries: a tool for health activism? Health Expectations, v.7, n.4, p.290-302, 2004.

KASSAHUN, B.; SAMINATHAN, M.; SEKUTOWSKI, J.C. Green design tool. Proceedings of the 1995 IEEE International Symposium on Electronics and the Environment . Orlando: [s.n.] p.118-125, 1995.

KELLNER, M.I.; MADACHY, R.J.; RAFFO, D.M. Software process simulation modeling: Why? What? How? Journal of Systems and Software, v.46, n.2/3, p.91105, 1999.

KENGPOL, A.; BOONKANIT, P. The decision support framework for developing Ecodesign at conceptual phase based upon ISO/TR 14062. International Journal of Production Economics, v.131, n.1, p.4-14, 2011.

KENNEDY, G.A.L.; SIEMIENIUCH, C.E.; SINCLAIR, M.A.; KIRWAN, B.A.; GIBSON, W.H. Proposal for a sustainable framework process for the generation, validation, and application of human reliability assessment within the engineering design lifecycle. Reliability Engineering \& System Safety, v.92, n.6, p.755-770, 2007.

KHAN, F.I.; SADIQ, R.; VEITCH, B. Life cycle iNdeX (LInX): a new indexing procedure for process and product design and decision-making. Journal of Cleaner Production, v.12, n.1, p.59-76, 2004.

KHOTA, I.; PRETORIUS, L. Intellectual property scorecard: Strategically capitalising on value created by innovation and R\&D. Portland International Conference on Management Engineering and Technology, Cape Town, South Africa, Jul, v.1-5, p.584-592, 2008.

KILMANN, R. A holistic program and critical success factors of corporate transformation. European Management Journal, v.13, n.2, p.175-186, 1995.

KIM, Y.G.; KIM, J.W.; SHIN, S.O.; BAIK, D.K. Managing variability for software product-line. 4th International Conference on Software Engineering Research, Management and Applications, Seattle, WA, Aug, p.74-81, 2006.

KINDLEIN J.W.; CÂNDIDO, L.H.; PLATCHECK, E. Analogia entre as Metodologias de Desenvolvimento de Produtos Atuais, com a Proposta de uma 
Metodologia com Ênfase no Ecodesign. In: II Congresso Internacional de Pesquisa em Design, 2003, Rio de Janeiro, 2003.

KLOPFFER, W. Life-cycle based methods for sustainable product development. International Journal of Life Cycle Assessment, v.8, n.3, p.157-159, 2003.

KLOPFFER, W. The role of SETAC in the development of LCA. International Journal of Life Cycle Assessment, v.11, n.1, p.116-122, 2006.

KNIGHT, P.; JENKINS, J.O. Adopting and applying eco-design techniques: a practitioners perspective, Journal of Cleaner Production, v.17, n.5, p.549-558, 2009.

KOBAYASHI H. Strategic evolution of eco-products: a product life cycle planning methodology. Research in Engineering Design, v.16, n.1/2, p.1-16, 2005.

KOBERG, C.S.; UHLENBRUCK, N.; SARASON, Y. Facilitators of organizational innovation: The role of life-cycle stage. Journal of Business Venturing, v.11, n.2, p.133-149, 1996.

KÖCHE, J.C. Fundamentos de metodologia científica: Teoria da ciência e iniciação à pesquisa. 20.ed. Petrópolis: Vozes, 2002.

KOHLER, N.; HASSLER, U. The building stock as a research object. Building Research and Information, v.30, n.4, p.226-236, 2002.

KOTLER, P. Atmospherics as a Marketing Tool. Journal of Retailing, v.49, n.winter, p.48-64, 1974.

KOTLER, P.; KARTAJAYA, H.; SETIAWAN, I. Marketing 3.0: as forças que estão definindo o novo marketing centrado no ser humano. Rio de Janeiro: Elsevier, 2010.

KOUSKOURAS, K.G; GEORGIOU, A.C. A discrete event simulation model in the case of managing a software project. European Journal of Operational Research, v.181, n.1, p.374-389, 2007.

KOVA'CS, G.; KOPA'CSI ,S.; HAIDEGGER, G.; MICHELINI, R. Ambient Intelligence in Product Life-cycle Management. Engineering Applications of Artificial Intelligence, v.19, p.953-965, 2006.

KOZLOWSKI, T.T.; PALLARDY, S.G. Acclimation and adaptive responses of woody plants to environmental stresses. Botanical review, v.68, n.2, p.270-334, 2002.

KRAUSE, F.L.; HAYKA, H.; PASEWALDT, B. Efficient product data sharing in collaboration life cycles. 14th International CIRP Design Seminar, Cairo, Egypt, May, p.365-375, 2006.

KRISHNAN, V.; LOCH, C.H. A retrospective look at production and operations management articles on new product development. Production and Operations Management, v.14, n.4, p.433-441, 2005. 
KRISHNAN, V.; ULRICH, K.T. Product Development Decisions: A review of the Literature. Management Science, v.47, n.1, p.1-21, 2001.

KRISHNAN, V; EPPINGER, S.D; WHITNEY, E.D. A model-based framework to overlap product development activities. Management Science, v.43, n.4, p.437-451, 1997.

KROTSCHECK, C.; NARODOSLAWSKY, M. The sustainable process index - A new dimension in ecological evaluation. Ecological Engineering, v.6, n.4, p.241-258, 1996.

KRUSE, S.A.; FLYSJO, A.; KASPERCZYK, N.; SCHOLZ, A.J. Socioeconomic indicators as a complement to life cycle assessment-an application to salmon production systems. International Journal of Life Cycle Assessment, v.14, n.1, p.8-18, 2009.

KURK, F.; EAGAN, P. The value of adding design-for-the-environment to pollution prevention assistance options. Journal of Cleaner Production, v.16, n.6, p.722-726, 2008.

KURK, F.; MCNAMARA, C. Better by Design Guide. Retrieved November 1, 2006 from http://www.moea.state.mn.us/publications/betterbydesign.pdf, 2006.

LAGERSTEDT, J. Functional and environmental factors in early phases of product development. Eco functional matrix. KTH, Maskinkonstruktion. [S.I.]. 2003.

LAURENT, A.; OLSEN, S.I.; HAUSCHILD, M.Z. Limitations of Carbon Footprint as Indicator of Environmental Sustainability. Environmental Science \& Technology, v.46, n.7, p.4100-4108, 2012.

LE POCHAT, S.; BERTOLUCI, G.; FROELICH, D. Integrating ecodesign by conducting changes in SMEs. Journal of Cleaner Production, n.15, p.671-680, 2007.

LEE, H.M.; LU, W.F.; SONG, B.; GAY, R. EOL framework for design advisory. 4th International Conference on Product Lifecycle Management, Stezzano, Italy, Jul, p.677-686, 2007.

LEE, J.; KIM, I.; KWON, E.; HUR, T. Comparison of Simplified LCA and Matrix Methods in Identifying the Environmental Aspects of Products. 3rd International Symposium on Environmentally Conscious Design and Inverse Manufacturing . [S.I.]: [s.n.], p.682-686, 2003.

LEE, S.; GEUM, Y.; LEE, H.; PARK, Y. Dynamic and multidimensional measurement of product-service system (PSS) sustainability: a triple bottom line (TBL)-based system dynamics approach. Journal of Cleaner Production, v.32, p.173-182, 2012

LEONTITSIS, A.; PAGGE, J.A simulation approach on Cronbach's alpha statistical significance. Mathematics and Computers in Simulation, v.73, p.336-340, 2007. 
LEVENE, H. Robust Test for Equality of Variances, in: I.O. et al., ed., 'Contributions to Probability and Statistics: Essays in Honor of Harold Hotteling', Stanford University Press, California, United States, p.278-292, 1960.

LEWANDOWSKA, A.; KURCZEWSKI, P. ISO 14062 in Theory and Practice Ecodesign Procedure. Part 1: Structure and Theory. The International Journal of Life Cycle Assessment, v.15, n.8, p.769-776, 2010.

LEWIS, H.; GERTSAKIS, J.; GRANT, T; MORELLI, N.; SWEATMAN, A. Design + Environment: A Global Guide to Designing Greener Goods, Greenleaf Publishing Limited, Sheffield, UK, 2001.

LI, J.T.; KOZHIKODE, R.K. Developing new innovation models: Shifts in the innovation landscapes in emerging economies and implications for global R\&D manage. Journal of International Management, v.15, n.3, p.328-339, 2009.

LI, M.; QIN, X.S.; XU, Y.B. An integrated modeling method supporting product development process optimization. 2nd International Conference on Research and Practical Issues of Enterprise Information Systems, Beijing, China, Oct, p.707716, 2008.

LICHTENVORT, K.; ALONSO, J.C.; JOHANSSON, G.; BARMETABEIIAD, L. Applying the grEEEn Method: Initial results from an Ecodesign Case Study. In: Proceedings of EcoDesign 2003. Third International Symposium on Environmentally Conscious Design and Inverse Manufacturing, 2003.

LIN, J.; CHAI, H.C.; WONG, Y.S.; BROMBACHER, A.C. A Dynamic Model for Managing Overlapped Iterative Product Development, European Journal of Operational Research, v.185, n.1, p.378-392, 2006.

LIN, J.; QIAN, Y.J.; CUI, W.T.; MIAO, Z.L. Overlapping and communication policies in product development. European Journal of Operational Research, v.201, n.3, p.737-750, 2010.

LINDAHL, M. E-FMEA - A New Promising Tool for Efficient Design for Environment, Proceedings Ecodesign'99, First International Symposium on Environmentally Conscious Design and Inverse Manufacturing, p.734, 1999.

LINDAHL, M. Engineering designers' requirements on design for environment methods and tools. Stockholm: Universitetsservice US AB. (Trita-MMK 2005:07). Diss. Royal Institute of Technology, KTH, 2005.

LINDAHL, M. Environmental Effect Analysis - How does the method stand in relation to lessons learned from the use of other Design for Environment Methods . University of Kalmar, 2001.

LINDAHL, M., EKERMANN, S. Structure for categorization of ecodesign methods and tools. In: 20th CIRP International Conference on Life Cycle Engineering, Singapore, 2013.

LINDAHL, M.; SKOGLUND, L.; SVENSSON, J.; KARLSSON, R. Use and perception of design for environment in small and medium sized enterprises in 
Sweden. 3rd International Symposium on Environmentally Conscious Design and Inverse Manufacturing, Tokyo, Japan, Union of EcoDesigners, 2003.

LINDNER, M.; SUOMINEN, T.; PALOSUO, T.; GARCIA-GONZALO, J.; VERWEIJ, P.; ZUDIN, S.; PAIVINEN, R. TOSIA-A tool for sustainability impact assessment of forest-wood-chains. Ecological Modelling, v.221, n.18, p.2197-2205, 2010.

LINTON, J.D.; KLASSEN, R.; JAYARAMAN, V. Sustainable supply chains: An introduction. Journal of Operations Management, v.25, n.6, p.1075-1082, 2007.

LIPPIATT, B.C. Selecting cost-effective green building products: BEES approach. Journal of Construction Engineering and Management-ASCE, v.125, n.6, p.448455, 1999.

LITTELL, J.H.; CORCORAN, J.; PILLAI, V. Systematic Reviews and MetaAnalysis. New York: Oxford University Press, Inc., 2008.

LOFTHOUSE, V. Ecodesign tools for designers: defining the requeriments. Journal of Cleaner Production, n.14, p.1386-1395, 2006.

LOFTHOUSE, V., BHAMRA, T. Making things Better - An Industrial Designers approach to Ecodesign. in D3 Desire, Designum, Design: 4th European Academy of Design Conference Proceedings, 10-12 April, Aveiro, Portugal, 2001.

LOPES, A.P.V.V; CARVALHO, M.M. Evolução da literatura de inovação em relações de cooperação: um estudo bibliométrico num período de vinte anos. Gestão \& Produção, v.19, n.1, p.203-217, 2012.

LU, I.Y.; YANG, C.Y.; TSENG, C.J. Push-Pull interactive model of service innovation cycle - under the service encounter framework. African Journal of Business Management, v.3, n.9, p.433-442, 2009.

LUNDTEIGEN, M.A.; RAUSAND, M.; UTNE, I.B. Integrating RAMS engineering and management with the safety life cycle of IEC 61508. Reliability Engineering \& System Safety, v.94, n.12, p.1894-1903, 2009.

LUTTROPP, C.; KARLSSON, R. The conflict of contradictory environmental targets. In: International Symposium on Environmental Conscious Design and Inverse Manufacturing, 2., 2001, Tokyo. Proceedings.

LUTTROPP, C.; LAGERSTEDT, J. Ecodesign and the ten golden rules: generic advice for merging environmental aspects into product development. Journal of Cleaner Production, v.14, n.15/16, p.1396-1408, 2006.

LYND, L.R.; WYMAN, C.E.; GERNGROSS, T.U. Biocommodity engineering. Biotechnology Progress, v.15, n.5, p.777-793, 1999.

MACCORMACK, A.; VERGANTI, R.; IANSITI, M. Developing products on "Internet time": The anatomy of a flexible development process. Management Science, v.47, n.1, p.133-150, 2001. 
MACFIE, H. Computer assisted product development. World of Ingredients, October, p.44-49, 1994.

MACGREGOR, S.P.; ARANA, J.; PARRA, I.; LORENZO, M.P. Supporting new product creation in the Mondragón Valley. European Journal of Innovation Management, v.9, n.4, p.418-443, 2006.

MALAGUTI, C. Requisitos ambientais para o desenvolvimento de produtos: manual técnico. São Paulo: Centro São Paulo Design, 2005.

MALTZ, E. et al. Influencing R\&D/marketing integration and the use of market information by $R \& D$ managers: intended and unintended effects of managerial actions. Journal of Business Research, v.52, n.1, p.69-82, 2001.

MANLAY, R.J.; FELLER, C.; SWIFT, M.J. Historical evolution of soil organic matter concepts and their relationships with the fertility and sustainability of cropping systems. Agriculture Ecosystems \& Environment, v.119, n.3-4, p.217-233, 2007.

MANZINI, E.; VEZZOLI, C. O desenvolvimento de produtos sustentáveis: os requisitos ambientais dos produtos industriais. São Paulo: USP, 2005.

MARCONI, M.D.A.; LAKATOS, E.M. Técnicas de pesquisa: planejamento e execução de pesquisas, amostragens e técnicas de pesquisas, elaboração, análise e interpretação de dados. 3.ed. São Paulo: Atlas, 1996.

MARIMON, F.; LLACH, J.; BERNARDO, M. Comparative analysis of diffusion of the ISO 14001 standard by sector of activity. Journal of Cleaner Production, v.19, p.1734-1744, 2011.

MARTENS, M.L., BRONES, F., CARVALHO, M.M. Lacunas e tendências na literatura de sustentabilidade no gerenciamento de projetos: uma revisão sistemática mesclando bibliometria e análise de conteúdo (Gaps and Trends in the Sustainability Literature on Project Management: a Systematic Review Merging Bibliometric and Content Analysis). Revista Gestão de Projetos, v.4, n.1, p.165-219, 2013.

MARTÍN, L.Á.G.; CABESTRE, F.J.R.; VEGA, A.V.R. El estado actual de la investigación empírica sobre economía de la empresa: análisis de las publicaciones españlas. Papeles de economía española, n.78-79, p.302-317, 1999.

MARTINS, P.G.; LAUGENI, F.P. Administração da Produção. São Paulo: Editora Saraiva, 2005.

MARTINS, R.A. Abordagens Quantitativa e Qualitativa. In: CAUCHICK MIGUEL, P. A. (Org.). Metodologia de pesquisa em engenharia de produção e gestão de operações. Rio de Janeiro: Elsevier, 2010.

MASUI, K.; SAKAO, T.; INABA, A. Quality Function Deployment for Environment: QFDE (1st Report) - A Methodology in Early Stage of DfE. In: International Symposium on Environmentally Conscious Design and Inverse Manufacturing, 2., 2001, Tokyo, Japan. Proceedings, Tokyo: IEEE, 2001. 
MASUI, K.; TOMOHIKO, S.; INABA, A. Applying quality function deployment to environmentally conciuos design. International Journal of Quality \& Reliability Management, v.20, n.1, p.90-106, 2003.

MATHIEUX, F. et al. Ecodesign in the European Electronics industry. The Journal of Sustainable Product Design, v.1, p.233-245, 2001.

MATHIEUX, F.; FROELICH, D.; MOSZKOWICZ, P. ReSICLED: a new recoveryconscious design method for complex products based on a multicriteria assessment of the recoverability. Journal of Cleaner Production, v.16, p.1-22, 2006.

MATTAR, F.N. Pesquisa de marketing: metodologia e planejamento. São Paulo: Atlas, 1996.

MAXWELL, D.; SHEATE, W.; VAN DER VORST, R. Functional and systems aspects of the sustainable product and service development approach for industry. Journal of Cleaner Production, v.14, n.17, p.1466-1479, 2006.

MAXWELL, D.; VAN DER VORST, R. Developing sustainable products and services. Journal of Cleaner Production, v.11, n.8, p.883-895, 2003.

MAYS, N.; POPE, C. Qualitative research in health care. Londres: BMJ Publishing Group, 1996.

McDONOUGH, W.; BRAUNGART, M. Cradle to cradle: remaking the way we make things. New York: North Point Press, 2002.

MCGRATH, M.E. Setting the PACE in Product Development: A Guide to Product and Cycle-Time Excellence (Revised edition), Butterworth-Heinemann, Boston, MA, 1996.

MENDES, G.H.S. O processo de desenvolvimento de produtos de empresas de base tecnológica: caracterização da gestão e proposta de modelo de referência. Tese (Doutorado). Universidade Federal de São Carlos. São Carlos/SP, 2008.

MENGONI, M.; GERMANI, M.; MANDORLI, F. A structured agile design approach to support customization in wellness product development. International Journal of Computer Integrated Manufacturing, v.22, n.1, p.42-54, 2009.

MERMUT, A.R.; ESWARAN, H. Some major developments in soil science since the mid-1960s. Geoderma, v.100, n.3-4, p.403-426, 2001.

MIGUEL, P.A.C. Estudo de caso na engenharia de produção: estruturação e recomendações para sua condução. Produção, v.17, n.1, p.216-229, 2007.

MILLSON, M.R.; RAJ, S.P.; WILEMON, D. A survey of major approaches for accelerating new product development. Journal of Product Innovation Management, v.9, n.1, p.53-69, 1992.

MOFFATT, S; KOHLER, N. Conceptualizing the built environment as a social ecological system. Building Research and Information, v.36, n.3, p.248-268, 2008. 
MOHANTY, A.K.; MISRA, M.; DRZAL, L.T. Sustainable bio-composites from renewable resources: Opportunities and challenges in the green materials world. Journal of Polymers and the Environment, v.10, n.1-2, p.19-26, 2002.

MONTGOMERY, D.C. Introdução ao Controle Estatístico da Qualidade. 4ª Edição. Rio de Janeiro: LTC, 2004.

MOSOVSKY, J.; DICKINSON, D.; MORABITO, J. Creating competetive advantage through resource productivity, eco-efficiency, and sustainability in the supply chain. Proceedings of the 2000 IEEE International Symposium on Electronics and the Environment, p.230-237, 2000.

MULDER, K.F. Innovation for sustainable development: from environmental design to transition management. Sustainability Science, v.2, n.2, p.253-263, 2007.

MURILLO-LUNA, J. L.; GARCÉS-AYERBE, C.; RIVERA-TORRES, P. Barriers to the adoption of proactive environmental strategies. Journal of Cleaner Production, v.19, n.13, p.1417-1425, 2011.

MURTAGH N., BAMBA T., IWAMA K. An evaluation tool for eco-design of electrical products. Environmentally Conscious Design and Inverse Manufacturing, 1999. Proceedings. EcoDesign'99: First International Symposium On, p.766-770, 1999.

NAGATA, K.; NOHTOMI, M.; AIZAWA, M.; ASAOKA, K.; USAMI, C. The development of the environmental efficiency potential assessment method. 2nd International Symposium on Environmentally Conscious Design and Inverse Manufacturing . [S.I.]: [s.n.], p.820-825, 2001.

NAKAMURA, S.; KONDO, Y. A waste input-output life-cycle cost analysis of the recycling of end-of-life electrical home appliances. Ecological Economics, v.57, n.3, p.494-506, 2006.

NAMIKAWA, O. Development of the evaluation tool that integrate. Design for Environment and Eco-efficiency at Hitachi. Ecodesign, p.240-241, 2005 4th International Symposium on Environmentally Conscious Design and Inverse Manufacturing, 2005.

NASCIMENTO, G.V. Um modelo de referêcia para o desenvolvimento ágil de software. (dissertação). Instituto de Ciências Matemáticas e Computação da Universidade de São Paulo, São Carlos/SP, 2008.

NEELY, A. The evolution of performance measurement research: developments in the last decade and a research agenda for the next. International Journal of Operations \& Production Management, v.25, n.12, p.1264-1277, 2005.

NIDUMOLU, R.; PRAHALAD, C.K.; RANGASWAMI, M.R., 2009. Why sustainability is now the key driver of innovation. Harvard Business Review, p.57-64, 2009.

NIJSSEN, E.J.; LIESHOUT, K.F.M. Awareness, use and effectiveness of models and methods for new product development. European Journal of Marketing, v.29, n.10, p.27-44, 1995. 
NIKOLOPOULOU, A.; IERAPETRITOU, M.G. Optimal design of sustainable chemical processes and supply chains: A review. Computers \& Chemical Engineering, v.44, p.94-103, 2012.

NOBELIUS, D. Linking product development to applied research: transfer experiences from an automotive company. Technovation, v.24, n.4, p.321-334, 2004.

NOEL, F.; ROUCOULES, L. The PPO design model with respect to digital enterprise technologies among product life cycle. International Journal of Computer Integrated Manufacturing, v.21, n.2, p.139-145, 2008.

NORRIS, G.A. Integrating life cycle cost analysis and LCA. International Journal of Life Cycle Assessment, v.6, n.2, p.118-120, 2001.

NORRIS, G.A. Social impacts in product life cycles - Towards life cycle attribute assessment. International Journal of Life Cycle Assessment, v.11, n.1, p.97-104, 2006.

NTIAMOAH, A.; AFRANE, G. Life cycle assessment of chocolate produced in Ghana. International Conference on Environmental Research, Technology and Policy, Ghana, South Africa, Jul, p.35-41, 2009.

NWABUEZE, U.; LAW, Z.C. The journey for survival: the case of new product development in the brewery industry, Journal of Product \& Brand Management, v.10, n.6, p.382-397, 2001.

NY, H.; MACDONALD, J.P.; BROMAN, G.; YAMAMOTO, R.; ROBERT, K.H. Sustainability constraints as system boundaries - An approach to making life-cycle management strategic. Journal of Industrial Ecology, v.10, n.1/2, p.61-77, 2006.

OBERENDER, C.; BIRKHOFER, H. The Eco-Value Analysis - An approach to assigning environmental impacts and costs to customers' demands. In: Proceedings of the 8th International Design Conference, May 17-20, Dubrovnik, Croatia, 2004.

O'HARE, J.; DEKONINCK, E.; MCMAHON, C.; TURNBULL, A. Adapting innovation tools to the eco- innovation requirements of industry: case study results, International Journal of Design Engineering, v.3, n.2, p.172-194, 2010.

ORTIZ, O.; CASTELLS, F.; SONNEMANN, G. Sustainability in the construction industry: A review of recent developments based on LCA. Construction and Building Materials, v.23, n.1, p.28-39, 2009.

PAHL, G.; BEITZ,W.; FELDHUSEN, J.; GROTE, K. Projeto na engenharia: fundamentos do desenvolvimento eficaz de produtos: métodos e aplicações. São Paulo: Edgard Blücher, 2005.

PAHL, G; BEITZ, W. Konstruktionslehre (English title: engineering design) (trans: Arnold Pomerans KW). Springer Verlag, English edition: The Design Council, Heidelberg, English edition: London, 1977. 
PAIVINEN, R.; LINDNER, M.; ROSEN, K.; LEXER, M.J. A concept for assessing sustainability impacts of forestry-wood chains. European Journal of Forest Research, v.131, n.1, p.7-19, 2012.

PARK, C.W.; ZALTMAN, G. Marketing management. Chicago: The Dryden Press, 1987.

PARK, P.; TAHARA, K. Quantifying producer and consumer-based eco-efficiencies for the identification of key ecodesign issues. Journal of Cleaner Production, v.16, p.95-104, 2008.

PARTIDARIO, P.J.; LAMBERT, J.; EVANS, S. Building more sustainable solutions in production-consumption systems: the case of food for people with reduced access. Journal of Cleaner Production, v.15, n.6, p.513-524, 2007.

PAULA, I.C. Proposta de um modelo de referência para o processo de desenvolvimento de produtos farmacêuticos. 2004. $316 \mathrm{f}$. Tese (Doutorado em Engenharia de Produção). Escola de Engenharia, Universidade Federal do Rio Grande do Sul, Porto Alegre, 2004.

PAULA, R.A.S.R.; CHENG, L.C. A transformação dos resultados de pesquisas científicas em novos produtos de base tecnológica, compreendida a partir do estudo de caso exploratório de projetos apoiados pela primeira experiência do Sebraetec na UFMG. In: V Congresso Brasileiro de Gestão de Desenvolvimento de Produtos. Anais, Curitiba, PR, 2005.

PENNINGTON, D.W; POTTING, J.; FINNVEDEN, G. Life cycle assessment Part 2: Current impact assessment practice. Environment international, v.30, n.5, p.721739, 2004.

PENSO, C.C. Modelo de referência para o processo de desenvolvimento de produtos na indústria de alimentos. 2003. 182 f. Dissertação (Mestre em Engenharia Mecânica). Engenharia Mecânica, Universidade Federal de Santa Catarina, Florianópolis, 2003.

PERO, M.; SIANESI, A. Aligning supply chain management and new product development: a general framework. 4th International Conference on Product Lifecycle Management, Stezzano, Italy, Jul, p.489-498, 2007.

PETALA, E.; WEVER, R.; DUTILH, C.; BREZET, H. The role of new product development briefs in implementing sustainability: A case study. Journal of Engineering and Technology Management, v.27, n.3/4, p.172-182, 2010.

PETERS, A.J.; ROONEY, E.M.; ROGERSON, J.H.; MCQUATER, R.E.; SPRING, M.; DALE, B.G. New product design and development: a generic model. The TQM Magazine, v.11, n.3, p.172-179, 1999.

PHAAL, R.; FARRUKH, C.J.P.; PROBERT, D.R. Technology management tools: concept, development and application. Technovation, v.26, p.336-344, 2006. 
PIGOSSO, D.; ROZENFELD, H. Métodos e ferramentas de Ecodesign: revisão bibliográfica sistemática. ${ }^{\text {a }}$ Congresso Brasileiro de Gestão de Desenvolvimento de Produtos. Porto Alegre, RS, 11-13 set., 2012.

PIGOSSO, D.; ZANETTE, A.; GUELERE FILHO, A.; OMETTO, A.; ROZENFELD, H. Ecodesign methods focused on remanufacturing. Journal of Cleaner Production, v.18, n.1, p.21-31, 2010.

PIGOSSO, D.C.A. Integração de métodos e ferramentas de ecodesign ao processo de desenvolvimento de produtos. Universidade de São Paulo Trabalho de Conclusão de Curso, São Carlos, 2008.

PIGOSSO, D.C.A. Modelo de maturidade para melhoria do desempenho ambiental na gestão do ciclo de vida dos produtos, 2012. Tese (Doutorado) Escola de Engenharia de São Carlos, Universidade de São Paulo, São Carlos, p.278, 2012.

PIGOSSO, D.C.A.; ROZENFELD, H.; MCALOONE, T.C. Ecodesign maturity model: a management framework to support ecodesign implementation into manufacturing companies. Journal of Cleaner Production, v.59, p.160-173, 2013.

PILKINGTON, A.; MEREDITH, J. The evolution of the intellectual structure of operations management-1980-2006: A citation/co-citation analysis. Journal of Operations Management, v.27, n.3, p.185-202, 2009.

PITCHER, T.J. Fisheries managed to rebuild ecosystems? Reconstructing the past to salvage the future. Ecological Applications, v.11, n.2, p.601-617, 2001.

PLATCHECK E.R.; SCHAEFFER L.; KINDLEIN, W.JR.; CÂNDIDO, L.H.A. Methodology of ecodesign for the development of more sustainable electro-electronic equipments. Journal of Cleaner Production, v.16, p.75-86, 2008.

PLOUFFE, S.; LANOIE, P.; BERNEMAN, C.; VERNIER, M.F. Economic benefits tied to ecodesign. Journal of Cleaner Production, v.19, n.6/7, p.573-579, 2011.

POPPER, K.R. A lógica da pesquisa cientifica (L.P.Sc.). Trad. Leonidas Hegenberg e Octanny Silveira da Mota. São Paulo: Ed. Cultrix: EDUSP, 1975.

POPPER, K.R. Conjeturas e refutações (C\&R). Trad. Sérgio Bath. Brasilia: Ed. UnB, 1982.

PORTER, M.E.; VANDERLINDE, C. Green and competitive - ending the stalemate. Harvard Business Review, v.73, n.5, p.120-134, 1995.

POULIKIDOU, S. A Literature Review on Methods and Tools for Environmentally Friendly Product Design and Development. Identification of Relevance to the Vehicle Design Context. KTH Royal Institute of Technology, Sweden, 2012.

POULIKIDOU, S. Integration of Design for Environment in the vehicle manufacturing industry in Sweden - Focus on practices and tools. Thesis, $\mathrm{KTH}$, Royal Institute of Technology, School of Architecture and the Built Environment, 
Department of Sustainable Development, Environmental Science and Engineering, Stockholm, Sweden, 2013.

POULIKIDOU, S.; BJORKLUND, A. Tools for sustainable product development. Experience and requirements from the vehicle manufacturing industry in Sweden. In: 6th International Conference on Life Cycle Management LCM 2013, Gothenburg, Sweden, 2013.

POULIKIDOU, S.; BJORKLUND, A.; TYSKENG, S. Empirical study on integration of environmental aspects into product development: processes, requirements and the use of tools in vehicle manufacturing companies in Sweden. Journal of Cleaner Production, v.81, p.34-45, 2014.

POYNER, J.R.; SIMON, M. Integration of DfE tools with product development. CONCEPT - Clean Electronics Products and Technology. Edinburgh: IEE. p.54$59,1995$.

PRASAD, B. Concurrent engineering fundamentals: integrated product and process organization. New Jersey, Prentice Hall International Series, v.1, 1996.

PRASAD, B. Concurrent engineering fundamentals: integrated product and process organization. New Jersey, Prentice Hall International Series, v.2, 1997.

PRASAD, S.; TATA, J. Publication patterns concerning the role of teams/groups in the information systems literature from 1990 to 1999. Information \& Management. v.42, n.8, p.1137-1148, 2005.

PRASNIKAR, J.; SKERLJ, T. New product development process and time-to-market in the generic pharmaceutical industry. Industrial Marketing Management, v.35, p.690-702, 2006.

PRÉ CONSULTANTS. Eco-indicator 99 Manual for Designers. Ministry of Housing, Spatial Planning and the Environment, The Hague, The Netherlands, 2000.

PUGH, S. Total design: integrated methods for successful product engineering. Addison Wesley Pub. Co., 1991.

PUJARI, D. Eco-innovation and new product development: understanding the influences on market performance. Technovation, v.26, n.1, p.76-85, 2006.

PULIDO, M.T.; VALVERDE, T.; CABALLERO, J. Variation in the population dynamics of the palm Sabal yapa in a landscape shaped by shifting cultivation in the Yucatan Peninsula, Mexico. Journal of Tropical Ecology, v.23, p.139-149, 2007.

QIAN, X.; YU, Y.; ZHANG, H.C. A semi-quantitative methodology of environmentally conscious design for electromechanical products. International Symposium on Electronics and the Environment . [S.I.]: [s.n.] p.156-160, 2001.

RAFFO, D.M.; KELLNER, M.I. Empirical analysis in software process simulation modeling. Journal of Systems and Software, v.53, n.1, p.31-41, 2000. 
RAMANI, K.; RAMANUJAN, D.; BERNSTEIN, W.Z.; ZHAO, F.; SUTHERLAND, J.; HANDWERKER, C.; CHOI, J.; KIM, H.; THURSTON, D. Integrated Sustainable Life Cycle Design: A Review. Journal of Mechanical Design, v.132, n.9, 2010.

RAMESH, B.; TIWANA, A. Supporting collaborative process knowledge management in new product development teams. Decision Support Systems, v.27, n.1/2, p.213235, 1999.

RAUSAND, M.; UTNE, I.B. Product safety - Principles and practices in a life cycle perspective. Safety Science, v.47, n.7, p.939-947, 2009.

RAYMOND, C.M.; FAZEY, I.; REED, M.S.; STRINGER, L.C.; ROBINSON, G.M.; EVELY, A.C. Integrating local and scientific knowledge for environmental management. Journal of Environmental Management, v.91, n.8, p.1766-1777, 2010.

RAZAVIAN, M.; KHOSRAVI, R. Modeling variability in business process models using UML. 5th International Conference on Information Technology - New Generations, Las Vegas, NV, Apr, p.82-87, 2008.

REBITZER, G. Integrating Life Cycle Costing and Life Cycle Assessment for Managing Costs and Environmental Impacts in Supply Chains. In: Seuring, S.; Goldbach, M.: Cost Management in Supply Chains. Berlin: Springer Verlag (Physica), p.128-146, 2002.

REBITZER, G.; EKVALL, T.; FRISCHKNECHT, R.; HUNKELER, D.; NORRIS, G.; RYDBERG, T.; SCHMIDT, W.P.; SUH, S.; WEIDEMAI, B.P.; PENNINGTON, D.W. Life cycle assessment. Part 1: Framework, goal and scope definition, inventory analysis, and applications. Environment International, v.30, n.5, p.701-720, 2004.

REBITZER, G.; HUNKELER, D.; JOLLIET, O. LCC - The economic pillar of sustainability: Methodology and application to wastewater treatment. Environmental Progress, v.22, n.4, p.241-249, 2003.

RENNINGS, K.; ZIEGLER, A.; ANKELE, K. The influence of different characteristics of the EU environmental management and auditing scheme on technical environmental innovations and economic performance. Ecological Economics, v.57, n.1, p.45-59, 2006.

REZAYAT, M. The Enterprise-Web portal for life-cycle support. Computer-Aided Design, v.32, n.2, p.85-96, 2000.

ROBICHAUD, L.B., ANANTATMULA, V.S. Greening project management practices for sustainable construction. Journal of Management Engineering, v.27, p.48-57, 2011.

ROGERS, W.M.; SCHIMITI, M.; MULLINS, M. E. Correction for unreliability of multifactor measures: comparison of Alpha and parallel forms approaches. Organizational Research Methods, v.5, p.184-199, 2002. 
ROMANO, L.N. Modelo de referência para o processo de desenvolvimento de máquinas agrícolas. Tese (Doutorado). Universidade Federal de Santa Catarina. Florianópolis/SC, 2003.

ROOZENBURG, N.F.M; EEKELS, J. Product design: fundamentals and methods. New York: John Wiley, xiii, p.408, 1995.

ROSENSTROM, U.; KYLLONEN, S. Impacts of a participatory approach to developing national level sustainable development indicators in Finland. Journal of Environmental Management, v.84, n.3, p.282-298, 2007.

ROSENTHAL, S.R. Effective Product Design and Development - How to cut lead time and increase customer satisfaction. New York, N.Y. Irwin Professional Publishing, 1992.

ROUIBAH, K.; OULD-ALI, S. Dynamic data sharing and security in a collaborative product definition management system. Robotics and Computer-Integrated Manufacturing, v.23, n.2, p.217-233, 2007.

ROY, P.; NEI, D.; ORIKASA, T.; XU, Q.; OKADOME, H.; NAKAMURA, N.; SHIINA, T. A review of life cycle assessment (LCA) on some food products. Journal of Food Engineering, v.90, n.1, p.1-10, 2009.

ROZENFELD, H.; FORCELLINI, F.A.; AMARAL, D.C.; TOLEDO, J.C.; SILVA, S.L.; ALLIPRANDINI, D.H.; SCALICE, R.K. Gestão de Desenvolvimento de Produtos: uma referência para a melhoria do processo. São Paulo: Saraiva, 2006.

RUDDER, A.; AINSWORTH, P.; HOLGATE D. Case study - New food product development: strategies for success? British Food Journal, v.103, n.9, p.657-670, 2001.

RUDOLPH, M.J. The food product development process. British Food Journal, v.97, n.3, p.3-11, 1995.

SAKAO, T.; KANEKO, K.; MASUI, K.; TSUBAKI, H. Combinatorial usage of QFDE and LCA for Environmentally Conscious Design. The Grammar of Technology Development, 2005.

SAKAO, T.; MASUI, K.; KOBAYASHI, M.; AIZAWA, S. Quality function deployment for environment: QFDE (2nd report) - verifying the applicability by two case studies, 2001.

SALGADO, E.G. Modelo de referência para o processo de desenvolvimento de produtos eletrônicos em empresas de base tecnológica: estudos de casos múltiplos com decisão multicriterial. Tese (doutorado) - Universidade Estadual Paulista, Faculdade de Engenharia de Guaratinguetá, Guaratinguetá, p.183, 2011.

SALGADO, E.G.; SALOMON, V.A.P.; MELLO, C.H.P.; FASS, F.D.M.; XAVIER, A.F. Modelos de referência para desenvolvimento de produtos: classificação, análise e sugestões para pesquisas futuras. Revista Produção Online, v.10, n.4, p.886-911, 2010. 
SALMINEN, V.; YASSINE, AL; RIITAHUHTA, A. A strategic management framework for collaborative product development. 4th International Conference on Engineering Design and Automation, ED\&A in Orlando, Florida. July 30 - August $2,2000$.

SALVIONI, C. Feedback and communication: the central role of the user during all the life-cycle of a technical product. Case study from a higher education intranet system. International Multi-Conference on Society, Cybernetics and Informatics, Orlando, FL, Jul, p.42-47, 2007.

SANCHEZ, R.; MAHONEY, J.T. Modularity, flexibility and knowledge management in product and organization design. Strategic Management Journal, v.17, p.63-76, 1996.

SANDERSON, S.; UZUMERI, M. Managing product families - the case of the sonywalkman. Research Policy, v.24, n.5, p.761-782, 1995.

SANTIAGO, L.P.; BIFANO, T.G. Management of R\&D projects under uncertainty: A multidimensional approach to managerial flexibility. IEEE Transactions on Engineering Management, v.52, n.2, p.269-280, 2005.

SANTOS, A. Níveis de maturidade do design sustentável na dimensão ambiental. Cadernos de Estudos Avançados em Design, Barbacena, v.3, p.13-26, 2009.

SANTOS, A.C. Modelo de referência para o processo de desenvolvimento de produtos alimentícios - PDPA, com ênfase no projeto do processo. Dissertação (Engenharia Mecânica) - Centro Tecnológico, Universidade Federal de Santa Catarina, Florianópolis, p.164, 2004.

SANTOS, A.C. Modelo de referência para o processo de desenvolvimento de produtos em um ambiente SCM. Tese (Engenharia Mecânica) - Centro Tecnológico, Universidade Federal de Santa Catarina, Florianópolis, p.415, 2008.

SANTOS, M.V.; BASTOS, A.V.B. Redes sociais informais e compartilhamento de significados sobre mudança organizacional. RAE, v.47, n.3, p.27-39, 2007.

SAREN, M.A. A classification and review of models of the intra-firm innovation process. R\&D Management, v.14, n.1, p.11-24, 1984.

SCHATTEN, A. Green supply chains: using information integration for sustainable development. 3th International Conference on Complex, Intelligent and Software Intensive Systems, Fukuoka, Japan, Mar, v.1/2, p.1124-1127, 2009.

SCHILDT, H.A. Sitkis: Software for bibliometric data management and analysis. Helsinki: Institute of Strategy and International Business; v.6.1, 2002.

SCHILDT, H.A.; MATTSSON, J.T. A dense network sub-grouping algorithm for cocitation analysis and its implementation in the software tool Sitkis. Scientometrics, v.67, n.1, p.143-163, 2006. 
SCHILLBERG, S.; TWYMAN, R.M.; FISCHER, R. Opportunities for recombinant antigen and antibody expression in transgenic plants - technology assessment. Vaccine, v.23, n.15, p.1764-1769, 2005.

SCHISCHKE, K. A guide for EcoDesign tools. Berlin: Fraunhofer IZM, 2005.

SCHMID, K.; JOHN, I. A customizable approach to full lifecycle variability management. Science of Computer Programming, v.53, n.3, p.259-284, 2004.

SCHMIDT, J.B.; SARANGEE, K.R., MONTOYA, M.M. Exploring new product development project review practices. Journal of Product Innovation Management, v.26, n.5, p.520-535, 2009.

SCHMIDT, W.P.; BUTT, F. Life cycle tools within Ford of Europe's Product Sustainability Index - Case study ford S-MAX \& Ford Galaxy. International Journal of Life Cycle Assessment, v.11, n.5, p.315-326, 2006.

SCOTT, J. Social network analysis: a handbook. 2.ed. London: Thousands Oaks, Calif.: Sage Publications, p.208, 2000.

SELIGER, G.; KERNBAUM, S.; ZETTL, M. Remanufacturing approaches contributing to sustainable engineering. Gestão \& Produção, v.13, n.3, p.367-384, 2006.

SELLTZ, C. et al. Métodos de pesquisa nas relações sociais. São Paulo: EDUSP, 1975.

SENTHIL KUMARAN, D.; ONG, S.K.; TAN, B.H.R; NEE, A.Y.C. Environmental life cycle cost analysis of products. Environmental Management and Health, v.12, p.260-276, 2001.

SEURING, S.; MULLER, M. From a literature review to a conceptual framework for sustainable supply chain management. Journal of Cleaner Production, v.16, n.9, p.1699-1710, 2008.

SHAO, X.Y.; WU, J.; DENG, C.; LI, P.G.; FENG, C.X.J. A web-enabled collaborative quality management system. Journal of Manufacturing Systems, v.25, n.2, p.25107, 2006.

SHERWIN, C.; BHAMRA, T. Beyond Engineering: Ecodesign as a proactive approach to product innovation. In: First International Symposium on Environmentally Conscious Design and Inverse Manufacturing. Tokyo. IEEE Computer Society, February 1-3, p.41-46, 1999.

SHERWIN, C.; EVANS, S. Ecodesign innovation: is "early" always "best"? In International Symposium on Electronics and the Environment, p.112-117, 2000.

SHORT, T.; LEE-MORTIMER, A.; LUTTROPP, C.; JOHANSSON, G. Manufacturing, sustainability, ecodesign and risk: lessons learned from a study of Swedish and English companies. Journal of Cleaner Production, v.37, p.342-352, 2012.

SLACK, N.; CHAMBERS, T.; HARLAND, C.; HARRISON, A.; JOHNSTON, R. Administração da Produção. São Paulo, Editora Atlas, 1993. 
SMITH, G.C.; TATUM, J.D.; BELK, K.E.; SCANGA, J.A.; GRANDIN, T.; SOFOS, J.N. Traceability from a US perspective. Meat Science, v.71, n.1, p.174-193, 2005.

SONG, CS. Global challenges and strategies for control, conversion and utilization of CO2 for sustainable development involving energy, catalysis, adsorption and chemical processing. Catalysis Today, v.115, n.1/4, p.2-32, 2006.

SONG, J.H.; MURPHY, R.J.; NARAYAN, R.; DAVIES, G.B.H. Biodegradable and compostable alternatives to conventional plastics. Philosophical Transactions of the Royal Society B-biological Sciences, v.364, n.1526, p.2127-2139, 2009.

SONG, M.; NOH, J. Best new product development and management practices in the Korean high-tech industry. Industrial Marketing Management, v.35, n.3, p.262-278, 2006.

SOOSAY, C.; FEARNE, A.; DENT, B. Sustainable value chain analysis - a case study of Oxford Landing from vine to dine. Supply Chain Management an International Journal, v.17, n.1, p.68-77, 2012.

SORDI, J.S. Análise da coesão entre seções de textos de documentos extensos a partir da aplicação conjunta das técnicas de análise de redes sociais e referências internas. Perspectivas em Ciência da Informação, v.14, n.1, p.152-169, 2009.

SOUSA MENDES, G.H.; TOLEDO, J.C. Modelo de referência para as atividades de pré- desenvolvimento de produto em empresas de base tecnológica da indústria de equipamentos médico- hospitalares. VIII Congresso Brasileiro de Gestão de Desenvolvimento do Produto. Porto Alegre, RS, 2011.

SOUSA MENDES, G.H.; TOLEDO, J.C. Uma visão dos principais arranjos organizacionais aplicados ao desenvolvimento de produto. IV Congresso Brasileiro de Gestão de Desenvolvimento do Produto. Gramado, RS, 2003.

SOUZA, J.F. Aplicação de projeto para manufatura e montagem em uma abordagem de engenharia reversa: estudo de caso. 2007. 135 f. Dissertação (Mestrado em Engenharia de Produção) - Universidade Federal de Itajubá, Itajubá, 2007.

SOUZA, P.F.D.; PEREIRA, H.B.D. Towards indicators of sustainable product design. IEEE International Engineering Management Conference, Salvador, Brazil, Sep, p.274-277, 2006.

SPENCE, R. Risk and regulation: can improved government action reduce the impacts of natural disasters? Building Research and Information, v.32, n.5, p.391402, 2004.

SPICER, A.; WANG, M.H. Environmental Design Industrial Template (EDIT): a software tool for analysis of product retirement. Journal of Cleaner Production, v.5, n.3, p.193-198, 1997.

STEVELS, A. Integration of EcoDesign into Business, A New Challenge. In: First International Symposium on Environmentally Conscious Design and Inverse Manufacturing. Tokyo. February 1-3, 1999. IEEE Computer Society. p.27-32, 1999. 
STEVELS, A. Moving companies towards sustainability through eco-design: conditions for success. Journal of Sustainable Product Design, v.3, p.47-55, 1997.

STEVELS, A.L.N. Application of EcoDesign: Ten Years of Dynamic Development. 2nd International Symposium on Environmentally Conscious Design and Inverse Manufacturing (EcoDesign'01), IEEE, p.905, 2001.Stevels, A. L. N. Adventures in EcoDesign of Electronic Products - 1993-2007. Delft University of Technology, The Netherlands, 2007.

STRATFUL, I.; BRETT, S.; SCRIMSHAW, M.D. Biological phosphorus removal, its role in phosphorus recycling. Environmental Technology, v.20, n.7, p.681-695, 1999.

STUMPF, A.L.; GANESHAN, R.; CHIN, S.Y. Object-oriented model for integrating construction product and process information. Journal of Computing in Civil Engineering, v.10, n.3, p.204-212, 1996.

SUBRAMONIAM, R.; HUISINGH, D.; CHINNAM, R.B. Remanufacturing for the automotive aftermarket-strategic factors: literature review and future research needs. Journal of Cleaner Production, v.17, n.13, p.1163-1174, 2009.

SUH, N.P. The principles of design. New York: Oxford Press, 1988.

SUN, J.; HAN, B.; EKWARO-OSIRE, S.; ZHANG, H.C. Design-for-Environment: Methodologies, Tools, and Implementation, Integrated Design and Process Technology, Austin, Texas, p.375-386, 2003.

TAIFI, N. Collaborative knowledge networks - Lessons to learn from a large automotive company. Joint Conference of the International-Federation-forInformation-Processing Working Group. 3rd International Summer School on the Future of Identity in the Information Society, Karlstad, Sweden, Aug 2007, p.423-429, 2008.

TAKEUCHI, H.; NONAKA, I. The new new product development game. Harvard Business Review, v.64, n.1, p.137-146, 1986.

TANG, D.B.; QIAN, X.M. Product lifecycle management for automotive development focusing on supplier integration. Computers in Industry, v.59, n.2/3, p.288-295, 2008.

TAO, L.; PROBERT, D.; PHAAL, R. Towards an integrated framework for managing the process of innovation. R\&D Management, v.40, n.1, p.19-30, 2010.

TELENKO, C. Developing green design guidelines: A formal method and case study. Thesis, The University of Texas at Austin December, p.231, 2009.

TELENKO, C.; SEEPERSAD, C.C.; WEBBER, M.E. A compilation of design for environment principles and guidelines. ASME 2008, International Design Engineering Technical Conferences \& Computers and Information in Engineering Conference August 3-6, 2008, New York, New York, USA, 2008. 
TEODOSIU, C.; BARJOVEANU, G.; ROBU, B.; ENE, S. Sustainability in the water use cycle: challenges in the Romanian context. Environmental Engineering and Management Journal, v.11, n.11, p.1987-2000, 2012.

TERVONEN, T.; LINKOV, I.; FIGUEIRA, J.R.; STEEVENS, J.; CHAPPELL, M.; MERAD, M. Risk-based classification system of nanomaterials. Journal of Nanoparticle Research, v.11, n.4, p.757-766, 2009.

THEYEL, G. Management practices for environmental innovation and performance. International Journal of Operations \& Production Management, v.20, n.2, p.249266, 2000.

THOMKE, S.H.; NIMGADE, A. IDEO Product Development. Harvard Business School Case, 600-143, p.1-21, June 2000. (Revised April 2007.)

THOMPSON, R.C.; MOORE, C.J.; VOM SAAL, F.S.; SWAN, S.H. Plastics, the environment and human health: current consensus and future trends. Philosophical Transactions of the Royal Society B-biological Sciences, v.364, n.1526, p.21532166, 2009.

TIDD, J.; BESSANT, J.; PAVITT, K. Gestão da inovação. 3. ed. Porto Alegre: Bookman, 2008.

TILCHE, A.; GALATOLA, M. The potential of bio-methane as bio-fuel/bio-energy for reducing greenhouse gas emissions: a qualitative assessment for Europe in a life cycle perspective. Water Science and Technology, v.57, n.11, p.1683-1692, 2008.

TINGSTROM, J.; SWANSTROM, L.; KARLSSON, R. Sustainability management in product development projects - the ABB experience. Journal of Cleaner Production, v.14, n.15/16, p.1377-1385, 2006.

TISCHNER, U.; CHARTER, M. Sustainable product design. In Charter, $M$ and Tischner, U. (eds.) Sustainable solutions: developing products and services for the future. Sheffield, UK: Greenleaf Publishing, p.118-138, 2001.

TISCHNER, U.; NICKEL, R. Eco-design in the printing industry, Lifecycle thinking: Implementation of eco-design concepts and tools into the routine procedures of companies. The Journal of Sustainable Product Design, v.3, p.19-27, 2003.

TISCHNER, U.; SCHMINCKE, E.; RUBIK, F.; PROSLER, M. How to Do Ecodesign?: A Guide for Environmentally and Economically Sound Design, Edited by the German Federal Environmental Agency, Verlag form (Praxis), Art Books Intl Ltd (2000).

TOLEDO, J.C.; ALLIPRANDINI, D.H.; FERRARI, F.M.; MARTINS, M.F.; MARTINS, R.A.; SILVA, S.L. A gestão do desenvolvimento de produtos na indústria brasileira de autopeças. Relatório de Pesquisa Fapesp. Grupo de Estudo e Pesquisa em Qualidade. DEP/ UFSCar, 2002.

TOMOVIC, C.; ANDERSON, H.; ANGLIN, A.; BARRETO, L.V.; FRILLMAN, S.A.; GEORGIADES, T.J.; HOMAN, S.R.; KOCHERT, J.F.; LECH, M.B.; SUKUP, J.E.; WILDE, K.L.; WISMA, M. Social issues of product lifecycle management: 
developing cross cultural virtual teams; supporting today's green manufacturing imperative; educating and preparing tomorrow's workforce; and impacting inter-organizational relationships in supply chain management. International Conference on Comprehensive Product Realization, Beijing, China, Jun, p.135-167, 2009.

TUGNOLI, A.; LANDUCCI, G.; COZZANI, V. Sustainability assessment of hydrogen production by steam reforming. International Journal of Hydrogen Energy, v.33, n.16, p.4345-4357, 2008.

TZOKAS, N., HULTINK, E.J., HART, S. Navigating the new product development process. Industrial Marketing Management, v.33, n.7, p.619-626, 2004.

UENO, K.; TAKAHASHI, T.; OYAMA, T.; SHIMAMURA, K.; MATSUMOTO, T.; HASEBE, Y. Efforts to improve the eco-efficiency for products of Mitsubishi Electric Corporation-factor $\mathbf{x}$ by using MET indicators. Proceedings EcoDesign 2001: Second International Symposium on Environmentally Conscious Design and Inverse Manufacturing . [S.I.]: [s.n.], p.836-841, 2001.

UHLIN, H.E. Why energy productivity is increasing: An I-O analysis of Swedish agriculture. Agricultural Systems, v.56, n.4, p.443-465, 1998.

ULRICH, K. The role of product architecture in the manufacturing firm. Research Policy, v.24, n.3, p.419-440, 1995.

ULRICH, K.T.; EPPINGER, S.D. Product design and development. New York: McGraw Hill/Irwin, p.368, 2007.

UNGER, D.W. Product development process design: improving development response to market, technical, and regulatory risks. Massachussetts, 2003. $205 \mathrm{f}$. Thesis (Doutorate in Engineering) - Technology Management and Policy Program, Massachussetts Institute of Technology, 2003.

UNITED NATIONS ENVIRONMENT PROGRAMME (UNEP). The role of product service systems in a sustainable society. Disponível em: <http://www.unep.fr/scp/design/pdf/pssbrochure-final.pdf>. Acesso em: 20 set., 2008.

URBAN, G.L.; HAUSER, J.R. Design and Marketing of New Products. 2E, Prentice-Hall, Second Edition, 1993.

VACHON, S.; KLASSEN, R.D. Environmental management and manufacturing performance: The role of collaboration in the supply chain. International Journal of Production Economics, v.111, n.2, p.299-315, 2008.

VAN BERKEL, R. Eco-efficiency in primary metals production: context, perspectives and methods. Resources Conservation and Recycling, v.51, n.3, p.511-540, 2007.

VAN DER WERF, H.M.G.; TZILIVAKIS, J; LEWIS, K. Environmental impacts of farm scenarios according to five assessment methods. Agriculture Ecosystems \& Environment, v.118, n.1-4, p.327-338, 2007. 
VAN DER ZWAN, F.; BHAMRA, T. Alternative Function Fulfilment: incorporating environmental considerations into increased design space, Journal of Cleaner Production, v.11, n.8, p.897-903, 2003.

VAN HEMEL, C.G. Ecodesign Empirically Explored. Design for Environment in Dutch Small and Medium Sized Enterprises. Design for Sustainability Research Programme, Delft University of Technology, Delft, the Netherlands, 1998.

VAN HEMEL, C.G. Tools for Setting Realizable Priorities at Strategic Level in Design for Environment. Proceedings of the 10th International Conference on Engineering Design (ICED'95) Prague, p.1040-1047, 1995.

VANZ, S.A.S.; CAREGNATO, S. E. Estudos de citação: uma ferramenta para entender a comunicação científica. Em Questão, Porto Alegre, v.9, n.2, p.295-307, jul./dez., 2003.

VARANDAS, A.J; MIGUEL, P.A.C. Análise do processo de preparação da produção no desenvolvimento de novos produtos por meio de um estudo de caso em uma empresa do setor siderúrgico. Produção, v.22, n.2, p.185-200, 2012.

VDI 2221. Methodik zum Entwickeln und Konstruieren Technischer Systeme und Produkte, 1985.

VENZKE, C.A Situação do Ecodesign em Empresas Moveleiras da Região de Bento Gonçalves - RS: Análise das Posturas e Práticas Ambientais. Porto Alegre, 2002. Dissertação - (Mestrado em Administração), Programa de Pós-graduação em Administração, UFRGS, 2002.

VERCALSTEREN, A. Integrating the ecodesign concept in small and medium-sized enterprises, experiences in the Flemish region of Belgium, Environmental Management and Health, v.12, n.4, p.347-355, 2001.

VERGHESE, K.L.; HORNE, R.; CARRE, A. PIQET: the design and development of an online 'streamlined' LCA tool for sustainable packaging design decision support. International Journal of Life Cycle Assessment, v.15, n.6, p.608-620, 2010.

VESHAGH, A.; OBAGUN, A. Survey of sustainable life cycle design and management. 14th CIRP Conference on Life Cycle Engineering, Tokyo, Japan, Jun, p.237-242, 2007.

VEZZOLI, C.; SCIAMA, D. Life cycle design: from general methods to product type specific guidelines and checklists: a method adopted to develop a set of guidelines/checklist handbook for the eco-efficient design of NECTA vending machines. Journal of Cleaner Production, v.14, n.15/16, p.1319-1325, 2006.

VIEGAS, J.C.; SALLES, M.T. A sustentabilidade em projetos de produto: uma abordagem ambiental, VIII Congresso Nacional de Excelência em Gestão, junho, 2012.

VINODH, S., RATHOD, G. Integration of ECQFD and LCA for sustainable product design. Journal of Cleaner Production Research, v.37, p.1075-1091, 2009. 
WAAGE, S.A. Re-considering product design: a practical "road-map" for integration of sustainability issues. Journal of Cleaner Production, v.15, n.7, p.638-649, 2007.

WACKER, J.G. A Theory of Formal Conceptual Definition: Developing Theorybuilding Measurement Instruments. Journal of Operations Management, v.22, p.629-650, 2004.

WACKERNAGEL, M.; REES, W.E. Our ecological footprint - Reducing human impact on the Earth. Environment and Urbanization, v.8, n.2, p.216-216, 1996.

WANG, D.J. et al. Measurement error in network data: a re-classification. Social Networks, v.34, p.396-409, 2012.

WANG, R.Y.; LEE, Y.W.; PIPINO, L.L. Manage your information as a product. Sloan Management Review, v.39, n.4, p.95, 1998.

WANG, S.Y.; CHANG, S.L.; WANG, R.C. Assessment of supplier performance based on product-development strategy by applying multi-granularity linguistic term sets. Omega-International Journal of Management Science, v.37, n.1, p.215-226, 2009.

WASSERMAN, S.; FAUST, K. Social Network Analysis: Methods and Applications. Cambridge, ENG and New York: Cambridge University Pres, 1994.

WEENEN, J.C. Towards sustainable product development. Journal of Cleaner Production, v.3, n.1/2, p.95-100, 1995.

WICKE, B; DORNBURG, V; JUNGINGER, M. Different palm oil production systems for energy purposes and their greenhouse gas implications. Biomass \& Bioenergy, v.32, n.12, p.1322-1337, 2008.

WILLEMS, B.; SELIGER, G.; DUFLOU, J.; BASDERE, B. Contribution to design for adaptation: method to assess the adaptability of products (MAAP). Proceedings of EcoDesign 2003: Third International Symposium on Environmentally Conscious Design and Inverse Manufacturing, Tokyo, Japan, December 8-11, p.589596, 2003.

WIMMER, W. The ecodesign cheklist method. In: HUNDAL, M. S. Mechanical life cycle handbook: good environmental design and manufacturing. New York: Marcel Dekker, Inc., 2002.

WIMMER, W.; ZUST, R.; LEE, K.M. Ecodesign implementation: a systematic guidance on integrating environmental considerations into product development. Springer, Heidelberg, 2004.

WRISBERG N.; UDO DE HAES, H.A.; TRIEBSWETTER, U.; EDER, P.; CLIFT, R.; (eds.). Analytical Tools for Environmental Design and Management in a Systems Perspective. The Combined Use of Analytical Tools, Dordrecht, Kluwer Academic Publishers. ISBN 0-4020-0626-8, 2002.

WU, Z.; PAGELL, M. Balancing priorities: Decision-making in sustainable supply chain management. Journal of Operations Management, v.29, n.6, p.577-590, 2011. 
XIE, S.Q.; HUANG, H.; TU, Y.L. A www-based information management system for rapid and integrated mould product development. International Journal of Advanced Manufacturing Technology, v.20, n.1, p.50-57, 2002.

YANG, Q.Z.; MIAO, C.Y.; ZHANG, Y.; GAY, R. LCA and LCC data semantics sharing across product lifecycle processes. 13th ISPE International Conference on Concurrent Engineering, Antibes, France, Sep, v.143, p.190-197, 2006.

YARWOOD, J.M.; EAGAN, P.D. Design for the Environment - Toolkit. Minnesota Office of Environmental Assistance. Minnesota, p.72, 1998.

YEH, T.M.; PAI, F.Y; YANG, C.C. Performance improvement in new product development with effective tools and techniques adoption for high-tech industries. Quality and Quantity, v.44, n.1, p.131-152, 2010.

YU, S.Y.; ZHANG, H.C.; ERTAS, A. Environmental Conscious Design: An Introduction To EDST. Journal of Integrated Design and Process Science, v.3, n.4, p.27-38, 1999.

ZANCUL, E.S. Gestão do ciclo de vida de produtos: seleção de sistemas PLM com base em modelos de referência. Tese de Doutorado. Escola de Engenharia de São Carlos da Universidade de São Paulo, p.227, 2009.

ZHANG, H.J.; HUANG, H.W. Reverse logistics system of waste electronic and electric equipment. International Conference on Management of Logistics, Sydney, Australia, Sep, p.212-218, 2006. 


\section{GLOSSÁRIO}

Análise bibliométrica - É um campo da ciência da informação, que infere sobre a produção bibliográfica de um determinado autor, grupo de pesquisa, instituição, localização geográfica, campo de pesquisa, ou área do conhecimento, tentando assim medir a sua produtividade e criar métodos de comparação entre eles.

Análise de rede social - Pode ser considerada uma análise bibliométrica, porém essa análise emprega os conceitos de atores e os relacionamentos, que são as transações, interações e conexões entre eles.

Aspecto ambiental - Todas as estratégias, princípios e práticas gerenciais e operacionais de ecodesign que visam integrar preocupações ambientais no PDP e processos relacionados, considerando o impacto ambiental durante todo o ciclo de vida do produto.

Atividade do PDP - As atividades são agrupadas por tipo e são subdivisões das fases do PDP, portanto estão num nível hierárquico inferior as fases.

Benchmarking - É o processo contínuo de medição de produtos, serviços e práticas em relação aos mais fortes concorrentes, ou às empresas reconhecidas como líderes.

Ciclo de vida do produto - Estágios consecutivos e interligados de um sistema de produção, desde a aquisição de matéria-prima ou geração de recursos naturais até a disposição final, chamado também de do berço ao túmulo.

Design for Environment (DfE) - Seu propósito é minimizar o impacto ambiental do produto e de sua produção. Apresenta aspectos relacionados com o domínio de estratégias de marketing e política de decisões, num nível operacional relacionado ao domínio de projeto de produtos. Assemelha-se com conceitos de projeto para a sustentabilidade e toda a gama de ecoferramentas e Green Design.

Design for X (DfX) - "X" representa as habilidades ou características que são tratadas nas áreas relacionadas ao desenvolvimento de produtos (manufaturados, 
reciclagem, montagem etc.). Os métodos de DfX podem ser considerados um conjunto de regras e procedimentos, estabelecidos de forma organizada, para dar suporte a um determinado problema referente ao ciclo ou fase da vida de um produto nas áreas (projeto, manufatura, qualidade etc.) de uma companhia.

Desmaterialização do produto - Verifica se o produto pode utilizar matéria-prima de fácil separação e ter um uso compartilhado sobre existência de funções integradas e buscando otimizar o produto e seus componentes e permitindo a melhor utilização dos materiais e uso em novos tipos de materiais, como os reciclados.

Ecologia industrial - Considera o sistema industrial não apenas interage com o ambiente, mas é parte dele e dele depende.

End of pipe solution - soluções de fim de tubo que tratam dos resíduos gerados no final do processo produtivo.

Estrutura de PDP - É uma forma de sistematizar, documentar e padronizar o processo de desenvolvimento de produtos, para que ele possa ser integrado e utilizado pelos envolvidos no PDP.

Fase do PDP - As fases são divisões do PDP utilizadas para melhor operacionalização do processo e baseiam-se nos tipos de atividade e numa seqüência lógica de entradas e saídas. Estão num nível hierárquico superior as atividades e servem para organizar as entregas das atividades por meio de critérios de passagem de fase (deliverables).

Gates - Termo em inglês que significa portão, sendo a passagem de uma fase para outra no PDP. Nos Gates são definidos critérios de avaliação para checar se cada requisito foi cumprido.

Gerenciamento do ciclo de vida do produto - Em inglês Product Lifecycle Management (PLM) é o processo de gerenciamento completo do ciclo de vida de um produto, desde a sua concepção, passando pelo desenvolvimento e manufatura, até a sua entrada em serviço operacional. Também, compreende a integração de pessoas, dados, processos e sistemas de negócio provendo um canal de informações sobre um produto para empresas e seus parceiros. 
ISO 14000 - Conjunto de normas para a padronização de sistemas de gestão ambiental.

Métodos e ferramentas de ecodesign - São todos os meios estruturados (instrumentos, melhores práticas, softwares, documentos de apoio, informações, diretrizes, estratégias, etc.) para lidar com aspectos ambientais durante o PDP.

Processo de Desenvolvimento de Produtos (PDP) - Pode ser definido como um conjunto de atividades, em que a organização transforma dados sobre oportunidades de mercado e possibilidades técnicas em bens e informações para a fabricação de um produto comercial, abrangendo todas as áreas de uma empresa, desde as funções de marketing, engenharia de produto, produção, podendo incluir também as atividades de planejamento estratégico, de acompanhamento da produção e a descontinuidade do produto no mercado.

Produção mais limpa - É a aplicação contínua de uma estratégia integrada de prevenção ambiental a processos, produtos e serviços, para aumentar a eficiência de produção e reduzir os riscos para o ser humano e o ambiente.

Produto ecoeficiente - É aquele que ao longo de todo seu ciclo de vida reduz os impactos ambientais adversos, uma vez que aumenta a conservação dos recursos naturais.

Rede social - É constituída por conjunto de atores (nós da rede) que se relacionam (traços entre si) e visa comunicação, troca e ajuda mútua, emerge a partir de interesses compartilhados e de situações vivenciadas.

Sitkis - É um software que serve para importação e depuração (correção de erros) dos dados salvos em arquivo de texto do ISI Web of Knowledge.

Sustentabilidade ambiental - É um ideal sistemático que se perfaz principalmente pela ação, e pela constante busca entre desenvolvimento econômico e ao mesmo tempo preservação do ecossistema. Além disso, a adoção das medidas que dêem sustentação ambiental garante, tanto no presente quanto no futuro, um planeta em boas condições para o desenvolvimento das diversas formas de vida garantindo a manutenção dos recursos naturais necessários para as próximas gerações. 
Tarefa do PDP - As tarefas são o nível mais baixo da estrutura do PDP e se concentra na elaboração das informações, utilização de recursos e aplicação de técnicas, métodos e ferramentas de apoio para desenvolver as atividades.

Triple bottom line - Termo conhecido como tripé da sustentabilidade ou 3Ps (People, Planet, Profit) que corresponde aos resultados de uma organização medidos em termos sociais, ambientais e econômicos. Esse conceito foi criado por John Elkington, o qual define que para ser sustentável uma organização deve ser financeiramente viável, socialmente justo e ambientalmente responsável.

Ucinet - Esse software auxilia na elaboração de matrizes e mapas gráficos das redes de trabalhos mais citados, referências, co-citações, citações cruzadas, palavras-chaves e temas correlatos, englobando um conjunto de técnicas para análise de redes sociais.

Varredura horizontal - É uma técnica de busca bibliográfica ampla sobre os conceitos relacionados à inquietação de pesquisa visando identificar de quais teorias pode-se partir ao abordar um fenômeno, termo conhecido como "literature research".

Varredura vertical - É uma técnica de busca bibliográfica mais focada e com profundidade sobre o conceito selecionado, termo conhecido como "literature review". 


\section{APÊNDICE I - Codificação da classificação dos trabalhos sobre Product Life Cycle Management (PLM), Product Development Process (PDP) e Environmental Sustainability (ES)}

\begin{tabular}{c|l}
\hline \multicolumn{2}{c}{ T1 - Tipo de Estudo } \\
\hline MO & Modelagem \\
\hline TC & Teórico - Conceitual \\
\hline RL & Revisão da Literatura \\
\hline SI & Simulação \\
\hline SU & Survey \\
\hline EC & Estudo de Caso \\
\hline PA & Pesquisa - Ação \\
\hline EX & Experimental \\
\hline
\end{tabular}

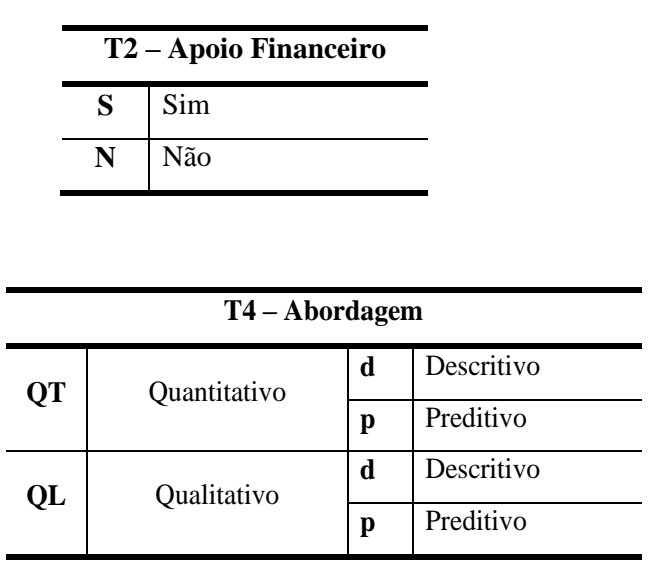

\begin{tabular}{c|l}
\hline \multicolumn{2}{c}{ T3 - Período de Análise } \\
\hline LO & Longitudinal \\
\hline RE & Retrospectivo \\
\hline AT & Atual \\
\hline
\end{tabular}

\begin{tabular}{c|l}
\hline \multicolumn{2}{c}{ T6 - Unidade de Análise } \\
\hline PE & Pessoas \\
\hline GR & Grupos \\
\hline UO & Unidade Organizacional \\
\hline EM & Empresas \\
\hline
\end{tabular}

\begin{tabular}{c|l}
\hline \multicolumn{2}{c}{ T7 - Documentação } \\
\hline QU & Questionário \\
\hline EN & Entrevistas \\
\hline AD & Análise Documental \\
\hline DP & Dados Públicos \\
\hline BI & Revisão \\
& Bibliográfica \\
\hline OB & Observação \\
\hline
\end{tabular}

\begin{tabular}{l|l}
\hline \multicolumn{2}{|c}{ T8 - Aplicação } \\
\hline $\mathbf{A 1}$ & Ambientes complexos \\
\hline $\mathbf{A 2}$ & Cadeia de demanda \\
\hline $\mathbf{A 3}$ & Cadeia de suprimentos \\
\hline $\mathbf{A 4}$ & Co-desenvolvimento \\
\hline $\mathbf{A 5}$ & $\begin{array}{l}\text { Processo de Desenvolvimento de } \\
\end{array}$ \\
\hline $\mathbf{A 6}$ & Produto \\
\hline $\mathbf{A 7}$ & Softwaramas de educação \\
\hline $\mathbf{A 8}$ & Tecnologia \\
\hline
\end{tabular}

\begin{tabular}{l|l}
\hline \multicolumn{2}{|c}{ T9 - Benefícios } \\
\hline B1 & Alinhamento \\
\hline B2 & Desempenho \\
\hline B3 & Integrar informações \\
\hline B4 & Melhorar o controle e planejamento \\
\hline B5 & Metodologia \\
\hline B6 & Sustentabilidade \\
\hline B7 & Tomada de decisão \\
\hline
\end{tabular}

\begin{tabular}{c|l}
\hline \multicolumn{1}{c}{ T10 - Conceitos } \\
\hline C1 & Sustentabilidade \\
\hline C2 & $\begin{array}{l}\text { Product Development Process } \\
\text { (PDP) }\end{array}$ \\
\hline C3 & $\begin{array}{l}\text { Product Life Cycle Management } \\
\text { (PLM) }\end{array}$ \\
\hline
\end{tabular}

\begin{tabular}{c|l}
\hline \multicolumn{2}{c}{ T5 - Abrangência Geográfica } \\
\hline RE & Regional \\
\hline NA & Nacional \\
\hline IN & Internacional \\
\hline
\end{tabular}




\section{APÊNDICE II - Apresentação dos trabalhos codificados em ordem alfabética}

T1: tipo de estudo; T2: apoio financeiro; T3: período de análise; T4: abordagens; T5: abrangência geográfica; T6: unidade de análise; T7: documentação; T8: aplicação; T9: benefícios; T10: conceitos.

\begin{tabular}{|c|c|c|c|c|c|c|c|c|c|c|}
\hline \begin{tabular}{|c|} 
Artigos \\
\end{tabular} & T1 & T2 & T3 & T4 & T5 & T6 & T7 & T8 & T9 & T10 \\
\hline Aurich; Schweitzer; Fuchs (2007) & $\mathrm{EC}$ & $\mathrm{S}$ & $\mathrm{RE}$ & $\mathrm{QL} / \mathrm{d}$ & NA & EM & $A D$ & $\mathrm{~A} 1$ & B6 & $\mathrm{C} 1 / \mathrm{C} 3$ \\
\hline $\begin{array}{l}\text { Baccile; Babonneau; Thomas; } \\
\text { Coradin (2009) }\end{array}$ & $R L$ & $\mathrm{~N}$ & $\mathrm{RE}$ & QL/d & NA & GR & $\mathrm{BI}$ & A5 & B2 & $\mathrm{C} 1 / \mathrm{C} 2$ \\
\hline Barry; Kemerer; Slaughter (2006) & $\mathrm{MO}$ & $\mathrm{S}$ & LO & QT/d & NA & EM & $\mathrm{OB} / \mathrm{AD} / \mathrm{BI}$ & A7 & B7 & $\mathrm{C} 1 / \mathrm{C} 3$ \\
\hline $\begin{array}{l}\text { Belkadi; Troussier; Huet; Gidel; } \\
\text { Bonjour; Eynard (2008) }\end{array}$ & EC & $\mathrm{N}$ & AT & QL/d & NA & EM & $\mathrm{AD} / \mathrm{BI}$ & A3 & B2 & C3 \\
\hline Ben Mahmoud-Jouini; Lenfle (2010) & EC & $\mathrm{N}$ & RE & QL/d & NA & EM & EN/AD & $\mathrm{A} 1$ & B2 & C3 \\
\hline $\begin{array}{l}\text { Bergea; Karlsson; Hedlund-Astrom; } \\
\text { Jacobsson; Luttropp (2006) }\end{array}$ & TC & $\mathrm{N}$ & $\mathrm{RE}$ & QL/d & NA & UO & OB & A5 & B5 & $\mathrm{C} 1 / \mathrm{C} 2$ \\
\hline $\begin{array}{l}\text { Bertolini; Colacino; Delnevo; Petroni } \\
(2007)\end{array}$ & SU/EC & S & $\mathrm{RE}$ & $\mathrm{QT} / \mathrm{d}$ & NA & EM & QU/EN & $\mathrm{A} 1$ & B7 & $\mathrm{C} 2$ \\
\hline Bidokhti (2008) & TC & $\mathrm{N}$ & $\mathrm{RE}$ & QL/d & NA & EM & $A D$ & A5 & $\mathrm{B} 2$ & $\mathrm{C} 3$ \\
\hline Bordoloi; Guerrero (2008) & TC & $\mathrm{N}$ & AT & $\mathrm{QL} / \mathrm{d}$ & NA & EM & $\mathrm{BI}$ & A7 & B3 & C3 \\
\hline Broy (2009) & MO & $\mathrm{N}$ & AT & $\mathrm{QL} / \mathrm{d}$ & NA & EM & \begin{tabular}{|l|}
$\mathrm{AD} / \mathrm{BI}$ \\
\end{tabular} & A5 & B3 & C3 \\
\hline Buganza; Verganti (2006) & EC/SU & $\mathrm{N}$ & RE & QT-QL/d & NA & EM & $\begin{array}{c}\text { QU/EN/AD } \\
/ O B\end{array}$ & $\mathrm{~A} 1$ & B2 & $\mathrm{C} 2$ \\
\hline Cebon; Hauptman; Shekhar (2008) & $\mathrm{TC}$ & $S$ & AT & QL/d & $\mathbb{N}$ & EM & $\mathrm{BI}$ & $\mathrm{A} 1$ & B2 & $\mathrm{C} 2 / \mathrm{C} 3$ \\
\hline Chang; Cheng; Wang (2007) & $\mathrm{EC}$ & $\mathrm{S}$ & $\mathrm{RE}$ & QL/d & NA & EM & $\mathrm{BI}$ & A1 & $\mathrm{B} 2$ & $\mathrm{C} 2 / \mathrm{C} 3$ \\
\hline Ciolkowski; Soto (2008) & $\mathrm{EC} / \mathrm{MO}$ & $\mathrm{S}$ & LO & $\mathrm{QL} / \mathrm{d}$ & NA & EM & EN & $\mathrm{A} 1$ & B5 & $\mathrm{C} 1 / \mathrm{C} 3$ \\
\hline Cooper; Godwin; Hall (2008) & MO & $\mathrm{N}$ & AT & $\mathrm{QL} / \mathrm{d}$ & NA & EM & $\mathrm{BI}$ & A7 & B7 & $\mathrm{C} 2 / \mathrm{C} 3$ \\
\hline Cooper (2007) & $\mathrm{TC}$ & $\mathrm{N}$ & $\mathrm{RE}$ & $\mathrm{QL} / \mathrm{d}$ & $\mathrm{RE}$ & UO & $\mathrm{DP}$ & A6 & B5 & $\mathrm{C} 1$ \\
\hline $\begin{array}{l}\text { Cordella; Tugnoli; Spadoni; } \\
\text { Santarelli; Zangrando (2008) }\end{array}$ & EC & $S$ & RE & $\mathrm{QT} / \mathrm{d}$ & NA & EM & $\mathrm{BV} / \mathrm{AD}$ & $\mathrm{A} 1$ & B2 & C1 \\
\hline Da Silva; Loubach; Cunha (2008) & $\mathrm{EC}$ & $\mathrm{S}$ & AT & QT/d & NA & GR & $\mathrm{BV} / \mathrm{AD}$ & A7 & B6 & $\mathrm{C} 2 / \mathrm{C} 3$ \\
\hline De Benedetto; Klemes (2009) & EC & $\mathrm{S}$ & $\mathrm{RE}$ & QT/d & NA & EM & $A D$ & $\mathrm{~A} 1$ & B7 & $\mathrm{C} 1 / \mathrm{C} 3$ \\
\hline Dehghanian; Mansour (2008) & $\mathrm{MO} / \mathrm{EC}$ & $\mathrm{N}$ & AT & QT/d & NA & EM & $\mathrm{AD} / \mathrm{BI}$ & A3 & B7 & $\mathrm{C} 1$ \\
\hline $\begin{array}{l}\text { Donnelly; Beckett-Furnell; Traeger; } \\
\text { Okrasinski; Holman (2006) }\end{array}$ & EC & $\mathrm{N}$ & RE & QL/d & NA & EM & $A D$ & A7 & B3 & $\mathrm{C} 1 / \mathrm{C} 2 / \mathrm{C} 3$ \\
\hline Ebert; De Man (2008) & $\mathrm{EC}$ & $\mathrm{N}$ & $\mathrm{RE}$ & $\mathrm{QL} / \mathrm{d}$ & NA & EM & $\mathrm{AD} / \mathrm{BI}$ & A5 & B5 & $\mathrm{C} 3$ \\
\hline Elghali; Clift; Begg; McLaren (2008) & $\mathrm{TC}$ & $\mathrm{N}$ & RE & QL/d & NA & EM & $\mathrm{BI}$ & $\mathrm{A} 1$ & B7 & $\mathrm{C} 1 / \mathrm{C} 2$ \\
\hline Eun; Son; Moon; Chung (2009) & $\mathrm{EC}$ & $\mathrm{N}$ & LO & QT/d & NA & UO & $\mathrm{BV} / \mathrm{AD}$ & A7 & B3 & $\mathrm{C} 1$ \\
\hline Fargnoli; Kimura (2006) & $\mathrm{SI}$ & $\mathrm{S}$ & LO & QT/d & NA & EM & $\mathrm{AD} / \mathrm{Bl} / \mathrm{DP}$ & A5 & B5 & $\mathrm{C} 1 / \mathrm{C} 2$ \\
\hline Fixson (2007) & $\mathrm{RL}$ & $\mathrm{N}$ & $\mathrm{RE}$ & $\mathrm{QL} / \mathrm{d}$ & NA & UO & $\mathrm{BI}$ & $\mathrm{A} 1$ & B5 & C3 \\
\hline Genaidy; Karwowski (2008) & $\mathrm{TC}$ & $\mathrm{N}$ & AT & $\mathrm{QL} / \mathrm{d}$ & NA & EM & $\mathrm{BI}$ & A8 & B6 & $\mathrm{C} 2 / \mathrm{C} 3$ \\
\hline Giudice; Ballisteri; Risitano (2009) & $\mathrm{MO} / \mathrm{EC}$ & $\mathrm{N}$ & AT & $\mathrm{QL} / \mathrm{d}$ & NA & UO & $A D$ & A7 & $\mathrm{B} 2$ & $\mathrm{C} 1 / \mathrm{C} 2$ \\
\hline Han; Do (2006) & MO & $\mathrm{N}$ & AT & QL/d & NA & EM & $\mathrm{OB} / \mathrm{AD} / \mathrm{BI}$ & A5 & B7 & $\mathrm{C} 2 / \mathrm{C} 3$ \\
\hline $\begin{array}{l}\text { Hauschild; Dreyer; Jorgensen } \\
(2008)\end{array}$ & $\mathrm{TC}$ & $\mathrm{N}$ & LO & QL/d & NA & EM & $\mathrm{BV} / \mathrm{AD}$ & A3 & B5 & $\mathrm{C} 1$ \\
\hline $\begin{array}{l}\text { Hobby; Rydell; Sjogren; Williams } \\
\text { (2009) }\end{array}$ & $\mathrm{TC}$ & $\mathrm{N}$ & AT & QL/d & NA & EM & $\mathrm{BI}$ & A8 & B2 & $\mathrm{C} 1$ \\
\hline Hochschorner; Finnveden (2006) & $\mathrm{EC}$ & $\mathrm{S}$ & $\mathrm{RE}$ & QT/d & NA & GR & EN & A8 & B6 & $\mathrm{C} 1$ \\
\hline Huang (2009) & $\mathrm{MO}$ & $\mathrm{N}$ & AT & $\mathrm{QL} / \mathrm{d}$ & $\mathbb{I N}$ & EM & $\mathrm{DP} / \mathrm{BI}$ & A7 & B6 & $\mathrm{C} 1 / \mathrm{C} 2$ \\
\hline $\begin{array}{l}\text { Jawahir; Rouch; Dillon; Holloway; } \\
\text { Hall (2007) }\end{array}$ & EC & $\mathrm{N}$ & $\mathrm{RE}$ & QL/d & NA & UO & $\mathrm{OB} / \mathrm{AD} / \mathrm{BI}$ & A6 & B5 & $\mathrm{C} 1 / \mathrm{C} 2$ \\
\hline Jiang; Zhang; Fu; Jiang (2008) & EC & $\mathrm{S}$ & AT & $\mathrm{QL} / \mathrm{d}$ & NA & EM & $\mathrm{AD} / \mathrm{BI}$ & A7 & B3 & C1 \\
\hline Joore (2008) & EC & $\mathrm{N}$ & $\mathrm{RE}$ & QL/d & NA & EM & EN/AD/OB & $\mathrm{A} 1$ & B5 & $\mathrm{C} 1 / \mathrm{C} 2$ \\
\hline Juttner; Godsell; Christopher (2006) & EC & S & $\mathrm{RE}$ & QL/d & NA & EM & EN/BV/AD & $\mathrm{A} 2$ & B1 & C3 \\
\hline $\begin{array}{l}\text { Kennedy; Siemieniuch; Sinclair; } \\
\text { Kirwan; Gibson (2007) }\end{array}$ & $\mathrm{EC}$ & $\mathrm{N}$ & RE & QL/d & NA & EM & QU/EN/AD & $\mathrm{A} 1$ & B5 & C2/C3 \\
\hline Khota; Pretorius (2008) & $\mathrm{TC}$ & $\mathrm{N}$ & AT & QL/d & NA & EM & $\mathrm{BI}$ & A5 & $\mathrm{B} 2$ & $\mathrm{C} 2$ \\
\hline Kim; Kim; Shin; Baik (2006) & $\mathrm{EC} / \mathrm{MO}$ & $\mathrm{S}$ & LO & QL/d & NA & EM & $\mathrm{AD} / \mathrm{BI}$ & $\mathrm{A} 1$ & B5 & $\mathrm{C} 2 / \mathrm{C} 3$ \\
\hline Klopffer (2006) & $\mathrm{TC}$ & $\mathrm{N}$ & $\mathrm{RE}$ & QL/d & NA & GR & $\mathrm{BI}$ & $\mathrm{A} 1$ & B5 & $\mathrm{C} 1$ \\
\hline Kouskouras; Georgiou (2007) & $\mathrm{MO} / \mathrm{SI}$ & $\mathrm{N}$ & AT & QT/d & NA & EM & $\mathrm{AD} / \mathrm{BI}$ & A7 & B4 & C3 \\
\hline Krause; Hayka; Pasewaldt (2006) & $\mathrm{MO}$ & $\mathrm{S}$ & AT & QL/d & NA & EM & $\mathrm{AD} / \mathrm{BI}$ & A5 & B5 & C3 \\
\hline
\end{tabular}




\begin{tabular}{|c|c|c|c|c|c|c|c|c|c|c|}
\hline \begin{tabular}{|c|} 
Artigos \\
\end{tabular} & T1 & T2 & T3 & T4 & T5 & T6 & $\mathrm{T7}$ & T8 & T9 & T10 \\
\hline $\begin{array}{l}\text { Kruse; Flysjo; Kasperczyk; Scholz } \\
(2009)\end{array}$ & TC & $\mathrm{N}$ & $\mathrm{RE}$ & QL/d & NA & EM & $A D / B I$ & A1 & B5 & $\mathrm{C} 1 / \mathrm{C} 3$ \\
\hline Kurk; Eagan (2008) & TC & $\mathrm{N}$ & AT & $\mathrm{QL/d}$ & NA & UO & $\mathrm{BI}$ & $\mathrm{A} 1$ & B5 & $\mathrm{C} 1 / \mathrm{C} 2$ \\
\hline Lee; Lu; Song; Gay (2007) & $\mathrm{MO}$ & $\mathrm{N}$ & AT & $\mathrm{QL} / \mathrm{d}$ & NA & EM & $\mathrm{BI}$ & A7 & B5 & $\mathrm{C} 3$ \\
\hline Li; Kozhikode (2009) & TC & $\mathrm{S}$ & $\mathrm{RE}$ & $\mathrm{QL/d}$ & $\mathrm{IN}$ & EM & B/DP & $\mathrm{A} 1$ & B5 & $\mathrm{C} 2 / \mathrm{C} 3$ \\
\hline Li; Qin; Xu (2008) & $\mathrm{EC}$ & $\mathrm{S}$ & $\mathrm{RE}$ & QL/d & NA & EM & $\mathrm{AD} / \mathrm{BI}$ & A7 & B3 & $\mathrm{C} 2 / \mathrm{C} 3$ \\
\hline Lin; Qian; Cui; Miao (2010) & $\mathrm{MO} / \mathrm{EC}$ & $\mathrm{N}$ & AT & QT/d & $\mathrm{NA}$ & EM & EN/AD & $\mathrm{A} 1$ & B2 & $\mathrm{C} 2$ \\
\hline Linton; Klassen; Jayaraman (2007) & $\mathrm{RL}$ & $\mathrm{N}$ & $\mathrm{RE}$ & QT/d & IN & GR & $\mathrm{BI}$ & A3 & B5 & $\mathrm{C} 1 / \mathrm{C} 3$ \\
\hline Lu; Yang; Tseng (2009) & EC & $\mathrm{S}$ & AT & QT-QL/d & NA & EM & QU/EN & $\mathrm{A} 1$ & B2 & $\mathrm{C} 2$ \\
\hline Lundteigen; Rausand; Utne (2009) & $\mathrm{MO} / \mathrm{TC}$ & $\mathrm{N}$ & AT & QL/d & NA & UO & $\mathrm{AD} / \mathrm{BI}$ & $\mathrm{A} 1$ & B5 & $\mathrm{C} 2 / \mathrm{C} 3$ \\
\hline Luttropp; Lagerstedt (2006) & EC & $\mathrm{N}$ & $\mathrm{RE}$ & QL/d & NA & EM & $\mathrm{AD} / \mathrm{BI}$ & A5 & B3 & $\mathrm{C} 1 / \mathrm{C} 2$ \\
\hline $\begin{array}{l}\text { Maxwell; Sheate; Van Der Vorst } \\
(2006)\end{array}$ & EC & $\mathrm{N}$ & LO & QT/d & NA & EM & QU/AD & A5 & B2 & $\mathrm{C} 1 / \mathrm{C} 2$ \\
\hline Mengoni; Germani; Mandorli (2009) & EC & $\mathrm{N}$ & AT & QL/d & NA & EM & $A D$ & A5 & B3 & $\mathrm{C} 1 / \mathrm{C} 2$ \\
\hline Mulder (2007) & $\mathrm{TC}$ & $\mathrm{N}$ & $\mathrm{RE}$ & $\mathrm{QL} / \mathrm{d}$ & NA & EM & $\mathrm{BI}$ & A8 & B2 & C1 \\
\hline Nakamura; Kondo (2006) & EC & $\mathrm{S}$ & $\mathrm{RE}$ & QT/d & NA & EM & AD/B/DP & $\mathrm{A} 1$ & B7 & C3 \\
\hline Noel; Roucoules (2008) & TC & $\mathrm{N}$ & AT & QL/d & NA & EM & $\mathrm{BI}$ & $\mathrm{A} 1$ & B5 & $\mathrm{C} 2 / \mathrm{C} 3$ \\
\hline Norris (2006) & EC & $\mathrm{S}$ & $\mathrm{RE}$ & QL/d & IN & EM & $\mathrm{AD} / \mathrm{BI}$ & $\mathrm{A} 1$ & B5 & $\mathrm{C} 1 / \mathrm{C} 2 / \mathrm{C} 3$ \\
\hline Ntiamoah; Afrane (2009) & EC & $\mathrm{N}$ & $\mathrm{RE}$ & QT/d & NA & GR & EN/DP & A1 & B6 & $\mathrm{C} 1$ \\
\hline $\begin{array}{l}\text { Ny; MacDonald; Broman; } \\
\text { Yamamoto; Robert (2006) } \\
\end{array}$ & TC & $\mathrm{s}$ & RE & QL/d & NA & EM & $\mathrm{BI}$ & A5 & B5 & $\mathrm{C} 1 / \mathrm{C} 3$ \\
\hline Partidario; Lambert; Evans (2007) & EC & N & RE & QL/d & NA & EM & EN/AD/OB & A4 & B5 & $\mathrm{C} 1 / \mathrm{C} 2$ \\
\hline Pero; Sianesi (2007) & EC & $\mathrm{N}$ & RE & QL/d & NA & EM & $\mathrm{EN} / \mathrm{AD} / \mathrm{OB}$ & A3 & B3 & $\mathrm{C} 2$ \\
\hline Pujari (2006) & SU & $\mathrm{N}$ & AT & QT/d & NA & EM & QU/EN & A5 & B2 & $\mathrm{C} 1 / \mathrm{C} 2$ \\
\hline Rausand; Utne (2009) & EC & $\mathrm{N}$ & AT & QL/d & NA & GR & $\mathrm{AD} / \mathrm{BI}$ & $\mathrm{A} 1$ & B2 & $\mathrm{C} 3$ \\
\hline Razavian; Khosravi (2008) & $\mathrm{MO} / \mathrm{EC}$ & $\mathrm{N}$ & AT & $\mathrm{QL/d}$ & NA & EM & $\mathrm{AD} / \mathrm{BI}$ & A7 & B3 & $\mathrm{C} 2 / \mathrm{C} 3$ \\
\hline Rosenstrom; Kyllonen (2007) & $\mathrm{EC}$ & $\mathrm{N}$ & $\mathrm{RE}$ & $\mathrm{QL} / \mathrm{d}$ & NA & UO & DP/B/OB & A5 & B2 & $\mathrm{C} 1$ \\
\hline Rouibah; Ould-Ali (2007) & EC & $\mathrm{S}$ & $\mathrm{RE}$ & QT/d & NA & EM & EN/QU & A4 & B3 & C3 \\
\hline Salvioni (2007) & EC & $\mathrm{N}$ & $\mathrm{RE}$ & QL/d & NA & EM & QU/AD/BI & A8 & B2 & $\mathrm{C} 3$ \\
\hline Schatten (2009) & TC & $\mathrm{N}$ & $\mathrm{RE}$ & $\mathrm{QL} / \mathrm{d}$ & $\mathrm{IN}$ & EM & B/DP & A3 & B3 & $\mathrm{C} 1 / \mathrm{C} 2$ \\
\hline Schmidt; Butt (2006) & EC & $\mathrm{N}$ & $\mathrm{RE}$ & $\mathrm{QL} / \mathrm{d}$ & NA & EM & $\mathrm{AD} / \mathrm{BI}$ & $\mathrm{A} 1$ & B2 & C1 \\
\hline Shao; Wu; Deng; Li; Feng (2006) & $\mathrm{EC} / \mathrm{MO}$ & $\mathrm{S}$ & $\mathrm{RE}$ & $\mathrm{QL} / \mathrm{d}$ & NA & EM & $\mathrm{AD} / \mathrm{BI}$ & A7 & B3 & C3 \\
\hline Souza; Pereira (2006) & $\mathrm{TC}$ & $\mathrm{S}$ & $\mathrm{RE}$ & $\mathrm{QL} / \mathrm{d}$ & $\mathrm{NA}$ & EM & $\mathrm{BI}$ & $\mathrm{A} 5$ & B7 & $\mathrm{C} 1$ \\
\hline $\begin{array}{l}\text { Subramoniam; Huisingh; Chinnam } \\
(2009)\end{array}$ & EC & $\mathrm{N}$ & AT & QL/d & NA & EM & EN/AD & $\mathrm{A} 1$ & B5 & $\mathrm{C} 1 / \mathrm{C} 3$ \\
\hline Taifi (2008) & EC & $\mathrm{N}$ & AT & $\mathrm{QL} / \mathrm{d}$ & NA & EM & EN/AD/QU & A4 & B5 & $\mathrm{C} 1 / \mathrm{C} 2$ \\
\hline Tang; Qian (2008) & EC & $\mathrm{S}$ & $\mathrm{RE}$ & QL/d & IN & EM & $\mathrm{AD} / \mathrm{BI}$ & A3 & B2 & $\mathrm{C} 2 / \mathrm{C} 3$ \\
\hline Tao; Probert; Phaal (2010) & EC & $\mathrm{N}$ & AT & QL/d & NA & EM & EN & $\mathrm{A} 1$ & B5 & $\mathrm{C} 2$ \\
\hline $\begin{array}{l}\text { Tingstrom; Swanstrom; Karlsson } \\
(2006)\end{array}$ & EC & S & AT & QL/d & NA & EM & EN/AD & A5 & B5 & $\mathrm{C} 1 / \mathrm{C} 2$ \\
\hline $\begin{array}{l}\text { Tomovic; Anderson; Anglin; Barreto; } \\
\text { Frillman; Georgiades; Homan; } \\
\text { Kochert; Lech; Sukup; Wilde; } \\
\text { Wisma (2009) }\end{array}$ & TC & $\mathrm{N}$ & AT & QL/d & NA & EM & $\mathrm{BI}$ & A5 & B2 & C3 \\
\hline Vachon; Klassen (2008) & SU & $\mathrm{N}$ & $\mathrm{RE}$ & QT/d & IN & EM & QU/EN & A3 & B2 & $\mathrm{C} 1$ \\
\hline Van Berkel (2007) & TC & $\mathrm{N}$ & $\mathrm{RE}$ & QL/d & NA & EM & $\mathrm{DP} / \mathrm{BI}$ & A5 & B2 & C1 \\
\hline Veshagh; Obagun (2007) & $\mathrm{EC} / \mathrm{SU}$ & N & RE & QL/d & NA & EM & EN/QU/AD & $\mathrm{A} 1$ & B5 & $\mathrm{C} 1 / \mathrm{C} 2$ \\
\hline Vezzoli; Sciama (2006) & $\mathrm{EC}$ & $\mathrm{N}$ & AT & $\mathrm{QL} / \mathrm{d}$ & $\mathrm{NA}$ & EM & \begin{tabular}{|l|}
$\mathrm{EN} / \mathrm{AD} / \mathrm{BI}$ \\
\end{tabular} & $\mathrm{A} 1$ & $\mathrm{~B} 6$ & $\mathrm{C} 1$ \\
\hline Waage (2007) & TC & $\mathrm{N}$ & RE & $\mathrm{QL} / \mathrm{d}$ & NA & EM & $\mathrm{DP} / \mathrm{BI}$ & $\mathrm{A} 1$ & B3 & $\mathrm{C} 1 / \mathrm{C} 2$ \\
\hline Wang; Chang; Wang (2009) & EC & $\mathrm{N}$ & AT & QT/d & NA & EM & $\mathrm{AD} / \mathrm{BI}$ & $\mathrm{A} 3$ & B2 & $\mathrm{C} 2$ \\
\hline Yang; Miao; Zhang; Gay (2006) & $\mathrm{MO}$ & $\mathrm{N}$ & AT & $\mathrm{QL} / \mathrm{d}$ & NA & EM & $\mathrm{AD} / \mathrm{BI}$ & A7 & B3 & $\mathrm{C} 1 / \mathrm{C} 3$ \\
\hline Zhang; Huang (2006) & EC & $\mathrm{N}$ & $\mathrm{RE}$ & $\mathrm{QL} / \mathrm{d}$ & $\mathrm{NA}$ & EM & $\mathrm{AD} / \mathrm{BI}$ & A3 & B2 & $\mathrm{C} 1 / \mathrm{C} 2$ \\
\hline
\end{tabular}


APÊNDICE III - Indicadores de centralidade, intermediação, proximidade e estatística descritiva das palavras-chaves sobre PDP, PLM e ES

Grau de Centralidade.

\begin{tabular}{|l|r|r|r|r|}
\hline \multicolumn{1}{|c|}{ Palavras chaves } & $\begin{array}{c}\text { Grau de } \\
\text { saída }\end{array}$ & $\begin{array}{c}\text { Grau de } \\
\text { entrada }\end{array}$ & $\begin{array}{c}\text { Grau de saída } \\
\text { normalizado (\%) }\end{array}$ & $\begin{array}{c}\text { Grau de entrada } \\
\text { normalizado (\%) }\end{array}$ \\
\hline Management & 174.000 & 174.000 & 6.493 & 6.493 \\
\hline Design & 134.000 & 134.000 & 5.000 & 5.000 \\
\hline Product development & 117.000 & 117.000 & 4.366 & 4.366 \\
\hline Model & 92.000 & 92.000 & 3.433 & 3.433 \\
\hline Framework & 90.000 & 90.000 & 3.358 & 3.358 \\
\hline Performance & 86.000 & 86.000 & 3.209 & 3.209 \\
\hline Product life cycle & 86.000 & 86.000 & 3.209 & 3.209 \\
\hline Life-cycle assessment & 72.000 & 72.000 & 2.687 & 2.687 \\
\hline Concurrent engineering & 68.000 & 68.000 & 2.537 & 2.537 \\
\hline Systems & 64.000 & 64.000 & 2.388 & 2.388 \\
\hline Technology & 52.000 & 52.000 & 1.940 & 1.940 \\
\hline Impact & 52.000 & 52.000 & 1.940 & 1.940 \\
\hline Innovation & 51.000 & 51.000 & 1.903 & 1.903 \\
\hline
\end{tabular}

Estatística descritiva do Grau de Centralidade.

\begin{tabular}{|l|r|r|r|r|}
\hline $\begin{array}{c}\text { Estatística } \\
\text { descritiva }\end{array}$ & \multicolumn{1}{c}{$\begin{array}{c}\text { Grau de } \\
\text { saída }\end{array}$} & $\begin{array}{c}\text { Grau de } \\
\text { entrada }\end{array}$ & $\begin{array}{c}\text { Grau de saída } \\
\text { normalizado (\%) }\end{array}$ & $\begin{array}{c}\text { Grau de entrada } \\
\text { normalizado (\%) }\end{array}$ \\
\hline Mean & 12.709 & 12.709 & 0.474 & 0.474 \\
\hline Std Dev & 14.917 & 14.917 & 0.557 & 0.557 \\
\hline Sum & 8.528 .000 & 8.528 .000 & 318.209 & 318.209 \\
\hline Variance & 222.525 & 222.525 & 0.310 & 0.310 \\
\hline SSQ & 257.700 .000 & 257.700 .000 & 358.794 & 358.794 \\
\hline MCSSQ & 149.314 .328 & 149.314 .328 & 207.889 & 207.889 \\
\hline Euc Norm & 507.642 & 507.642 & 18.942 & 18.942 \\
\hline Minimum & 2.000 & 2.000 & 0.075 & 0.075 \\
\hline Maximum & 178.000 & 178.000 & 6.642 & 6.642 \\
\hline N of Obs & 671.000 & 671.000 & 671.000 & 671.000 \\
\hline
\end{tabular}

Grau de Intermediação.

\begin{tabular}{|l|r|r|}
\hline \multicolumn{1}{|c|}{ Palavras chaves } & $\begin{array}{c}\text { Grau de } \\
\text { intermediação }\end{array}$ & $\begin{array}{c}\text { Grau de intermediação } \\
\text { normalizado (\%) }\end{array}$ \\
\hline Management & 36.977 .570 & 16.499 \\
\hline Product development & 23.118 .309 & 10.315 \\
\hline Life-cycle assessment & 22.529 .600 & 10.053 \\
\hline Product life cycle & 19.247 .836 & 8.588 \\
\hline Design & 18.271 .787 & 8.153 \\
\hline Framework & 15.593 .890 & 6.958 \\
\hline Systems & 11.563 .325 & 5.160 \\
\hline Model & 11.474 .301 & 5.120 \\
\hline Life cycle assessment & 11.068 .125 & 4.939 \\
\hline Concurrent engineering & 10.178 .165 & 4.541 \\
\hline Project management & 8.052 .331 & 3.593 \\
\hline Integration & 7.921 .329 & 3.534 \\
\hline Quality & 6.509 .140 & 2.904 \\
\hline
\end{tabular}


Estatística descritiva do Grau de Intermediação.

\begin{tabular}{|l|r|r|}
\hline \multicolumn{1}{|c|}{ Estatística descritiva } & Grau de intermediação & $\begin{array}{c}\text { Grau de intermediação } \\
\text { normalizado (\%) }\end{array}$ \\
\hline Mean & 541.958 & 0.242 \\
\hline Std Dev & 3.640 .315 & 1.624 \\
\hline Sum & 363.654 .000 & 162.262 \\
\hline Variance & 13.251 .892 .000 & 2.638 \\
\hline SSQ & 9.089 .104 .896 .000 & 1.809 .586 \\
\hline MCSSQ & 8.892 .019 .712 .000 & 1.770 .348 \\
\hline Euc Norm & 95.336 .797 & 42.539 \\
\hline Minimum & 0.000 & 0.000 \\
\hline Maximum & 69.489 .641 & 31.006 \\
\hline N of Obs & 671.000 & 671.000 \\
\hline
\end{tabular}

Grau de Proximidade.

\begin{tabular}{|l|r|r|}
\hline \multicolumn{1}{|c|}{ Palavras chaves } & Distância & Grau de proximidade \\
\hline Management & 36.778 .000 & 1.822 \\
\hline Product development & 36.790 .000 & 1.821 \\
\hline Product life cycle & 36.819 .000 & 1.820 \\
\hline Design & 36.869 .000 & 1.817 \\
\hline Framework & 36.876 .000 & 1.817 \\
\hline Concurrent engineering & 36.883 .000 & 1.817 \\
\hline Allocation & 36.891 .000 & 1.816 \\
\hline Life-cycle assessment & 36.900 .000 & 1.816 \\
\hline Project management & 36.905 .000 & 1.815 \\
\hline Integration & 36.907 .000 & 1.815 \\
\hline Model & 36.908 .000 & 1.815 \\
\hline Performance & 36.940 .000 & 1.814 \\
\hline Design for environment & 36.964 .000 & 1.813 \\
\hline
\end{tabular}

Estatística descritiva do grau de intermediação.

\begin{tabular}{|l|r|r|}
\hline \multicolumn{1}{|c|}{ Estatística descritiva } & \multicolumn{1}{c|}{ Distância } & Grau de proximidade \\
\hline Mean & 69.518 .773 & 1.664 \\
\hline Std Dev & 109.825 .148 & 0.443 \\
\hline Sum & 46.647 .096 .000 & 1.116 .410 \\
\hline Variance & 12.061 .563 .904 .000 & 0.196 \\
\hline SSQ & 11336158281728.000 & 1989.286 \\
\hline MCSSQ & 8.093 .309 .075 .456 .000 & 131.802 \\
\hline Euc Norm & 3.366 .921 .250 & 44.601 \\
\hline Minimum & 36.771 .000 & 0.149 \\
\hline Maximum & 448.230 .000 & 1.822 \\
\hline N of Obs & 671.000 & 671.000 \\
\hline
\end{tabular}




\section{APÊNDICE IV - Lista completa dos 154 métodos e ferramentas de ecodesign encontrados na literatura}

\begin{tabular}{|c|c|}
\hline $\begin{array}{l}154 \text { Métodos e Ferramentas de } \\
\text { Ecodesign }\end{array}$ & Aspectos Ambientais (Forma Bruta) \\
\hline 1. 10 Guidelines for ecodesign & $\begin{array}{l}\text { - Focar na redução do consumo de energia em todas as } \\
\text { fases do ciclo de vida do produto } \\
\text { - Aumento do tempo de vida do produto } \\
\text { - Usar o mínimo de material possível } \\
\text { - Usar materiais reciclados } \\
\text { - Fazer seu produto reciclável }\end{array}$ \\
\hline 2. $\mathrm{ABC}$ analysis & $\begin{array}{l}\text { - Toxidade de materiais } \\
\text { - Extração de matéria prima } \\
\text { - Poluição do ar e da água } \\
\text { - Avaliação dos impactos ambientais do produto } \\
\text { - Perspectiva de ciclo de vida }\end{array}$ \\
\hline $\begin{array}{l}\text { 3. Alternative function fulfillment } \\
\text { (AFF) }\end{array}$ & $\begin{array}{l}\text { - Entrada de materiais } \\
\text { - Uso e consumo de energia } \\
\text { - Emissões tóxicas } \\
\text { - Atentar aos regulamentos externos } \\
\text { - Solução alternativa com menos impacto ambiental } \\
\text { - Fazer um perfil ambiental do produto } \\
\text { - Análise comparativa da alternativa ambiental com o } \\
\text { produto atual com utilização de métricas }\end{array}$ \\
\hline 4. $\quad$ AT\&T matrix & $\begin{array}{l}\text { - Consumo de materiais } \\
\text { - Uso de energia } \\
\text { - Resíduos líquidos, sólidos e gasosos } \\
\text { - Quantificar o impacto ambiental do produto }\end{array}$ \\
\hline 5. ATROiD ecodesign & $\begin{array}{l}\text { - Desenvolver partes e produtos que possam ser } \\
\text { - } \text { desmontados de maneira rápida e econômica } \\
\text { - Reciclagem } \\
\text { - Resíduos perigosos } \\
\text { - End of life } \\
\text { - Identificar os pontos ambientais fracos }\end{array}$ \\
\hline $\begin{array}{l}\text { 6. Checklist-based assessment } \\
\text { support system for ecodesign } \\
\text { (CHASSE) }\end{array}$ & $\begin{array}{l}\text { - Reduzir a emissão de CO2 } \\
\text { - Reduzir a utilização de substâncias tóxicas } \\
\text { - Desmontagem }\end{array}$ \\
\hline $\begin{array}{l}\text { 7. Computer-based cooperative } \\
\text { method to consider the entire life } \\
\text { cycle }\end{array}$ & $\begin{array}{l}\text { - Considerar os aspectos ambientais de todo o ciclo de vida } \\
\text { do produto } \\
\text { - Extração de matéria-prima } \\
\text { - Gerenciamento de perdas } \\
\text { - Reciclagem } \\
\text { - Desmontagem } \\
\text { - Redução do uso de recursos e energia }\end{array}$ \\
\hline $\begin{array}{l}\text { 8. Conceptual design tool for } \\
\text { resolving conflicts between } \\
\text { product functionality and } \\
\text { environmental }\end{array}$ & $\begin{array}{l}\text { - Reduzir utilização de materiais } \\
\text { - Redução do uso de energia } \\
\text { - Reduzir a dispersão de substâncias tóxicas } \\
\text { - Aumentar a reciclagem } \\
\text { - Aumentar o uso de fontes renováveis } \\
\text { - Durabilidade do produto }\end{array}$ \\
\hline 9. $\quad \mathrm{D} 4 \mathrm{~N}$ & $\begin{array}{l}\text { - Reduzir impacto dos materiais } \\
\text { - Reduzir custos de fim de vida }\end{array}$ \\
\hline
\end{tabular}




\begin{tabular}{|c|c|}
\hline & $\begin{array}{l}\text { - Desmontagem } \\
\text { - Disposição } \\
\text { - Reciclagem } \\
\text { - Análise do ciclo de vida } \\
\text { - End-of-life } \\
\text { - Redesign } \\
\text { - Medida de impacto ambiental (eco-indicator) }\end{array}$ \\
\hline $\begin{array}{l}\text { 10. Decision supporting tool for } \\
\text { environmental conscious product } \\
\text { design }\end{array}$ & $\begin{array}{l}\text { - Análise do ciclo de vida } \\
\text { - Identificar os processos responsáveis pelos impactos } \\
\text { - Ambientais } \\
\text { - Análise ecológica do produto } \\
\text { - Identificar os pontos ambientais fracos }\end{array}$ \\
\hline 11. Design abacus & $\begin{array}{l}\text { - Analisar a sustentabilidade de dois produtos comparando } \\
\text { as suas características ambientais }\end{array}$ \\
\hline 12. Design environment of CRC 392 & - Avaliar o ciclo de vida do produto \\
\hline 13. Design for recycling & $\begin{array}{l}\text { - Reuso } \\
\text { - Reciclagem } \\
\text { - Recuperação de energia } \\
\text { - Desmontagem } \\
\text { - End-of-life }\end{array}$ \\
\hline $\begin{array}{l}\text { 14. Design for upgradability } \\
\text { involving changes of functions }\end{array}$ & - Mudança das funções e de performance \\
\hline $\begin{array}{l}\text { 15. Design guidelines for renewable } \\
\text { energy powered products }\end{array}$ & - Utilizar tecnologia, materiais e energia renovável \\
\hline $\begin{array}{l}\text { 16. Design structure matrix (DSM) or } \\
\text { Dependency structure matrix } \\
\text { 17. Problem solving matrix (PSM) or } \\
\text { Design precedence matrix }\end{array}$ & $\begin{array}{l}\text { - Decomposição e integração de materiais e componentes } \\
\text { - Energia } \\
\text { - Informação } \\
\text { - Funcionalidade do produto }\end{array}$ \\
\hline 18. DfE matrix & $\begin{array}{l}\text { - Materiais perigosos } \\
\text { - Uso de energia } \\
\text { - Resíduos líquido, sólido e gás } \\
\text { - Escolha de embalagens reutilizável } \\
\text { - Desmontagem } \\
\text { - Reuso } \\
\text { - Reciclagem } \\
\text { - Manutenção e reparo de componentes } \\
\text { - Contaminante de água }\end{array}$ \\
\hline $\begin{array}{l}\text { 19. Dominance matrix or Paired } \\
\text { comparison }\end{array}$ & - Não cita aspectos ambientais \\
\hline $\begin{array}{l}\text { 20. ECMA } 341 \text { - Environmental } \\
\text { design considerations for ICT \& } \\
\text { CE products }\end{array}$ & $\begin{array}{l}\text { - Eficiência de energia } \\
\text { - Eficiência de material } \\
\text { - Consumíveis e baterias } \\
\text { - Químicos e emissões de ruído } \\
\text { - Extensão do tempo de vida do produto e considerações } \\
\text { - Ee fim de vida } \\
\text { - Especial atenção nas preparações e substâncias } \\
\text { - Documentação }\end{array}$ \\
\hline 21. Eco communication matrix & $\begin{array}{l}\text { - Consumo de energia } \\
\text { - Aplicação dos Materiais } \\
\text { - Embalagem e Transporte } \\
\text { - Substâncias } \\
\text { - Durabilidade } \\
\text { - Reciclabilidade } \\
\text { - Manufatura } \\
\text { - Perspectiva do ciclo de vida }\end{array}$ \\
\hline
\end{tabular}




\begin{tabular}{|c|c|c|}
\hline & $\begin{array}{l}\text { Eco design integration method } \\
\text { for SMEs (EDIMS) based on the } \\
\text { Typological environmental } \\
\text { analysis (TEA) }\end{array}$ & $\begin{array}{l}\text { - Alternativas de projeto para reduzir o impacto ambiental } \\
\text { do produto }\end{array}$ \\
\hline & Eco Functional matrix & $\begin{array}{l}\text { - Estabelecer uma plataforma de comunicação entre as } \\
\text { prioridades funcionais e os impactos ambientais } \\
\text { - Uso de materiais tóxicos e escassos } \\
\text { - Intensidade de energia e fontes de energia } \\
\text { - Intensidade do material (tamanho, peso, número de } \\
\text { produtos por ano) } \\
\text { - Composição do material (número de componentes, } \\
\text { número de diferentes materiais) } \\
\text { - Demandas ambientais (durabilidade, flexibilidade, estético } \\
\text { e ergonômico) }\end{array}$ \\
\hline & EcoBenchmarking & $\begin{array}{l}\text { - Prevenção de poluição } \\
\text { - Desmontagem } \\
\text { - Considerar a viabilidade ambiental, social, técnica, para } \\
\text { os consumidores e financeira } \\
\text { - Considerar a percepção ambiental científica, } \\
\text { - } \text { Invernamental e do cliente } \\
\text { - Reciclagem e disposição } \\
\text { - Substância perigosa } \\
\text { - Consumo de energia } \\
\text { - Embalagem } \\
\text { - Identificar melhorias ambientais }\end{array}$ \\
\hline & Eco-compass technique & $\begin{array}{l}\text { - Intensidade de materiais } \\
\text { - Intensidade de energia } \\
\text { - Riscos potenciais à saúde e ao meio ambiente } \\
\text { - Revalorização (reuso e reciclagem) } \\
\text { - Conservação de recursos } \\
\text { - Extensão de serviços }\end{array}$ \\
\hline & $\begin{array}{l}\text { Ecodesign checklist method } \\
\text { (ECM) }\end{array}$ & $\begin{array}{l}\text { - Usabilidade do produto (orientado as necessidades do } \\
\text { cliente) } \\
\text { - Consumo baixo de produtos } \\
\text { - Consumo baixo de recursos } \\
\text { - Evitar perdas (manufatura) } \\
\text { - Produto durável } \\
\text { - Reuso das partes do produto } \\
\text { - Reciclagem de produtos e materiais }\end{array}$ \\
\hline & $\begin{array}{l}\text { Ecodesign checklist technique } \\
\text { (ECT) }\end{array}$ & $\begin{array}{l}\text { - Desmaterialização } \\
\text { - Uso compartilhado do produto } \\
\text { - Integração de funçães } \\
\text { - Otimização funcional de produtos e componentes } \\
\text { - Redução da utilização de material (peso e volume } \\
\text { transportado) } \\
\text { - Otimização do sistema de distribuição (embalagem } \\
\text { reutilizável, modelo de transporte e logística eficiente) } \\
\text { - Seleção de materiais de baixo impacto (materiais limpos, } \\
\text { renováveis, com baixa energia, reciclados e recicláveis) } \\
\text { - Redução do impacto no uso (baixo consumo de energia, } \\
\text { fonte de energia limpa, poucos consumíveis, consumíveis } \\
\text { - } \text { limpos, sem desperdícios de energia ou consumíveis) } \\
\text { reparoção e dananutenção, estrutura de produto modular, } \\
\text { - design clássico e forte relação produto usuário) } \\
\text { - Otimização de técnicas de produção (técnicas de } \\
\text { produção alternativa, poucas etapas de produção, baixo }\end{array}$ \\
\hline
\end{tabular}




\begin{tabular}{|c|c|}
\hline & $\begin{array}{l}\text { consumo de energia, consumo de energia limpa, menos } \\
\text { resíduo de produção, poucos consumíveis de produção e } \\
\text { consumíveis de produção limpa) } \\
\text { - Otimização do sistema end-of-life (reuso de produtos e } \\
\text { componentes, remanufatura, remodelações, reciclagem } \\
\text { de materiais e incineração segura) }\end{array}$ \\
\hline 28. Ecodesign online & $\begin{array}{l}\text { - Identificação das fases do ciclo de vida do produto que } \\
\text { apresentam o maior impacto ambiental, considerando } \\
\text { balanço de massa e energia } \\
\text { - Extração da matéria-prima, manufatura, transporte, uso e } \\
\text { disposição }\end{array}$ \\
\hline $\begin{array}{l}\text { 29. Ecodesign technique for } \\
\text { electronics products }\end{array}$ & $\begin{array}{l}\text { - Fases do ciclo de vida (matéria-prima aquisição, produtos } \\
\text { fabricação, distribuição, uso e descarte) } \\
\text { - Simplificação } \\
\text { - Requerimentos legais } \\
\text { - Requerimentos técnicos } \\
\text { - Restrições de custo } \\
\text { - Tempo de desenvolvimento }\end{array}$ \\
\hline 30. Ecodesign web & $\begin{array}{l}\text { - Seleção de materiais (tipo e número de materiais, } \\
\text { renovável, reciclado, reciclável e riscos) } \\
\text { - Uso de materiais (quantidade adequada para número de } \\
\text { funções e partes) } \\
\text { - Distribuição (tipo e quantidade de embalagem, tipo de } \\
\text { transporte e distância) } \\
\text { - Uso do produto (tipo e quantidade de energia usada, refil } \\
\text { e consumíveis) } \\
\text { - Tempo de vida ótimo (confiança, durabilidade, fácil de } \\
\text { reparar e manutenção, design clássico e atualizável) } \\
\text { - Fim de vida (reuso de produtos e componentes, } \\
\text { remodelação e reciclagem de materiais e componentes) } \\
\text { - Novas maneiras de fazer (uso compartilhado, produtos } \\
\text { com multi-função, serviços e aluguel) }\end{array}$ \\
\hline 31. Ecodesign X Pro & $\begin{array}{l}\text { - Processos industriais incluindo os materiais e manufatura } \\
\text { do produto } \\
\text { - Avaliação do impacto ambiental do ciclo de vida do } \\
\text { produto }\end{array}$ \\
\hline 32. Eco-efficiency & $\begin{array}{l}\text { - Life cycle cost (LCC) } \\
\text { - Prevenção do aquecimento global } \\
\text { - Efetiva utilização de recursos renováveis } \\
\text { - Reduzir a intensidade de energia } \\
\text { - Reduzir o uso de materiais tóxicos } \\
\text { - Reduzir a intensidade de materiais nos produtos } \\
\text { - Melhorar a reciclabilidade dos materiais } \\
\text { - Aumentar a durabilidade dos produtos } \\
\text { - Aumentar a intensidade de serviço dos produtos }\end{array}$ \\
\hline 33. Eco-FMEA & $\begin{array}{l}\text { - Identificar os comportamentos errados e a influência } \\
\text { durante todo o ciclo de vida do produto e qual o impacto } \\
\text { aos seres humanos }\end{array}$ \\
\hline 34. Eco-indicator 99 & $\begin{array}{l}\text { - Inventariar e calcular o impacto ambiental de todas as } \\
\text { - Inissões relevantes } \\
\text { - Inventariar e calcular o impacto ambiental da extração de } \\
\text { recursos } \\
\text { - Inventariar e calcular o impacto ambiental do uso da terra } \\
\text { - Análise de destinação dos resíduos } \\
\text { - Análise de efeito a exposição das substâncias químicas }\end{array}$ \\
\hline 35. Eco-indicator tool (Eco-it) & $\begin{array}{l}\text { - Definir o ciclo de vida do produto } \\
\text { - Quantificar materiais e processos } \\
\text { - Disposição de resíduos (incineração, reciclagem e aterro) }\end{array}$ \\
\hline
\end{tabular}




\begin{tabular}{|c|c|}
\hline $\begin{array}{l}\text { 36. Eco-indicators in product } \\
\text { development }\end{array}$ & $\begin{array}{l}\text { - Contabilidade do fluxo de materiais } \\
\text { - Análise do fluxo de energia } \\
\text { - } \text { Quantidade de material usada no produto } \\
\text { - Análise do fluxo de substâncias } \\
\text { - Restâncias e materiais diferentes usados no produto } \\
\text { - Eficiência na reciclagem de materiais } \\
\text { - Materiais de fontes naturais escassas } \\
\text { - Materiais tóxicos ou prejudiciais ao meio ambiente } \\
\text { - Limitada capacidade de armazenamento e destruição de } \\
\text { - } \text { resíduos } \\
\text { - } \text { Desmonontagem, trituração e separação de materiais } \\
\text { - Reuso } \\
\text { - Prolongar a vida útil do produto } \\
\text { - Adaptabilidade do produto } \\
\text { - Logística, distribuição e distância do transporte } \\
\text { - Reduzir o fluxo de massa } \\
\text { - Coluzir a necessidade de energia } \\
\text { - Comparar alternativas de projeto considerando a } \\
\text { - funcionalidade e utilidade } \\
\text { Avaliação do ciclo de vida do produto }\end{array}$ \\
\hline $\begin{array}{l}\text { 37. Eco-innovative product design } \\
\text { technique }\end{array}$ & $\begin{array}{l}\text { - Life cycle planning (LCP) } \\
\text { - Especificação ambiental } \\
\text { - Atualização } \\
\text { - Manutenção } \\
\text { - Reuso } \\
\text { - Reciclagem }\end{array}$ \\
\hline 38. Ecoinvent & $\begin{array}{l}\text { - Consumo de energia } \\
\text { - Composição dos materiais } \\
\text { - Produtos renováveis } \\
\text { - Substâncias químicas } \\
\text { - Gerenciamento e tratamento de resíduos } \\
\text { - Inventário do ciclo de vida do produto } \\
\text { - Avaliação do impacto do ciclo de vida do produto } \\
\text { - Embalagens } \\
\text { - Transporte e distâncias } \\
\text { - Ease de dados } \\
\text { - Emissões para o ar }\end{array}$ \\
\hline 39. Eco-it & $\begin{array}{l}\text { - Inventário de processo e produção } \\
\text { - Uso } \\
\text { - Disposição } \\
\text { - Estágios do ciclo de vida do produto } \\
\text { - Pegada de carbono } \\
\text { - ReCiPe }\end{array}$ \\
\hline 40. Eco-Kit & $\begin{array}{l}\text { - Impacto ambiental de processos, materiais e substâncias } \\
\text { - químicas } \\
\text { - Restâncias perigosas } \\
\text { - Res de embalagens }\end{array}$ \\
\hline 41. EcologiCAD & $\begin{array}{l}\text { - Indicadores de impacto ambiental } \\
\text { - Emissões de CO2 } \\
\text { - Requisitos de energia acumulada } \\
\text { - Requisitos de material acumulado } \\
\text { - Resíduos de produção } \\
\text { - Uso de terra }\end{array}$ \\
\hline 42. Ecological Quality Function & - Focar nos parâmetros ambientais internos (propriedades \\
\hline
\end{tabular}




\begin{tabular}{|c|c|}
\hline Deployment (Eco-QFD) & dos produtos) \\
\hline 43. Eco-material evaluation diagram & $\begin{array}{l}\text { - Solidez } \\
\text { - Segurança } \\
\text { - Reciclabilidade } \\
\text { - Durabilidade }\end{array}$ \\
\hline 44. Econcept spiderweb & $\begin{array}{l}\text { - Eficiência de materiais, energia e espaço } \\
\text { - Substâncias perigosas e emissões } \\
\text { - Reuso, possibilidades de reciclagem, resíduos e } \\
\text { disposição } \\
\text { - Transporte e mobilidade }\end{array}$ \\
\hline $\begin{array}{l}\text { 45. Eco-products and environmental } \\
\text { efficiency }\end{array}$ & $\begin{array}{l}\text { - Redução de volume e massa } \\
\text { - Longevidade do produto } \\
\text { - Reciclagem } \\
\text { - Facilidade de desmontagem e tratamento } \\
\text { - Proteção ambiental } \\
\text { - Conservação de energia } \\
\text { - Fornecimento de informações } \\
\text { - Materiais de embalagem }\end{array}$ \\
\hline 46. Eco-products tool & $\begin{array}{l}\text { - Prevenção do aquecimento global } \\
\text { - Eficiência de recursos }\end{array}$ \\
\hline 47. Ecoquest & $\begin{array}{l}\text { - Estimular a responsabilidade ambiental por toda a cadeia } \\
\text { - de suprimentos } \\
\text { - } \text { - Numenumo de energia } \\
\text { - Peso dos materiais } \\
\text { - Distribuição e embalagens } \\
\text { - Substâncias relevantes ambientalmente } \\
\text { - Aplicação de materiais } \\
\text { - Fim de vida e durabilidade } \\
\text { - Práticas de política ambiental } \\
\text { - Sistema de gestão ambiental e programas de ecodesign } \\
\text { - Prioridades ambientais para o produto }\end{array}$ \\
\hline 48. Eco-Redesign & $\begin{array}{l}\text { - Avaliação do ciclo de vida do produto } \\
\text { - Custo do ciclo de vida do produto } \\
\text { - Impacto ambiental dos componentes do produto } \\
\text { - Análise comparativa do impacto ambiental dos } \\
\text { - Expoctativas ambientais do cliente } \\
\text { - Substituir materiais e componentes } \\
\text { - Reduzir consumo de materiais e embalagens } \\
\text { - Reprojeto }\end{array}$ \\
\hline 49. Eco-roadmap & $\begin{array}{l}\text { Analisar a legislação atual e futura e as necessidades } \\
\text { atuais e emergentes do cliente em termos de } \\
\text { sustentabilidade e meio ambiente relevantes ao produto }\end{array}$ \\
\hline $\begin{array}{l}\text { 50. Eco-Value Analysis (Eco-VA) } \\
\text { 51. Extended Eco-VA }\end{array}$ & $\begin{array}{l}\text { - Identificar a importância das funções do produto para o } \\
\text { cliente } \\
\text { - Cumprir as funções técnicas } \\
\text { - Estimar o impacto ambiental de cada componente e } \\
\text { processo durante o ciclo de vida do produto } \\
\text { - Determinar o custo econômico para produção e uso } \\
\text { - Estratégia para melhorar a funcionalidade do produto com } \\
\text { base na necessidade do cliente, impacto ambiente e } \\
\text { custo de produção }\end{array}$ \\
\hline 52. ElAtrack & $\begin{array}{l}\text { - Conhecimentos de conformidade ambiental } \\
\text { - Substâncias perigosas } \\
\text { - Reciclagem } \\
\text { - Componentes }\end{array}$ \\
\hline
\end{tabular}




\begin{tabular}{|c|c|}
\hline & $\begin{array}{l}\text { - Embalagem e rótulos ambientais } \\
\text { - Controle de resíduos } \\
\text { - Eficiência energética }\end{array}$ \\
\hline 53. EIME software & $\begin{array}{l}\text { - Materiais e aditivos que definem as partes e componentes } \\
\text { - Redução do uso de matéria prima, energia e água } \\
\text { - Aquecimento global } \\
\text { - Produção de resíduos perigosos } \\
\text { - Peso e volume } \\
\text { - Consumo de energia e vida útil } \\
\text { - Critérios de fim de vida }\end{array}$ \\
\hline $\begin{array}{l}\text { 54. End of life design advisor } \\
\text { (ELDA) }\end{array}$ & $\begin{array}{l}\text { - Estratégias do fim de vida (vida do produto, ciclo } \\
\text { tecnológico, nível de integração, ciclo de design, número } \\
\text { de partes e razão para o redesign) } \\
\text { - Reuso } \\
\text { - Serviço } \\
\text { - Remanufatura } \\
\text { - Reciclagem } \\
\text { - Disposição } \\
\text { - Materiais perigosos }\end{array}$ \\
\hline $\begin{array}{l}\text { 55. Energy using products (EUP) } \\
\text { EcoReport }\end{array}$ & $\begin{array}{l}\text { - Indicadores de consumo de energia, água e materiais } \\
\text { - Reciclagem } \\
\text { - Geração de resíduos } \\
\text { - Emissões para o ar e água } \\
\text { - Uso e disposição } \\
\text { - Distribuição } \\
\text { - Manutenção e reparo } \\
\text { - Reuso e disposição } \\
\text { - Seleção de materiais do processo } \\
\text { - Extração de materiais e produção } \\
\text { - Volume e peso do produto embalado } \\
\text { - Incineração de substâncias não perigosas } \\
\text { - Otimização do recuperação de energia }\end{array}$ \\
\hline $\begin{array}{l}\text { 56. Environmental value chain } \\
\text { analysis (EVCA) }\end{array}$ & $\begin{array}{l}\text { - } \text { Consume de energia } \\
\text { - Redução de peso } \\
\text { - Embalagem e transporte } \\
\text { - Substâncias perigosas } \\
\text { - Reciclagem }\end{array}$ \\
\hline $\begin{array}{l}\text { 57. Environmental design industrial } \\
\text { template (EDIT) }\end{array}$ & $\begin{array}{l}\text { - Fim de vida do produto } \\
\text { - Peso } \\
\text { - Toxicidade } \\
\text { - Custo de disposição } \\
\text { - } \text { Custo para reciclagem do material } \\
\text { - Remanua utilizada para reciclagem } \\
\text { - Tempo e energia gastos no processo de desmontagem }\end{array}$ \\
\hline $\begin{array}{l}\text { 58. Environmental design strategy } \\
\text { matrix (EDSM) }\end{array}$ & $\begin{array}{l}\text { - Duração do ciclo de vida } \\
\text { - Consumo de energia } \\
\text { - Consumo de recursos } \\
\text { - Requisitos de material } \\
\text { - Configuração } \\
\text { - Rota de disposição }\end{array}$ \\
\hline $\begin{array}{l}\text { 59. Environmental design support } \\
\text { tool (EDST) }\end{array}$ & $\begin{array}{l}\text { - Seleção de materiais } \\
\text { - Avaliação da reciclabilidade } \\
\text { - Análises de desmontagem } \\
\text { - Peso total do produto } \\
\text { - Uso de materiais diferentes }\end{array}$ \\
\hline
\end{tabular}




\begin{tabular}{|c|c|}
\hline & $\begin{array}{l}\text { - Materiais perigosos } \\
\text { - Gerenciamento dos resíduos sólidos e controle da } \\
\text { poluição } \\
\text { - Fim de vida do material (reuso, remanufatura, reciclagem } \\
\text { para um material de classe elevada, reciclagem para um } \\
\text { material de classe menor, incineração para geração de } \\
\text { energia e disposição final) } \\
\text { - Regulamentos e políticas ambientais }\end{array}$ \\
\hline $\begin{array}{l}\text { 60. Environmental effect analysis } \\
\text { (EEA) }\end{array}$ & $\begin{array}{l}\text { - Identificar e avaliar potenciais impactos ambientais em } \\
\text { todas as fases do ciclo de vida do produto desde a } \\
\text { extração de matéria prima até a disposição final de forma } \\
\text { sistemática }\end{array}$ \\
\hline $\begin{array}{l}\text { 61. Environmental efficiency } \\
\text { potential assessment method } \\
\text { (E2-PA) }\end{array}$ & $\begin{array}{l}\text { - Intensidade de materiais (quantidade de materiais } \\
\text { utilizados para produzir o produto) } \\
\text { - Intensidade de energia (energia consumida para } \\
\text { produção) } \\
\text { - Intensidade de materiais perigosos (avalia o consumo de } \\
\text { recursos requeridos para a remoção da poluição causada } \\
\text { pelo uso de materiais perigosos no produto) } \\
\text { - Intensidade de recuperação (economia de recursos por } \\
\text { recuperação de materiais) } \\
\text { - Intensidade de duração (avalia as economias de recursos } \\
\text { para a produção e manutenção de um produto que tem } \\
\text { - Intensida útil maior) } \\
\text { - In produde de utilidade (avalia a eficiência durante o uso } \\
\text { - Intensidade de resíduos } \\
\text { - Intensidade de poluição }\end{array}$ \\
\hline $\begin{array}{l}\text { 62. Environmental failure mode and } \\
\text { effects analysis (E-FMEA) }\end{array}$ & $\begin{array}{l}\text { - Identificar e avaliar potenciais impactos ambientais } \\
\text { durante o ciclo de vida do produto } \\
\text { - Requisitos da função ambiental } \\
\text { - Requisitos externos e legais } \\
\text { - Avaliação do ciclo de vida de áreas específicas } \\
\text { - Emissões para atmosfera } \\
\text { - Contaminação do solo } \\
\text { - Resíduos } \\
\text { - Produção } \\
\text { - Uso de recursos e eletricidade } \\
\text { - Disposição }\end{array}$ \\
\hline $\begin{array}{l}\text { 63. Environmental Impact and } \\
\text { Factor Analysis (EIFA) }\end{array}$ & $\begin{array}{l}\text { - Reduzir os componentes dos produtos } \\
\text { - Reutilizar os componentes dos produtos } \\
\text { - Reciclar os componentes dos produtos }\end{array}$ \\
\hline $\begin{array}{l}\text { 64. Environmental information and } \\
\text { management explorer (EIME) }\end{array}$ & $\begin{array}{l}\text { - Requerimentos de legislação } \\
\text { - Normas internas da organização } \\
\text { - Necessidades dos clientes } \\
\text { - Número e tipo de partes } \\
\text { - Número e tipo de materiais } \\
\text { - Nubmontagens } \\
\text { - Eśmero de ligações que não podem ser desfeitas } \\
\text { - Riscos a saúde } \\
\text { - Mudanças climáticas } \\
\text { - Toxidade da água e ar } \\
\text { - Tratamento de resíduos de produção } \\
\text { - } \text { Fim de fida dos resíduos de produção } \\
\text { - } \text { Checar o perfil ecológico dos produtos } \\
\quad \text { externos }\end{array}$ \\
\hline
\end{tabular}




\begin{tabular}{|c|c|}
\hline & $\begin{array}{l}\text { - Acumular conhecimentos com os feedbacks das } \\
\text { implicações das escolhas feitas } \\
\text { - Life cycle inventory (embalagens, geração de eletricidade } \\
\text { e produção de papel) }\end{array}$ \\
\hline $\begin{array}{l}\text { 65. Environmental input-output } \\
\text { analyses }\end{array}$ & $\begin{array}{l}\text { - Fluxo de uso de materiais } \\
\text { - Fluxo de uso de energia } \\
\text { - Fluxo de geração de emissões } \\
\text { - Perspectiva de ciclo de vida do produto }\end{array}$ \\
\hline $\begin{array}{l}\text { 66. Environmental Objective } \\
\text { Deployment (EOD) }\end{array}$ & $\begin{array}{l}\text { - Material } \\
\text { - Reparabilidade } \\
\text { - Eficiência de energia } \\
\text { - Uso de material } \\
\text { - Reduzir o peso } \\
\text { - Uso de materiais reciclados }\end{array}$ \\
\hline $\begin{array}{l}\text { 67. Environmental performance } \\
\text { resource impact indicator } \\
\text { (EPRII) }\end{array}$ & $\begin{array}{l}\text { - Uso de água } \\
\text { - Uso de energia } \\
\text { - } \text { Produção de resíduo } \\
\text { - Montaão de recursos } \\
\text { - Gerenciamento do ciclo de vida do produto } \\
\text { - Avaliação do impacto do ciclo de vida } \\
\text { - Inventário do ciclo de vida } \\
\text { - Redução da camada de ozônio } \\
\text { - Totencial de aquecimento global } \\
\text { - Uso e ocupação de solo }\end{array}$ \\
\hline $\begin{array}{l}\text { 68. Environmental Performance } \\
\text { Strategy Map }\end{array}$ & $\begin{array}{l}\text { - Indicadores de impacto ambiental } \\
\text { - Análise das pegadas ecológicas (carbono, água, energia, } \\
\text { emissão, ambiente de trabalho e impactos tóxicos) } \\
\text { - Consumos de água e energia } \\
\text { - Emissões } \\
\text { - Ambiente de trabalho (ausência por acidentes no } \\
\text { trabalho) }\end{array}$ \\
\hline $\begin{array}{l}\text { 69. Environmental Product Life } \\
\text { Cycle Matrix (EPLC) }\end{array}$ & $\begin{array}{l}\text { - Aquecimento global } \\
\text { - Depleção da matéria prima } \\
\text { - Acidificação } \\
\text { - Toxidade } \\
\text { - Depleção da camada de ozônio } \\
\text { - Polução do ar, água etc. } \\
\text { - Resíduo sólido } \\
\text { - Redução da biodiversidade }\end{array}$ \\
\hline $\begin{array}{l}\text { 70. Environmental quality function } \\
\text { deployment (EQFD) }\end{array}$ & $\begin{array}{l}\text { - Reduzir as substâncias perigosas } \\
\text { - Aumento da eficiência energética } \\
\text { - Produtos mais leves } \\
\text { - Composição do material } \\
\text { - Tempo de vida }\end{array}$ \\
\hline $\begin{array}{l}\text { 71. Environmental risk assessment } \\
\text { (ERA) }\end{array}$ & $\begin{array}{l}\text { - Identificar riscos potenciais para saúde humana e } \\
\text { ecossistema originados de substâncias, processos e } \\
\text { tecnologias } \\
\text { - Substâncias tóxicas e químicas }\end{array}$ \\
\hline $\begin{array}{l}\text { 72. Environmentally conscious QFD } \\
\text { (ECQFD) }\end{array}$ & $\begin{array}{l}\text { - Environmental voice of customer (EVoC) } \\
\text { - Redução do consumo de material prima e energia } \\
\text { - Redução de resíduo } \\
\text { - Redução dos riscos a segurança da saúde humana } \\
\text { - Degradação ecológica } \\
\text { - Produto simples e seguro } \\
\text { - Aumento do ciclo de vida do produto }\end{array}$ \\
\hline
\end{tabular}




\begin{tabular}{|c|c|}
\hline & $\begin{array}{l}\text { - Portabilidade do produto } \\
\text { - Redução do uso de embalagens } \\
\text { - Facilitar o transporte e estocagem } \\
\text { - Facilitar o processo e desmontagem } \\
\text { - Fácil de limpar e separar } \\
\text { - Aumentar a durabilidade } \\
\text { - Fácil de reusar } \\
\text { - Inofensivo ao ambiente e aos usuários } \\
\text { - Fácil de descartar } \\
\text { - Environmental engineering metrics (EEM) } \\
\text { - Temperatura e brilho quando o produto está operando } \\
\text { - Emissões durante a operação do produto } \\
\text { - Rarulho e espaço para estocar o produto } \\
\text { - } \text { Utilizar o número de partes } \\
\text { - Reduzir o peso e volume } \\
\text { - Reduzir a quantidade de energia } \\
\text { - Reduzir o tipo de materiais } \\
\text { - Biodegradabilidade e toxidade dos materiais }\end{array}$ \\
\hline $\begin{array}{l}\text { 73. Environmentally preferred } \\
\text { product design tool (EPP) }\end{array}$ & $\begin{array}{l}\text { - Redução do uso de materiais perigosos e tóxicos } \\
\text { - Aumento da reciclabilidade } \\
\text { - Uso de produtos reciclados } \\
\text { - Redução no consumo de energia e água } \\
\text { - Redução do aquecimento global } \\
\text { - Durabilidade } \\
\text { - Descarte } \\
\text { - Reuso } \\
\text { - Remanufatura } \\
\text { - Recarregável } \\
\text { - Redução de embalagem }\end{array}$ \\
\hline $\begin{array}{l}\text { 74. Environmentally responsible } \\
\text { product assessment matrix } \\
\text { (ERPA) }\end{array}$ & $\begin{array}{l}\text { - Escolha de materiais } \\
\text { - Uso de energia } \\
\text { - Resíduos sólidos } \\
\text { - Efluentes líquidos } \\
\text { - Emissões gasosas }\end{array}$ \\
\hline 75. ENVRIZ & $\begin{array}{l}\text { - Resolver contradições entre o desempenho ambiental e o } \\
\text { - Reduzir da utilidade do produto } \\
\text { - Reduzir a intensidade de materiais } \\
\text { - Reduzir a dispersão de energia } \\
\text { - Aumentar a reciclabilidade } \\
\text { - Aumentar o uso de recursos renováveis } \\
\text { - } \text { Durabilidade do produto }\end{array}$ \\
\hline 76. EuPeco-profiler & $\begin{array}{l}\text { - Manufatura } \\
\text { - Distribuição } \\
\text { - Uso } \\
\text { - Fim de vida } \\
\text { - Seleção de diferentes materiais e processos } \\
\text { - Indicadores de impacto ambiental } \\
\text { - Aquecimento global } \\
\text { - Requisitos de eletricidade } \\
\text { - Ueração de resíduos e desperdícios } \\
\text { - Uso de água }\end{array}$ \\
\hline 77. EuroMat & $\begin{array}{l}\text { - Definir o perfil dos requerimentos tecnológicos } \\
\text { - Seleção de materiais tecnicamente viáveis, considerando } \\
\text { a funcionalidade do produto e a identificação de } \\
\text { processos de manufatura e reciclagem adequados }\end{array}$ \\
\hline
\end{tabular}




\begin{tabular}{|c|c|}
\hline & $\begin{array}{l}\text { - Utilização do LCA simplificado } \\
\text { - Utilização do LCC e avaliação dos riscos e do ambiente } \\
\text { de trabalho }\end{array}$ \\
\hline 78. eVerdEE & $\begin{array}{l}\text { - Consumo de materiais e recursos } \\
\text { - Biomassa } \\
\text { - Água limpa } \\
\text { - Energia não renovável e renovável } \\
\text { - Mudança no clima } \\
\text { - Redução da camada de ozônio } \\
\text { - } \text { Quantidade de resíduos perigosos } \\
\text { - Estimar a perda total de processo }\end{array}$ \\
\hline 79. Factor X Tool 2001 & $\begin{array}{l}\text { - Prevenção do aquecimento global } \\
\text { - Utilização eficaz dos recursos naturais } \\
\text { - Uso de materiais não tóxicos }\end{array}$ \\
\hline 80. Gabi & $\begin{array}{l}\text { - Reciclagem } \\
\text { - Cumprimento } \\
\text { - Meio ambiente } \\
\text { - Desmontagem } \\
\text { - Considera todo o ciclo de vida do produto }\end{array}$ \\
\hline $\begin{array}{l}\text { 81. Generic environmental } \\
\text { benchmark technique }\end{array}$ & $\begin{array}{l}\text { - Análise e medição das fontes de energia e eficiência } \\
\text { - Análise e medição do produto físico, embalagem e } \\
\text { durabilidade } \\
\text { - Montagem e desmontagem e cenários de fim de vida } \\
\text { - Opções de geração verdes }\end{array}$ \\
\hline 82. GrEEEn method & $\begin{array}{l}\text { - Massa } \\
\text { - Indice de toxicidade } \\
\text { - Indicadores de inventário (consumo de energia, geração } \\
\text { total de resíduos) } \\
\text { - Design para reciclagem (taxa de material recuperado, } \\
\text { taxa de eficiência de reciclagem) } \\
\text { - Indicadores de avaliação de impacto ambiental (índice de } \\
\text { gases de efeito estufa, índice de depleção da camada de } \\
\text { ozônio) } \\
\text { - Pontuações simples de impacto ambiental (Eco-Indicator } \\
\text { 95 ou 99) } \\
\text { - Conformidade legal e legislações }\end{array}$ \\
\hline 83. Green design advisor (GDA) & $\begin{array}{l}\text { - Estrutura do produto (componentes, materiais, peso, } \\
\text { - número, tipo e arranjo de conexões) } \\
\text { - } \text { Massa de materiais } \\
\text { - Conteúdo de material reciclado } \\
\text { - Reciclabilidade } \\
\text { - Toxicidade } \\
\text { - Consumo de energia } \\
\text { - Tempo para desmontagem } \\
\text { - Custo de disposição }\end{array}$ \\
\hline 84. AT\&T's Green design tool & $\begin{array}{l}\text { - Reconhecer quais são os atributos ambientais que mais } \\
\text { precisam ser melhorados e os métodos de manufatura } \\
\text { utilizados } \\
\text { - Utilizar submontagens reutilizáveis } \\
\text { - Materiais recicláveis } \\
\text { - Toxidade de materiais } \\
\text { - Melhorar os atributos verdes do produto }\end{array}$ \\
\hline $\begin{array}{l}\text { 85. Green pack material declaration } \\
\text { tool }\end{array}$ & $\begin{array}{l}\text { - Legislação e regulamentações ambientais } \\
\text { - Responsabilidade do produtor } \\
\text { - Declaração do material com dados ambientais } \\
\text { - Reciclagem }\end{array}$ \\
\hline
\end{tabular}




\begin{tabular}{|c|c|}
\hline & $\begin{array}{l}\text { - Inventário do ciclo de vida do produto } \\
\text { - Avaliação do ciclo de vida do produto }\end{array}$ \\
\hline 86. Green Pro & $\begin{array}{l}\text { - Minimizar o impacto ambiental analisando questões } \\
\text { ambientais, tecnológicas e economicas na fase de } \\
\text { projeto. }\end{array}$ \\
\hline 87. Hierarchy of focusing & $\begin{array}{l}\text { - Identificar os impactos ambientais mais importantes do } \\
\text { produto ao longo do seu ciclo de vida } \\
\text { - Selecionar as melhores ferramentas do ecodesign }\end{array}$ \\
\hline $\begin{array}{l}\text { 88. House of Ecology }(\mathrm{HoE}) \text { or } \\
\text { House of Environment }(\mathrm{HoE})\end{array}$ & $\begin{array}{l}\text { - Redução de emissões de substâncias tóxicas } \\
\text { - Inserir requisitos ambientais na tomada de decisão }\end{array}$ \\
\hline 89. Idemat & $\begin{array}{l}\text { - Seleção de material durante o projeto do produto e } \\
\text { desenvolvimento } \\
\text { - Demanda de matéria prima, água e energia } \\
\text { - Emissões }\end{array}$ \\
\hline $\begin{array}{l}\text { 90. Information Inspiration web- } \\
\text { based tool }\end{array}$ & $\begin{array}{l}\text { - Estratégias } \\
\text { - Legislação } \\
\text { - Reciclagem } \\
\text { - Uso } \\
\text { - Materiais } \\
\text { - Embalagem } \\
\text { - Fim de vida } \\
\text { - Energia }\end{array}$ \\
\hline 91. Instep-DfE & $\begin{array}{l}\text { - Substâncias perigosas } \\
\text { - Reciclabilidade } \\
\text { - } \text { Desmontagem, desmontagem e acessibilidade } \\
\text { - Uso de material } \\
\text { - Eficiência energética } \\
\text { - Emissões } \\
\text { - } \text { (Biblioteca) } \\
\text { - Indicadores de impactos ambientais (Ponto } \\
\text { - Ambiental (EP), Potencial de Depleção de Recursos } \\
\text { - } \text { (RDP) e valor do ciclo de vida do CO2) } \\
\text { - Informações regulatórias } \\
\text { - Ciclo de vida do produto } \\
\text { - Informações de manufatura, transporte, uso e disposição } \\
\text { - Consumo de eletricidade }\end{array}$ \\
\hline $\begin{array}{l}\text { 92. Integrated Approach to } \\
\text { Sustainable Product } \\
\text { Development }\end{array}$ & $\begin{array}{l}\text { - Banco de dados com o impacto ambiental de cada lista de } \\
\text { - Materiais durante o ciclo de vida do produto } \\
\text { - Minimizar a emissão de CO2 } \\
\text { - Mrentagem de componentes } \\
\text { - Manufaţara da matéria prima } \\
\text { - Distribuição } \\
\text { - Capacidade de produção dos fornecedores } \\
\text { - Tipo de materiais dos componentes } \\
\text { - Inventário (material, combustível, energia elétrica, água, } \\
\text { emissões de gás e água e resíduos sólidos) }\end{array}$ \\
\hline 93. IZM-EE ToolBox & $\begin{array}{l}\text { - Quantificar e comparar riscos ambientais de substâncias } \\
\text { (Indicador de Potencial Toxicidade (TPI)) } \\
\text { - Energia utilizada para extração da matéria-prima } \\
\text { - Consumo de energia durante a manufatura } \\
\text { - Balanço dos materiais tóxicos utilizados nos processos } \\
\text { - Emissões Tóxicas Potenciais } \\
\text { - Consumo de Energia durante o uso } \\
\text { - Quantificar as emissões causadas por um material }\end{array}$ \\
\hline
\end{tabular}




\begin{tabular}{|c|c|}
\hline & $\begin{array}{l}\text { durante a incineração dos resíduos } \\
\text { - Indicador do Potencial de Reciclagem (quantifica a } \\
\text { aplicabilidade de um produto/material para diferentes } \\
\text { rotas de reciclagem) } \\
\text { - Energia utilizada ou recuperada durante a reciclagem }\end{array}$ \\
\hline $\begin{array}{l}\text { 94. Key environmental performance } \\
\text { indicators (KEPI) }\end{array}$ & $\begin{array}{l}\text { - } \text { Consumo de energia } \\
\text { - Aquecimento global } \\
\text { - Uso de substâncias químicas e perigosas } \\
\text { - Redução da camada de ozônio } \\
\text { - Redução do toxidade para o ser humano de recursos } \\
\text { - Poluição do ar } \\
\text { - Disposição } \\
\text { - Perspectiva legal } \\
\text { - Análise do impacto ambiental de componentes e materiais } \\
\text { - Recursos escassos } \\
\text { - Transporte e embalagem }\end{array}$ \\
\hline 95. LCA Light & $\begin{array}{l}\text { - Impacto ambiental de materiais } \\
\text { - Impacto ambiental de energia } \\
\text { - Impacto ambiental de transporte }\end{array}$ \\
\hline 96. LCA-E & $\begin{array}{l}\text { - Seleção de components diferentes } \\
\text { - Diferentes condições de operação } \\
\text { - Quantidade de components } \\
\text { - Uso de energia } \\
\text { - Avaliação do ciclo de vida de produto }\end{array}$ \\
\hline $\begin{array}{l}\text { 97. LiDS (Lifetime Design } \\
\text { Strategies) wheel }\end{array}$ & $\begin{array}{l}\text { - Desenvolvimento de novos conceitos (desmaterialização, } \\
\text { uso compartilhado do produto, integração de funções, } \\
\text { otimização de funçães do produto e componentes) } \\
\text { - Seleção de material de baixo impacto (materiais limpos, } \\
\text { materiais renováveis, materiais com baixo consumo de } \\
\text { energia, materiais reciclados e recicláveis) } \\
\text { - Redução do uso de material (peso e volume transportado) } \\
\text { - Otimização das técnicas de produção (escolha de } \\
\text { processos de fabricação com menor impacto ambiental, } \\
\text { energeticamente mais eficiente que produza menor } \\
\text { quantidade de resíduos sólidos e efluentes, menor } \\
\text { consome de recursos tóxicos) } \\
\text { - Otimização do sistema de distribuição (menos uso de } \\
\text { embalagens, utilizar embalagens mais limpas e reusáveis } \\
\text { modelo de transporte mais eficiente e logística mais } \\
\text { eficiente em termos de energia) } \\
\text { - Redução do impacto do uso (consumo de menos energia, } \\
\text { fonte de energia mais limpa, menos consumíveis e sem } \\
\text { desperdício de energia e consumíveis) } \\
\text { - Otimização do tempo de vida (durabilidade e confiança, } \\
\text { fácil reparo e manutenção, estrutura modular, design } \\
\text { simples e forte relação usuário e produto) } \\
\text { - Otimização do fim de vida (reuso do produto, } \\
\text { remanufatura e renovação, reciclagem de materiais e } \\
\text { incineração segura) }\end{array}$ \\
\hline $\begin{array}{l}\text { 98. Life cycle assessment (LCA) } \\
\text { 99. Abridged life cycle analysis } \\
\text { (ALCA) matrix }\end{array}$ & $\begin{array}{l}\text { - Identificar a energia e materiais utilizados e os resíduos } \\
\text { lançados para o meio ambiente } \\
\text { - Ciclo de vida do produto desde a aquisição da matéria } \\
\text { prima até o fim de vida e disposição } \\
\text { - Considerar todos os atributos ou aspectos do ambiente } \\
\text { natural, de saúde e de recursos humanos } \\
\text { - Avaliar o impacto do ciclo de vida }\end{array}$ \\
\hline
\end{tabular}




\begin{tabular}{|c|c|}
\hline & $\begin{array}{l}\text { - Emissões para o ar, água e resíduos } \\
\text { - Comparação entre diferentes produtos } \\
\text { - Processo de inventário }\end{array}$ \\
\hline 100. Life cycle check (LCC) & $\begin{array}{l}\text { - Visão geral dos potenciais efeitos ambientais dos } \\
\text { produtos, baseado nas propriedades do produto } \\
\text { - Breve análise do sistema em que o produto está inserido } \\
\text { - Unidade funcional (quantidade, durabilidade e qualidade) } \\
\text { - Materiais e embalagens } \\
\text { - Consumo de energia } \\
\text { - Manutenção } \\
\text { - Substâncias que causam problemas ambientais } \\
\text { - Manufatura } \\
\text { - Uso } \\
\text { - Disposição } \\
\text { - Distribuição e transporte } \\
\text { - Incineração com recuperação de energia } \\
\text { - Reciclagem }\end{array}$ \\
\hline 101. Life cycle costing tool (LICCOS) & $\begin{array}{l}\text { - Considerar fatores como facilidades, materiais e recursos } \\
\text { - } \text { Requnos para a produção, uso e reciclagem } \\
\text { - Efeitos ambientais de manufatura } \\
\text { - Consumo de energia } \\
\text { - Desmontagem } \\
\text { - Adequação de reciclagem } \\
\text { - Calcular o custo do produto considerando todo o ciclo de } \\
\text { vida do produto }\end{array}$ \\
\hline $\begin{array}{l}\text { 102. Life cycle design structure matrix } \\
\text { (LC-DSM) }\end{array}$ & $\begin{array}{l}\text { - Identificar os pontos ambientais críticos para desenvolver } \\
\text { indicadores ambientais } \\
\text { - Fluxo de material } \\
\text { - Fluxo de energia } \\
\text { - Fluxo de emissões }\end{array}$ \\
\hline $\begin{array}{l}\text { 103. Life Cycle Environmental Cost } \\
\text { Analysis (LCECA) }\end{array}$ & $\begin{array}{l}\text { - Incluir os custos diretos e indiretos dos impactos } \\
\text { ambientais causados pelo produto durante todo o ciclo de } \\
\text { - } \text { Idda } \\
\text { - Análificare do custernativas ambientais para partes e produtos de vida } \\
\text { - Prevenção de poluição } \\
\text { - Substituição de materiais } \\
\text { - Re-projeto } \\
\text { - Controle de efluentes } \\
\text { - Tratamento de efluentes e resíduos } \\
\text { - Disposição de resíduos } \\
\text { - Sistema de gerenciamento ambiental } \\
\text { - Taxas e penalidades ecológicas } \\
\text { - Reabilitação em caso de acidente ambiental } \\
\text { - Energia } \\
\text { - Estratégia de reciclagem e reuso } \\
\text { - Desmontagem } \\
\text { - Material reciclado } \\
\text { - Reuso de produto } \\
\text { - Uso de energia renovável } \\
\text { - Aumimização de materiais perigosos } \\
\text { - Uso de embalagens ecológicas } \\
\text { - Economizar recursos } \\
\text { - Disposição ecológica } \\
\text { - Indicadores de impacto ambiental }\end{array}$ \\
\hline
\end{tabular}




\begin{tabular}{|c|c|}
\hline & $\begin{array}{l}\text { - Operação e manutenção } \\
\text { - Aterro e incineração } \\
\text { - Transporte } \\
\text { - Coleta } \\
\text { - Certificação ambiental } \\
\text { - Prejuízos ambientais e a saúde }\end{array}$ \\
\hline $\begin{array}{l}\text { 104. Life Cycle House of Quality (LC- } \\
\text { HoQ) }\end{array}$ & $\begin{array}{l}\text { - Considerar os requisitos da qualidade (HoQ) para } \\
\text { componentes, processo e produção e avaliar todo o ciclo } \\
\text { de vida do produto, }\end{array}$ \\
\hline $\begin{array}{l}\text { 105. Life Cycle Quality Function } \\
\text { Deployment (LC-QFD) }\end{array}$ & $\begin{array}{l}\text { - Considerar os requisitos do cliente }(\mathrm{HoC}) \\
\text { - Considerar os requisitos ambientais }(\mathrm{HoE}) \\
\text { - Considerar os requisitos da legislação e regulamentos } \\
\text { (HoR) }\end{array}$ \\
\hline $\begin{array}{l}\text { 106. Life cycle scenario description } \\
\text { support tool }\end{array}$ & $\begin{array}{l}\text { - Estabelecer os objetivos gerais e ambientais do ciclo de } \\
\text { vida alvo através da análise de recursos de produtos } \\
\text { similares e seus mercados } \\
\text { - Reuso } \\
\text { - Reciclagem } \\
\text { - Disposição } \\
\text { - Fluxo do ciclo de vida do produto } \\
\text { - Life cycle assessment (LCA) } \\
\text { - Life cycle simulation (LCS) }\end{array}$ \\
\hline 107. LIME method & $\begin{array}{l}\text { - Transformar os impactos ambientais em valores } \\
\text { monetários } \\
\text { - Life cycle impact assessment (LCIA) } \\
\text { - Caracterização (aquecimento global, esgotamento da } \\
\text { camada de ozônio, poluição do ar, toxidade humana, } \\
\text { toxidade ambiental, uso e consumo dos recursos naturais } \\
\text { e desperdício) } \\
\text { - Avaliação do prejuízo (saúde humana, bem estar social, } \\
\text { biodiversidade, ecossistema e vegetação) } \\
\text { - Integração e ponderação dos indicadores }\end{array}$ \\
\hline $\begin{array}{l}\text { 108. Material input per service unit } \\
\text { (MIPS) }\end{array}$ & $\begin{array}{l}\text { - Extração de recursos } \\
\text { - Manufatura } \\
\text { - Transporte } \\
\text { - Embalagem } \\
\text { - Operação } \\
\text { - Reuso } \\
\text { - Reciclagem } \\
\text { - Remanufatura } \\
\text { - Insposição final dos resíduos } \\
\text { - Produdade do material em relação a consumo de energia }\end{array}$ \\
\hline $\begin{array}{l}\text { 109. Matrix MECO (Materials, } \\
\text { Energy, Chemicals and Others) }\end{array}$ & $\begin{array}{l}\text { - Estimativas de impacto ambiental considerando as } \\
\text { quantidades de materiais (M) utilizados na produção e } \\
\text { uso do produto } \\
\text { - Estimativas de impacto ambiental considerando as } \\
\text { quantidades de energia (E) utilizadas na produção e uso } \\
\text { do produto } \\
\text { - Estimativas de impacto ambiental considerando as } \\
\text { quantidades de químicos (C) utilizados na produção e uso } \\
\text { do produto } \\
\text { - Estimativas de impacto ambiental considerando as } \\
\text { quantidades de outros materiais }(\mathrm{O}) \text { utilizados na } \\
\text { produção e uso do produto }\end{array}$ \\
\hline $\begin{array}{l}\text { 110. Matrix MET (Materials, Energy, } \\
\text { and Toxicity) }\end{array}$ & $\begin{array}{l}\text { Estimativas de impacto ambiental considerando as } \\
\text { quantidades de materiais }(\mathrm{M}) \text { utilizados na produção e } \\
\text { uso do produto }\end{array}$ \\
\hline
\end{tabular}




\begin{tabular}{|c|c|}
\hline & $\begin{array}{l}\text { - Estimativas de impacto ambiental considerando as } \\
\text { quantidades de energia (E) utilizadas na produção e uso } \\
\text { do produto } \\
\text { - Estimativas de impacto ambiental considerando as } \\
\text { emissões de substâncias tóxicas }(T) \text { utilizados na } \\
\text { produção e uso do produto }\end{array}$ \\
\hline $\begin{array}{l}\text { 111. Method for sustainable product } \\
\text { development (MSPD) }\end{array}$ & $\begin{array}{l}\text { - Extração de recursos } \\
\text { - Processos de produção } \\
\text { - } \text { Eransporte } \\
\text { - Emissões } \\
\text { - Escoamento } \\
\text { - Eficiência } \\
\text { - Ustribuição } \\
\text { - Reuso } \\
\text { - Materiais } \\
\text { - Tratamento de disposição } \\
\text { - Substâncias perigosas }\end{array}$ \\
\hline $\begin{array}{l}\text { 112. Method to assess the } \\
\text { adaptability of products (MAAP) }\end{array}$ & $\begin{array}{l}\text { - Utilizar menos recursos } \\
\text { - Desmontagem } \\
\text { - Manutenção e reparo } \\
\text { - Remanufatura } \\
\text { - Deterioração e adaptação } \\
\text { - } \text { Atualizaçãa }\end{array}$ \\
\hline $\begin{array}{l}\text { 113. Methodology based on MCDM } \\
\text { techniques to identifying the } \\
\text { greatest environmental impact } \\
\text { value }\end{array}$ & $\begin{array}{l}\text { - Identificação das fases do ciclo de vida do produto } \\
\text { - Identificação dos principais impactos ambientais em cada } \\
\text { fase } \\
\text { - Legislação } \\
\text { - Análise do impacto na saúde humana, meio ambiente e } \\
\text { - Unservação dos recursos naturais } \\
\text { - Utilizar o Ecodesign Strategy Wheel }\end{array}$ \\
\hline $\begin{array}{l}\text { 114. Modular design technique for } \\
\text { inverse manufacturing }\end{array}$ & $\begin{array}{l}\text { - Considerar todo o ciclo de vida do produto } \\
\text { - Agrupar os componentes com o mesmo ciclo de vida em } \\
\text { - } \text { ódulo para minimizar o seu impacto ambiental } \\
\text { - Reciclagem } \\
\text { - Reusonção } \\
\text { - Atualização } \\
\text { - Recolhimento e disposição de materiais perigosos } \\
\text { - Montagem e desmontagem }\end{array}$ \\
\hline $\begin{array}{l}\text { 115. Multi life cycle assessment } \\
\text { (MLCA) }\end{array}$ & $\begin{array}{l}\text { - } \text { Quantificar o consumo de recursos e o impacto ambiental } \\
\text { - } \text { Delacionados ao processo ou produto } \\
\text { - Remanufatura } \\
\text { - Reengenharia } \\
\text { - Reuso de materiais e componentes } \\
\text { - Reciclagem (circuito aberto e circuito fechado) } \\
\text { - Extração de material } \\
\text { - Síntese de material } \\
\text { - Quantidade de material usado } \\
\text { - Processo de embalagem } \\
\text { - Métodos de transporte } \\
\text { - Distância da viagem } \\
\text { - Emissões associadas ao processo } \\
\text { - Recuperação de energia } \\
\text { - Distribuição }\end{array}$ \\
\hline
\end{tabular}




\begin{tabular}{|c|c|}
\hline & - Montagem e submontagem \\
\hline $\begin{array}{l}\text { 116. Multi-attribute decision-making } \\
\text { (MADM) }\end{array}$ & - Não cita aspectos ambientais \\
\hline $\begin{array}{l}\text { 117. Multicriteria decision analysis } \\
\text { (MCDA) or Multicriteria } \\
\text { assessment (MCA) }\end{array}$ & $\begin{array}{l}\text { - Identificar alternativas para comparar } \\
\text { - Avaliar a performance das alternativas com base em } \\
\text { critérios definidos }\end{array}$ \\
\hline $\begin{array}{l}\text { 118. New DFE targeting and tracking } \\
\text { System - HP }\end{array}$ & $\begin{array}{l}\text { - Base de conhecimento } \\
\text { - Especificação geral para o meio ambiente } \\
\text { - Guias para projetos ambientais } \\
\text { - Requisitos de informaçãa para embalagens e baterias } \\
\text { - Requisitos de documentação ambiental } \\
\text { - Necessidades ambientais futuras } \\
\text { - Regulamentos } \\
\text { - Requisitos de mercado } \\
\text { - Evitar emissões perigosas } \\
\text { - Reduzir o uso de energia na operação } \\
\text { - Inserir aspectos ambientais na cadeia de suprimentos }\end{array}$ \\
\hline $\begin{array}{l}\text { 119. Novel design methodology for } \\
\text { services to increase value } \\
\text { combining service and product }\end{array}$ & - Não cita aspectos ambientais \\
\hline $\begin{array}{l}\text { 120. Packaging impact quick } \\
\text { evaluation tool (PIQET) }\end{array}$ & $\begin{array}{l}\text { - Re-design de embalagens } \\
\text { - } \text { Gerenciamento de resíduos da embalagem } \\
\text { - Reciclagem } \\
\text { - } \text { Extração da matéria prima } \\
\text { - } \text { Empatatura da embalagem } \\
\text { - Disposição final em aterro } \\
\text { - Reuso e recuperação de materiais } \\
\text { - Redução de recursos não renováveis } \\
\text { - Geração de gases de efeito estufa } \\
\text { - Uso de energia } \\
\text { - Uso de água } \\
\text { - Simplificação do LCA } \\
\text { - Material } \\
\text { - Desperdício } \\
\text { - Muantidade de materiais diferentes na embalagem } \\
\text { - Métricas de sustentabilidade de embalagem }\end{array}$ \\
\hline 121. Philips Fast Five Awareness & $\begin{array}{l}\text { - Energia } \\
\text { - Reciclabilidade } \\
\text { - Resíduos perigosos } \\
\text { - Durabilidade } \\
\text { - Reparabilidade } \\
\text { - Preciosidade } \\
\text { - Maneiras alternativas para fornecer o mesmo serviço }\end{array}$ \\
\hline $\begin{array}{l}\text { 122. Philips strategic environmental } \\
\text { challenge (STRETCH) }\end{array}$ & $\begin{array}{l}\text { - } \text { Formular e implementar uma estratégia ambiental } \\
\text { - } \text { Minimização do impacto ambiental ao longo do ciclo de } \\
\text { - Minimização do consumo de energia } \\
\text { - Minimização do uso de materiais } \\
\text { - Minimização no uso de substâncias perigosas ou tóxicas } \\
\text { - Minimização do uso de recursos não-renováveis } \\
\text { - Distribuição e logística eficientes (produzir onde consome, } \\
\text { - distribuição direta ao consumidor) } \\
\text { - } \text { - Aplicanalidade alternativa } \\
\text { - Aumento da funcionalidade do produto }\end{array}$ \\
\hline
\end{tabular}




\begin{tabular}{|c|c|}
\hline & 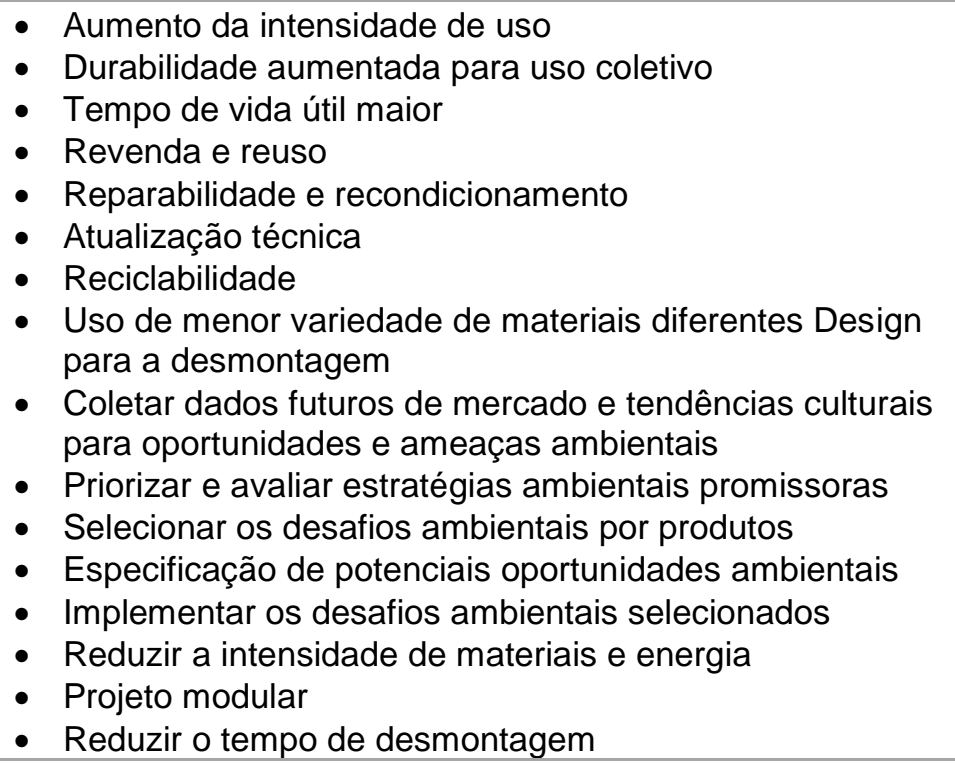 \\
\hline 123. ProBas & $\begin{array}{l}\text { Desenvolver base de dados para uma variedade de } \\
\text { processos e materiais com objetivo de avaliar o ciclo de } \\
\text { vida dos produtos (LCA) }\end{array}$ \\
\hline 124. Product Ecology & $\begin{array}{l}\text { - Comparar diferentes opções de projeto e processo } \\
\text { - Garantir a conformidade com a regulamentação existente } \\
\text { - Considerar todo o ciclo de vida do produto } \\
\text { - Comparar emissões de CO2, água e resíduos } \\
\text { - Avaliar os produtos com base nos requisitos e } \\
\text { regulamentações }\end{array}$ \\
\hline 125. Product improvement matrix & $\begin{array}{l}\text { - Extração da matéria prima } \\
\text { - Manufatura } \\
\text { - Embalagem e distribuição } \\
\text { - Uso } \\
\text { - Fim de vida } \\
\text { - Escolha dos materiais } \\
\text { - } \text { Resíduos de energidos, líquidos e gasosos }\end{array}$ \\
\hline $\begin{array}{l}\text { 126. Product Investigation, Learning } \\
\text { and Optimization Tool (PILOT) } \\
\text { 127. EEE-Pilot } \\
\text { 128. Ecodesign Pilot and Eco Design } \\
\text { Pilot Assistant }\end{array}$ & 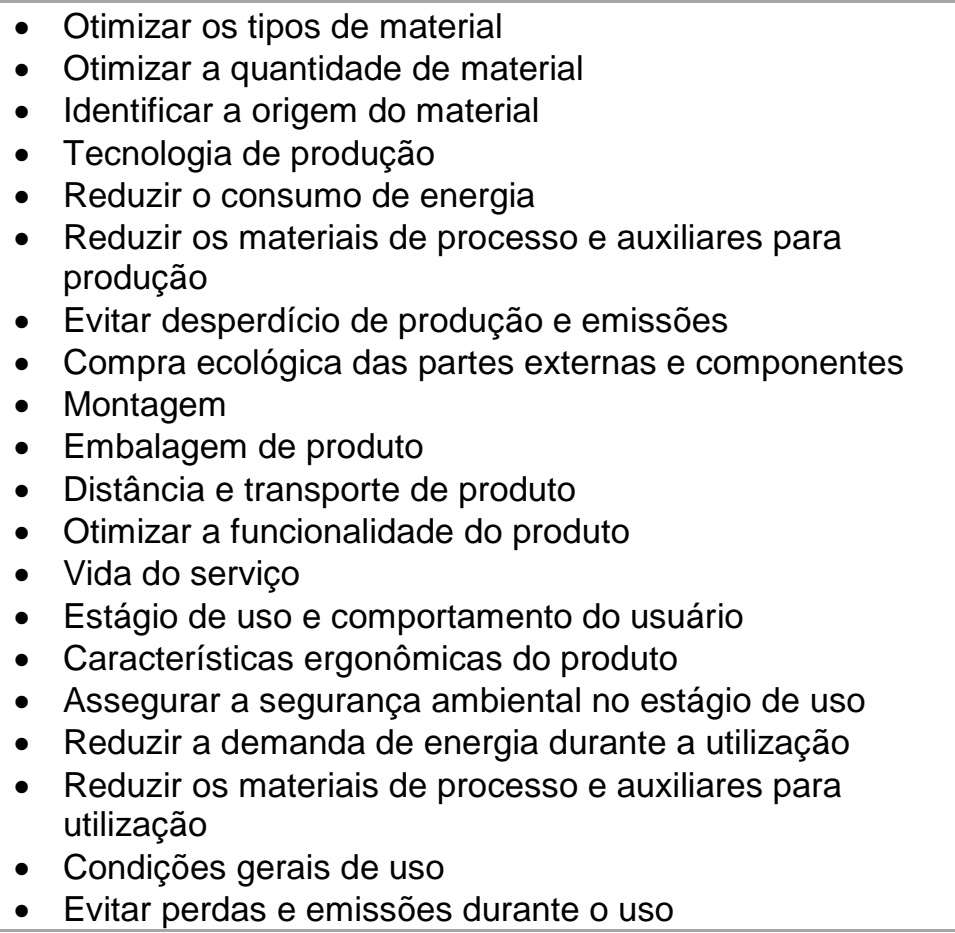 \\
\hline
\end{tabular}




\begin{tabular}{|c|c|}
\hline & $\begin{array}{l}\text { - Melhorar a manutenção do produto } \\
\text { - Melhorar a desmontagem } \\
\text { - Retorno do produto } \\
\text { - Remodelação do produto } \\
\text { - } \text { Aumento da durabilidade do produto } \\
\text { - Reuso de partes } \\
\text { - Melhorar a reparabilidade } \\
\text { - Reciclagem } \\
\text { - } \text { - Subsposição de partes não utilizáveis do produto } \\
\text { - Leis ambientais } \\
\text { - } \text { Base de conhecimento ambiental }\end{array}$ \\
\hline 129. Product life cycle planning (LCP) & $\begin{array}{l}\text { - Planejamento do ciclo de vida do produto } \\
\text { - Atualização de produtos } \\
\text { - Manutenção de produtos } \\
\text { - Extensão da vida útil } \\
\text { - Reuso de componente ou do produto } \\
\text { - Reciclagem do material } \\
\text { - } \text { Disposição em aterro ou incineração } \\
\text { - Recuperação de energia } \\
\text { - Reduzir o consumo de energia } \\
\text { - Desmaterialização } \\
\text { - Especificação ecológica } \\
\text { - Requisitos ambientais } \\
\text { - Valor de degradação dos componentes } \\
\text { - Requisitos do cliente } \\
\text { - Emissões de CO2 } \\
\text { - Substâncias perigosas } \\
\text { - Trade-off entre ambiente, qualidade e custo }\end{array}$ \\
\hline $\begin{array}{l}\text { 130. Quality function deployment for } \\
\text { environment (QFDE) }\end{array}$ & $\begin{array}{l}\text { - } \text { Incorporar aspectos ambientais com base no Voice of } \\
\text { - } \text { Diminuição do uso de materiais } \\
\text { - } \text { Facilidade de transporte e retenção } \\
\text { - } \text { Facilidade de produção e montagem } \\
\text { - } \text { Diminuição do consumo de energia } \\
\text { - } \text { Alta durabilidade } \\
\text { - Uso de menos material } \\
\text { - Facilidade para transporte e guardar } \\
\text { - Facilidade para processar e montar } \\
\text { - Menos consumo de energia } \\
\text { - Facilidade para reuso } \\
\text { - Facilidade de desmontagem } \\
\text { - Facilidade de limpeza } \\
\text { - Facilidade de compactação no fim de vida } \\
\text { - Facilidade de separação e classificação } \\
\text { - Facilidade de incineração } \\
\text { - Segurança em aterros sanitários } \\
\text { - Não perigoso para o meio biológico } \\
\text { - } \text { Emissão de substâncias não perigosas } \\
\text { - Pessibilidade de disposição sem maiores problemas } \\
\text { - Volume do produto } \\
\text { - Número de partes } \\
\text { - Fúmero de tipos de materiais } \\
\text { - } \text { Facilidade de ficar sujo } \\
\text { - Tempo de vida físico }\end{array}$ \\
\hline
\end{tabular}




\begin{tabular}{|c|c|}
\hline & $\begin{array}{l}\text { - Porcentagem de material reciclado } \\
\text { - Barulho, vibração e ondas eletromagnéticas } \\
\text { - Massa de poluidores do ar } \\
\text { - Massa poluidores da água } \\
\text { - Massa de poluidores do solo } \\
\text { - Biodegradabilidade } \\
\text { - Toxicidade dos materiais }\end{array}$ \\
\hline $\begin{array}{l}\text { 131. Quotes for environmentally } \\
\text { weighted recyclability and eco- } \\
\text { efficiency approach (QWERTY- } \\
\text { EE) }\end{array}$ & $\begin{array}{l}\text { - Reciclabilidade } \\
\text { - Reciclagem ao longo de toda cadeia } \\
\text { - } \text { Logística e transporte } \\
\text { - } \text { Atualização e consumo de energia } \\
\text { - Perdas de processos } \\
\text { - Comparar tecnologias diferentes para sistemas de } \\
\text { - } \text { reciclagem } \\
\text { - } \text { Deparação de materiais } \\
\text { - Incineração e aterro } \\
\text { - Composição dos materiais dos produtos } \\
\text { - } \text { Desmontagem } \\
\text { - Aumentar a taxa de coleta de materiais em geral } \\
\text { - Priorizar as opções de melhoria ambiental conforme o } \\
\text { - Renceito de eco-eficiência } \\
\text { - Realocir e substituir materiais indesejáveis } \\
\quad \text { separação }\end{array}$ \\
\hline $\begin{array}{l}\text { 132. Readiness Assessment for } \\
\text { Implementing DfE Strategies } \\
\text { (RAILS) }\end{array}$ & $\begin{array}{l}\text { - Utiliza os mesmos aspectos ambientais descritos no LiDS } \\
\text { (Lifetime Design Strategies) wheel e LCA. }\end{array}$ \\
\hline $\begin{array}{l}\text { 133. Recovery systems modeling and } \\
\text { indicator calculation leading to } \\
\text { end-of-life-conscious Design } \\
\text { (ReSICLED) }\end{array}$ & $\begin{array}{l}\text { - Material reciclado } \\
\text { - Energia recuperada } \\
\text { - Resíduos } \\
\text { - Indicador de recuperação do produto em peso } \\
\text { - Indicador de recuperação econômica do produto } \\
\text { - Indicador de recuperação do impacto ambiental do } \\
\text { - Pressãa da legislação ambiental } \\
\text { - Minimizar a quantidade de resíduos dispostos em aterros } \\
\text { - Criar sistemas de recuperação que sejam } \\
\text { - } \text { economicamente viáveis } \\
\text { - Redução da poluição } \\
\text { - } \text { Desmontagem } \\
\text { - Trituração } \\
\text { - Triagem } \\
\text { - Reciclagem } \\
\text { - Incineração com recuperação de energia } \\
\text { - Utilizar aterro controlado } \\
\text { - Impacto de atributos, partes e componentes do produto } \\
\text { - Identificar oportunidades de melhorias }\end{array}$ \\
\hline 134. Recyclability evaluation method & $\begin{array}{l}\text { - Grau de unificação dos diferentes tipos de materiais } \\
\text { presentes no produto } \\
\text { - O grau de distribuição do material } \\
\text { - Modularização do produto para a reciclagem } \\
\text { - Proporção de material reciclável }\end{array}$ \\
\hline
\end{tabular}




\begin{tabular}{|c|c|}
\hline & $\begin{array}{l}\text { - Separabilidade dos diferentes materiais } \\
\text { - Nível de desmontagem dos materiais } \\
\text { - Toxicidade dos materiais utilizados } \\
\text { - Reciclabilidade } \\
\text { - Unidades, materiais e peso } \\
\text { - Transporte } \\
\text { - } \text { Degradação dos materiais } \\
\text { - Aterro } \\
\text { - Trituração e separação } \\
\text { tecnsiderar o mercado para material reciclado e novas }\end{array}$ \\
\hline 135. Remanufacturing guideline & $\begin{array}{l}\text { - Remanufatura } \\
\text { - Recondicionamento } \\
\text { - Reparo } \\
\text { - Reduzir a perda durante a extração do material } \\
\text { - Reduzir a perda durante o processo de manufatura } \\
\text { - Considerar todo o ciclo de vida do produto } \\
\text { - Legislação } \\
\text { - Montagem e desmontagem }\end{array}$ \\
\hline 136. Requirements Matrix & $\begin{array}{l}\text { - Consumo de materiais (quantidade, tipo, fonte, } \\
\text { característica, impacto associado com extração, processo } \\
\text { - } \text { Uso) } \\
\text { - Gonsumo de energia } \\
\text { - Risção de resíduos } \\
\text { - } \text { Degradação ecológica } \\
\text { - Retirada } \\
\text { - Tratamento e disposição } \\
\text { - Uso e serviço } \\
\text { - Montagem e manufatura } \\
\text { - Entrada e saída de materiais } \\
\text { - Entrada e saída de energia } \\
\text { - Resíduos de materiais } \\
\text { - Distribuição, transporte, materiais e embalagens } \\
\text { - Legislação ambiental }\end{array}$ \\
\hline $\begin{array}{l}\text { 137. Simple additive weighting (SAW) } \\
\text { method }\end{array}$ & - Não cita aspectos ambientais \\
\hline $\begin{array}{l}\text { 138. Simple life cycle assessment } \\
\text { method for green product } \\
\text { conceptual design }\end{array}$ & $\begin{array}{l}\text { - Recursos do produto } \\
\text { - Tipos de materiais utilizados } \\
\text { - Peso dos componentes } \\
\text { - Processo de produção } \\
\text { - Estratégias de fim-de-vida (reuso, reciclagem, aterro e } \\
\text { incineração) } \\
\text { - Emissões de substâncias tóxicas para o ar, solo e água } \\
\text { - Resíduos }\end{array}$ \\
\hline 139. Smart ecodesign checklists & $\begin{array}{l}\text { - Projeto para desmontagem } \\
\text { - Reduzir o uso de componentes } \\
\text { - Reduzir o uso de plásticos } \\
\text { - Uso de materiais reciclados } \\
\text { - Uso de materiais verdes de forma inteligente } \\
\text { - Remover as substâncias perigosas } \\
\text { - Melhorar a funcionalidade do produto } \\
\text { - Aumento da eficiência energética } \\
\text { - Desmaterialização }\end{array}$ \\
\hline 140. Strategy list & $\begin{array}{l}\text { - Melhorar o desempenho ambiental do conceito de um } \\
\text { produto } \\
\text { - Comparar diferentes alternativas de conceitos de }\end{array}$ \\
\hline
\end{tabular}




\begin{tabular}{|c|c|}
\hline & $\begin{array}{l}\text { - } \text { Produtos } \\
\text { - } \text { vida umascando melhorar o desempenho ambiental } \\
\text { - } \text { Manufatura } \\
\text { - Uso } \\
\text { - Reciclagem } \\
\text { - Disposição } \\
\text { - } \text { Distribuição } \\
\text { - Otimizar a entrada de materiais } \\
\text { - Otimizar o uso de energia } \\
\text { - Reduzir a quantidade de uso de terra } \\
\text { - Aumentar o potencial de serviço } \\
\text { - Reduzir poluentes } \\
\text { - Reduzir resíduos } \\
\text { - Reduzir emissões } \\
\text { - Reduzir o risco à saúde e meio ambiente }\end{array}$ \\
\hline $\begin{array}{l}\text { 141. Streamlined Life Cycle } \\
\text { Assessment (SLCA) }\end{array}$ & $\begin{array}{l}\text { - Identificar fases do ciclo de vida e impactos ambientais } \\
\text { - } \text { Ese mereçam atenção } \\
\text { - Uso de energia } \\
\text { - Resíduos líquidos, sólidos e gasosos } \\
\text { - Pré-manufatura } \\
\text { - Manufatura do produto } \\
\text { - Entrega do produto } \\
\text { - Uso do produto } \\
\text { - Recuperação, reciclagem e disposição }\end{array}$ \\
\hline $\begin{array}{l}\text { 142. Sustainable product and service } \\
\text { development (SPSD) }\end{array}$ & $\begin{array}{l}\text { - Sistemas de produção mais limpa } \\
\text { - Considerar todas as fases do ciclo de vida } \\
\text { - } \text { Considerar toda a cadeia de suprimentos } \\
\text { - Redução do volume de produtos produzidos } \\
\text { - } \text { Aumento da desmaterialização dos produtos } \\
\text { - Redução da geração de resíduos e efluentes } \\
\text { - Reduzir o volume utilizado e extração de matérias primas } \\
\text { - Reduzir e substituir o uso de materiais perigosos } \\
\text { - Reciclagem e reuso } \\
\text { - Embalagem retornável } \\
\text { - Numero de materiais } \\
\text { - Reduzir o uso de materiais não renováveis } \\
\text { - Reduzir emissões para o ar } \\
\text { - Ristribuição e transporte } \\
\text { - Reduzir desperdícios vindos do produto e embalagem } \\
\text { - Projeto modular } \\
\text { - Estejonder a vida do produto } \\
\text { - Facilitar a recuperação de componentes } \\
\text { - Reduzir impactos a saúde humana } \\
\text { - Tratamento e disposição }\end{array}$ \\
\hline $\begin{array}{l}\text { 143. Technique to grasp the } \\
\text { corporate profit contribution rate } \\
\text { of eco-friendly products }\end{array}$ & $\begin{array}{l}\text { - Redução do impacto ambiental direto e indireto } \\
\text { - Conservação de energia } \\
\text { - Conservação de recursos } \\
\text { - Prevenção de poluição } \\
\text { - Reciclagem } \\
\text { - Redução de substâncias perigosas } \\
\text { - Uso e reuso de partes } \\
\text { - Sistema de coleta } \\
\text { - Combate a embalem dos materiais }\end{array}$ \\
\hline
\end{tabular}




\begin{tabular}{|c|c|}
\hline $\begin{array}{l}\text { 144. Technique to support } \\
\text { environmentally conscious } \\
\text { service design using QFD }\end{array}$ & $\begin{array}{l}\text { - Desmaterialização } \\
\text { - Efeitos das emissões } \\
\text { - Uso de material } \\
\text { - Uso de energia } \\
\text { - Longo tempo de uso } \\
\text { - Número de partes } \\
\text { - Quantidade de substâncias tóxicas } \\
\text { - Quantidade de materiais na embalagem }\end{array}$ \\
\hline 145. Ten golden rules & $\begin{array}{l}\text { - Não utilize substâncias tóxicas, ou utiliza ciclos fechados } \\
\text { - Mara substâncias tóxicas } \\
\text { - } \text { Mroduçize o consumo e transporte } \\
\text { - } \text { qualidade para mergia e recursos na fase de } \\
\text { - Minimize o consumo de energia e recursos na fase de uso } \\
\text { - Promova reparos e atualizações } \\
\text { - Promova vida longa, especialmente para produtos com } \\
\text { impactos ambientais significantes fora da sua fase de uso } \\
\text { - Investir em melhores materiais, tratamentos de superfície } \\
\text { ou arranjos estruturais para proteger o produto de sujeira, } \\
\text { corrosão e desgaste } \\
\text { - Organize atualizações, reparos e reciclagem através do } \\
\text { acesso à habilidade, rotulagem, módulos, pontos de } \\
\text { ruptura e manuais } \\
\text { - Promova a atualização, reparo e reciclagem } \\
\text { - Use a menor quantidade possível de elementos de junção }\end{array}$ \\
\hline $\begin{array}{l}\text { 146. Ternary diagrams and emergy } \\
\text { accounting }\end{array}$ & $\begin{array}{l}\text { - Energia renovável } \\
\text { - Emissões } \\
\text { - Tratamento de resíduos } \\
\text { - } \text { Qualidade do ecossistema } \\
\text { - Recursos de energia }\end{array}$ \\
\hline 147. The eco-function matrix & $\begin{array}{l}\text { - Combinar o perfil ambiental com o perfil funcional do } \\
\text { produto } \\
\text { - Número de produtos produzidos por ano } \\
\text { - Peso e volume do produto } \\
\text { - Número de materiais diferentes } \\
\text { - Uso de materiais raros } \\
\text { - Uso de materiais tóxicos } \\
\text { - Uso de energia e fonte de energia }\end{array}$ \\
\hline 148. The ideal-eco-product approach & $\begin{array}{l}\text { - Reciclabilidade } \\
\text { - } \text { - Baicil de desmontar poluição durante o uso do produto } \\
\text { - Alta eficiência energética } \\
\text { - Não prejudicial ao meio ambiente após incineração } \\
\text { - Reduzir a quantidade de resíduos perigosos } \\
\text { - Reduzir as emissões tóxicas } \\
\text { - Não contaminar outras substâncias } \\
\text { - Reduzir o consumo de material } \\
\text { - Reduzir a geração de resíduos } \\
\text { - Incineração } \\
\text { - Disposição } \\
\text { - Reciclagem e reprocessamento de material } \\
\text { - Remanufatura } \\
\text { - Reuso de materiais } \\
\text { - Uma longa vida útil } \\
\text { - Separar os materiais perigosos dos demais }\end{array}$ \\
\hline
\end{tabular}




\begin{tabular}{|c|c|}
\hline & $\begin{array}{l}\text { - Evitar materiais compostos } \\
\text { - Baixo número de conexões } \\
\text { - Fácil de limpar } \\
\text { - Estrutura de projeto simples } \\
\text { - Estrutura modular } \\
\text { - Bom para atualização e modernização } \\
\text { - Poluição de água } \\
\text { - Minimizar o consumo de energia } \\
\text { - Minimizar o consumo de água } \\
\text { - Analisar os impactos ambientais que a tecnologia pode } \\
\text { causar }\end{array}$ \\
\hline 149. The morphological box & - Componentes do produto \\
\hline 150. TRIZ and Eco-innovation & $\begin{array}{l}\text { - Substâncias perigosas } \\
\text { - Reduzir o consumo de recursos } \\
\text { - Reciclagem de resíduos } \\
\text { - Risco ambiental e a saúde } \\
\text { - Revalorização e conservação de energia } \\
\text { - Intensidade de massa dos componentes } \\
\text { - Intensidade de energia } \\
\text { - Rumento da funcionalidade do produto } \\
\text { - Reuso de resíduos }\end{array}$ \\
\hline 151. Two-dimensional diagram & $\begin{array}{l}\text { - Impactos ambientais dos componentes } \\
\text { - Reciclagem } \\
\text { - Analisar todas as informações ambientais e econômicas } \\
\text { de um produto }\end{array}$ \\
\hline 152. Umberto & $\begin{array}{l}\text { - Eficiência de materiais } \\
\text { - Otimização de processos } \\
\text { - Gerenciamento de energia } \\
\text { - Indicadores de impacto ambiental e econômico } \\
\text { - Avaliação do ciclo de vida do produto }\end{array}$ \\
\hline $\begin{array}{l}\text { 153. Use phase analysis (UPA) } \\
\text { matrix }\end{array}$ & $\begin{array}{l}\text { - Inventário de dados relevantes } \\
\text { - Fluxo de materiais no processo } \\
\text { - Disposição, doação e venda } \\
\text { - Emissões tóxicas } \\
\text { - Desperdício de embalagens } \\
\text { - Manutenção e reparo } \\
\text { - Transporte e distância }\end{array}$ \\
\hline $\begin{array}{l}\text { 154. Volvo's black, gray and white } \\
\text { lists }\end{array}$ & $\begin{array}{l}\text { - Classificar e selecionar as substâncias químicas que } \\
\text { podem ser críticas ao meio ambiente e saúde humana } \\
\text { - Utilizar materiais alternativos }\end{array}$ \\
\hline
\end{tabular}




\section{APÊNDICE V - Os 365 aspectos ambientais identificados e extraídos dos métodos e ferramentas de ecodesign}

\begin{tabular}{|c|c|}
\hline Código & Aspectos Ambientais \\
\hline 1 & Acumular conhecimentos com os feedbacks das implicações das escolhas feitas. \\
\hline 2 & $\begin{array}{l}\text { Agrupar os componentes com o mesmo ciclo de vida em módulo para minimizar o } \\
\text { seu impacto ambiental. }\end{array}$ \\
\hline 3 & Ajustar automáticamente para consumo mínimo de energia. \\
\hline 4 & Alterar para baterias recarregáveis. \\
\hline 5 & Analisar a biodegradabilidade e toxidade dos materiais. \\
\hline 6 & $\begin{array}{l}\text { Analisar a composição do material (número de componentes, número de diferentes } \\
\text { materiais). }\end{array}$ \\
\hline 7 & Analisar a destinação dos resíduos. \\
\hline 8 & Analisar a deterioração e adaptação do produto. \\
\hline 9 & $\begin{array}{l}\text { Analisar a legislação atual e futura e as necessidades atuais e emergentes do cliente } \\
\text { em termos de sustentabilidade e meio ambiente relevantes ao produto. }\end{array}$ \\
\hline 10 & Analisar a rota de disposição. \\
\hline 11 & $\begin{array}{l}\text { Analisar a sustentabilidade de dois produtos comparando as suas características } \\
\text { ambientais. }\end{array}$ \\
\hline 12 & Analisar as condições gerais de uso. \\
\hline 13 & Analisar as diferentes condições de operação. \\
\hline 14 & Analisar as opções de empacotamento do produto e distribuição da embalagem. \\
\hline 15 & $\begin{array}{l}\text { Analisar as pegadas ecológicas (carbono, água, energia, emissão, ambiente de } \\
\text { trabalho e impactos tóxicos). }\end{array}$ \\
\hline 16 & $\begin{array}{l}\text { Analisar comparativamente a alternativa ambiental com o produto atual utilizando de } \\
\text { métricas. }\end{array}$ \\
\hline 17 & Analisar e medir as fontes de energia e sua eficiência. \\
\hline 18 & Analisar e monitorar a viabilidade ambiental dos projetos. \\
\hline 19 & Analisar o balanço dos materiais tóxicos utilizados nos processos. \\
\hline 20 & Analisar o custo de disposição. \\
\hline 21 & Analisar o efeito a exposição das substâncias químicas. \\
\hline 22 & Analisar o sistema em que o produto está inserido. \\
\hline 23 & Analisar os impactos ambientais que a tecnologia pode causar. \\
\hline 24 & Analisar os impactos na Biomassa. \\
\hline 25 & Analisar todas as informações ambientais e econômicas de um produto. \\
\hline 26 & Aplicar estruturas entrelaçadas para aumentar a rigidez. \\
\hline 27 & $\begin{array}{l}\text { Aplicar novos conceitos (desmaterialização, uso compartilhado do produto, integração } \\
\text { de funções, otimização de funções do produto e componentes). }\end{array}$ \\
\hline 28 & Aplicar técnicas estruturais de materiais para minimizar o volume total do material. \\
\hline 29 & Atentar aos regulamentos externos. \\
\hline 30 & Atentar nas preparacões e substâncias. \\
\hline 31 & Aumentar a durabilidade do produto. \\
\hline 32 & Aumentar a eficiencia da distribuição e logística. \\
\hline 33 & Aumentar a eficiência energética. \\
\hline 34 & Aumentar a funcionalidade do produto. \\
\hline 35 & Aumentar a produtividade dos recursos. \\
\hline 36 & Aumentar a resistência do produto. \\
\hline 37 & Aumentar a taxa de coleta de materiais em geral. \\
\hline 38 & Aumentar o conhecimento das pessoas sobre as oportunidades do ecodesign. \\
\hline 39 & Aumentar o tempo de vida do produto. \\
\hline 40 & Aumentar o uso de fontes renováveis. \\
\hline 41 & Avaliar a capacidade de armazenamento e destruição de resíduos. \\
\hline 42 & Avaliar a capacidade de produção dos fornecedores. \\
\hline 43 & Avaliar a eficiência durante o uso do produto. \\
\hline 44 & Avaliar a entrada de materiais no processo. \\
\hline
\end{tabular}




\begin{tabular}{|c|c|}
\hline 45 & $\begin{array}{l}\text { Avaliar a intensidade de duração (avalia as economias de recursos para a produção e } \\
\text { manutenção de um produto que tem uma vida útil maior). }\end{array}$ \\
\hline 46 & $\begin{array}{l}\text { Avaliar a intensidade de recuperação (economia de recursos por recuperação de } \\
\text { materiais). }\end{array}$ \\
\hline 47 & Avaliar a necessidade de energia utilizada para reciclagem. \\
\hline 48 & Avaliar a necessidade de preparação da matéria prima. \\
\hline 49 & Avaliar a perda total de processo. \\
\hline 50 & Avaliar a performance ambiental dos produtos. \\
\hline 51 & Avaliar a performance das alternativas com base em critérios definidos. \\
\hline 52 & Avaliar a perspectiva legal do produto. \\
\hline 53 & Avaliar a porcentagem de material reciclado. \\
\hline 54 & Avaliar a portabilidade do produto. \\
\hline 55 & Avaliar a pressão da legislação ambiental. \\
\hline 56 & Avaliar a segurança em aterros sanitários. \\
\hline 57 & Avaliar alternativas para embalagem. \\
\hline 58 & Avaliar as necessidades ambientais futuras. \\
\hline 59 & Avaliar as opções de geração verdes. \\
\hline 60 & Avaliar as prioridades ambientais para o produto. \\
\hline 61 & $\begin{array}{l}\text { Avaliar o prejuízo (saúde humana, bem estar social, biodiversidade, ecossistema e } \\
\text { vegetação). }\end{array}$ \\
\hline 62 & Avaliar o tempo de desenvolvimento. \\
\hline 63 & Avaliar o tempo e energia gastos no processo de desmontagem. \\
\hline 64 & Avaliar o trade-off entre ambiente, qualidade e custo. \\
\hline 65 & Avaliar o uso e geração da voz do cliente na produção. \\
\hline 66 & Avaliar o valor de degradação dos componentes. \\
\hline 67 & Avaliar os impactos ambientais do produto. \\
\hline 68 & Avaliar os produtos com base nos requisitos e regulamentações. \\
\hline 69 & Avaliar os riscos potenciais à saúde e ao meio ambiente. \\
\hline 70 & Avaliar potenciais oportunidades ambientais. \\
\hline 71 & Balancear as diferentes características do produto. \\
\hline 72 & Calcular o custo do produto considerando todo o ciclo de vida do produto. \\
\hline 73 & $\begin{array}{l}\text { Caracterizar o produto (aquecimento global, esgotamento da camada de ozônio, } \\
\text { poluição do ar, toxidade humana, toxidade ambiental, uso e consumo dos recursos } \\
\text { naturais e desperdício). }\end{array}$ \\
\hline 74 & $\begin{array}{l}\text { Checar a tendência dos produtos com base em padrões internos e externos a } \\
\text { empresa. }\end{array}$ \\
\hline 75 & $\begin{array}{l}\text { Classificar e selecionar as substâncias químicas que podem ser críticas ao meio } \\
\text { ambiente e saúde humana. }\end{array}$ \\
\hline 76 & $\begin{array}{l}\text { Coletar dados futuros de mercado e tendências culturais para oportunidades e } \\
\text { ameaças ambientais. }\end{array}$ \\
\hline 77 & Combinar o perfil ambiental com o perfil funcional do produto. \\
\hline 78 & Comparar alternativas de projeto considerando a funcionalidade e utilidade. \\
\hline 79 & Comparar diferentes opções de processo. \\
\hline 80 & Comprar partes externas e componentes ecológicos. \\
\hline 81 & Concentrar elementos tóxicos para fácil remoção e tratamento. \\
\hline 82 & Conduzir teste piloto para avaliar alternativas ao uso de materiais tóxicos. \\
\hline 83 & Conservar os recursos. \\
\hline 84 & Considerar a percepção ambiental científica, governamental e do cliente. \\
\hline 85 & Considerar a possibilidade de revenda e reuso. \\
\hline 86 & Considerar a viabilidade ambiental, social, técnica, para os consumidores e financeira. \\
\hline 87 & Considerar as características ergonômicas do produto. \\
\hline 88 & Considerar as expectativas ambientais do cliente. \\
\hline 89 & Considerar as taxas e penalidades ecológicas. \\
\hline 90 & Considerar o mercado para material reciclado e novas tecnologias. \\
\hline 91 & Considerar trituração e triagem. \\
\hline 92 & $\begin{array}{l}\text { Criar Indicador do Potencial de Reciclagem (quantifica a aplicabilidade de um } \\
\text { produto/material para diferentes rotas de reciclagem). }\end{array}$ \\
\hline
\end{tabular}




\begin{tabular}{|c|c|}
\hline 93 & $\begin{array}{l}\text { Criar indicadores de avaliação de impacto ambiental (índice de gases de efeito estufa, } \\
\text { índice de depleção da camada de ozônio). }\end{array}$ \\
\hline 94 & Criar indicadores de consumo de energia, água e materiais. \\
\hline 95 & Criar normas ambientais internas da organização. \\
\hline 96 & Criar sistemas de recuperação que sejam economicamente viáveis. \\
\hline 97 & $\begin{array}{l}\text { Criar uma lista de sugestões para cada fase do ciclo de vida buscando melhorar o } \\
\text { desempenho ambiental. }\end{array}$ \\
\hline 98 & Cumprir as funções técnicas. \\
\hline 99 & Declarar o material com os respectivos dados ambientais. \\
\hline 100 & Decompor e integrar materiais e componentes. \\
\hline 101 & Definir parâmetros de tolerância. \\
\hline 102 & Descentralizar atividades para reduzir volumes transportados. \\
\hline 103 & $\begin{array}{l}\text { Desenvolver e implantar uma base de dados com impacto ambiental dos materiais, } \\
\text { processos e componentes (Biblioteca) durante o ciclo de vida do produto. }\end{array}$ \\
\hline 104 & $\begin{array}{l}\text { Desenvolver partes e produtos que possam ser desmontados (desmanufatura) de } \\
\text { maneira rápida e econômica. }\end{array}$ \\
\hline 105 & Desenvolver plano de contingência para reabilitação em caso de acidente ambiental. \\
\hline 106 & Desenvolver processos para consumir menos consumíveis. \\
\hline 107 & Desenvolver processos para reciclar grande quantidade de resíduos do processo. \\
\hline 108 & Desenvolver produto modular. \\
\hline 109 & Desenvolver projeto modular. \\
\hline 110 & Desmaterializar o produto ou alguns dos seus componentes. \\
\hline 111 & Disponibilizar ao usuário final instruções para disposição e tratamento. \\
\hline 112 & Disponibilizar informações para o usuário otimizar a operação do produto. \\
\hline 113 & Disponibilizar informações para os clientes para o fornecimento das embalagens. \\
\hline 114 & Disponibilizar informações regulatórias. \\
\hline 115 & Elaborar e controlar a documentação. \\
\hline 116 & Eliminar embalagens secundárias e terciárias quando possível. \\
\hline 117 & Eliminar encaixes fracos entre os componentes. \\
\hline 118 & Encorajar os fornecedores a coletar as embalagens. \\
\hline 119 & Encorajar os fornecedores a reduzir a quantidade e tipo de embalagem. \\
\hline 120 & $\begin{array}{l}\text { Envolver toda a cadeia de suprimentos e fornecimento para melhorar a performance } \\
\text { ambiental. }\end{array}$ \\
\hline 121 & Escolher embalagens reutilizáveis. \\
\hline 122 & $\begin{array}{l}\text { Especificar adesivos compatíveis com as etiquetas, revestimentos de superfície, } \\
\text { pigmentos, etc, que não interferem com a limpeza. }\end{array}$ \\
\hline 123 & Especificar componentes de alta eficiência energética. \\
\hline 124 & Especificar energia de fonte mais limpa. \\
\hline 125 & Especificar materiais e componentes ambientais. \\
\hline 126 & Especificar materiais e componentes leves. \\
\hline 127 & $\begin{array}{l}\text { Especificar materiais e elementos de fixação para a reciclagem mutuamente } \\
\text { compatível. }\end{array}$ \\
\hline 128 & Especificar materiais não misturados, não compostos e não ligados. \\
\hline 129 & $\begin{array}{l}\text { Especificar materiais que não necessitam de tratamento adicional de superfície ou } \\
\text { tintas. }\end{array}$ \\
\hline 130 & $\begin{array}{l}\text { Especificar materiais recicláveis ou reciclados, especialmente aqueles dentro da } \\
\text { empresa ou para os quais existe um mercado ou precisa ser estimulado. }\end{array}$ \\
\hline 131 & $\begin{array}{l}\text { Especificar os melhores materiais, tratamentos de superfície, ou arranjos estruturais } \\
\text { para proteger os produtos da sujeira, corrosão e uso. }\end{array}$ \\
\hline 132 & Especificar processos limpos com alta eficiência de produção. \\
\hline 133 & Especificar recursos e formas de energia renováveis. \\
\hline 134 & Especificar requisitos ambientais. \\
\hline 135 & $\begin{array}{l}\text { Especificar substâncias não perigosas e de forma ambientalmente limpa, } \\
\text { especialmente no que diz respeito à saúde do usuário. }\end{array}$ \\
\hline 136 & $\begin{array}{l}\text { Especificar todas as articulações de modo que elas sejam separáveis manualmente ou } \\
\text { empreguem apenas ferramentas simples. }\end{array}$ \\
\hline 137 & Especificar um único tipo de material para o produto e seus subconjuntos. \\
\hline
\end{tabular}




\begin{tabular}{|c|c|}
\hline 138 & $\begin{array}{l}\text { Estabelecer os objetivos gerais e ambientais do ciclo de vida alvo através da análise de } \\
\text { recursos de produtos similares e seus mercados. }\end{array}$ \\
\hline 139 & $\begin{array}{l}\text { Estabelecer uma plataforma de comunicação entre as prioridades funcionais e os } \\
\text { impactos ambientais. }\end{array}$ \\
\hline 140 & Estender a expectativa de vida dos materiais e serviços. \\
\hline 141 & Estimular a responsabilidade ambiental por toda a cadeia de suprimentos. \\
\hline 142 & Estratégia de reciclagem e reuso. \\
\hline 143 & $\begin{array}{l}\text { Estruturar o produto para evitar gerar resíduos e minimizar o desperdício de material na } \\
\text { produção. }\end{array}$ \\
\hline 144 & Evitar a utilização de embalagens sem função específica. \\
\hline 145 & Evitar colagem com adesivos. \\
\hline 146 & Evitar componentes de difícil manuseio. \\
\hline 147 & Evitar dobras estreitas e buracos, para facilitar a limpeza. \\
\hline 148 & Evitar emissões gasosas. \\
\hline 149 & Evitar grandes dimensões. \\
\hline 150 & Evitar materiais tóxicos na embalagem do produto. \\
\hline 151 & Evitar o uso de consumíveis tóxicos ou indesejáveis. \\
\hline 152 & Evitar perdas de manufatura. \\
\hline 153 & Evitar procedimentos na embalagem que consome energia. \\
\hline 154 & Evitar tecnologias que utilizem materiais tóxicos. \\
\hline 155 & Evitar uso de matéria prima e componentes de fontes problemáticas. \\
\hline 156 & Evitar uso de materiais compostos inseparáveis. \\
\hline 157 & Evitar uso de materiais escassos. \\
\hline 158 & Evitar uso de plástico pigmentado. \\
\hline 159 & Exigir alguns serviços e ferramentas de inspeção. \\
\hline 160 & Explorar as propriedades únicas de materiais reciclados. \\
\hline 161 & Explorar o uso de embalagens reutilizáveis durante a distribuição. \\
\hline 162 & Facilitar a atualização e adaptação do produto. \\
\hline 163 & Facilitar a coleta e transporte no fim de vida do produto. \\
\hline 164 & Facilitar a combustão na incineração, utilizar materiais com alta energia. \\
\hline 165 & Facilitar a compactação do produto no fim de vida. \\
\hline 166 & Facilitar a desmontagem, reparos e tratamento. \\
\hline 167 & Facilitar a manutenção. \\
\hline 168 & Facilitar a manutenção e reparo de componentes. \\
\hline 169 & Facilitar a remanufatura. \\
\hline 170 & Facilitar a separação dos diferentes tipos de materiais da embalagem do produto. \\
\hline 171 & Facilitar a separação e classificação. \\
\hline 172 & Facilitar o teste de componentes. \\
\hline 173 & Facilitar o transporte e retenção. \\
\hline 174 & Fazer seu produto reciclável. \\
\hline 175 & Fazer um perfil ambiental do produto. \\
\hline 176 & Focar nos parâmetros ambientais internos (propriedades dos produtos). \\
\hline 177 & Formular e implementar uma estratégia ou política ambiental. \\
\hline 178 & Fornecimento de informações ambientais dos produtos. \\
\hline 179 & Garantir a conformidade com a regulamentação existente. \\
\hline 180 & Garantir a segurança ambiental no estágio de uso. \\
\hline 181 & Garantir alta confiança do produto. \\
\hline 182 & Garantir alta taxa de retorno de produtos no fim de vida. \\
\hline 183 & $\begin{array}{l}\text { Garantir o mínimo de manutenção e minimizar os modos de falha do produto e de seus } \\
\text { componentes. }\end{array}$ \\
\hline 184 & Garantir que as juntas e parafusos são facilmente acessíveis. \\
\hline 185 & Garantir que as partes reutilizáveis possam ser facilmente limpas e sem danos. \\
\hline 186 & $\begin{array}{l}\text { Garantir que as técnicas de desmontagem destrutivas não irão prejudicar as pessoas } \\
\text { ou componentes reutilizáveis. }\end{array}$ \\
\hline 187 & Garantir que os controles de recursos sejam faceis de operar e entender. \\
\hline 188 & Garantir que os materiais incompatíveis sejam facilmente separados. \\
\hline 189 & Garantir que os resíduos são à base de água ou biodegradáveis. \\
\hline
\end{tabular}




\begin{tabular}{|c|c|}
\hline 190 & Gerenciar a energia e perdas. \\
\hline 191 & Identificar a importância das funções do produto para o cliente. \\
\hline 192 & Identificar a origem do material. \\
\hline 193 & Identificar alternativas ambientais para partes e produtos. \\
\hline 194 & $\begin{array}{l}\text { Identificar as fases do ciclo de vida do produto que apresentam o maior impacto } \\
\text { ambiental, considerando o balanço de massa e energia. }\end{array}$ \\
\hline 195 & Identificar oportunidades de melhorias ambientais. \\
\hline 196 & Identificar os pontos ambientais críticos para desenvolver indicadores ambientais. \\
\hline 197 & Identificar os processos responsáveis pelos impactos ambientais. \\
\hline 198 & $\begin{array}{l}\text { Implantar mecanismos automáticos para reiniciar o produto na sua configuração mais } \\
\text { eficiente. }\end{array}$ \\
\hline 199 & Implantar os desafios ambientais selecionados. \\
\hline 200 & Implantar plataformas reutilizáveis e substituíveis de módulos e componentes. \\
\hline 201 & Implantar regras de tratamento. \\
\hline 202 & Imprimir instruções claras para reciclagem da embalagem. \\
\hline 203 & Incineração de substâncias não perigosas e com recuperação de energia. \\
\hline 204 & $\begin{array}{l}\text { Incluir os custos diretos e indiretos dos impactos ambientais causados pelo produto } \\
\text { durante todo o ciclo de vida. }\end{array}$ \\
\hline 205 & Incluir rótulos e instruções para o manuseio seguro de materiais tóxicos \\
\hline 206 & Incorporar características que impedem o desperdício de materiais pelo usuário \\
\hline 207 & Incorporar controles intuitivos para economia de recursos. \\
\hline 208 & $\begin{array}{l}\text { Incorporar operação parcial e permitir que os usuários possam desligar os sistemas } \\
\text { parcialmente ou totalmente. }\end{array}$ \\
\hline 209 & Incorporar projetos com conservação de energia. \\
\hline 210 & Indicar como o produto deve ser aberto e fazer pontos de acesso óbvio. \\
\hline 211 & $\begin{array}{l}\text { Indicar no produto quais as peças que têm que ser limpas ou mantidas de uma forma } \\
\text { específica. }\end{array}$ \\
\hline 212 & Inserir requisitos ambientais na tomada de decisão. \\
\hline 213 & Instalar proteção contra a emissão de poluentes e substâncias perigosas. \\
\hline 214 & Integrar as funções do produto. \\
\hline 215 & Integrar e ponderar os indicadores. \\
\hline 216 & $\begin{array}{l}\text { Integrar o desenvolvimento da embalagem para transporte e embalagem para } 0 \\
\text { produto. }\end{array}$ \\
\hline 217 & Intensificar o uso e longevidade do produto. \\
\hline 218 & $\begin{array}{l}\text { Interligar os fluxos de energia disponíveis nos materiais do produto e entre o produto e } \\
\text { seu ambiente. }\end{array}$ \\
\hline 219 & Introduzir mais opções de operação (stand by). \\
\hline 220 & $\begin{array}{l}\text { Inventariar e calcular o impacto ambiental da extração de recursos, emissões } \\
\text { relevantes e uso do solo. }\end{array}$ \\
\hline 221 & Investigar alternativas para uso de solventes tóxicos e óleos. \\
\hline 222 & $\begin{array}{l}\text { Investigar alternativas tecnológicas com as mesmas funções do produto e com menos } \\
\text { volume de material. }\end{array}$ \\
\hline 223 & Logística, distribuição e distância do transporte. \\
\hline 224 & Manter estabilidade na colocação das partes durante a montagem. \\
\hline 225 & Marcar os materiais em moldes por tipos e protocolos de reutilização. \\
\hline 226 & Maximizar a eficiência do sistema para toda uma gama de condições de uso. \\
\hline 227 & $\begin{array}{l}\text { Maximizar oportunidades de reuso e redução de perdas de embalagens durante } 0 \\
\text { transporte. }\end{array}$ \\
\hline 228 & $\begin{array}{l}\text { Melhorar a eficiência de energia dos edifícios (calor, luz, ventilação, ar condicionado, } \\
\text { etc.). }\end{array}$ \\
\hline 229 & $\begin{array}{l}\text { Melhorar a estética e funcionalidade para assegurar a vida estética ao período de vida } \\
\text { técnica. }\end{array}$ \\
\hline 230 & Melhorar o desempenho ambiental do conceito de um produto. \\
\hline 231 & Melhorar o perfil ecológico e atributos verdes dos produtos. \\
\hline 232 & Miniaturizar. \\
\hline 233 & Minimizar a degradação ecológica. \\
\hline 234 & Minimizar a necessidade de disposição periódica de resíduos sólidos (cartuchos, \\
\hline
\end{tabular}




\begin{tabular}{|c|c|}
\hline & baterias, etc.). \\
\hline 235 & Minimizar a necessidade de substituição de materias refrigerantes e lubrificantes. \\
\hline 236 & Minimizar a necessidade de transporte de materiais e componentes. \\
\hline 237 & Minimizar a quantidade de resíduos dispostos em aterros. \\
\hline 238 & Minimizar cabos e fios entre as submontagens para arquitetura do produto apropriada. \\
\hline 239 & Minimizar o espaço necessário para estocar o produto. \\
\hline 240 & Minimizar o numero de diferentes materiais utilizados para produzir a embalagem \\
\hline 241 & Minimizar o numero de materiais incompatíveis. \\
\hline 242 & Minimizar o número e a duração das operações de desmontagem. \\
\hline 243 & Minimizar o número e a variedade de elementos para montagem. \\
\hline 244 & Minimizar o peso e volume da embalagem. \\
\hline 245 & Minimizar o tempo requerido para preparação e monitoramento do produto. \\
\hline 246 & $\begin{array}{l}\text { Minimizar o volume, área e peso de peças e materiais para os quais a energia é } \\
\text { transferida. }\end{array}$ \\
\hline 247 & Modularizar o produto para a reciclagem. \\
\hline 248 & Monitorar o consumo de energia dos equipamentos. \\
\hline 249 & Não contaminar outras substâncias. \\
\hline 250 & Obter certificação ambiental. \\
\hline 251 & $\begin{array}{l}\text { Organizar atualizações, reparos e reciclagem através do acesso à habilidade, } \\
\text { rotulagem, módulos, pontos de ruptura e manuais. }\end{array}$ \\
\hline 252 & $\begin{array}{l}\text { Organizar o produto ou sistema em módulos hierárquicos por estética, reparação e } \\
\text { protocolo de fim de vida. }\end{array}$ \\
\hline 253 & Organizar o retorno da embalagem para reuso ou reciclagem. \\
\hline 254 & Padronizar o uso de componentes. \\
\hline 255 & Pensar em desmontagem. \\
\hline 256 & Pensar em disposição de resíduos (incineração, reciclagem, aterro, doação e venda). \\
\hline 257 & Pensar em maneiras alternativas para fornecer o mesmo serviço. \\
\hline 258 & $\begin{array}{l}\text { Pensar em novas maneiras de fazer (uso compartilhado, produtos com multi-função, } \\
\text { serviços e aluguel). }\end{array}$ \\
\hline 259 & Permitir desmontagem repetitiva. \\
\hline 260 & $\begin{array}{l}\text { Permitir fácil reparação e modernização, especialmente para os componentes que } \\
\text { sofrem rápidas mudanças. }\end{array}$ \\
\hline 261 & Pesquisar leis sobre uso de substâncias tóxicas. \\
\hline 262 & Planejar curso de melhorias de eficiência. \\
\hline 263 & Planejar o ciclo de vida do produto. \\
\hline 264 & Planejar rotas de transporte para minimizar emissões dos veículos. \\
\hline 265 & Possuir conhecimentos de conformidade ambiental. \\
\hline 266 & Preferir embalagem e rótulos ambientais. \\
\hline 267 & Preferir embalagem retornável. \\
\hline 268 & Preferir produtos com adaptabilidade. \\
\hline 269 & Preferir uso de energia de fonte local. \\
\hline 270 & Prevenir a contaminação do solo. \\
\hline 271 & Priorizar as opções de melhoria ambiental conforme o conceito de eco-eficiência. \\
\hline 272 & Priorizar e avaliar estratégias ambientais promissoras. \\
\hline 273 & Projetar componentes comuns e remanufaturados. \\
\hline 274 & Projetar consumo de fontes de energia passiva. \\
\hline 275 & Projetar desmontagem em uma única direção sem reorientação. \\
\hline 276 & Projetar embalagem como parte do produto. \\
\hline 277 & Projetar juntas que abrem com as mesmas ferramentas. \\
\hline 278 & $\begin{array}{l}\text { Projetar material dobrável, flexível, de encaixe ou desmontável para distribuir os } \\
\text { produtos em um estado compacto. }\end{array}$ \\
\hline 279 & $\begin{array}{l}\text { Projetar para reciclagem (taxa de material recuperado, taxa de eficiência de } \\
\text { reciclagem). }\end{array}$ \\
\hline 280 & Projetar produto para cumprir a expectativa de vida. \\
\hline 281 & Projetar produto para uso mais eficiente de materiais de manutenção. \\
\hline 282 & Projetar produtos compactos com alta densidade de estoque. \\
\hline 283 & Projetar produtos de uso coletivo. \\
\hline
\end{tabular}




\begin{tabular}{|c|c|}
\hline 284 & $\begin{array}{l}\text { Projetar produtos multifuncionais para facilitar adaptação do produto as mudanças } \\
\text { culturais e físicas. }\end{array}$ \\
\hline 285 & Projetar produtos para substituir os componentes conforme planejado. \\
\hline 286 & Projetar produtos para uso secundário. \\
\hline 287 & Projetar produtos que não consomem materiais tóxicos. \\
\hline 288 & Projetar produtos que precisem de menos manutenção. \\
\hline 289 & Quantificar as emissões causadas por um material durante a incineração dos resíduos. \\
\hline 290 & Realizar a contabilidade do fluxo de materiais. \\
\hline 291 & Realizar o controle de efluentes e resíduos. \\
\hline 292 & Realizar treinamento dos funcionários sobre ecodesign. \\
\hline 293 & Reaproveitar energia de componentes altamente embutidos. \\
\hline 294 & $\begin{array}{l}\text { Reconhecer quais são os atributos ambientais que mais precisam ser melhorados e os } \\
\text { métodos de manufatura utilizados. }\end{array}$ \\
\hline 295 & Recuperar energia. \\
\hline 296 & Reduzir a espessura do material. \\
\hline 297 & Reduzir a perda durante a extração do material. \\
\hline 298 & Reduzir a perda durante o processo de manufatura. \\
\hline 299 & Reduzir a poluição do ar e da água. \\
\hline 300 & Reduzir as etapas de produção quando possível. \\
\hline 301 & Reduzir custos de fim de vida. \\
\hline 302 & Reduzir o barulho, vibração e ondas eletromagnéticas. \\
\hline 303 & Reduzir o consumo de eletricidade. \\
\hline 304 & Reduzir o desperdício de embalagens. \\
\hline 305 & Reduzir o número de conexões. \\
\hline 306 & Reduzir o número de ligações que não podem ser desfeitas. \\
\hline 307 & Reduzir o numero de parafusos. \\
\hline 308 & Reduzir o padrão de energia dos subsistemas que não estão em uso. \\
\hline 309 & Reduzir o tempo de desmontagem. \\
\hline 310 & Reduzir o uso de consumíveis e baterias. \\
\hline 311 & Reduzir o uso de materiais de fontes naturais escassas. \\
\hline 312 & Reduzir o uso de plásticos. \\
\hline 313 & Reduzir o uso e ocupação de solo. \\
\hline 314 & Reduzir o volume de material integrando as funções. \\
\hline 315 & Reduzir os materiais de processo e auxiliares para produção. \\
\hline 316 & Reduzir os materiais e aditivos que definem as partes e componentes. \\
\hline 317 & Reduzir para um número mínimo de peças. \\
\hline 318 & Reduzir perda de calor e perda de material. \\
\hline 319 & Repensar a forma das estruturas, dos componentes, juntas e partes. \\
\hline 320 & Re-projeto de módulos. \\
\hline 321 & Requisitos da função ambiental. \\
\hline 322 & Requisitos de documentação ambiental. \\
\hline 323 & Requisitos de informação para embalagens e baterias. \\
\hline 324 & $\begin{array}{l}\text { Resolver contradições entre o desempenho ambiental e o aumento da utilidade do } \\
\text { produto. }\end{array}$ \\
\hline 325 & Responsabilidade do produtor. \\
\hline 326 & Restrições de custo. \\
\hline 327 & Reutilizar líquidos do processo. \\
\hline 328 & $\begin{array}{l}\text { Selecionar critérios e estratégias de fim de vida (vida do produto, ciclo tecnológico, } \\
\text { nível de integração, ciclo de design, número de partes e razão para o re-design). }\end{array}$ \\
\hline 329 & Selecionar energia renovável. \\
\hline 330 & Selecionar materiais com tecnologia mais eficiente de reciclagem. \\
\hline 331 & $\begin{array}{l}\text { Selecionar processos que reduzem resíduos e descartes de materiais durante a } \\
\text { produção. }\end{array}$ \\
\hline 332 & Selecionar sistemas com eficiência de energia nos estágios de operação e uso. \\
\hline 333 & Separar os materiais perigosos dos demais. \\
\hline 334 & Simplificar a operação. \\
\hline 335 & Simplificar os acessos a desmontagem dos componentes para manutenção. \\
\hline
\end{tabular}




\begin{tabular}{|c|c|}
\hline 336 & Sistema de gestão ambiental e programas de ecodesign. \\
\hline 337 & Sistemas de produção mais limpa. \\
\hline 338 & Soldar com materiais compatíveis. \\
\hline 339 & Substituir as funções e recursos de embalagens através de projeto do produto. \\
\hline 340 & $\begin{array}{l}\text { Tornar a distribuição e logística eficientes (produzir onde há consumo, distribuição } \\
\text { direta ao consumidor). }\end{array}$ \\
\hline 341 & Tornar as interfaces de componentes simples e reversivelmente separáveis. \\
\hline 342 & Tornar detectável para fácil visualização o desgaste do produto e componentes. \\
\hline 343 & Transformar os impactos ambientais em valores monetários. \\
\hline 344 & Usar a menor quantidade possível de elementos de junção. \\
\hline 345 & Usar aterro controlado. \\
\hline 346 & Usar camadas de material reciclado onde o material virgem é necessário. \\
\hline 347 & $\begin{array}{l}\text { Usar características estruturais e materiais de alta qualidade para minimizar o peso dos } \\
\text { produtos. }\end{array}$ \\
\hline 348 & Usar co-geração de energia. \\
\hline 349 & Usar embalagem reciclável, retornável e reutilizável. \\
\hline 350 & Usar embalagens ecológicas. \\
\hline 351 & Usar estrutura superficial ou aberta para facilitar o acesso aos subconjuntos. \\
\hline 352 & Usar máquinas e equipamentos eficientes. \\
\hline 353 & Usar materiais verdes de forma inteligente. \\
\hline 354 & $\begin{array}{l}\text { Usar mecanismos de feedback para indicar a quantidade de energia, água e recursos } \\
\text { que estão sendo consumidos. }\end{array}$ \\
\hline 355 & Usar o conceito de reengenharia. \\
\hline 356 & Usar o conceito de re-projeto. \\
\hline 357 & Usar refil para produtos de consumo. \\
\hline 358 & Usar sistemas de simulação para otimizar processo de transformação. \\
\hline 359 & Usar sistemas para controle do consumo de energia. \\
\hline 360 & Usar submontagens reutilizáveis. \\
\hline 361 & Usar tecnologia, materiais e energia renovável. \\
\hline 362 & Utilizar equipamentos para montagem de produtos no mesmo local de fabricação. \\
\hline 363 & Utilizar o conceito de recondicionamento e reparabilidade. \\
\hline 364 & Utilizar substâncias não tóxicas, ou utilizar ciclos fechados para substâncias tóxicas. \\
\hline 365 & Verificar o grau de unificação dos diferentes tipos de materiais presentes no produto. \\
\hline
\end{tabular}




\title{
APÊNDICE VI - Questionário utilizado na consulta aos especialistas
}

\author{
a) E-mail enviado aos especialistas para convidá-los a participar da pesquisa
}

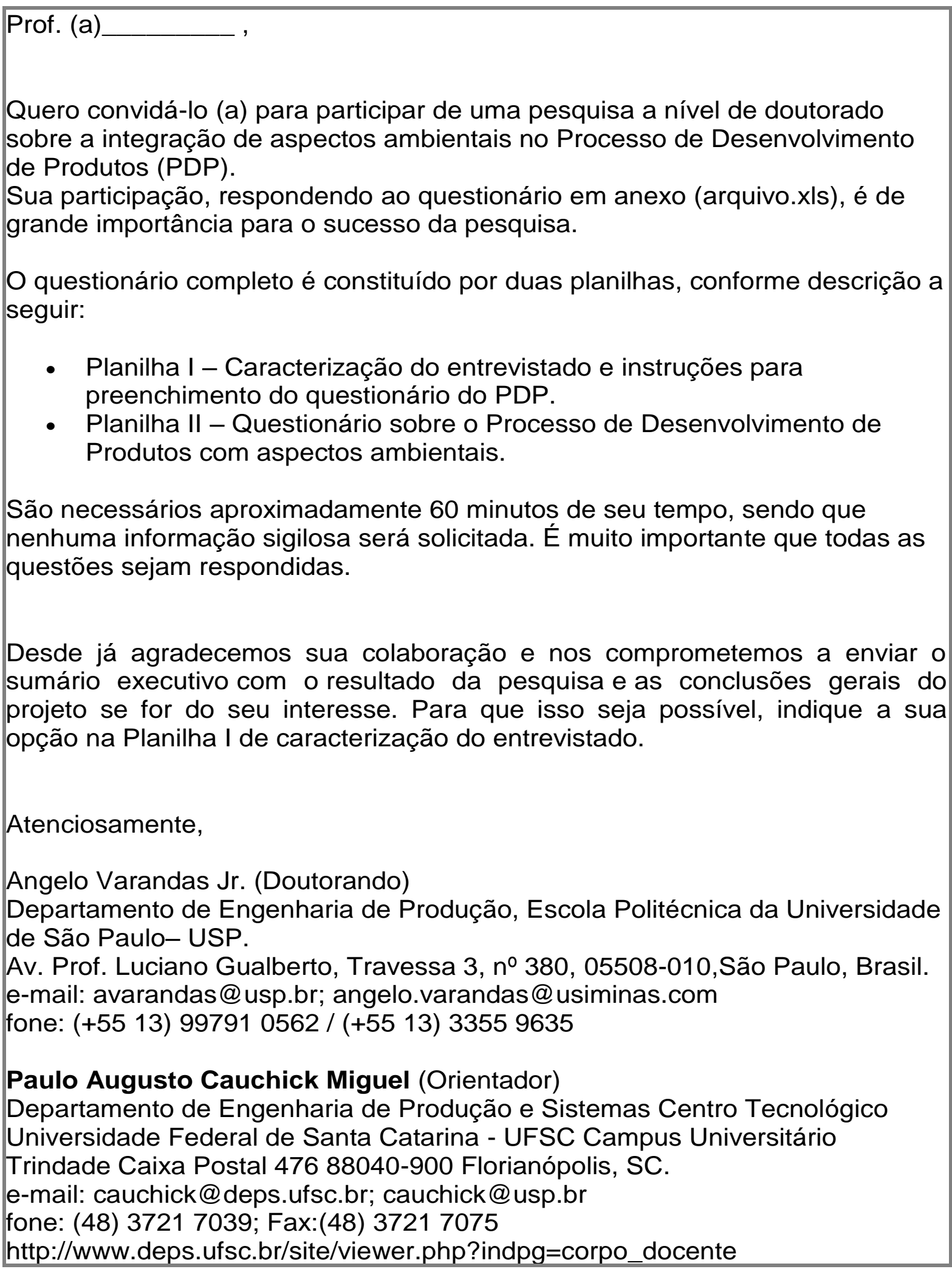




\title{
b) Carta convite enviada aos especialistas para participarem da pesquisa
}

\author{
Escola Politécnica da Universidade de São Paulo \\ Departamento de Engenharia de Produção
}

Prezado (a)

Sou aluno do curso de Doutorado em Engenharia de Produção da Escola Politécnica da USP.

Gostaria de solicitar seu apoio no desenvolvimento da parte prática da minha pesquisa de Doutorado, que tem como objetivo propor uma estruturação do Processo de Desenvolvimento de Produtos (PDP) que considere aspectos ambientais nas fases desse processo.

O tema da pesquisa se baseia na extração dos aspectos ambientais dos métodos e ferramentas de ecodesign, que têm sido considerad os como uma das principais alternativas para se minimizar o impacto ambiental nos processos industriais, sem comprometer 0 desempenho, custo e características do produto.

Para que a pesquisa tenha a qualidade necessária e consiga englobar a opinião dos especialistas na proposta, convidamos todos os acadêmicos envolvidos com esse tema (PDP e ecodesign) que tenham interesse em contribuir com a pesquisa a responder ao questionário no arquivo denominado survey.xls.

Para analisar as informações colhidas, o estudo utilizará da análise de correspondência, visando melhorar a proposta de estruturação do PDP com base na opinião dos especialistas sobre a iserção de aspectos ambientais nas fases do PDP.

Lembrando que não serão divulgados os nomes das instituições nem dos respondentes.

Descle já agradeço a atenção de todos e me coloco a disposição para o caso de dúvidas.

Quinta, 18 de Outubro de 2013.

Angelo Varandas $J r$. (+55 13) 99791-0562 (+55 13) 3355-9635

avarandas@usp.br anqelo.varandas@usiminas.com

Paulo Augusto Cauchick Miguel (Orientador) (+55 48) 37217039 cauchick@deps.ufsc.br cauchick@.usp.br 


\section{c) Planilha I - Para caracterização do entrevistado e instruções para preenchimento do questionário do PDP com aspectos ambientais}

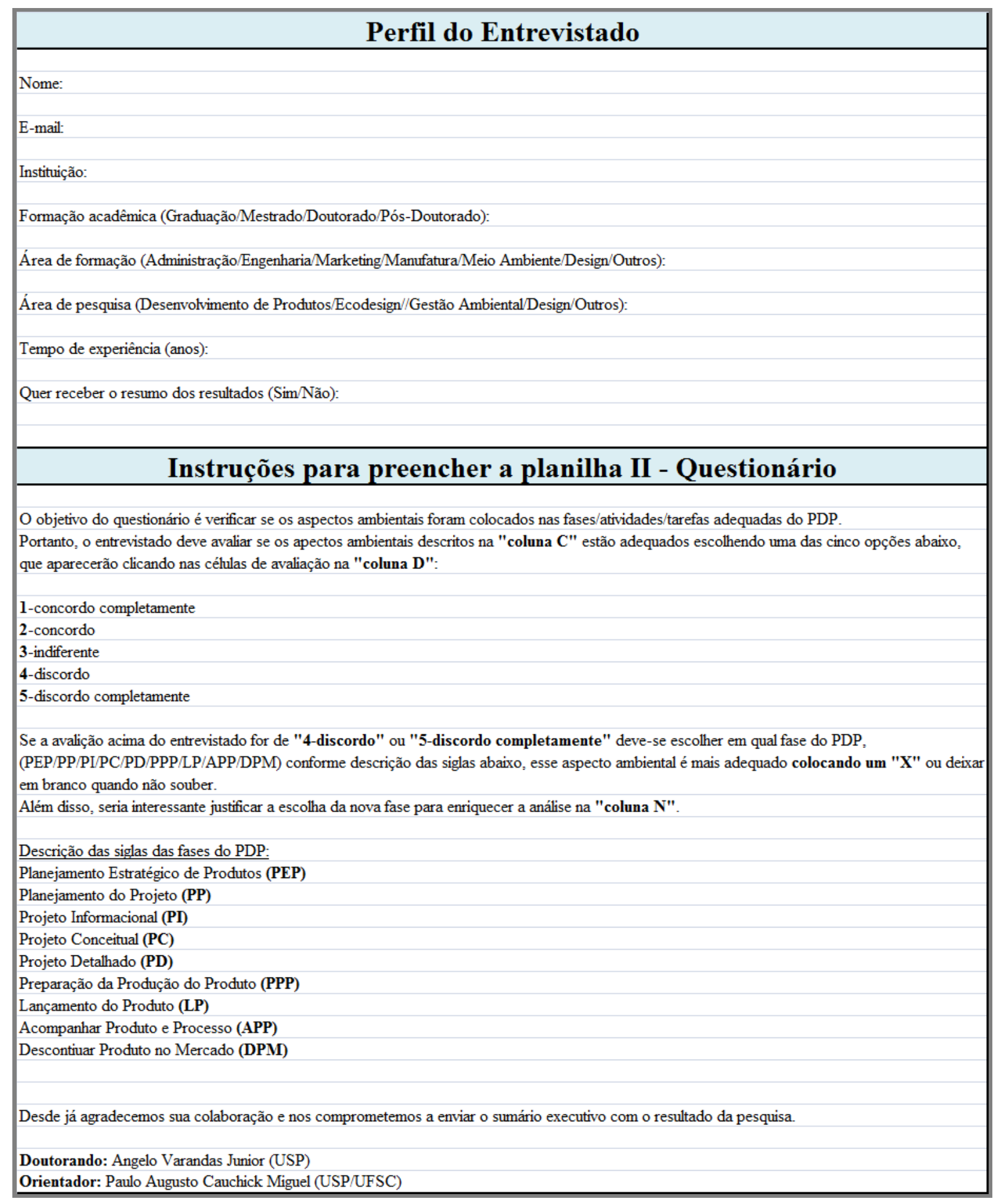




\section{d) Planilha II - Questionário sobre o PDP com aspectos ambientais para avaliação dos especialistas}

Foi utilizada a escala ordinal de avaliação Likert com amplitude de 1-5 ("1-concordo completamente", "2-concordo", "3-indiferente", "4-discordo" e "5-discordo completamente"). No caso da avaliação ser de "4-discordo" ou "5-discordo completamente" é solicitado ao respondente que justifique sua opinião e indique em qual fase do PDP é mais adequado integrar esse aspecto ambiental.

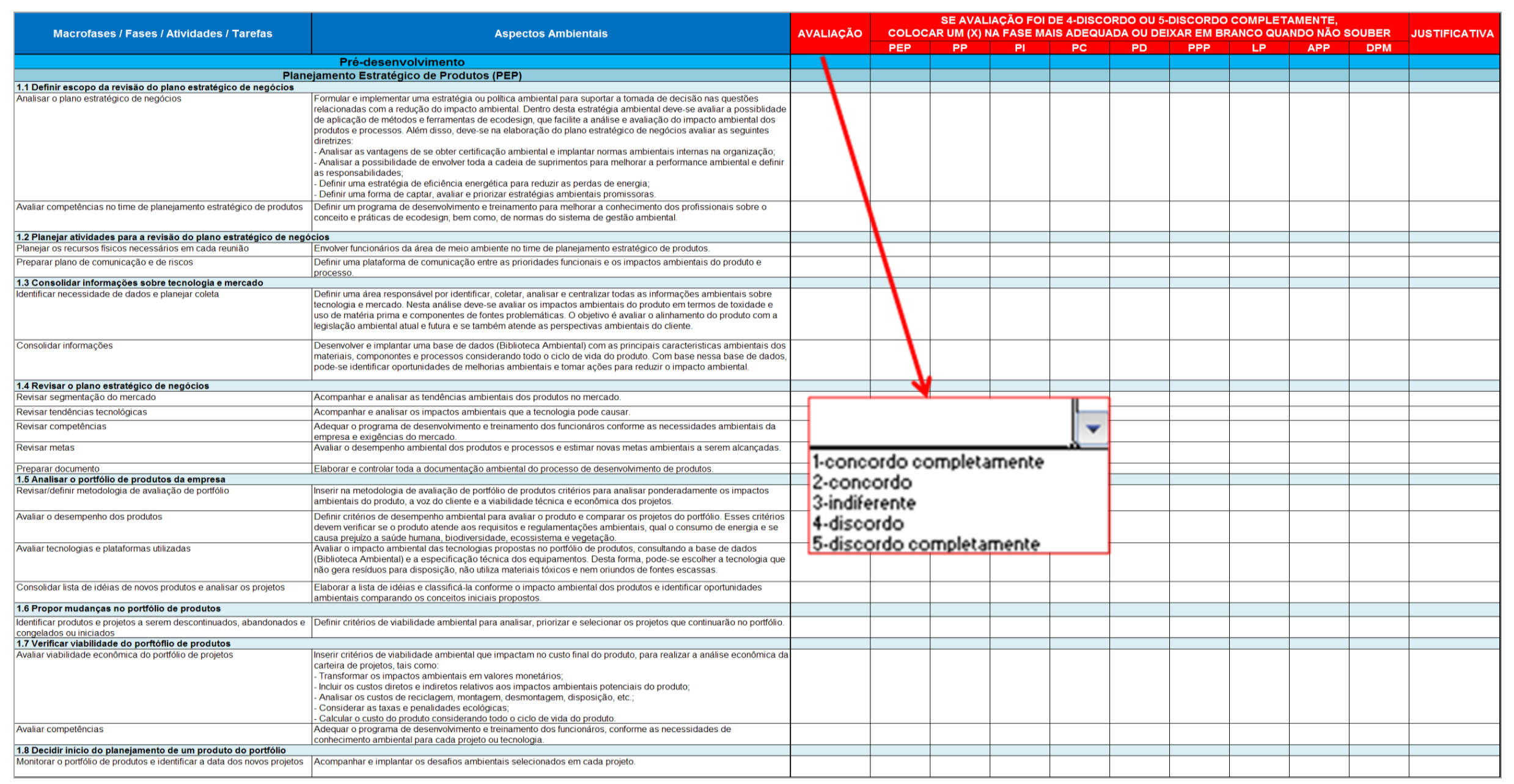


SE AVALIAÇÄO FOI DE 4-DISCORDO OU 5-DISCORDO COMFLETAMENTE

Macrofases / Fases / Atividades / Tarefas

\section{Definiri interessados do projeto}

Montagem da ecuipe com os interessados do projeto

Desenvolvimento da equipe para a execuçăa do projetto

2.2 Definir escopo do produto

effiri diretrizes básicas que o produtto deveráa atender

2.3 Avaliar riscos

Planejar avaliaçâo de iisco do proetto de DP

Identficar e caracteizizar os riscos potenciais

\section{Analisar qualiativivamente e quantifitivamente os iscos potencieis}

Planejar, controlar e monitorara açōes em resposta aos riscos potencias

2.4 Preparar orçamento do projeto
Previsōes dos custos relacionados às atividades e recursos

2.5 Analisar a viabilidade econômica do projeto Definir custo-alvo

Realizar avaliaç̃̃o econômica

2.6 Definir indicadores de desempenho

Selecionar indicadores de desempenho mais adequados para o presente projeto

2.7 Planejar e preparar aquisiç̧öes

Preparar requerimentos de aquisição e identificar fornecedores

potenciais

2.8 Preparar plano de projeto

Discussãoe redaçẵo do plano de projeto

\section{Planejamento do Projeto (PP)}

Envover a área de meio ambiente na equipe de PDP e utilizar o conhecimento dos interesssados e envovidos no projeto (cadelia de supiimentros, stakeholders e clientes) para contibuir com a melhoria da performance ambiental do produto.
Adequar o programa de desenvolkimentio etreinamentio dos profissionais envolvidos no desenvolimento do projeto conforme as necessidades de conhecimentio ambiental para cada produto, processo etennologia

Definii as remissas ambientais que o produto deve atender com basen nos requisitos do cliente, nas normas do sistema de gestăa a ambientalal eleaislacáa a ambiental

Planejar avaliar os riscos de impacto ambiental do produto para cada pasagem de fase do PDP dando um mair enfoque nas fases iniciais de desenvolimento do conceito do produto

Identificar os In scos potencialas de impacto ambiental do produto e a responsabiliddade da empressa durante todo o icicl de vida do produto. Para isso, deve-se caracterizar o perfil ambiental do produto comparando coma base de dados Biblioter Anbigta)

- mpacios ambientals da teccnologia;

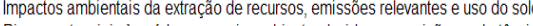

(a)

Analisar os riscos potenciais do perfl ambiental do produto com relaçãao a legislaçẵo ambientale eas necessidades atuais e emergentes do cliente.

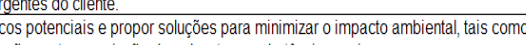

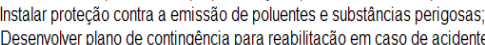

Planejar custos com implantacacáo, desenvolvimento e treinamento dos profissionais em métodos eferramentas

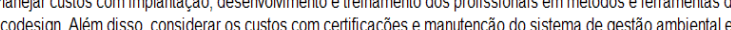
divulgação das mehores práticas de ecodesign

Definir metas de custo do projett considerando as estimativas de custos a ambiertais para todo o ciclo de vida do rioditio. custos para realizar una analise econônica mais precisa dos projetos

Selecionar, integrar e ponderar os indicadores de desempenho ambiential com base nos Dontos ambientiais criticos

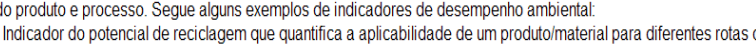
ecilagem;

- Indicadores de emissão de gases de eféto estufa e deplecäo da camada de orônio,

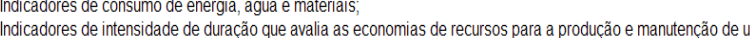
produto que tem uma vida ứil maior,

cão gue mede a economia de recursos por recuperaçăa de materiais ou a prcentagam de material recicicado

Avalara a capacidade de produção dos fornecedores e a sua adequaçăa a legislaçåa a ambiental.

Envolver toda a cadeia de supiimentos para contibibuir com a melhoria da performance ambiental do produto

Discutit os aspectos ambientais do produto e seus impactos e inserir toda a documentaçăo petinente no plano de projeto.
AVALACÃO COLOCAR UM (X) NA FASE MAIS ADEQUADA OU DEIXAR EM BRANCO QUANDO NÃO SOUBER

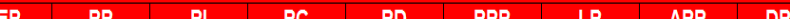

JUSTIFICATIVA

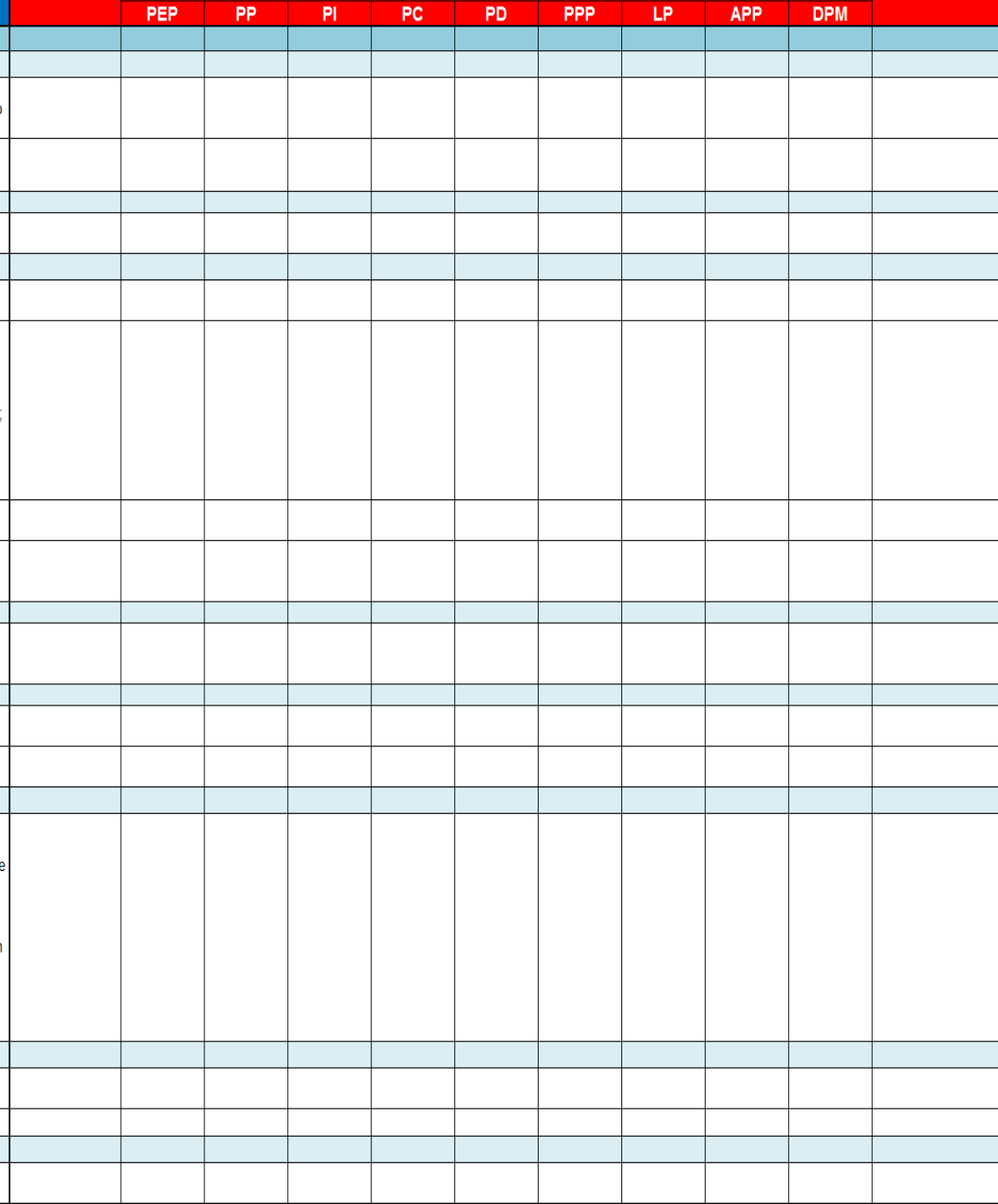




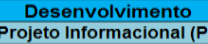

3.1. Atualizar o plano do projeto informacional Atuaizar estimativa de orçamento do projeto Avaliar novos riscos

Definiratatualizar os crtiténos de passagem dos gates 3.2 Revisar e atualizar o escopo do produto

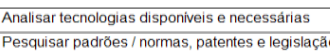
Pesquisar produtos concorrentes es similares

3.3 Detalhar cleclo de vida do produto e deffiri seus clientes Refinaro ciclo de vida do produtio

Deffinir os clientes do projelto ao longo do cecilo de vida

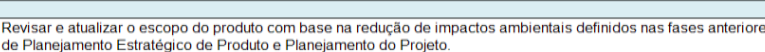

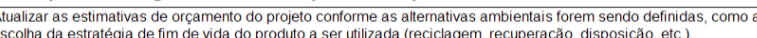

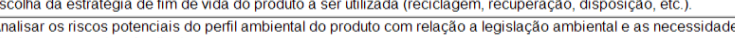

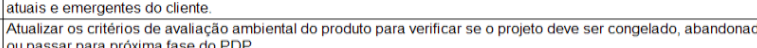

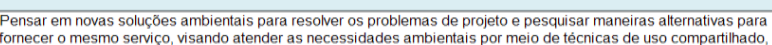

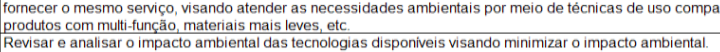

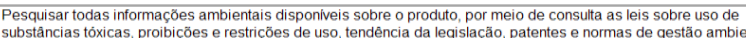

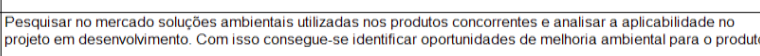

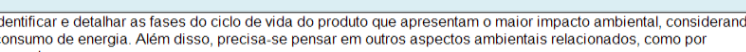

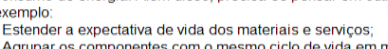

módulo para minimizar o seu impacto ambiental no fim de

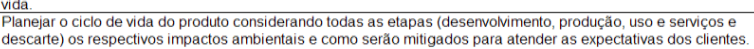

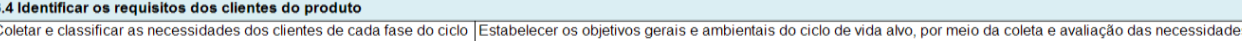
devida

valorar os requisitos dos clientes Deinini os requuistos ambentais do produto com base na analise poncererda das necessidades dos clientes em

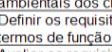

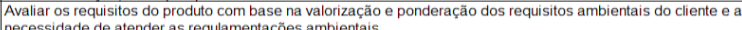

\section{Convernerer requisistos de clientes em expressöes mensuráveis} Analisar, classificar e hierarautizar os requistos do produto 3.6 Definir especificą̧,es meta do produto

Valorar requisitios do produto

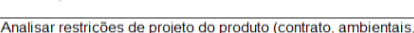
legisiacáa, normas, $]$,

3.7 Monitorar a viabililidade economico-financeira do produto indicadores

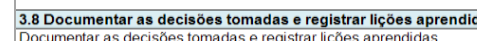

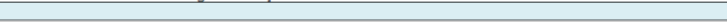

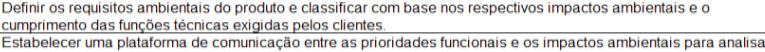

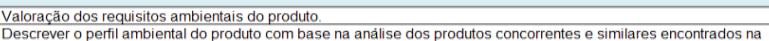
pesquisa de mercado.

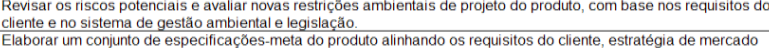

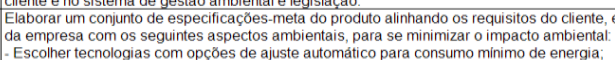

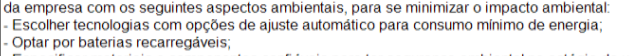

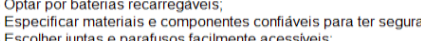

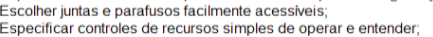

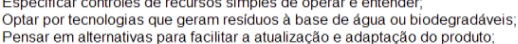

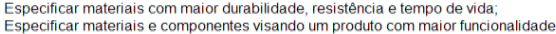

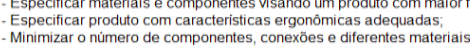

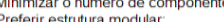

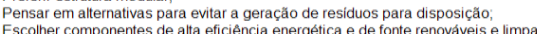

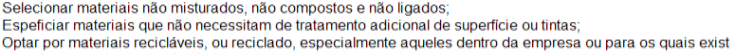

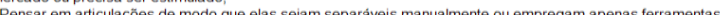

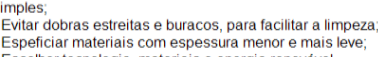

Monitorar as condiçöes do mercado eaveliar potenciais opotturidades ambienteits.

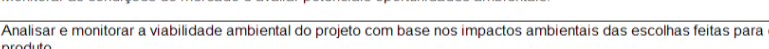

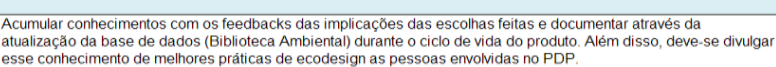

\begin{tabular}{|l|l|l|l|l|l|l|l|l|}
\hline & & & & & & & & \\
\hline
\end{tabular}


Macrofases / Fases / Atividades / Tarefas

\section{Aspectos Ambientais}

4.1 Atualizar o plano do projett conceltual iualizar o escopo do produto

Aualizar estimativa de orçamento do projeito

Atualizar, monitorar, valorare e deffnir novos indicicadores de desemperno Avaiar novos iscos

Definiritaulizizar os critérios de passagem dos gates

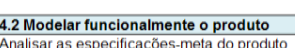

Identificar as tunç̧es do produlo e estabelecer a funçăo g global

Estabelecer estruturas

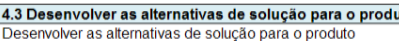

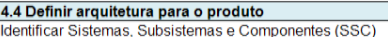

(1)

in integraç̧ơo entre SSCs das atternativas de projele 4.5 Analisar Sistemas, Subsistemas e Componentes (SSC)

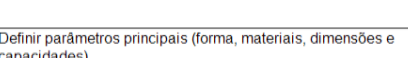

\section{Projeto Conceitual (PC)} oupassar pará próxima fase do $\mathrm{PLD}$ Atentar nas preparaçöes e substancias toxicas cas;

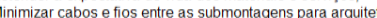

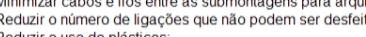
Reduiri p padrão de consumo de energia dos subsistemas que năo estẫo em uso

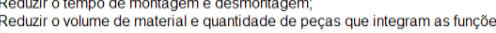
Usar c concetito de reengenharia e modularicade, Seleccionar materiais recicildiveis:

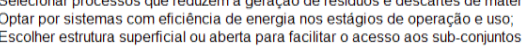

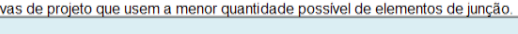

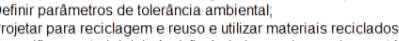

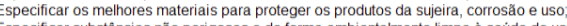

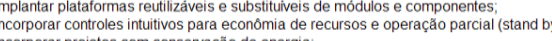

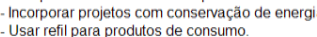

Revisar e atualizar o escopo do procuto com base na reduçăo de impactos ambientelis definidos na fase anterior de Atualizar as estimativas de orcamento do proieto conforme as atternativas ambientais forem sendo definidas con a

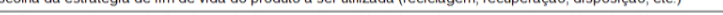
ald prodto para verifcar se o proieto deve ser congalado, abandona

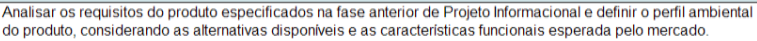

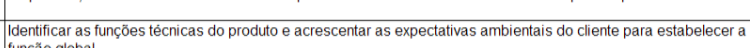

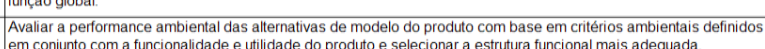

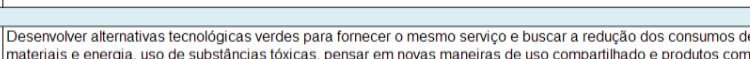

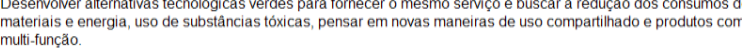

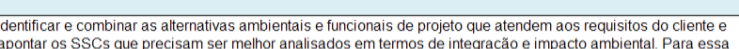
elhor essruturacáa do produto, deve-se dirircionar as escolhas com base nos seguintes aspectos ambientiais

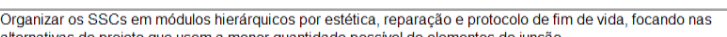

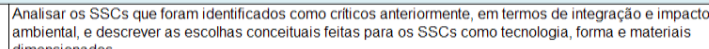

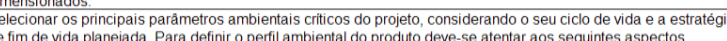

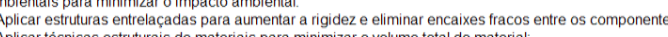

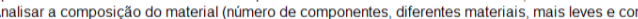

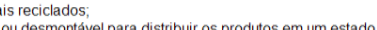

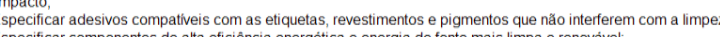

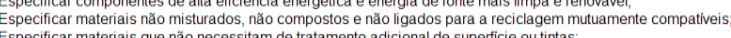

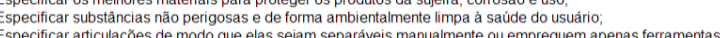

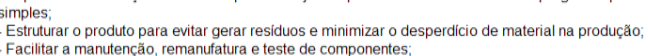

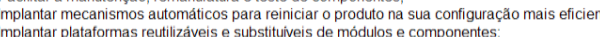

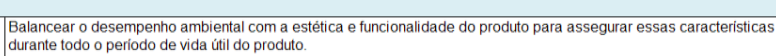

SEAVALIACCAO FOI DE 4-DISCORDO OU 5-DISCORDO COMPLETAMENTE,

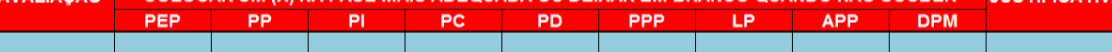

\begin{tabular}{|l|l|l|l|l|l|l|l|}
\hline & & & & & & & \\
\hline
\end{tabular}


Macrofases / Fases / Atividades / Tarefas

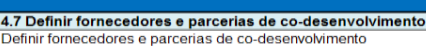

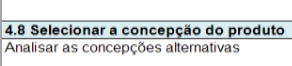

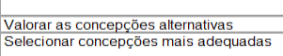

4.9 Planelar o processso de manutatura macroiDefinit plano ma
Planeialo

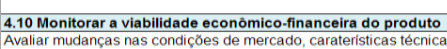
indicicadores
Avalar possiveis desvios e impactos no projeto

Anailisar novas premissas e indicadores

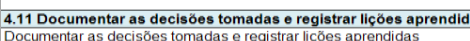

\subsection{Atualizar o plano do projeto detalliado}

Atuatizar estimativa de orçamento do projeto e definir novos indilicadores de desempen

Definiratualizar os critérios de passagem dos gates 5.2 Criar edetahnar SsCs, documentaçaioe confguracaio

Especticar toleräncias Integrar os SSCS

Completar BOM

cos Devantar intormaḉes de custos, tempo, capacidades e competéncisis

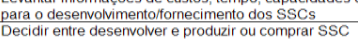

5.4 Desenvolver fornecedor
Selecionar fornecedres

5.5 Planejar o processo de fabicacăo e montagen

Planejar processo de montagem macro

Desdobrar parametros crticcos dos componentes sabricados Definire Sequenciar operaçées

Especticar fixaçăo

\begin{tabular}{l} 
Especticar inspeçáo \\
\hline Selecionar / Especificar métodos eferrament
\end{tabular} Calcular parämetros de trabairo Descrever instruçęes de trabaliho Criar informaç6es I documentos de apoio a o operador

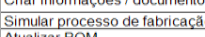

Aspectos Ambientais

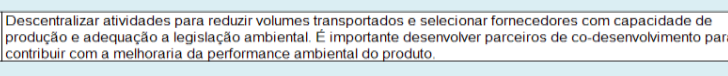

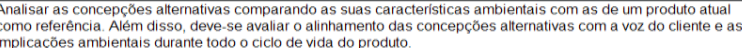

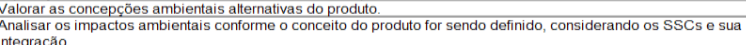

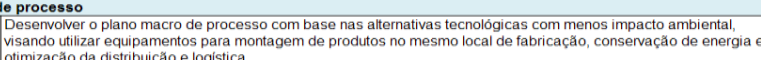

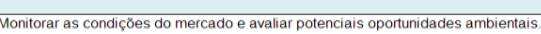

Malisar e montica

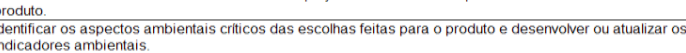

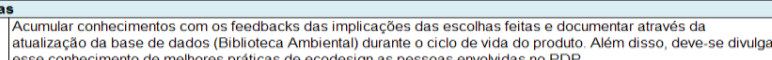
Projeto Detalhado (PD)

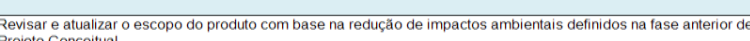
Troeto Concettual

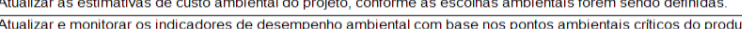
processos.

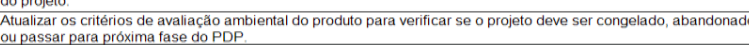

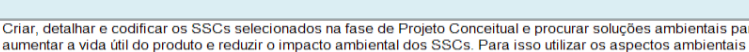

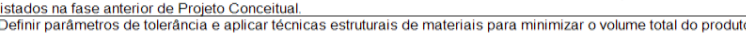

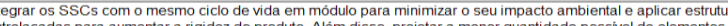

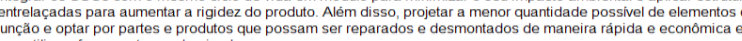

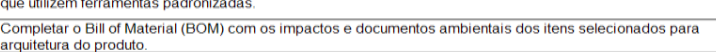

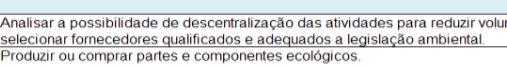

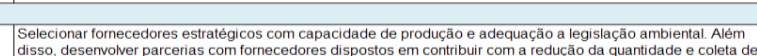
ambalanons

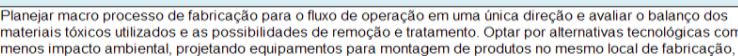

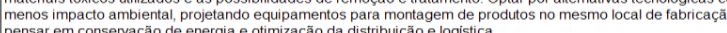

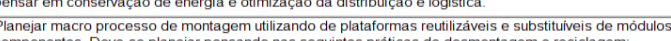

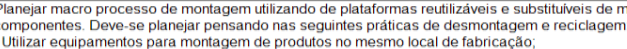

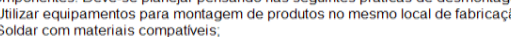

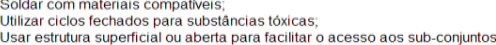

Descobbrar os parämetros criticos dos SSCS com base nos aspectos ambientiais Iistados na tase de Projejto

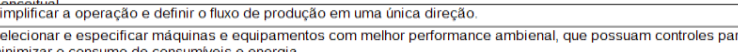

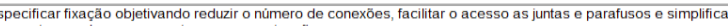

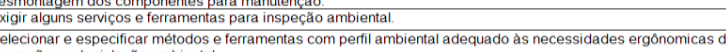

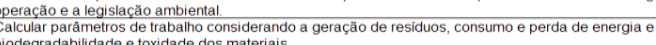

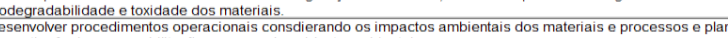

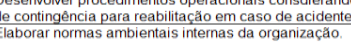

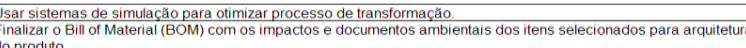

AVALIAÇÃO SE AVALIACÃO FOIDE 4-DISCORDO OU 5-DISCORDO COMPLETAMENTE,

Jus TIFICATIVA

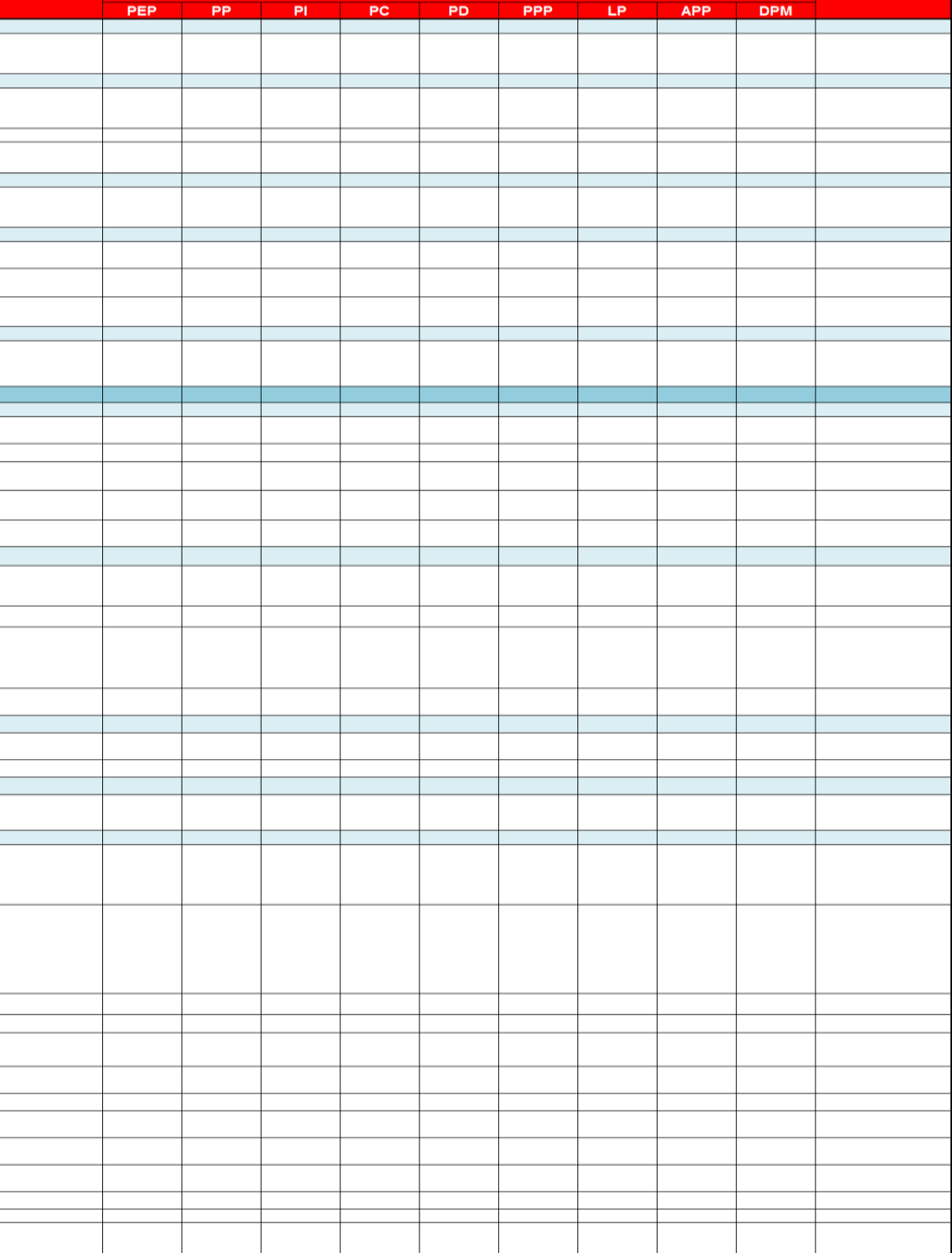


Macrofases / Fases / Atividades / Tarefas

.6 Projetar recursos de fabicicachal

Projetar Mácuinas es Eovipastivos

Projetar instalaç̧eses (Fabrica)

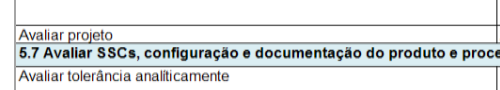

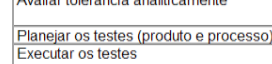

Avaliar os resuttados $\mathrm{e}$ planejara açöes

Avaiar consonância da documentaçăo com as normas

5.8 otimizar produto e processo

Austar tolerância dos SSCS

Executara açöes de correçăo de fallas

5.9 Crarar material de suporte do produ
Criar manual de operacaço do procotio

Criar maténal de treinaments

Criar manual de descontinuidade do produto

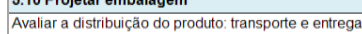

Definiri as formas eas sinalizaçōes das embalagens do prodưo

Identificar os elementios criticos

Adequar embalagem a oos elementios crtiticos

Projetar embalagem

Planejar processso de embalagem

\section{Aspectos Ambientais}

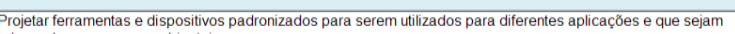

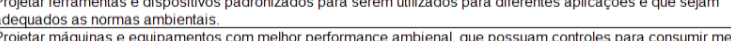
consurivivis e energic

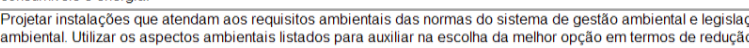

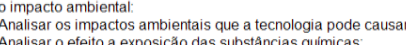

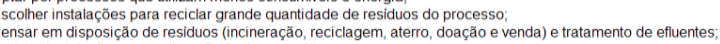

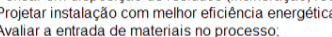

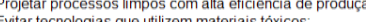

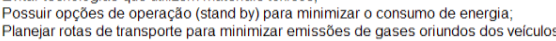

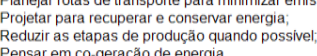

Avaliar o projeto com base nos impactos ambientais das escolhas de recursos de fabricacăâ.

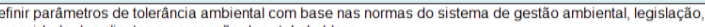

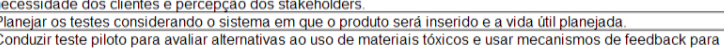

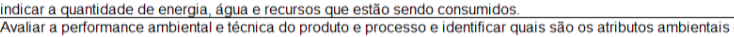

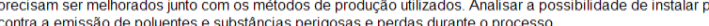

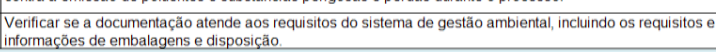

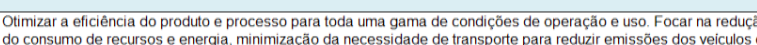

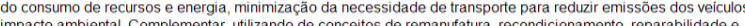

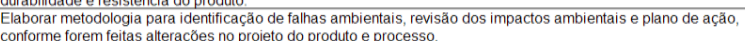
Elaborar manual de operaçăo do produto, inserindo instuç̋̈es e perfil ambiental do produto, tais como: composiçă da e plano de contingencicia parar reabilitiaçá em caso de acidente ambiental

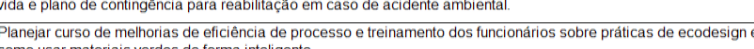

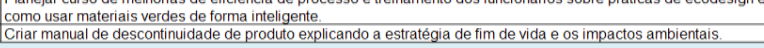

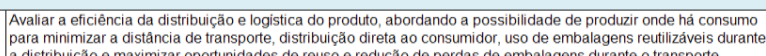

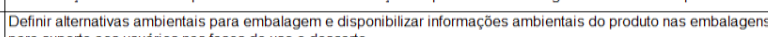

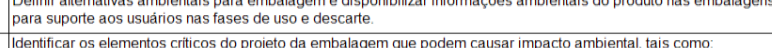

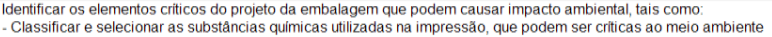

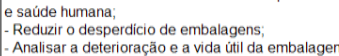

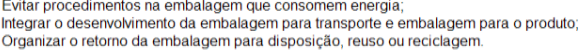

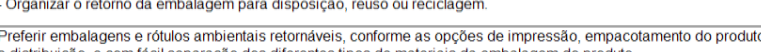

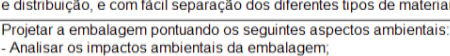

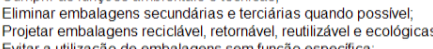

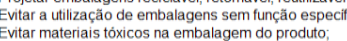

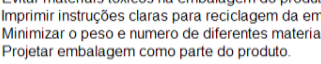

Proetar enbalagem como parte do produtio.

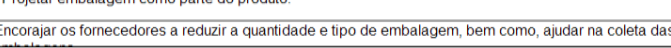

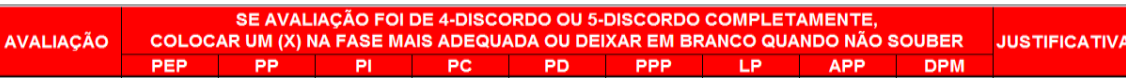

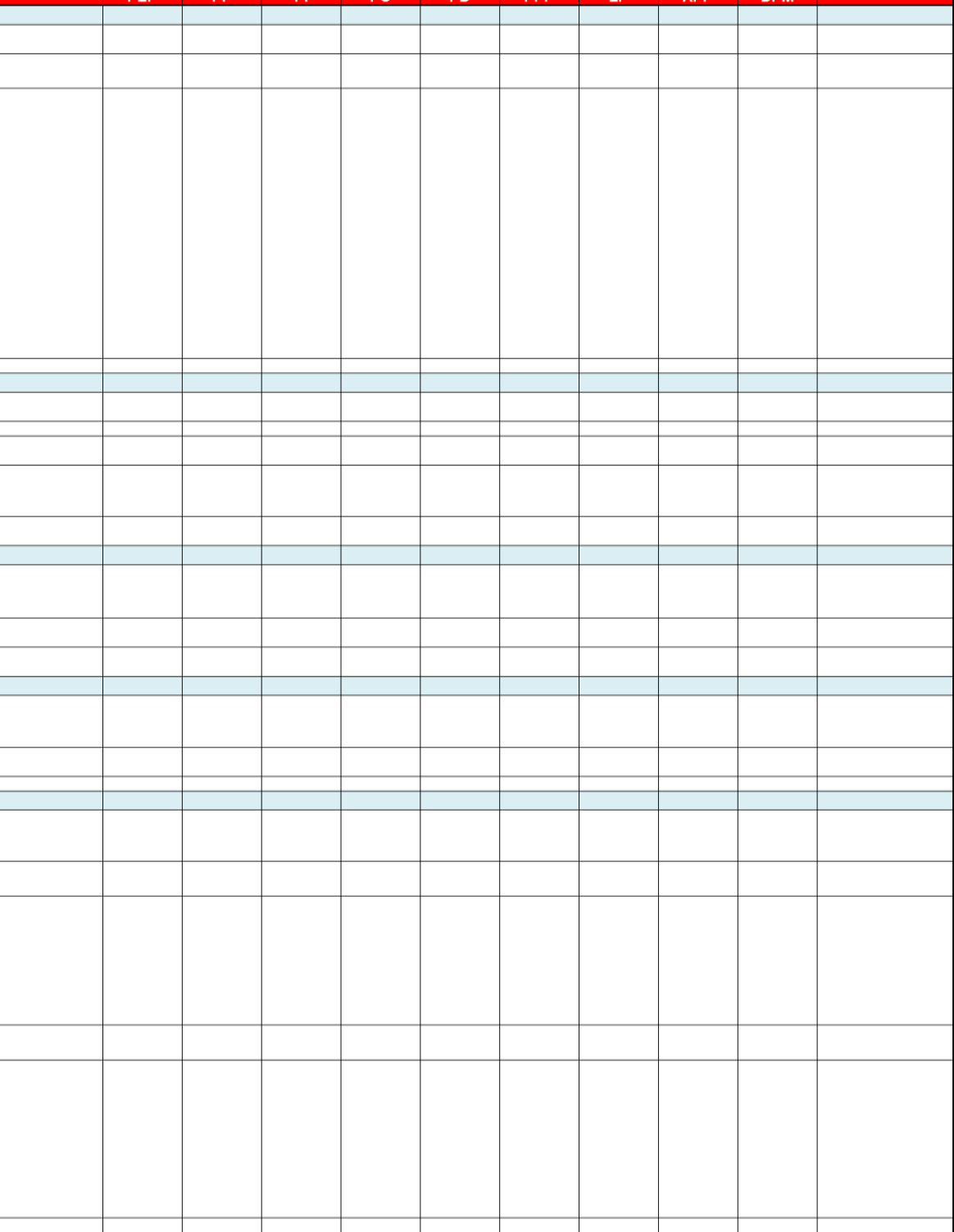




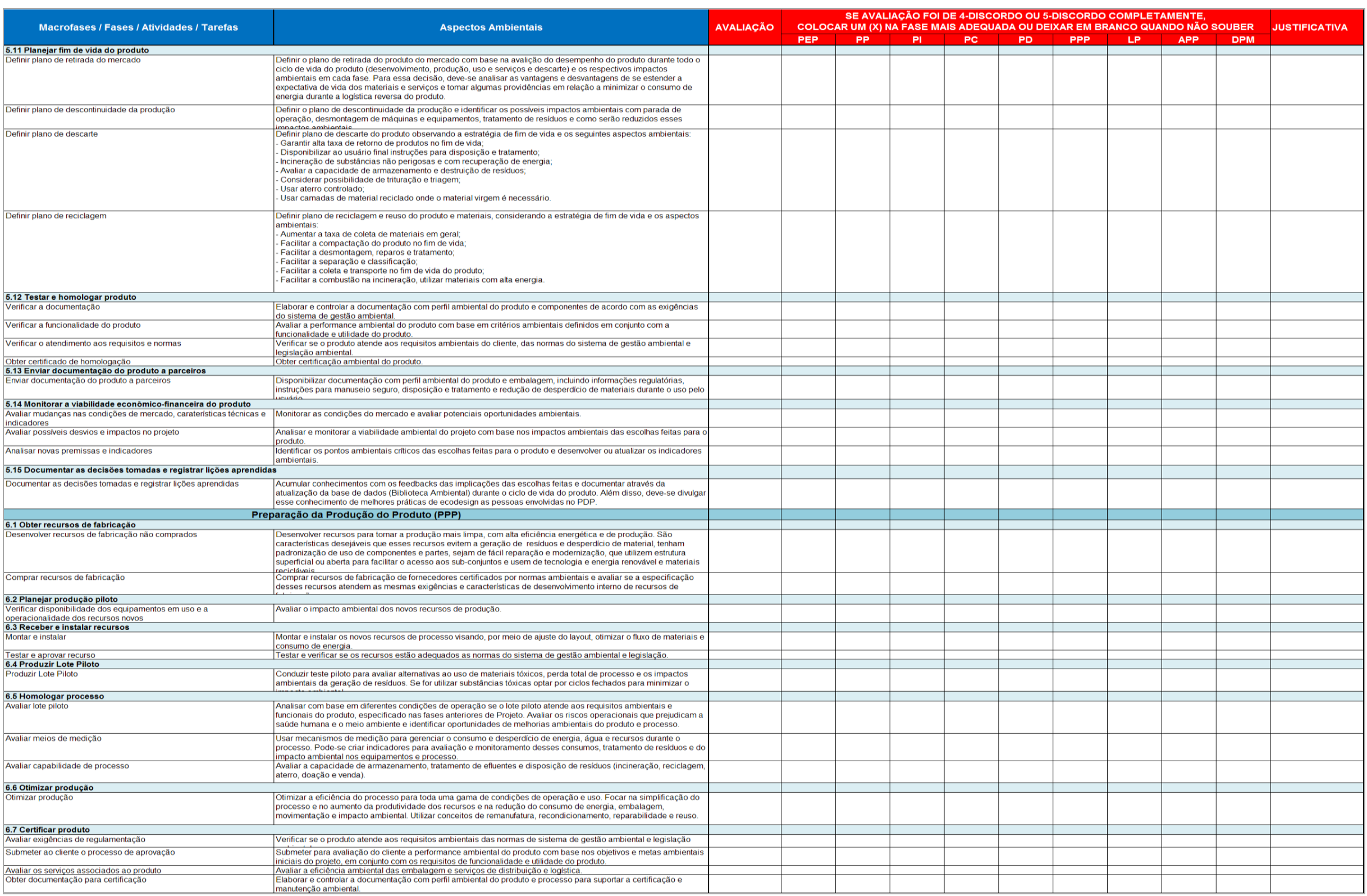


Macrofases / Fases / Atividades / Tarefas

6.8 Desenvolver processo de produçio

Desenhar os processos de logisiticae relaçăo de entrega de produtos
aos clienies

Selecionarddesenvover ferramentas de apoic

6.9 Desenvolver processo de manutençăo
Definir politica de manutençắ

Deffini procedimentos da manutençầ

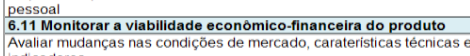
indicadores

Anailsar novas premilssas e indicadores

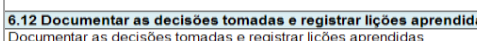

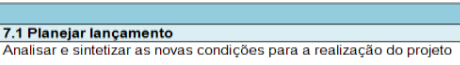
Autualizar o escopo do produto

Autualizar estimatva de orcamento do projeto Avaliar novos risc

Definiriatualizar os criterios de passagem dos gate

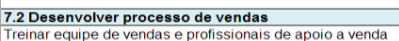

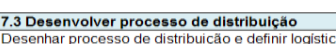

Fechar acordos com distribuidores

7.4 Desenvolver processso de atendimento ao cliento
Desenviverer sistema de apoio a atendimento ao cliente

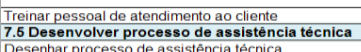

Desenvover documentaçăo de assistênncia lécrica

Desenvover sistema de apoio a assistencelia teccric

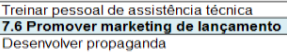

7.7 Gerenclar rancamento 7.8 Atualizar plano de fim de
Atualizar plano de fim de vida

ade economico-financeira do produto indicadores
Avaluaras possivis des desvios e impactos no projel

Anailsar novas premissas e indicadores

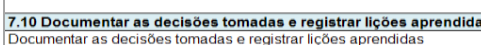

Aspectos Ambientals

\begin{tabular}{l|l} 
SEAVALIACÃO FOI DE A-DISCORDO OU 5-DISCORDO COMPLETAMENTE, \\
AVALIAÇÃO & COLOGAR UM (X) NAFASE MAIS ADEQUADA OU DEIXAR EM BRANCO QUANDO NÄO
\end{tabular}

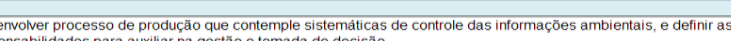

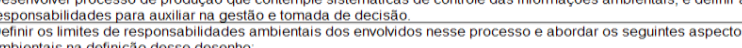

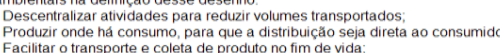

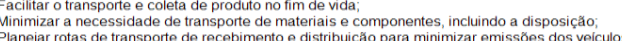

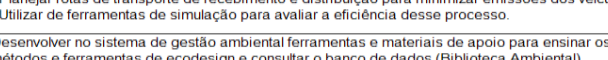

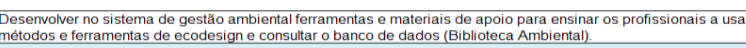

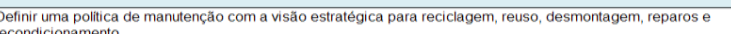

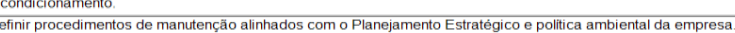

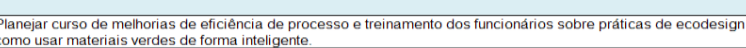

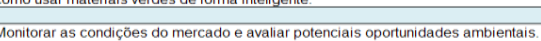

Merer

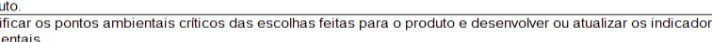
mbiertais.

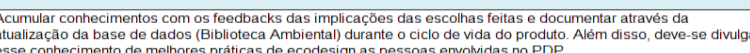
Lançamento do Produto (LP)

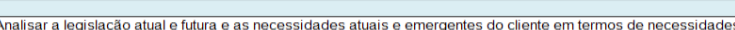
mbiertails ele evantes a a produto.

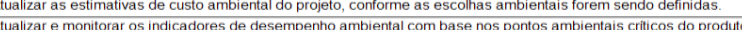

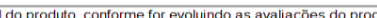

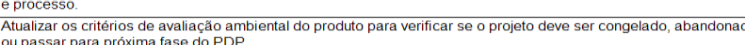

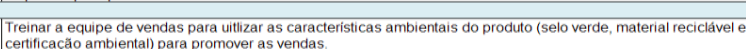

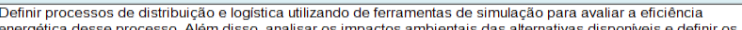

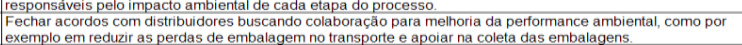

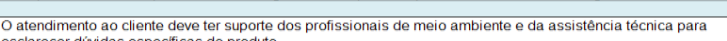

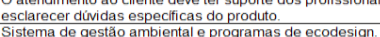

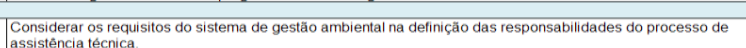

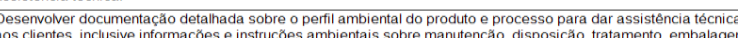

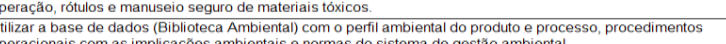
Sistema de gestäo a ambientale programas de ecodesign.

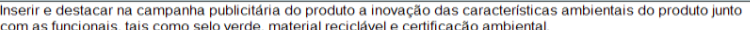
Tompanhar e eanal sar se os resuttados do produton no mercado estāo atendendo aos requisitos ambientiais e

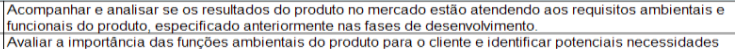
Acompanhar a vida iutil dos componentes e produto e atualizar o plano de fim de vida em termos de retirada do Montorara as condiç̧̄es do mercado e aveliar potenciais oporturidades ambientais

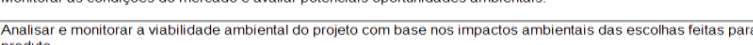

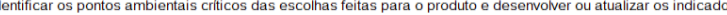
ambier

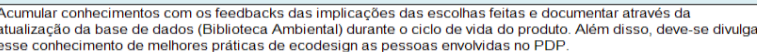

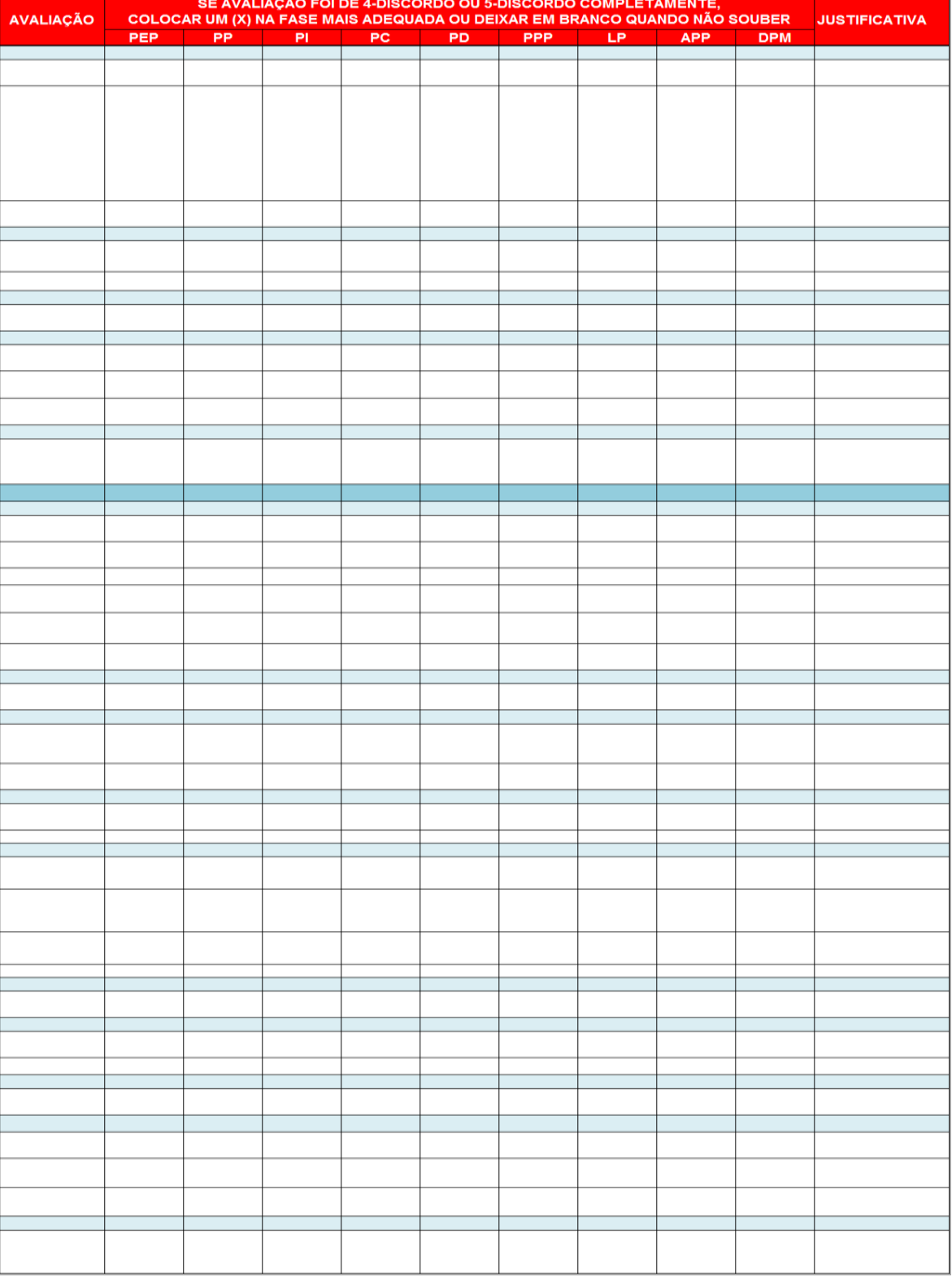


Macrofases / Fases / Afividades / Tarefás

8.1 Avaliar satisfaçăo do clien

8.2 Monitorar desempenh

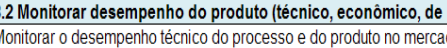

enos sericos associados

Monitorar aspectos relacionados ao meio-ambiente

Consoidar informaçōes sobre desempenho (téćnico, econônico

ambiental, de produção e de seviç̧os)

8.3 Realizar auditoria pós-projeto

Planejar os focos da auditoria

Registrarlicōoss aprendidas

1 Analisar e aprovar descontinuidade do produto \begin{tabular}{l} 
Analisar, planejar e e aprovar descontinuidade do produto \\
\hline
\end{tabular}

9.2 Preparar e acompanhar o recebimento do produto

Prepararar a acompannanar o recebimentio do prodoto

\section{Pós-desenvolvimento}

\section{Acompanhar Produto e Processo (APP)}

Utilizar indicadores para avaliar a impotânncia das funçōes ambientais do produlto no cliente e identificar loportunidades de mehorias ambientais

Avaliar o o desempenho ambiental do produto e processo com base no atendimento das conformidades e conilibilidade ambiental: Avaliar a performance ambientala do produto $c$ con 政

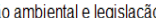
Acumular conhecimentos com os feedbacks do cliente, durante o ciclo de vida do produto. Aém ciisso, deve-se

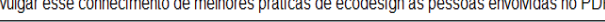

Planejar coleta dos resultados ambientais do produto para direcionar melhorias na gestlä do PDP

Acumular conhecimentos com os feedbacks das implicaçães das escollhas feitas e documentara aravéés dar

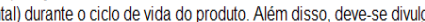
esse corhecimento de mehores práiticas de ecodesign as pessoas envolidas no PDP

\section{Descontiuar Produto no Mercado (DPM)} \begin{tabular}{|l}
\hline 9.3 Finalizar suporte ao produto \\
\hline Finalizar suporte ao produto \\
\hline
\end{tabular}

Analisar toda as fases da vida útil do prod
ambientais e como seräa solucionados.

Preparar o recebimento do produto com base na estratégia de fim de vida selecionada (reciclagem, desmontagem

Finalizar suporte ao produto de forma a preservar a imagem da empresa em temos de responsabilidade ambiental

9.4 Avaliaçäo geral e encerramento do projeto

Avalacẵă gerale encerramento do projeto

Avaliar os resultados do produto e os impactos ambientiais das escolhas feitas para o o desernvovimento de produtio,

SE AVALIAÇÃO FOI DE 4-DISCORDO OU 5-DISCORDO COMPLETAMENTE,
AVALIACÁO COLOCAR UM (X) NA FASE MAIS ADEQUADA OU DEIXAR EM BRANCO QUANDO NÄO SOUBER

\begin{tabular}{|l|l|l|l|l|l|l|l|l|}
\hline PEP & PP & PI & PC & PD & PPP & LP & APP & DPM \\
\hline
\end{tabular}

JUSTIFICATIVA

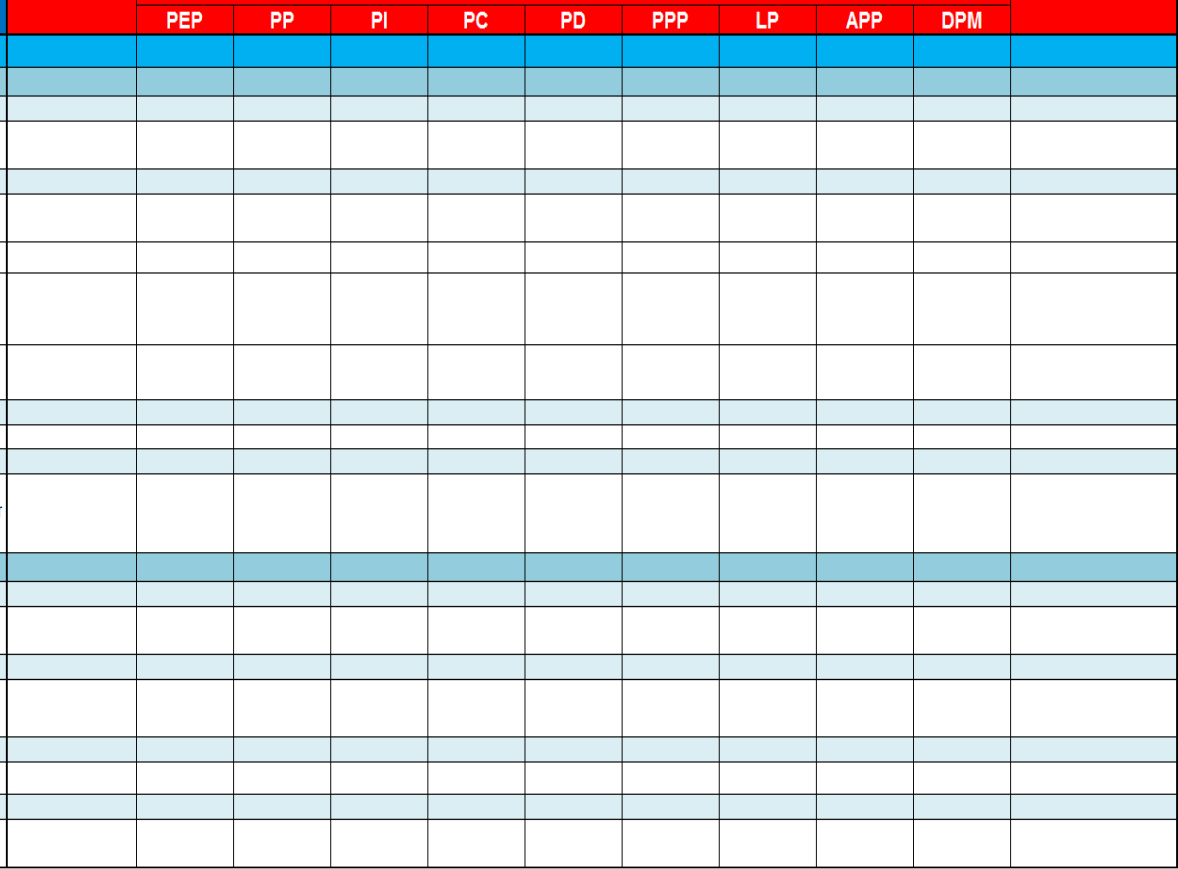




\section{APÊNDICE VII - Sugestões dos especialistas para melhoria da proposta}

\begin{tabular}{|c|c|}
\hline Fase 1 & $\begin{array}{l}\text { Macrofase - Pré-Desenvolvimento } \\
\text { Planejamento Estratégico de Produtos (PEP) }\end{array}$ \\
\hline Atividade - 1.1 Definir e & copo da revisão do plano estratégico de negócios \\
\hline Tarefa & Sugestão de Melhoria \\
\hline $\begin{array}{l}\text { 1.1.2 - Avaliar } \\
\text { competências no time } \\
\text { de planejamento } \\
\text { estratégico de produtos }\end{array}$ & $\begin{array}{l}\text { Especialista B: Avaliar competências é diferente de treinamentos. } \\
\text { Dependendo de quais as competências são necessárias, pode ser } \\
\text { viável a contratação. }\end{array}$ \\
\hline Atividade - 1.2 Planejar & atividades para a revisão do plano estratégico de negócios \\
\hline Tarefa & Sugestão de Melhoria \\
\hline $\begin{array}{l}\text { 1.2.1 - Preparar plano } \\
\text { de comunicação e de } \\
\text { riscos }\end{array}$ & Especialista I: Deve acontecer na fase de Planejamento do Projeto (PP). \\
\hline Atividade - 1.3 Consolic & ar informações sobre tecnologia e mercado \\
\hline Tarefa & Sugestão de Melhoria \\
\hline $\begin{array}{l}\text { 1.3.1 - Identificar } \\
\text { necessidade de dados e } \\
\text { planejar coleta }\end{array}$ & $\begin{array}{l}\text { Especialista B: Fiquei na dúvida se seria responsabilidade de um dos } \\
\text { membros da equipe de projeto, com as informações sobre o ciclo de } \\
\text { vida do produto. } \\
\text { Especialista M: Mas tenho dúvidas, quando você fala de avaliação do } \\
\text { produto, se algumas análises específicas colocadas aqui não ficariam } \\
\text { melhores no planejamento do produto ou projeto informacional. } \\
\text { Especialista N: Deve acontecer na fase de Projeto Informacional (PI). }\end{array}$ \\
\hline $\begin{array}{l}\text { 1.3.2 - Consolidar } \\
\text { informações }\end{array}$ & $\begin{array}{l}\text { Especialista A: Qual produto? No PEP ainda não há um projeto de } \\
\text { desenvolvimento de produto, então a proposta da Biblioteca seria para } \\
\text { consolidar as informações de quais produtos? } \\
\text { Especialista B: Prospecção tecnológica ambiental? } \\
\text { Especialista E: Coletar informações é algo muito genérico. Poderia estar } \\
\text { em qualquer uma das etapas. } \\
\text { Especialista M: Mas tenho dúvidas, quando você fala de avaliação do } \\
\text { produto, se algumas análises específicas colocadas aqui não ficariam } \\
\text { melhores no Planejamento do Produto ou Projeto Informacional. } \\
\text { Especialista N: Deve acontecer na fase de Projeto Informacional (PI). }\end{array}$ \\
\hline Atividade - 1.4 Revisar & plano estratégico de negócios \\
\hline Tarefa & Sugestão de Melhoria \\
\hline $\begin{array}{l}1.4 .2 \text { - Revisar } \\
\text { tendências tecnológicas }\end{array}$ & Especialista N: Deve acontecer na fase de Projeto Informacional (PI). \\
\hline 1.4.4 - Revisar metas & $\begin{array}{l}\text { Especialista L: Deve acontecer na fase de Planejamento do Projeto } \\
\text { (PP). }\end{array}$ \\
\hline $\begin{array}{l}\text { 1.4.5 - Preparar } \\
\text { documento }\end{array}$ & $\begin{array}{l}\text { Especialista E: Atividade muito genérica. } \\
\text { Especialista G: Sem justificativa. } \\
\text { Especialista G: Somente entendo que a documentação se iniciará nesta } \\
\text { etapa, mas deve ser desenvolvida e atualizada ao longo do ciclo de vida } \\
\text { do produto, a fase está correta, mas me parece difícil estar concluída } \\
\text { nesta fase. } \\
\text { Especialista L: Deve acontecer na fase de Planejamento do Projeto } \\
\text { (PP). }\end{array}$ \\
\hline Atividade - 1.5 Analisa & o portfólio de produtos da empresa \\
\hline Tarefa & Sugestão de Melhoria \\
\hline $\begin{array}{l}1.5 .1 \text { - Revisar/definir } \\
\text { metodologia de } \\
\text { avaliação de portfólio }\end{array}$ & $\begin{array}{l}\text { Especialista G: Não acho que o critério ambiental seja para muitas } \\
\text { empresas um critério para constar na definição do portfólio. O produto } \\
\text { não será priorizado se for "verde". A priorização vem de fatores }\end{array}$ \\
\hline
\end{tabular}




\begin{tabular}{|c|c|}
\hline & $\begin{array}{l}\text { competitivos. Dado que a empresa vai fazer um produto, que ele seja o } \\
\text { mais "verde" possível. Uma alternativa seria definir critérios mínimos. A } \\
\text { empresa não iria fazer um produto ambientalmente incorreto. Mas em } \\
\text { geral a legislação já é suficiente para barrar os casos mais graves. }\end{array}$ \\
\hline $\begin{array}{l}\mathbf{1 . 5 . 2} \text { - Avaliar o } \\
\text { desempenho dos } \\
\text { produtos }\end{array}$ & Especialista E: Deve acontecer na fase de Projeto Informacional (PI). \\
\hline $\begin{array}{l}\text { 1.5.3 - Avaliar } \\
\text { tecnologias e } \\
\text { plataformas utilizadas }\end{array}$ & $\begin{array}{l}\text { Especialista N: Achei estranho "equipamentos". Estes seriam claros em } \\
\text { projetos incrementais, mas em radicais não. }\end{array}$ \\
\hline $\begin{array}{l}\text { 1.5.4 - Consolidar lista } \\
\text { de idéias de novos } \\
\text { produtos e analisar os } \\
\text { projetos }\end{array}$ & Especialista G: Sem justificativa. \\
\hline \multicolumn{2}{|c|}{ Atividade - 1.6 Propor mudanças no portfólio de produtos } \\
\hline Tarefa & Sugestão de Melhoria \\
\hline $\begin{array}{l}\mathbf{1 . 6 . 1} \text { - Identificar } \\
\text { produtos e projetos a } \\
\text { serem descontinuados, } \\
\text { abandonados e } \\
\text { congelados ou iniciados }\end{array}$ & $\begin{array}{l}\text { Especialista G: Um produto pouco eficiente pode ser substituído por } \\
\text { outro. }\end{array}$ \\
\hline \multicolumn{2}{|c|}{ Atividade - 1.7 Verificar viabilidade do porftóflio de produtos } \\
\hline Tarefa & Sugestão de Melhoria \\
\hline $\begin{array}{l}\text { 1.7.1 - Avaliar } \\
\text { viabilidade econômica } \\
\text { do portfólio de projetos }\end{array}$ & $\begin{array}{l}\text { Especialista L: Só é válido isso em caso de projetos sem grandes } \\
\text { alterações, se a idéia for muito inovadora isso pode ser feito após o } \\
\text { Projeto Conceitual. } \\
\text { Especialista N: Deve acontecer na fase de Projeto Informacional (PI). }\end{array}$ \\
\hline $\begin{array}{l}\text { 1.7.2 - Avaliar } \\
\text { competências }\end{array}$ & $\begin{array}{l}\text { Especialista B: Sem justificativa. } \\
\text { Especialista E: Competências para cada projeto? Veja se está no } \\
\text { portfólio. O aspecto ambiental descrito faria sentido para um único } \\
\text { projeto e não para o conjunto de projetos. E seria impossível realizar } \\
\text { para todos de uma vez. } \\
\text { Especialista G: Vai acontecer naturalmente pela necessidade. }\end{array}$ \\
\hline \multicolumn{2}{|c|}{ Atividade - 1.8 Decidir início do planejamento de um produto do portfólio } \\
\hline Tarefa & Sugestão de Melhoria \\
\hline $\begin{array}{l}\text { 1.8.1 - Monitorar o } \\
\text { portfólio de produtos e } \\
\text { identificar a data dos } \\
\text { novos projetos }\end{array}$ & Especialista N: Acompanhar projetos deve ser em outras fases. \\
\hline \multicolumn{2}{|c|}{ Fase 2 - Planejamento do Projeto (PP) } \\
\hline \multicolumn{2}{|c|}{ Atividade - 2.1 Definir interessados do projeto } \\
\hline Tarefa & Sugestão de Melhoria \\
\hline $\begin{array}{l}\text { 2.1.1 - Montagem da } \\
\text { equipe com os } \\
\text { interessados do projeto }\end{array}$ & $\begin{array}{l}\text { Especialista E: Esta atividade está errada, interessados é muito mais } \\
\text { que a equipe. }\end{array}$ \\
\hline $\begin{array}{l}\text { 2.1.2 - Desenvolvimento } \\
\text { da equipe para a } \\
\text { execução do projeto }\end{array}$ & $\begin{array}{l}\text { Especialista B: Sem justificativa. } \\
\text { Especialista E: Desenvolver equipe, no meu entendimento, é treinar, } \\
\text { fazer com que se integrem e tal. Deve acontecer na fase de Projeto } \\
\text { Informacional (PI). } \\
\text { Especialista L: Depende do grau de novidade incluído, pois depende da } \\
\text { solução a ser adotada no projeto preliminar. }\end{array}$ \\
\hline \multicolumn{2}{|c|}{ Atividade - 2.2 Definir escopo do produto } \\
\hline Tarefa & Sugestão de Melhoria \\
\hline $\begin{array}{l}\text { 2.2.1 - Definir diretrizes } \\
\text { básicas que o produto } \\
\text { deverá atender }\end{array}$ & $\begin{array}{l}\text { Especialista D: Penso que neste ponto se está utilizando uma } \\
\text { abordagem excessivamente técnica do PDP. Os aspectos do usuário } \\
\text { devem vir antes, acredito que desde a etapa estratégica. Uma imersão } \\
\text { etnográfica preliminar à avaliação do portfólio é importante para saber o }\end{array}$ \\
\hline
\end{tabular}


Atividade - 2.3 Avaliar riscos

\begin{tabular}{|l|l|}
\hline Tarefa & Sugestão de Melhoria \\
\hline $\begin{array}{l}\text { 2.3.2 - Identificar e } \\
\text { caracterizar os riscos } \\
\text { potenciais }\end{array}$ & $\begin{array}{l}\text { Especialista D: Ferramentas preliminares de avaliação de impacto } \\
\text { ambiental podem ser usadas nesse momento, tanto quantitativas } \\
\text { quanto qualitativas. }\end{array}$ \\
$\begin{array}{l}\text { Especialista L: Depende do grau de novidade das soluções adotadas no } \\
\text { Projeto Conceitual. } \\
\text { Especialista N: Projeto Informacional, Conceitual, outras fases... Mas } \\
\text { aqui acho que ainda faltará informação. }\end{array}$ \\
$\begin{array}{l}\text { 2.3.3 - Analisar } \\
\text { qualitativamente e }\end{array}$ & $\begin{array}{l}\text { Especialista N: É possível estabelecer metas amplas, não avaliar se } \\
\text { estas serão atingidas. }\end{array}$ \\
\hline
\end{tabular}

quantitativamente os

riscos potenciais

2.3.4 - Planejar, controlar e monitorar ações em resposta aos riscos potenciais

que as pessoas querem. Entendo que a estratégia deve partir daí, e não do portfólio interno e dos recursos disponíveis, que devem ser analisados num segundo momento. Logo, deve acontecer no Planejamento Estratégico de Produtos (PEP).

de Melhoria

Atividade - 2.4 Preparar orçamento do projeto

Tarefa Sugestão de Melhoria

2.4.1 - Previsões dos custos relacionados às atividades e recursos

Especialista D: A prevenção da poluição é importante, mas entendo que, nesse momento, uma abordagem "zero waste" pode ser mais útil, antes de se pensar em abordagens corretivas.

Especialista L: Depende do grau de novidade das soluções adotadas no Projeto Conceitual.

\section{Sugestão de Melhoria}

Especialista N: A parte de certificação parece mais estratégica que projeto específico.

\section{Atividade - 2.5 Analisar a viabilidade econômica do projeto}

\section{Tarefa Sugestão de Melhoria}

2.5.1 - Definir custo-alvo Especialista L: Depende do grau de novidade/ineditismo a ser exigido para criação e seleção de soluções tanto conceituais como tecnológicas. Depende das requisições de projeto e desempenho das características de uso e estima, bem como das especificações do produto. Depende do preço meta definido, lucro desejado, volume de produção, lugar de venda, etc. Deve acontecer no Projeto Informacional (PI).

2.5.2 - Realizar avaliação econômica

Especialista I: Deve acontecer na fase de Projeto Conceitual (PC).

Especialista L: Depende do grau de novidade/ineditismo a ser exigido para criação e seleção de soluções tanto conceituais como tecnológicas. Deve acontecer no Projeto Informacional (PI).

\section{Atividade - 2.6 Definir indicadores de desempenho}

\section{Tarefa}

2.6.1 - Selecionar

indicadores de desempenho mais adequados para o presente projeto

\section{Sugestão de Melhoria}

Especialista D: Entendo que todos esses indicadores são importantes, mas poderia se incluir questões como reuso, reparo e remanufatura, e suas possibilidades econômicas. Sabe-se, pela literatura, que essas estratégias apresentam grande potencial de redução de impacto ambiental.

Especialista I: Deve acontecer na fase de Planejamento Estratégico de Produtos (PEP).

Especialista N: Parecem-me indicadores amplos. Não pode ser do sistema como um todo, ao invés do projeto ou produto?

\section{Atividade - 2.7 Planejar e preparar aquisições}

\section{Tarefa \\ Sugestão de Melhoria}

2.7.1 - Preparar requerimentos de aquisição e identificar fornecedores potenciais
Especialista B: Cuidado a legislação ambiental não é suficiente, seja necessário impacto ao longo do ciclo de vida.

Especialista l: Deve acontecer na fase de Projeto Conceitual (PC).

Especialista L: Depende do grau de novidade/ineditismo a ser exigido para criação e seleção de soluções tanto conceituais como tecnológicas. Depende das requisições de projeto e desempenho das 
2.7.2 - Planejar a gestão dos relacionamentos com os fornecedores

características de uso e estima, bem como das especificações do produto. Depende do preço meta definido, lucro desejado, volume de produção, lugar de venda, etc. Deve acontecer na fase de Projeto Detalhado (PD) e Preparação da Produção do Produto (PPP).

Especialista N: Se o Projeto Informacional (PI) ainda não foi conduzido, será que tem informação suficiente para isso? Acho que não. Creio que nesta fase só seria possível estabelecer metas amplas, não avaliar se estas serão atingidas.

Especialista L: Deve acontecer na fase de Projeto Detalhado (PD) e Preparação da Produção do Produto (PPP).

Especialista N: Se o Projeto Informacional (PI) ainda não foi conduzido, será que tem informação suficiente para isso? Acho que não. Creio que nesta fase só seria possível estabelecer metas amplas, não avaliar se estas serão atingidas.

\section{Macrofase - Desenvolvimento}

\section{Fase 3 - Projeto Informacional (PI)}

Atividade - 3.1 Atualizar o plano do projeto informacional

\section{Tarefa}

3.1.1 - Atualizar o escopo do produto

3.1.2 - Atualizar estimativa de orçamento do projeto

3.1.3 - Avaliar novos riscos

3.1.4 - Definir/atualizar os critérios de passagem dos gates

\section{Sugestão de Melhoria}

Especialista I: O plano do projeto foi aprovado, não vejo sentido em uma atividade de atualização do plano de Projeto Informacional, a não ser que exista um período de tempo muito grande entre a aprovação do plano do projeto e o início da execução do projeto.

Especialista H: Não seria no Projeto Detalhado (PD)? Nesta fase já se tem maiores informações para definição do ciclo de vida.

Especialista I: O plano do projeto foi aprovado, não vejo sentido em uma atividade de atualização do plano de Projeto Informacional, a não ser que exista um período de tempo muito grande entre a aprovação do plano do projeto e o início da execução do projeto.

\section{Especialista B: Riscos da cadeia?}

Especialista I: O plano do projeto foi aprovado, não vejo sentido em uma atividade de atualização do plano de Projeto Informacional, a não ser que exista um período de tempo muito grande entre a aprovação do plano do projeto e o início da execução do projeto.

Especialista B: Acho que esta etapa tem que ser feita já no Planejamento do Projeto.

Especialista I: O plano do projeto foi aprovado, não vejo sentido em uma atividade de atualização do plano de Projeto Informacional, a não ser que exista um período de tempo muito grande entre a aprovação do plano do projeto e o início da execução do projeto.

Especialista L: Definir isto antes no Planejamento do Projeto (PP).

\section{Atividade - 3.2 Revisar e atualizar o escopo do produto}

\section{Tarefa}

3.2.3 - Pesquisar

padrões / normas, patentes e legislação

3.2.4 - Pesquisar produtos concorrentes e similares

\section{Atividade - similares \\ Atividade - 3.3 Detalhar ciclo de vida do produto e definir seus clientes}

\section{Tarefa}

3.3.1 - Refinar o ciclo de vida do produto

3.3.2 - Definir os clientes do projeto ao longo do ciclo de vida

\section{Sugestão de Melhoria}

Especialista B: Falta à visão dos fornecedores, a cadeia pode ter um impacto alto.

Especialista H: Não seria no Projeto Detalhado? Nesta fase já se tem maiores informações para definição do ciclo de vida.

Especialista J: A estratégia de estender a expectativa de vida do produto nem sempre é a mais adequada para todos os tipos de produto. Para aqueles que têm o maior consumo de energia durante a fase de uso e que estão sujeito à obsolescência técnica, não é o caso. Não está muito clara a relação entre o "impacto ambiental" e a "tarefa". 


\begin{tabular}{|c|c|}
\hline & $\begin{array}{l}\text { Especialista M: Além das expectativas do cliente, considere também os } \\
\text { papéis do cliente e suas responsabilidades de usos para reduzir o } \\
\text { impacto ambiental. Enfim, impacto ambiental requer também } \\
\text { responsabilidade dos clientes, que acho precisa ser bem alertado disso } \\
\text { pelo desenvolvedor do produto. }\end{array}$ \\
\hline \multicolumn{2}{|c|}{ Atividade - 3.4 Identificar os requisitos dos clientes do produto } \\
\hline Tarefa & Sugestão de Melhoria \\
\hline $\begin{array}{l}\text { 3.4.1 - Coletar e } \\
\text { classificar as } \\
\text { necessidades dos } \\
\text { clientes de cada fase do } \\
\text { ciclo de vida }\end{array}$ & $\begin{array}{l}\text { Especialista D: Concordo, mas também penso que essas necessidades } \\
\text { devem ser levantadas já no início do processo. }\end{array}$ \\
\hline $\begin{array}{l}\text { 3.4.1 - Coletar e } \\
\text { classificar as } \\
\text { necessidades dos } \\
\text { clientes de cada fase do } \\
\text { ciclo de vida } \\
\text { 3.4.2 - Definir os }\end{array}$ & \multirow{2}{*}{$\begin{array}{l}\text { Especialista B: Clientes do ciclo de vida não são suficientes. } \\
\text { Especialista J: Ainda não estão falando em requisitos do produto (que } \\
\text { normalmente equivale aos requisitos de projeto do produto), mas sim } \\
\text { aos requisitos dos clientes (relacionados às necessidades e } \\
\text { expectativas dos clientes). Relacionar requisitos do produto com } \\
\text { necessidades é realizado mais adiante. } \\
\text { Especialista M: Apenas colocaria, além de necessidades e requisitos do } \\
\text { cliente, também o papel do desenvolvedor em planejar como informar } \\
\text { ao cliente de suas responsabilidades de bom uso, considerando o } \\
\text { impacto ambiental. }\end{array}$} \\
\hline $\begin{array}{l}\text { requisitos dos clientes } \\
\text { 3.4.3 - Valorar os } \\
\text { requisitos dos clientes }\end{array}$ & \\
\hline \multicolumn{2}{|c|}{ Atividade - 3.6 Definir especificações meta do produto } \\
\hline Tarefa & Sugestão de Melhoria \\
\hline $\begin{array}{l}\text { 3.6.1 - Valorar requisitos } \\
\text { do produto }\end{array}$ & Especialista J: Pouco claro. \\
\hline $\begin{array}{l}\text { 3.6.4 - Elaborar o } \\
\text { conjunto de } \\
\text { especificações-meta do } \\
\text { produto }\end{array}$ & $\begin{array}{l}\text { Especialista B: Fiquei na dúvida se você está inserindo DFE aqui, onde } \\
\text { estão as restrições? } \\
\text { Especialista E: As especificações meta do QFD são valores de } \\
\text { desempenho. Elas não podem trazer solução. O tipo de bateria que } \\
\text { será utilizada é uma solução já. Uma especificação meta seria a } \\
\text { quantidade de horas de energia, o consumo de energia por tempo ou } \\
\text { uso etc. } \\
\text { Especialista J: Diversas diretrizes expostas nesta tarefa se relacionam } \\
\text { mais ao final do Projeto Conceitual que ao Projeto Informacional. } \\
\text { Especialista L: Depende das requisições de projeto e desempenho das } \\
\text { características de uso e estima, bem como das especificações do } \\
\text { produto. }\end{array}$ \\
\hline \multicolumn{2}{|c|}{ Atividade - 3.7 Monitorar a viabilidade econômico-financeira do produto } \\
\hline Tarefa & Sugestão de Melhoria \\
\hline $\begin{array}{l}\text { 3.7.1 - Avaliar } \\
\text { mudanças nas } \\
\text { condições de mercado, } \\
\text { características técnicas } \\
\text { e indicadores }\end{array}$ & $\begin{array}{l}\text { Especialista N: Será que não seria nas etapas mais iniciais? Parece } \\
\text { questão de idéia para projetos, para ser aprovado ou não na avaliação } \\
\text { de portfólio. }\end{array}$ \\
\hline $\begin{array}{l}\text { 3.7.2 - Avaliar possíveis } \\
\text { desvios e impactos no } \\
\text { projeto }\end{array}$ & $\begin{array}{l}\text { Especialista L: Deve acontecer nas fases de Projeto Conceitual (PC) e } \\
\text { Projeto Detalhado (PD). }\end{array}$ \\
\hline \multicolumn{2}{|c|}{ Atividade - 3.8 Documentar as decisões tomadas e registrar lições aprendidas } \\
\hline Tarefa & Sugestão de Melhoria \\
\hline $\begin{array}{l}\text { 3.8.1 - Documentar as } \\
\text { decisões tomadas e } \\
\text { registrar lições } \\
\text { aprendidas }\end{array}$ & $\begin{array}{l}\text { Especialista L: Deve acontecer nas fases de Projeto Detalhado (PD) e } \\
\text { Acompanhar Produto e Processo (APP). } \\
\text { Especialista N: Não seria de final de projeto? }\end{array}$ \\
\hline \multicolumn{2}{|r|}{$\begin{array}{l}\text { Macrofase - Desenvolvimento } \\
\text { Fase } 4 \text { - Projeto Conceitual (PC) }\end{array}$} \\
\hline \multicolumn{2}{|c|}{ Atividade - 4.1 Atualizar o plano do projeto conceitual } \\
\hline Tarefa & Sugestão de Melhoria \\
\hline
\end{tabular}




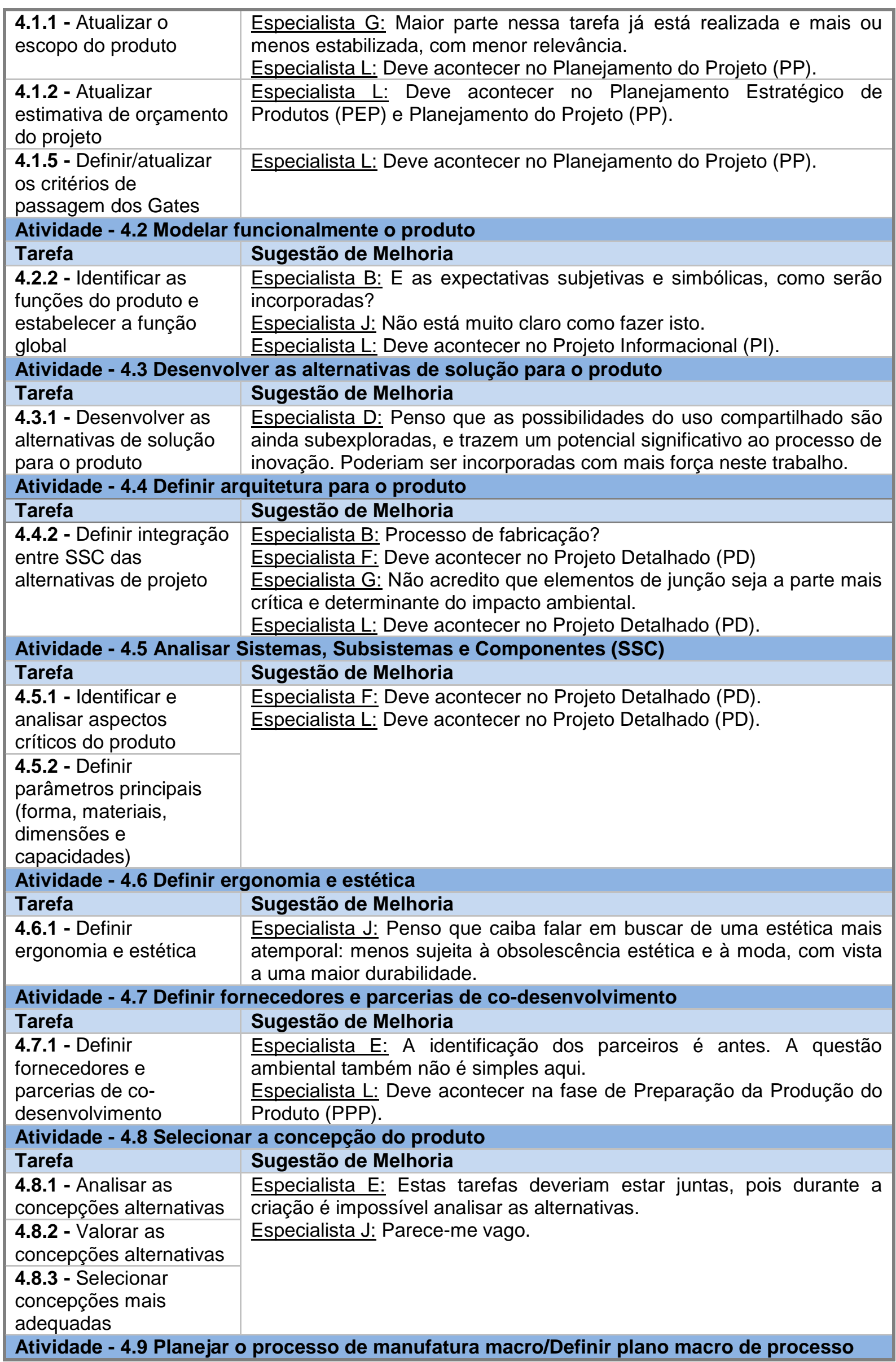




\begin{tabular}{|c|c|}
\hline Tarefa & Sugestão de Melhoria \\
\hline $\begin{array}{l}\text { 4.9.1 - Planejar o } \\
\text { processo de manufatura } \\
\text { macro/Definir plano } \\
\text { macro de processo }\end{array}$ & $\begin{array}{l}\text { Especialista L: Deve acontecer na fase de Projeto Detalhado (PD) e } \\
\text { Preparação da Produção do Produto (PPP). }\end{array}$ \\
\hline \multicolumn{2}{|c|}{ Atividade - 4.10 Monitorar a viabilidade econômico-financeira do produto } \\
\hline Tarefa & Sugestão de Melhoria \\
\hline $\begin{array}{l}4.10 .1 \text { - Avaliar } \\
\text { mudanças nas } \\
\text { condições de mercado, } \\
\text { características técnicas } \\
\text { e indicadores }\end{array}$ & $\begin{array}{l}\text { Especialista J: Monitorar o que mudou em termos das exigências em } \\
\text { termos ambientais impostas pelo mercado, órgãos governamentais, etc. } \\
\text { Especialista L: Deve acontecer na fase de Projeto Detalhado (PD). }\end{array}$ \\
\hline \multicolumn{2}{|c|}{$\begin{array}{l}\text { Macrofase - Desenvolvimento } \\
\text { Fase } 5 \text { - Projeto Detalhado (PD) }\end{array}$} \\
\hline \multicolumn{2}{|c|}{ Atividade - 5.1 Atualizar o plano do projeto detalhado } \\
\hline Tarefa & Sugestão de Melhoria \\
\hline $\begin{array}{l}\text { 5.1.1 - Atualizar o } \\
\text { escopo do produto }\end{array}$ & $\begin{array}{l}\text { Especialista E: Sem justificativa. } \\
\text { Especialista L: Deve acontecer na fase de Planejamento do Projeto } \\
\text { (PP). }\end{array}$ \\
\hline $\begin{array}{l}5.1 .2 \text { - Atualizar } \\
\text { estimativa de orçamento } \\
\text { do projeto }\end{array}$ & Especialista E: Sem justificativa. \\
\hline \multicolumn{2}{|c|}{ Atividade - 5.2 Criar e detalhar SSC, documentação e configuração } \\
\hline Tarefa & Sugestão de Melhoria \\
\hline $\begin{array}{l}\text { 5.2.1 - Criar, reutilizar, } \\
\text { procurar e codificar SSC }\end{array}$ & Especialista L: Deve acontecer na fase de Projeto Conceitual (PC). \\
\hline $\begin{array}{l}5.2 .2 \text { - Especificar } \\
\text { tolerâncias }\end{array}$ & $\begin{array}{l}\text { Especialista G: O ponto das tolerâncias não é minimizar o volume, mas } \\
\text { especificar as tolerâncias necessárias, sem exageros, porque o exagero } \\
\text { exige mais operações de fabricação e mais gasto de energia. } \\
\text { Especialista J: Não entendi. }\end{array}$ \\
\hline 5.2.3 - Integrar os SSC & Especialista L: Deve acontecer na fase de Projeto Conceitual (PC). \\
\hline \multicolumn{2}{|c|}{ Atividade - 5.3 Decidir por fazer ou comprar SSC } \\
\hline Tarefa & Sugestão de Melhoria \\
\hline $\begin{array}{l}\text { 5.3.1 - Levantar } \\
\text { informações de custos, } \\
\text { tempo, capacidades e } \\
\text { competências para o } \\
\text { desenvolvimento/forneci } \\
\text { mento dos SSC }\end{array}$ & $\begin{array}{l}\text { Especialista L: Pode acontecer na fase de Projeto Detalhado (PD) ou } \\
\text { Preparação da Produção do Produto (PPP). }\end{array}$ \\
\hline $\begin{array}{l}\text { 5.3.2 - Decidir entre } \\
\text { desenvolver e produzir } \\
\text { ou comprar SSC }\end{array}$ & $\begin{array}{l}\text { Especialista E: Use termos técnicos. O que são componentes } \\
\text { ecológicos? } \\
\text { Especialista J: Apenas é preciso entender o que significa "componentes } \\
\text { ecológicos". } \\
\text { Especialista L: Pode acontecer na fase de Projeto Detalhado (PD) ou } \\
\text { Projeto Conceitual (PC). }\end{array}$ \\
\hline \multicolumn{2}{|c|}{ Atividade - 5.4 Desenvolver fornecedores } \\
\hline Tarefa & Sugestão de Melhoria \\
\hline $\begin{array}{l}5.4 .1 \text { - Selecionar } \\
\text { fornecedores }\end{array}$ & $\begin{array}{l}\text { Especialista L: Pode acontecer na fase de Projeto Detalhado (PD) ou } \\
\text { Preparação da Produção do Produto (PPP). }\end{array}$ \\
\hline \multicolumn{2}{|c|}{ Atividade - 5.5 Planejar o processo de fabricação e montagem } \\
\hline Tarefa & Sugestão de Melhoria \\
\hline $\begin{array}{l}\text { 5.5.1 - Planejar } \\
\text { processo de fabricação } \\
\text { macro }\end{array}$ & \multirow[t]{2}{*}{$\begin{array}{l}\text { Especialista L: Pode acontecer na fase de Projeto Conceitual (PC) ou } \\
\text { Preparação da Produção do Produto (PPP). }\end{array}$} \\
\hline $\begin{array}{l}\text { 5.5.2 - Planejar } \\
\text { processo de montagem } \\
\text { macro }\end{array}$ & \\
\hline 5.5.3 - Desdobrar & Especialista E: Deve acontecer no Projeto Conceitual (PC). \\
\hline
\end{tabular}


parâmetros críticos dos componentes fabricados 5.5.4 - Definir e Sequenciar operações 5.5.5 - Selecionar / Especificar máquinas e equipamentos

\begin{tabular}{|c|}
\hline $\begin{array}{l}5.5 .6 \text { - Especificar } \\
\text { fixação }\end{array}$ \\
\hline $\begin{array}{l}\text { 5.5.7 - Especificar } \\
\text { inspeção }\end{array}$ \\
\hline $\begin{array}{l}\text { 5.5.8 - Selecionar / } \\
\text { Especificar métodos e } \\
\text { ferramental }\end{array}$ \\
\hline $\begin{array}{l}\text { 5.5.9 - Calcular } \\
\text { parâmetros de trabalho }\end{array}$ \\
\hline $\begin{array}{l}\text { 5.5.10 - Descrever } \\
\text { instruções de trabalho }\end{array}$ \\
\hline $\begin{array}{l}\mathbf{5 . 5 . 1 1} \text { - Criar } \\
\text { informações / } \\
\text { documentos de apoio ao } \\
\text { operador }\end{array}$ \\
\hline
\end{tabular}

5.5.12 - Simular processo de fabricação

5.5.13 - Atualizar BOM
Especialista L: Pode acontecer na fase de Projeto Detalhado (PD) ou Preparação da Produção do Produto (PPP).

Especialista L: Pode acontecer na fase de Projeto Conceitual (PC), Projeto Detalhado (PD) ou Preparação da Produção do Produto (PPP).

Especialista L: Pode acontecer na fase de Projeto Conceitual (PC) ou Projeto Detalhado (PD).

Especialista J: Vago.

Especialista N: Exigir de quem? Não está claro.

Especialista J: Vago com relação às necessidades ergonômicas.

Especialista L: Pode acontecer na fase de Projeto Detalhado (PD) ou Preparação da Produção do Produto (PPP).

Especialista L: Pode acontecer na fase de Projeto Conceitual (PC) ou Projeto Detalhado (PD).

Especialista L: Pode acontecer na fase de Preparação da Produção do Produto (PPP).

Especialista G: Sem justificativa.

Especialista J: Aqui a tarefa se refere aos documentos de apoio ao operador, e não às normas ambientais da empresa.

Especialista L: Pode acontecer na fase de Projeto Detalhado (PD) ou Preparação da Produção do Produto (PPP).

Especialista E: Sem justificativa.

Especialista L: Pode acontecer na fase de Projeto Detalhado (PD) ou Preparação da Produção do Produto (PPP).

Especialista L: Pode acontecer na fase de Projeto Detalhado (PD) ou Preparação da Produção do Produto (PPP).

Atividade - 5.6 Projetar recursos de fabricação

Tarefa

Sugestão de Melhoria

5.6.2 - Projetar

Máquinas e

Equipamentos

5.6.3 - Projetar

Instalações (Fábrica)

Atividade - 5.7 Avaliar SSC, configuração e documentação do produto e processo

Tarefa

Sugestão de Melhoria

5.7.1 - Avaliar tolerância Especialista J: Não me está claro o que vem a ser "tolerância analiticamente

5.7.2 - Planejar os testes (produto e processo)

5.7.3 - Executar os testes

5.7.4 - Avaliar os resultados e planejar ações

5.7.5 - Avaliar consonância da documentação com as normas

Atividade - 5.8 Otimizar produto e processo

Tarefa Sugestão de Melhoria

5.8.2 - Ajustar tolerância Especialista J: Não está claro para mim.
Especialista G: Nessa fase no teste piloto não estão mais avaliando alternativas de materiais, já seria material final.

Especialista J: Não me está claro o que vem a ser "tolerância ambiental".

Especialista L: Pode acontecer na fase de Preparação da Produção do Produto (PPP).

Especialista J: Não me está claro o que vem a ser "tolerância ambiental".

Especialista L: Pode acontecer na fase de Preparação da Produção do Produto (PPP).

Especialista J: Não me está claro o que vem a ser "tolerância ambiental". 


\begin{tabular}{|c|c|}
\hline dos SSC & $\begin{array}{l}\text { Especialista L: Pode acontecer na fase de Projeto Detalhado (PD) ou } \\
\text { Preparação da Produção do Produto (PPP). }\end{array}$ \\
\hline $\begin{array}{l}\text { 5.8.3 - Executar ações } \\
\text { de correção de falhas }\end{array}$ & $\begin{array}{l}\text { Especialista G: No desenvolvimento de produto não se deve elaborar } \\
\text { metodologia, mas sim aplicar. }\end{array}$ \\
\hline \multicolumn{2}{|c|}{ Atividade - 5.9 Criar material de suporte do produto } \\
\hline Tarefa & Sugestão de Melhoria \\
\hline $\begin{array}{l}\text { 5.9.1 - Criar manual de } \\
\text { operação do produto }\end{array}$ & \multirow{3}{*}{$\begin{array}{l}\text { Especialista L: Pode acontecer na fase de Projeto Detalhado (PD), } \\
\text { Preparação da Produção do Produto (PPP) ou Acompanhar Produto e } \\
\text { Processo (APP). } \\
\text { Especialista M: Concordo, mas vou além. Os manuais de operações, } \\
\text { treinamento e descontinuidade devem ser pensados de forma mais } \\
\text { arrojada de como são feitos hoje. Propostas multimídia e com } \\
\text { interações on-line com o desenvolvedor durante toda a vida útil do } \\
\text { produto, de forma que este possa perceber usos ruins do ponto de vista } \\
\text { ambiental e alertar cada usuário individualmente, otimizando usos } \\
\text { ambientalmente adequados. A informatização e conectividade podem } \\
\text { abrir boas e novas possibilidades nesse campo. }\end{array}$} \\
\hline $\begin{array}{l}5.9 .2 \text { - Criar material de } \\
\text { treinamento }\end{array}$ & \\
\hline $\begin{array}{l}5.9 .3 \text { - Criar manual de } \\
\text { descontinuidade do } \\
\text { produto }\end{array}$ & \\
\hline \multicolumn{2}{|c|}{ Atividade - 5.10 Projetar embalagem } \\
\hline Tarefa & \\
\hline $\begin{array}{l}5.10 .1 \text { - Avaliar a } \\
\text { distribuição do produto: } \\
\text { transporte e entrega }\end{array}$ & \multirow{4}{*}{$\begin{array}{l}\text { Especialista A: Muitas vezes há grandes oportunidades de ganhos } \\
\text { ambientais nas embalagens. E de modo geral, realizar alterações nas } \\
\text { embalagens visando à redução dos impactos ambientais nas } \\
\text { embalagens é mais simples que alterar o produto em si. Por isso, o } \\
\text { desenvolvimento da embalagem deve ser feito em paralelo com o } \\
\text { desenvolvimento do produto, iniciando no Projeto Informacional, ou até } \\
\text { antes (quando o impacto da embalagem for identificado como crítico). } \\
\text { Importante ressaltar que o desenvolvimento da embalagem deve } \\
\text { "conversar" com o desenvolvimento do produto, pois muitas vezes uma } \\
\text { definição da embalagem depende de algum aspecto do produto e vice } \\
\text { versa. Considerando que o desenvolvimento da embalagem deve } \\
\text { ocorrer em paralelo com o produto, nessa fase ambos se encontram. } \\
\text { Deve acontecer no Projeto Informacional (PI) e Projeto Conceitual (PC). } \\
\text { Especialista E: Deve acontecer no Projeto Conceitual (PC). } \\
\text { Especialista L: Pode acontecer na fase de Projeto Conceitual (PC), } \\
\text { Projeto Detalhado (PD) ou Preparação da Produção do Produto (PPP). }\end{array}$} \\
\hline $\begin{array}{l}\mathbf{5 . 1 0 . 2} \text { - Definir as } \\
\text { formas e as sinalizações } \\
\text { das embalagens do } \\
\text { produto }\end{array}$ & \\
\hline $\begin{array}{l}\mathbf{5 . 1 0 . 3} \text { - Identificar os } \\
\text { elementos críticos }\end{array}$ & \\
\hline $\begin{array}{l}\mathbf{5 . 1 0 . 4} \text { - Adequar } \\
\text { embalagem aos } \\
\text { elementos críticos }\end{array}$ & \\
\hline $\begin{array}{l}5.10 .5 \text { - Projetar } \\
\text { embalagem }\end{array}$ & $\begin{array}{l}\text { Especialista D: Entendo também que a embalagem não é algo que deva } \\
\text { ser projetado posteriormente ao produto, mas sim junto com ele. Sobre } \\
\text { isso, a empresa IKEA é um exemplo emblemático de desenvolvimento } \\
\text { simultâneo produto-embalagem, e que pode levar a soluções criativas, } \\
\text { econômicas e ambientalmente muito interessantes. Há artigos sobre } \\
\text { isso na literatura científica. } \\
\text { Especialista F: A embalagem necessita ser concebida junto com o } \\
\text { produto para uma melhor adequação dos aspectos ambientais e a } \\
\text { sustentabilidade como um todo. Devem acontecer nas fases anteriores } \\
\text { Planejamento Estratégico de Produtos (PEP), Planejamento do Projeto } \\
\text { (PP), Projeto Informacional (PI) e Projeto Conceitual (PC). } \\
\text { Especialista L: Pode acontecer na fase de Projeto Conceitual (PC), } \\
\text { Projeto Detalhado (PD) ou Preparação da Produção do Produto (PPP). }\end{array}$ \\
\hline $\begin{array}{l}5.10 .6 \text { - Planejar } \\
\text { processo de embalagem }\end{array}$ & $\begin{array}{l}\text { Especialista D: Não se deve ignorar o fato de que os fornecedores irão } \\
\text { querer ganhar algo nesse processo de recolha. Definir claramente quais } \\
\text { são esses ganhos é importante (mesmo que seja um ganho de } \\
\text { imagem). } \\
\text { Especialista L: Pode acontecer na fase de Projeto Conceitual (PC), } \\
\text { Projeto Detalhado (PD) ou Preparação da Produção do Produto (PPP). }\end{array}$ \\
\hline \multicolumn{2}{|c|}{ Atividade - 5.11 Planejar fim de vida do produto } \\
\hline Tarefa & Sugestão de Melhoria \\
\hline $\begin{array}{l}5.11 .1 \text { - Definir plano de } \\
\text { retirada do mercado }\end{array}$ & $\begin{array}{l}\text { Especialista L: Podem acontecer na fase de Planejamento Estratégico } \\
\text { de Produtos (PEP), Planejamento do Projeto (PP), Projeto Informacional } \\
\text { (PI) e Acompanhar Produto e Processo (APP). }\end{array}$ \\
\hline
\end{tabular}


5.11.2 - Definir plano de descontinuidade da produção

5.11.3 - Definir plano de descarte

5.11.4 - Definir plano de reciclagem
Especialista M: Mas como balancear o trade-off entre interesses comerciais da empresa, que quer que o consumidor troque com frequência de produtos, para novas versões, do mérito ambiental de produtos duradouros, com funções efetivamente bem utilizadas. llustrando: para a empresa, em uma visão tradicional, é melhor cada pessoa ter seu carro, individualidade, para o meio-ambiente, o melhor é carros alugados, cooperativismo e coletividade no uso de carros. A segunda opção leva a uma utilização mais plena do que a primeira que requer muito mais equipamentos que na maior parte do tempo está ocioso e ocupando espaço nas cidades saturadas. Legislações mais rígidas e conscientização que começamos a ver em centros urbanos mais desenvolvidos parecem sinalizar para uma ruptura desse paradigma de priorização do consumo individual em favor do coletivo.

Especialista L: Podem acontecer na fase de Planejamento Estratégico de Produtos (PEP), Planejamento do Projeto (PP), Acompanhar Produto e Processo (APP) e Descontinuar Produto no Mercado (DPM).

Especialista L: Podem acontecer na fase de Planejamento do Projeto (PP), Projeto Informacional (PI), Projeto Conceitual (PC), Projeto Detalhado (PD) e Acompanhar Produto e Processo (APP).

Especialista D: É importante considerar quem poderá absorver esses resíduos, numa lógica de "cadeia alimentar".

Especialista L: Pode acontecer na fase de Planejamento do Projeto (PP), Acompanhar Produto e Processo (APP) e Descontinuar Produto no Mercado (DPM).

Atividade - 5.12 Testar e homologar produto

\section{Tarefa}

\section{Sugestão de Melhoria}

5.12.1 - Verificar a documentação

Especialista L: Podem acontecer na fase de Projeto Detalhado (PD), Preparação da Produção do Produto (PPP), Lançamento do Produto (LP) e Acompanhar Produto e Processo (APP).

5.12.2 - Verificar a funcionalidade do produto

5.12.3 - Verificar o atendimento aos requisitos e normas

5.12.4 - Obter certificado de homologação Especialista L: Podem acontecer na fase de Preparação da Produção do Produto (PPP), Lançamento do Produto (LP) e Acompanhar Produto e Processo (APP).

Especialista G: Muito tarde, poderia ser feito antes.

Especialista L: Podem acontecer na fase de Projeto Detalhado (PD), Preparação da Produção do Produto (PPP), Acompanhar Produto e Processo (APP) e Descontinuar Produto no Mercado (DPM).

Especialista L: Pode acontecer na fase de Preparação da Produção do Produto (PPP) e Lançamento do Produto (LP).

\section{Atividade - 5.13 Enviar documentação do produto a parceiros}

\section{Tarefa}

\section{Sugestão de Melhoria}

5.13.1 - Enviar documentação do produto a parceiros

Especialista L: Podem acontecer na fase de Preparação da Produção do Produto (PPP), Lançamento do Produto (LP) e Acompanhar Produto e Processo (APP).

\section{Atividade - 5.14 Monitorar a viabilidade econômico-financeira do produto}

\section{Tarefa}

5.14.1 - Avaliar

mudanças nas

condições de mercado,

características técnicas

e indicadores

5.14.2 - Avaliar

possíveis desvios e

impactos no projeto

5.14.3 - Analisar novas

premissas e indicadores

Atividade - 5.15 Documentar as decisões tomadas e registrar lições aprendidas

Tarefa Sugestão de Melhoria

5.15.1 - Documentar as Especialista L: Pode acontecer na fase de Projeto Detalhado (PD) ou

\section{Sugestão de Melhoria}

Especialista L: Pode acontecer na fase de Lançamento do Produto (LP) e Acompanhar Produto e Processo (APP).

Especialista L: Pode acontecer na fase de Projeto Detalhado (PD) ou Preparação da Produção do Produto (PPP). 


\begin{tabular}{|c|c|}
\hline $\begin{array}{l}\text { decisões tomadas e } \\
\text { registrar lições } \\
\text { aprendidas }\end{array}$ & Preparação da Produção do Produto (PPP). \\
\hline \multicolumn{2}{|c|}{$\begin{array}{l}\text { Macrofase - Desenvolvimento } \\
\text { Fase } 6 \text { - Preparação da Produção do Produto (PPP) }\end{array}$} \\
\hline \multicolumn{2}{|c|}{ Atividade - 6.1 Obter recursos de fabricação } \\
\hline Tarefa & Sugestão de Melhoria \\
\hline $\begin{array}{l}\text { 6.1.1 - Desenvolver } \\
\text { recursos de fabricação } \\
\text { não comprados }\end{array}$ & $\begin{array}{l}\text { Especialista L: Podem acontecer na fase de Projeto Conceitual (PC), } \\
\text { Projeto Detalhado (PD) e Preparação da Produção do Produto (PPP). }\end{array}$ \\
\hline $\begin{array}{l}\text { 6.1.2 - Comprar } \\
\text { recursos de fabricação }\end{array}$ & $\begin{array}{l}\text { Especialista L: Pode acontecer na fase de Projeto Detalhado (PD) e } \\
\text { Preparação da Produção do Produto (PPP). }\end{array}$ \\
\hline \multicolumn{2}{|c|}{ Atividade - 6.2 Planejar produção piloto } \\
\hline Tarefa & Sugestão de Melhoria \\
\hline $\begin{array}{l}6.2 .1 \text { - Verificar } \\
\text { disponibilidade dos } \\
\text { equipamentos em uso e } \\
\text { a operacionalidade dos } \\
\text { recursos novos }\end{array}$ & $\begin{array}{l}\text { Especialista L: Pode acontecer na fase de Projeto Detalhado (PD) e } \\
\text { Preparação da Produção do Produto (PPP). } \\
\text { Especialista M: Complementaria com otimizar a redução dos impactos } \\
\text { ambientais dos equipamentos em uso para a produção do novo produto. }\end{array}$ \\
\hline \multicolumn{2}{|c|}{ Atividade - 6.4 Produzir Lote Piloto } \\
\hline Tarefa & Sugestão de Melhoria \\
\hline $\begin{array}{l}\text { 6.4.1 - Produzir Lote } \\
\text { Piloto }\end{array}$ & $\begin{array}{l}\text { Especialista G: Não tem como avaliar alternativas mais, já está } \\
\text { especificado. Se forem avaliar alternativas já é um reprojeto. } \\
\text { Especialista M: Otimizar a realização do lote piloto, buscando realizar o } \\
\text { número mínimo necessário para homologar a produção, evitando lotes } \\
\text { desnecessariamente grandes. }\end{array}$ \\
\hline \multicolumn{2}{|c|}{ Atividade - 6.7 Certificar produto } \\
\hline Tarefa & Sugestão de Melhoria \\
\hline $\begin{array}{l}\text { 6.7.1 - Avaliar } \\
\text { exigências de } \\
\text { regulamentação }\end{array}$ & $\begin{array}{l}\text { Especialista L: Pode acontecer na fase de Projeto Detalhado (PD) e } \\
\text { Preparação da Produção do Produto (PPP). } \\
\text { Especialista M: Em geral, e particularmente esse item, do ponto de vista } \\
\text { de se o produto atende a legislação ambiental, acho que precisaria vir } \\
\text { bem antes, ou pelo menos começar bem antes, acho que no Projeto } \\
\text { Detalhado (PD). }\end{array}$ \\
\hline $\begin{array}{l}\text { 6.7.2 - Submeter ao } \\
\text { cliente o processo de } \\
\text { aprovação }\end{array}$ & $\begin{array}{l}\text { Especialista D: Como serão considerados os critérios subjetivos do } \\
\text { cliente, inclusive em relação à sustentabilidade ambiental, mas não } \\
\text { restrito somente a ela. Por exemplo, a questão do status é relevante } \\
\text { (em que o produto contribui para o consumidor se sentir um cidadão } \\
\text { ambientalmente mais responsável, e permite a ele mostrar isso aos } \\
\text { outros). Entendo que essa questão é muito importante, e muitas vezes } \\
\text { subvalorizada. Entendo que ter no time, desde o inicio, algum } \\
\text { antropólogo ou mesmo um designer treinado em métodos etnográficos } \\
\text { pode ser muito útil. } \\
\text { Especialista K: Depende do tipo de produto e de cliente, produtos } \\
\text { destinados ao consumidor final devem ser tratados de modo distinto, } \\
\text { pois esse consumidor não tem competências para avaliar impactos dos } \\
\text { produtos. } \\
\text { Especialista L: Pode acontecer na fase de Preparação da Produção do } \\
\text { Produto (PPP) e Lançamento do Produto (LP). }\end{array}$ \\
\hline $\begin{array}{l}\text { 6.7.3 - Avaliar os } \\
\text { serviços associados ao } \\
\text { produto }\end{array}$ & \multirow[t]{2}{*}{$\begin{array}{l}\text { Especialista L: Pode acontecer na fase de Preparação da Produção do } \\
\text { Produto (PPP) e Lançamento do Produto (LP). }\end{array}$} \\
\hline $\begin{array}{l}\text { 6.7.4 - Obter } \\
\text { documentação para } \\
\text { certificação }\end{array}$ & \\
\hline \multicolumn{2}{|c|}{ Atividade - 6.9 Desenvolver processo de manutenção } \\
\hline Tarefa & Sugestão de Melhoria \\
\hline 6.9.1 - Definir política de & Especialista D: Concordo, mas acho que deve vir já no inicio, como \\
\hline
\end{tabular}




\begin{tabular}{|c|c|}
\hline manutenção & $\begin{array}{l}\text { elemento estratégico do processo. } \\
\text { Especialista L: Podem acontecer na fase de Planejamento do Projeto } \\
\text { (PP), Projeto Informacional (PI) e Projeto Conceitual (PC). }\end{array}$ \\
\hline $\begin{array}{l}6.9 .2 \text { - Definir } \\
\text { procedimentos da } \\
\text { manutenção }\end{array}$ & $\begin{array}{l}\text { Especialista L: Pode acontecer na fase de Projeto Detalhado (PD) e } \\
\text { Preparação da Produção do Produto (PPP). }\end{array}$ \\
\hline \multicolumn{2}{|c|}{ Atividade - 6.10 Ensinar pessoal } \\
\hline Tarefa & Sugestão de Melhoria \\
\hline $\begin{array}{l}6.10 .1 \text { - Mapear } \\
\text { competências } \\
\text { necessárias e definir } \\
\text { cursos de treinamento } \\
\text { de pessoal }\end{array}$ & $\begin{array}{l}\text { Especialista B: Sem justificativa. } \\
\text { Especialista L: Pode acontecer na fase de Projeto Detalhado (PD) e } \\
\text { Preparação da Produção do Produto (PPP). } \\
\text { Especialista M: Concordo, mas algumas ações de ecodesign e uso de } \\
\text { materiais "verdes" precisam ser pensadas em etapas anteriores, até } \\
\text { para planejar ações e ter tempo necessário para treinar o pessoal da } \\
\text { produção. }\end{array}$ \\
\hline \multicolumn{2}{|c|}{ Atividade - 6.11 Monitorar a viabilidade econômico-financeira do produto } \\
\hline Tarefa & Sugestão de Melhoria \\
\hline $\begin{array}{l}\text { 6.11.1 - Avaliar } \\
\text { mudanças nas } \\
\text { condições de mercado, } \\
\text { características técnicas } \\
\text { e indicadores }\end{array}$ & $\begin{array}{l}\text { Especialista G: Sem justificativa. } \\
\text { Especialista L: Pode acontecer na fase de Planejamento do Projeto } \\
\text { (PP), Projeto Informacional (PI), Preparação da Produção do Produto } \\
\text { (PPP) e Lançamento do Produto (LP). }\end{array}$ \\
\hline $\begin{array}{l}\text { 6.11.2 - Avaliar } \\
\text { possíveis desvios e } \\
\text { impactos no projeto }\end{array}$ & $\begin{array}{l}\text { Especialista L: Pode acontecer na fase de Lançamento do Produto (LP) } \\
\text { e Acompanhar Produto e Processo (APP). }\end{array}$ \\
\hline $\begin{array}{l}\text { 6.11.3 - Analisar novas } \\
\text { premissas e indicadores }\end{array}$ & $\begin{array}{l}\text { Especialista L: Podem acontecer na fase de Preparação da Produção } \\
\text { do Produto (PPP), Lançamento do Produto (LP) e Acompanhar Produto } \\
\text { e Processo (APP). }\end{array}$ \\
\hline \multicolumn{2}{|c|}{$\begin{array}{l}\text { Macrofase - Desenvolvimento } \\
\text { Fase } 7 \text { - Lançamento do Produto (LP) }\end{array}$} \\
\hline \multicolumn{2}{|c|}{ Atividade - 7.1 Planejar lançamento } \\
\hline Tarefa & Sugestão de Melhoria \\
\hline $\begin{array}{l}7.1 .1 \text { - Analisar e } \\
\text { sintetizar as novas } \\
\text { condições para a } \\
\text { realização do projeto }\end{array}$ & $\begin{array}{l}\text { Especialista L: Pode acontecer na fase de Planejamento do Projeto } \\
\text { (PP). }\end{array}$ \\
\hline $\begin{array}{l}\text { 7.1.3 - Atualizar } \\
\text { estimativa de orçamento } \\
\text { do projeto }\end{array}$ & $\begin{array}{l}\text { Especialista L: Pode acontecer na fase de Preparação da Produção do } \\
\text { Produto (PPP) e Lançamento do Produto (LP). }\end{array}$ \\
\hline \multicolumn{2}{|c|}{ Atividade - 7.3 Desenvolver processo de distribuição } \\
\hline Tarefa & Sugestão de Melhoria \\
\hline $\begin{array}{l}\text { 7.3.1 - Desenhar } \\
\text { processo de distribuição } \\
\text { e definir logística }\end{array}$ & $\begin{array}{l}\text { Especialista M: Lembre, porém, que certas escolhas de distribuição e } \\
\text { logística do produto, ambientalmente melhores, estão } \\
\text { ligadas/condicionadas a decisões sobre materiais, embalagens, design, } \\
\text { etc. do produto, que são tomadas bem antes, no Projeto Conceitual e } \\
\text { Projeto Detalhado. }\end{array}$ \\
\hline $\begin{array}{l}\text { 7.3.2 - Fechar acordos } \\
\text { com distribuidores }\end{array}$ & $\begin{array}{l}\text { Especialista K: Concordo, porém deve ser considerado o caso em que o } \\
\text { fornecedor tem pleno poder sobre a transação comercial (ele domina o } \\
\text { mercado e estabelece as regras dos mesmos seria "quase" monopólio, } \\
\text { situação em que empresas compradoras não têm influência nenhuma } \\
\text { sobre este tipo de fornecedor) }\end{array}$ \\
\hline \multicolumn{2}{|c|}{ Atividade - 7.5 Desenvolver processo de assistência técnica } \\
\hline Tarefa & Sugestão de Melhoria \\
\hline $\begin{array}{l}\text { 7.5.1 - Desenhar } \\
\text { processo de assistência } \\
\text { técnica }\end{array}$ & $\begin{array}{l}\text { Especialista M: Lembre, porém, que certas escolhas de distribuição e } \\
\text { logística do produto, ambientalmente melhores, estão } \\
\text { ligadas/condicionadas a decisões sobre materiais, embalagens, design, } \\
\text { etc. do produto, que são tomadas bem antes, no Projeto Conceitual, } \\
\text { Detalhado. }\end{array}$ \\
\hline
\end{tabular}




\begin{tabular}{|c|c|}
\hline $\begin{array}{l}\text { 7.5.2 - Desenvolver } \\
\text { documentação de } \\
\text { assistência técnica } \\
\text { 7.5.3 - Desenvolver } \\
\text { sistema de apoio a } \\
\text { assistência técnica }\end{array}$ & $\begin{array}{l}\text { Especialista L: Pode acontecer na fase de Projeto Detalhado (PD), } \\
\text { Preparação da Produção do Produto (PPP). }\end{array}$ \\
\hline \multicolumn{2}{|c|}{ Atividade - 7.7 Gerenciar lançamento } \\
\hline Tarefa & Sugestão de Melhoria \\
\hline $\begin{array}{l}\text { 7.7.1 - Gerenciar } \\
\text { resultados e aceitação } \\
\text { inicial }\end{array}$ & $\begin{array}{l}\text { Especialista F: Deve acontecer na fase Acompanhar Produto e } \\
\text { Processo (APP). }\end{array}$ \\
\hline \multicolumn{2}{|c|}{ Atividade - 7.8 Atualizar plano de fim de vida } \\
\hline Tarefa & Sugestão de Melhoria \\
\hline $\begin{array}{l}\text { 7.8.1 - Atualizar plano } \\
\text { de fim de vida }\end{array}$ & $\begin{array}{l}\text { Especialista F: Deve acontecer na fase Acompanhar Produto e } \\
\text { Processo (APP). } \\
\text { Especialista L: Pode acontecer na fase de Lançamento do Produto (LP), } \\
\text { Acompanhar Produto e Processo (APP) e Descontinuar Produto no } \\
\text { Mercado (DPM). }\end{array}$ \\
\hline \multicolumn{2}{|c|}{ Atividade - 7.9 Monitorar a viabilidade econômico-financeira do produto } \\
\hline Tarefa & Sugestão de Melhoria \\
\hline $\begin{array}{l}\text { 7.9.1 - Avaliar } \\
\text { mudanças nas } \\
\text { condições de mercado, } \\
\text { características técnicas } \\
\text { e indicadores }\end{array}$ & Especialista G: Sem justificativa. \\
\hline $\begin{array}{l}\text { 7.9.2 - Avaliar possíveis } \\
\text { desvios e impactos no } \\
\text { projeto }\end{array}$ & Especialista G: Sem justificativa. \\
\hline $\begin{array}{l}\text { 7.9.3 - Analisar novas } \\
\text { premissas e indicadores }\end{array}$ & $\begin{array}{l}\text { Especialista N: Creio que deveria inserir em algum lugar a consideração } \\
\text { e monitoramento de alterações de comportamentos "eco" de clientes, a } \\
\text { tendência é ficarem mais rigorosos, mas em que sentido? Em quais } \\
\text { aspectos? Estas exigências são tecnicamente embasadas? Em relação } \\
\text { às quais aspectos (impacto do produto e substâncias contidas? da } \\
\text { embalagem? do destino de resíduos? do consumo energético? da } \\
\text { geração de ruído/calor? Mais relacionadas à marca e certificação? }\end{array}$ \\
\hline Fase & $\begin{array}{l}\text { Macrofase - Pós-Desenvolvimento } \\
8 \text { - Acompanhar Produto e Processo (APP) }\end{array}$ \\
\hline \multicolumn{2}{|c|}{$\begin{array}{l}\text { Atividade - } 8.2 \text { Monitorar desempenho do produto (técnico, econômico, de produção e de } \\
\text { serviços) }\end{array}$} \\
\hline Tarefa & Sugestão de Melhoria \\
\hline $\begin{array}{l}\text { 8.2.1 - Monitorar o } \\
\text { desempenho técnico do } \\
\text { processo e do produto } \\
\text { no mercado e nos } \\
\text { serviços associados }\end{array}$ & $\begin{array}{l}\text { Especialista N: Creio que deveria inserir em algum lugar a consideração } \\
\text { e monitoramento de alterações de comportamentos "eco" de clientes, } \\
\text { pois a tendência é ficarem mais rigorosos, mas em que sentido? Em } \\
\text { quais aspectos? Estas exigências são tecnicamente embasadas? Em } \\
\text { relação às quais aspectos (impacto do produto e substâncias contidas? } \\
\text { da embalagem? do destino de resíduos? do consumo energético? da } \\
\text { geração de ruído/calor?). Mais relacionados à marca e certificação? }\end{array}$ \\
\hline & $\begin{array}{l}\text { Macrofase - Pós-Desenvolvimento } \\
\text { - Descontinuar Produto no Mercado (DPM) }\end{array}$ \\
\hline \multicolumn{2}{|c|}{ Atividade - 9.2 Preparar e acompanhar o recebimento do produto } \\
\hline Tarefa & Sugestão de Melhoria \\
\hline $\begin{array}{l}\text { 9.2.1 - Preparar e } \\
\text { acompanhar o } \\
\text { recebimento do produto }\end{array}$ & $\begin{array}{l}\text { Especialista N: O recolhimento não acontece só após a descontinuação } \\
\text { da venda dos produtos, mas sempre, se produto não for consumido com } \\
\text { o uso, com vida útil determinado. }\end{array}$ \\
\hline
\end{tabular}

